\title{
MEASUREMENTS VERSUS PREDICTIONS FOR THE STATIC AND DYNAMIC CHARACTERISTICS OF A FOUR-PAD, ROCKER-PIVOT, TILTING-PAD JOURNAL BEARING
}

\author{
A Thesis \\ by \\ DAVID PATRICK TSCHOEPE \\ Submitted to the Office of Graduate Studies of \\ Texas A\&M University \\ in partial fulfillment of the requirements IRUthe degree of \\ MASTER OF SCIENCE
}

Approved by:

Chair of Committee, Dara W. Childs

Committee Members, Alan Palazzolo

Lynn Beason

Head of Department, Jerald A. Caton

December 2012

Major Subject: Mechanical Engineering

Copyright 2012 ' DYGBDDNFN77 VFKRHH 


\begin{abstract}
Measured and predicted static and dynamic characteristics are provided for a fourpad, rocker-pivot, tilting-pad journal bearing in the load-on-pad and load-between-pad orientations. The bearing has the following characteristics: 4 pads, .57 pad pivot offset, 0.6 $L D$ ratio, $60.33 \mathrm{~mm}$ (2.375in) pad axial length, $0.08255 \mathrm{~mm}(0.00325 \mathrm{in})$ radial clearance in the load-on-pad orientation, and $0.1189 \mathrm{~mm}$ (0.00468 in) radial clearance in the loadbetween-pad orientation. Tests were conducted on a floating test bearing design with unit loads ranging from 0 to $2903 \mathrm{kPa}(421.1 \mathrm{psi})$ and speeds from 6.8 to $13.2 \mathrm{krpm}$.

For all rotor speeds, hot-clearance measurements were taken to show the reduction in bearing clearance due to thermal expansion of the shaft and pads during testing. As the testing conditions get hotter, the rotor, pads, and bearing expand, decreasing radial bearing clearance. Hot-clearance measurements showed a 16-25\% decrease in clearance compared to a clearance measurement at room temperature.

For all test conditions, dynamic tests were performed over a range of excitation frequencies to obtain complex dynamic stiffness coefficients as a function of frequency. The direct real dynamic stiffness coefficients were then fitted with a quadratic function with respect to frequency. From the curve fit, the frequency dependence was captured by including a virtual-mass matrix $[\mathrm{M}]$ to produce a frequency independent $[\mathrm{K}][\mathrm{C}][\mathrm{M}]$ model.
\end{abstract}

The direct dynamic stiffness coefficients for the load-on-pad orientation showed significant orthotropy, while the load-between-pad did not. The load-between-pad showed slight orthotropy as load increased. Experimental cross-coupled stiffness coefficients were measured in both load orientations, but were of the same sign and significantly less than direct stiffness coefficients.

In both orientations the imaginary part of the measured dynamic stiffness increased linearly with increasing frequency, allowing for frequency independent direct damping coefficients.

Rotordynamic coefficients presented were compared to predictions from two different Reynolds-based models. Both models showed the importance of taking into 
account pivot flexibility and different pad geometries (due to the reduction in bearing clearance during testing) in predicting rotordynamic coefficients. If either of these two inputs were incorrect, then predictions for the bearings impedance coefficients were very inaccurate. The main difference between prediction codes is that one of the codes incorporates pad flexibility in predicting the impedance coefficients for a tilting-pad journal bearing.

To look at the effects that pad flexibility has on predicting the impedance coefficients, a series of predictions were created by changing the magnitude of the pad's bending stiffness. Increasing the bending stiffness used in predictions by a factor of 10 typically caused a 3-11\% increase in predicted $K_{x x}$ and $K_{y y}$, and a $10-24 \%$ increase in predicted $C_{x x}$ and $C_{y y}$. In all cases, increasing the calculated bending stiffness from ten to a hundred times the calculated value caused slight if any change in $K_{x x}, K_{y y}, C_{x x}$, and $C_{y y}$. For a flexible pad an increase in bending stiffness can have a large effect on predictions; however, for a more rigid pad an increase in pad bending stiffness will have a much lesser effect.

Results showed that the pad's structural bending stiffness can be an important factor in predicting impedance coefficients. Even though the pads tested in this thesis are extremely stiff, changes are still seen in predictions when the magnitude of the pad's bending stiffness is increased, especially in $C_{x x}$, and $C_{y y}$. The code without pad flexibility predicted $K_{x x}$ and $K_{y y}$ much more accurately than the code with pad flexibility. The code with pad flexibility predicts $C_{x x}$ more accurately, while the code without pad flexibility predicted $C_{y y}$ more accurately. Regardless of prediction Code used, the $K_{x x}$ and $K_{y y}$ were over-predicted at low loads, but predicted more accurately as load increased. $C_{x x}$, and $C_{y y}$ were modeled very well in the load-on-pad orientation, while slightly overpredicted in the load-between-pad orientation. For solid pads, like the ones tested here, both codes do a decent job at predicting impedance coefficients. 


\title{
DEDICATION
}

\author{
For my family,
}

You don't choose your family. They are God's gift to you, as you are to them.

Desmond Tutu 


\section{ACKNOWLEDGEMENTS}

First I would like to express my thanks to Dr. Dara Childs for this opportunity to work at the Turbomachinery Laboratory. What I have learned will stay with me for the rest of my engineering career.

I would like to thank Dr. Alan Palazzolo and Dr. Lynn Beason for serving on my committee.

My sincere thanks to Dr. Jason Wilkes for all of his guidance and support through my time at Texas A\&M. Without Jason, the tests rig would not have been in its current condition, and my research would not have been possible.

I would like to thank all of the other students out at the Turbomachinery Laboratory - Michael Murphey, David Coghlan, Stephen Arthur, and Naitik Mehta, who made working at the lab enjoyable.

I would like to graciously thank my parents, Phil and Helen Tschoepe, for their constant love and support. They have given me so much in life and have never asked for anything in return. I would also like to thank my sisters: Elizabeth, Mary, and Rebecca. You will always be my best friends.

Lastly I would like to thank God for all that he has given me. Without Him, nothing is possible. 


\section{NOMENCLATURE}

$\boldsymbol{A}_{i j} \quad$ Fourier transforms for the measured stator acceleration. (e.g. $\mathrm{A}_{\mathrm{ij}}$ is the acceleration in the " $\mathrm{j}$ " direction, due to an excitation force in the "i $i$ " direction) $\left[\mathrm{L} / \mathrm{t}^{2}\right]$

$C_{i j} \quad$ Direct and cross-coupled damping coefficients [F.t/L]

$\Delta C_{i j} \quad$ Uncertainty of direct and cross-coupled damping coefficients [F.t/L]

$C_{b} \quad$ Radial bearing clearance [L]

$C_{p} \quad$ Radial pad clearance [L]

$c_{p} \quad$ Lubricant specific heat [FL/(M.t)]

D Bearing diameter [L]

$\boldsymbol{D}_{i j} \quad$ Fourier transforms for the measured stator relative motion [L]

$e_{x o} e_{y o} \quad$ Bearing equilibrium position in the $x, y$ directions [L]

$\boldsymbol{F}_{i j} \quad$ Fourier transforms for the measured stator force $[\mathrm{F}]$

$F_{s} \quad$ Static force applied by pneumatic loader [F]

$f_{b x} f_{b y} \quad$ Bearing reaction force component in the $x, y$ directions [F]

$f_{x} f_{y} \quad$ Measured excitation force component in the $x, y$ directions [F]

$\boldsymbol{H}_{i j} \quad$ Direct and cross-coupled dynamic stiffness [F/L]

$\Delta \boldsymbol{H}_{i j} \quad$ Uncertainty of direct and cross-coupled dynamic stiffness [F/L]

j Imaginary unit, $\sqrt{-1} \quad$ [-]

$k_{c_{p}} \quad$ Pad's structural bending stiffness [N]

$K_{i j} \quad$ Direct and cross-coupled stiffness coefficients [F/L]

$\Delta K_{i j} \quad$ Uncertainty of direct and cross-coupled stiffness coefficients [F/L]

$L \quad$ Pad length [L]

$M_{s} \quad$ Mass of the stator [M]

$M_{i j} \quad$ Direct and cross-coupled virtual-mass coefficients [M]

$\Delta M_{i j} \quad$ Uncertainty of virtual-mass coefficients [M]

$P \quad$ Bearing unit load, $\left(\frac{F_{S}}{L D}\right) \quad\left[\mathrm{F} / \mathrm{L}^{2}\right]$ 


\begin{tabular}{|c|c|}
\hline$\dot{Q}$ & Bearing oil supply flow rate $\left[\mathrm{L}^{3} / \mathrm{t}\right]$ \\
\hline$R$ & Bearing radius $[\mathrm{L}]$ \\
\hline $\operatorname{Re}$ & Reynolds number, $R e=\frac{\rho C_{b} R \omega}{\mu}[-]$ \\
\hline$r^{2}{ }_{i j}$ & Square of the correlation coefficient [-] \\
\hline$S$ & Sommerfeld number, $S=\frac{\mu N L D}{W}\left(\frac{R}{C_{b}}\right)^{2}[-]$ \\
\hline$T_{\text {in }}$ & Oil inlet temperature $[\mathrm{T}]$ \\
\hline$T_{\text {out }}$ & Oil outlet temperature (non-drive end) $[\mathrm{T}]$ \\
\hline$\ddot{x}_{s} \ddot{y}_{s}$ & Absolute acceleration of the stator in the $x, y$ directions $\left.\left[\mathrm{L} / \mathrm{t}^{2}\right]\right]$ \\
\hline$\Delta x \Delta y$ & Relative motion between the rotor and the stator in the $x, y$ directions [L] \\
\hline$\varepsilon_{0}$ & Static eccentricity ratio [-] \\
\hline$\phi$ & Attitude angle measured from the $+y$ axis to the $+x$ axis [Angle] \\
\hline$\Lambda$ & Square of the excitation frequency, $\Omega^{2}\left[(1 / \mathrm{t})^{2}\right]$ \\
\hline$\rho$ & Lubricant density $\left[\mathrm{M} / \mathrm{L}^{3}\right]$ \\
\hline$\mu$ & Lubricant viscosity $\left[\mathrm{F} . t / \mathrm{L}^{2}\right]$ \\
\hline$\omega$ & Running speed of rotor $[1 / t]$ \\
\hline$\Omega$ & Excitation frequency of stator $[1 / \mathrm{t}]$ \\
\hline \multicolumn{2}{|c|}{ Subscripts } \\
\hline$x, y$ & $x$ and $y$ direction \\
\hline$i, j$ & $x, y$ \\
\hline
\end{tabular}

\section{Abbreviations}

DE, NDE Drive end, non-drive end

LBP Load-between-pad

LOP Load-on-pad

rpm Revolutions per minute

TPJB Tilting-pad journal bearing

WFR Whirl frequency ratio 


\section{TABLE OF CONTENTS}

Page

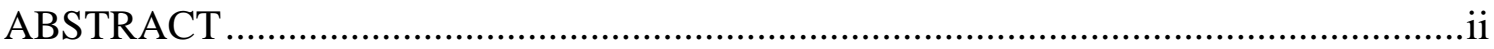

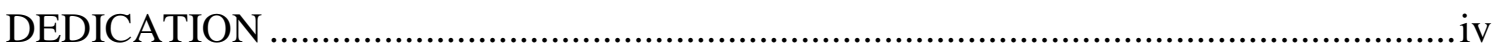

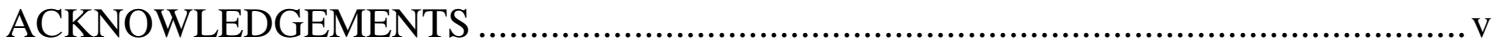

NOMENCLATURE ........................................................................................... vi

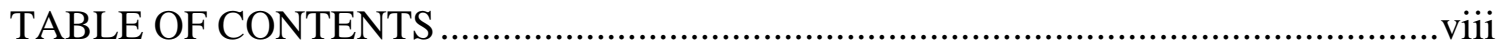

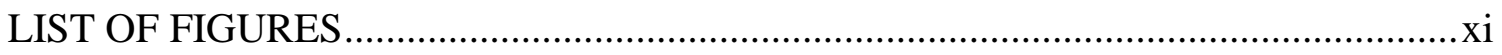

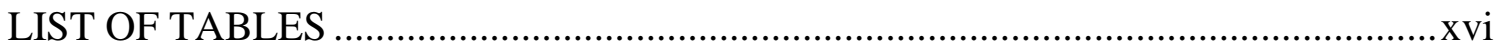

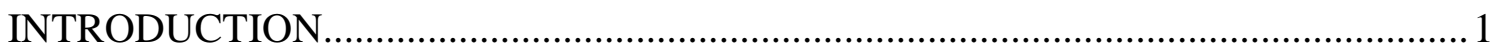

DESCRIPTION OF THE TEST RIG ................................................................. 11

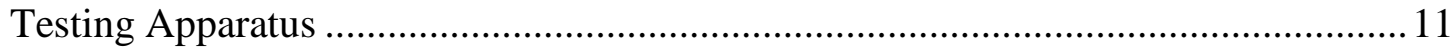

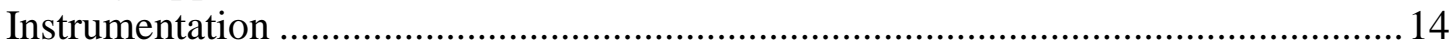

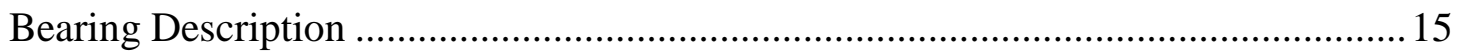

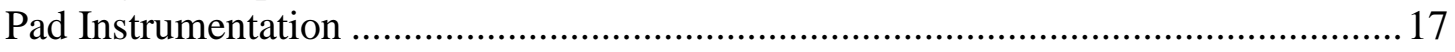

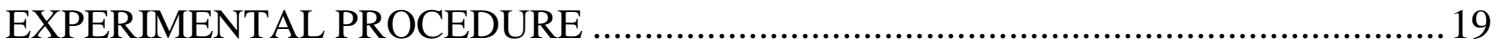

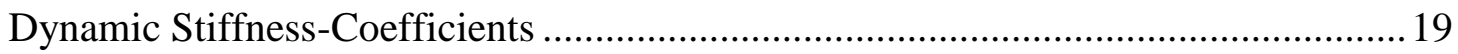

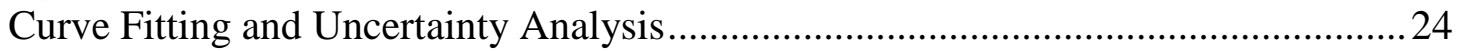

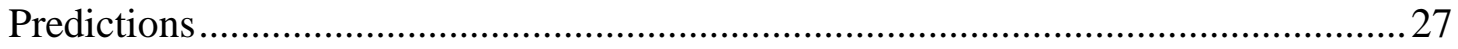

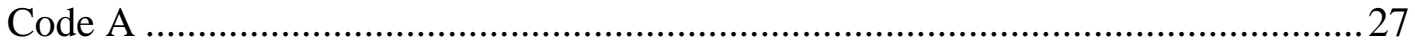

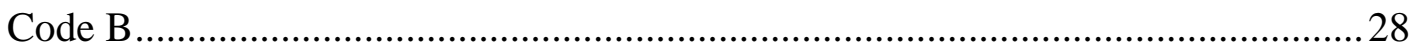

Input Parameters for Prediction Codes .................................................................... 30

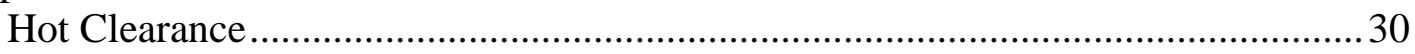

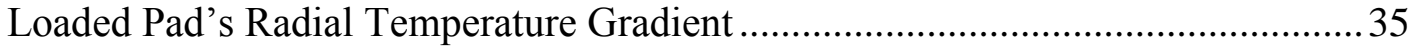

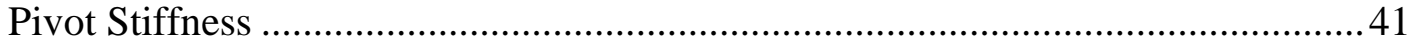

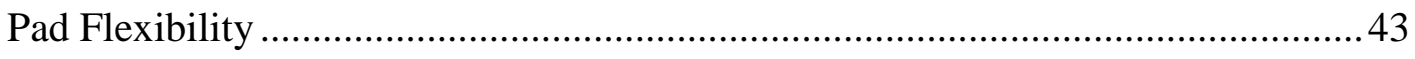


STATIC RESULTS

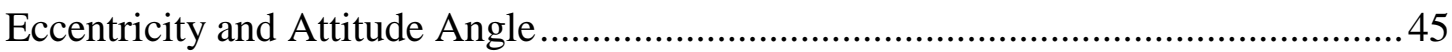

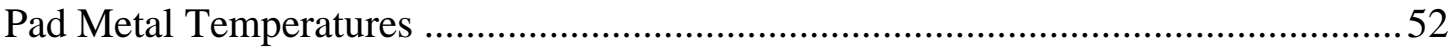

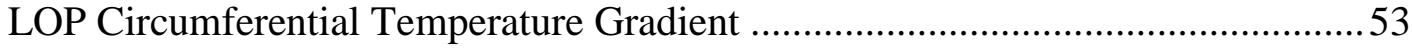

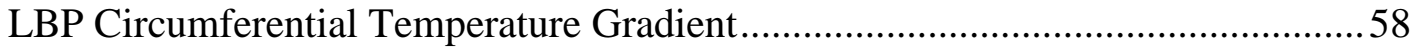

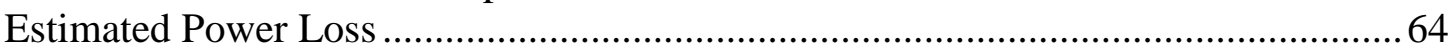

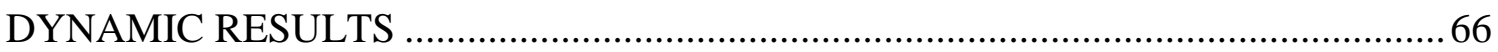

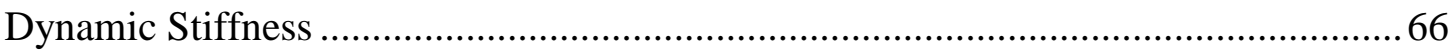

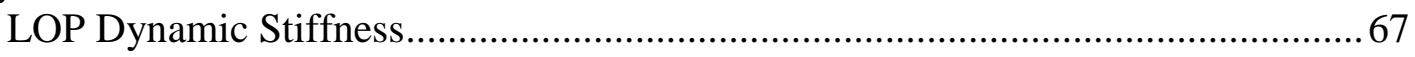

Importance of Pad Flexibility in Predictions ................................................. 75

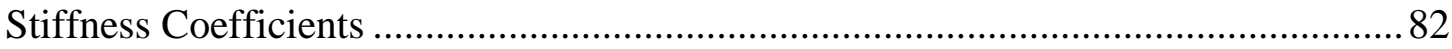

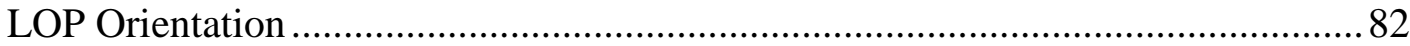

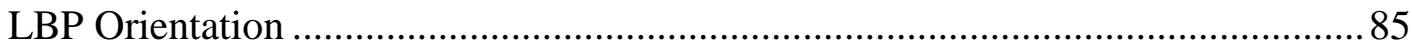

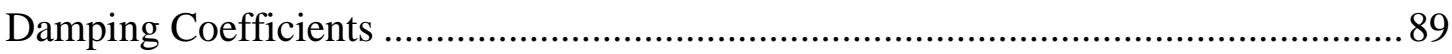

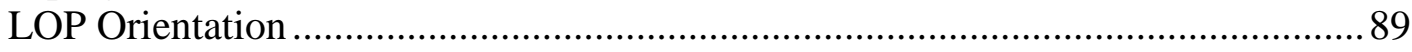

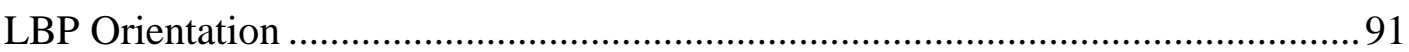

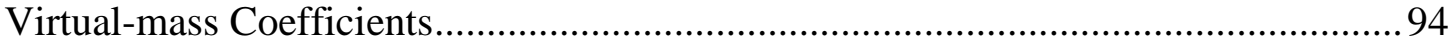

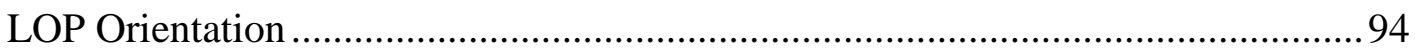

LBP Orientation ................................................................................... 97

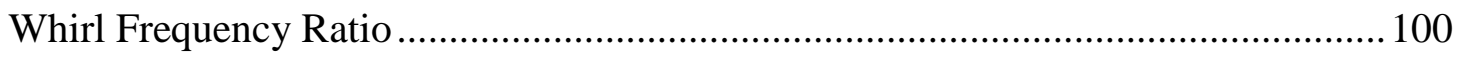

SUMMARY, DISCUSSION, AND CONCLUSIONS ......................................... 101

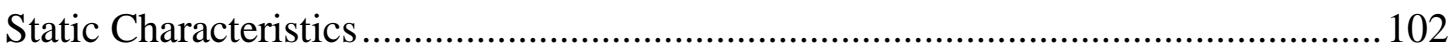

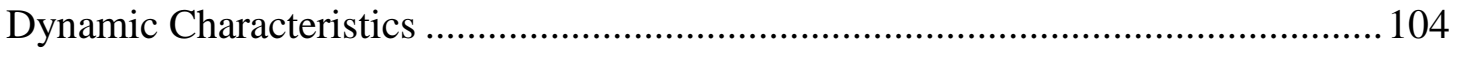

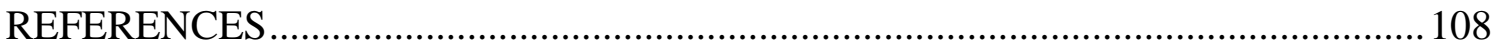

APPENDIX A: MEASURED ECCENTRICITY ............................................... 111

APPENDIX B: PAD METAL TEMPERATURES ….............................................. 113

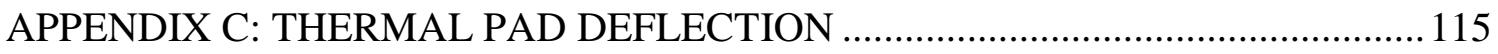

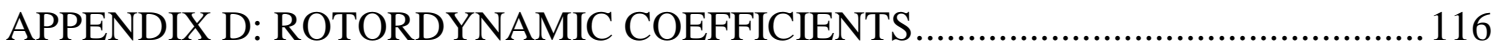

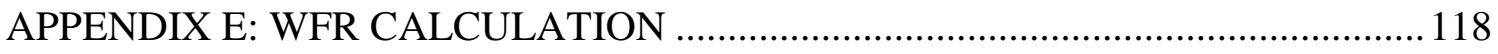

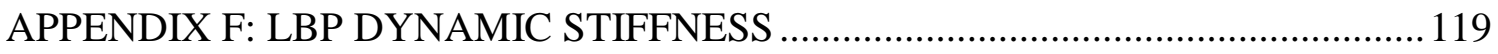


APPENDIX G: LBP IMPORTANCE OF PAD FLEXIBILITY …........................... 127

APPENDIX H: EXPERIMENTAL DYNAMIC STIFFNESS ................................. 133 


\section{LIST OF FIGURES}

Page

Figure 1: Rocker-Pivot Tilting-Pad Journal Bearing [1] ......................................... 1

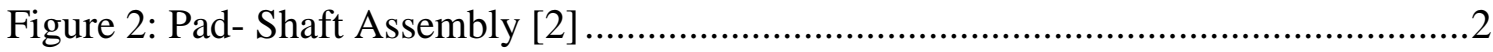

Figure 3: Flexure-Pivot Tilting-Pad Journal Bearing [15] .........................................

Figure 4: Change in Pad Curvature Resulting from Applied End Moments [14]............8

Figure 5: Test Rig Main Section [19] .............................................................. 11

Figure 6: Shaker-Stinger Arrangement (Adapted from [13]) ...................................13

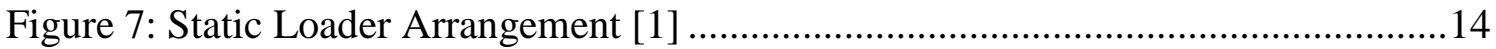

Figure 8: Bearing Configuration and Instrumentation (Adapted from [13])..................15

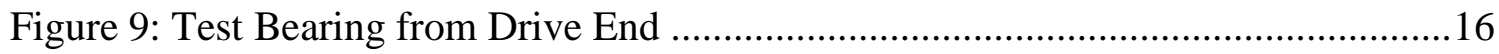

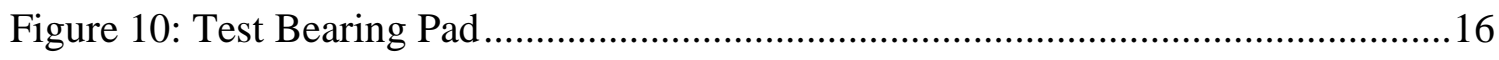

Figure 11: Proximity Probe Orientation on Loaded Pad (Adapted from [17]) ...............18

Figure 12: Baseline Real Direct and Cross-coupled Dynamic Stiffness ........................23

Figure 13: Baseline Imaginary Direct and Cross-coupled Dynamic Stiffness................23

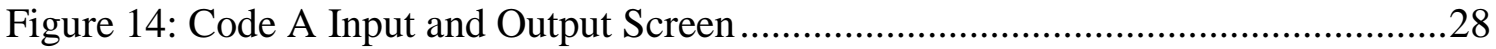

Figure 15: Measured Clearance at Room Temperature .............................................. 31

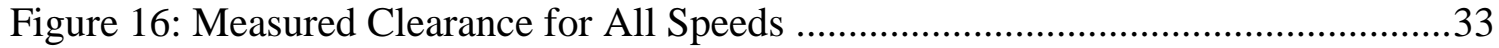

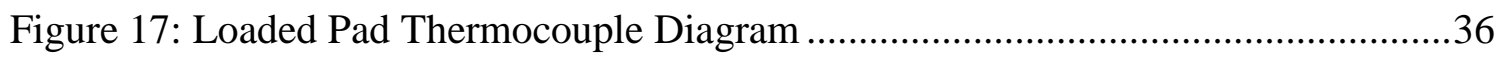

Figure 18: Loaded Pad Radial Temperature Difference ............................................37

Figure 19: FEA Temperature Distribution for LOP Orientation $13.2 \mathrm{krpm}$ with $1452 \mathrm{kPa}$ 
Figure 20: FEA Thermal Deflection for LOP Orientation $13.2 \mathrm{krpm}$ with 1452 $\mathrm{kPa}$

Figure 21: Comparison of Measured Pivot Load-Versus-Deflection .42

Figure 22: Illustration of Pad with a Pivot Insert [14] .44

Figure 23: LOP Measured Static Eccentricity at Various Speeds with Unit Loads in the Y-Direction from 0-2903 $\mathrm{kPa}$. .46

Figure 24: LBP Measured Static Eccentricity at Various Speeds with Unit Loads in the Y-Direction from 0-2903 kPa

Figure 25: LOP Bearing Loci................................................................................48

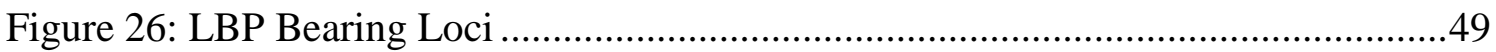

Figure 27: Measured and Predicted Attitude Angles LOP Orientation ...........................51

Figure 28: Measured and Predicted Attitude Angles LBP Orientation.............................52

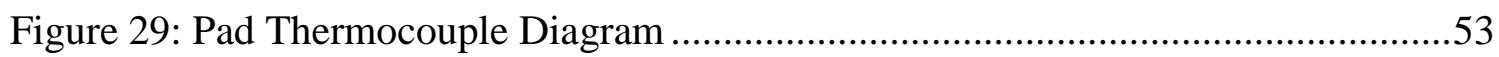

Figure 30: LOP Measured Pad Bearing Temperatures ...................................................54

Figure 31: LOP Measured Pad and Predicted Lubricant Temperatures at 6.8 krpm

Figure 32: LOP Measured Pad and Predicted Lubricant Temperatures at 13.2 $\mathrm{krpm}$

Figure 33: LBP Measured Pad Bearing Temperatures.

Figure 34: LBP Measured Pad and Predicted Lubricant Temperatures at 6.8 $\mathrm{krpm}$

Figure 35: LBP Measured Pad and Predicted Lubricant Temperatures at 13.2 $\mathrm{krpm}$ 62

Figure 36: Estimated and Predicted Power Loss .65 
Figure 37: LOP Components of Measurements and Predicted (Code B) Bearing Impedance Coefficients at $6.8 \mathrm{krpm}$ with $725 \mathrm{kPa}$ (105.3 psi) Static Load.

Figure 38: LOP Components of Measurements and Predicted (Code B) Bearing Impedance Coefficients at $6.8 \mathrm{krpm}$ with $2903 \mathrm{kPa}$ (421.1 psi) Static Load.

Figure 39: LOP Components of Measurements and Predicted (Code B) Bearing Impedance Coefficients at $13.2 \mathrm{krpm}$ with $725 \mathrm{kPa}$ (105.3 psi) Static Load.

Figure 40: LOP Components of Measurements and Predicted (Code B) Bearing Impedance Coefficients at $13.2 \mathrm{krpm}$ with $2903 \mathrm{kPa}$ (421.1 psi) Static Load. .73

Figure 41: Measured and Predicted Direct Stiffness Coefficients for LOP Orientation .76

Figure 42: Measured and Predicted Direct Stiffness Coefficients for LOP Orientation .

Figure 43: Measured and Predicted Direct Stiffness Coefficients for LOP Orientation

Figure 44: Measured and Predicted Direct Stiffness Coefficients for LOP Orientation

Figure 45: LOP Measured and Predicted $K_{x x}$ and $K_{y y}$ (A) $6.8 \mathrm{krpm}$, (B) $9 \mathrm{krpm}$, (C) $10.8 \mathrm{krpm}$, (D) $13.2 \mathrm{krpm}$

Figure 46: LOP Measured and Predicted $K_{x y}$ and $K_{y x}$ (A) $6.8 \mathrm{krpm}$, (B) $9 \mathrm{krpm}$, (C) $10.8 \mathrm{krpm}$, (D) $13.2 \mathrm{krpm}$ .84

Figure 47: LBP Measured and Predicted $K_{x x}$ and $K_{y y}$ (A) $6.8 \mathrm{krpm}$, (B) $9 \mathrm{krpm}$, (C) $10.8 \mathrm{krpm}$, (D) $13.2 \mathrm{krpm}$ .86

Figure 48: LBP Measured and Predicted $K_{x y}$ and $K_{y x}$ (A) $6.8 \mathrm{krpm}$, (B) $9 \mathrm{krpm}$, (C) $10.8 \mathrm{krpm}$, (D) $13.2 \mathrm{krpm}$

Figure 49: LOP Measured and Predicted $C_{x x}$ and $C_{y y}$ (A) $6.8 \mathrm{krpm}$, (B) $9 \mathrm{krpm}$, (C) $10.8 \mathrm{krpm}$, (D) $13.2 \mathrm{krpm}$ 
Figure 50: LOP Measured and Predicted $C_{x y}$ and $C_{y x}$ (A) $6.8 \mathrm{krpm}$, (B) $9 \mathrm{krpm}$,

(C) $10.8 \mathrm{krpm}$, (D) $13.2 \mathrm{krpm}$

Figure 51: LBP Measured and Predicted $C_{x x}$ and $C_{y y}$ (A) $6.8 \mathrm{krpm}$, (B) $9 \mathrm{krpm}$,

(C) $10.8 \mathrm{krpm}$, (D) $13.2 \mathrm{krpm}$

Figure 52: LBP Measured and Predicted $C_{x y}$ and $C_{y x}$ (A) $6.8 \mathrm{krpm}$, (B) $9 \mathrm{krpm}$,

(C) $10.8 \mathrm{krpm}$, (D) $13.2 \mathrm{krpm}$

Figure 53: LOP Measured and Predicted $M_{x x}$ and $M_{y y}$ (A) $6.8 \mathrm{krpm}$, (B) $9 \mathrm{krpm}$,

(C) $10.8 \mathrm{krpm}$, (D) $13.2 \mathrm{krpm}$

Figure 54: LOP Measured and Predicted $M_{x y}$ and $M_{y x}$ (A) $6.8 \mathrm{krpm}$, (B) $9 \mathrm{krpm}$, (C) $10.8 \mathrm{krpm}$, (D) $13.2 \mathrm{krpm}$ .96

Figure 55: LBP Measured and Predicted $M_{x x}$ and $M_{y y}$ (A) $6.8 \mathrm{krpm}$, (B) $9 \mathrm{krpm}$,

(C) $10.8 \mathrm{krpm}$, (D) $13.2 \mathrm{krpm}$.

Figure 56: LBP Measured and Predicted $M_{x y}$ and $M_{y x}$ (A) $6.8 \mathrm{krpm}$, (B) $9 \mathrm{krpm}$,

(C) $10.8 \mathrm{krpm}$, (D) $13.2 \mathrm{krpm}$

Figure 57: LBP Components of Measurements and Predicted (Code B) Bearing Impedance Coefficients at 6,800 rpm with $725 \mathrm{kPa}$ (105.3 psi) Static Load.

Figure 58: LBP Components of Measurements and Predicted (Code B) Bearing Impedance Coefficients at 6,800 rpm with $2903 \mathrm{kPa}$ (421.1 psi) Static Load.

Figure 59: LBP Components of Measurements and Predicted (Code B) Bearing Impedance Coefficients at $13.2 \mathrm{krpm}$ with $725 \mathrm{kPa}$ (105.3 psi) Static Load

Figure 60: LBP Components of Measurements and Predicted (Code B) Bearing Impedance Coefficients at $13.2 \mathrm{krpm}$ with $2903 \mathrm{kPa}$ (421.1 psi) Static Load.

Figure 61: Measured and Predicted Direct Stiffness Coefficients for LBP Orientation ..... 
Figure 62: Measured and Predicted Direct Stiffness Coefficients for LBP

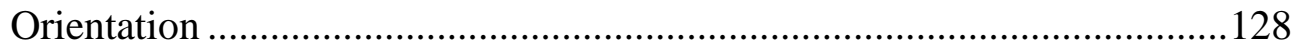

Figure 63: Measured and Predicted Direct Stiffness Coefficients for LBP

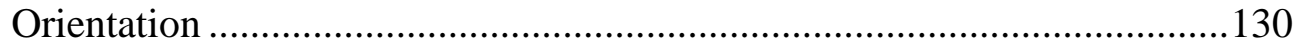

Figure 64: Measured and Predicted Direct Stiffness Coefficients for LBP

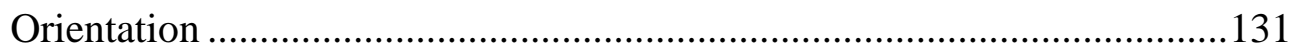




\section{LIST OF TABLES}

Table 1: Definitions of Tilting-Pad Bearing Geometry Parameters ..................................2

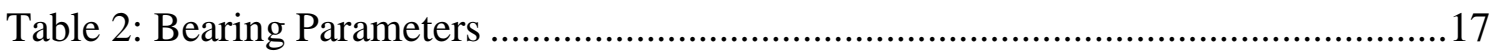

Table 3: Matrix of Nominal Test Conditions .................................................................19

Table 4: Experimental Uncertainties for the LOP Orientation at $13.2 \mathrm{krpm}$ and

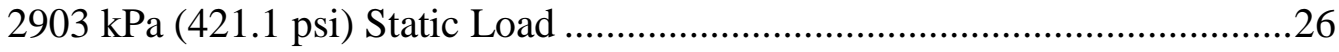

Table 5: Difference Between Predictions....................................................................29

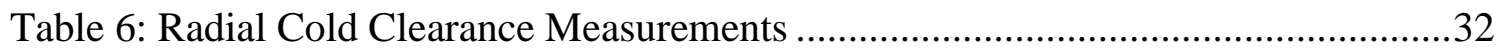

Table 7: LOP Radial Hot Clearance Measurements ......................................................34

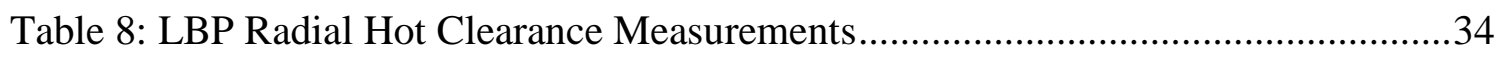

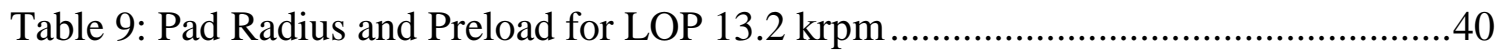

Table 10: Prediction Comparisons of 13.2 krpm with 2903 kPa Static Load .................81

Table 11: LOP Measured Attitude Angle and Eccentricity ......................................111

Table 12: LBP Measured Attitude Angle and Eccentricity .....................................112

Table 13: LOP Pad Metal Temperatures ............................................................. 113

Table 14: LBP Pad Metal Temperatures ........................................................... 114

Table 15: LOP Experimental Rotordynamic Coefficients .......................................116

Table 16: LBP Experimental Rotordynamic Coefficients .......................................117

Table 17: Dynamic Stiffness Real and Imaginary Parts at $6800 \mathrm{rpm}$ and $0 \mathrm{kPa}$ $(\mathrm{MN} / \mathrm{m})$

Table 18: Dynamic Stiffness Real and Imaginary Parts at $6800 \mathrm{rpm}$ and $783 \mathrm{kPa}$ $(\mathrm{MN} / \mathrm{m})$ 
Table 19: Dynamic Stiffness Real and Imaginary Parts at $6800 \mathrm{rpm}$ and 1567 $\mathrm{kPa}(\mathrm{MN} / \mathrm{m})$

Table 20: Dynamic Stiffness Real and Imaginary Parts at $6800 \mathrm{rpm}$ and 2350 $\mathrm{kPa}(\mathrm{MN} / \mathrm{m})$

Table 21: Dynamic Stiffness Real and Imaginary Parts at $6800 \mathrm{rpm}$ and 3134 $\mathrm{kPa}(\mathrm{MN} / \mathrm{m})$

Table 22: Dynamic Stiffness Real and Imaginary Parts at $9000 \mathrm{rpm}$ and $0 \mathrm{kPa}$ $(\mathrm{MN} / \mathrm{m})$

Table 23: Dynamic Stiffness Real and Imaginary Parts at $9000 \mathrm{rpm}$ and $783 \mathrm{kPa}$ $(\mathrm{MN} / \mathrm{m})$

Table 24: Dynamic Stiffness Real and Imaginary Parts at $9000 \mathrm{rpm}$ and 1567 $\mathrm{kPa}(\mathrm{MN} / \mathrm{m})$.

Table 25: Dynamic Stiffness Real and Imaginary Parts at $9000 \mathrm{rpm}$ and 2350 $\mathrm{kPa}(\mathrm{MN} / \mathrm{m})$.

Table 26: Dynamic Stiffness Real and Imaginary Parts at $9000 \mathrm{rpm}$ and 3134 $\mathrm{kPa}(\mathrm{MN} / \mathrm{m})$.

Table 27: Dynamic Stiffness Real and Imaginary Parts at $10800 \mathrm{rpm}$ and $0 \mathrm{kPa}$ $(\mathrm{MN} / \mathrm{m})$

Table 28: Dynamic Stiffness Real and Imaginary Parts at 10800 rpm and 783 $\mathrm{kPa}(\mathrm{MN} / \mathrm{m})$.

Table 29: Dynamic Stiffness Real and Imaginary Parts at 10800 rpm and 1567 $\mathrm{kPa}(\mathrm{MN} / \mathrm{m})$

Table 30: Dynamic Stiffness Real and Imaginary Parts at 10800 rpm and 2350 $\mathrm{kPa}(\mathrm{MN} / \mathrm{m})$.

Table 31: Dynamic Stiffness Real and Imaginary Parts at 10800 rpm and 3134 $\mathrm{kPa}(\mathrm{MN} / \mathrm{m})$.

Table 32: Dynamic Stiffness Real and Imaginary Parts at $13200 \mathrm{rpm}$ and $0 \mathrm{kPa}$ $(\mathrm{MN} / \mathrm{m})$ 
Table 33: Dynamic Stiffness Real and Imaginary Parts at 13200 rpm and 783 $\mathrm{kPa}(\mathrm{MN} / \mathrm{m})$

Table 34: Dynamic Stiffness Real and Imaginary Parts at $13200 \mathrm{rpm}$ and 1567 $\mathrm{kPa}(\mathrm{MN} / \mathrm{m})$

Table 35: Dynamic Stiffness Real and Imaginary Parts at $13200 \mathrm{rpm}$ and 2350 $\mathrm{kPa}(\mathrm{MN} / \mathrm{m})$

Table 36: Dynamic Stiffness Real and Imaginary Parts at $13200 \mathrm{rpm}$ and 3134 $\mathrm{kPa}(\mathrm{MN} / \mathrm{m})$

Table 37: Dynamic Stiffness Real and Imaginary Parts at $6800 \mathrm{rpm}$ and $0 \mathrm{kPa}$ $(\mathrm{MN} / \mathrm{m})$

Table 38: Dynamic Stiffness Real and Imaginary Parts at $6800 \mathrm{rpm}$ and $783 \mathrm{kPa}$ $(\mathrm{MN} / \mathrm{m})$

Table 39: Dynamic Stiffness Real and Imaginary Parts at $6800 \mathrm{rpm}$ and 1567 $\mathrm{kPa}(\mathrm{MN} / \mathrm{m})$

Table 40: Dynamic Stiffness Real and Imaginary Parts at $6800 \mathrm{rpm}$ and 2350 $\mathrm{kPa}(\mathrm{MN} / \mathrm{m})$

Table 41: Dynamic Stiffness Real and Imaginary Parts at $6800 \mathrm{rpm}$ and 3134 $\mathrm{kPa}(\mathrm{MN} / \mathrm{m})$

Table 42: Dynamic Stiffness Real and Imaginary Parts at $9000 \mathrm{rpm}$ and $0 \mathrm{kPa}$ $(\mathrm{MN} / \mathrm{m})$

Table 43: Dynamic Stiffness Real and Imaginary Parts at $9000 \mathrm{rpm}$ and $783 \mathrm{kPa}$ $(\mathrm{MN} / \mathrm{m})$

Table 44: Dynamic Stiffness Real and Imaginary Parts at $9000 \mathrm{rpm}$ and 1567 $\mathrm{kPa}(\mathrm{MN} / \mathrm{m})$

Table 45: Dynamic Stiffness Real and Imaginary Parts at $9000 \mathrm{rpm}$ and 2350 $\mathrm{kPa}(\mathrm{MN} / \mathrm{m})$

Table 46: Dynamic Stiffness Real and Imaginary Parts at $9000 \mathrm{rpm}$ and 3134 $\mathrm{kPa}(\mathrm{MN} / \mathrm{m})$ 
Table 47: Dynamic Stiffness Real and Imaginary Parts at $10800 \mathrm{rpm}$ and $0 \mathrm{kPa}$ $(\mathrm{MN} / \mathrm{m})$

Table 48: Dynamic Stiffness Real and Imaginary Parts at $10800 \mathrm{rpm}$ and 783 $\mathrm{kPa}(\mathrm{MN} / \mathrm{m})$

Table 49: Dynamic Stiffness Real and Imaginary Parts at 10800 rpm and 1567 $\mathrm{kPa}(\mathrm{MN} / \mathrm{m})$

Table 50: Dynamic Stiffness Real and Imaginary Parts at $10800 \mathrm{rpm}$ and 2350 $\mathrm{kPa}(\mathrm{MN} / \mathrm{m})$..... 166

Table 51: Dynamic Stiffness Real and Imaginary Parts at 10800 rpm and 3134 $\mathrm{kPa}(\mathrm{MN} / \mathrm{m})$

Table 52: Dynamic Stiffness Real and Imaginary Parts at $13200 \mathrm{rpm}$ and $0 \mathrm{kPa}$ $(\mathrm{MN} / \mathrm{m})$

Table 53: Dynamic Stiffness Real and Imaginary Parts at $13200 \mathrm{rpm}$ and 783 $\mathrm{kPa}(\mathrm{MN} / \mathrm{m})$

Table 54: Dynamic Stiffness Real and Imaginary Parts at 13200 rpm and 1567 $\mathrm{kPa}(\mathrm{MN} / \mathrm{m})$

Table 55: Dynamic Stiffness Real and Imaginary Parts at $13200 \mathrm{rpm}$ and 2350 $\mathrm{kPa}(\mathrm{MN} / \mathrm{m})$....

Table 56: Dynamic Stiffness Real and Imaginary Parts at 13200 rpm and 3134 $\mathrm{kPa}(\mathrm{MN} / \mathrm{m})$ 


\section{INTRODUCTION}

Bearings, which are essential components of most mechanical designs, allow for rotation between objects while transferring reaction forces from one object to another. As a component in rotating machinery, tilting-pad journal bearings (TPJBs) are widely used to increase the limit of stability over fixed-geometry bearings. TPJBs allow for rotor support, by lifting the rotor to avoid contact through the combined actions of the shaft rotation and the lubricant's viscosity. Figure 1 below provides a general rocker-pivot TPJB schematic. For a vertical downward load, a load-betweenpad (LBP) orientation is illustrated. A rocker-pivot TPJB frequently uses cylindricalbacked pads inside the curvature of the bearing housing, ideally allowing the pads to roll without slip.

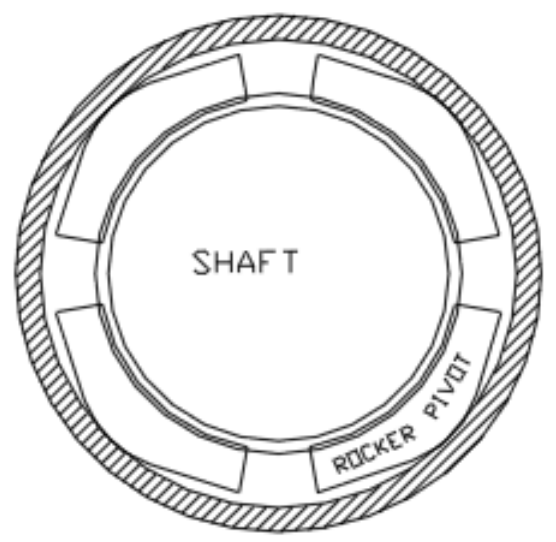

Figure 1: Rocker-Pivot Tilting-Pad Journal Bearing [1] 
TPJB performance can be affected by various geometric parameters. The applicable parameters are defined in Table 1 and shown in Figure 2 below. In a vertical downward load, Figure 2 illustrates a load-on-pad (LOP) configuration with a spherical seat support.

Table 1: Definitions of Tilting-Pad Bearing Geometry Parameters

\begin{tabular}{|c|c|}
\hline SYMBOL & DEFINITION \\
\hline $\mathrm{R}_{\mathrm{b}}$ & Bearing Radius \\
\hline $\mathrm{R}_{\mathrm{p}}$ & Pad Radius \\
\hline $\mathrm{R}_{\mathrm{s}}$ & Shaft Radius \\
\hline$\theta_{\mathrm{pad}}$ & Pad Arc Angle \\
\hline$\theta_{\text {pivot }}$ & Pivot Arc Angle \\
\hline $\mathrm{L}$ & Pad Axial Length \\
\hline $\mathrm{L} / \mathrm{D}$ & Length to Diameter Ratio \\
\hline $\mathrm{C}_{\mathrm{b}}$ & Radial Bearing Clearance, $\mathrm{C}_{\mathrm{b}}=\mathrm{R}_{\mathrm{b}}-\mathrm{R}_{\mathrm{s}}$ \\
\hline $\mathrm{C}_{\mathrm{p}}$ & Radial Pad Clearance, $\mathrm{C}_{\mathrm{p}}=\mathrm{R}_{\mathrm{p}}-\mathrm{R}_{\mathrm{s}}$ \\
\hline
\end{tabular}

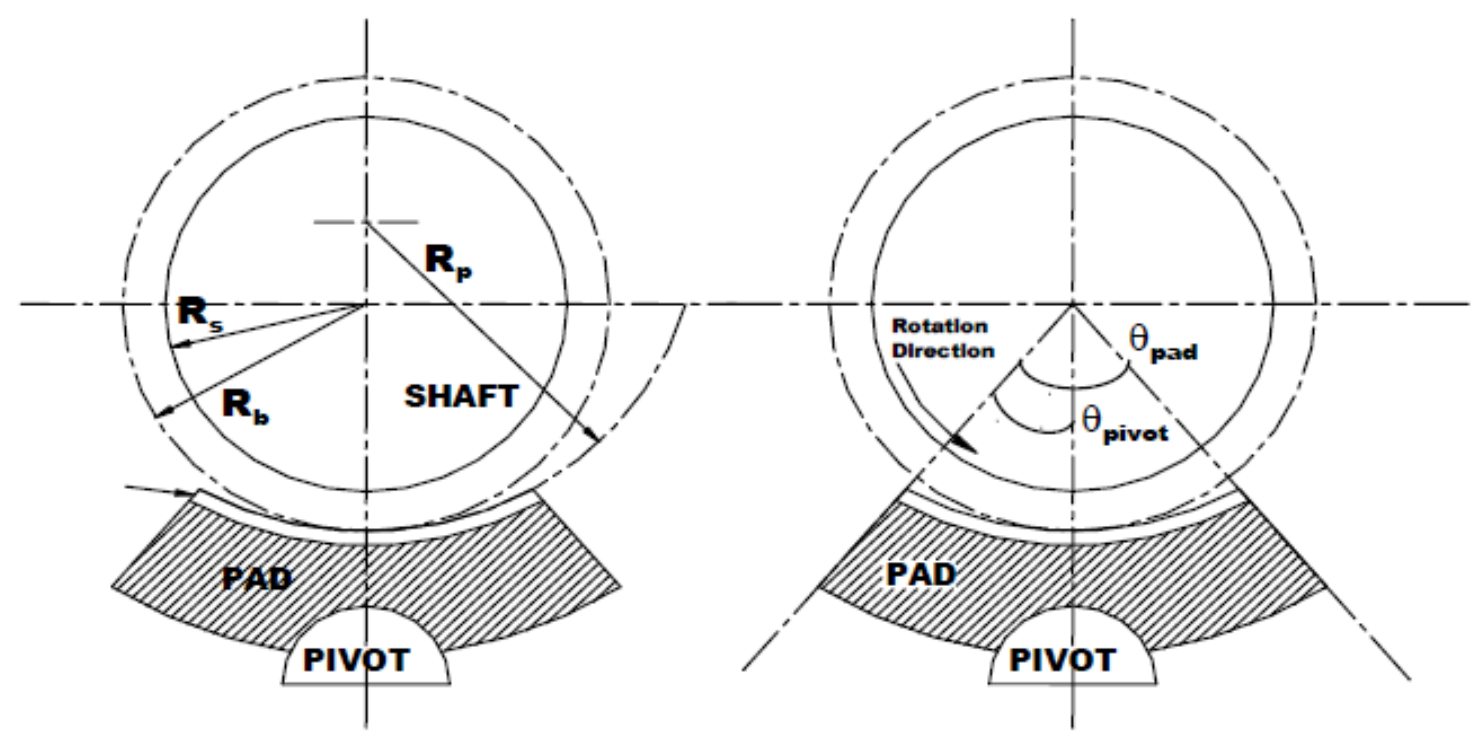

Figure 2: Pad- Shaft Assembly [2] 
Figure 2 shows the radius of the pad, bearing, and shaft as well as the pad's pivot offset. Pivot offset is the location of the pivot relative to the leading and trailing edges of the pad, defined by

$$
\text { PIVOT OFFSET }=\frac{\theta_{\text {pivot }}}{\theta_{\text {pad }}}
$$

For a pad with a centered pivot, the offset is 0.5 . Pad offsets of 0.5 to 0.6 are commonly used in industrial applications.

Table 1 shows the radial pad and bearing clearance, $C_{p}$ and $C_{b}$ respectively. The bearing and pad clearance are commonly related by preload. Preload is a nondimensional parameter quantifying the difference in pad and journal radius defined by

$$
P A D \text { PRELOAD }=1-\frac{C_{b}}{C_{p}}
$$

For a TPJB, a positive preload typically prevents pad flutter. Pad flutter is an instability that can arise during unloaded bearing operation, where the unloaded pads vibrate due to an absence of fluid film forces. Negative preload is typically avoided.

Static external loads are generally applied to a TPJB in either the load-on-pad (LOP) or load-between-pad (LBP) configuration. Typically, the LBP orientation is used to support heavier rotors and is expected to provide more symmetric rotordynamic coefficients. Generally the LOP orientation is expected to provide stiffness orthotropy (to enhance stability), or stiffness asymmetry in that the loaded direction has a larger stiffness. 
Using small motions about equilibrium, the dynamic reaction fluid forces acting between a TPJB and rotor can be modeled as a linearized two degree-of-freedom system with stiffness and damping matrices, as shown in Eq. (3).

$$
-\left\{\begin{array}{l}
f_{x} \\
f_{y}
\end{array}\right\}=\left[\begin{array}{ll}
K_{x x} & K_{x y} \\
K_{y x} & K_{y y}
\end{array}\right]\left\{\begin{array}{l}
\Delta \mathrm{x} \\
\Delta \mathrm{y}
\end{array}\right\}+\left[\begin{array}{ll}
C_{x x} & C_{x y} \\
C_{y x} & C_{y y}
\end{array}\right]\left\{\begin{array}{l}
\Delta \dot{\mathrm{x}} \\
\Delta \dot{\mathrm{y}}
\end{array}\right\}
$$

Here, $\Delta x$ and $\Delta y$ and their time derivatives define the relative motion between the rotor and the stator. Similar subscripts $(x x, y y)$ represent direct coefficients while, different subscripts $(x y, y x)$ represent cross-coupled coefficients. Direct coefficients produce reactions forces against the direction of the displacement or velocity vectors. Crosscoupled terms produce reaction forces perpendicular to the displacement or velocity vectors.

In 1964, Lund [3] pioneered the analysis for predicting dynamic force coefficients of TPJBs. The bearing model is obtained by summing the contribution of each pad to acquire the stiffness and damping in two orthogonal directions. Lund presented a basis used to predict the dynamic performance of TPJBs and was able to present stiffness and damping design curves for numerous bearing configurations.

Following Lund's work, other analytical studies [4]-[6] indicated that TPJB rotordynamic coefficients may be frequency dependent, but experimental data to confirm these predictions were more limited. In 1978, Nicolas, Gunter, and Allaire [4] calculated pad dynamic data with a finite-element method and determined bearing stiffness and damping design curves. In 1983, Parsell et al. [5] derived rotordynamic coefficients for a 
5-pad TPJB and predicted that the resulting direct damping coefficients increased with increasing precession frequency while the stiffness coefficients decreased with increasing frequency.

In 1999, Ha and Yang [7] tested a 5-pad, $300 \mathrm{~mm}$ (11.8 in) diameter rocker-pivot TPJB in the load-on-pad (LOP) orientation. The rotordynamic coefficients were obtained at a frequency range of $25-60 \mathrm{~Hz}$ and a rotor speed of 3,600 rpm. Testing was conducted at a single excitation frequency, ranging from 0.5 to 2 times the running speed. Their results indicated that the stiffness coefficients slightly decreased with increasing excitation frequency, while the damping coefficients slightly increased. Wygant's [8] measurements showed that, when the $[\mathrm{K}][\mathrm{C}]$ model in Eq. (3) is used, the stiffness and damping coefficients depend slightly on precession frequency.

In 2006, Rodriguez and Childs [9] tested a four-pad, $116.8 \mathrm{~mm}$ (4.6 in) diameter, LOP, 0.25 preload, $50 \%$ pad pivot offset, flexure-pivot TPJB. Figure 3 shows the flexurepivot design.

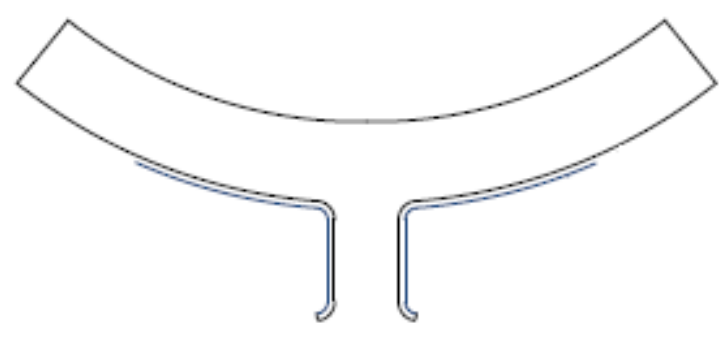

Figure 3: Flexure-Pivot Tilting-Pad Journal Bearing [15] 
Through their results, the authors investigated the conventional frequency dependency of TPJB rotordynamic coefficients in more detail by applying a $[\mathrm{K}][\mathrm{C}][\mathrm{M}]$ model.

$$
-\left\{\begin{array}{l}
f_{x} \\
f_{y}
\end{array}\right\}=\left[\begin{array}{ll}
K_{x x} & K_{x y} \\
K_{y x} & K_{y y}
\end{array}\right]\left\{\begin{array}{l}
\Delta \mathrm{x} \\
\Delta \mathrm{y}
\end{array}\right\}+\left[\begin{array}{ll}
C_{x x} & C_{x y} \\
C_{y x} & C_{y y}
\end{array}\right]\left\{\begin{array}{l}
\Delta \dot{\mathrm{x}} \\
\Delta \dot{\mathrm{y}}
\end{array}\right\}+\left[\begin{array}{ll}
M_{x x} & M_{x y} \\
M_{y x} & M_{y y}
\end{array}\right]\left\{\begin{array}{l}
\Delta \ddot{\mathrm{x}} \\
\Delta \ddot{\mathrm{y}}
\end{array}\right\}
$$

The $[\mathrm{K}][\mathrm{C}][\mathrm{M}]$ model, described in Eq. (4), uses a virtual-mass matrix to capture the frequency dependency of the stiffness in a $[\mathrm{K}][\mathrm{C}]$ model. When the real dynamicstiffness coefficients were curve fitted as a quadratic function of excitation frequency, frequency-independent stiffness and virtual-mass coefficients arose. Rodriguez and Childs used multi-frequency excitation ranging from 20 to $300 \mathrm{~Hz}$ in $20 \mathrm{~Hz}$ increments. Results showed that a $[\mathrm{K}][\mathrm{C}][\mathrm{M}]$ model correlated closely with the data. In particular, the measured damping coefficients were independent of excitation frequency. The validity of the frequency-independent $[\mathrm{K}][\mathrm{C}][\mathrm{M}]$ model was further verified by $\mathrm{Al}$ Ghasem and Childs [1] and Hensley and Childs [10] for flexure-pivot TPJBs.

In 2008, Carter and Childs [11] tested a 5-pad, 60\% pivot offset, rocker-pivot TPJB in the LBP and LOP configurations. The bearing included a half-flooded design with one seal preventing axial leakage in one direction. Experimental results showed direct damping coefficients to be independent of frequency with very little change with respect to load and speed. Reviewers of their paper suggested that pads with a 50\% pivot offset were more likely to exhibit frequency dependence than pads with a $60 \%$ pivot offset in the rocker-pivot TPJB design.

In 2010, Delgado et al. [12] tested both a 5-pad LOP, and 4-pad LBP rocker- 
pivot tilting-pad journal bearing to study the frequency dependency of the rotordynamic coefficients. Both bearings had a $109 \mathrm{~mm}$ (4.29 in) diameter, 50\% and 60\% pad pivot offset, and $0.4 \mathrm{~L} / \mathrm{D}$ ratio. Testing was performed at $7.5,10$, and $17 \mathrm{krpm}$ with a static unit load of $300 \mathrm{kPa}$ (44 psi). Through utilizing a multi-frequency excitation, dynamic stiffness coefficients were acquired. When using a $[\mathrm{K}][\mathrm{C}][\mathrm{M}]$ model, the data showed that all rotordynamic coefficients exhibit slight or no dependency regarding excitation frequency.

In 2010, Kulhanek and Childs [13] tested a five-pad, LBP, 0.3 preload, rockerpivot TPJB with $50 \%$ and $60 \%$ pad offsets. Testing was performed with static unit loads from zero to $3,101 \mathrm{kPa}$ (450 psi). Using a virtual-mass coefficient they accounted for an increasing direct dynamic stiffness that occurred with an increasing excitation frequency in both pivot offsets tested. Overall, using the same $[\mathrm{K}][\mathrm{C}][\mathrm{M}]$ model, Kulhanek produced rotordynamic coefficients and dynamic stiffness results that agreed with the findings by Delgado et al. [12].

In 2012, Wilkes and Childs [14] tested a five-pad, LOP, 0.44 preload, 50\% offset, rocker-pivot TPJB. Through the authors' study, a new bearing perturbation model was proposed allowing for both journal and bearing motion, including pad rotation, pad compliance, and radial pivot flexibility. A Reynolds-equation finite-difference code was used producing real and imaginary dynamic stiffness coefficients. The model shows the importance of pivot and pad flexibility in predicting the impedance coefficients for a tilting-pad journal bearing. The pivot stiffness, or pivot flexibility, refers to the flexibility of the pad relative to the bearing housing and partially results from Hertzian 
contact stiffness [15]. As shown in Figure 4, the pad flexibility refers to the change in pad curvature resulting from an applied moment at the end of the pad from the fluid film pressure.

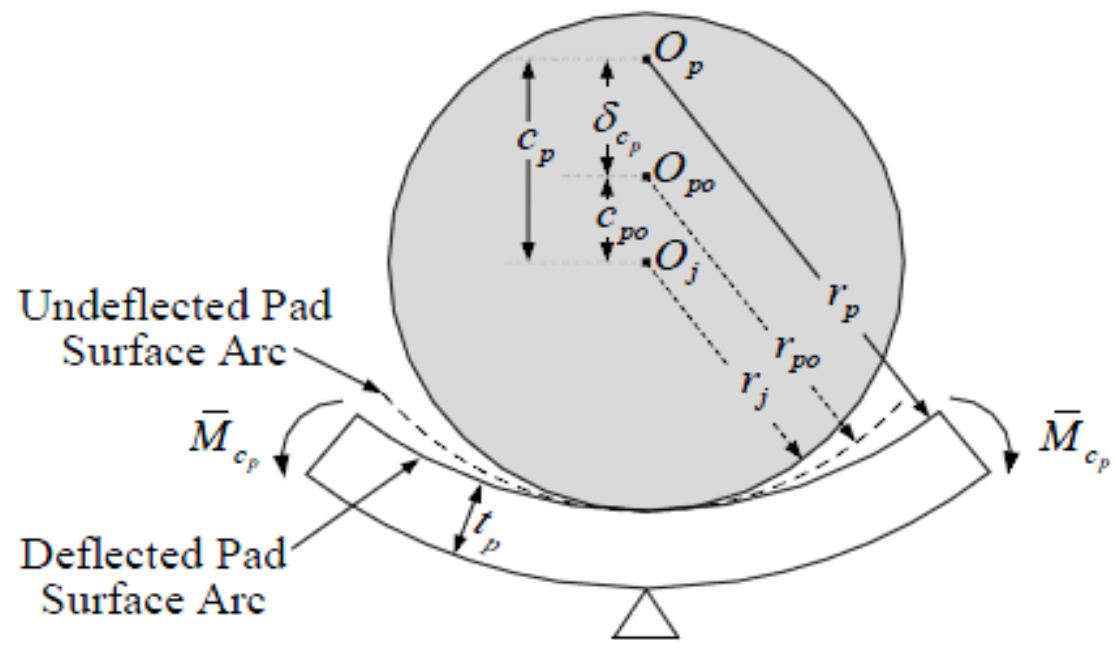

Figure 4: Change in Pad Curvature Resulting from Applied End Moments [14]

where $O_{j}$ and $O_{p}$ represent the centers of the journal and bearing respectively and $\delta_{c_{p}}$ is the change in pad radius resulting from the applied pressure field.

From Figure 4, the deflected pad surface resulting from the applied end moments has a radius $r_{p}$, defined by

$$
r_{p}=r_{p o}+\delta_{c_{p}}
$$

In taking a modified version of Branagan and Barrett [16], Wilkes obtained the following model for pad stiffness 


$$
\delta_{c_{p}}=\frac{M_{c_{p}}}{k_{c_{p}}}
$$

where $M_{c_{p}}$ is the average applied fluid-film moment and $k_{c_{p}}$ represents the pad's structural bending stiffness that relates the moment to the change in pad clearance. Overall, the model by Wilkes and Childs showed significant improvements in predicted direct stiffness and damping coefficients when pivot and pad flexibility were included.

This thesis presents the measured and predicted dynamic and static characteristics for a 4-pad rocker-pivot tilting-pad journal bearing in the load-on-pad and load-betweenpad orientations. This work focuses on the frequency dependence of the rotordynamic coefficients at a pivot offset and $L / D$ ratio not typically tested: .57 and 0.6 , respectively.

In addition to testing a different offset and $L / D$ ratio, this thesis will explore unit loads greater than that of Delgado et al. [12]. Test results include static unit loads from zero to $2903 \mathrm{kPa}$ (421.1 psi). Test results will also be delivered in both the LOP and LBP orientation. Delgado only presented results for a 4-pad bearing in the LBP orientation.

To study the radial temperature gradient experienced during testing, pad metal temperatures were taken with thermocouples embedded just below the surface of the loaded pad as well as, near the bearing housing. In 1988, Branagan and Barrett [16] studied the thermal deflection associated with a TPJB pad during operation, but pad temperatures at the back of the pad (bearing housing side of the pad) were not measured. The bearing housing side of the pad was modeled to be dominated by a stagnant sump region behind the pad, and was characterized to be fixed at the inlet oil temperature to the bearing. Through a finite-element (FE) analysis, Branagan found that the thermal 
deformed pad showed a radial growth of $0.0034-0.0059 \mathrm{~mm}(0.00013-0.00023 \mathrm{in})$, increasing the radial pad clearance. Branagan found that the sharp drop in bearing clearance had a greater effect on pad preload and was not counteracted by the slight increase in radial pad clearance. He established that taking into account all pad and especially pivot deformations resulted in dramatic changes in predicting dynamic coefficients.

Static results and rotordynamic coefficients presented will be compared to predictions from a new rotordynamic bearing code, "Code A" developed by Tao and San Andrés at the Texas A\&M Turbomachinery Laboratory. The predictions come from the first version of this code to be published in the near future. A full description of Code A can be found in the Predictions section. Code A takes into account pivot flexibility with a user-defined load-versus-deflection approximation, and if needed, different pad geometries (preloads and clearances) to predict the static and dynamic behavior of a TPJB.

Dynamic stiffness results presented will be compared to the model of Wilkes and Childs [14][17][18], "Code B”. Wilkes dissertation [15] uses a Reynolds-based model to predict dynamic results, utilizing pivot and pad flexibility. A full description of Wilkes code can be found in the Predictions section. In taking into account pad and contact flexibility, Wilkes was able to substantially improve predictions for the direct stiffness and damping coefficients for a five-pad, rocker-pivot TPJB. 


\section{DESCRIPTION OF THE TEST RIG}

\section{Testing Apparatus}

Figure 5 shows the bearing test rig used to measure the static and dynamic performance of the high-speed TPJB. Kaul [19] presents a detailed account of the floating test rig design and facility at the Texas A\&M Turbomachinery Laboratory. Similar to Glienicke' approach [20], the main features of the test rig are described below.

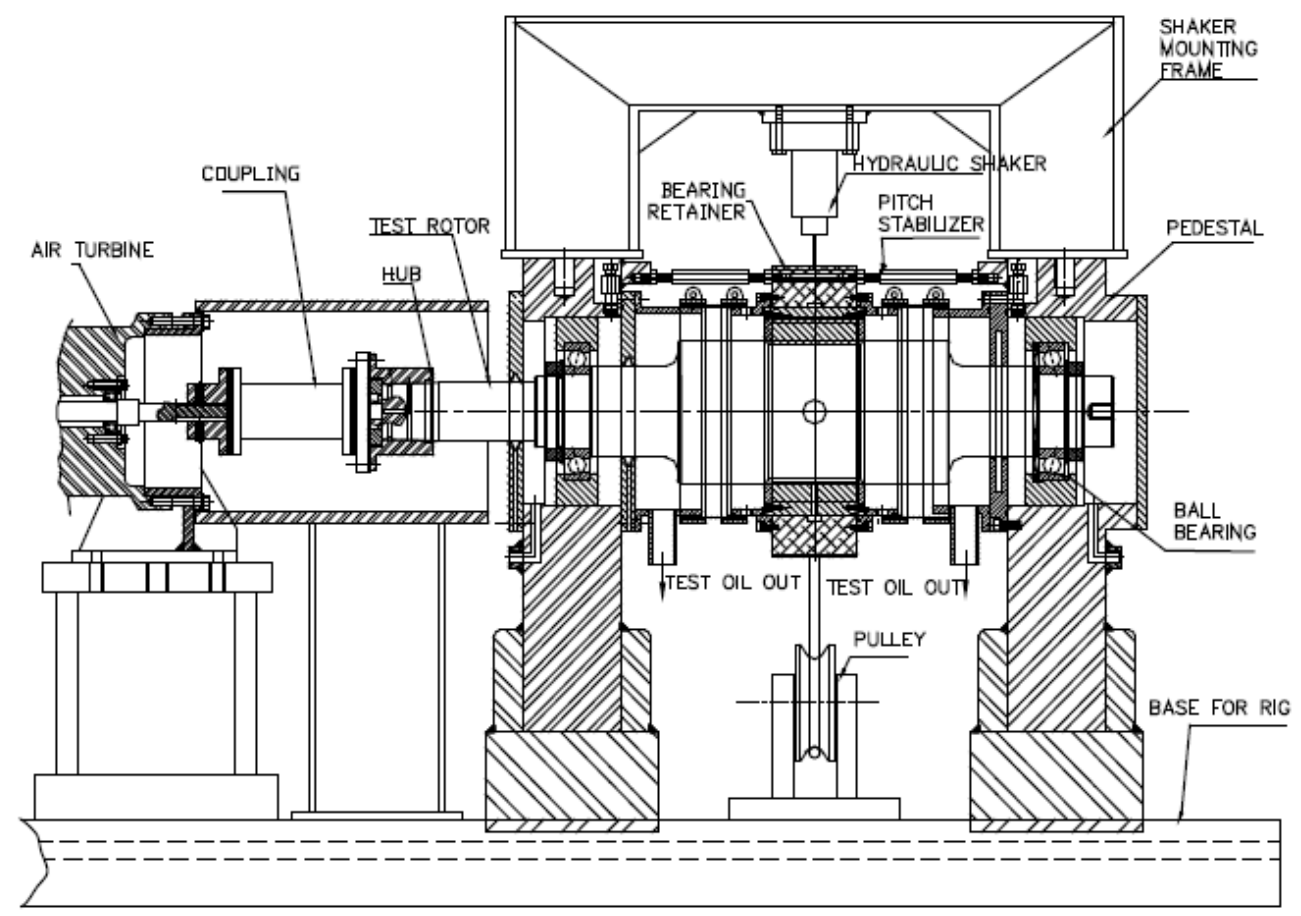

Figure 5: Test Rig Main Section [19] 
The rig consists of a steel base that supports the main test section and the air turbine that drives the shaft. A $65 \mathrm{~kW}$-power air turbine with a high-speed flexible disc coupling can run up to $17,000 \mathrm{rpm}$. The test shaft is made of 4140 steel and machined to a precise diameter of $101.59 \mathrm{~mm}$ (3.9997 in) at the bearing. The balanced shaft is supported at the pedestals by two hybrid-ceramic angular contact ball bearings. An oil-mist lubrication system lubricates the ball bearings, and pressurized buffer air seals are used to prevent oil from the outlet chambers entering the ball bearing section. As shown in Figure 5, six pitch stabilizers provide angular alignment between the bearing and the shaft.

ISO VG32 turbine oil is delivered to the test bearing from an oil supply system. The supply system can deliver oil at up to 82.7 bars supply pressure and a volumetric flow rate of 75 liters per minute. A heat exchanger and a set of pneumatically driven valves allow for control of the test-oil temperature.

A stator holds the test bearing and all the associated instruments, specifically the accelerometers, non-contacting eddy-current proximity sensors, and pressure transducers. In combination with a press fit, an anti-rotation pin hole secures the bearing from rotating within the stator. A pneumatic loader and two hydraulic shakers apply static and dynamic loads to the bearing stator.

The stator-shaker-stinger arrangement is shown in Figure 6, as observed from the non-drive end. The shaker in the $x$ direction can excite the stator with dynamic loads up to $4450 \mathrm{~N}$ in tension and compression, while the shaker in the $y$-direction can excite the stator with dynamic loads up to $4450 \mathrm{~N}$ in tension and $11125 \mathrm{~N}$ in compression. Both 
shakers can provide excitation frequencies up to $1000 \mathrm{~Hz}$. Stingers isolate the test structure from the dynamics of the shakers structure.

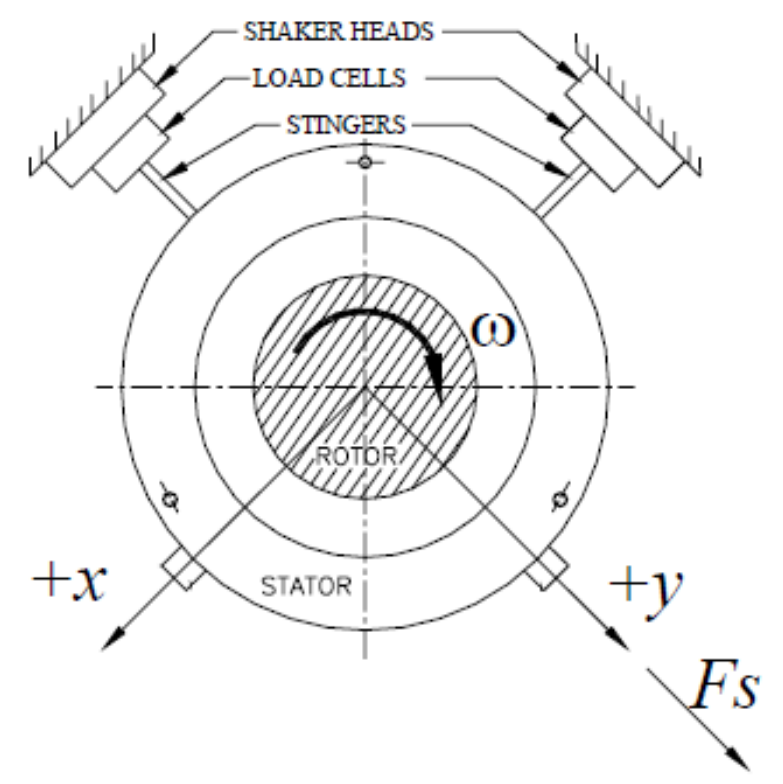

Figure 6: Shaker-Stinger Arrangement (Adapted from [13])

The pneumatic loader applies a static tensile load to the stator in the $+y$ direction. As shown in Figure 7, a cable connects the stator assembly to the loader through a pulley and a yoke with a maximum available load of 22,240 N (5,000 lbf). 


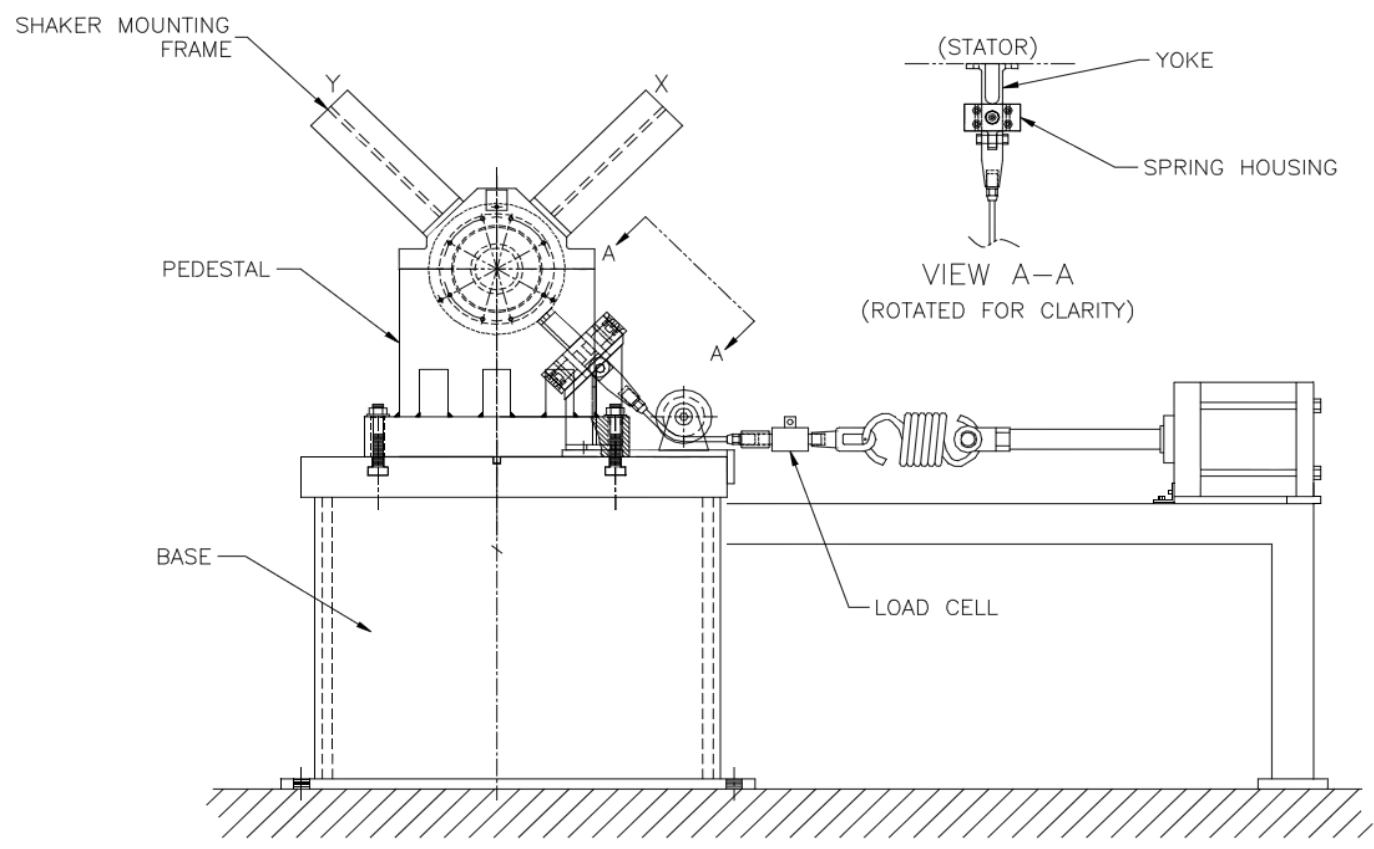

Figure 7: Static Loader Arrangement [1]

\section{Instrumentation}

To record the relative motion of the stator with respect to the rotor for each direction of excitation, two proximity probes are placed in a plane at the non-drive end (NDE), and two proximity probes are placed in a parallel plane at the drive end (DE). As shown in Figure 8, to measure the stator's acceleration, two accelerometers are positioned in the $x$ and $y$ directions. Four proximity probes, positioned in the stator end caps, define an average test bearing location and allow for monitoring of the stator's pitch. 


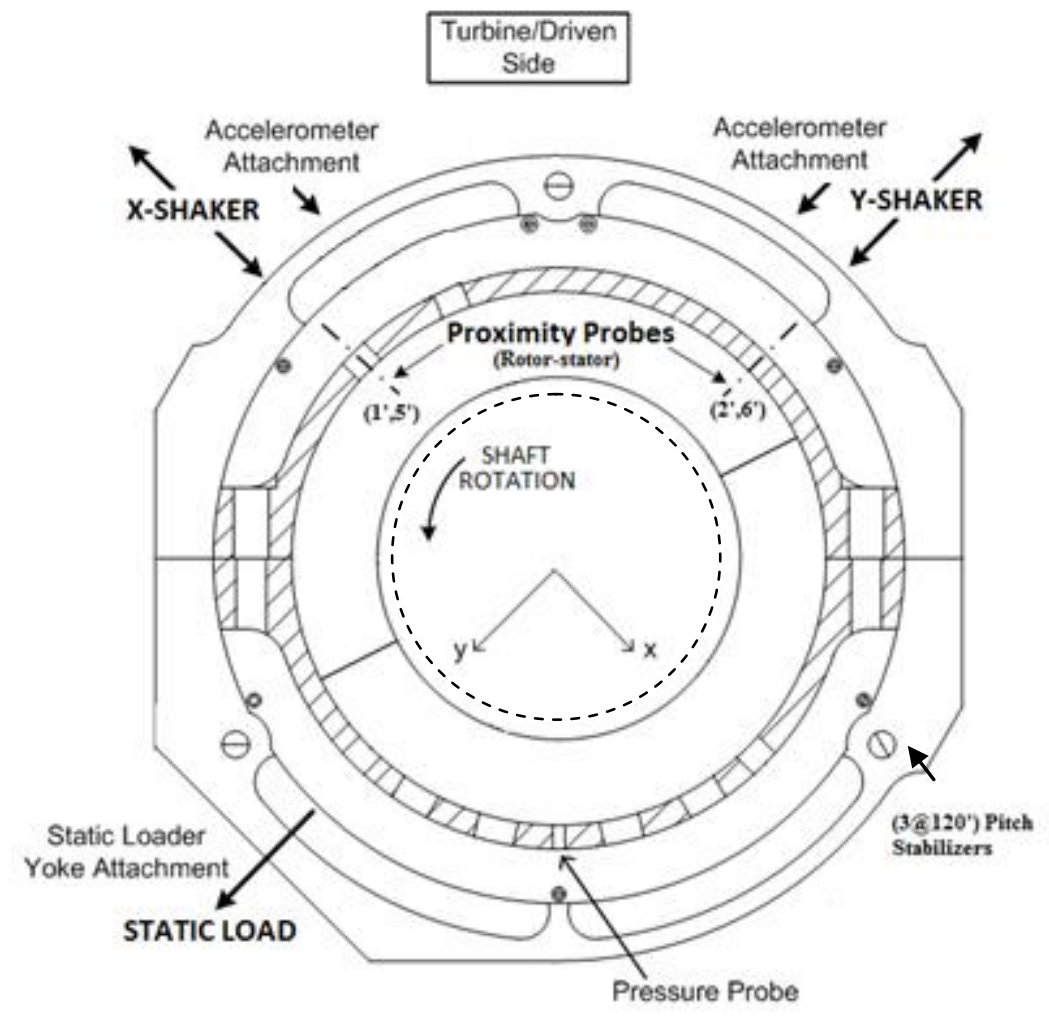

Figure 8: Bearing Configuration and Instrumentation (Adapted from [13])

Static pressure probes are used to measure the oil pressure at the inlet and outlet locations. Thermocouples are located in the oil-inlet chambers, downstream end caps, and ball bearing cartridges.

\section{Bearing Description}

As illustrated in Figure 9, the bearing is a 4-pad, rocker-pivot, tilting-pad journal bearing manufactured by Bearings Plus Inc. The bearing assembly uses a flooded configuration and contains pads with a pad pivot offset of 0.57 . 


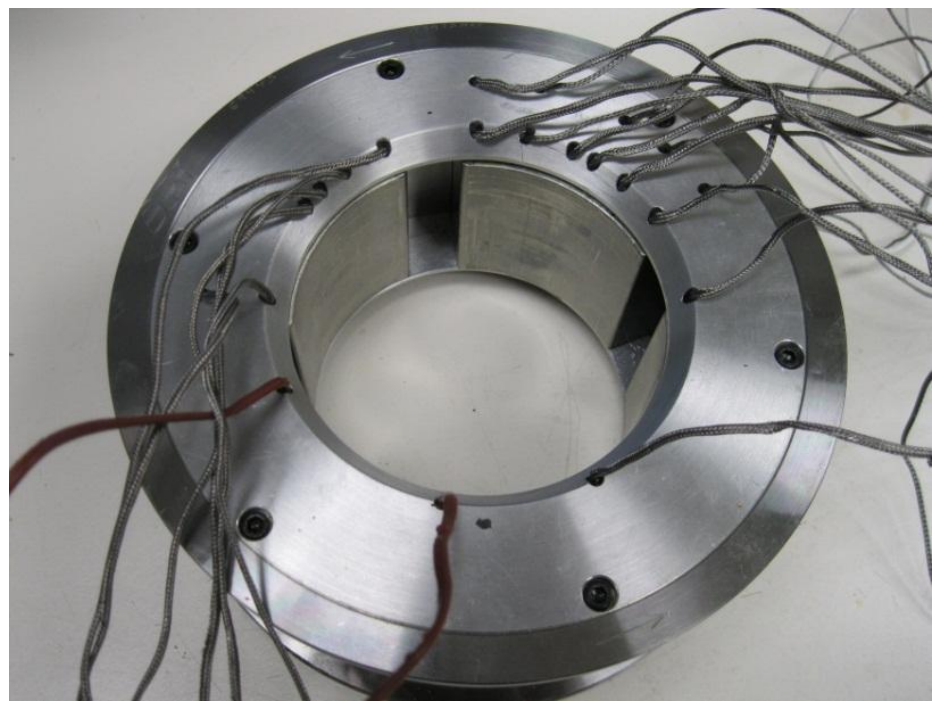

Figure 9: Test Bearing from Drive End

Figure 10 below is a picture of the test bearing pad, and details of the test bearing's geometry, loading style, and lubricant type are presented in Table 2.

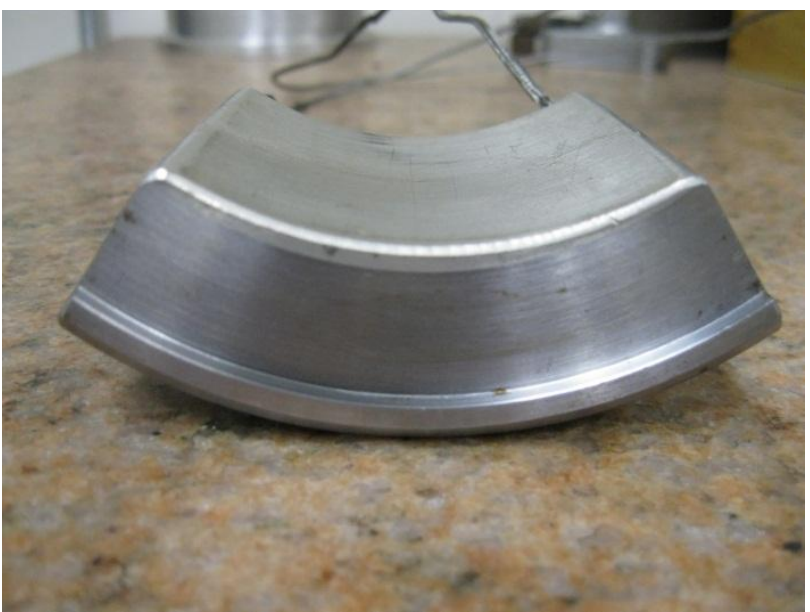

Figure 10: Test Bearing Pad 
Table 2: Bearing Parameters

\begin{tabular}{|c|c|}
\hline Rotor Diameter & $101.5238 \mathrm{~mm}$ (3.997 in) \\
\hline Number of Pads & 4 \\
\hline Configuration & LOP/LBP \\
\hline Bearing (Bore) Diameter & $101.7575 \mathrm{~mm}(4.0062 \mathrm{in})$ \\
\hline Radial Pad Clearance, $\mathrm{C}_{\mathrm{p}}$ & $0.1118 \mathrm{~mm}(0.0044 \mathrm{in})$ \\
\hline Radial Bearing Clearance & $0.0826 \mathrm{~mm}(0.00325 \mathrm{in})$ \\
\hline Pad Axial Length & $60.33 \mathrm{~mm}(2.375 \mathrm{in})$ \\
\hline Pad Arc Angle & $72^{\circ}$ \\
\hline Pivot Offset & 0.57 \\
\hline Measured Preload & 0.3 \\
\hline Pad Mass & $0.96 \mathrm{~kg}(2.12 \mathrm{lbm})$ \\
\hline Lubricant Type & $\mathrm{ISO}$ VG 32 \\
\hline Oil Inlet Temperature & $110^{\circ} \mathrm{F}$ \\
\hline
\end{tabular}

\section{Pad Instrumentation}

Embedded thermocouples provide pad metal temperature just below the bearing's surface. The twenty-one thermocouples help define the temperatures experienced by the bearing pads during testing. In the loaded pad, embedded thermocouples were introduced near the bearing housing, radially opposite from the thermocouples below the Babbitt surface. These thermocouples, along with the near-surface thermocouples define the radial temperature gradient experienced during testing. The remaining thermocouples are embedded in the other pads to give an idea of the circumferential temperature distribution.

Three radial probes $\left(M_{11}-M_{13}\right)$ in Figure 11, were added in the LOP orientation to the loaded pad similar to the procedure performed in Wilkes and Childs [17]. These three radial probes, pad-stator probes, were added in a triangular pattern to measure the back of the loaded pad while a force is applied directly through the pivot, to more 
closely show the stiffness of the pad relative to the housing (see Predictions).

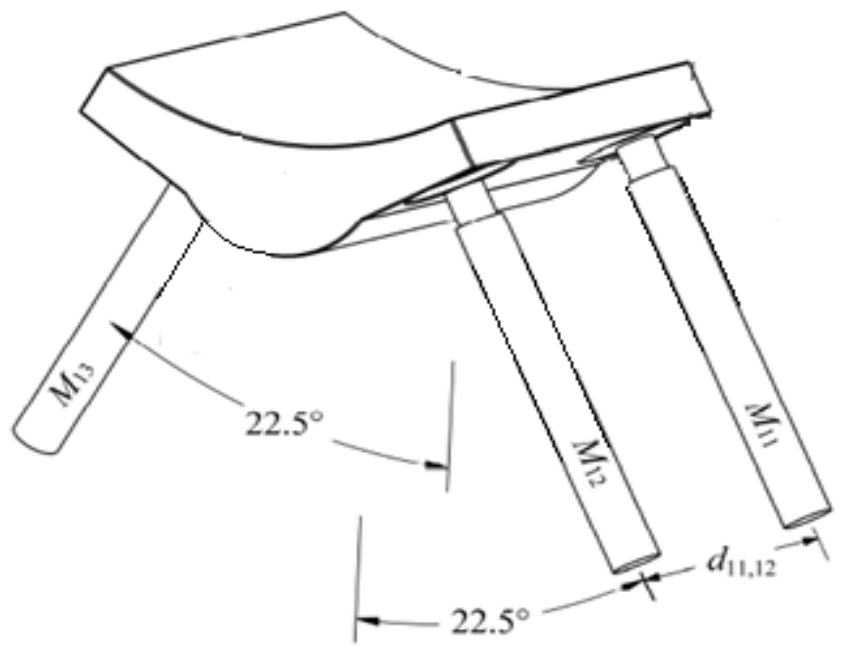

Figure 11: Proximity Probe Orientation on Loaded Pad (Adapted from [17]) 


\section{EXPERIMENTAL PROCEDURE}

The general testing procedure includes achieving steady state operating conditions. To attain steady state conditions, the rotor is held at a constant rotational speed, oil inlet temperature, and static load. Testing conditions include four running speeds varying from 6800 to $13200 \mathrm{rpm}$ and five static loads from $0 \mathrm{kPa}$ to $2903 \mathrm{kPa}$ (421.1 psi). Table 3 presents the test matrix for nominal test conditions.

Table 3: Matrix of Nominal Test Conditions

\begin{tabular}{|c|c|c|c|c|}
\hline Static Load & \multicolumn{4}{|c|}{ Speed [RPM], (Flow-rate [L/min] @ $\left.110^{\circ} \mathrm{F}\right)$} \\
\hline $\mathrm{kPa}(\mathrm{psi})$ & $6800,(22.7)$ & $9000,(26.5)$ & $10800,(30.3)$ & $13200,(34.1)$ \\
\hline 0 & $\mathrm{x}$ & $\mathrm{x}$ & $\mathrm{x}$ & $\mathrm{x}$ \\
\hline $725(105.3)$ & $\mathrm{x}$ & $\mathrm{x}$ & $\mathrm{x}$ & $\mathrm{x}$ \\
\hline $1452(210.5)$ & $\mathrm{x}$ & $\mathrm{x}$ & $\mathrm{x}$ & $\mathrm{x}$ \\
\hline $2178(315.8)$ & $\mathrm{x}$ & $\mathrm{x}$ & $\mathrm{x}$ & $\mathrm{x}$ \\
\hline $2903(421.1)$ & $\mathrm{x}$ & $\mathrm{x}$ & $\mathrm{x}$ & $\mathrm{x}$ \\
\hline
\end{tabular}

After achieving steady state conditions, the bearing stator is alternately excited in the $x$ and $y$ directions using the hydraulic shakers with a pre-specified pseudo-random dynamic excitation waveform. The excitation waveform has frequencies from $10 \mathrm{~Hz}$ to $320 \mathrm{~Hz}$ in $10 \mathrm{~Hz}$ increments in two orthogonal directions, the $x$-direction and the $y$ direction (static load direction). To avoid noise at $60 \mathrm{~Hz}$ and its multipliers, the actual excitation frequencies are slightly offset from the nominal values.

\section{Dynamic Stiffness-Coefficients}

Rotordynamic coefficients are obtained through the parameter identification model adapted from Childs and Hale [21]. Their approach uses an equation of motion for the 
stator mass $M_{s}$ that can be written as:

$$
M_{s}\left\{\begin{array}{l}
\ddot{x}_{s} \\
\ddot{y}_{s}
\end{array}\right\}=\left\{\begin{array}{l}
f_{x} \\
f_{y}
\end{array}\right\}-\left\{\begin{array}{l}
f_{b x} \\
f_{b y}
\end{array}\right\}
$$

In this equation, $\ddot{x}_{s}$ and $\ddot{y}_{s}$ are measured components of the stator's acceleration, $f_{x}$ and $f_{y}$ are the measured excitation forces, and $f_{b x}$ and $f_{b y}$ are the bearing reaction force components.

Substituting the $[\mathrm{K}][\mathrm{C}][\mathrm{M}]$ model from Eq. (4) into the equation above, the bearing reaction force as a function of the rotordynamic coefficients becomes:

$$
\left\{\begin{array}{l}
f_{x}-M_{s} \ddot{x}_{s} \\
f_{y}-M_{s} \ddot{y}_{s}
\end{array}\right\}=-\left[\begin{array}{ll}
K_{x x} & K_{x y} \\
K_{y x} & K_{y y}
\end{array}\right]\left\{\begin{array}{l}
\Delta x \\
\Delta y
\end{array}\right\}-\left[\begin{array}{ll}
C_{x x} & C_{x y} \\
C_{y x} & C_{y y}
\end{array}\right]\left\{\begin{array}{l}
\Delta \dot{x} \\
\Delta \dot{y}
\end{array}\right\}-\left[\begin{array}{ll}
M_{x x} & M_{x y} \\
M_{y x} & M_{y y}
\end{array}\right]\left\{\begin{array}{l}
\Delta \ddot{x} \\
\Delta \ddot{y}
\end{array}\right\}
$$

Here, $\Delta x$ and $\Delta y$ define the relative motion between the rotor and the stator, and $K_{i j}, C_{i j}$, and $M_{i j}$ are stiffness, damping, and virtual-mass coefficients, respectively. Both the lefthand vector of Eq. (8) and $\Delta x$ and $\Delta y$ are measured functions of time.

Using a fast Fourier transform, the rotordynamic coefficients are determined in the frequency domain:

$$
\left\{\begin{array}{l}
\boldsymbol{F}_{x}-M_{s} \boldsymbol{A}_{x} \\
\boldsymbol{F}_{y}-M_{s} \boldsymbol{A}_{y}
\end{array}\right\}=-\left[\begin{array}{ll}
\boldsymbol{H}_{x x} & \boldsymbol{H}_{x y} \\
\boldsymbol{H}_{y x} & \boldsymbol{H}_{y y}
\end{array}\right]\left\{\begin{array}{l}
\boldsymbol{D}_{x} \\
\boldsymbol{D}_{y}
\end{array}\right\}
$$

$\boldsymbol{F}_{\boldsymbol{i}}, \boldsymbol{A}_{\boldsymbol{i}}$, and $\boldsymbol{D}_{\boldsymbol{i}}$ are the Fourier transforms of the excitation force, the stators acceleration, and the relative stator to rotor motion in $x$ and $y$ directions. The elements of the bearing dynamic stiffness function $\boldsymbol{H}_{i j}$ are related to the coefficients defined by:

$$
\boldsymbol{H}_{i j}=\left(K_{i j}-\Omega^{2} \mathrm{M}_{\mathrm{ij}}\right)+j\left(\Omega C_{i j}\right)
$$


$\boldsymbol{H}_{i j}$ is the complex dynamic stiffness that relates the force in the "i" direction due to the motion in the "j" direction. The real and imaginary components yield,

$$
\begin{gathered}
\operatorname{Re}\left(\boldsymbol{H}_{i j}\right)=K_{i j}-\Omega^{2} \mathrm{M}_{\mathrm{ij}} \\
\operatorname{Im}\left(\boldsymbol{H}_{i j}\right)=\Omega C_{i j}
\end{gathered}
$$

$\Omega$ represents the excitation frequency.

If $\operatorname{Re}\left(\boldsymbol{H}_{i j}\right)$ can be fitted as a quadratic function of $\Omega$, Eq. (11) exhibits how the stiffness and virtual-mass coefficients can be estimated. $K_{i j}$ represents the zero-frequency intercept and $M_{i j}$ represents the curvature. From Eq. (12), the damping coefficients can be defined as the slope of the $\operatorname{Im}\left(\boldsymbol{H}_{i j}\right)$ with respect to $\Omega$.

Looking back, Eq. (9) provides only two equations for four unknowns $\boldsymbol{H}_{x x}, \boldsymbol{H}_{x y}$, $\boldsymbol{H}_{\boldsymbol{y} \boldsymbol{x}}$, and $\boldsymbol{H}_{y y}$. To obtain four independent equations, alternate shakes at a given steadystate rotor position are conducted in the $X$ and $Y$ directions while measuring the response in both directions. The equations are given by:

$$
\left[\begin{array}{ll}
\boldsymbol{F}_{x x}-M_{s} \boldsymbol{A}_{x x} & \boldsymbol{F}_{x y}-M_{s} \boldsymbol{A}_{x y} \\
\boldsymbol{F}_{y x}-M_{s} \boldsymbol{A}_{y x} & \boldsymbol{F}_{y y}-M_{s} \boldsymbol{A}_{y y}
\end{array}\right]=-\left[\begin{array}{ll}
\boldsymbol{H}_{x x} & \boldsymbol{H}_{x y} \\
\boldsymbol{H}_{y x} & \boldsymbol{H}_{y y}
\end{array}\right]\left[\begin{array}{ll}
\boldsymbol{D}_{x x} & \boldsymbol{D}_{x y} \\
\boldsymbol{D}_{y x} & \boldsymbol{D}_{y y}
\end{array}\right]
$$

One set of frequency-dependent dynamic stiffness coefficients, $\left(\boldsymbol{H}_{x x}, \boldsymbol{H}_{x y}, \boldsymbol{H}_{y x}\right.$, and $\boldsymbol{H}_{y y}$ ) is obtained from a simultaneous excitation that is applied through a frequency range of $10 \mathrm{~Hz}$ to $320 \mathrm{~Hz}$ in increments of $10 \mathrm{~Hz}$. The dynamic waveform takes less than a second to execute and is applied along each the $X$ and $Y$ directions. For each experimental condition, 10 consecutive shakes are conducted in each direction. The measurements in each $X$ and $Y$ directions are then broken into five groups. The five 
groups provide a significant number of averages and a decent resolution from the fast Fourier transform. The five groups of data in the $X$ direction are combined alternately with the five groups in the $Y$ direction, resulting in a total of 25 complex dynamic stiffness matrices. The dynamic repeatability of an experimental condition is the standard deviation from the 25 complex dynamic stiffness matrices.

To obtain the dynamic stiffness of the fluid film only, a baseline result needs to be subtracted from the dynamic stiffness measured during tests. The baseline result accounts for the stiffness and damping of all the stator attachments (pitch stabilizers, hose connections, etc.). To gather the baseline dynamic stiffness, a dry shake is performed at zero rotor speed with no oil allowed in the bearing. Both loaded and unloaded dynamic-stiffness baseline data are obtained. The dynamic stiffness of the fluid film is found by subtracting the baseline data from the data obtained during a test, shown in Eq. (14).

$$
\boldsymbol{H}_{i j}=\boldsymbol{H}_{i j, T E S T}-\boldsymbol{H}_{i j, B A S E L I N E}
$$

Figure 12 shows the real direct and cross-coupled baseline dynamic stiffness, while Figure 13 shows the imaginary direct and cross-coupled baseline dynamic stiffness for zero loads. 


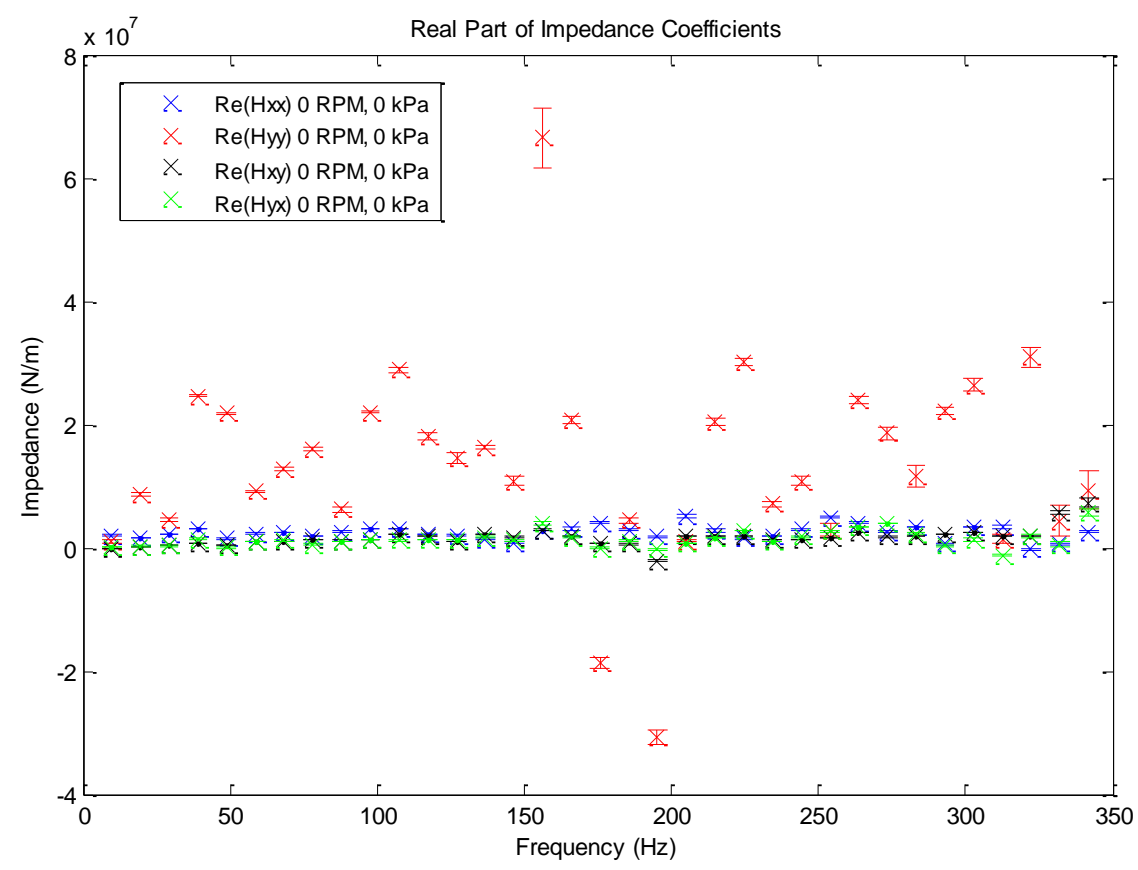

Figure 12: Baseline Real Direct and Cross-coupled Dynamic Stiffness

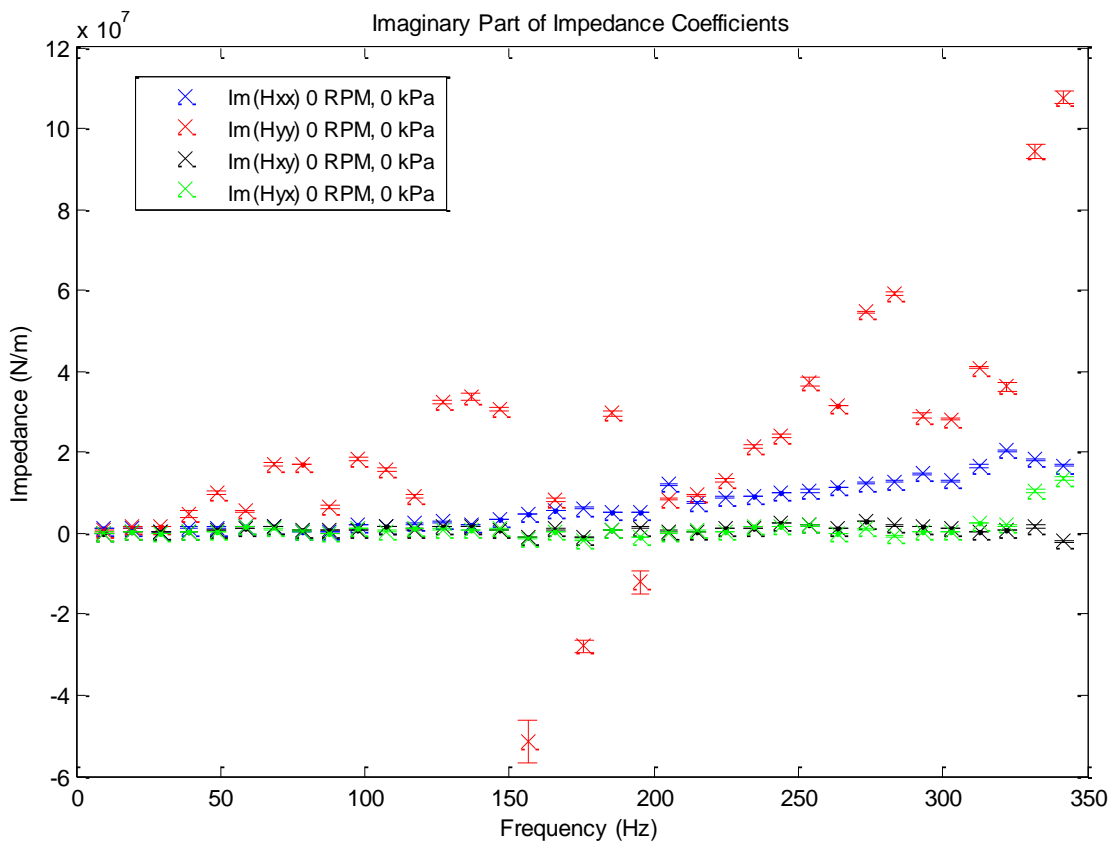

Figure 13: Baseline Imaginary Direct and Cross-coupled Dynamic Stiffness 


\section{Curve Fitting and Uncertainty Analysis}

As mentioned above, the dynamic repeatability of an experimental condition is the standard deviation from the 25 complex dynamic stiffness matrices. From these shakes, an average dynamic stiffness $\boldsymbol{H}_{i j}$ is obtained at each excitation frequency for each test condition, Eq. (15).

$$
\boldsymbol{H}_{i j}=\frac{1}{N} \sum_{k=1}^{N}\left(\boldsymbol{h}_{i j}\right)_{k}
$$

$N$ is the number of shakes and $\left(\boldsymbol{h}_{i j}\right)_{k}$ is the dynamic stiffness of each individual shake.

The uncertainty of each dynamic stiffness data point can be described as two times the standard deviation, shown in Eq. (16).

$$
\Delta \boldsymbol{H}_{i j}=2 \sigma_{\boldsymbol{H}_{i j}}=2 \sqrt{\frac{\sum_{k=1}^{N}\left[\left(\boldsymbol{h}_{i j}\right)-\boldsymbol{H}_{i j}\right]^{2}}{N-1}}
$$

Eq. (16) is used to calculate the uncertainties for the baseline dynamic stiffness and the tested dynamic stiffness. The uncertainty of $\Delta \boldsymbol{H}_{i j}$ qualifies the repeatability of each test. These uncertainties are shown as error bars in the dynamic stiffness plots.

As shown above in Eq. (11), $K_{i j}$ represents the zero-frequency intercept of $\operatorname{Re}\left(\boldsymbol{H}_{i j}\right)$, and $M_{i j}$ represents the curvature of $\operatorname{Re}\left(\boldsymbol{H}_{i j}\right)$. By taking Eq. (11), and setting $\Omega^{2}=\Lambda$, the $\operatorname{Re}\left(\boldsymbol{H}_{i j}\right)$ becomes a linear function of $\Lambda$, where $K_{i j}$ is the $y$-intercept and $M_{i j}$ is the slope, defined by

$$
\operatorname{Re}\left(\boldsymbol{H}_{i j}\right)=K_{i j}-\Lambda M_{i j}
$$

$K_{i j}$ and $M_{i j}$ are then determined from the least squares linear regression, in the form of Eq. (18) that is applied to $\operatorname{Re}\left(\boldsymbol{H}_{i j}\right)$ versus $\Lambda$ data: 


$$
y=m x+b
$$

where, $x$ and $y$ represent the independent and dependent variables respectively.

From Eq. (18), the $y$-intercept $b$ and slope $m$ of the linear regression are given in Eqs. (19) and (20), respectively.

$$
\begin{array}{r}
b=\left(\frac{1}{n} \sum_{k=1}^{n} x_{k}\right)-m\left(\frac{1}{n} \sum_{k=1}^{n} y_{k}\right) \\
m=\frac{n \sum_{k=1}^{n} x_{k} y_{k}-\sum_{k=1}^{n} x_{k} \sum_{k=1}^{n} y_{k}}{n \sum_{k=1}^{n} x_{k}^{2}-\left(\sum_{k=1}^{n} x_{k}\right)^{2}}
\end{array}
$$

where, $x_{k}$ and $y_{k}$ represent the data points that are fitted and $n$ is the number of data pairs.

The $y$-intercept $b$ is equal to the stiffness coefficient $K_{i j}$, and the slope of the line $m$ is equal to the virtual-mass $M_{i j}$. The linear regression is used for both the direct and cross-coupled coefficients. The frequency independent damping coefficients $C_{i j}$ are the slope of the $\operatorname{Im}\left(\boldsymbol{H}_{i j}\right)$ with respect to $\Omega$ and are equal to the slope $m$ given in Eq. (20). The $y$-intercept $b$ has no physical meaning in $\operatorname{Im}\left(\boldsymbol{H}_{i j}\right)$.

The uncertainties of the stiffness, damping, and virtual-mass coefficients are determined by the correlation of the linear regression with the dynamic stiffness data. The final coefficient of uncertainty is a function of the mean square error $\left(\hat{\sigma}^{2}\right)$ and the quantity $S_{x x}$, Eqs. (21) and (22) respectively.

$$
\begin{gathered}
\hat{\sigma}^{2}=\frac{\sum_{k=1}^{n}\left(y_{k}-\hat{y}_{k}\right)^{2}}{n-2} \\
S_{x x}=\sum_{k=1}^{N}\left(x_{k}^{2}-\bar{x}_{k}^{2}\right)
\end{gathered}
$$


where, $\hat{y}_{k}$ represents the dependent variable fit data, $x$ represent the independent variables, and $y$ represent the dependent variables.

The uncertainties of the $y$-intercept $b$ are calculated using Eq. (23), and the uncertainties of the slope $m$ are calculated using Eq. (24).

$$
\begin{gathered}
\Delta b=t \sqrt{\hat{\sigma}^{2}\left(\frac{1}{n}+\frac{\bar{x}^{2}}{S_{x x}}\right)} \\
\Delta m=t \sqrt{\frac{\hat{\sigma}^{2}}{S_{x x}}}
\end{gathered}
$$

Note that $t$ is a multiplicative factor derived by using a $95 \%$ confidence interval, and $n$ is the number of fitted data points. For a large number of data points, $t=1.96$.

Table 4 shows a summary of the rotordynamic coefficients and uncertainties in the LOP orientation at $13.2 \mathrm{krpm}$ and $2903 \mathrm{kPa}(421.1 \mathrm{psi})$ static load.

Table 4: Experimental Uncertainties for the LOP Orientation at $13.2 \mathrm{krpm}$ and $2903 \mathrm{kPa}$ (421.1 psi) Static Load

\begin{tabular}{|c|c|c|c|c|}
\hline Units & Coefficient & Value & Uncert. & \%Uncert. \\
\hline \multirow{3}{*}{ Mn/m } & Kxx & 293.9 & 10.6 & 3.6 \\
& Kxy & -24.7 & 5.6 & 22.5 \\
& Kyx & -38.3 & 2.2 & 5.6 \\
& $\mathrm{Kyy}$ & 705.9 & 24.4 & 3.5 \\
\hline \multirow{3}{*}{$\mathrm{kN}-\mathrm{s} / \mathrm{m}$} & $\mathrm{Cxx}$ & 232.0 & 8.3 & 3.6 \\
& $\mathrm{Cxy}$ & 11.7 & 4.2 & 36.0 \\
& $\mathrm{Cyx}$ & -5.4 & 3.6 & 66.6 \\
\hline \multirow{3}{*}{$\mathrm{MN} / \mathrm{m}$} & $\mathrm{Cyy}$ & 210.1 & 33.2 & 15.8 \\
\hline & Mxx & -22.9 & 9.6 & 42.1 \\
& Mxy & -34.8 & 5.0 & 14.5 \\
& Myx & -15.8 & 1.9 & 12.3 \\
& Myy & 13.0 & 22.1 & 169.3 \\
\hline
\end{tabular}

Note that the uncertainties presented in Table 4 are representative of the majority of the test results. A full list of the rotordynamic uncertainties can be found in Appendix D. Large uncertainties occur when coefficient values are small. 


\section{Predictions}

\section{Code A}

As mentioned earlier, static results and rotordynamic coefficients presented will be compared to predictions from a new rotordynamic bearing code, Code A developed by Tao and San Andrés at the Texas A\&M Turbomachinery Laboratory. Code A uses a laminar-flow Reynolds-equation model to predict the static and dynamic behavior of a TPJB, and uses an adiabatic energy transport equation to account for the thermal effects in fluid flow. The lubricant's viscosity is modeled as temperature dependent. Code A takes into account pivot flexibility with a user defined load-versus-deflection curve, and individual geometries for each pad. A multi-frequency option allows for stiffness and damping predictions to be obtained over the range of excitation frequencies (e.g. 0-360 Hz). The output from Code A presents stiffness, and damping coefficients as well as static parameters (journal eccentricity, attitude angle, estimated power loss, and circumferential fluid temperatures). Virtual-mass terms are obtained by curve fitting the frequency-dependent stiffness coefficients. Figure 14 provides the input and output screen for Code A. 


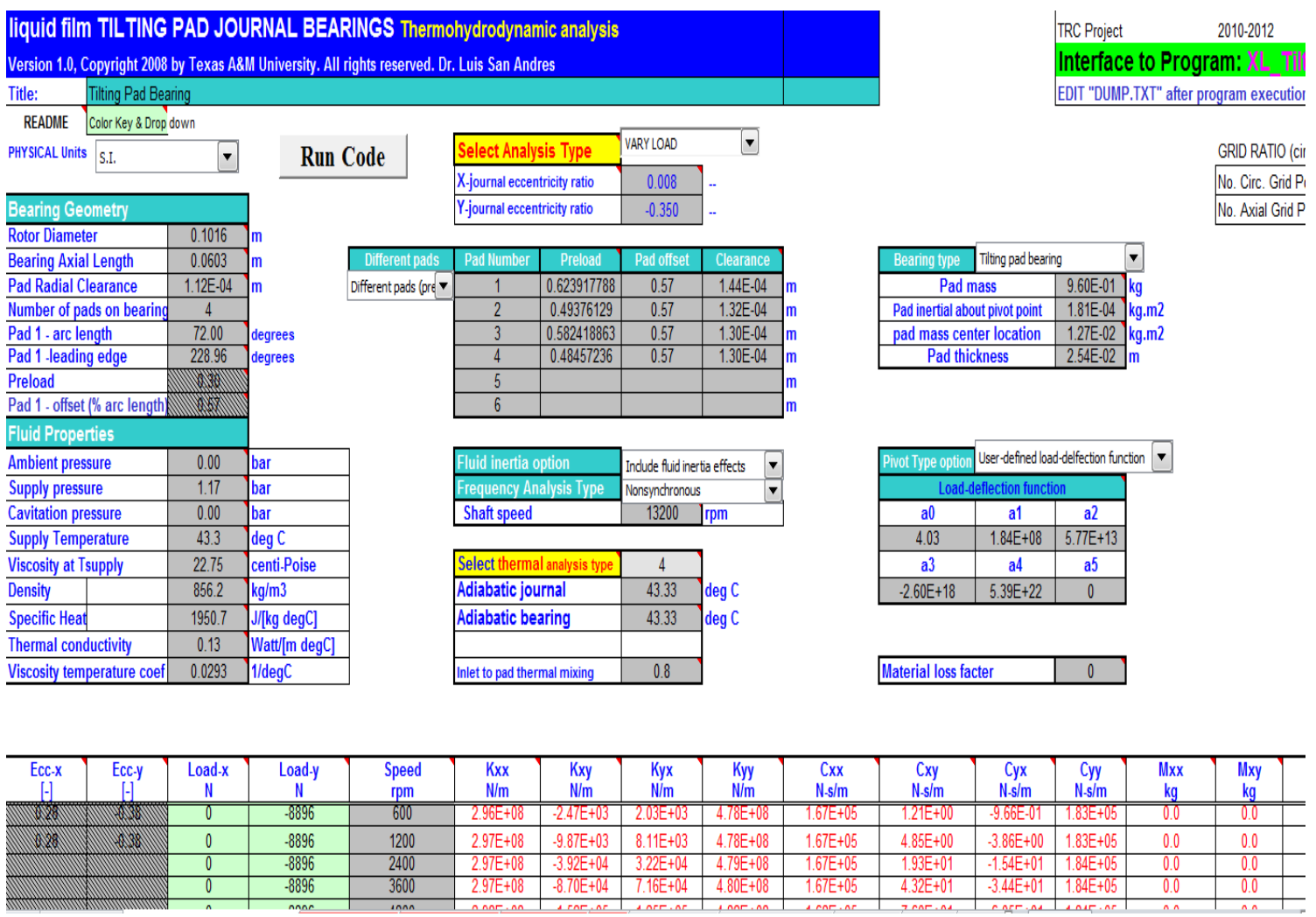

Figure 14: Code A Input and Output Screen

Figure 14 shows that a value of 0.8 is used as the input for the inlet to pad thermal mixing. This value represents the fraction of hot oil carry from trailing the edge of a pad to the leading edge of the preceding pad. Increasing the inlet to pad thermal mixing value, increases the influence that the trailing edge of the one pad has on the preceding pad, and results in higher circumferential temperature predictions.

\section{Code B}

Dynamic stiffness results presented will be compared to predictions from the model of Wilkes and Childs [14][17][18], which will be referenced as Code B. Wilkes dissertation [15] uses a laminar-flow Reynolds-based model to predict dynamic results, 
utilizing pivot and pad flexibility in predicting the impedance coefficients for a tiltingpad journal bearing. Code B takes into account different pad geometries. It does not include an energy equation to calculate temperature and viscosity distributions, but experimental temperature measurements are used to estimate the lubricant's viscosity distribution. The output from Code B presents plots of the impedance coefficients. Since experimental temperature measurements are used in the model, circumferential fluid temperatures are not predicted. Static parameters (journal eccentricity and attitude angles) are also predicted by Code B. Code B utilizes a MATLAB interface that will not be shown in this thesis.

Table 5 below shows the main features and differences between prediction codes.

Table 5: Difference Between Predictions

\begin{tabular}{|c|c|c|}
\hline Code Developer & Tao and San Andrés & Wilkes \\
\hline Code Name & Code A & Code B \\
\hline Model Type & Reynolds-based & Reynolds-based \\
\hline Pad Geometry & User-defined & User-defined \\
\hline Thermal Analysis & $\begin{array}{c}\text { Adiabatic Energy Transport } \\
\text { Equation } \\
\end{array}$ & $\begin{array}{c}\text { Experimental Temperature } \\
\text { Measurements }\end{array}$ \\
\hline Pivot Stiffness & $\begin{array}{l}\text { User-defined Load-versus- } \\
\text { Deflection Curve }\end{array}$ & $\begin{array}{l}\text { User-defined Load-versus- } \\
\text { Deflection Curve }\end{array}$ \\
\hline Pad Flexibility & Assumed Rigid & User Defined Flexibility \\
\hline Static Outputs & $\begin{array}{c}\text { Journal Eccentricity, } \\
\text { Attitude Angle, Estimated } \\
\text { Power Loss, and } \\
\text { Circumferential Fluid } \\
\text { Temperatures } \\
\end{array}$ & $\begin{array}{l}\text { Journal Eccentricity and } \\
\text { Attitude Angle }\end{array}$ \\
\hline Dynamic Outputs & $\begin{array}{l}\text { Dynamic Stiffness } \\
\text { Coefficients }\end{array}$ & $\begin{array}{l}\text { Plots of Impedance } \\
\text { Coefficients }\end{array}$ \\
\hline
\end{tabular}




\section{Input Parameters for Prediction Codes}

\section{Hot Clearance}

A bearing clearance measurement is taken by slowly precessing the stator around the non-rotating shaft with a sufficiently small circular force to prevent significant pivot deflection. A clearance measurement is the boundary of the bearing when the pads have not deflected radially due to the fluid film loads. "Cold clearance" refers to the measurement taken at room temperature prior to testing, while "Hot clearance" refers to the measurement taken immediately after shutting down the test rig after tests. Hot clearance measurements occur approximately 10 seconds after shutting down the test rig from steady state conditions.

Figure 15 shows the bearing's rectangular cold clearance. The static load is applied in the $+Y$ direction. As can be seen, the bearing tested shows non-symmetry in that two of the parallel pad clearances are larger. 


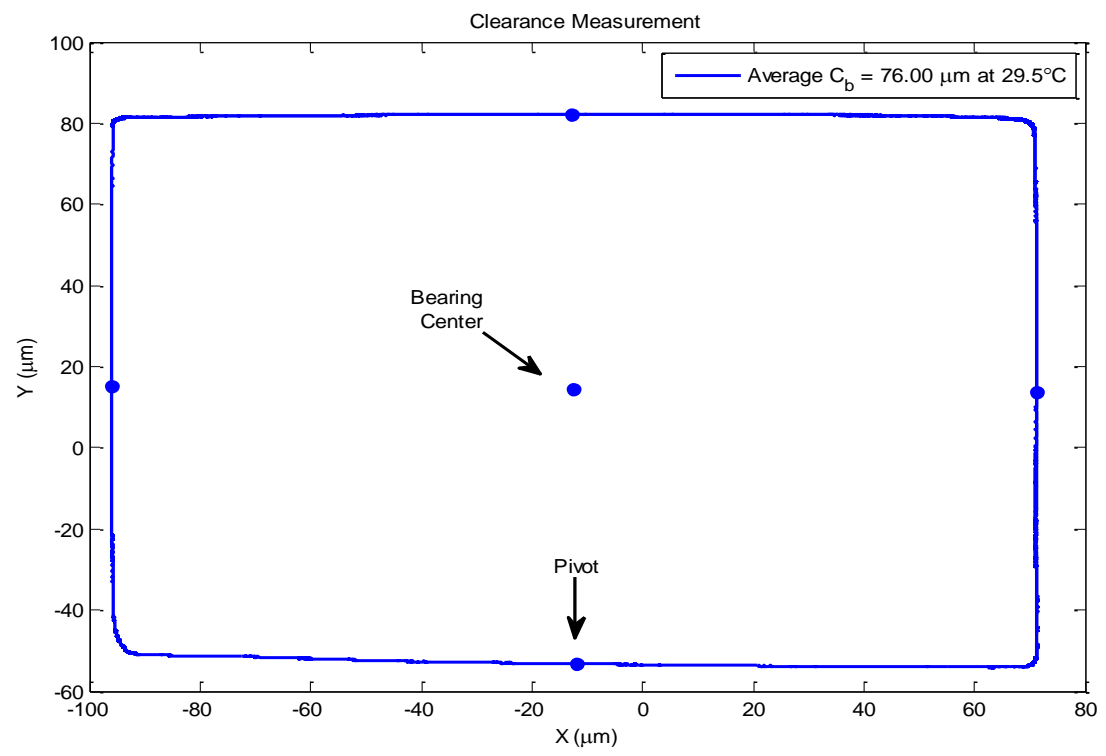

(A) LOP Orientation

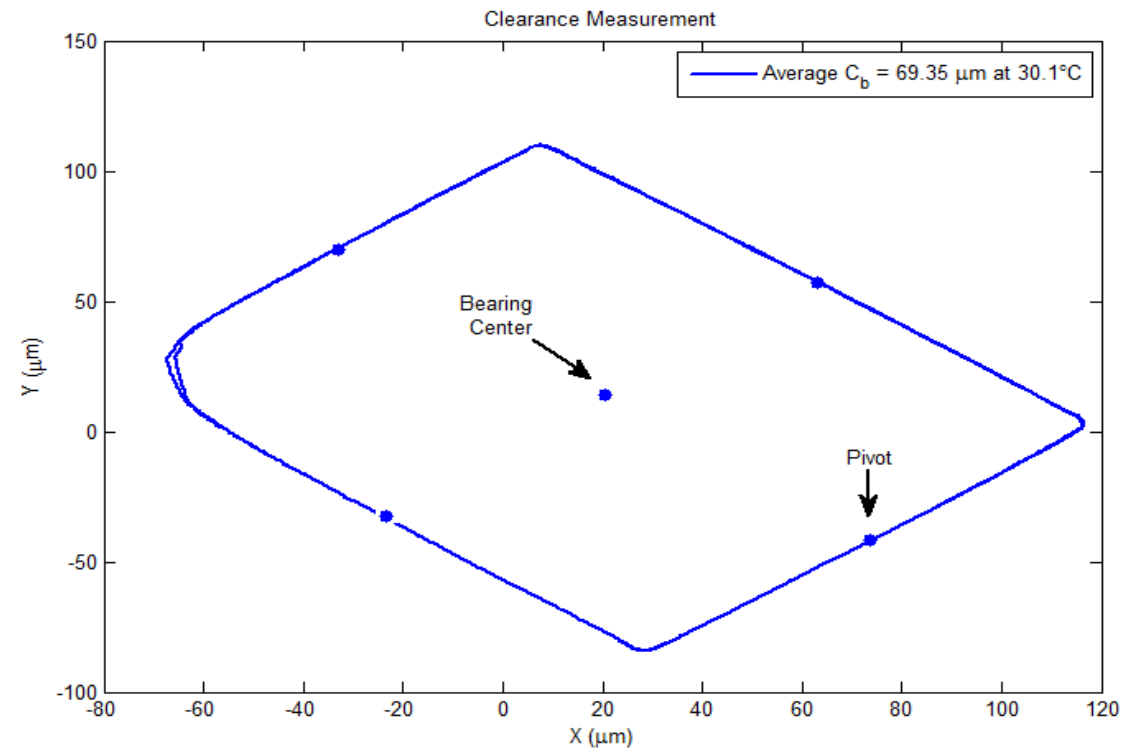

(B) LBP Orientation

Figure 15: Measured Clearance at Room Temperature 
In comparing Figure 15 to the manufactured bearing clearance previously shown in Table 2, different results are obtained. The manufactured cold bearing clearance for each pad was averaged to be $82.55 \mu \mathrm{m}$. Table 6 gives a summary of the cold bearing clearance for each pad.

Table 6: Radial Cold Clearance Measurements

\begin{tabular}{|c|c|c|c|c|}
\hline \multicolumn{5}{|c|}{ Cold Clearance $(\mu \mathrm{m})$} \\
\hline Orientation & 3 (Loaded Pad) & 4 & 1 & 2 \\
\hline LOP & 68.4 & 83.6 & 68.4 & 83.6 \\
\hline LBP & 69.4 & 75.7 & 69.4 & 75.7 \\
\hline
\end{tabular}

Figure 16 shows the bearings LOP hot and cold clearances. The figure shows a clearance measurement taken corresponding to each running speed. The temperature of the clearance measurement is the mean pad surface temperature experienced at the time of the clearance measurement. The colored dots in the middle show each measured bearing center in reference to the clearance measurement taken. 


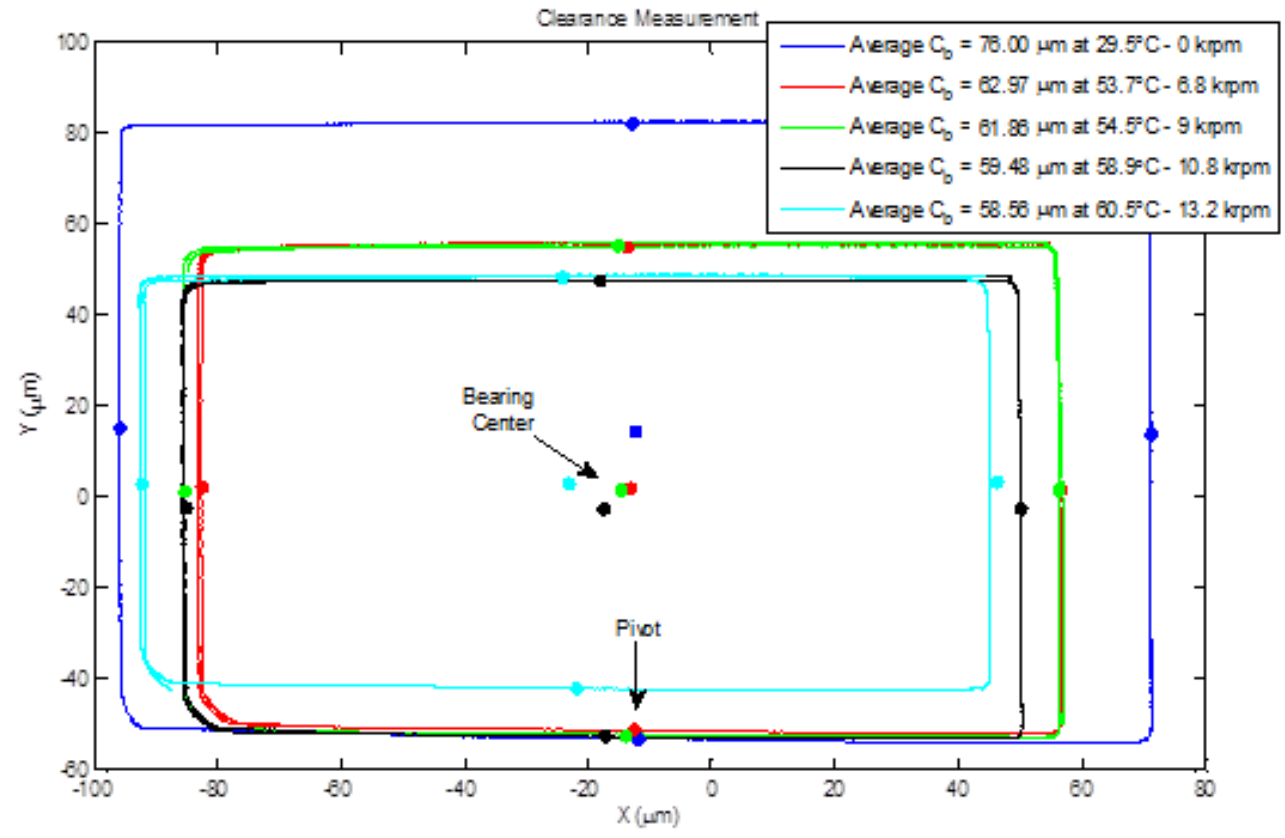

(A) LOP Orientation

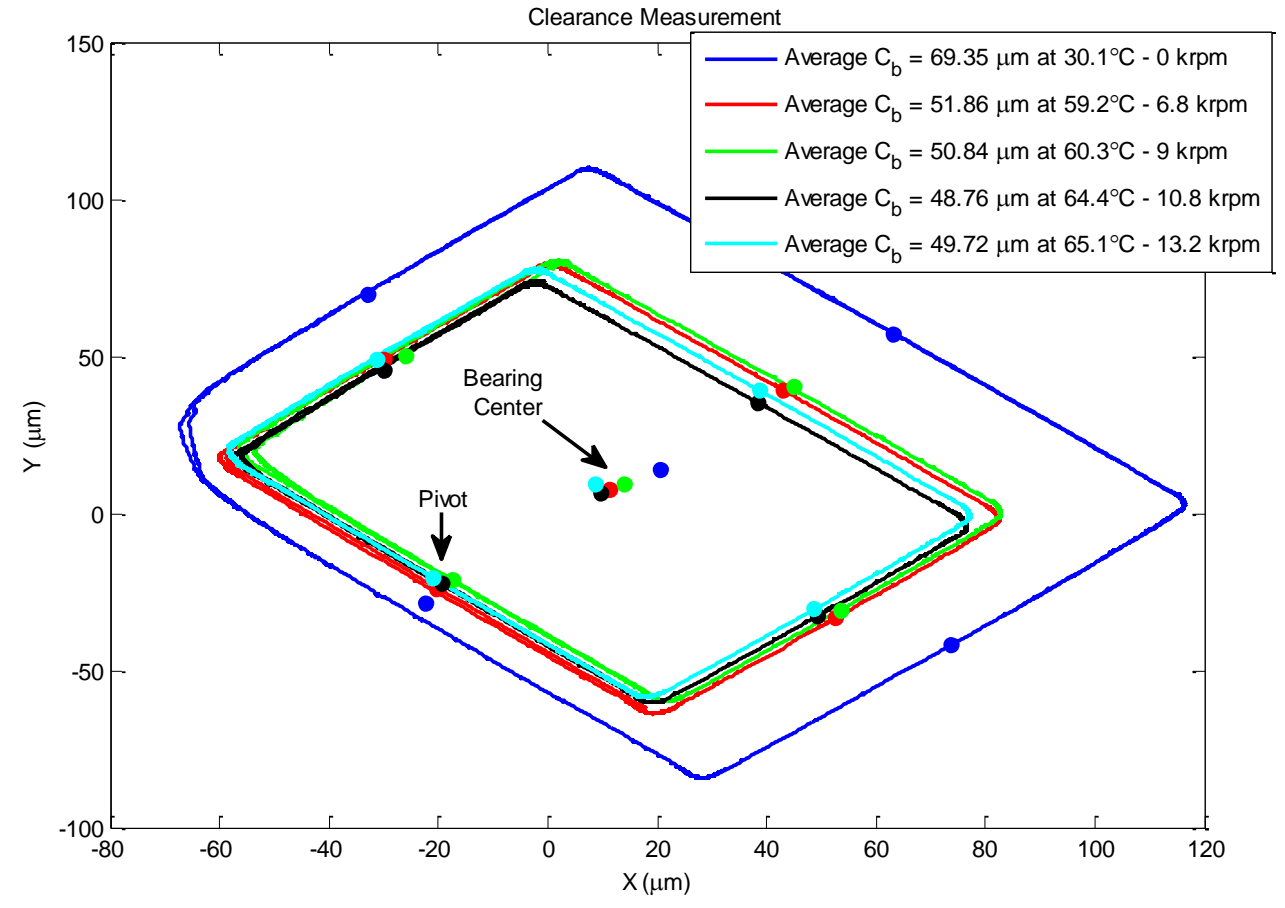

(B) LBP Orientation

Figure 16: Measured Clearance for All Speeds 
The hot-clearance measurements of Figure 16 show the reduction in bearing clearance due to thermal expansion of the shaft and pads during testing. As testing conditions get hotter radial bearing clearances decrease. Except for one clearance measurement above, all measurements show this outcome. The clearance measurement at $13.2 \mathrm{krpm}$ in the LBP orientation increases compared to the $10.8 \mathrm{krpm}$ case. Similar to the cold clearance measurement, the hot clearances show that the clearances of adjacent pads are different. The measured hot clearance for each pad will be used in modeling predictions to give the most accurate representation of the bearing clearance during testing. Table 7 and Table 8 give a summary of the LOP and LBP hot bearing clearance used for prediction calculations.

Table 7: LOP Radial Hot Clearance Measurements

\begin{tabular}{|c|c|c|c|c|c|}
\hline \multicolumn{5}{|c|}{ Hot Clearance $(\mu \mathrm{m})$} \\
\hline Orientation & Speed $(\mathrm{rpm})$ & 3 (Loaded Pad) & 4 & 1 & 2 \\
\hline \multirow{3}{*}{ LOP } & 6800 & 56.6 & 69.3 & 56.6 & 69.3 \\
\cline { 2 - 6 } & 9000 & 56.1 & 68.8 & 56.1 & 68.8 \\
\cline { 2 - 6 } & 10800 & 55.1 & 67.8 & 55.1 & 67.8 \\
\cline { 2 - 6 } & 13200 & 54.2 & 66.9 & 54.2 & 66.9 \\
\hline
\end{tabular}

Table 8: LBP Radial Hot Clearance Measurements

\begin{tabular}{|c|c|c|c|c|c|}
\hline \multicolumn{7}{|c|}{ Hot Clearance $(\mu \mathrm{m})$} \\
\hline Orientation & Speed $(\mathrm{rpm})$ & 3 & 4 & 1 & 2 \\
\hline \multirow{4}{*}{ LBP } & 6800 & 52.6 & 50.2 & 52.6 & 50.2 \\
\cline { 2 - 6 } & 9000 & 50.4 & 49.8 & 50.4 & 49.8 \\
\cline { 2 - 6 } & 10800 & 47.6 & 47.4 & 47.6 & 47.4 \\
\cline { 2 - 6 } & 13200 & 48.9 & 48.4 & 48.9 & 48.4 \\
\hline
\end{tabular}




\section{Loaded Pad's Radial Temperature Gradient}

In 1988, Branagan and Barrett [16] studied the thermal deflection associated with a TPJB pad during operation. They looked into the differential heating of a pad and its effects on pad clearance. To model the differential heating associated with the front of the pad (rotor side of the pad) Branagan used the circumferential temperatures along the Babbitt surface. To model the back of the pad (bearing housing side of the pad), Branagan assumed the heat transfer would be dominated by a stagnant sump region behind the pad. This sump region temperature was set at the inlet oil temperature to the bearing. The model was created by assuming the entire pad was initially at the sump temperature, and then the higher temperatures were applied along the Babbitt surface. Through a finite-element (FE) analysis, Branagan found that the thermal deformed pad showed a radial growth of $0.0034-0.0059 \mathrm{~mm}(0.00013-0.00023 \mathrm{in})$, increasing the curvature of the pad and thus the radial pad clearance and preload. The increase in pad clearance due to thermal deflection alone was found to have little impact on the static and dynamic bearing characteristics.

In the present study, the thermal gradient in the loaded pad was defined by embedded thermocouples inserted inside the bearing pad near the bearing housing. In combination with measurements on the rotor side of the pad these thermocouples define the radial temperature difference experienced during tests. Figure 17 details the 11 thermocouples in the loaded pad. All pad-temperature data are given in Appendix B. 


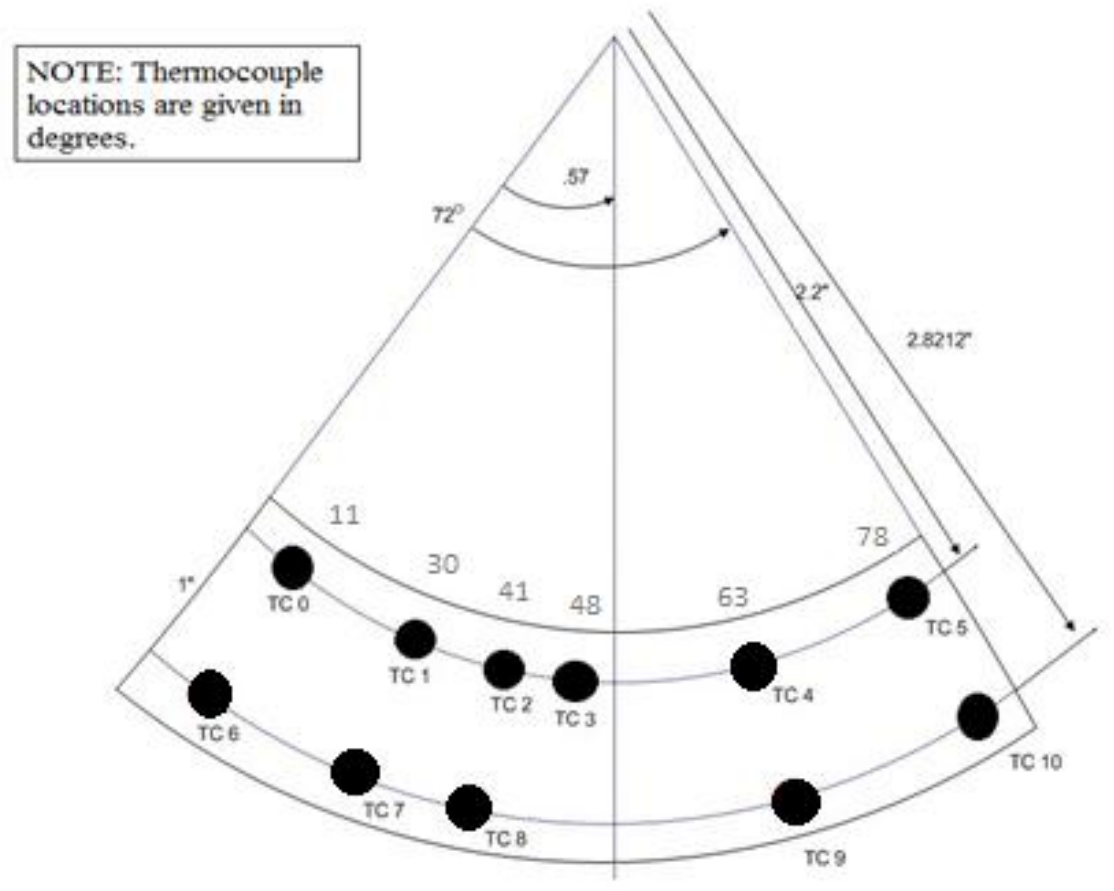

Figure 17: Loaded Pad Thermocouple Diagram

Figure 18 shows the loaded pad's radial temperature difference (pad surface temperature minus back-side temperatures) measured during the 6.8 and $13.2 \mathrm{krpm}$ cases. Note that a negative temperature represents a higher temperature measurement at the bearing housing side of the pad. 


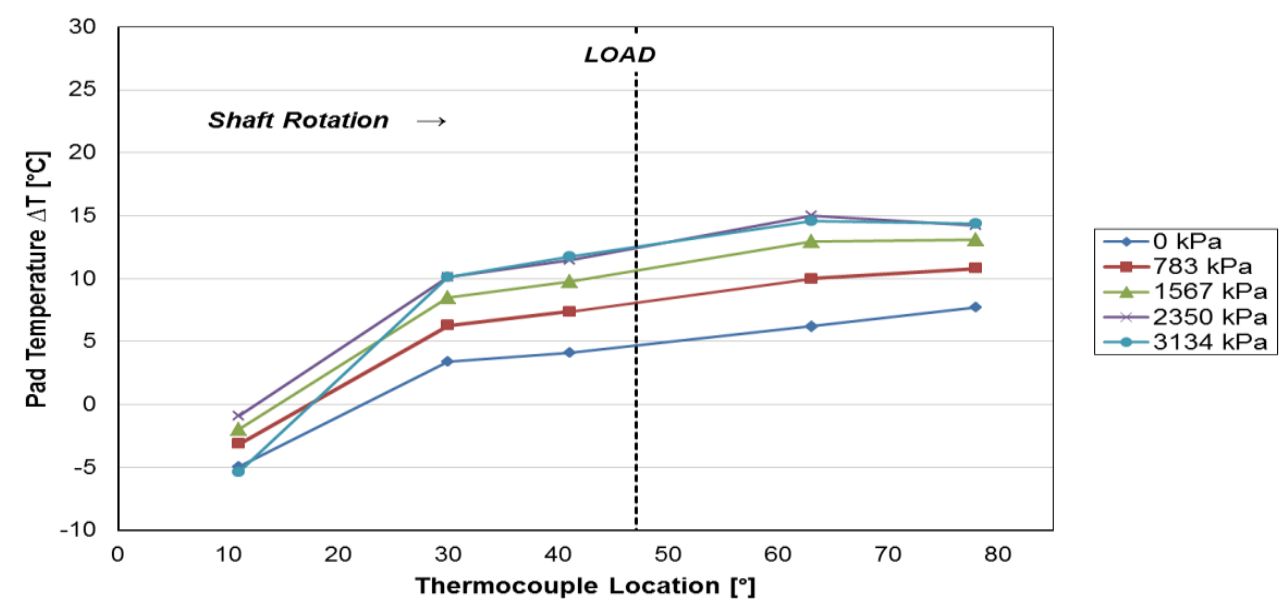

(A) $6.8 \mathrm{krpm}$

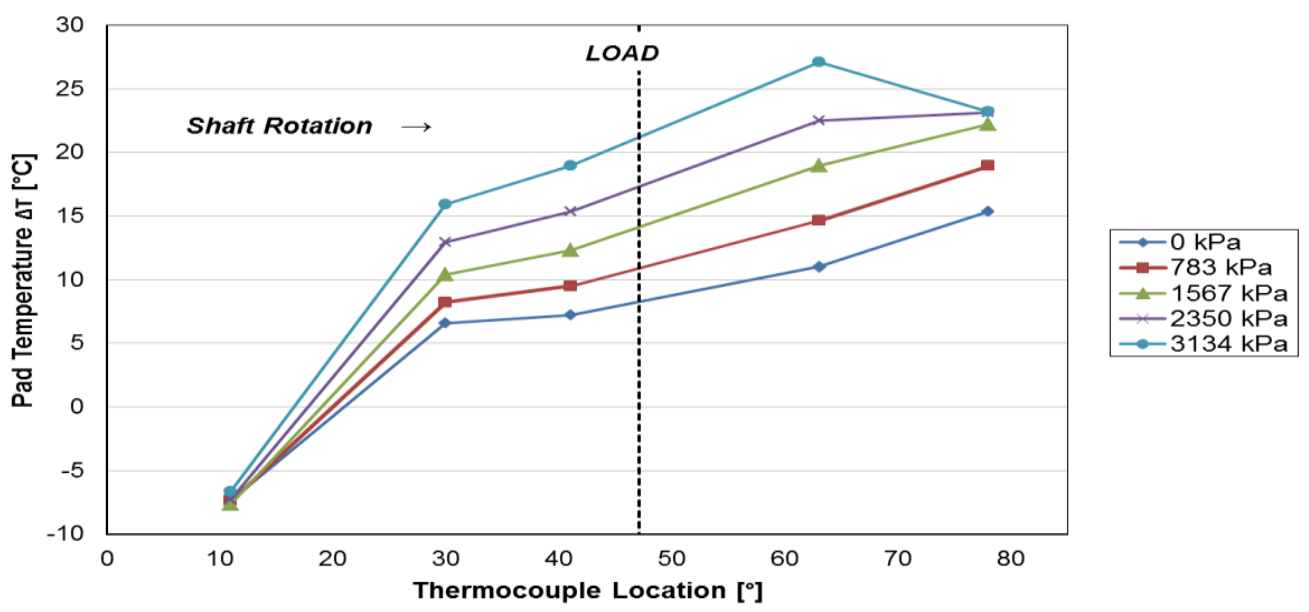

(B) $13.2 \mathrm{krpm}$

Figure 18: Loaded Pad Radial Temperature Difference

The thermal gradient in the loaded pad generally shows a radial temperature decrease from the rotor side of the pad to the bearing housing. Only the thermocouples on the leading edge of the pad showed a radial temperature increase. This temperature increase can be attributed to the thermocouple location; being located in the proximity of the oil inlet to the bearing. Overall, the radial temperature difference from the rotor side of 
the pad to the bearing housing increases with increasing load and speed. The radial temperature difference increases across the face of the pad in the direction of rotation.

An FEA model was created to look at the thermal gradients present in the pads during dynamic tests. As seen above, the temperature increases experienced along the pad, is not uniform. The temperature of the rotor side of the pad is usually greater than the temperature near the bearing housing. This radial temperature gradient will cause an uneven thermal deflection in the pad, changing the pad's radius of curvature. From Eq. (2), the change in pad radius will affect the preload of the pad. Note that thermal effects on the radial bearing clearance were taken into account using the measured hot clearance.

Using measured temperatures a thermal model in ANSYS was created. Thermal conditions were modeled by assuming the whole pad is at room temperature and then applying the measured temperatures to the Babbitt surface and back of the pad. Oil inlet temperatures were applied to the sides of the pad. The line of contact at the pad pivot was constrained to allow zero translation in the $x, y$, and $z$ axes to prevent pad rotation, allowing for the thermal deflection to be studied. Figure 19 shows the thermal distribution obtained for the FEA analysis, for the $13.2 \mathrm{krpm}$ dynamic test. Note that the temperature does not change axially across the face of the pad. 


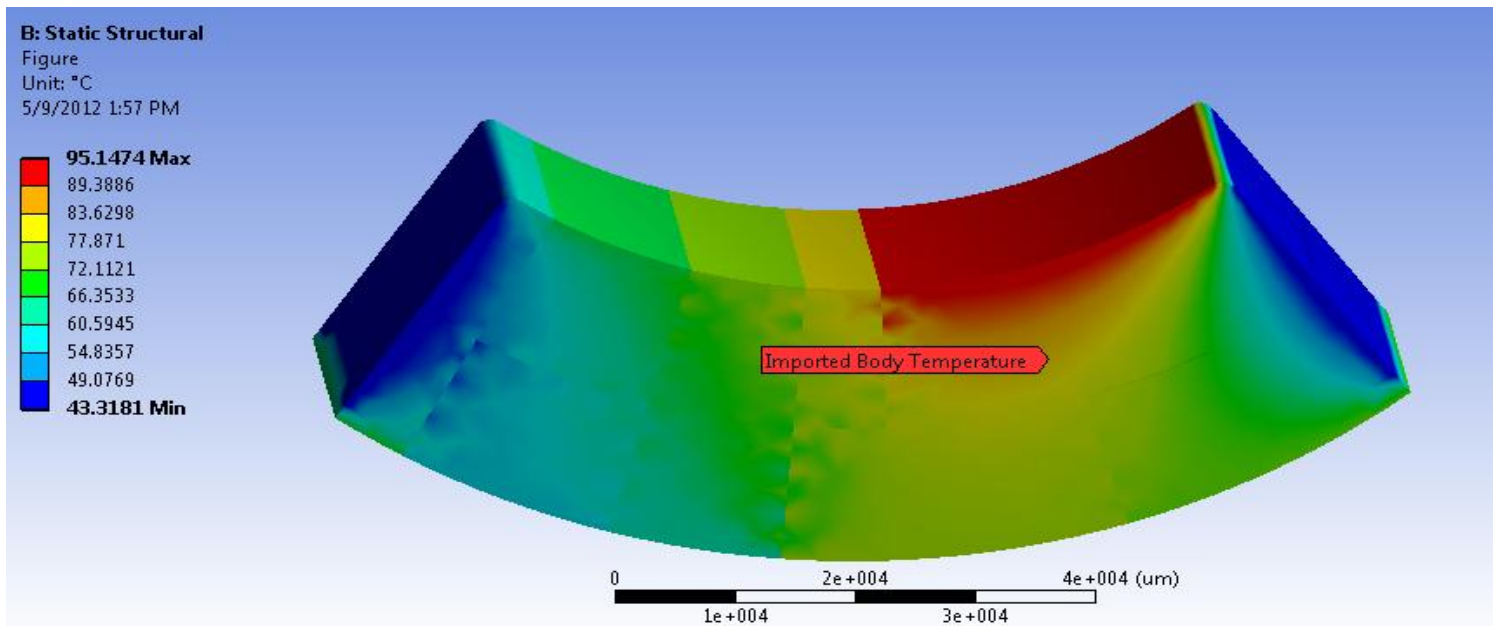

Figure 19: FEA Temperature Distribution for LOP Orientation $13.2 \mathrm{krpm}$ with $1452 \mathrm{kPa}$ (210.5 psi) Static Load

In supplying the thermal load above, Figure 20 shows the thermal deflection results from the FEA analysis.

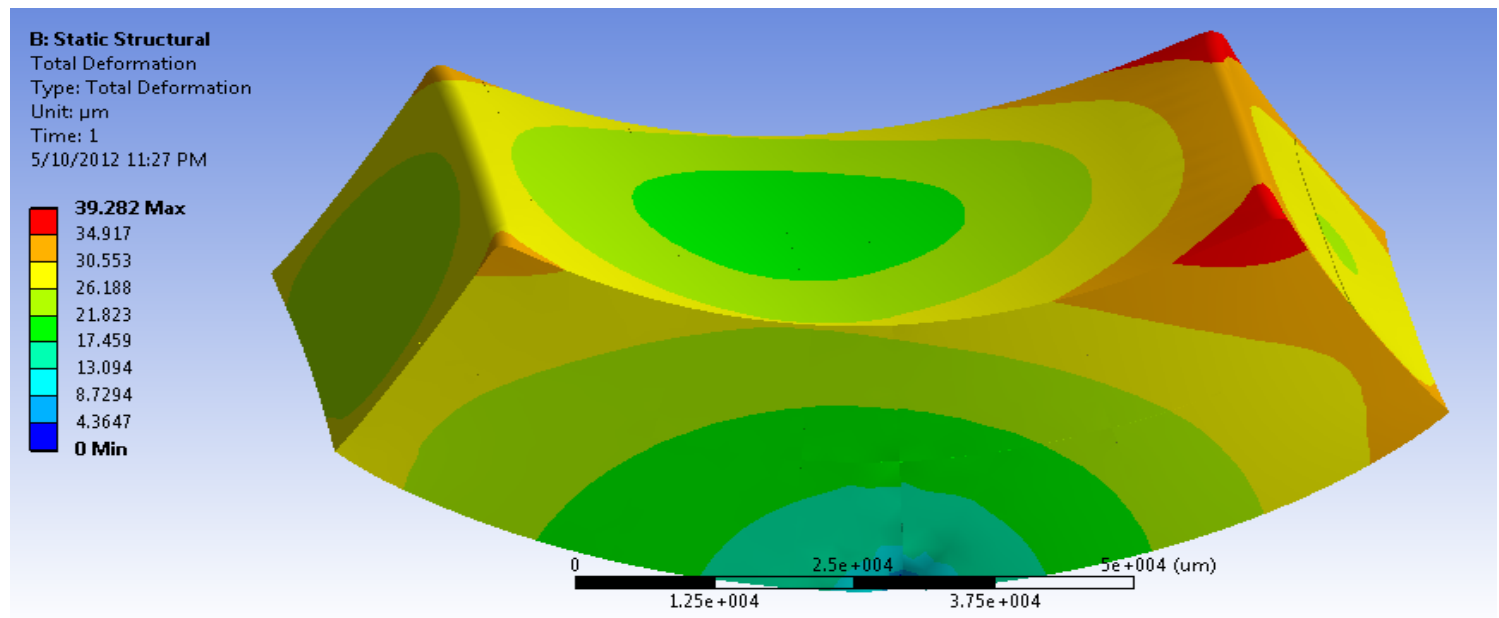

Figure 20: FEA Thermal Deflection for LOP Orientation $13.2 \mathrm{krpm}$ with $1452 \mathrm{kPa}$ (210.5 psi) Static Load

Figure 20 shows an increase in thermal deflection circumferentially across the face of the pad. These results seem reasonable since the trailing edge of the pad is where 
the larger thermal loads are applied. In obtaining the thermal deflection for multiple points across the mid-axial location of the pad, the resulting change in radius of curvature was established. The FEA results showed a 0.016-0.036 mm (0.00063-0.0014 in) increase in the loaded pad's radius depending on running speed and load.

To model the other pads, the same procedure was performed using the specific pad's metal temperatures. Since radial temperatures were not recorded for the other pads, the temperature near the bearing housing was modeled as the measured bearing inlet oil temperature. In the LBP orientation, pad 4 supports more of the unit load and resulted in higher temperature measurements than pad 3. The radial temperatures from pad 3 were modeled as the temperatures near the bearing housing for pad 4. Due to similar temperature measurements, pads 1 and 2 were modeled only once, resulting in the same change in pad radius. Table 9 shows the predicted change in radius of curvature for the $13.2 \mathrm{krpm}$ LOP orientation.

Table 9: Pad Radius and Preload for LOP $13.2 \mathrm{krpm}$

\begin{tabular}{|c|c|c|c|c|}
\hline Pad Number & Machined Pad Radius $(\mathrm{mm})$ & Preload & Thermal Change in Pad Radius $(\mathrm{mm})$ & Resulting Preload \\
\hline 3 (Loaded Pad) & 0.112 & 0.516 & 0.034 & 0.628 \\
\hline 4 & 0.112 & 0.403 & 0.021 & 0.497 \\
\hline 1 & 0.112 & 0.516 & 0.020 & 0.588 \\
\hline 2 & 0.112 & 0.403 & 0.020 & 0.492 \\
\hline
\end{tabular}

Using Eq. (2) for preload, Table 9 shows that, as the radius of curvature increases, the resulting preload of the pad's increase by $0.065-0.136$. Overall, the change in preload slightly affected the predicted bearing impedance coefficients. A higher preload per pad resulted in lowered predictions for the impedance coefficients (see 
DYNAMIC RESULTS). Including the change in pad's radius resulted in slightly poorer predictions, but gives a more accurate representation of the pad's radial clearance during testing. Appendix $\mathrm{C}$ shows the complete FEA results for the change in pad radius of curvature and preload for 6.8 and $13.3 \mathrm{krpm}$ in the LOP and LBP orientations.

\section{Pivot Stiffness}

Both codes use a polynomial load-versus-deflection curve that describes the static nonlinear stiffness of the pivot. The pivot stiffness, or pivot flexibility, refers to the flexibility of the pad relative to the bearing housing (partially from Hertzian-contact), Wilkes and Childs [14]. The Hertzian-contact flexibility arises from the localized strains that develop between elastically curved bodies distorted from imposed loads. Pivot flexibility characteristics are obtained by pressing the rotor into the pad while increasing the force applied directly through the pivot (LOP orientation) with the static loader, similar to the approach taken by Harris and Childs [22]. Figure 21 compares the measured load-versus-deflection curves for the pivot. In Figure 21, the blue crosses represent the pivot displacement as seen by the relative rotor-stator probes, shown in Figure 8 , while the black crosses represent the pivot deflection as seen by the pad-stator probes, shown in Figure 11. 


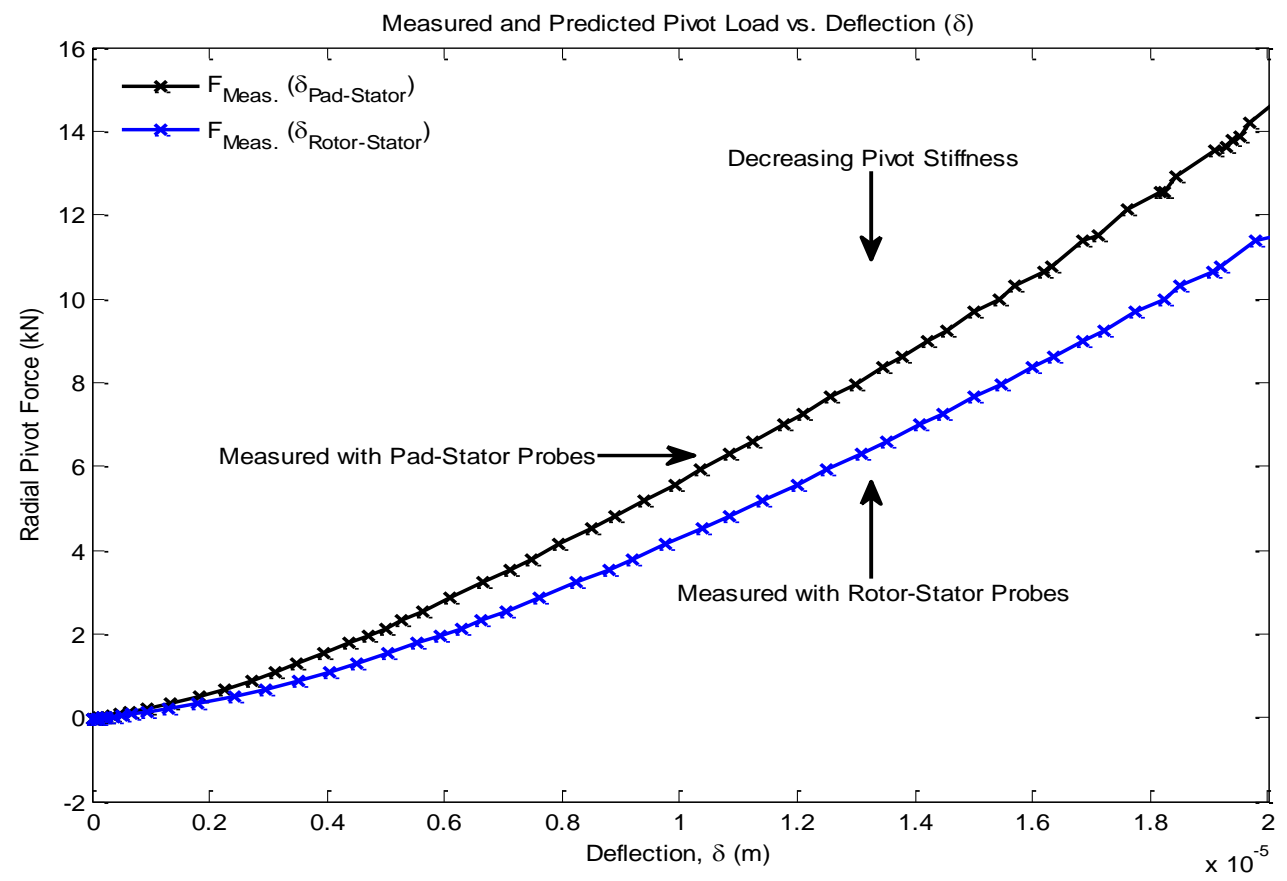

Figure 21: Comparison of Measured Pivot Load-Versus-Deflection

The pad-stator load-deflection curve shows the pivot to be significantly stiffer than the rotor-stator load-deflection curve. This observation agrees with Wilkes and suggests that the rotor-stator probes include the pivot, pad, rotor, and Babbitt stiffness. The pad-stator probes measure the back of the loaded pad while a force is applied directly through the pivot and more closely show the stiffness of the pad relative to the housing. The load-versus-deflection curve from the pad-stator probes will be used in both bearing prediction codes. A fourth-order approximation fits the measured loadversus-deflection curve and will be used as a numerical input for the pivot stiffness. This polynomial is given by:

$$
f_{c}=4.03+1.836 \times 10^{8} \delta+5.771 \times 10^{13} \delta^{2}-2.598 \times 10^{18} \delta^{3}+5.393 \times 10^{22} \delta^{4}
$$

where $f_{c}$ is in Newton's, and $\delta$ is in meters. 


\section{Pad Flexibility}

In addition to pivot stiffness, Code B also incorporates pad flexibility. Pad flexibility is the change in pad curvature resulting from an applied moment at the end of the pad from the fluid film pressure, Figure 4 and Eq. (6) from Wilkes and Childs [14].

In 1988 Branagan and Barrett [16] studied the mechanical pad deflection experienced in a TPJB during operation. This mechanical deflection is found by characterizing the pad as a curved beam with uniform thickness and an applied moment at the ends of the pad. The beam was considered to have a free-free boundary condition (extending from leading to trailing edge of the pad) or to have clamped-free boundary conditions (extending from the pivot to the trailing edge). Branagan analyzed the accuracy of several analytical bending stiffness formulas, comparing them with a finiteelement prediction. In regards to $k_{c_{p}}$ in Eq. (6), Deutschman et al.'s [23] formula was found to be the most accurate equation.

$$
k_{c_{p}}=\frac{E_{p} L_{p} t_{p}}{\Theta-1} \frac{\left(\Theta^{2}-1\right)^{2}-[2 \Theta \ln (\Theta)]^{2}}{4\left\{1-\Theta^{2}[1-2 \ln (\Theta)]\right\}}
$$

Eq. (26) determines the change in radius using the analytically determined stress field of

a curved beam with end moments [15]. Where $\Theta=\left(r_{p}+t_{p}\right) / r_{p}$ is the ratio of outer to inner pad radii, $t_{p}$ is the thickness of the pad, $L_{p}$ is the length of the pad, and $E_{p}$ is the elastic modulus of the pad.

From Eq. (26) the following constant bending stiffness will be used as a numerical input for Code B, in Eq. (6). 


$$
k_{c_{p}}=22.049 \mathrm{MN}\left(4.957 \times 10^{6} \mathrm{lbf}\right)
$$

Note that the bearing tested in Wilkes consisted of pads with a hardened pivot insert to reduce wear, different from the pads tested in this thesis. Figure 22 shows a typical tilting-pad with pivot insert and is similar to the pads used in the tests by Wilkes [15].

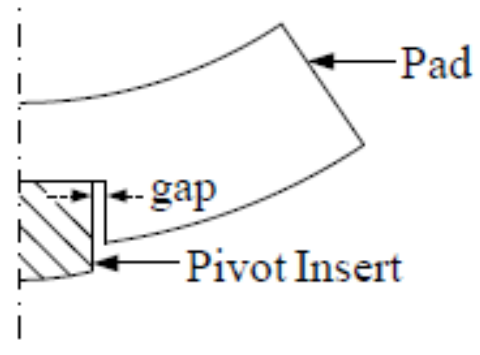

Figure 22: Illustration of Pad with a Pivot Insert [14]

The cut-out slot shown in Figure 22 greatly affected the pad's ability to resist bending moments, invalidating Deutschman et al.'s formula. For this reason, Wilkes predictions used a bending stiffness from measured load-defection results. 


\section{STATIC RESULTS}

The static results include the measured journal eccentricity, bearing loci, attitude angle, estimated power loss, and circumferential pad metal temperatures in both the LOP and LBP configuration. As stated, Code B does not include an energy equation to calculate temperature and viscosity distributions, and experimental temperature measurements were used in predictions. To be consistent, all static results will be compared to predictions from Code A.

\section{Eccentricity and Attitude Angle}

The position of the bearing at operating conditions may be described with the static eccentricity $\varepsilon_{0}$ and the attitude angle $\phi_{0}$. Eccentricity provides the distance between the bearing center and the shaft center. $\varepsilon_{\mathrm{o}}$ and $\phi_{\mathrm{o}}$ are defined by:

$$
\begin{gathered}
\varepsilon_{o x}=e_{o x} \\
\varepsilon_{o y}=e_{o y} \\
\varepsilon_{o}=\sqrt{\left(\varepsilon_{o x}\right)^{2}+\left(\varepsilon_{o y}\right)^{2}} \\
\phi_{o}=\tan ^{(-1)}\left(\frac{\varepsilon_{o x}}{\varepsilon_{o y}}\right) \frac{180}{\pi}[\mathrm{deg}]
\end{gathered}
$$

An eccentricity of zero indicates a centered bearing. An eccentricity of one would suggest contact between the shaft and bearing. The attitude angle indicates the relative transverse displacement of the shaft from the load-axis. 
Figure 23 show the measured static $\varepsilon_{0}$ and attitude angle $\phi_{\mathrm{o}}$ results for the LOP orientation. Results are generated by increasing the unit load applied to the bearing from zero to $2903 \mathrm{kPa}$ (421.1 psi), while keeping a constant rotor speed. This figure shows the measured static eccentricity vector within the cold and hottest LOP bearing clearance.

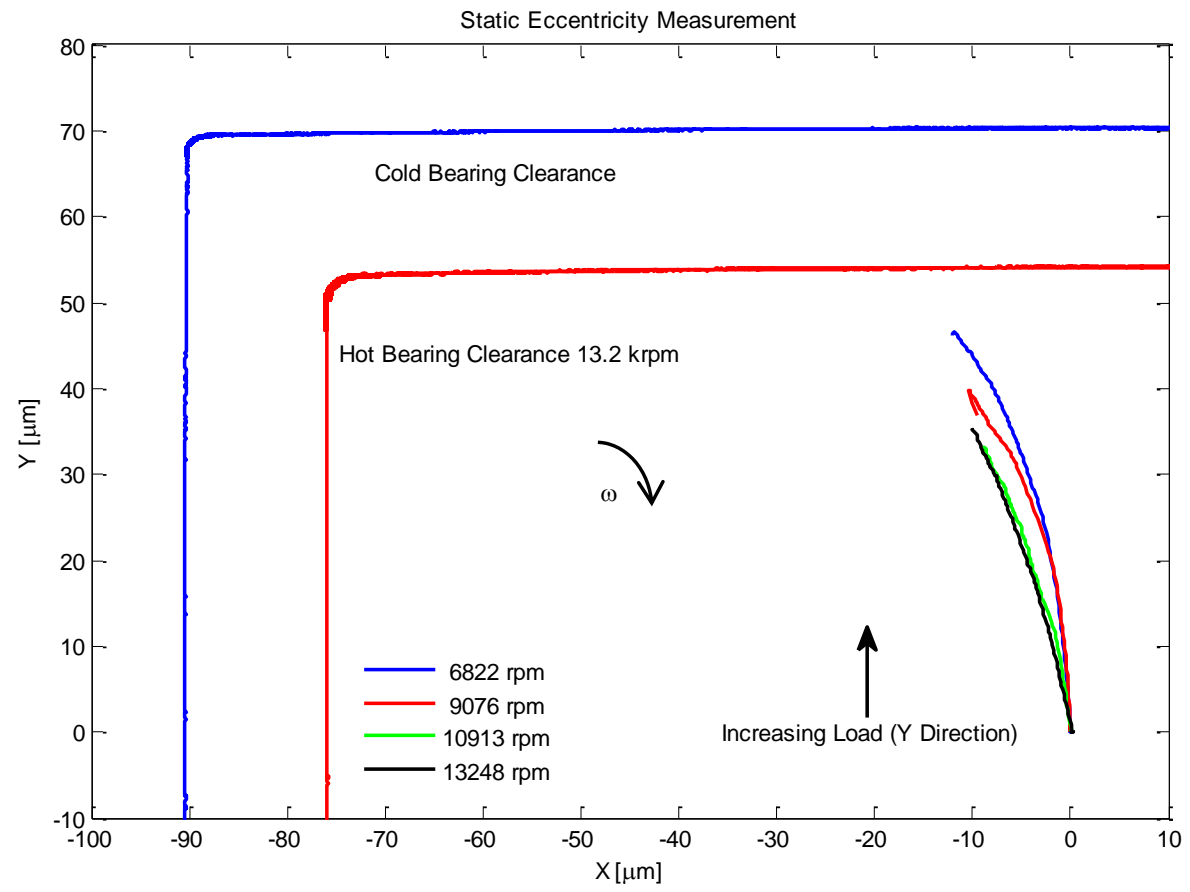

Figure 23: LOP Measured Static Eccentricity at Various Speeds with Unit Loads in the YDirection from 0-2903 kPa

Figure 23 shows that the measured static eccentricity vector changes with increasing load and speed. As speed increases, the static eccentricity vector decreases. In looking at the $13.2 \mathrm{krpm}$ case and the hot bearing clearance shown, Figure 23 supports the notion of using the hot bearing clearance in predicting journal eccentricity. Using a cold clearance measurement for predictions would greatly under predict $\varepsilon_{\mathrm{o}}$ in Eq. (28). 
Figure 24 show the measured static $\varepsilon_{\mathrm{o}}$ and attitude angle $\phi_{\mathrm{o}}$ results for the LBP orientation. Similar to the LOP orientation, this figure shows the measured static eccentricity vector within the cold and hottest LBP bearing clearance.

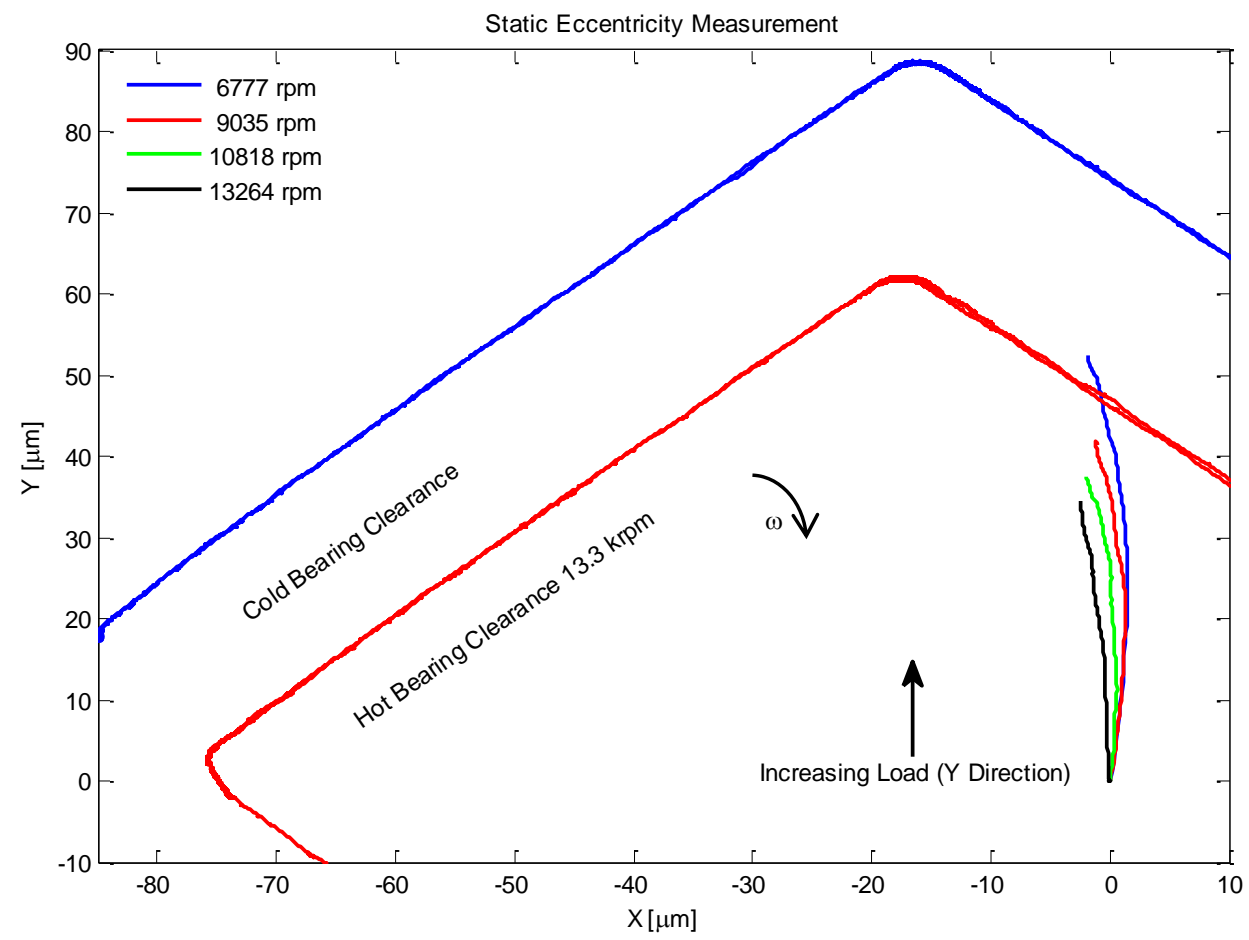

Figure 24: LBP Measured Static Eccentricity at Various Speeds with Unit Loads in the YDirection from 0-2903 kPa

Similar to the LOP orientation, Figure 24 shows that the measured static eccentricity vector changes with increasing load and speed in the LBP orientation. As speed increases, the static eccentricity vector decreases. The static data shows that for high static loads at low speeds the journal exceeds the measured hottest bearing clearance. The static eccentricity of $13.2 \mathrm{krpm}$ is not as close to this measured bearing 
clearance. Figure 24 supports using the hot bearing clearance in predicting journal eccentricity in the LBP orientation.

Figure 25 provides the measured and predicted loci plots to Code A for the LOP orientation. Each data point represents a static load condition, and the point furthest from the origin signifies the highest load condition, $2903 \mathrm{kPa}$ (421.1 psi).

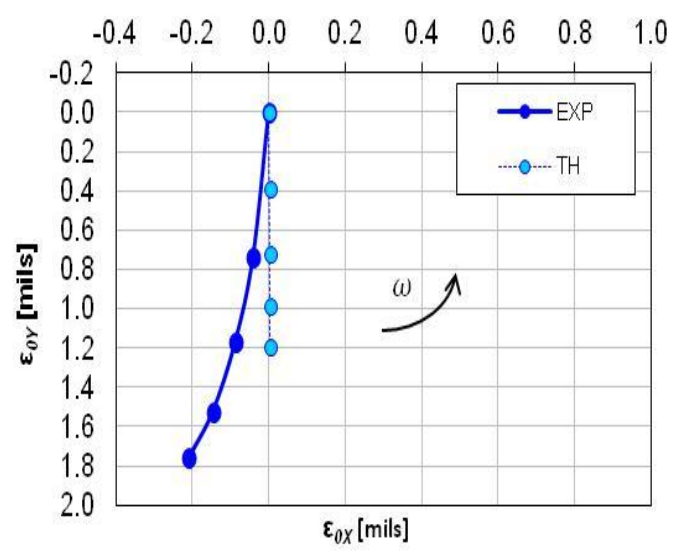

(A) $6.8 \mathrm{krpm}$

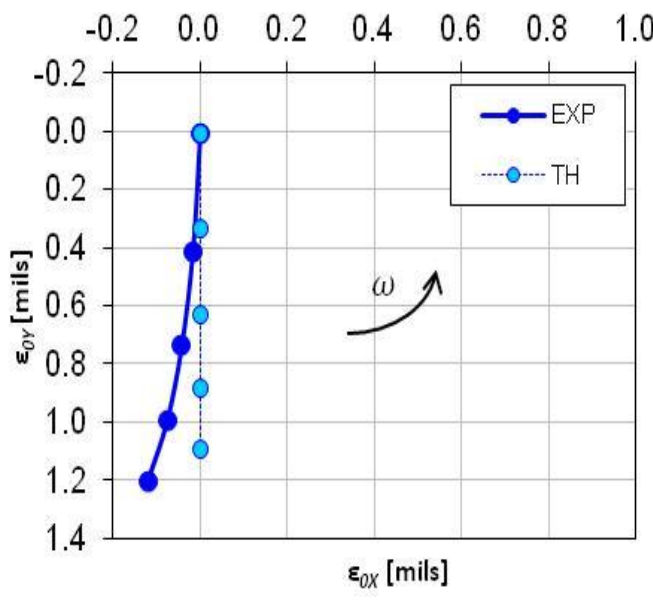

(C) $10.8 \mathrm{krpm}$

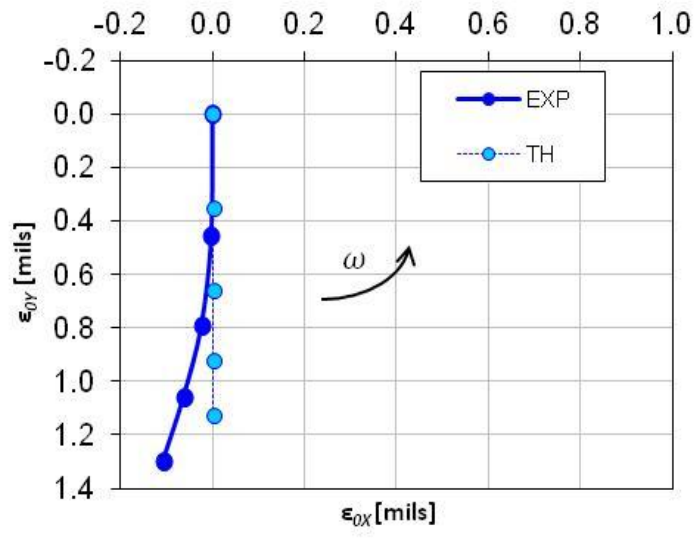

(B) $9 \mathrm{krpm}$

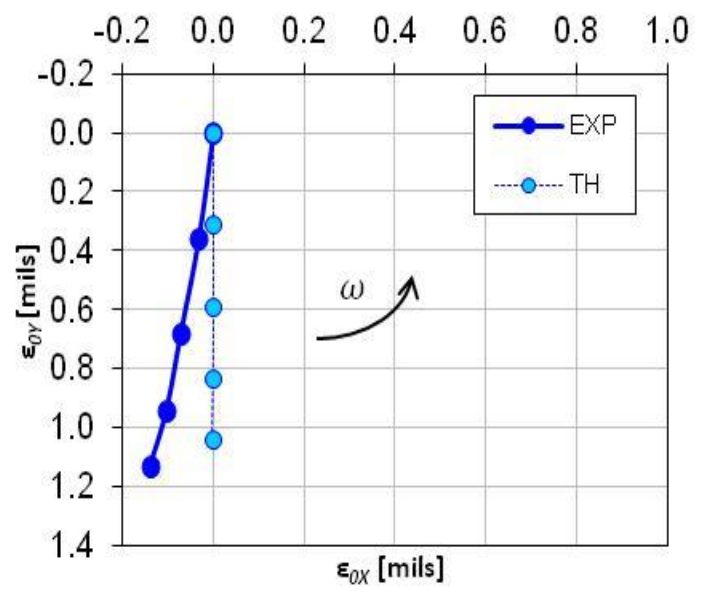

(D) $13.2 \mathrm{krpm}$

Figure 25: LOP Bearing Loci 
At low speeds, the $\varepsilon_{\mathrm{o}}$ predictions are less than measured values. At higher speeds, the $\varepsilon_{\mathrm{o}}$ predictions are more accurate. The predicted bearing loci plots show less movement in the $\varepsilon_{\text {oy }}$ direction than measurements, predicting a stiffer bearing. Comparing these predictions to the measured load-versus-deflection curve in Figure 21 showed that the loci predictions were in fact more flexible than the measured loadversus-deflection curve from the pad-stator probes. The measured load-versus-deflection curve from the pad-stator probes was used as a numerical input for the pivot stiffness of Code A. At all speeds, the unpredicted lateral displacement $\varepsilon_{\mathrm{ox}}$ is substantial. Note that a change in $\varepsilon_{\mathrm{o}}$ and $\phi_{\mathrm{o}}$ can be attributed to a change in probe length due to temperature, suggested by Wilkes and Childs [15]. In ideal conditions, a lateral displacement from the loaded $y$ axis indicates cross-coupled stiffness.

The LBP loci plots are presented in Figure 26.

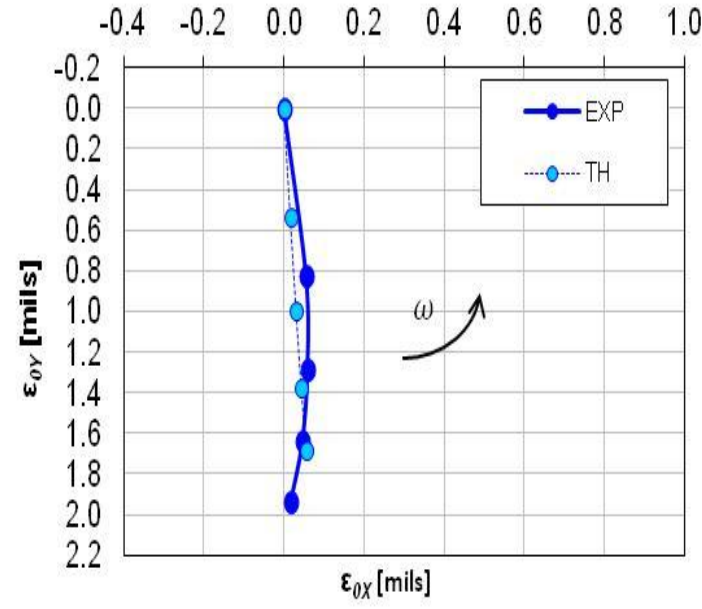

(A) $6.8 \mathrm{krpm}$

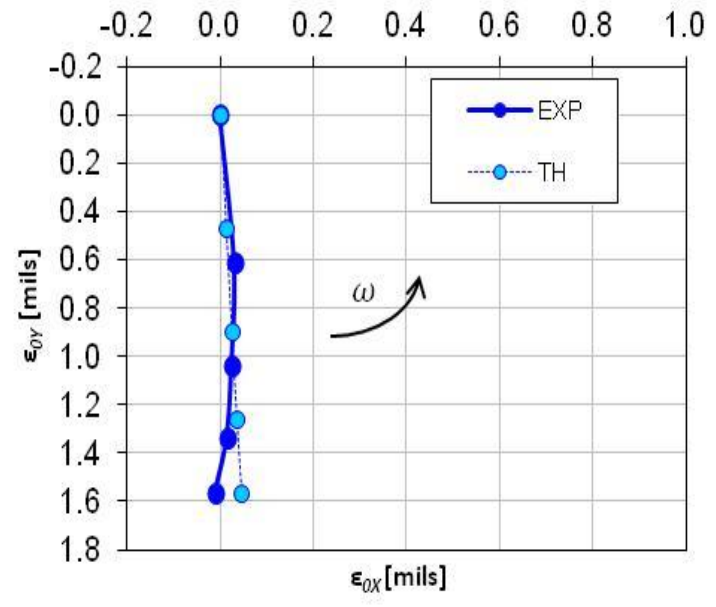

(B) $9 \mathrm{krpm}$

Figure 26: LBP Bearing Loci 


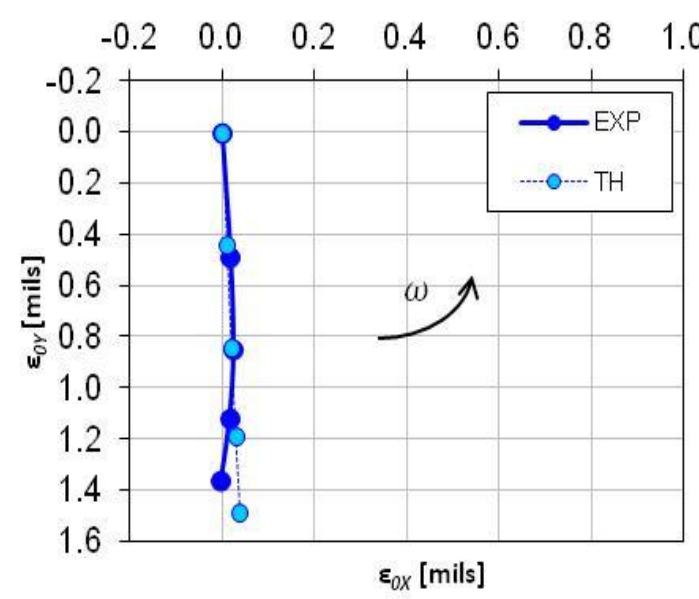

(C) $10.8 \mathrm{krpm}$

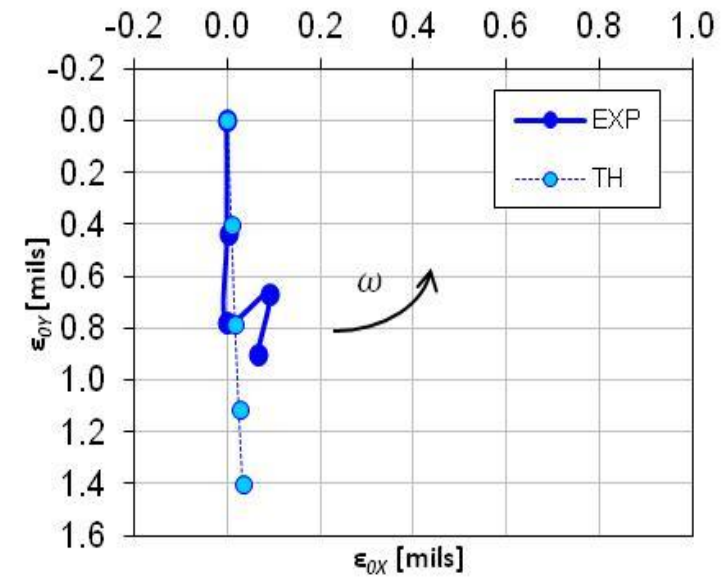

(D) $13.2 \mathrm{krpm}$

Figure 26: Continued

For high speeds, the eccentricity is predicted well and better than the LOP plots.

Except for the deviation experienced in Figure 26(D), the eccentricity predictions are more accurate for LBP than LOP. Overall, the lateral displacement from the loaded $y$ axis or cross-coupling is less significant in the LBP orientation.

The measured and predicted attitude angles for the LOP configuration are presented in Figure 27. 


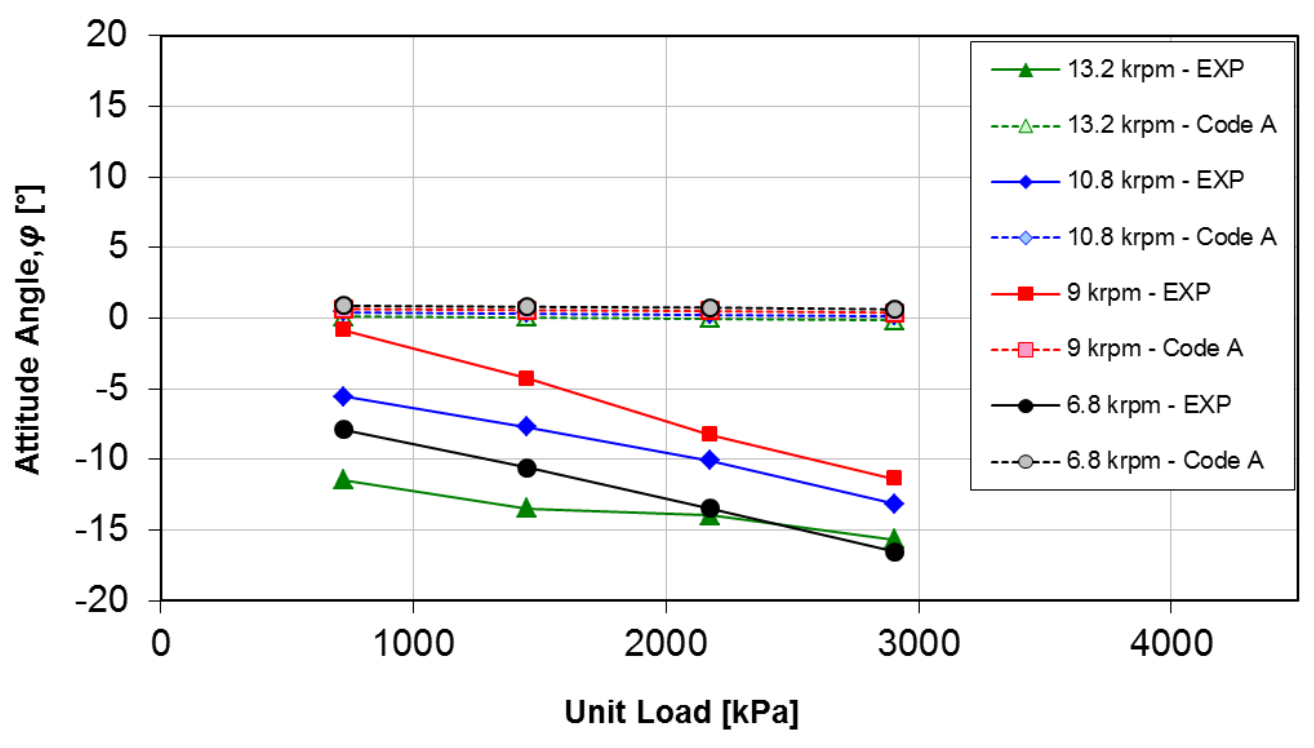

Figure 27: Measured and Predicted Attitude Angles LOP Orientation

For the most part, the measured attitude angle in the LOP orientation decreases (is more negative) with increasing load. The measured values are considerably different from the predicted attitude angles by Code A, which are approximately zero. From fluid rotation, typical attitude angles in fixed-arc bearings are expected to be positive and result from rotor movement in the same transverse direction as shaft rotation. Appendix D shows that all experimental $K_{x y}$ and $K_{y x}$ coefficients are negative (same sign), and thus do not promote instability.

The measured and predicted attitude angles for the LBP configuration are presented in Figure 28. 


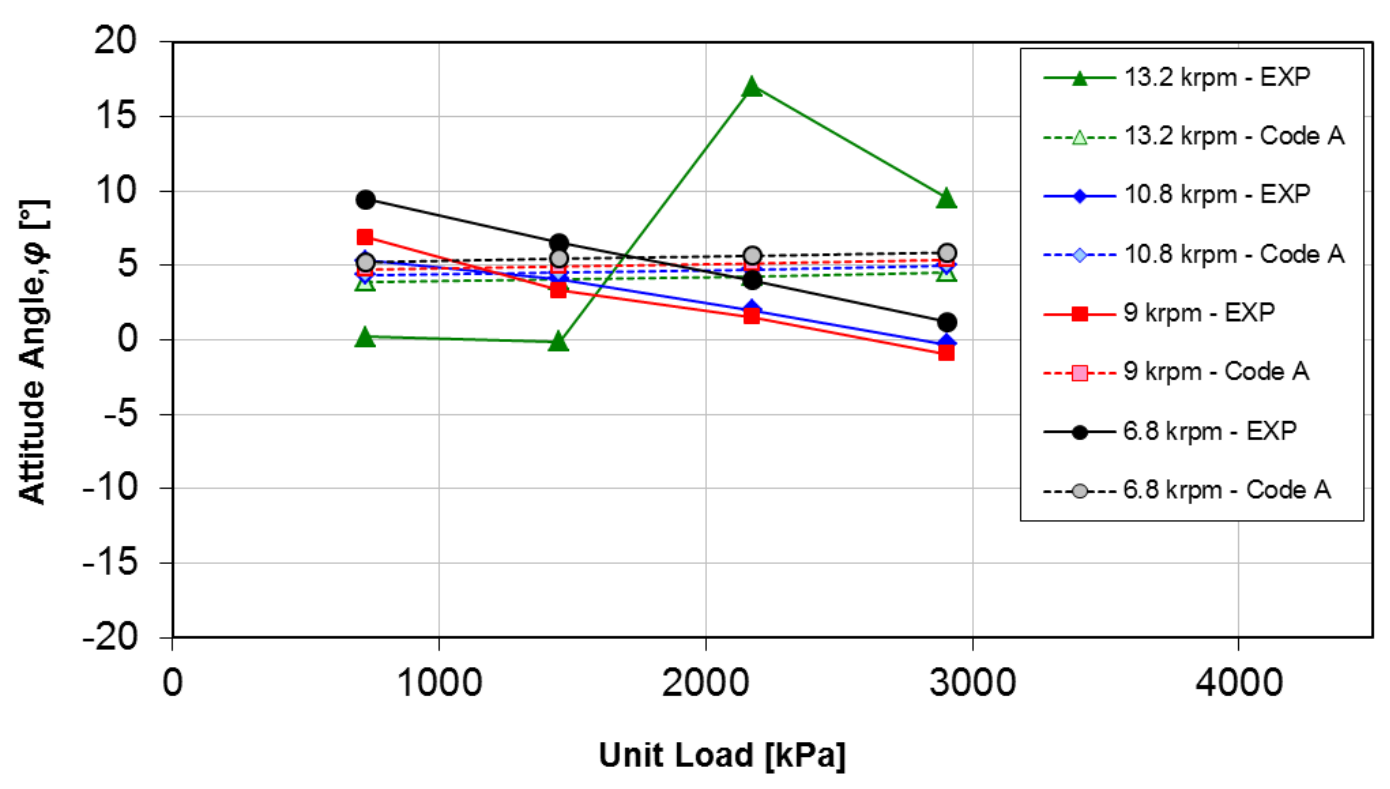

Figure 28: Measured and Predicted Attitude Angles LBP Orientation

In the LBP orientation, the measured attitude angle decreases (more negative) with speed and load, except at $13.2 \mathrm{krpm}$. The predicted values slightly increase as load increases. The measured values decrease through the predicted values. Code A's LBP predicted values are more accurate than the LOP. Overall, both conditions show that the measured cross-coupling effects between the $x$ and $y$ direction are significant.

\section{Pad Metal Temperatures}

Embedded thermocouples provide pad metal temperature just below the surface of the Babbitt. Measured surface temperatures provide an idea of the lubricant temperatures experienced during testing. Figure 29 shows the 21 thermocouples used during testing. All pad temperature data are given in Appendix B. 


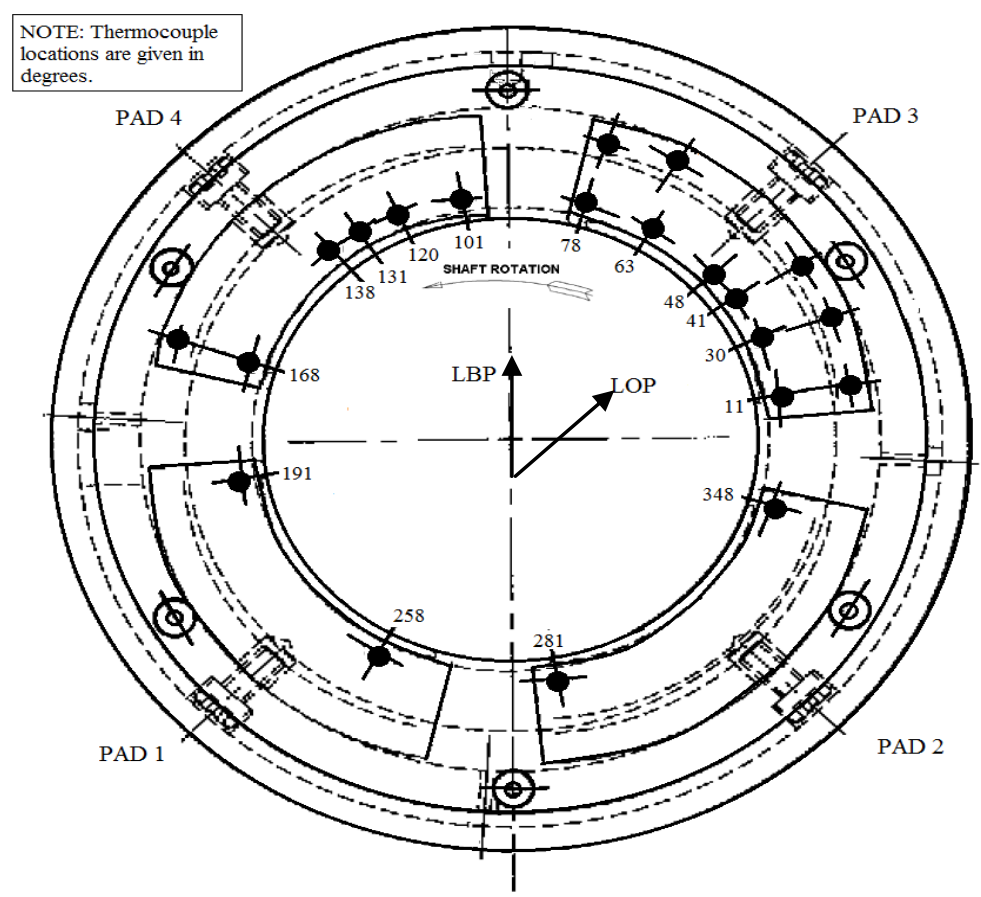

Figure 29: Pad Thermocouple Diagram

\section{LOP Circumferential Temperature Gradient}

Figure 30 shows all of the thermocouple readings in the LOP orientation at a rotor speed of $6.8 \mathrm{krpm}$ and $13.2 \mathrm{krpm}$. 


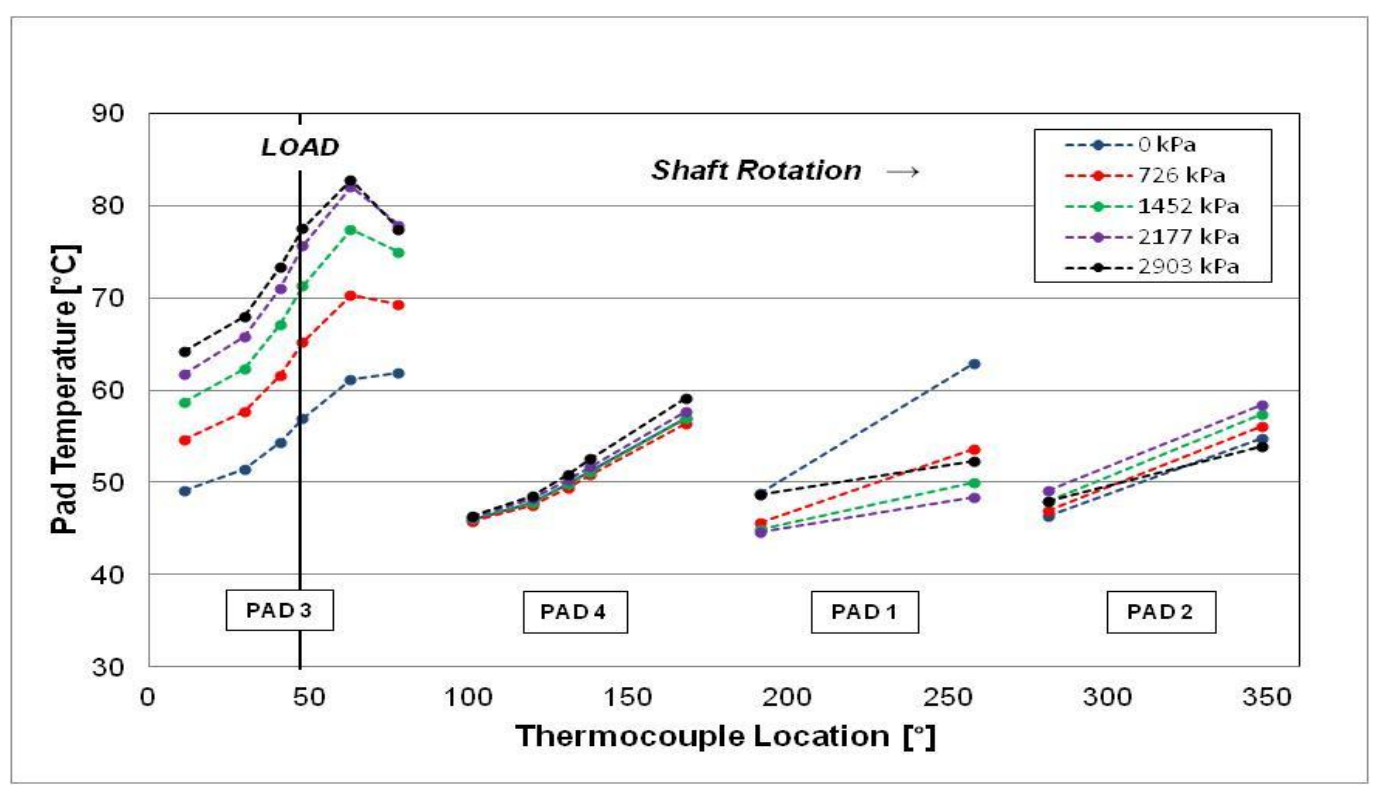

(A) $6.8 \mathrm{krpm}$

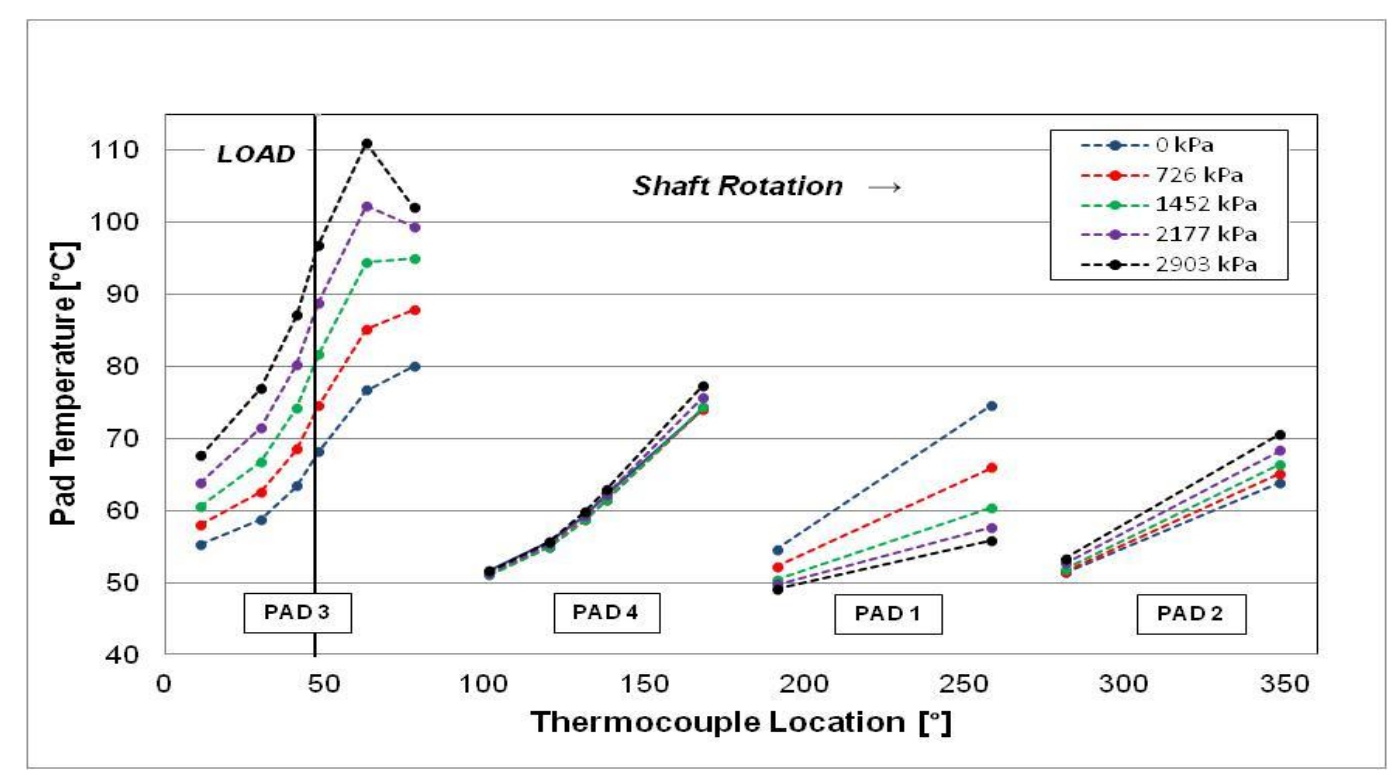

(B) $13.2 \mathrm{krpm}$

Figure 30: LOP Measured Pad Bearing Temperatures

The loaded pad has higher temperatures than the remaining three pads (supporting more of the static unit load), and the temperature increases circumferentially 
across the pad with shaft rotation (from leading to trailing edge of the pads). The remaining 3 pads experienced similar temperature measurements for a certain rotor speed or load.

To compare measured temperatures to predictions, Code A predicts the temperature distribution for the lubricant at a circumferential angle. Code A accounts for the thermal effects in fluid flow via the energy transport equation. Note that Code A predicts the lubricant's temperature, but pad metal temperatures are measured. Input for Code A can be found in Table 2 for bearing parameters, Table 7 and Table 8 for hot bearing clearances, and the Predictions section for pivot flexibility.

Figure 31 shows the measured and predicted pad temperatures at $6.8 \mathrm{krpm}$.

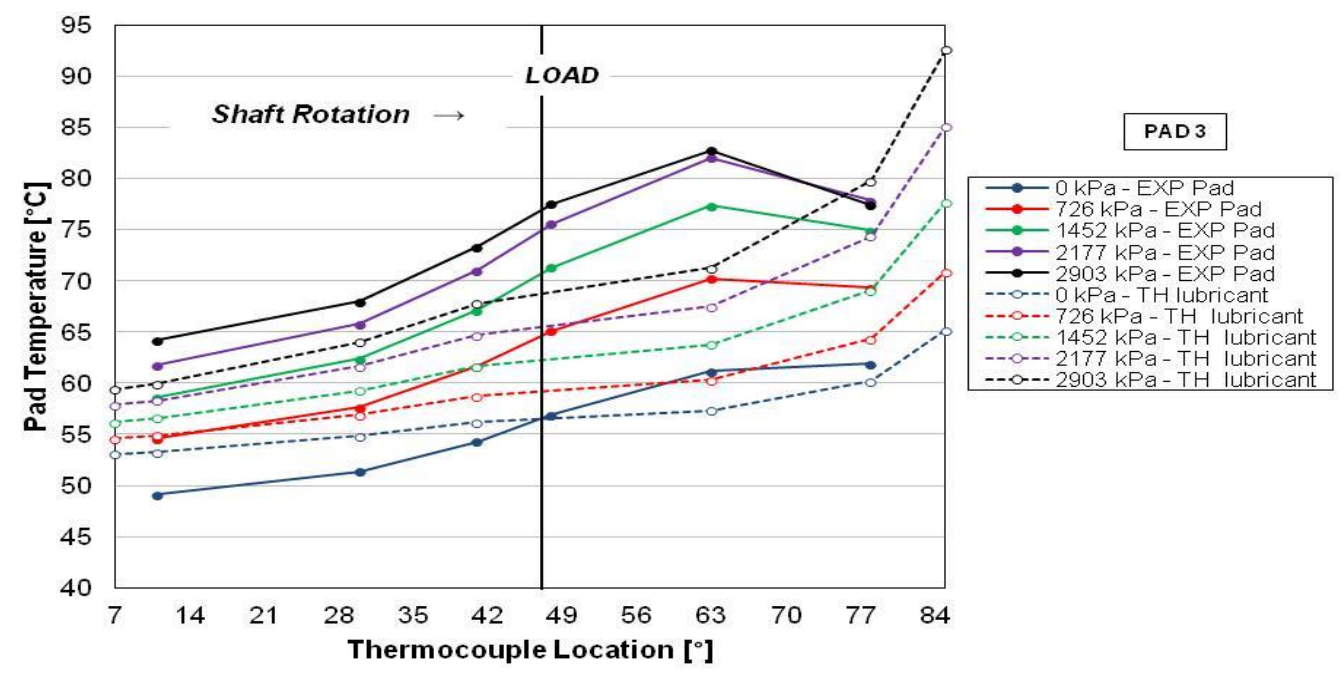

(A) Pad 3 (Loaded Pad)

Figure 31: LOP Measured Pad and Predicted Lubricant Temperatures at 6.8 krpm 


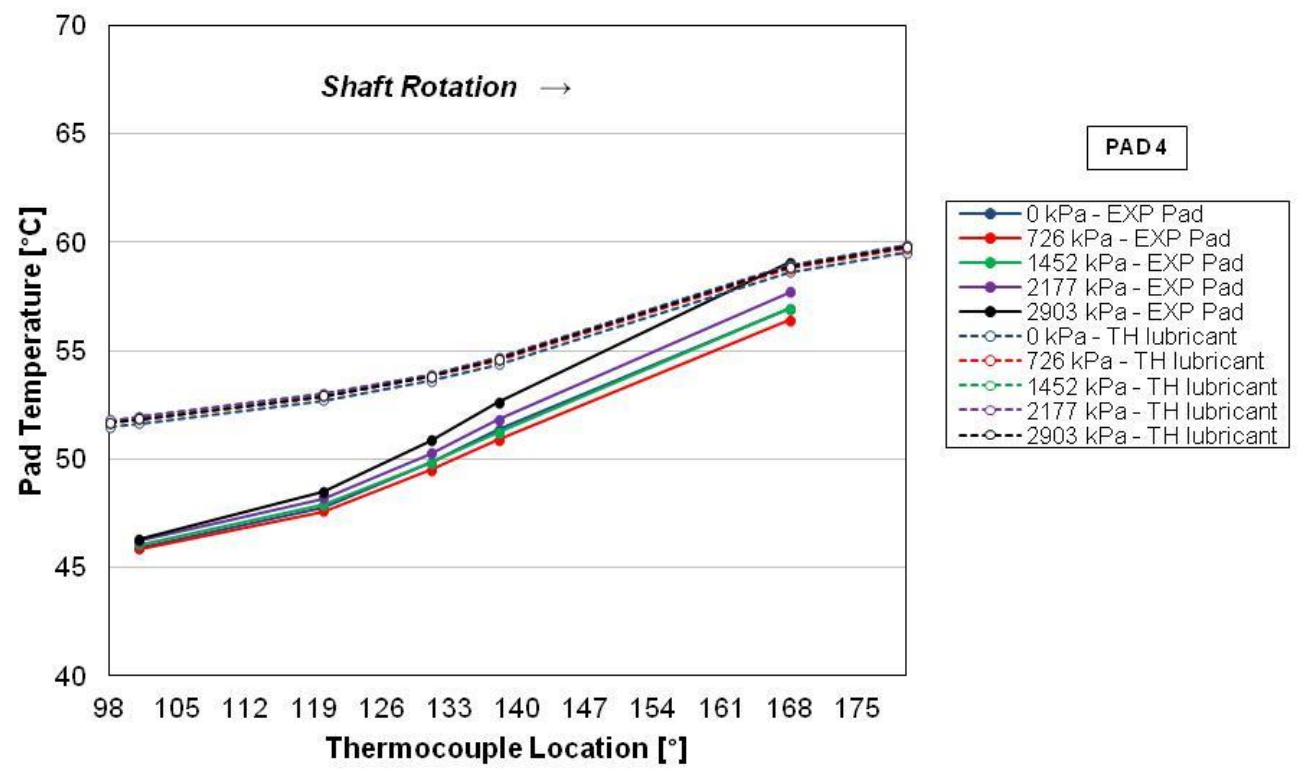

(B) Pad 4 (Following Loaded Pad)

Figure 31: Continued

The code also predicts a circumferential temperature increases with increasing load. For the loaded pad, all pad temperatures are slightly lower than predicted lubricant temperatures, except the unloaded case. Predicted lubricants temperature should be slightly greater that the pad's metal temperatures.

Thermocouple readings from pad 4 (following the loaded pad) show similar results in that measurements and predictions both show a circumferential temperature increase. Measured temperatures for pad 4 were over-predicted regardless of load or location. Temperatures for pads one and two are given in Appendix B.

Figure 32 shows the measured and predicted pad temperatures at $13.2 \mathrm{krpm}$. 


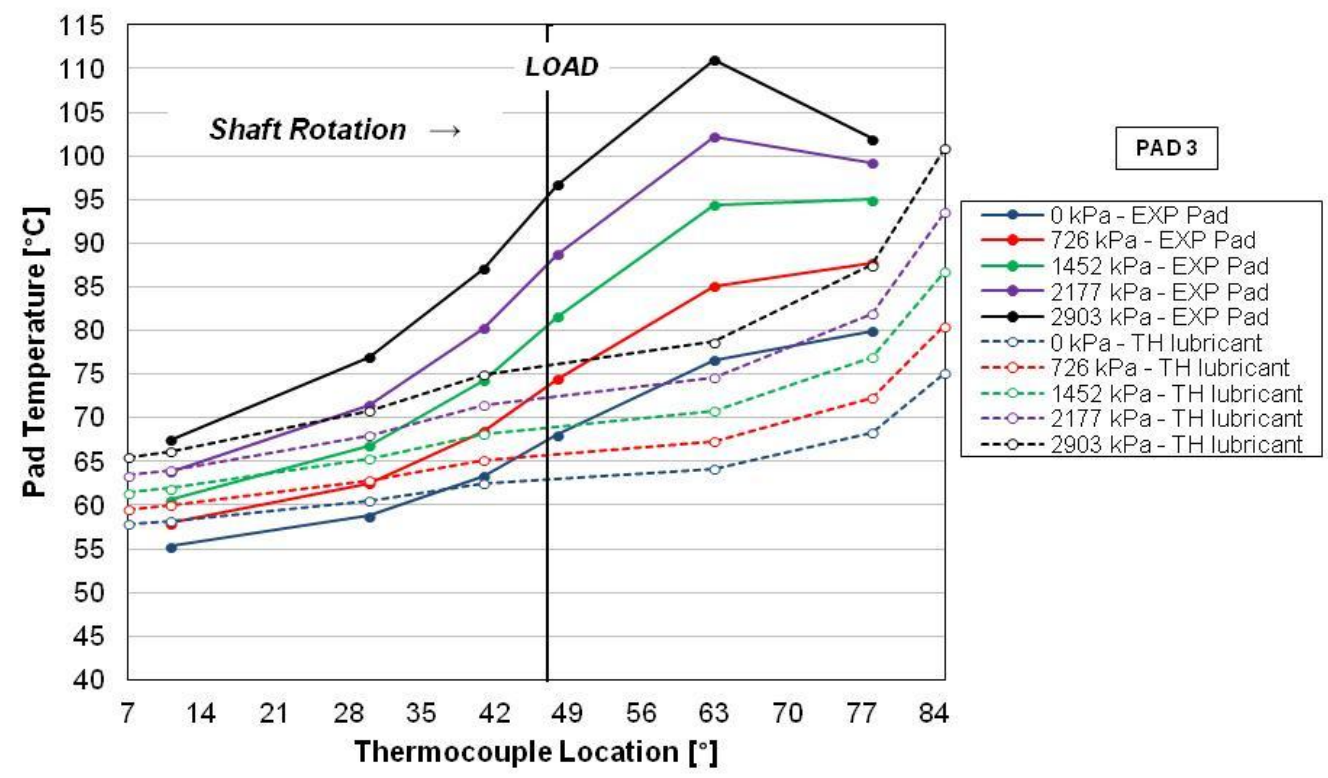

(A) Pad 3 (Loaded Pad)

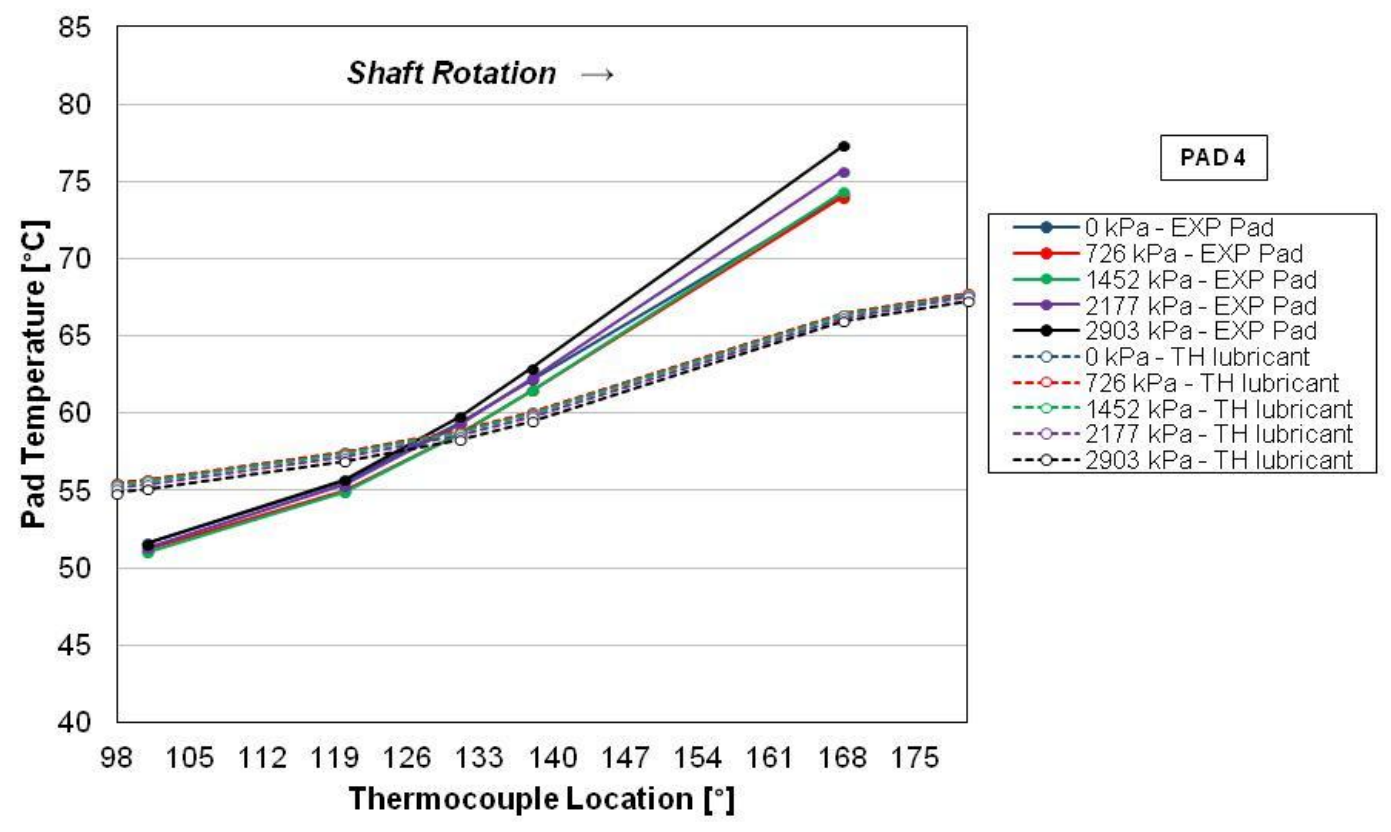

(B) Pad 4 (Following Loaded Pad)

Figure 32: LOP Measured Pad and Predicted Lubricant Temperatures at $13.2 \mathrm{krpm}$ 
Similar to the $6.8 \mathrm{krpm}$ case, the code predicts that pad temperature increases circumferentially in the direction of shaft rotation. The measured and predicted temperatures increase with increasing load. For the loaded pad, all temperatures are under-predicted except for the thermocouple at the leading edge of the pad. In pad 4, the temperatures are over-predicted at the leading edge of the pad and under predicted at the trailing edge of the pad. Predictions at $13.2 \mathrm{krpm}$ are more accurate than predictions at $6.8 \mathrm{krpm}$.

\section{LBP Circumferential Temperature Gradient}

Figure 33 shows the circumferential temperature gradient at $6.8 \mathrm{krpm}$ and 13.2 $\mathrm{krpm}$ in the LBP orientation. The static load is applied between pad 3, (loaded pad in LOP orientation) and pad 4. In looking back, Figure 15 shows that since the bearing is non-symmetric, pad 4 supports more of the unit load in the LBP configuration and may result in higher temperature measurements. Note that in Figure 33(A), the temperature at the leading edge of pad 3 is greater than the temperature at the leading edge of pad 4 . This finding is interesting since the temperature at the leading edge of the pad is typically controlled by the oil inlet temperature, and results in similar temperature measurements at the leading edge between pads. The LBP $6.8 \mathrm{krpm}$ test, is the only condition where these findings were made. 


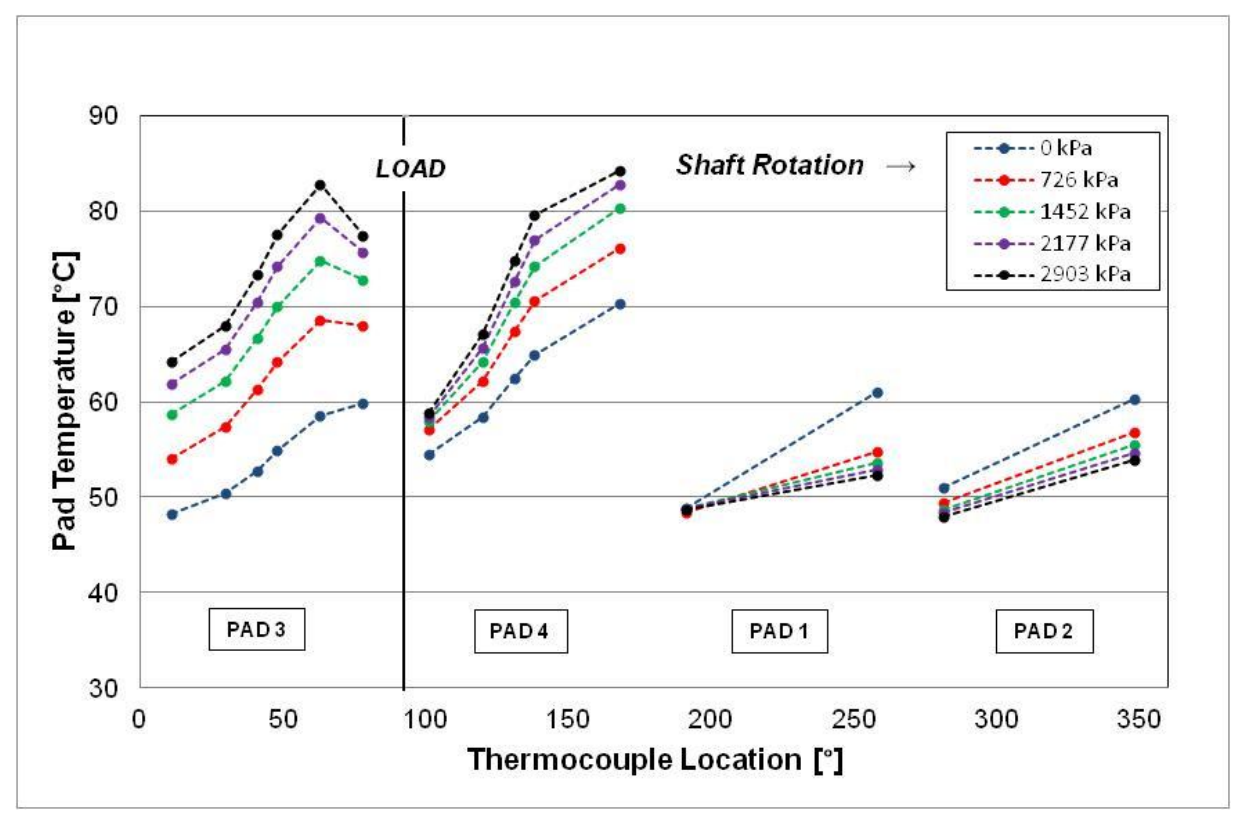

(A) $6.8 \mathrm{krpm}$

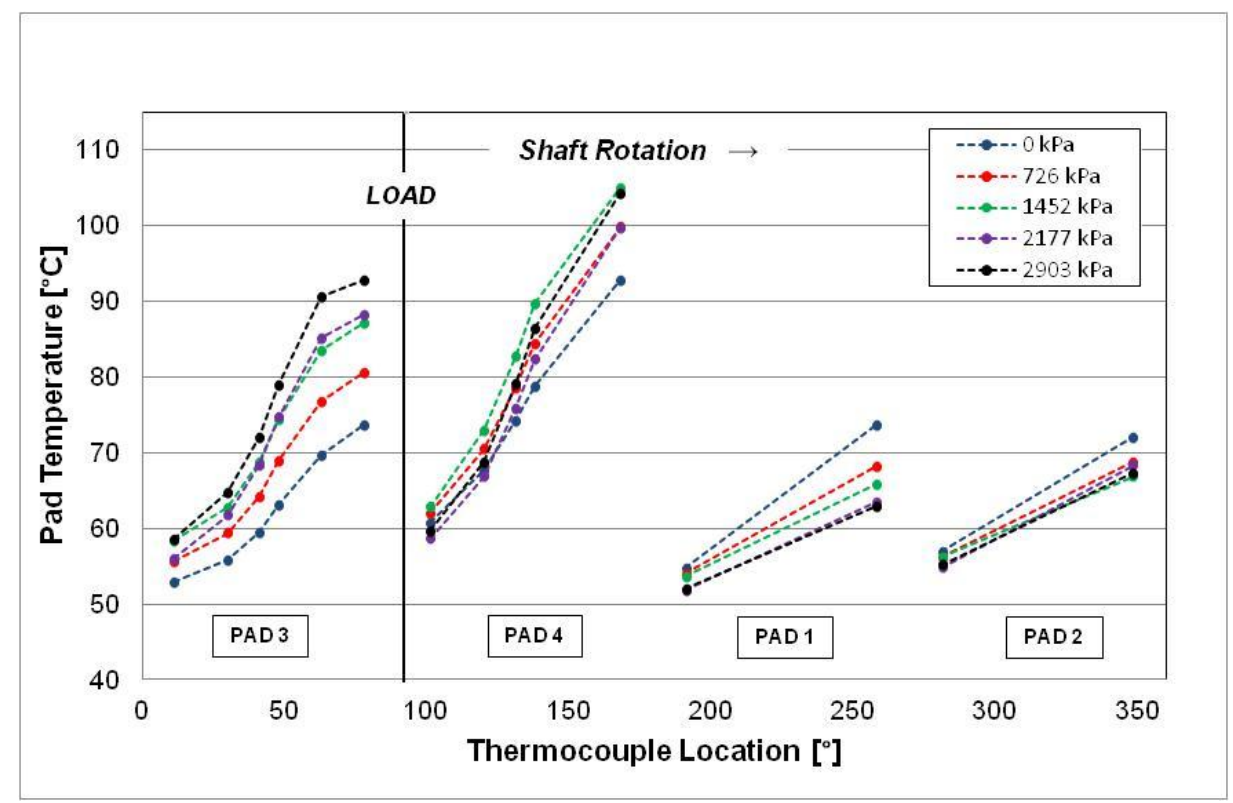

(B) $13.2 \mathrm{krpm}$

Figure 33: LBP Measured Pad Bearing Temperatures 
Similar to the LOP orientation, the temperature increases circumferentially along the pad with shaft rotation (from leading to trailing edge of the pads). Pad 4 does have slightly higher temperature measurements than pad 3, showing that pad 4 did support more of the applied load in the LBP orientation.

Figure 34 shows the LBP measured and predicted pad temperatures at $6.8 \mathrm{krpm}$.

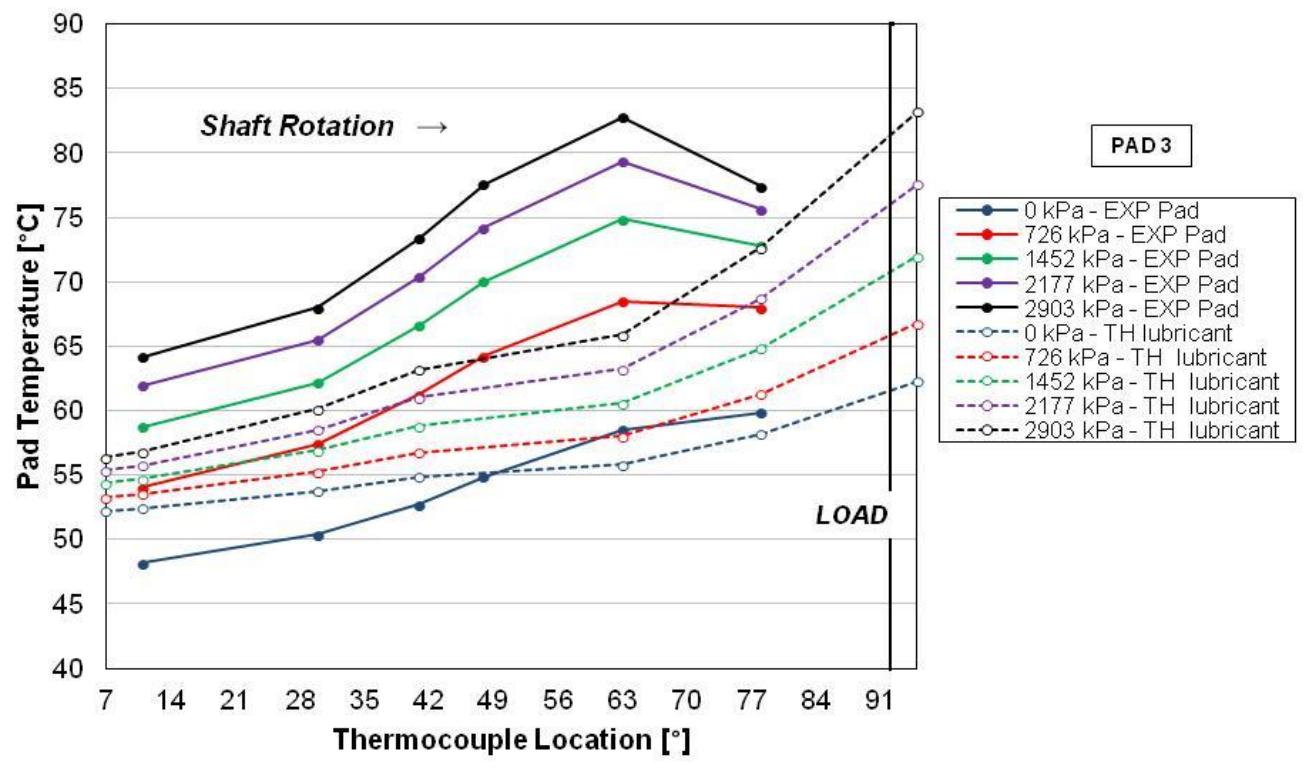

(A) Pad 3

Figure 34: LBP Measured Pad and Predicted Lubricant Temperatures at 6.8 krpm 

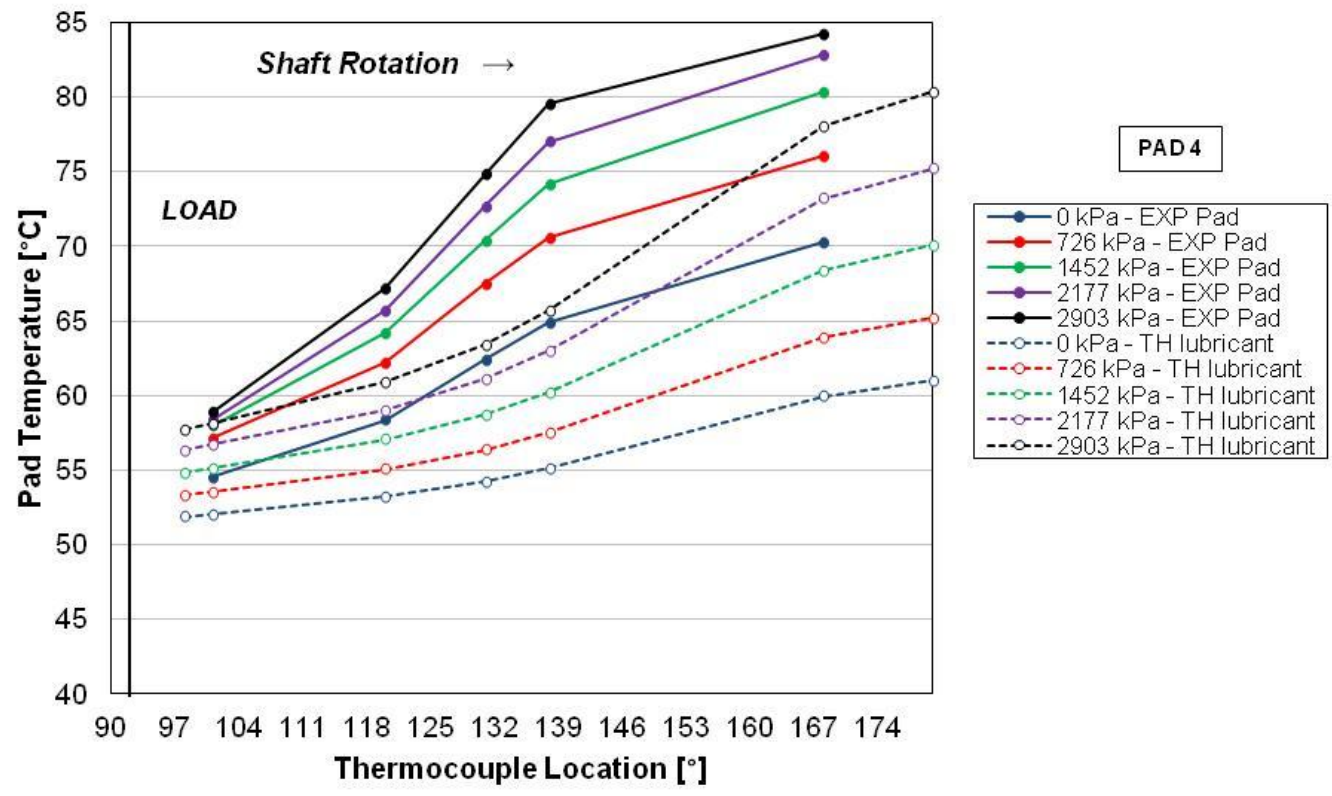

(B) Pad 4
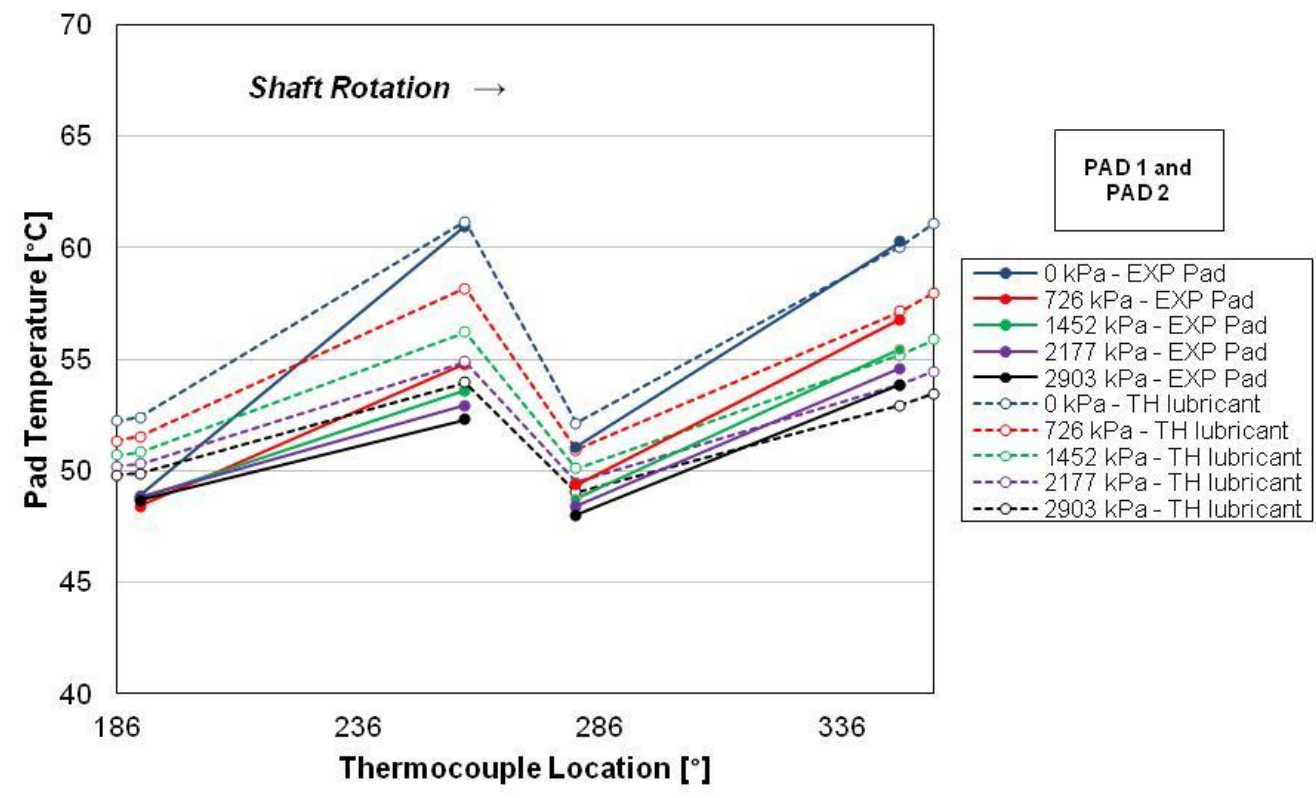

(C) Pad 1 and Pad 2

Figure 34: Continued 
Except for pads 1 and 2, most measured pad metal temperatures are lower than predicted. Pad 4 shows the largest difference from measurements to predictions. Agreeing with measurements, predictions showed pad 4 to experience greater temperatures than pad 3. Figure 34(C) shows the temperature drop from the trailing edge of pad 1 , to the leading edge of pad 2. Pads 1 and 2 were generally predicted higher than measurements.

Figur shows the LBP measured and predicted pad temperatures at $13.2 \mathrm{krpm}$.

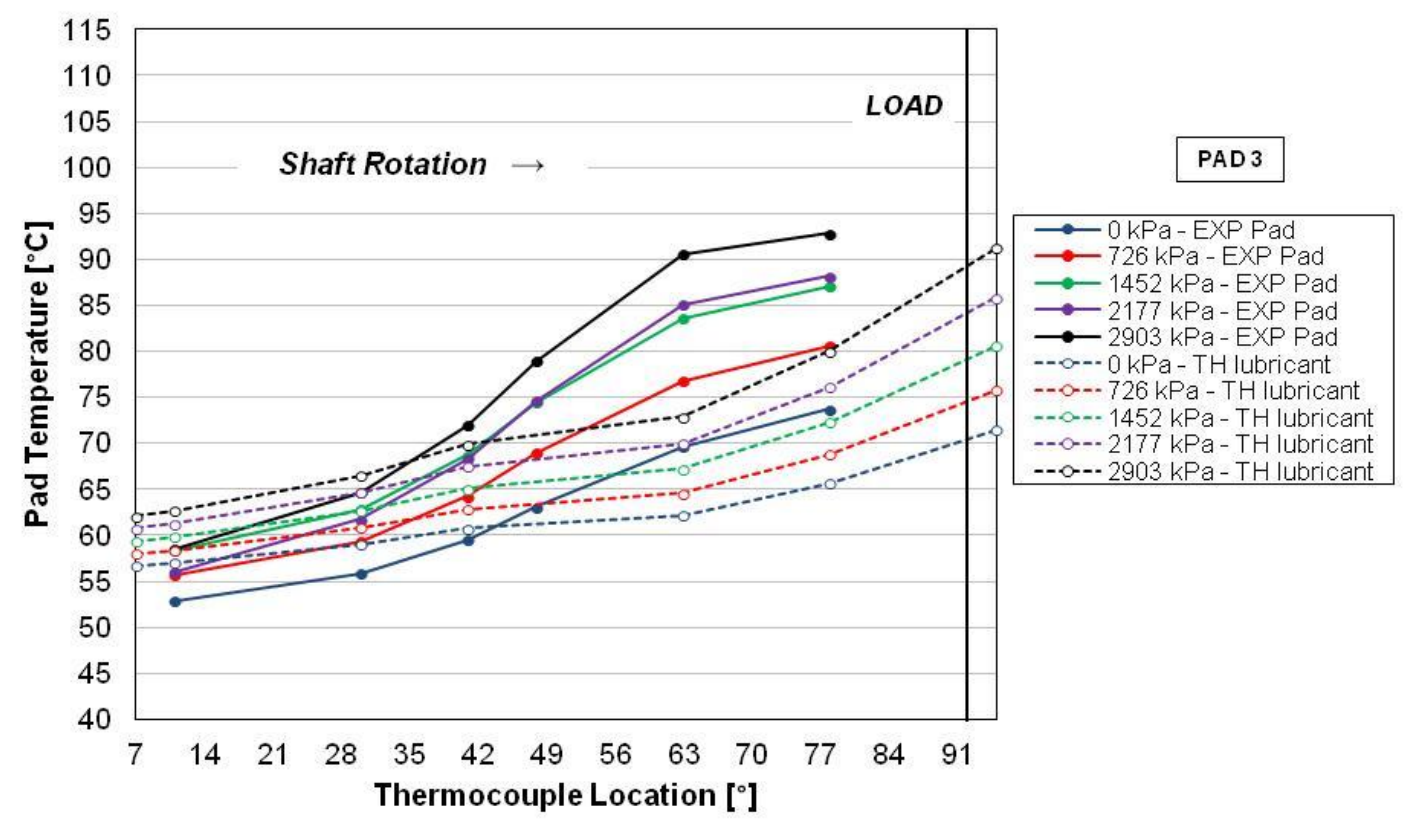

(A) Pad 3

Figure 35: LBP Measured Pad and Predicted Lubricant Temperatures at 13.2 krpm 


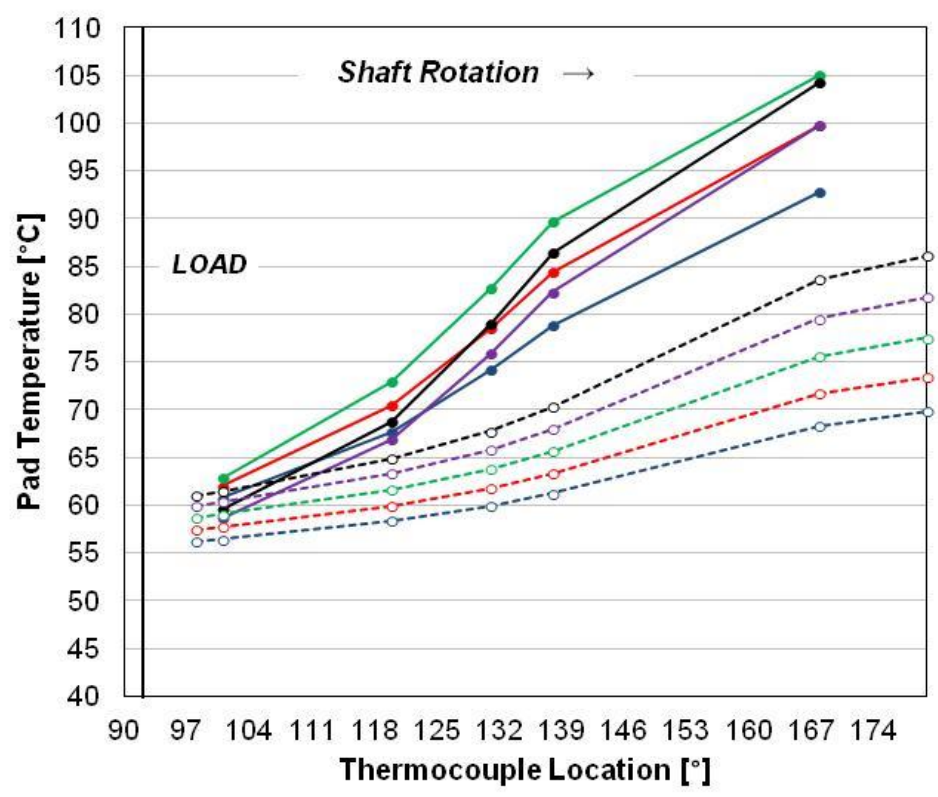

(B) Pad 4

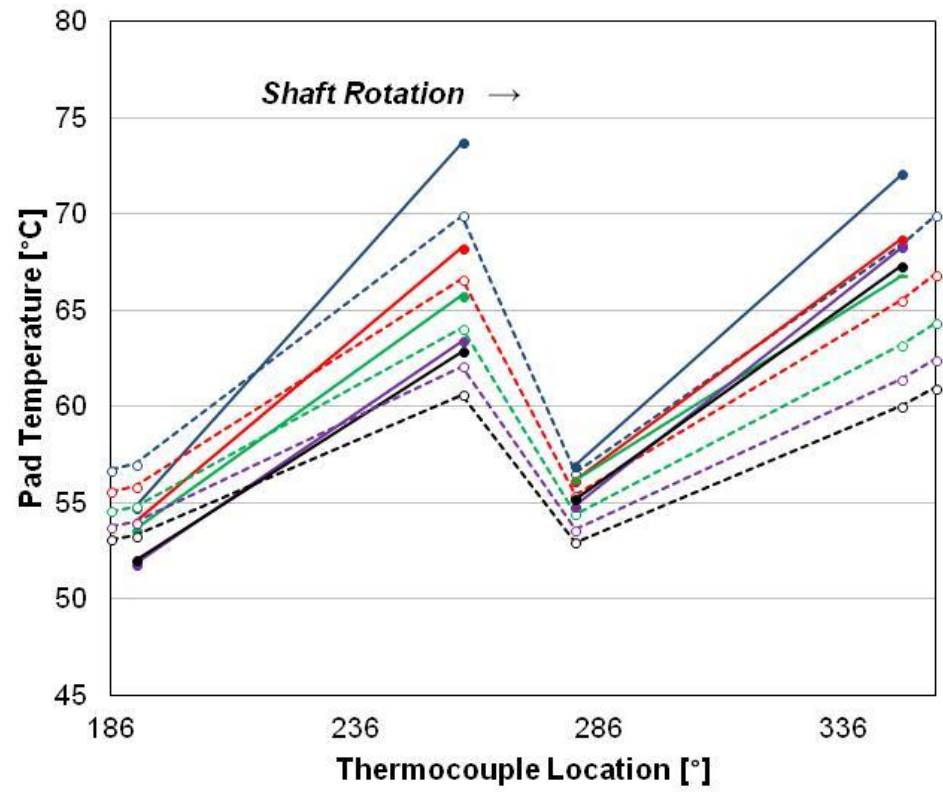

(C) Pad 1 and Pad 2

Figure 35: Continued

\section{PAD 4}

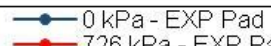

$\longrightarrow 726 \mathrm{kPa}-$ EXP Pad

$\because 1452 \mathrm{kPa}-$ EXP Pad

$\because 2177 \mathrm{kPa}-$ EXP Pad

$\longrightarrow-2903 \mathrm{kPa}-$ EXP Pad

- $0 \mathrm{kPa}-\mathrm{TH}$ lubricant

- $726 \mathrm{kPa}-\mathrm{TH}$ lubricant

- $1452 \mathrm{kPa}-\mathrm{TH}$ lubricant

-- - $2177 \mathrm{kPa}-\mathrm{TH}$ lubricant

-- $2903 \mathrm{kPa}-\mathrm{TH}$ lubricant 
As with the $6.8 \mathrm{krpm}$ case, the code predicts that pad temperature increases circumferentially in the shaft rotation direction in the loaded pad and increases with increasing load. The figure also shows that pad 4 supports more of the static load, and as speed increases, there is more of a temperature difference in measurements between pad 3 and 4. Predictions are more accurate at the leading edge of the pads. Figur(C) shows the temperature drop from the trailing edge of pad 1, to the leading edge of pad 2. Pads 1 and 2 were predicted well.

\section{Estimated Power Loss}

Estimated power loss values are obtained from an energy-balanced equation assuming adiabatic conditions, Eq. (31)

$$
\text { Power }_{\text {Loss }}=Q_{\text {ave }}\left(T_{\text {out }} \rho_{\text {out }} c_{p, \text { out }}-T_{\text {in }} \rho_{\text {in }} c_{p, \text { in }}\right)
$$

where $Q_{\text {ave }}, \rho, c_{p}$, and $T$ are the mass flow rate $\left(\mathrm{m}^{3} / \mathrm{s}\right)$, the oil density $\left(\mathrm{kg} / \mathrm{m}^{3}\right)$, the specific heat $(\mathrm{J} /(\mathrm{kg}-\mathrm{K}))$, and the oil temperature $(\mathrm{K})$, respectively [13]. Figure 36 shows the estimated and predicted power loss from Code A, using temperature measurements for the LOP and LBP orientations. 


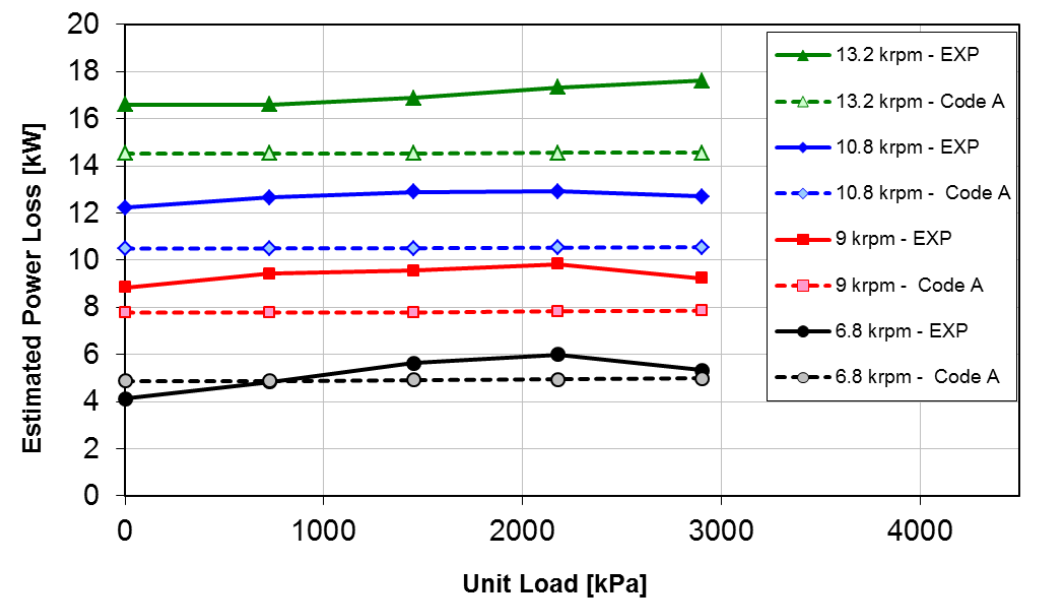

(A) LOP

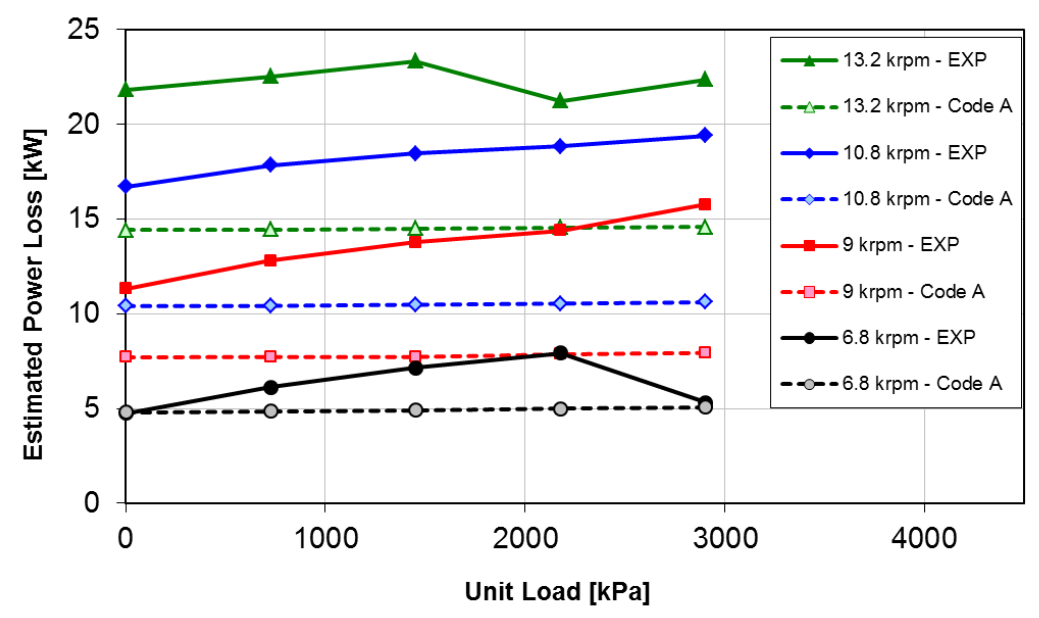

(B) LBP

Figure 36: Estimated and Predicted Power Loss

As can be seen, the power loss predictions are lower than the estimated power loss in both the LOP and LBP orientation. The predictions are modeled independently from load. For the most part, the LOP power loss is independent of load while the LBP power loss shows a slight increase as load increases. Similar to measurements, Code A predicts that power loss increases with speed. 


\section{DYNAMIC RESULTS}

The following sections provide the experimental and theoretical stiffness, damping, and virtual-mass data for the 4-pad, rocker-pivot TPJB in LOP and LBP configuration. Appendix D presents the rotordynamic coefficients for all tested speeds and loads, while Appendix $\mathrm{H}$ presents the dynamic data used to determine the rotordynamic coefficients. The predicted values in the dynamic stiffness sections were obtained from the perturbation model created in Wilkes and Childs [18]. Predictions from both Code A and Code B for stiffness and damping coefficients will be compared to measurements. Input parameters to prediction codes can be found in the Prediction section. A major difference between codes is that Code B incorporates pad flexibility in predicting the impedance coefficients for a tilting-pad journal bearing. The effects that pad flexibility has on predictions will be discussed in the following sections.

Looking back to EXPERIMENTAL PROCEDURES, the dynamic stiffness functions are written in terms of the rotordynamic coefficients:

$$
\begin{gathered}
\boldsymbol{H}_{i j}=\left(K_{i j}-\Omega^{2} \mathrm{M}_{\mathrm{ij}}\right)+j\left(\Omega C_{i j}\right) \\
\operatorname{Re}\left(\boldsymbol{H}_{i j}\right)=K_{i j}-\Omega^{2} \mathrm{M}_{\mathrm{ij}} \\
\operatorname{Im}\left(\boldsymbol{H}_{i j}\right)=\Omega C_{i j}
\end{gathered}
$$

\section{Dynamic Stiffness}

The following section presents the measured and predicted dynamic stiffness functions for the LOP orientation. The conditions shown include rotor speeds of 6.8 and 
13.2 krpm with a light static load of $725 \mathrm{kPa}$ (105.3 psi) and a large unit load of 2903 $\mathrm{kPa}$ (421.1 psi). Predictions are generated using Code B. For the best curve fit and to obtain the most precise predictions, erratic data especially at high frequencies $(>250 \mathrm{~Hz})$ were discarded. This is mainly true for lightly loaded cases. The baseline results, shown in Figure 12 and Figure 13, were subtracted from the dynamic stiffness to obtain the dynamic response of the fluid-film only. Input for Code B can be found in Table 2 for bearing parameters, Table 7 and

for hot bearing clearances, and the Predictions section for pivot stiffness and pad flexibility. For brevity, the results for the LBP dynamic stiffness can be found in Appendix F.

\section{LOP Dynamic Stiffness}

Figure 37 presents the experimental and predicted dynamic stiffness functions for the LOP orientation at $6.8 \mathrm{krpm}$ with a $725 \mathrm{kPa}$ unit load. Figure 37 (A) shows the real dynamic stiffness functions, while Figure 37 (B) shows the imaginary dynamic stiffness functions. Both figures depict the direct and cross-coupled dynamic stiffness functions. Note that the impedances shown in the following figures represent complex numbers, and that the static load is being applied in the $y$-direction. The running speed for each test condition is represented by $\omega$, and is shown by a black vertical line. 

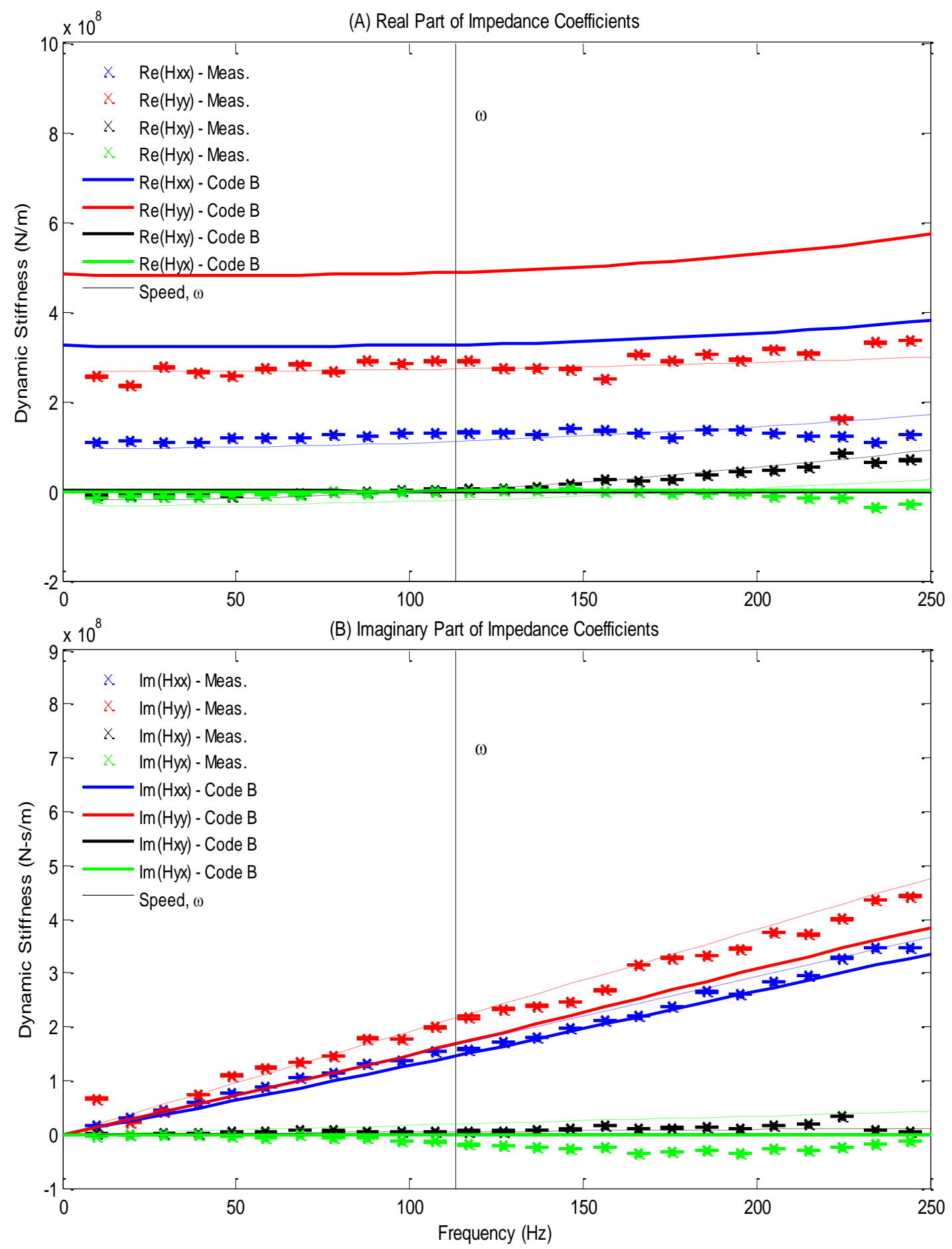

Figure 37: LOP Components of Measurements and Predicted (Code B) Bearing Impedance Coefficients at $6.8 \mathrm{krpm}$ with $725 \mathrm{kPa}(105.3 \mathrm{psi})$ Static Load 
In Figure 37(A), measured $\operatorname{Re}\left(\boldsymbol{H}_{y y}\right)$ is larger than measured $\operatorname{Re}\left(\boldsymbol{H}_{x \boldsymbol{x}}\right)$ and shows stiffness orthotropy. The measured dynamic stiffness shows a very slight dependence on $\Omega$. At around running speed $(150 \mathrm{~Hz}), \operatorname{Re}\left(\boldsymbol{H}_{x y}\right)$ becomes slightly larger than $\operatorname{Re}\left(\boldsymbol{H}_{\boldsymbol{y} x}\right)$. At larger frequencies $\operatorname{Re}\left(\boldsymbol{H}_{x y}\right)$ and $\operatorname{Re}\left(\boldsymbol{H}_{y x}\right)$ have opposite signs, suggesting different signs for $M_{x y}$ and $M_{y x}$ with a possible impact on stability (See Whirl Frequency Ratio).

Figure 37(B) shows that the direct imaginary dynamic stiffness functions increases linearly with increasing frequency, resulting in frequency-independent direct damping coefficients. Measured $\operatorname{Im}\left(\boldsymbol{H}_{\boldsymbol{y} y}\right)$ is larger than measured $\operatorname{Im}\left(\boldsymbol{H}_{\boldsymbol{x} x}\right) \cdot \operatorname{Im}\left(\boldsymbol{H}_{x \boldsymbol{y}}\right)$ is slightly larger than $\operatorname{Im}\left(\boldsymbol{H}_{\boldsymbol{y} x}\right)$, and both terms are negative.

Figure 37 shows that the model does well at predicting damping, but over-predicts stiffness. Measured stiffness coefficients are smaller than predicted at all frequencies, while damping is modestly larger than predicted at high frequencies. The over-predicted $\operatorname{Re}\left(\boldsymbol{H}_{x x}\right)$ and $\operatorname{Re}\left(\boldsymbol{H}_{\boldsymbol{y} y}\right)$ values agree with the under-predicted bearing loci plots, shown in Figure 25(A). The predicted bearing loci plots show less movement in the $\varepsilon_{\mathrm{oy}}$ than measurements, typically resulting in greater $\operatorname{Re}\left(\boldsymbol{H}_{x x}\right)$ and $\operatorname{Re}\left(\boldsymbol{H}_{y y}\right)$ predictions. The magnitude differences between $\operatorname{Re}\left(\boldsymbol{H}_{x x}\right)$ and $\operatorname{Re}\left(\boldsymbol{H}_{y y}\right)$ is predicted well. At around $100 \mathrm{~Hz}$ (close to running speed) the stiffness predictions begin to increase as $\Omega$ increases. $\operatorname{Im}\left(\boldsymbol{H}_{x x}\right)$ is predicted very accurately and $\operatorname{Im}\left(\boldsymbol{H}_{y y}\right)$ is slightly predicted under measurements. The code predicts real and imaginary cross-coupled dynamic stiffness to be zero, which does not match measured results at high frequencies.

Figure 38 presents the experimental and predicted dynamic stiffness functions for the LOP orientation $6.8 \mathrm{krpm}$ and $2903 \mathrm{kPa}$ unit load 

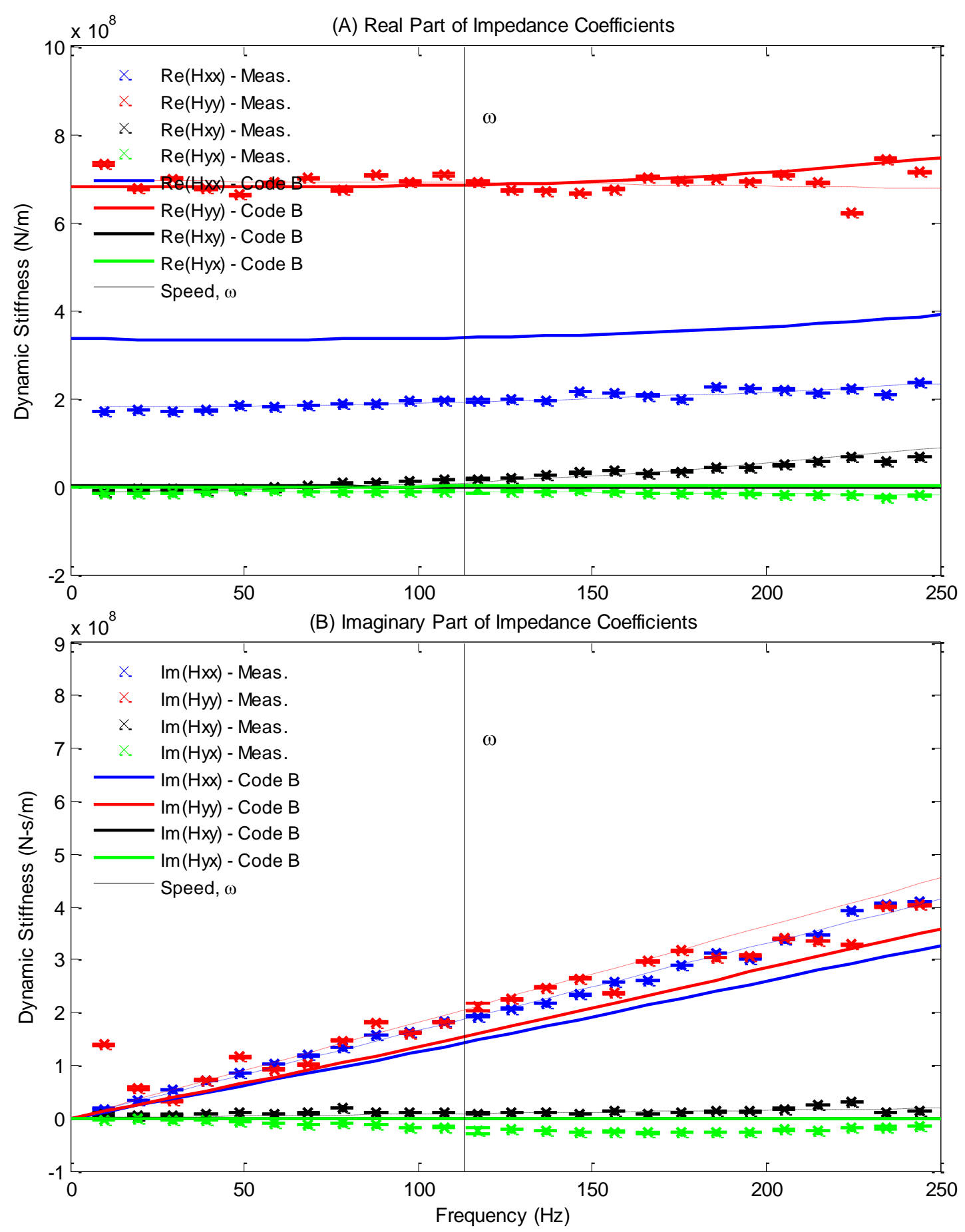

Figure 38: LOP Components of Measurements and Predicted (Code B) Bearing Impedance Coefficients at $6.8 \mathrm{krpm}$ with $2903 \mathrm{kPa}(421.1 \mathrm{psi})$ Static Load 
Similar to the lightly loaded case but to a larger degree, measured $\operatorname{Re}\left(\boldsymbol{H}_{\boldsymbol{y} y}\right)$ is larger than measured $\operatorname{Re}\left(\boldsymbol{H}_{x \boldsymbol{x}}\right)$, showing significant stiffness orthotropy. Measured $\operatorname{Re}\left(\boldsymbol{H}_{x \boldsymbol{x}}\right)$ and $\operatorname{Re}\left(\boldsymbol{H}_{\boldsymbol{y} y}\right)$ have no dependency on $\Omega$. Similar to the lightly loaded case, around running speed $(113.3 \mathrm{~Hz}), \operatorname{Re}\left(\boldsymbol{H}_{x y}\right)$ becomes slightly larger than $\operatorname{Re}\left(\boldsymbol{H}_{\boldsymbol{y} x}\right)$. At larger frequencies $\operatorname{Re}\left(\boldsymbol{H}_{\boldsymbol{x} y}\right)$ and $\operatorname{Re}\left(\boldsymbol{H}_{\boldsymbol{y} \boldsymbol{x}}\right)$ have opposite signs. $\operatorname{Im}\left(\boldsymbol{H}_{\boldsymbol{x} \boldsymbol{x}}\right)$ and $\operatorname{Im}\left(\boldsymbol{H}_{\boldsymbol{y} \boldsymbol{y}}\right)$ are measured to be the same. The cross-coupled damping terms are approximately zero. At higher frequencies, $\operatorname{Im}\left(\boldsymbol{H}_{\boldsymbol{x} y}\right)$ and $\operatorname{Im}\left(\boldsymbol{H}_{\boldsymbol{y} x}\right)$ have opposite signs.

Figure 38 shows that the model more accurately predicts dynamic stiffness at the higher loaded case. $\operatorname{Re}\left(\boldsymbol{H}_{\boldsymbol{y} y}\right)$ is predicted very accurately, while $\operatorname{Re}\left(\boldsymbol{H}_{\boldsymbol{x} x}\right)$ is predicted higher than measurements. The predicted $\operatorname{Re}\left(\boldsymbol{H}_{\boldsymbol{x}}\right)$ and $\operatorname{Re}\left(\boldsymbol{H}_{\boldsymbol{y} y}\right)$ values are more accurate than the under-predicted bearing loci plots, shown in Figure 25(A). The difference in magnitudes between $\operatorname{Re}\left(\boldsymbol{H}_{\boldsymbol{x} x}\right)$ and $\operatorname{Re}\left(\boldsymbol{H}_{\boldsymbol{y} \boldsymbol{y}}\right)$ is predicted well. The code predicts $\operatorname{Re}\left(\boldsymbol{H}_{\boldsymbol{x} \boldsymbol{y}}\right)$ and $\operatorname{Re}\left(\boldsymbol{H}_{y x}\right)$ to be zero which does not match measurements at high frequencies. $\operatorname{Im}\left(\boldsymbol{H}_{\boldsymbol{y} y}\right)$ and $\operatorname{Im}\left(\boldsymbol{H}_{\boldsymbol{x}}\right)$ are slightly under-predicted.

Figure 39 and Figure 40 show that the model follows the same trend with increasing speed, but with a better accuracy. 

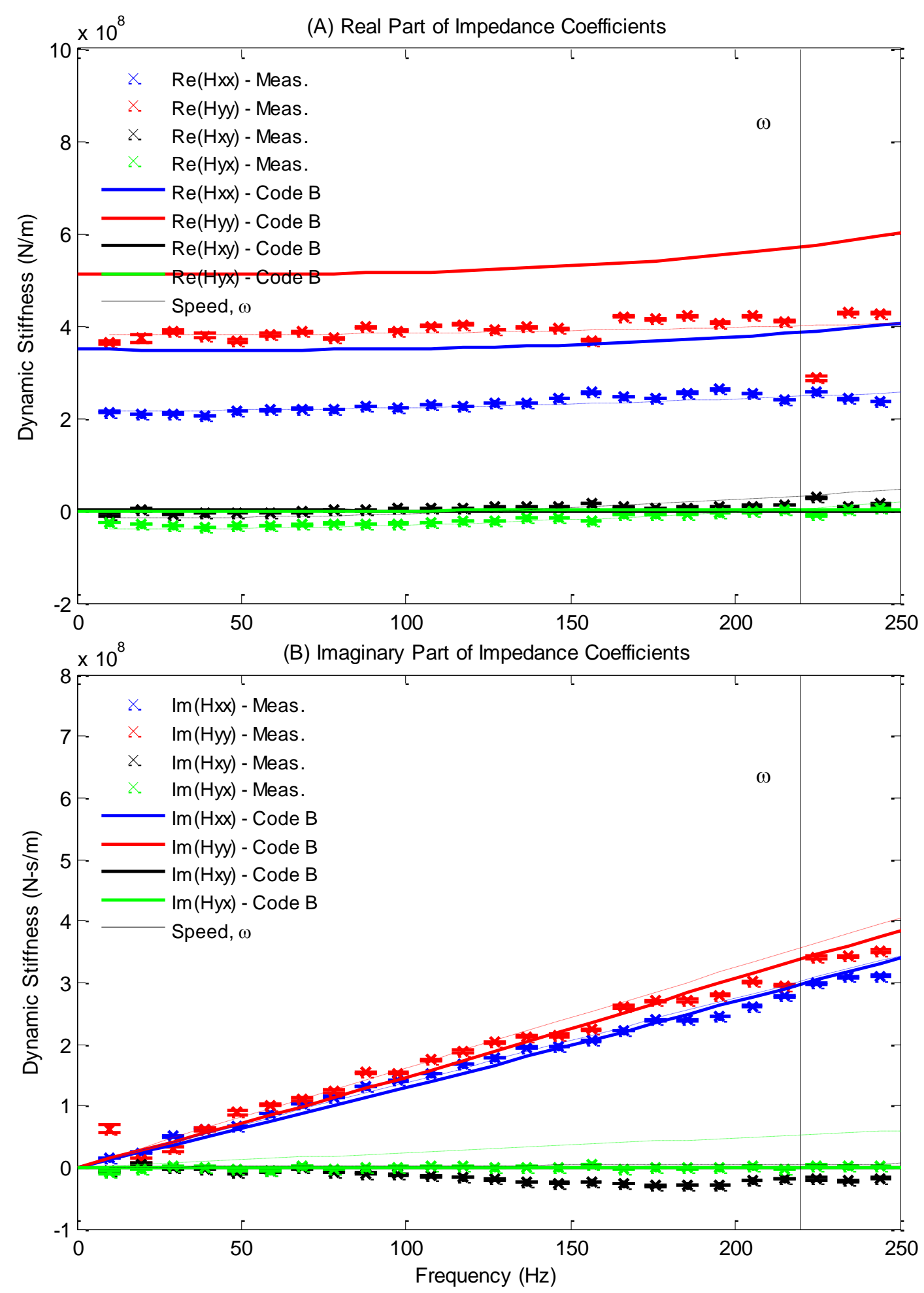

Figure 39: LOP Components of Measurements and Predicted (Code B) Bearing Impedance Coefficients at $13.2 \mathrm{krpm}$ with $725 \mathrm{kPa}(105.3 \mathrm{psi})$ Static Load 

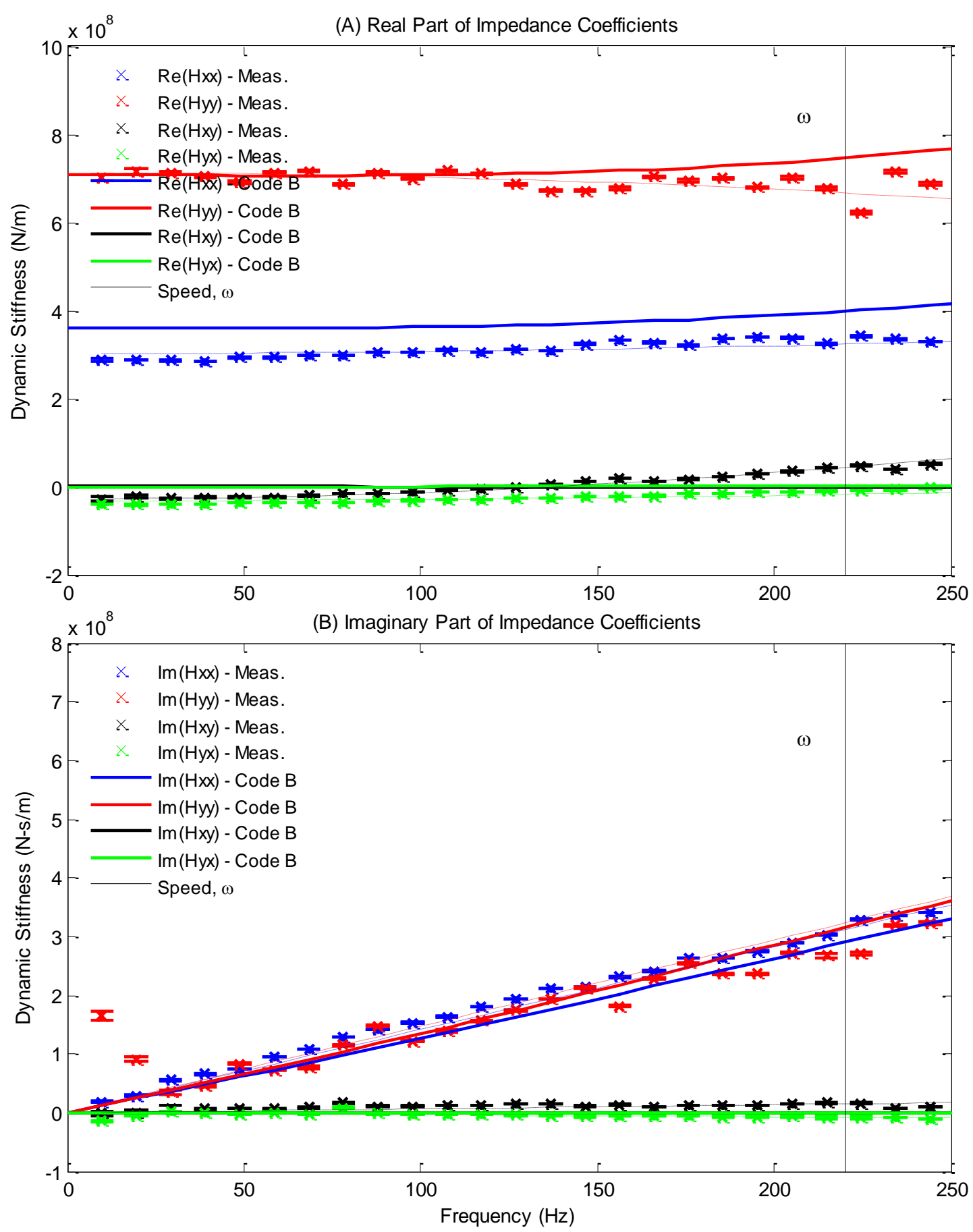

Figure 40: LOP Components of Measurements and Predicted (Code B) Bearing Impedance Coefficients at $13.2 \mathrm{krpm}$ with $2903 \mathrm{kPa}(421.1 \mathrm{psi})$ Static Load 
Similar to $6.8 \mathrm{krpm}$ results (Figure 37 and Figure 38), at $13.2 \mathrm{krpm} \operatorname{Re}\left(\boldsymbol{H}_{\boldsymbol{y y}}\right)$ is measured to be larger than $\operatorname{Re}\left(\boldsymbol{H}_{x x}\right)$ and show stiffness orthotropy. In the lightly loaded case, the measured dynamic stiffness coefficients show a slight dependence on $\Omega$, while the loaded dynamic stiffness shows no dependence. $\operatorname{Re}\left(\boldsymbol{H}_{\boldsymbol{x y}}\right)$ is slightly larger than $\operatorname{Re}\left(\boldsymbol{H}_{\boldsymbol{y} x}\right)$ in the heavily loaded case. At larger frequencies $\operatorname{Re}\left(\boldsymbol{H}_{\boldsymbol{x} y}\right)$ and $\operatorname{Re}\left(\boldsymbol{H}_{\boldsymbol{y} \boldsymbol{x}}\right)$ have opposite signs.

Both figures show that $\operatorname{Im}\left(\boldsymbol{H}_{\boldsymbol{x} x}\right)$ and $\operatorname{Im}\left(\boldsymbol{H}_{\boldsymbol{y} y}\right)$ increase linearly with increasing frequency, resulting in frequency-independent direct damping coefficients. In the unloaded case, $\operatorname{Im}\left(\boldsymbol{H}_{y y}\right)$ is slightly larger than $\operatorname{Im}\left(\boldsymbol{H}_{x \boldsymbol{x}}\right)$ while the opposite is true in the loaded case. In the lightly loaded case, $\operatorname{Im}\left(\boldsymbol{H}_{\boldsymbol{y} x}\right)$ is slightly larger than $\operatorname{Im}\left(\boldsymbol{H}_{\boldsymbol{x} y}\right)$.

At low loads, the model predicts damping well, but over-predicts stiffness. Stiffness is predicted much more accurately at the higher speed and load combination. $\operatorname{Re}\left(\boldsymbol{H}_{\boldsymbol{y} y}\right)$ is predicted very accurately, while $\operatorname{Re}\left(\boldsymbol{H}_{\boldsymbol{x} x}\right)$ is slightly smaller than predicted. Similar to $6.8 \mathrm{krpm}$ at low loads, the over-predicted $\operatorname{Re}\left(\boldsymbol{H}_{x \boldsymbol{x}}\right)$ and $\operatorname{Re}\left(\boldsymbol{H}_{\boldsymbol{y} y}\right)$ values agree with the under-predicted bearing loci plots, shown in Figure 25(D). At low static loads the predicted bearing loci plots show less movement in the $\varepsilon_{\mathrm{oy}}$ than measurements, typically resulting in greater $\operatorname{Re}\left(\boldsymbol{H}_{\boldsymbol{x} x}\right)$ and $\operatorname{Re}\left(\boldsymbol{H}_{\boldsymbol{y} y}\right)$ predictions. The magnitude differences between $\operatorname{Re}\left(\boldsymbol{H}_{x \boldsymbol{x}}\right)$ and $\operatorname{Re}\left(\boldsymbol{H}_{y y}\right)$ is predicted well. Orthotropy is predicted reasonably well at the higher rotor speed. Again, at around $100 \mathrm{~Hz}, \operatorname{Re}\left(\boldsymbol{H}_{\boldsymbol{x} x}\right)$ and $\operatorname{Re}\left(\boldsymbol{H}_{\boldsymbol{y} y}\right)$ begin to increase with frequency. $\operatorname{Im}\left(\boldsymbol{H}_{\boldsymbol{y} y}\right)$ and $\operatorname{Im}\left(\boldsymbol{H}_{\boldsymbol{x} x}\right)$ predictions are very accurate. $\operatorname{In}$ both cases the code predicts $\operatorname{Re}\left(\boldsymbol{H}_{x y}\right)$ and $\operatorname{Re}\left(\boldsymbol{H}_{y x}\right)$ to be zero which does not match results at high frequencies. 
Results for the LBP dynamic stiffness are not shown for brevity, and can be found in Appendix F. For LOP and LBP cases, the $\operatorname{Re}\left(\boldsymbol{H}_{x \boldsymbol{x}}\right), \operatorname{Re}\left(\boldsymbol{H}_{\boldsymbol{y} y}\right), \operatorname{Re}\left(\boldsymbol{H}_{x y}\right)$, and $\operatorname{Re}\left(\boldsymbol{H}_{\boldsymbol{y}}\right)$ functions showed a dependence on excitation frequency that could be accounted for with virtual-mass coefficients, producing frequency-independent stiffness and virtual-mass coefficients. In both orientations, $\operatorname{Im}\left(\boldsymbol{H}_{\boldsymbol{y} y}\right)$ and $\operatorname{Im}\left(\boldsymbol{H}_{\boldsymbol{x} x}\right)$ increase linearly with $\Omega$, allowing for frequency independent damping coefficients. Overall, both the LOP and LBP orientations show that the frequency dependency of the test bearing was modeled well with a $[\mathrm{K}][\mathrm{C}][\mathrm{M}]$ model.

\section{Importance of Pad Flexibility in Predictions}

As previously mentioned, the main difference between codes $\mathrm{A}$ and $\mathrm{B}$ is that Code B incorporates pad flexibility in predicting the impedance coefficients for a tiltingpad journal bearing, while Code A generates predictions assuming an infinitely rigid pad. The pad flexibility refers to the change in pad curvature resulting from an applied moment at the end of the pad from the fluid film pressure (see Predictions). Both codes account for pivot flexibility with the same user-defined load-versus-deflection model, and allow for different pad geometry (clearances and preloads) entries. Code B does not include an energy equation to calculate temperature and viscosity distributions, but experimental temperature measurements were used to estimate the lubricant's viscosity.

To look at the effects that pad flexibility has on predicting the impedance coefficients, a series of predictions were created with Code B by changing the magnitude of the pad's calculated bending stiffness from Eq. (27). Figure 41 presents the measured 
and predicted $K_{x x}$ and $K_{y y}$ predictions for Code A and Code B in the LOP configuration. Results for the LBP orientation can be found in Appendix G. Measured values are shown here for reference, but will be discussed in the following sections.

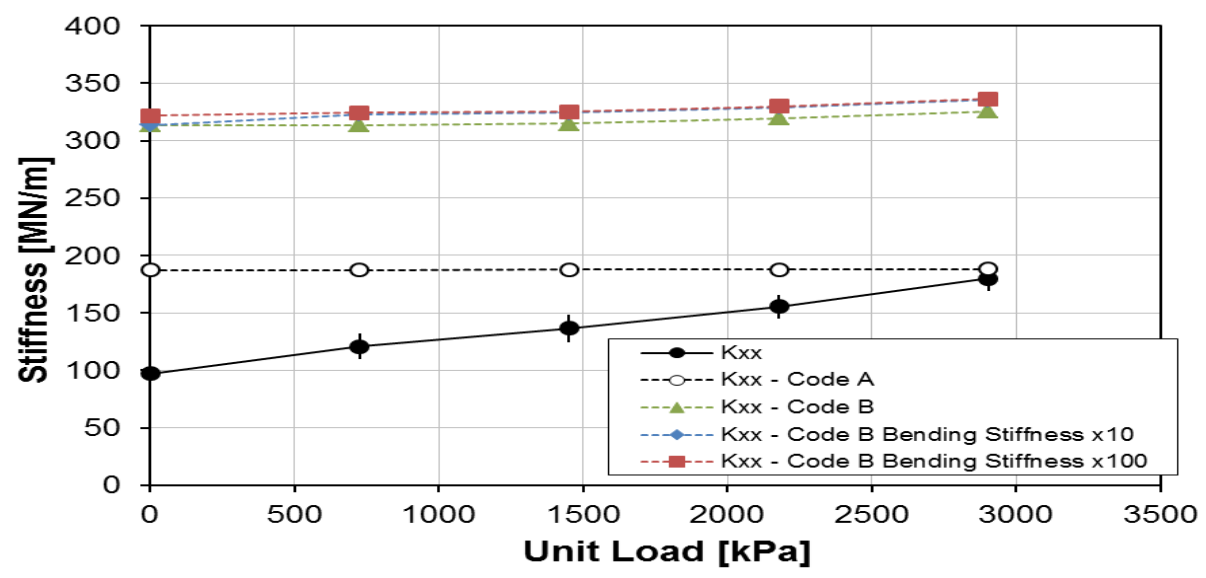

(A) $K_{x x}$ at $6.8 \mathrm{krpm}$

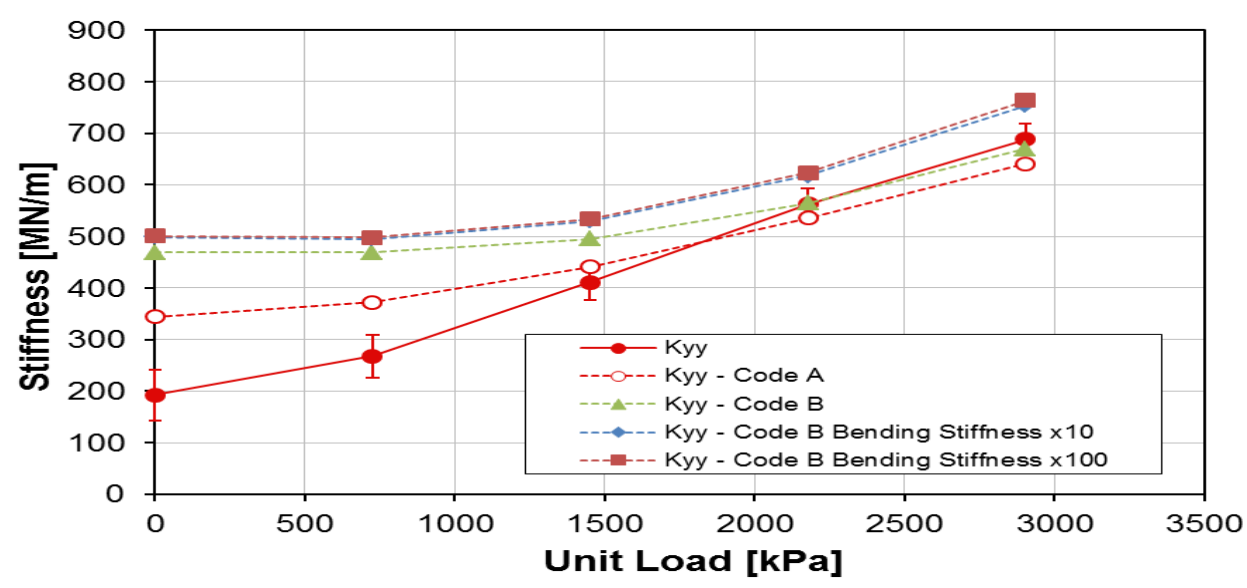

(B) $K_{y y}$ at $6.8 \mathrm{krpm}$

Figure 41: Measured and Predicted Direct Stiffness Coefficients for LOP Orientation

As seen from Figure 41, Code B predicted higher $K_{x x}$ and $K_{y y}$ values than Code A. Code A predicts $K_{x x}$ and $K_{y y}$ much more accurately than Code B. Both predictions are 
more accurate as load increases. Changing the bending stiffness from its actual value by a factor of 10 or by a factor of 100 in Code B, showed a $3 \%$ increase in predictions for $K_{x x}$ and an $11 \%$ increase in predictions for $K_{y y}$.

Figure 42 presents measured and predicted $K_{x x}$ and $K_{y y}$ values for Code A and Code B in the LOP configuration at $13.2 \mathrm{krpm}$.

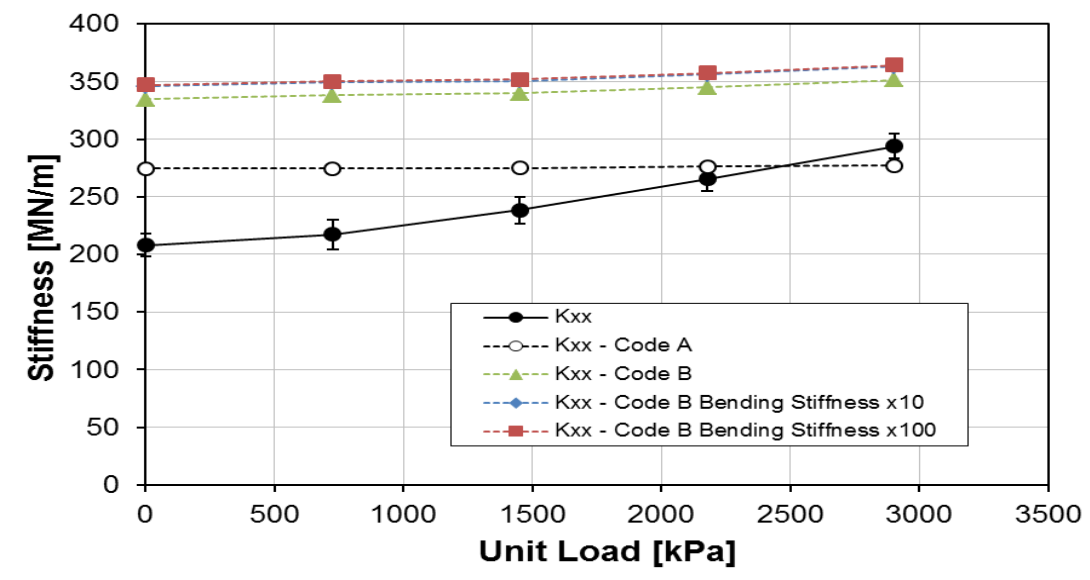

(A) $K_{x x}$ at $13.2 \mathrm{krpm}$

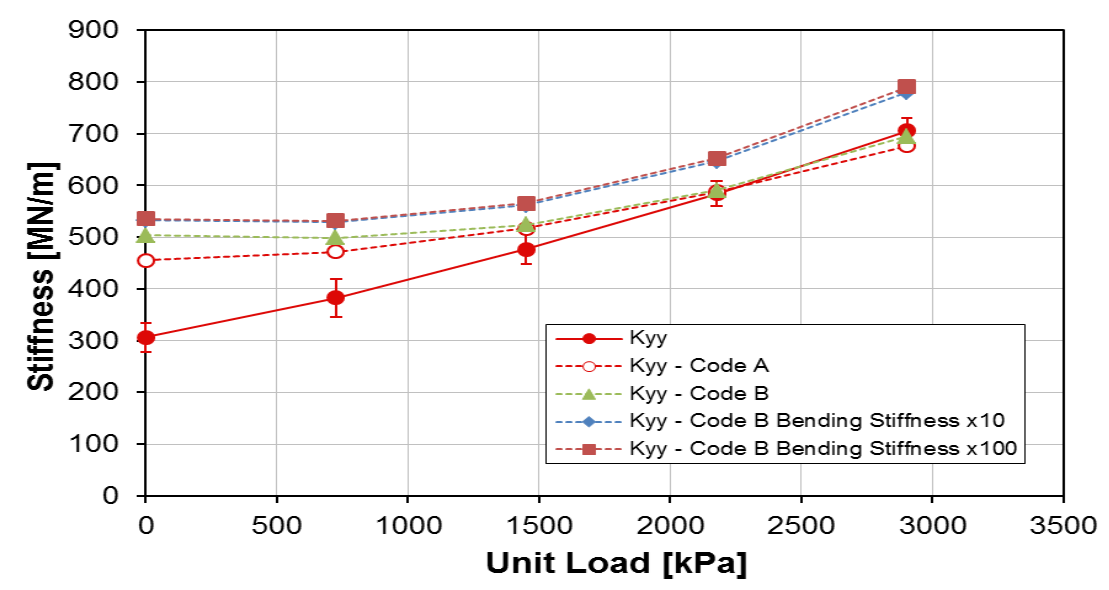

(B) $K_{y y}$ at $13.2 \mathrm{krpm}$

Figure 42: Measured and Predicted Direct Stiffness Coefficients for LOP Orientation 
As with the $6.8 \mathrm{krpm}$ case, Code B predicted higher $K_{x x}$ and $K_{y y}$ values than Code A, and Code A predicts $K_{x x}$ and $K_{y y}$ more accurately than Code B

Changing the bending stiffness from its actual value by a factor of 10 or by a factor of 100 in Code B showed a $3 \%$ increase in predictions for $K_{x x}$ and an $11 \%$ increase in predictions for $K_{y y}$. For a flexible pad an increase in bending stiffness can have a large effect on predictions; however, for a more rigid pad an increase in pad bending stiffness will have a much lesser effect. When the bending stiffness was increased by a factor of 10 to a factor of 100 , no changes in predictions resulted. These findings suggest that if the calculated bending stiffness of $22 \mathrm{MN}$ was 10 times greater, then the pads would be effectively rigid.

Figure presents the measured and predicted direct damping coefficients for Code A and Code B in the LOP configuration.

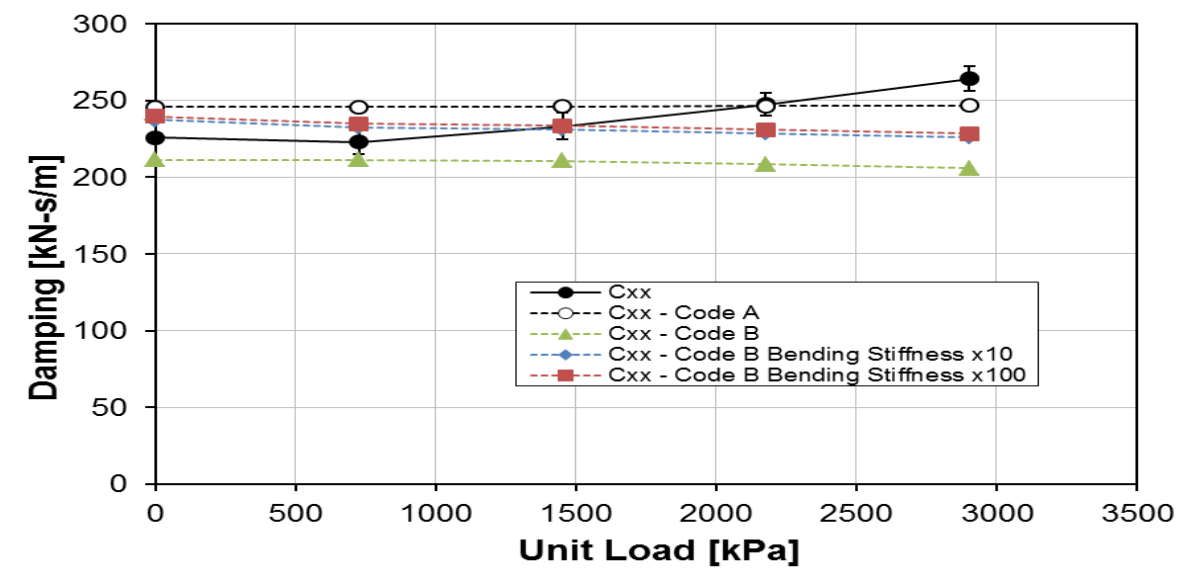

(A) $C_{x x}$ at $6.8 \mathrm{krpm}$

Figure 43: Measured and Predicted Direct Stiffness Coefficients for LOP Orientation 


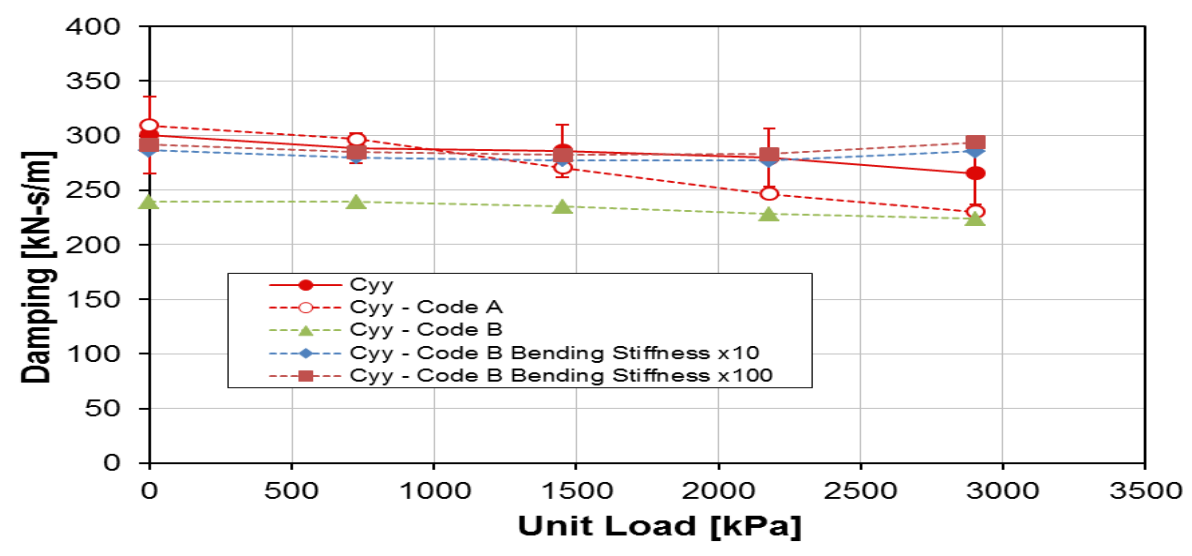

(B) $C_{y y}$ at $6.8 \mathrm{krpm}$

Figure 43: Continued

Figure, shows that both codes predict $C_{x x}$ and $C_{y y}$ fairly accurately. Changing the bending stiffness from its actual value by a factor of 10 in Code B showed a $10 \%$ increase in predictions for $C_{x x}$ and a $22 \%$ increase in predictions for $C_{y y}$. When the bending stiffness was increased from a factor of 10 to a factor of 100 , very slight changes in predictions were made.

Figure 44 presents the measured and predicted $C_{x x}$ and $C_{y y}$ for Code $\mathrm{A}$ and Code $\mathrm{B}$ in the LOP configuration at $13.2 \mathrm{krpm}$. 


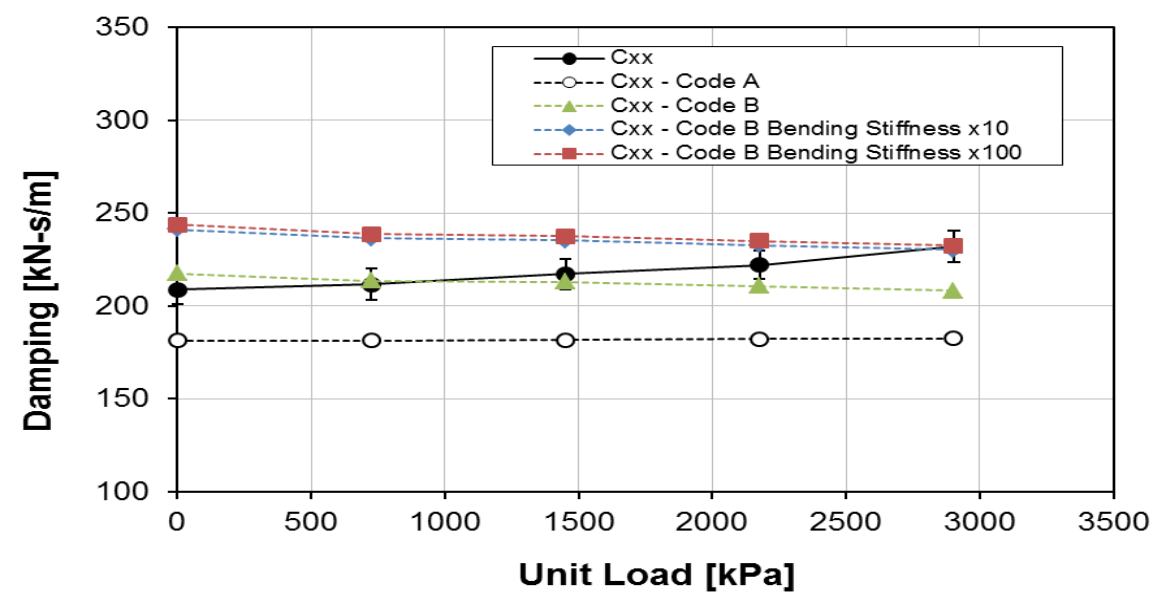

(A) $C_{x x}$ at $13.2 \mathrm{krpm}$

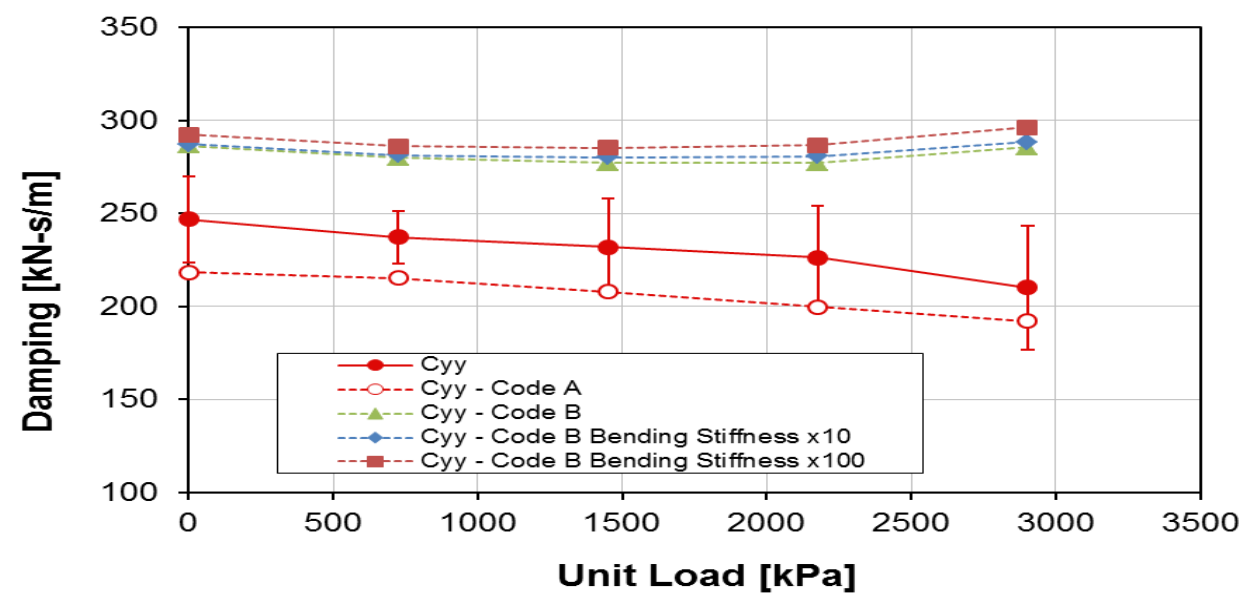

(B) $\mathrm{C}_{y y}$ at $13.2 \mathrm{krpm}$

Figure 44: Measured and Predicted Direct Stiffness Coefficients for LOP Orientation

At $13.2 \mathrm{krpm}$ Code B predicts $C_{x x}$ and $C_{y y}$ to be greater than Code A. As speed increases, Code B predicts $C_{x x}$ much more accurately, while Code A predicts $C_{y y}$ more accurately. Code B shows relatively no increase in $C_{y y}$ when the pad bending stiffness is increased, but shows a $24 \%$ increase in $C_{x x}$ when the pad bending stiffness is increased.

In an attempt to obtain identical predictions from both codes, predicted lubricant 
temperature from Code $\mathrm{A}$ and a calculated bending stiffness of 100 times greater were used as an input to Code B to assume that both codes were using an infinitely rigid pad, allowing for all input parameters to be identical between prediction codes.

Table 10: Prediction Comparisons of 13.2 krpm with 2903 kPa Static Load

\begin{tabular}{|c|c|c|c|c|}
\hline Coefficient & Code A & Code B Bending stiffness x100 & Code B Bending stiffness x100 (Temperature Change) & Larger Difference \\
\hline $\mathrm{Kxx}$ & 277.1 & 364.3 & 383.2 & $5 \%$ \\
\hline $\mathrm{Kyy}$ & 676.8 & 790.1 & 809.8 & $2 \%$ \\
\hline $\mathrm{Cxx}$ & 182.6 & 232.4 & 245.4 & $5 \%$ \\
\hline $\mathrm{Cyy}$ & 192.2 & 296.3 & 320.0 & $7 \%$ \\
\hline
\end{tabular}

Table 10 shows that when the temperatures are changed to match between codes, the difference between the two codes predictions increase. As shown in the Pad Metal Temperatures section, the predicted circumferential temperature gradient from Code A is lower than measured values. Decreasing the temperature input to Code B, increases the fluid viscosity, increasing the stiffness and damping coefficients, causing a greater difference between prediction codes. These results raise and interesting question, why do the two prediction codes still generate different rotordynamic coefficients when all input parameters are identical?

Overall, increasing the bending stiffness used in Code B typically caused a 3$11 \%$ increase in $K_{x x}$ and $K_{y y}$, and a $10-24 \%$ increase in $C_{x x}$ and $C_{y y}$ in the LOP orientation. In all cases, increasing the calculated bending stiffness, given in Eq. (27) by a factor of ten to hundred times caused slight if any change in $K_{x x}, K_{y y}, C_{x x}$, and $C_{y y}$. For a more flexible pad, an increase in bending stiffness can have a large effect on predictions; however, for a nearly rigid pad, an increase in pad bending stiffness will 
have much less effect. These findings suggest that if the calculated bending stiffness of $22 \mathrm{MN}$ were 10 times greater, then the pads could be considered rigid.

Results from Code B show that the pad's structural bending stiffness can be an important factor in predicting impedance coefficients. Even though the pads tested in this thesis are extremely stiff, changes are still seen in Code B's predictions when the magnitude of the pad's bending stiffness is increased, especially in $C_{x x}$ and $C_{y y}$. Overall, Code A predicts $K_{x x}$ and $K_{y y}$ more accurately than Code B in both load orientations. In the LOP orientation, Code B predicts $C_{x x}$ more accurately, while Code A predicts $C_{y y}$ more accurately. For solid pads, like the ones tested in this thesis, both codes do a decent job at predicting dynamic stiffness coefficients.

\section{Stiffness Coefficients}

For brevity, predictions for stiffness, damping, and virtual-mass coefficients will be generated using only Code A. Code A predicted $K_{x x}$ and $K_{y y}$ much more accurately than Code B. Input for Code A can be found in Table 2 for bearing parameters, Table 7 and Table 8 for hot bearing clearances, and the Predictions section for pivot flexibility.

\section{LOP Orientation}

Figure 45 presents the experimental and predicted direct stiffness coefficients in the LOP configuration. 


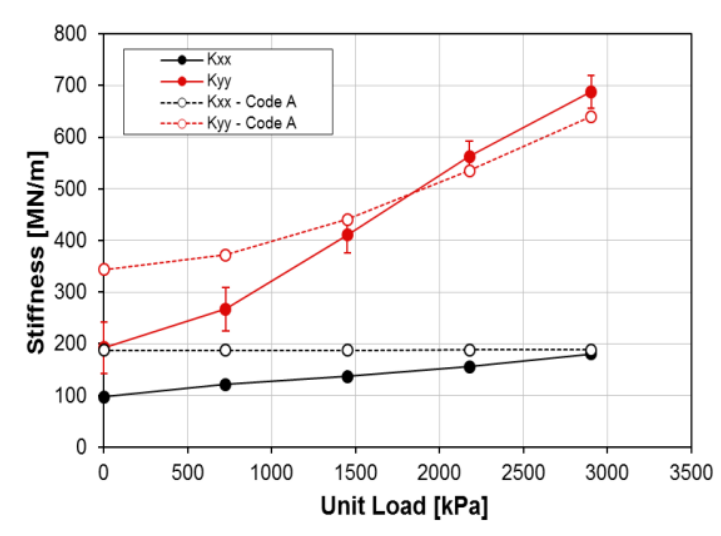

(A) $6.8 \mathrm{krpm}$

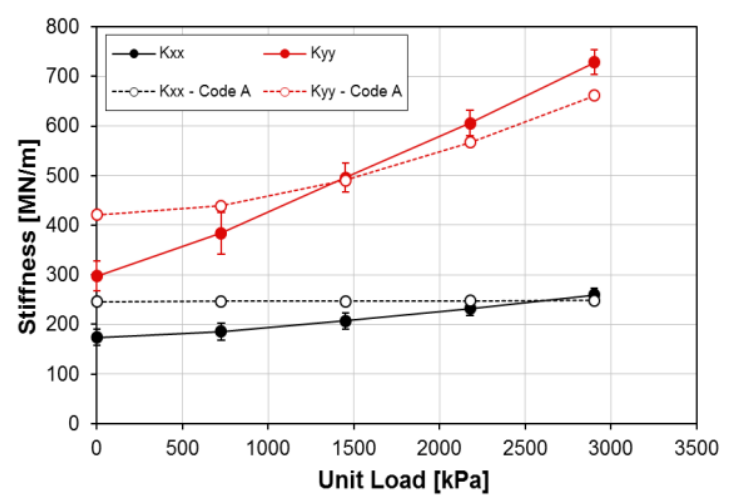

(C) $10.8 \mathrm{krpm}$

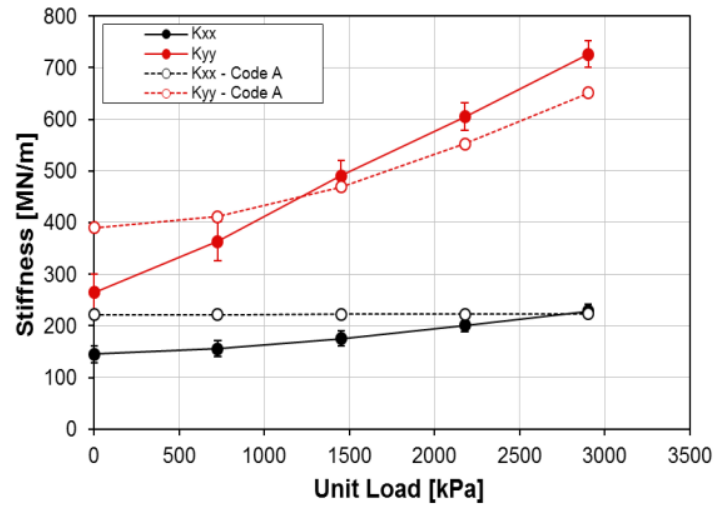

(B) 9 krpm

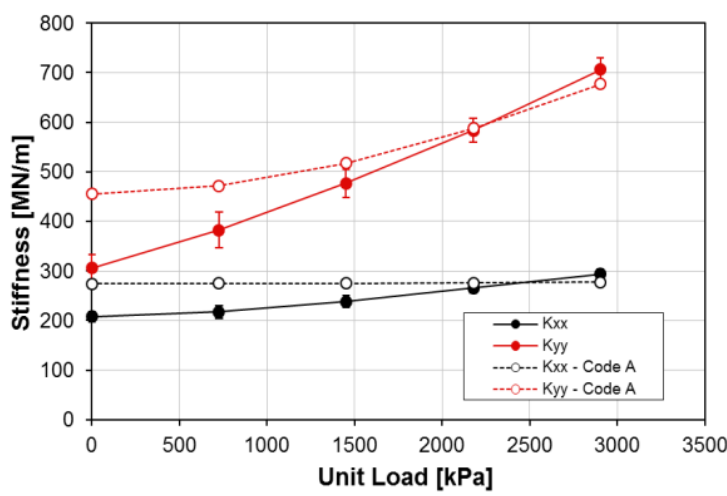

(D) $13.2 \mathrm{krpm}$

Figure 45: LOP Measured and Predicted $K_{x x}$ and $K_{y y}(\mathrm{~A}) 6.8 \mathrm{krpm},(\mathrm{B}) 9 \mathrm{krpm}$, (C) 10.8 krpm, (D) $13.2 \mathrm{krpm}$

Figure 45 shows measured $K_{x x}$ and $K_{y y}$ increasing with increasing static unit load, and $K_{y y}$ increases at a considerably greater rate than $K_{x x}$. At high loads, the loaded direction, $K_{y y}$ was $\sim 70 \%$ greater than $K_{x x} . K_{x x}$ increases with increasing rotor speed while $K_{y y}$ stays relatively independent (slight increase). $K_{y y}$ shows a larger dependency on unit load and rotor speed. At all conditions, the direct stiffness coefficients are predicted well at high unit loads, but are larger than predicted at light unit loads. Measured $K_{x x}$ 
increases slightly due to static unit loads, while the predicted $K_{x x}$ remains constant relative to unit loads. The bearing orthotropy is predicted well at high unit loads.

Figure 46 presents the measured and predicted cross-coupled stiffness coefficients in the LOP configuration.

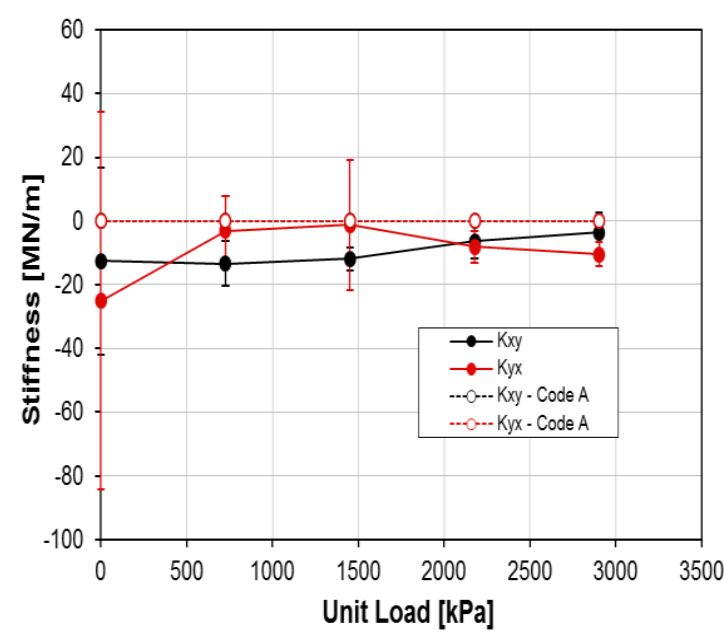

(A) $6.8 \mathrm{krpm}$

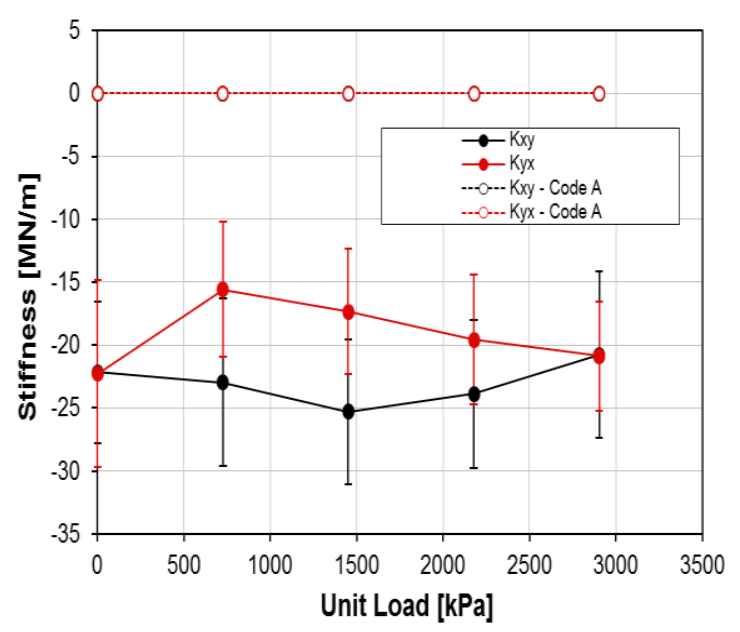

(C) $10.8 \mathrm{krpm}$

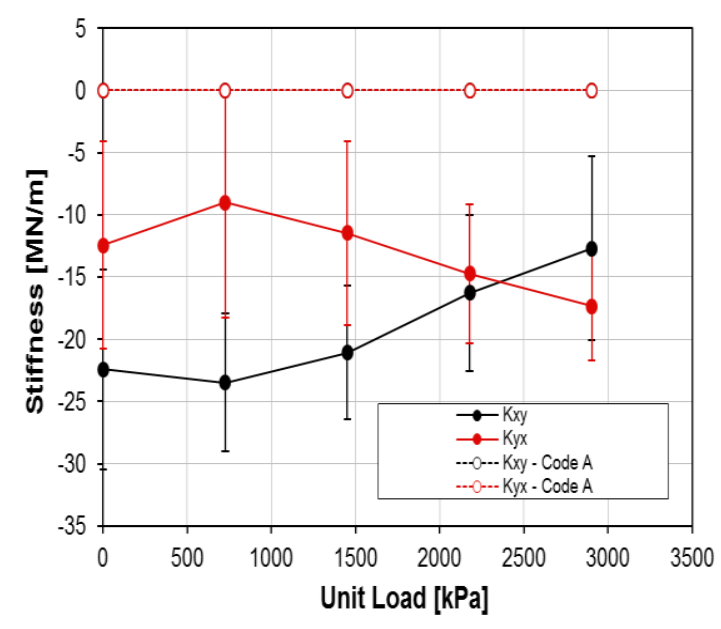

(B) 9 krpm

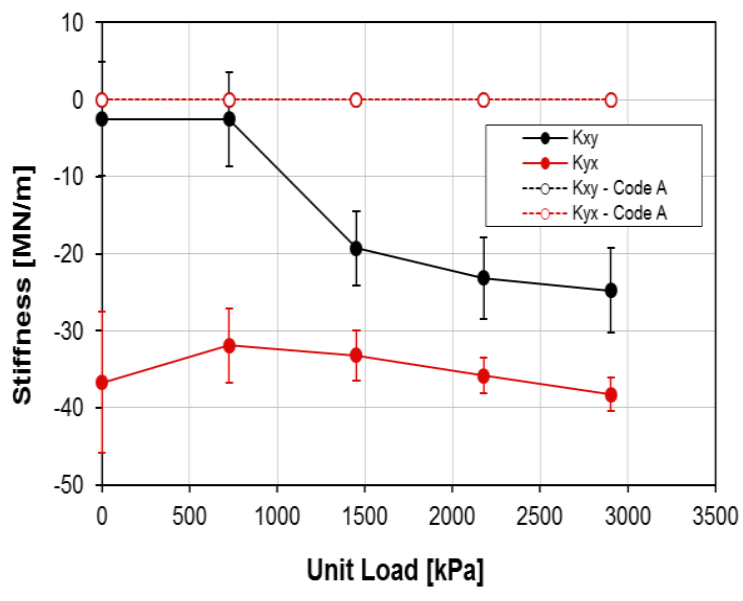

(D) $13.2 \mathrm{krpm}$

Figure 46: LOP Measured and Predicted $K_{x y}$ and $K_{y x}(\mathrm{~A}) 6.8 \mathrm{krpm},(\mathrm{B}) 9 \mathrm{krpm}$, (C) 10.8 krpm, (D) $13.2 \mathrm{krpm}$ 
Figure 46 shows that significant measured cross-coupled stiffness coefficients were obtained at all rotor speeds. All $K_{x y}$ and $K_{y x}$ coefficients are negative (have the same sign), and do not promote instability. No trend in cross-coupled stiffness terms can be seen in regards to changes in either load or speed. At all conditions, the cross-coupled stiffness coefficients are predicted to be zero. Only at $6.8 \mathrm{krpm}$ are the $K_{x y}$ and $K_{y x}$ predictions similar to the experimental results. Measured negative $K_{x y}$ and $K_{y x}$ have a much smaller magnitude than the direct stiffness coefficients.

Experimental results shown above agree with the trends of the LOP loci plots and attitude angles of Figure 25 and Figure 27 that suggest cross-coupled stiffness. Note that a change in $\varepsilon_{o}$ and $\phi_{o}$ can be attributed to a change in probe length due to temperature, suggested by Wilkes [15]. All $K_{x y}$ and $K_{y x}$ coefficients are negative and do not promote instability. Testing was performed twice in the LOP orientation, and both times negative cross-coupled stiffness results were found.

\section{LBP Orientation}

Figure 47 presents the experimental and predicted direct stiffness coefficients in the LBP configuration. 


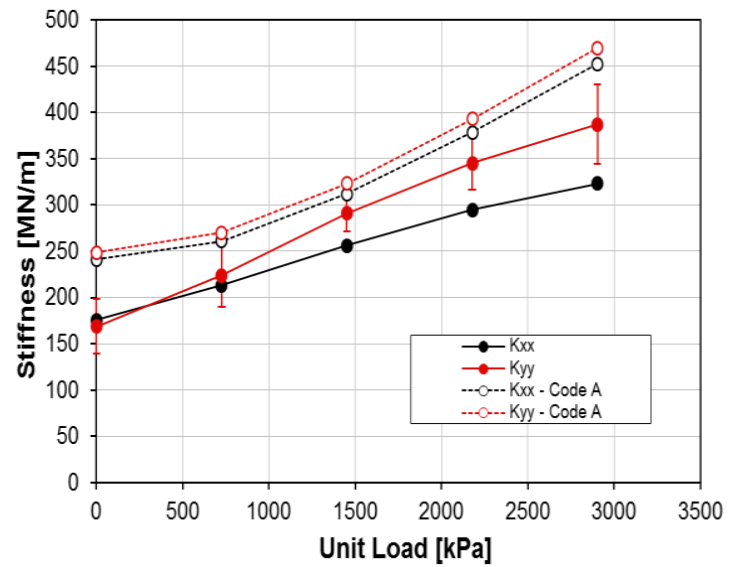

(A) $6.8 \mathrm{krpm}$

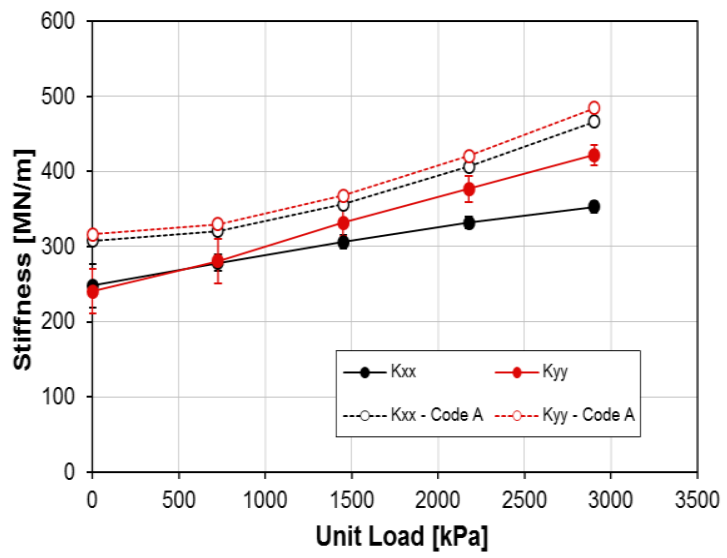

(C) $10.8 \mathrm{krpm}$

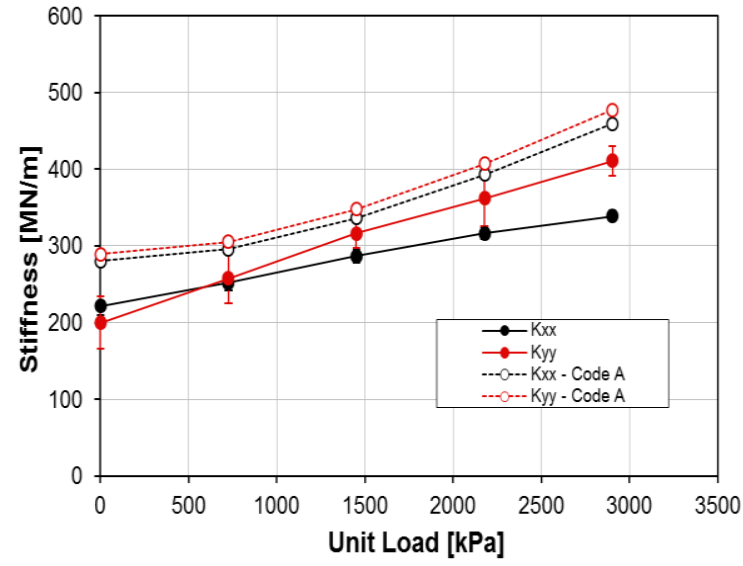

(B) 9 krpm

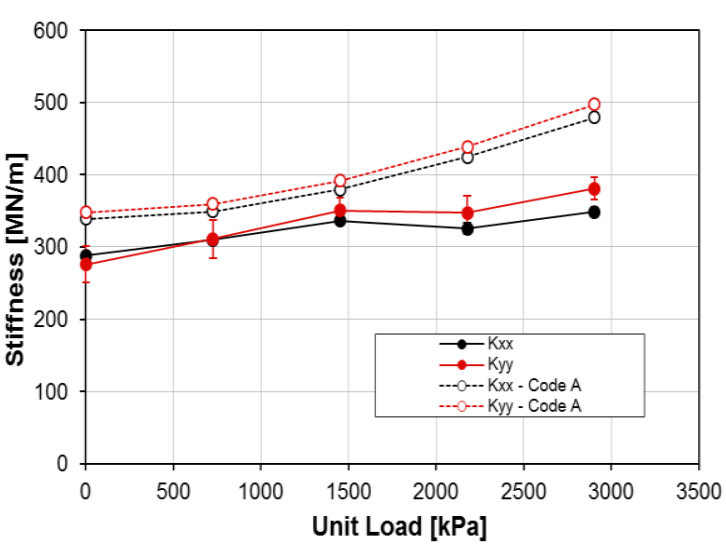

(D) $13.2 \mathrm{krpm}$

Figure 47: LBP Measured and Predicted $K_{x x}$ and $K_{y y}(\mathrm{~A}) 6.8 \mathrm{krpm},(\mathrm{B}) 9 \mathrm{krpm}$, (C) 10.8 krpm, (D) $13.2 \mathrm{krpm}$

In the LBP orientation, measured $K_{x x}$ and $K_{y y}$ values increase with increasing static unit load, and $K_{y y}$ increases at a rate slightly greater than $K_{x x}$. Both $K_{x x}$ and $K_{y y}$ increase with increasing rotor speed. At all conditions, $K_{x x}$ and $K_{y y}$ are predicted well and follow similar trends to predictions. In comparison to the LOP configuration, $K_{y y}$ coefficients are smaller in the LBP orientation, and the $K_{x x}$ coefficients are greater. The 
lack of orthotropy in the LBP orientation is predicted well.

Figure 48 presents the measured and predicted $K_{x y}$ and $K_{y x}$ in the LBP configuration.

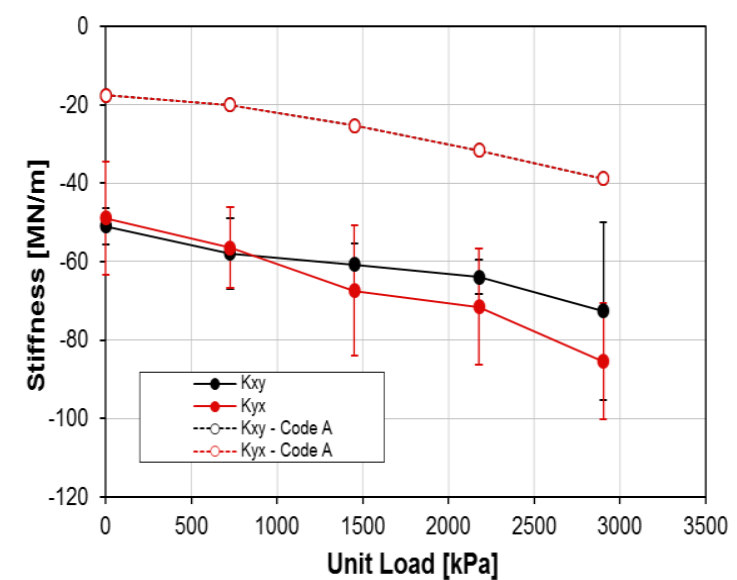

(A) $6.8 \mathrm{krpm}$

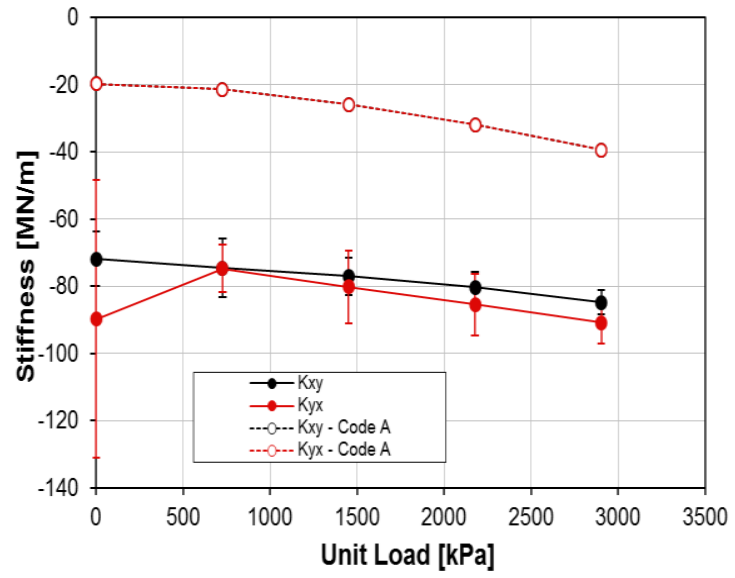

(C) $10.8 \mathrm{krpm}$

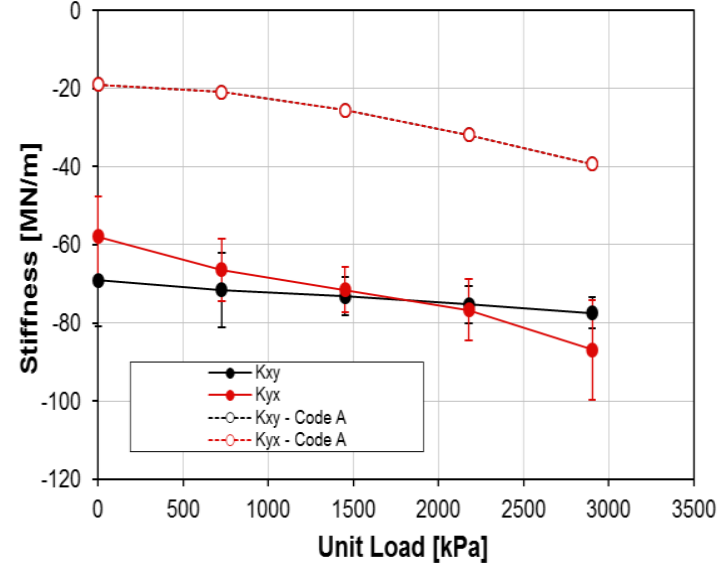

(B) 9 krpm

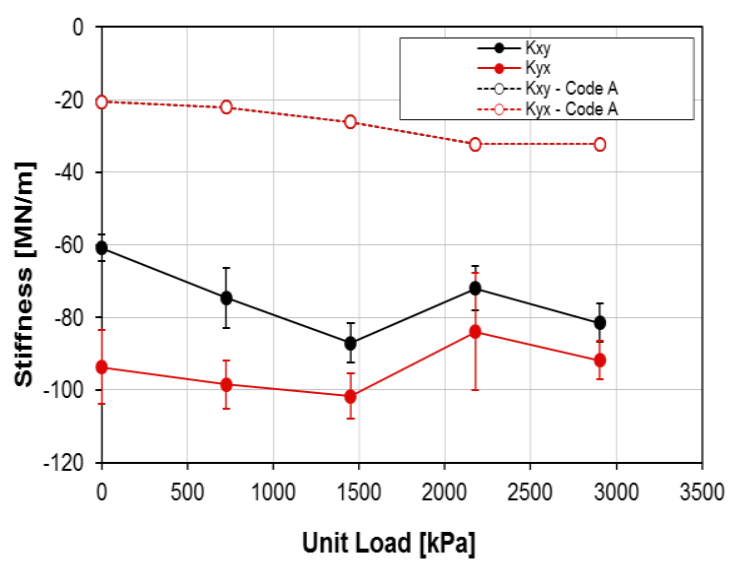

(D) $13.2 \mathrm{krpm}$

Figure 48: LBP Measured and Predicted $K_{x y}$ and $K_{y x}(\mathrm{~A}) 6.8 \mathrm{krpm}$, (B) $9 \mathrm{krpm},(\mathrm{C}) 10.8$ krpm, (D) $13.2 \mathrm{krpm}$

As with the LOP configuration, the bearing experienced cross-coupled stiffness at all rotor speeds in the LBP orientation. All measured $K_{x y}$ and $K_{y x}$ coefficients are negative, and generally $K_{y x}$ has a larger magnitude than $K_{\mathrm{xy}}$. Because all $K_{x y}$ and $K_{y x}$ 
coefficients have the same signs they do not promote instability. At all conditions, the predicted $K_{x y}$ and $K_{y x}$ have similar trends to measured results, but are much closer to zero. Measured and predicted values become more negative as load increases. Experimental results shown above agree with the trends of the LOP loci plots and attitude angles of Figure 26 and Figure 28 that suggest cross-coupled stiffness.

The bearing tested showed significant orthotropy in the LOP orientation and slight orthotropy in the heavier load cases in the LBP orientation. In 2010, Delgado et al. [12] tested both a 5-pad LOP, and 4-pad LBP rocker-pivot tilting-pad journal bearing with $50 \%$ and $60 \%$ pad pivot offset and a $0.4 \mathrm{~L} / \mathrm{D}$ ratio with much lower static unit loads than the one in this thesis. Delgado reported ( 25\%) orthotropy in the loaded direction for the LOP orientation when testing a 5-pad TPJB. Delgado did not test the 4-pad TPJB in the LOP orientation. The bearing in this thesis showed much larger coefficients $(\sim 70 \%)$ in the loaded direction when testing at large static unit load.

In the LBP orientation, Delgado experience similar coefficients in both the loaded and orthogonal direction. At low static loads, similar orthotropy to Delgado was shown in this thesis, but with much greater $K_{x x}$ and $K_{y y}$ values. Note that Delgado tested with much lower static unit loads. The present findings support Zeidan and Herbage [2] predictions that much higher levels of stiffness orthotropy will be experienced in the LOP configuration than the LBP orientation for a 4-pad TPJB. 


\section{Damping Coefficients}

The following section presents measured and predicted $C_{x x}, C_{y y}, C_{x y}$, and $C_{y x}$ values at all speeds and static unit loads for both the LOP or LBP orientation.

\section{/ 23 Orientation}

Figure 49 presents measured and predicted $C_{x x}$ and $C_{y y}$ in the LOP configuration.

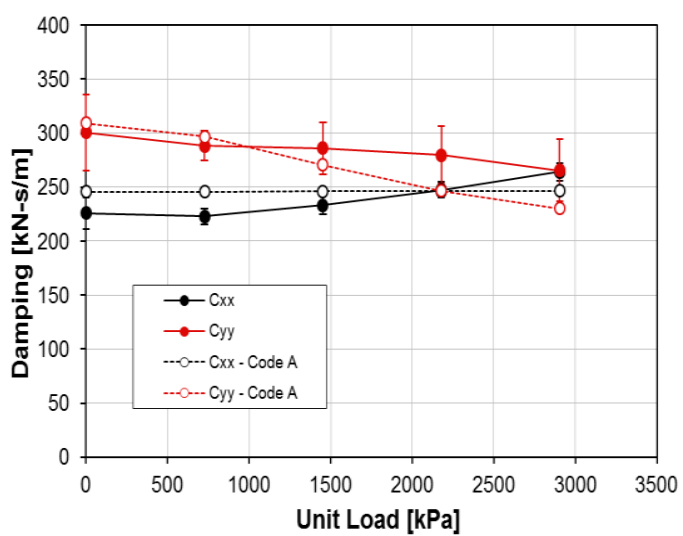

(A) $6.8 \mathrm{krpm}$

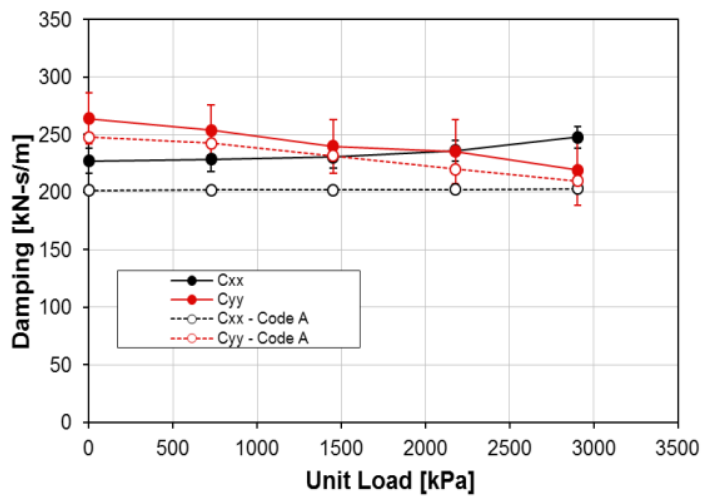

(C) $10.8 \mathrm{krpm}$

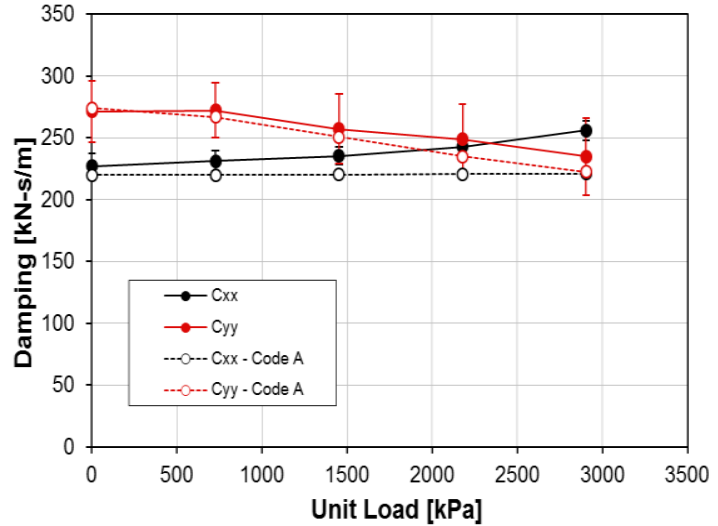

(B) 9 krpm

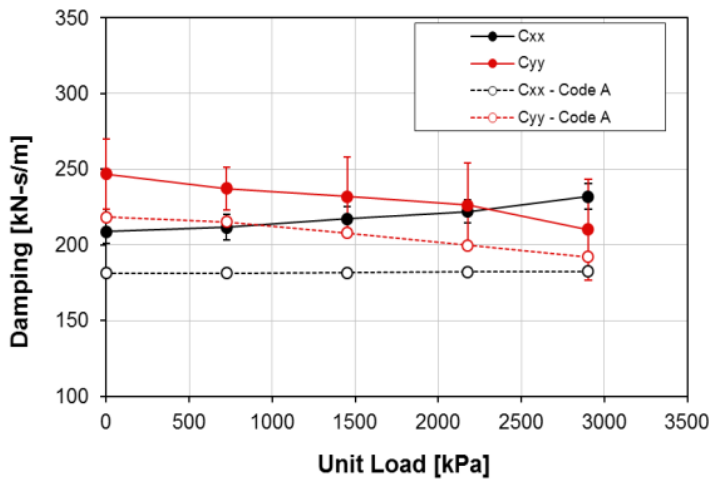

(D) $13.2 \mathrm{krpm}$

Figure 49: LOP Measured and Predicted $C_{x x}$ and $C_{y y}$ (A) $6.8 \mathrm{krpm},(\mathrm{B}) 9 \mathrm{krpm},(\mathrm{C}) 10.8$ krpm, (D) $13.2 \mathrm{krpm}$ 
$C_{x x}$ slightly increase with increasing unit load, while $C_{y y}$ slightly decreases. Both measured $C_{x x}$ and $C_{y y}$ slightly decrease as rotor speed increases. For the most part, measured $C_{y y}$ values are greater than measured $C_{x x}$ values, except for the highest loaded case. All predicted $C_{y y}$ values are greater than $C_{x x}$. Both coefficients are predicted well. Measured values are slightly smaller than predicted as unit load and speed increase. The damping predictions match the experimental results best at $9 \mathrm{krpm}$.

Figure 50 below presents the experimental and theoretical cross-coupled damping coefficients in the LOP configuration.

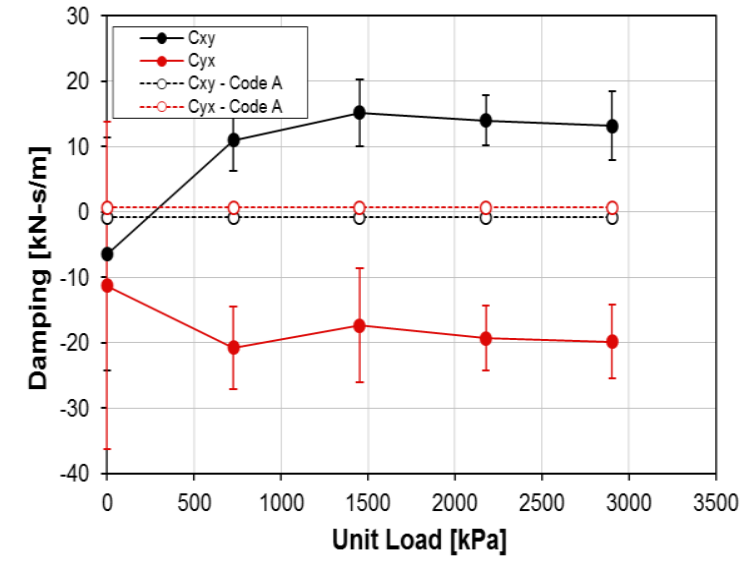

(A) $6.8 \mathrm{krpm}$

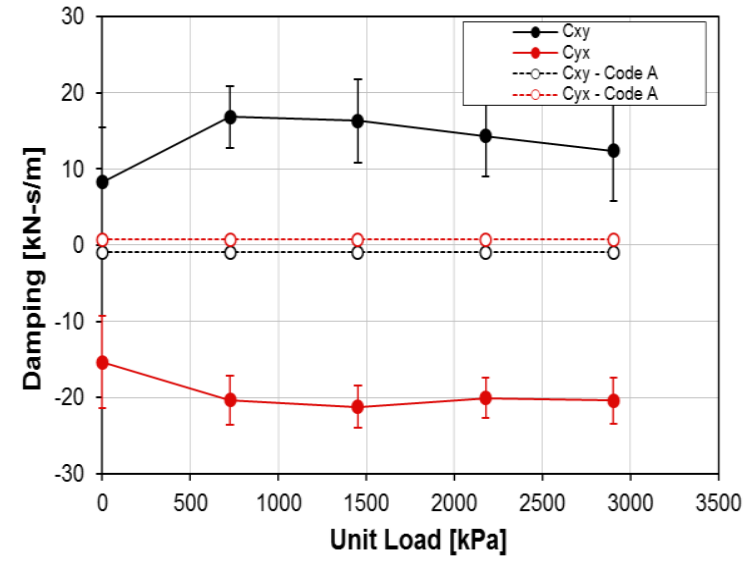

(B) 9 krpm

Figure 50: LOP Measured and Predicted $C_{x y}$ and $C_{y x}$ (A) $6.8 \mathrm{krpm},(\mathrm{B}) 9 \mathrm{krpm},(\mathrm{C}) 10.8$ krpm, (D) $13.2 \mathrm{krpm}$ 


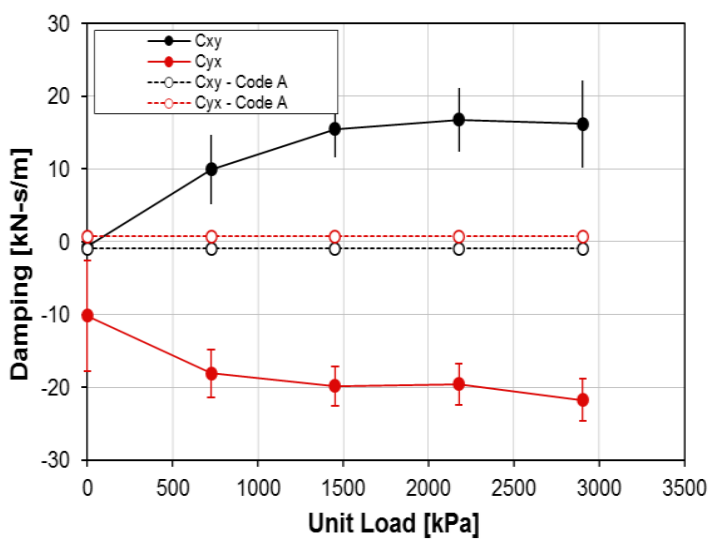

(C) $10.8 \mathrm{krpm}$

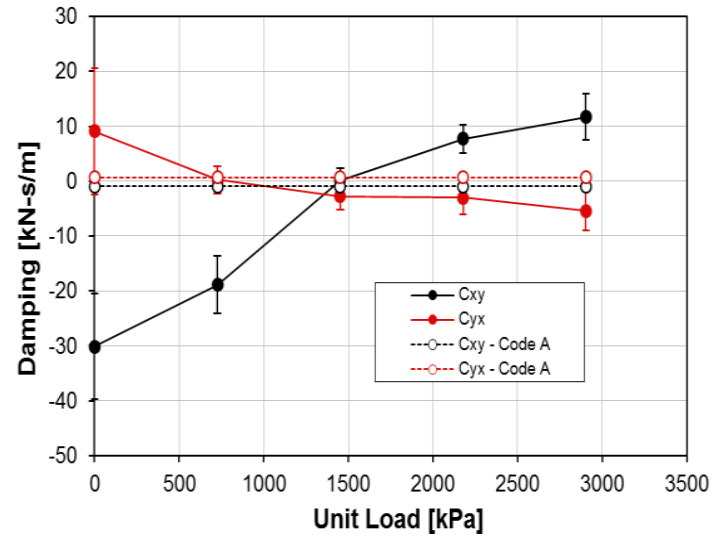

(D) $13.2 \mathrm{krpm}$

Figure 50: Continued

Significant measured $C_{x y}$ and $C_{y x}$ values were obtained at all rotor speeds. Measured $C_{x y}$ and $C_{y x}$ values have opposite signs. At all rotor speeds, $C_{x y}$ is positive while $C_{y x}$ is negative, signifying gyroscopic (not dissipative) damping. Only at 13.2 krpm do the signs of the $C_{x y}$ and $C_{y x}$ change with increasing unit load. The cross-coupled damping coefficients are much smaller than the direct damping terms shown in Figure 49. At all conditions, $C_{x y}$ and $C_{y x}$ are predicted to be zero.

\section{/\%3 Orientation}

Figure 51 presents measured and predicted $C_{x x}$ and $C_{y y}$ values in the LBP configuration. 


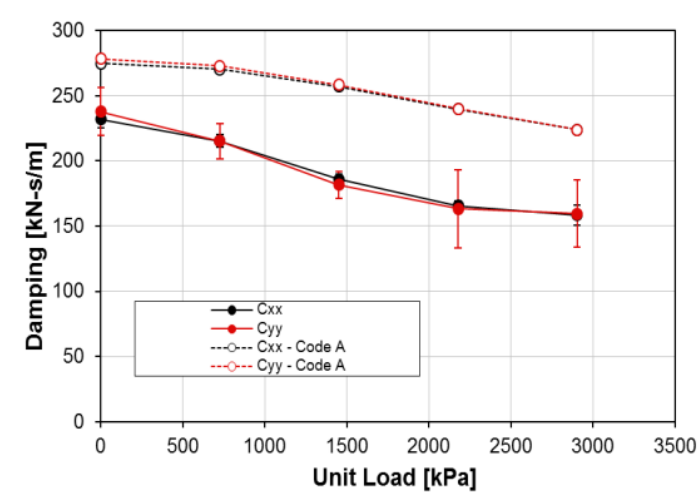

(A) $6.8 \mathrm{krpm}$

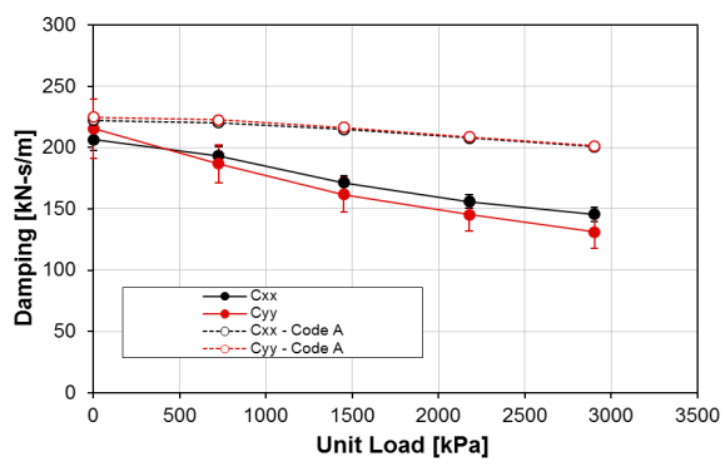

(C) $10.8 \mathrm{krpm}$

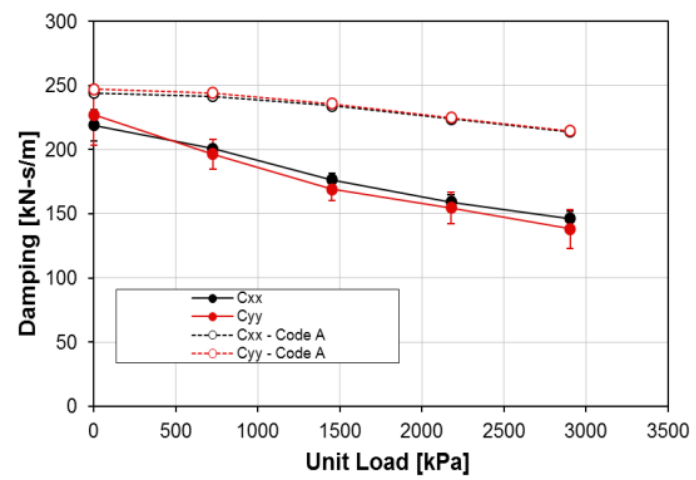

(B) 9 krpm

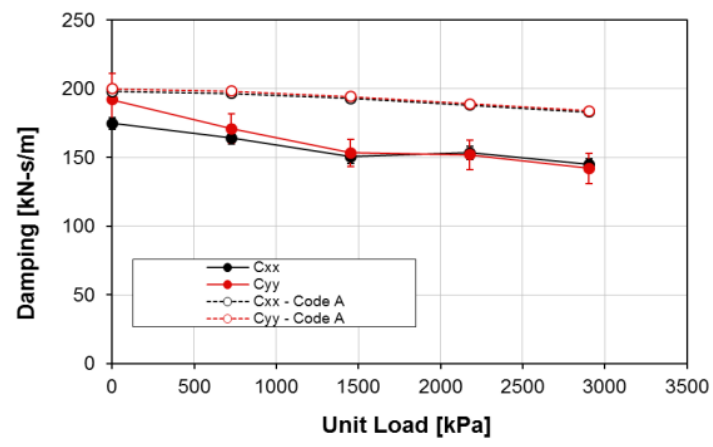

(D) $13.2 \mathrm{krpm}$

Figure 51: LBP Measured and Predicted $C_{x x}$ and $C_{y y}(\mathrm{~A}) 6.8 \mathrm{krpm},(\mathrm{B}) 9 \mathrm{krpm},(\mathrm{C}) 10.8$ krpm, (D) $13.2 \mathrm{krpm}$

At all speeds, $C_{x x}$ and $C_{y y}$ decrease with increasing unit load. $C_{x x}$ and $C_{y y}$ slightly decrease with increasing rotor speed. At all conditions, $C_{x x}$ and $C_{y y}$ are smaller than predicted. In looking at all the predictions, the damping predictions match the experimental results best at $13.2 \mathrm{krpm}$. Predictions became more accurate as rotor speed increased. Predictions from Code A follow similar trends to measured results; specifically with a slight decrease with increasing load. 
By comparing Figure 49 and Figure 51, $C_{x x}$ and $C_{y y}$ are lower in the LBP orientation than the LOP orientation. $C_{x x}$ and $C_{y y}$ in the LBP orientation are greater than Delgado et al. [12] for a 4-pad TPJB. The bearing tested by Delgado had different pivot offsets, different $L / D$ ratios, and experienced much lower static unit loads than the one in this thesis.

Figure 52 below presents the measured and predicted $C_{x y}$ and $C_{y x}$ values in the LBP configuration.

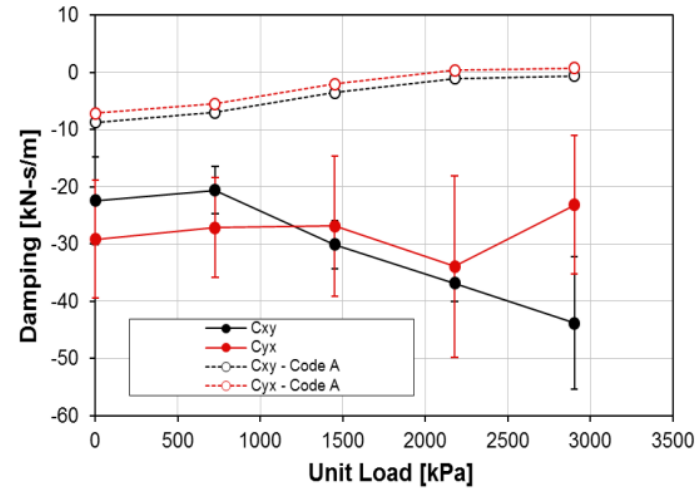

(A) $6.8 \mathrm{krpm}$

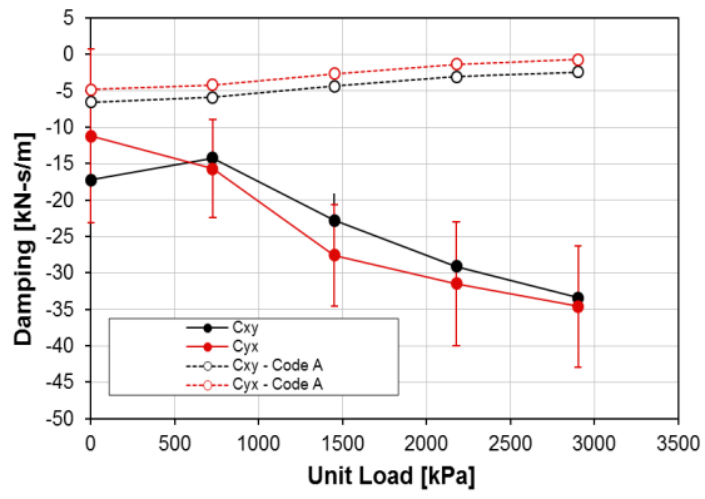

(C) $10.8 \mathrm{krpm}$

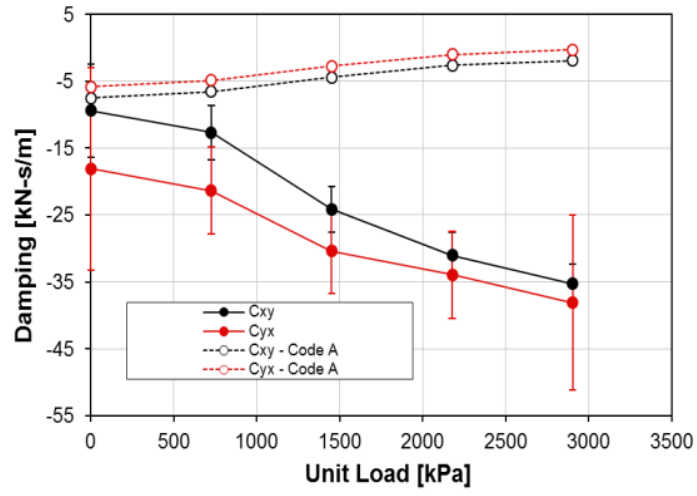

(B) 9 krpm

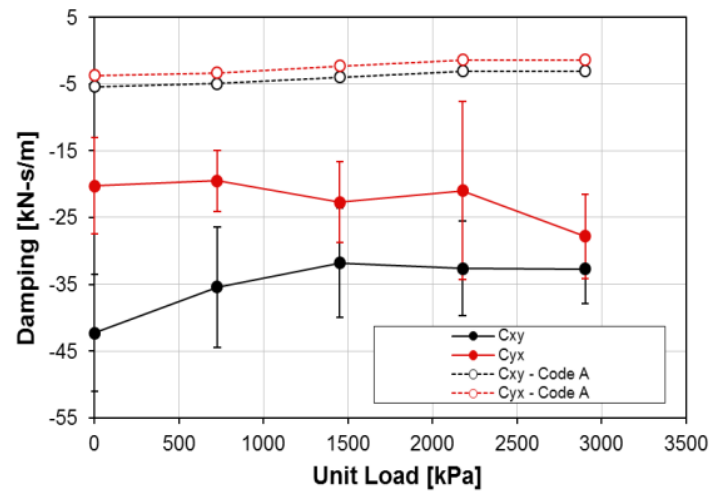

(D) $13.2 \mathrm{krpm}$

Figure 52: LBP Measured and Predicted $C_{x y}$ and $C_{y x}(\mathrm{~A}) 6.8 \mathrm{krpm},(\mathrm{B}) 9 \mathrm{krpm},(\mathrm{C}) 10.8$ krpm, (D) $13.2 \mathrm{krpm}$ 
In the LBP orientation, all measured $C_{x y}$ and $C_{y x}$ values are negative regardless of unit load or rotor speed. Predicted values for $C_{x y}$ and $C_{y x}$ follow different trends from measurements. Measured $C_{x y}$ and $C_{y x}$ values tend to decrease with increasing unit load, versus a predicted increase. Measured $C_{x y}$ and $C_{y x}$ magnitudes are much larger than predicted. The $C_{x y}$ and $C_{y x}$ are much smaller than the $C_{x x}$ and $C_{y y}$ terms in Figure 51. Unlike the LOP orientation, $C_{x y}$ and $C_{y x}$ have the same sign in the LBP orientation, signifying physical damping.

\section{Virtual-mass Coefficients}

This section presents the measured and predicted $M_{x x}, M_{y y}, M_{x y}$, and $M_{y x}$ virtualmass coefficients at all speeds and static loads tested for either the LOP or LBP orientation. A positive $M_{i j}$ represents a negative curvature and acts like a real physical mass.

\section{LOP Orientation}

The experimental and predicted virtual-mass coefficients are given in Figure 53 below. 


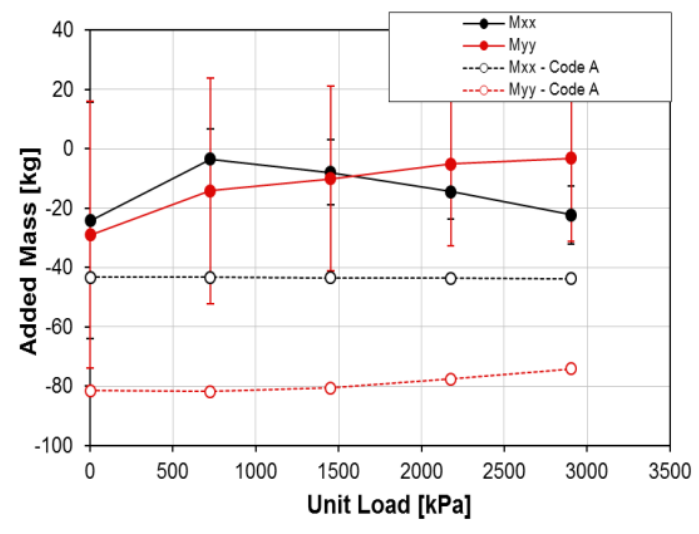

(A) $6.8 \mathrm{krpm}$

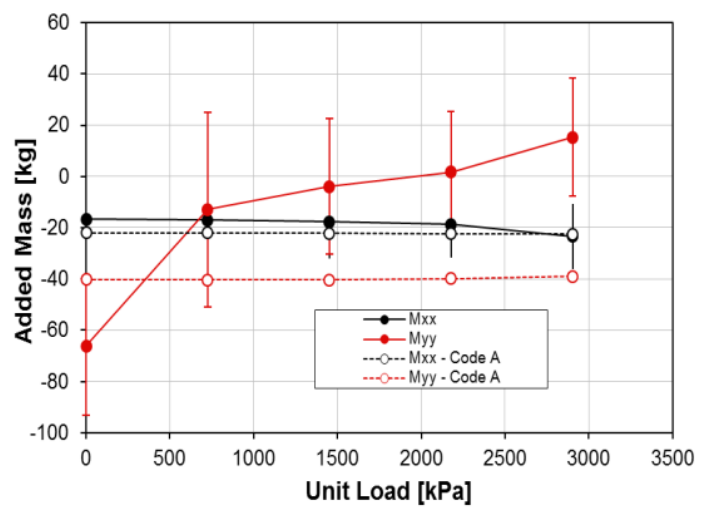

(C) $10.8 \mathrm{krpm}$

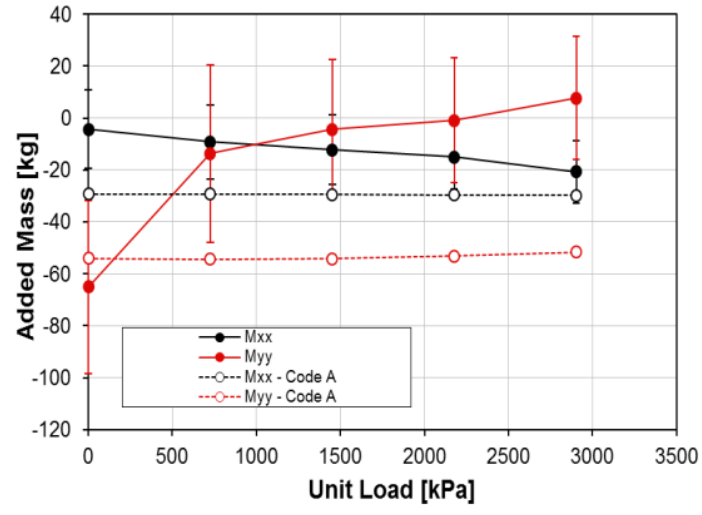

(B) 9 krpm

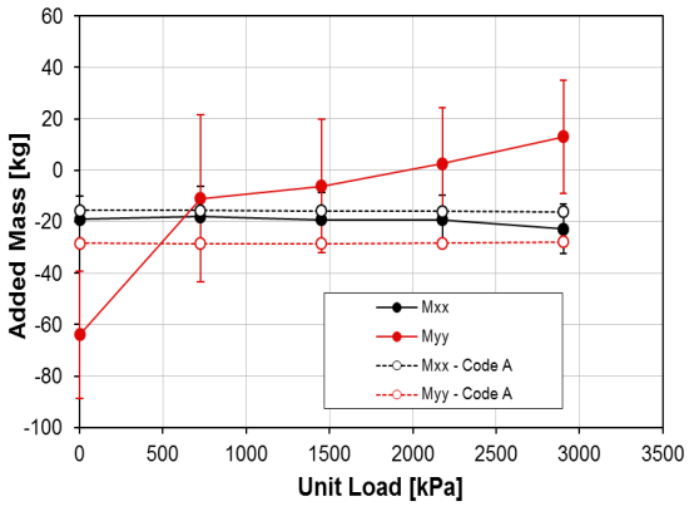

(D) $13.2 \mathrm{krpm}$

Figure 53: LOP Measured and Predicted $M_{x x}$ and $M_{y y}$ (A) $6.8 \mathrm{krpm},(\mathrm{B}) 9 \mathrm{krpm}$, (C) 10.8 krpm, (D) $13.2 \mathrm{krpm}$

Measured $M_{y y}$ values increase with increasing static unit load. The increasing curvature of $\operatorname{Re}\left(\boldsymbol{H}_{i j}\right)$ led to all of the $M_{x x}$ coefficients being negative, while the $M_{y y}$ coefficients sign changes as load increases, agreeing with the dynamic stiffness plots of Figure 37 - Figure 40. At low speeds, the predicted virtual-mass coefficients are much larger than measured values. $M_{x x}$ coefficients are predicted more accurately as speed 
increases, even though neither coefficient is predicted well. All measured $M_{y y}$ values have large uncertainties.

Figure 54 shows the measured and predicted $M_{x y}$ and $M_{y x}$ coefficients in the LOP configuration.

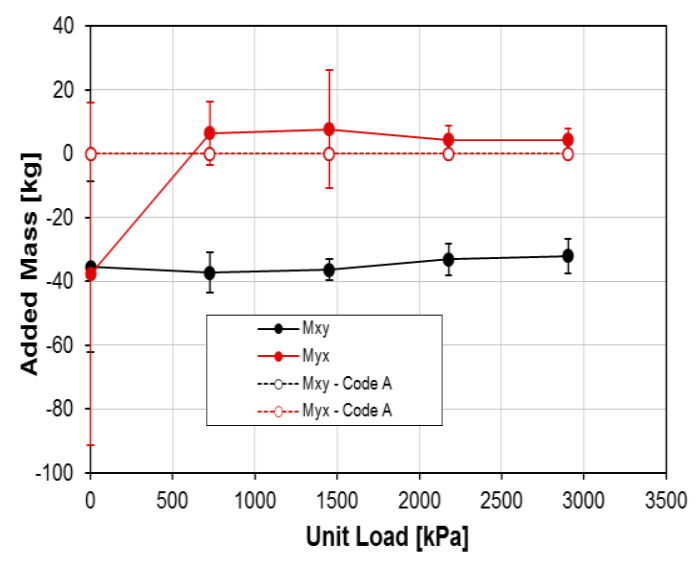

(A) $6.8 \mathrm{krpm}$

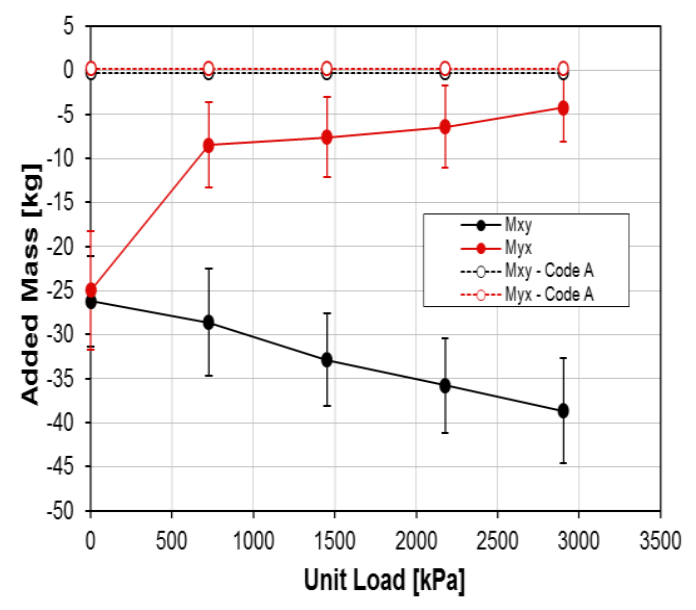

(C) $10.8 \mathrm{krpm}$

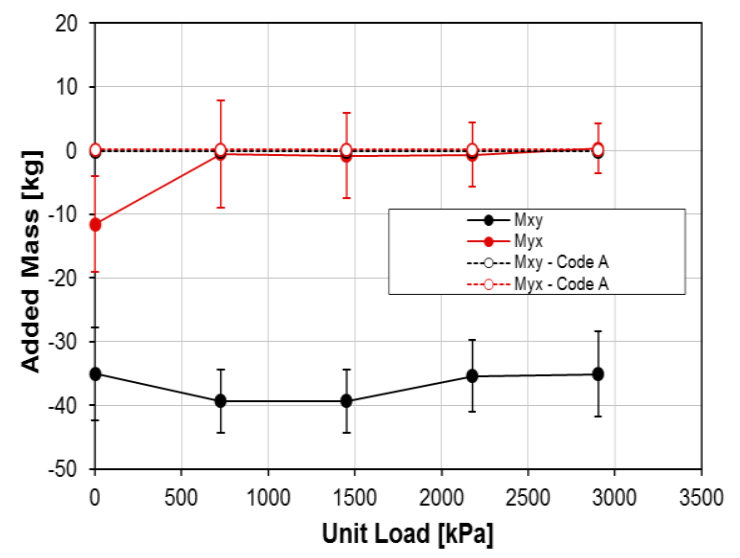

(B) 9 krpm

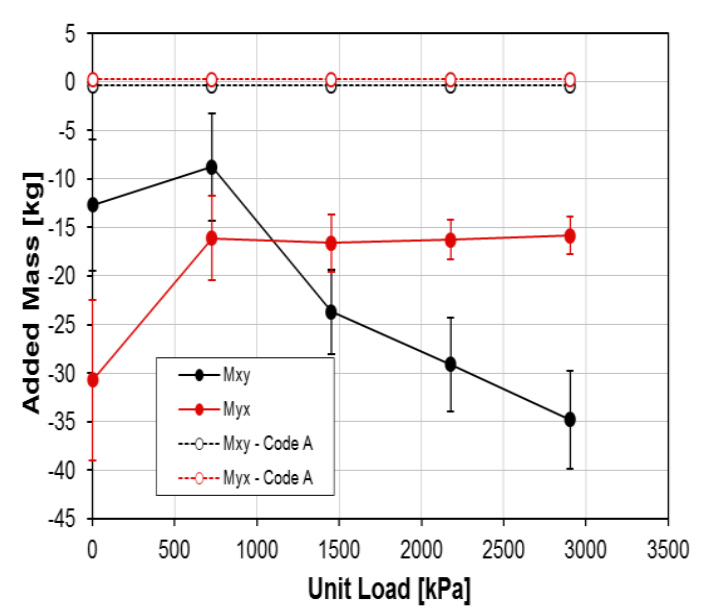

(D) $13.2 \mathrm{krpm}$

Figure 54: LOP Measured and Predicted $M_{x y}$ and $M_{y x}$ (A) $6.8 \mathrm{krpm}$, (B) $9 \mathrm{krpm}$, (C) 10.8 krpm, (D) $13.2 \mathrm{krpm}$ 
$M_{x y}$ and $M_{y x}$ are mostly negative, except at $6.8 \mathrm{krpm}$. For higher rotor speeds, $M_{x y}$ and $M_{y x}$ are both negative. The virtual-mass coefficients at $6.8 \mathrm{krpm}$ have opposite signs, suggesting an impact on stability (See Whirl Frequency Ratio). At all test conditions, $M_{x y}$ and $M_{y x}$ are predicted to be zero. At low speeds, $M_{y x}$ values are similar to predicted values. Most cross-coupled virtual mass coefficients in the LOP orientation have large uncertainties.

\section{LBP Orientation}

Measured and predicted virtual-mass coefficients are given in Figure 55 for the LBP configuration.

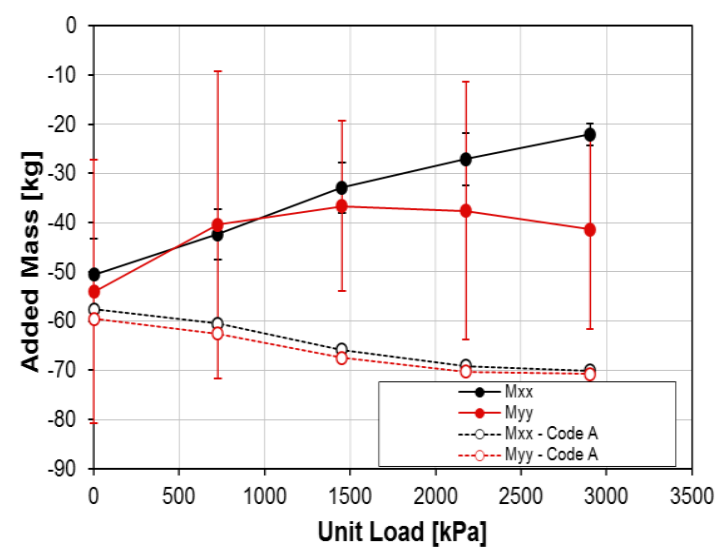

(A) $6.8 \mathrm{krpm}$

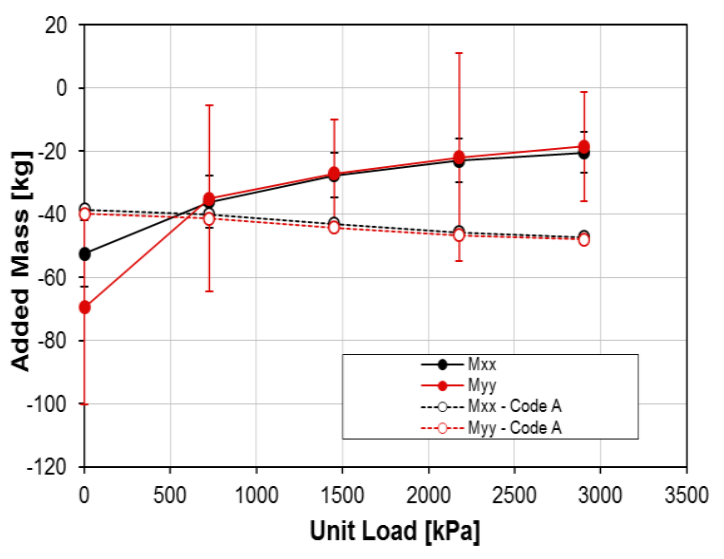

(B) 9 krpm

Figure 55: LBP Measured and Predicted $M_{x x}$ and $M_{y y}$ (A) $6.8 \mathrm{krpm},(\mathrm{B}) 9 \mathrm{krpm}$, (C) 10.8 krpm, (D) $13.2 \mathrm{krpm}$ 


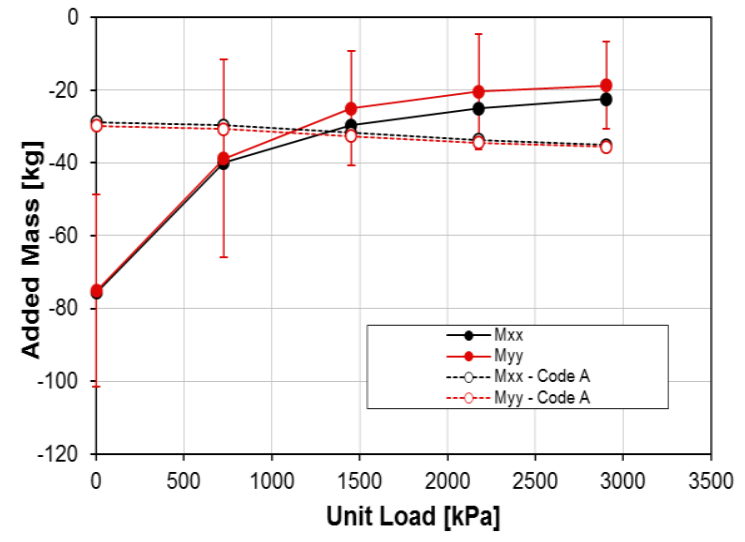

(C) $10.8 \mathrm{krpm}$

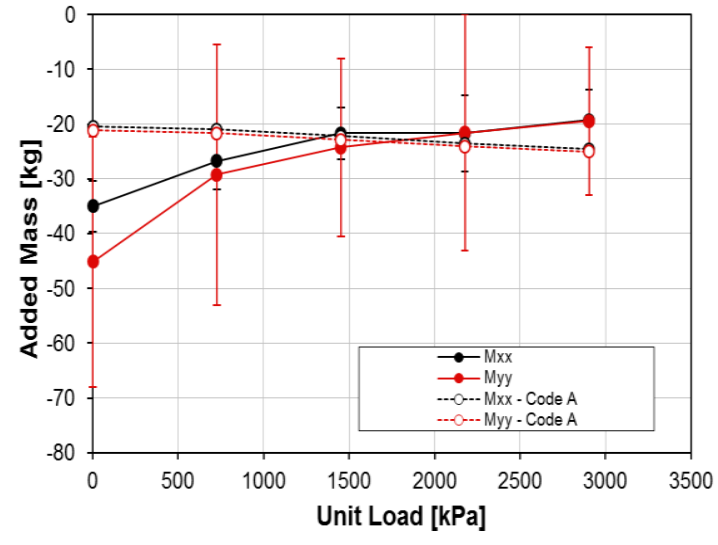

(D) $13.2 \mathrm{krpm}$

Figure 55: Continued

$M_{y y}$ and $M_{x x}$ coefficients follow similar trends with respect to changing rotor speed and loads. All of the $M_{x x}$ and $M_{y y}$ coefficients are negative with the zero-load case having the largest magnitudes, agreeing with the dynamic stiffness plots of Figure 57 Figure 60. $M_{x x}$ and $M_{y y}$ coefficients are predicted more accurately as speed increases, even though neither coefficient is predicted well. The predicted values show a slight decrease with respect to increasing unit load and speed. For the most part, the experimental results show the opposite trends. Results are comparable to the LOP orientation. All measured $M_{y y}$ coefficients have large uncertainties.

Figure 56 shows measured and predicted $M_{x y}$ and $M_{y x}$ coefficient's for the LBP configuration. 


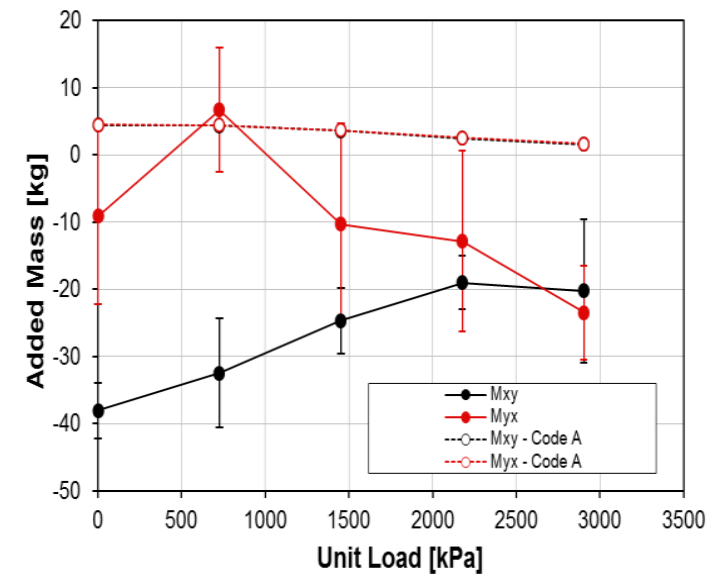

(A) $6.8 \mathrm{krpm}$

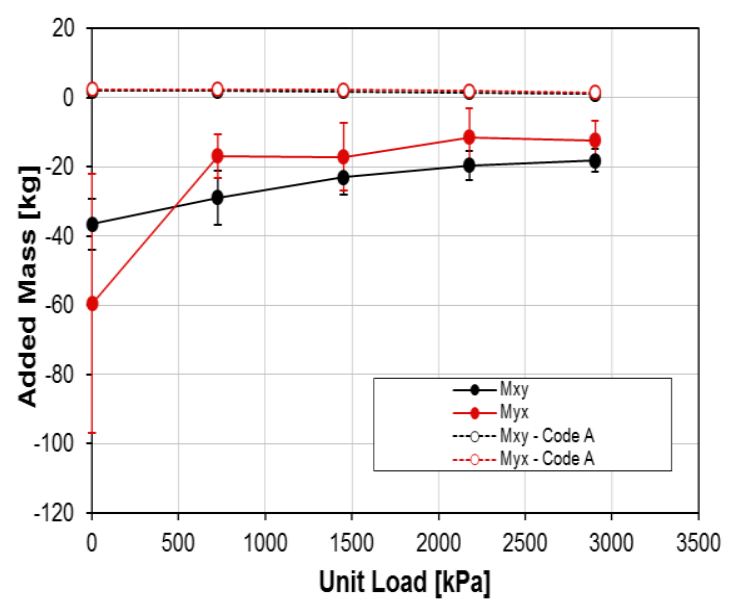

(C) $10.8 \mathrm{krpm}$

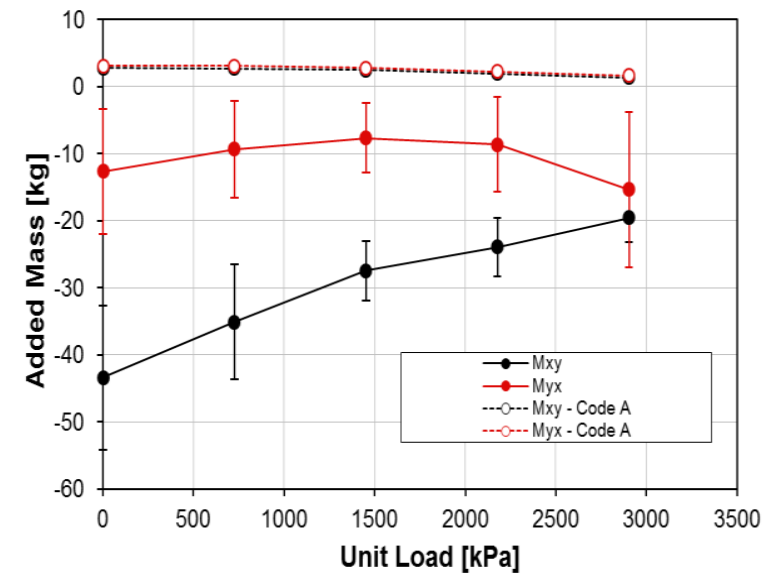

(B) 9 krpm

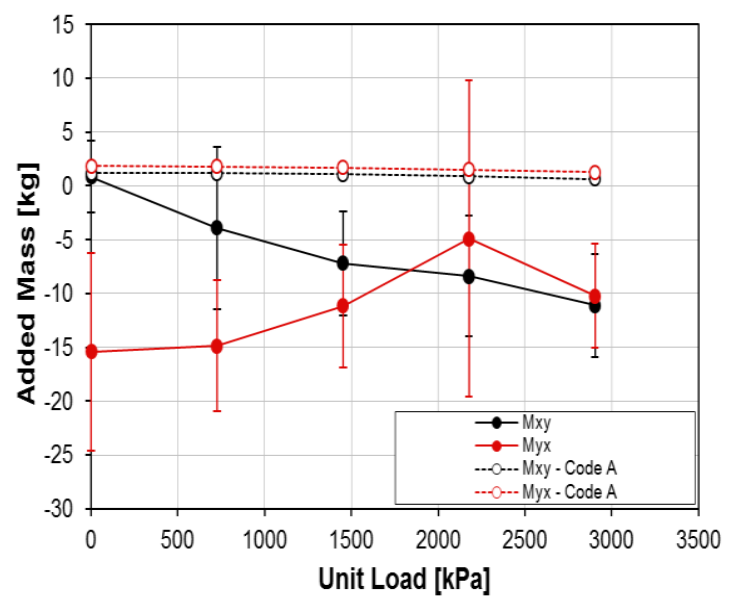

(D) $13.2 \mathrm{krpm}$

Figure 56: LBP Measured and Predicted $M_{x y}$ and $M_{y x}$ (A) $6.8 \mathrm{krpm}$, (B) $9 \mathrm{krpm},(\mathrm{C}) 10.8$ krpm, (D) $13.2 \mathrm{krpm}$

$M_{x y}$ and $M_{y x}$ are generally negative, except for the rotor speed of $6.8 \mathrm{krpm}$. At 6.8 $\mathrm{krpm}$ and $725 \mathrm{kPa}(105.3 \mathrm{psi}) M_{x y}$ is negative and $M_{y x}$ is positive, implying an effect on stability (See Whirl Frequency Ratio). $M_{x y}$ increases with increasing unit load except for a rotor speed of $13.2 \mathrm{krpm}$. At low rotor speeds both $M_{x y}$ and $M_{y x}$ slightly decrease with increasing load. 


\section{Whirl Frequency Ratio}

In Figure 54(A) and Figure 56(A) above, the virtual-mass coefficients for $\operatorname{Re}\left(\boldsymbol{H}_{\boldsymbol{x} y}\right)$ and $\operatorname{Re}\left(\boldsymbol{H}_{\boldsymbol{y} x}\right)$ have approximately equal but opposite signs, suggesting an impact on stability. The whirl frequency ratio (WFR) defines the stability characteristics of a bearing. If a bearing has zero cross-coupling effects than the whirl frequency ratio would be zero. The whirl frequency ratio is defined as the ratio of the rotor whirl or precessional frequency to the rotor's onset speed of instability. San Andrés [24] extended Lund's [25] definition of WFR to include the impact of cross-couples mass terms. The formulas used to calculate WFR can be found in Appendix E and are from San Andrés [24]. A small WFR will raise the onset speed of instability and thus produce a more stable system. For a typical journal bearing, the whirl frequency ratio is 0.5 . At all conditions in both the LOP and LBP orientations the WFR was negative or zero, showing no impact on stability. 


\section{SUMMARY, DISCUSSION, AND CONCLUSIONS}

Measured and predicted static and dynamic characteristics are presented for a 4pad, rocker-pivot, tilting-pad journal bearing (TPJB) in load-on-pad (LOP) and loadbetween-pad (LBP) orientations. The bearing has the following characteristics: 4 pads, .57 pad pivot offset, $0.6 \mathrm{~L} / \mathrm{D}$ ratio, and $60.33 \mathrm{~mm}$ (2.375in) pad axial length. Tests were conducted on a floating bearing test rig with unit loads ranging from 0 to $2903 \mathrm{kPa}(421.1$ psi) and speeds from 6.8 to $13.2 \mathrm{krpm}$.

Two newly developed prediction codes utilizing slightly different variables were used to compare to measured results. Static results and rotordynamic coefficients presented will be compared to predictions from a new rotordynamic bearing code, "Code A," developed by Tao and San Andrés at the Texas A\&M Turbomachinery Laboratory. The predictions come from the first version of this code to be published in the near future. A full description of Code A can be found in the Predictions section. Code A takes into account pivot flexibility with a user-defined load-versus-deflection approximation, and if needed, different pad geometries (preloads and clearances for each pad) to predict the static and dynamic behavior of a TPJB.

Dynamic stiffness results presented will be compared to the model of Wilkes and Childs [14][17][18], “Code B”. Wilkes dissertation [15] uses a Reynolds-based model to predict dynamic results, utilizing pivot and pad flexibility. Experimental temperature measurements are used to model the lubricant's viscosity. A full description of Code B can be found in the Predictions section. 


\section{Static Characteristics}

The static results presented include the measured cold and hot clearance differences, bearing loci plots, journal eccentricity ratios, attitude angle, estimated power loss, and pad metal temperatures. Both cold and the hot clearance measurements show that the clearance of adjacent pads are different. Hot-clearance measurements showed a $16-25 \%$ decrease in clearance compared to a clearance measurement at room temperature. Because of this difference, measured hot clearances were used in predictions; giving a more accurate representation of the bearing clearances.

The measured attitude angle and eccentricity loci plots show that cross-coupled effects (lateral displacement) between the $x$ displacement and $y$ load direction are significant. However, the deviation from the loaded $y$ axis and $x$ axis motion was less significant in the LBP orientation. Wilkes and Childs [18] suggest that some observed change in eccentricity and attitude angle can be attributed to a change in probe length due to temperature, and not necessarily true cross-coupling effects. In comparison, Code A's LOP loci plots predicted no cross-coupling effects due to fluid rotation. The predicted bearing loci plots showed less movement in the $\varepsilon_{\text {oy }}$ direction than measurements, predicting a stiffer bearing. LOP attitude angles were predicted to be zero while measured values were negative. Code A predicted small positive attitude angles in the LBP configuration, matching measured values.

Embedded thermocouples provide pad metal temperature just below the surface of the Babbitt. The circumferentially-spaced thermocouples showed a temperature increase along the faces of the pad in the shaft-rotation direction that increases with increasing 
running speed. In the LOP orientation, temperatures at the trailing edge of the pad were much greater than temperatures at the leading edge of the pad (in some cases $+40^{\circ} \mathrm{C}$ ). Due to the difference in bearing clearances, in the LBP orientation, one of the loaded pads experienced greater temperatures because it was supporting more of the static load. Code A predictions showed an increase in temperature circumferentially across the pad with shaft rotation, agreeing with measurements. In the LOP orientation, all circumferential temperatures in the loaded pad were under predicted by Code A except for the temperature at the leading edge of the pad. In some cases, Code A underpredicted temperature measurements by $30^{\circ} \mathrm{C}$ at the trailing edge of the pad. In the unloaded pads, the leading edge of the pads are all over predicted by Code A, and the trailing edge of the pads are under predicted $\left( \pm 10^{\circ} \mathrm{C}\right)$. Overall, Code A did not predict the temperatures of trailing edge of the loaded pads well, but reasonable prediction results for rotordynamic coefficients were still obtained.

In the loaded pad, not only were thermocouples installed just below the surface of the Babbitt (rotor side of the pad), but thermocouples were also installed near the bearing housing. The thermocouples in the loaded pad showed a radial temperature decrease from the rotor side of the pad to the bearing-housing side. A finite-element (FE) analysis in ANSYS predicted that the measured radial temperature gradient caused an uneven thermal deflection in the pad, changing the pad's radius of curvature. The FEA predictions showed a $0.019-0.032 \mathrm{~mm}(0.00077-0.00126 \mathrm{in})$ increase in the loaded pad's radius depending on running speed and load. As the radius of curvature increased, the resulting preload of the pad's increased by $0.065-0.136$. Overall, the change in radius of 
curvature and preload only slightly affected the predicted bearing impedance coefficients, leading to slightly poorer predictions.

Estimated power loss values were obtained from an energy-balance equation assuming adiabatic conditions. Code-A power loss predictions were lower than the estimated power loss in the LBP orientation, but higher than the estimated power loss values for the LOP orientation. The LOP estimated power loss values were modeled well. Consistent with the measurements, Code A predicts that power loss is independent of load but increases with increasing speed.

\section{Dynamic Characteristics}

Rotordynamic coefficients including stiffness, damping, and virtual-mass coefficients were determined from measured $\boldsymbol{H}_{i j}$ dynamic-stiffness functions. For LOP and LBP cases, the $\operatorname{Re}\left(\boldsymbol{H}_{\boldsymbol{x} x}\right), \operatorname{Re}\left(\boldsymbol{H}_{\boldsymbol{y} \boldsymbol{y}}\right), \operatorname{Re}\left(\boldsymbol{H}_{\boldsymbol{x} y}\right)$, and $\operatorname{Re}\left(\boldsymbol{H}_{\boldsymbol{y} \boldsymbol{x}}\right)$ functions showed a dependence on excitation frequency that could be accounted for with virtual-mass coefficients, producing frequency-independent stiffness and virtual-mass coefficients.

In both orientations, $\operatorname{Im}\left(\boldsymbol{H}_{\boldsymbol{x} x}\right), \operatorname{Im}\left(\boldsymbol{H}_{\boldsymbol{y} \boldsymbol{y}}\right), \operatorname{Im}\left(\boldsymbol{H}_{\boldsymbol{x} y}\right)$, and $\operatorname{Im}\left(\boldsymbol{H}_{\boldsymbol{y} \boldsymbol{x}}\right)$ increased linearly with increasing $\Omega$, allowing for frequency independent damping coefficients. Overall, for all test conditions the frequency dependency of the test bearing was modeled well with a $[\mathrm{K}][\mathrm{C}][\mathrm{M}]$ model. Similar results were obtained by Delgado et al. [12] for a 4-pad TPJB.

Except for some unloaded cases, measured $K_{y y}$ was larger than $K_{x x}$ regardless of orientation. In the LOP orientation, $K_{y y}$ was much greater than $K_{x x}(\sim 70 \%$ with large 
static loads). In the LBP orientation, $K_{y y}$ was slightly greater than $K_{x x}$ when testing with low static loads, but greater than $K_{x x}$ when testing with heavier loads $(\sim 17 \%)$. In both orientations, measured $K_{x y}$ and $K_{y x}$ coefficients were negative and considerably smaller than the $K_{y y}$ and $K_{x x}$ coefficients. All measured $K_{x y}$ and $K_{y x}$ coefficients were the same sign (negative), and do not promote instability. Measured rotordynamic coefficients were compared to predictions from Code A. For both orientations $K_{x x}$ and $K_{y y}$ were smaller than Code A's predictions at light loads, but were more accurately predicted as load increased.

Measured $C_{x x}$ and $C_{y y}$ coefficients were mostly constant with respect to unit load in the LOP orientation, but decreased slightly with increasing unit load in the LBP orientation. Both orientations showed $C_{x x}$ and $C_{y y}$ decreasing slightly with increasing rotor speed. $C_{y y}$ and $C_{x x}$ predictions by Code A were very accurate in the LOP orientation. In the LBP orientation, Code A predicted higher $C_{x x}$ and $C_{y y}$ values than were measured. The measured $C_{x y}$ and $C_{y x}$ coefficients were considerably smaller than the $C_{x x}$ and $C_{y y}$.

The main difference between prediction codes is that Code B incorporates pad flexibility in predicting the impedance coefficients for a tilting-pad journal bearing. The pad flexibility refers to the change in pad curvature resulting from an applied moment at the end of the pad from the fluid film pressure. To look at the effects that pad flexibility has on predicting the impedance coefficients, a series of predictions were created with Code B by changing the magnitude of the pad's bending stiffness. Increasing the bending stiffness used in Code B by a factor of 10 typically caused a 3-11\% increase in 
predicted $K_{x x}$ and $K_{y y}$, and a $10-24 \%$ increase in predicted $C_{x x}$ and $C_{y y}$. In all cases, increasing the calculated bending stiffness from ten to a hundred times the calculated value caused slight if any change in $K_{x x}, K_{y y}, C_{x x}$, and $C_{y y}$. For a flexible pad an increase in bending stiffness can have a large effect on predictions; however, for a more rigid pad an increase in pad bending stiffness will have a much lesser effect.

Overall, Code B's predictions showed that the pad's structural bending stiffness can be an important factor in predicting impedance coefficients. Even though the pads tested in this thesis are extremely stiff, changes are still seen in Code B's predictions when the magnitude of the pad's bending stiffness is increased, especially in $C_{x x}$, and $C_{y y}$. For the most part, Code A predicted $K_{x x}$ and $K_{y y}$ much more accurately than Code B showing that pad flexibility may not be as large of a factor in predicting $K_{x x}$ and $K_{y y}$ coefficients. Code B predicts $C_{x x}$ more accurately, while Code A predicted $C_{y y}$ more accurately.

For solid pads, like the ones tested here, both codes did a decent job at predicting the impedance coefficients. That said, both codes show the importance of including pivot-flexibility and the reduction of bearing clearance due to thermal expansion in predicting the impedance coefficients of a TPJB with solid pads. If either of these two inputs were incorrect, then predictions for the bearings impedance coefficients were very inaccurate.

Virtual-mass coefficients for both orientations were able to capture the frequency dependence of the measured $\operatorname{Re}\left(\boldsymbol{H}_{i j}\right)$ values at all test conditions. For the most part, all $M_{x x}$ and $M_{y y}$ coefficients were negative regardless of orientation. Uncertainties for most 
virtual-mass coefficients were significant. Delgado et al. and Kulhanek obtained $M_{y y}$ and $M_{x x}$ coefficients comparable to this thesis.

For the LOP and LBP $6.8 \mathrm{krpm}$ case, the cross-coupled virtual-mass coefficients had approximately equal but opposite signs, suggesting an impact on stability. The whirl frequency ratio (WFR) was used to examine the stability characteristics of the bearing. At all conditions in both the LOP and LBP orientations the WFR was negative or zero, showing no impact on stability.

Overall, the measured dynamic stiffness and rotordynamic coefficients in the thesis were larger, but comparable to the test results of Delgado et al. [12]. The bearing tested have displayed significant orthotropy in the LOP orientation and slight orthotropy in the heavier load cases in the LBP orientation. Delgado reported ( $25 \%)$ orthotropy in the loaded direction for the LOP orientation when testing a 5-pad TPJB. Delgado did not test the 4-pad TPJB in the LOP orientation. The bearing tested has showed much larger coefficients $(\sim 70 \%)$ in the loaded direction when testing at large static unit load. In the LBP orientation, Delgado experience similar coefficients in both the loaded and orthogonal direction. At low static loads, similar orthotropy was shown in this thesis, but with much greater $K_{x x}$ and $K_{y y}$ values. Delgado tested with much lower static unit loads. The present findings supported Zeidan and Herbage's [2] predictions that much higher levels of stiffness orthotropy will be experienced in the LOP configuration than the LBP orientation for a 4-pad TPJB. 


\section{REFERENCES}

[1] Al-Ghasem, A., and Childs, D., 2006, "Rotordynamic Coefficients Measurement Versus Predictions for a High-Speed Flexure-Pivot Tilting-Pad Bearing (Load-between-Pad Configuration),” ASME J. Tribol., 128, pp. 896906.

[2] Zeidan, F., and Herbage B., 1991, "Fluid Film Bearing Fundamentals and Failure Analysis," Proceedings of the $20^{\text {th }}$ Turbomachinery Symposium, pp. 161-186, June 17-19, Dallas, Texas.

[3] Lund, J.W., "Spring and Damping Coefficients for the Tilting-Pad Journal Bearing," ASLE Trans., 7 (3), pp. 342-352.

[4] Nicholas, J.C., Gunter, E.J., Allaire, P.E., 1979, "Stiffness and Damping Coefficients for the Five Pad Tilting Pad Bearing," ASLE Trans., 22 (2), pp. 112124.

[5] Parsell, J.K., Allaire, P.E., and Wilson, B.W., 1988, "The Eigenvalue Dependence of Reduced Tilting Pad Bearing Stiffness and Damping Coefficients," ASLE Trans., 31, pp. 411-419.

[6] White M. F., and Chan S. H., 1992, "The Subsynchronous Dynamic Behavior of Tilting-Pad Journal Bearings,” J. Tribol., 114 (1) pp. 167-174.

[7] Ha, H., and Yang, S., 1999, "Excitation Frequency Effects on the Stiffness and Damping Coefficients of a Five-Pad Tilting Pad Journal Bearing," ASME J. Tribol., 121, pp. 517-522.

[8] Wygant, K. D., 2001 "The Influence of Negative Preload and Nonsynchronous Excitation on the Performance of Tilting Pad Journal Bearings," Ph.D. Dissertation, Univ. of Virginia, Charlottesville, Virginia.

[9] Rodriguez, L., and Childs, D., 2006, “l Frequency-Dependency of Measured and Predicted Rotordynamic Coefficients for a Load-on-Pad, Flexible-Pivot Tilting-Pad Bearing,” ASME J. Tribol., 128 (2), pp. 388-395. 
[10] Hensley, E. J., and Childs, D., 2008, "Measurements versus Predictions for the Rotordynamic Characteristics of a Flexure Pivot-Pad Tilting Pad Bearing in an LBP Condition at Higher Unit Loads," Proceedings of the ASME Turbo Expo 2008, Paper GT2008-50069, June 9-13, Berlin, Germany.

[11] Carter, C., and Childs, D., 2008 "Measurements versus Predictions for the Rotordynamic Characteristics of a 5-pad, Rocker-Pivot, Tilting-Pad Bearing in the Load Between Pad Configuration, “ Proceedings of ASME Turbo Expo 2008, Paper GT2008-50069, June 9-13, Berlin, Germany.

[12] Delgado, A., Ertas, B., Drexel M., Naldi, L., and Vannini, G., 2010, “A

Component Level Test Rig for Dynamic Characterization of Oil Lubricated Bearing Using Different Input Excitations," Proceedings of ISROMAC Thirteenth International Symposium on Transport Phenomena and Dynamics of Rotating Machinery, April 4-9, Honolulu, Hawaii.

[13] Kulhanek, C., 2010, "Dynamic and Static Characteristics of a Rocker-Pivot, Tilting-Pad Bearing with 50\% and 60\% Offsets," M.S. thesis, Texas A\&M University, College Station, TX.

[14] Wilkes, J., and Childs, D., 2012, "Improving Tilting-Pad Journal Bearing Predictions: Part I - Model Development and Impact of Rotor Excited Versus Bearing Excited Impedance Coefficients," Proceedings of ASME Turbo Expo 2012, Paper GT2012-69804, June 11-15, Copenhagen, Denmark.

[15] Wilkes, J., 2011, "Measured and Predicted Rotor-pad Transfer Functions for a Rocker-pivot Tilting-pad Journal Bearing,” Doctoral Dissertation, Texas A\&M University, College Station, TX.

[16] Branagan, L., and Barrett, L., 1988, “Thermal Analysis of Fixed and Tilting Pad Journal bearings Including Cross-Field Viscosity Variations and Deformation," ROMAC Report No. 276, UVA Report No. UVA/643092/MAE88/376.

[17] Wilkes, J., and Childs, D., 2012, "Improving Tilting-Pad Journal Bearing Predictions: Part II - Comparison of Measured and Predicted Rotor-Pad Transfer Functions for a Rocker-Pivot Tilting-Pad Journal Bearing," 
Proceedings of ASME Turbo Expo 2012, Paper GT2012-69808, June 11-15, Copenhagen, Denmark.

[18] Wilkes, J., and Childs, D., 2012, “Tilting Pad Journal Bearings - A Discussion on Stability Calculation, Frequency Dependence, and Pad and Pivot Flexibility," Proceedings of ASME Turbo Expo 2012, Paper GT2012-69809, June 11-15, Copenhagen, Denmark.

[19] Kaul, A., 1999, "Design and Development of a Test Setup for the Experimental Determination of the Rotordynamic and Leakage Characteristics of Annular Bushing Oil Seals,” M.S. Thesis, Mechanical Engineering, Texas A\&M University.

[20] Glienicke, J., 1966, "Experimental Investigation of the Stiffness and Damping Coefficients of Turbine Bearings and Their Application to Instability Predictions," Proceedings of the International Mech. E., 181 (3B), pp. 116-129.

[21] Childs, D., and Hale, K., 1994, "A Test Apparatus and Facility to Identify the Rotordynamic Coefficients of High-Speed Hydrostatic Bearings," ASME Journal of Tribology, 116, pp. 337-344.

[22] Harris, J., and Childs, D., 2008, "Static Performance Characteristics and Rotordynamic Coefficients for a Four-Pad Ball-In-Socket Tilting Pad Journal Bearing," Proc. Of ASME Turbo Expo 2008, Paper GT2008-50063, June 9-13, Berlin, Germany.

[23] Deutschman, A., Michaels, W., and Wilson, C., 1975, Machine Design, Macmillan Publishing Co., Inc., New York, pp. 862-863.

[24] San Andrés, L. A., 1991, "Effect of Eccentricity on the Force Response of a Hybrid Bearing,” STLE Tribology Transactions, 34, 4, pp. 537- 544.

[25] Lund, J.W., "The Stability of an elastic Rotor in Journal Bearings with Flexible, Damped Supports," ASME Jour. of Applied Mechanics, pp. 911920 (1965). 


\section{APPENDIX A: MEASURED ECCENTRICITY}

Table 11: LOP Measured Attitude Angle and Eccentricity

\begin{tabular}{|c|c|c|c|c|c|c|c|c|c|c|c|c|c|c|c|c|c|c|}
\hline \multirow[b]{2}{*}{$\begin{array}{c}\text { Running } \\
\text { Speed [rpm] }\end{array}$} & \multirow{2}{*}{$\begin{array}{l}\text { Unit Loading } \\
\text { [kPa] }\end{array}$} & \multirow{2}{*}{$\begin{array}{l}\text { Unit Loading } \\
\text { [psi] }\end{array}$} & \multicolumn{6}{|c|}{ US Customary Units } & \multicolumn{6}{|c|}{ Metric Units } & \multirow[b]{2}{*}{$\varepsilon_{\mathrm{x}}[-]$} & \multirow[b]{2}{*}{$\varepsilon_{\mathrm{Y}}[-]$} & \multirow[b]{2}{*}{$\varepsilon_{0}[-]$} & \multirow[b]{2}{*}{$\varphi[\mathrm{deg}$} \\
\hline & & & $\begin{array}{c}\mathbf{X}_{\mathrm{NTS}} \\
{[\mathrm{mils}]}\end{array}$ & $\begin{array}{c}\mathbf{Y}_{\mathrm{NTS}} \\
{[\mathrm{mils}]}\end{array}$ & $\begin{array}{c}X_{T s} \\
{[m i l s]}\end{array}$ & $\begin{array}{c}Y_{\mathrm{TS}} \\
{[\mathrm{mils}]}\end{array}$ & $\begin{array}{l}\mathbf{e}_{\mathbf{x}, \text { ave }} \\
{[\mathrm{mils}]}\end{array}$ & $\begin{array}{l}\mathbf{e}_{\mathrm{Y}, \text { ave }} \\
\text { [mils] }\end{array}$ & $\begin{array}{l}\mathbf{X}_{\mathrm{NTS}} \\
{[\mu \mathrm{m}]}\end{array}$ & $\begin{array}{l}\mathbf{Y}_{\mathrm{NTS}} \\
{[\mu \mathrm{m}]}\end{array}$ & $\begin{array}{c}X_{\mathrm{Ts}} \\
{[\mu \mathrm{m}]}\end{array}$ & $\begin{array}{c}Y_{\mathrm{Ts}} \\
{[\mu \mathrm{m}]}\end{array}$ & $\begin{array}{l}e_{x, \text { ave }} \\
{[\mu \mathrm{m}]}\end{array}$ & $\begin{array}{l}e_{Y, \text { ave }} \\
{[\mu \mathrm{m}]}\end{array}$ & & & & \\
\hline \multirow{5}{*}{6800} & 0 & 0.0 & -0.64 & 0.20 & -0.36 & 0.05 & 0.50 & 0.12 & -16.20 & 5.08 & -9.02 & 1.18 & -12.61 & 3.13 & 0.00 & 0.00 & 0.00 & - \\
\hline & 726 & 105.3 & -0.55 & 1.05 & -0.23 & 0.67 & 0.39 & 0.86 & -14.07 & 26.68 & -5.96 & 16.97 & -10.02 & 21.83 & -0.03 & 0.23 & 0.23 & -7.90 \\
\hline & 1452 & 210.5 & -0.45 & 1.48 & -0.10 & 1.11 & 0.28 & 1.30 & -11.43 & 37.65 & -2.67 & 28.14 & -7.05 & 32.89 & -0.07 & 0.36 & 0.37 & -10.59 \\
\hline & 2177 & 315.8 & -0.32 & 1.85 & 0.05 & 1.45 & 0.13 & 1.65 & -8.02 & 46.87 & 1.33 & 36.80 & -3.34 & 41.84 & -0.11 & 0.47 & 0.48 & -13.47 \\
\hline & 2903 & 421.1 & -0.18 & 2.10 & 0.23 & 1.67 & -0.03 & 1.88 & -4.46 & 53.27 & 5.75 & 42.32 & 0.64 & 47.80 & -0.16 & 0.54 & 0.56 & -16.53 \\
\hline \multirow{5}{*}{9000} & 0 & 0.0 & -0.28 & 0.48 & 0.14 & 0.22 & 0.07 & 0.35 & -7.17 & 12.27 & 3.61 & 5.70 & -1.78 & 8.98 & 0.00 & 0.00 & 0.00 & - \\
\hline & 726 & 105.3 & -0.32 & 0.94 & 0.20 & 0.68 & 0.06 & 0.81 & -8.17 & 23.88 & 4.95 & 17.19 & -1.61 & 20.53 & 0.00 & 0.14 & 0.14 & -0.84 \\
\hline & 1452 & 210.5 & -0.28 & 1.27 & 0.26 & 1.02 & 0.01 & 1.15 & -7.18 & 32.31 & 6.64 & 25.90 & -0.27 & 29.10 & -0.02 & 0.24 & 0.24 & -4.28 \\
\hline & 2177 & 315.8 & -0.19 & 1.54 & 0.36 & 1.28 & -0.08 & 1.41 & -4.84 & 39.21 & 9.09 & 32.56 & 2.13 & 35.89 & -0.05 & 0.33 & 0.33 & -8.26 \\
\hline & 2903 & 421.1 & -0.09 & 1.78 & 0.47 & 1.51 & -0.19 & 1.65 & -2.20 & 45.31 & 11.88 & 38.47 & 4.84 & 41.89 & -0.08 & 0.40 & 0.41 & -11.37 \\
\hline \multirow{5}{*}{10800} & 0 & 0.0 & -0.42 & 0.33 & 0.10 & 0.16 & 0.16 & 0.24 & -10.67 & 8.34 & 2.58 & 3.95 & -4.04 & 6.14 & 0.00 & 0.00 & 0.00 & - \\
\hline & 726 & 105.3 & -0.42 & 0.74 & 0.18 & 0.56 & 0.12 & 0.65 & -10.55 & 18.73 & 4.47 & 14.18 & -3.04 & 16.46 & -0.01 & 0.12 & 0.13 & -5.57 \\
\hline & 1452 & 210.5 & -0.37 & 1.05 & 0.25 & 0.89 & 0.06 & 0.97 & -9.35 & 26.75 & 6.27 & 22.62 & -1.54 & 24.68 & -0.03 & 0.22 & 0.23 & -7.68 \\
\hline & 2177 & 315.8 & -0.30 & 1.32 & 0.33 & 1.14 & -0.02 & 1.23 & -7.62 & 33.55 & 8.47 & 28.98 & 0.43 & 31.27 & -0.05 & 0.30 & 0.31 & -10.08 \\
\hline & 2903 & 421.1 & -0.20 & 1.54 & 0.44 & 1.33 & -0.12 & 1.44 & -5.04 & 39.23 & 11.11 & 33.78 & 3.03 & 36.51 & -0.09 & 0.37 & 0.38 & -13.12 \\
\hline \multirow{5}{*}{13200} & 0 & 0.0 & -0.67 & 0.12 & -0.01 & -0.03 & 0.34 & 0.05 & -16.90 & 3.14 & -0.25 & -0.73 & -8.57 & 1.21 & 0.00 & 0.00 & 0.00 & - \\
\hline & 726 & 105.3 & -0.61 & 0.50 & 0.08 & 0.32 & 0.26 & 0.41 & -15.38 & 12.73 & 1.94 & 8.02 & -6.72 & 10.37 & -0.02 & 0.11 & 0.11 & -11.44 \\
\hline & 1452 & 210.5 & -0.52 & 0.82 & 0.17 & 0.64 & 0.17 & 0.73 & -13.20 & 20.76 & 4.32 & 16.19 & -4.44 & 18.48 & -0.05 & 0.21 & 0.22 & -13.45 \\
\hline & 2177 & 315.8 & -0.45 & 1.07 & 0.24 & 0.91 & 0.10 & 0.99 & -11.34 & 27.07 & 6.10 & 23.20 & -2.62 & 25.13 & -0.07 & 0.29 & 0.30 & -13.98 \\
\hline & 2903 & 421.1 & -0.37 & 1.27 & 0.33 & 1.10 & 0.02 & 1.18 & -9.43 & 32.19 & 8.42 & 27.83 & -0.51 & 30.01 & -0.10 & 0.35 & 0.36 & -15.65 \\
\hline
\end{tabular}


Table 12: LBP Measured Attitude Angle and Eccentricity

\begin{tabular}{|c|c|c|c|c|c|c|c|c|c|c|c|c|c|c|c|c|c|c|}
\hline \multirow{2}{*}{$\begin{array}{c}\text { Running } \\
\text { Speed [rpm] }\end{array}$} & \multirow{2}{*}{$\begin{array}{l}\text { Unit Loading } \\
\text { [kPa] }\end{array}$} & \multirow{2}{*}{$\begin{array}{l}\text { Unit Loading } \\
\text { [psi] }\end{array}$} & \multicolumn{6}{|c|}{ US Customary Units } & \multicolumn{6}{|c|}{ Metric Units } & \multirow[b]{2}{*}{$\varepsilon_{\mathrm{x}}[-]$} & \multirow[b]{2}{*}{$\varepsilon_{\mathrm{Y}}[-]$} & \multirow[b]{2}{*}{$\varepsilon_{0}[-]$} & \multirow[b]{2}{*}{$\varphi[$ deg] } \\
\hline & & & $\begin{array}{c}\mathbf{X}_{\mathrm{NTs}} \\
{[\mathrm{mils}]}\end{array}$ & $\begin{array}{c}\mathrm{Y}_{\mathrm{NTS}} \\
{[\mathrm{mils}]}\end{array}$ & $\begin{array}{c}\mathbf{X}_{\mathrm{TS}} \\
{[\mathrm{mils}]}\end{array}$ & $\begin{array}{c}\mathbf{Y}_{\mathrm{TS}} \\
{[\mathrm{mils}]}\end{array}$ & $\begin{array}{l}\mathbf{e}_{\mathbf{x}, \text { ave }} \\
\text { [mils] }\end{array}$ & $\begin{array}{c}\mathbf{e}_{\mathrm{Y}, \text { ave }} \\
\text { [mils] }\end{array}$ & $\begin{array}{l}\mathbf{X}_{\mathrm{NTS}} \\
{[\mu \mathrm{m}]}\end{array}$ & $\begin{array}{l}\mathbf{Y}_{\mathrm{NTS}} \\
{[\mu \mathrm{m}]}\end{array}$ & $\begin{array}{c}X_{\mathrm{TS}} \\
{[\mu \mathrm{m}]}\end{array}$ & $\begin{array}{c}Y_{\mathrm{Ts}} \\
{[\mu \mathrm{m}]}\end{array}$ & $\begin{array}{l}e_{\mathrm{x}, \text { ave }} \\
{[\mu \mathrm{m}]}\end{array}$ & $\begin{array}{l}e_{\mathrm{Y}, \text { ave }} \\
{[\mu \mathrm{m}]}\end{array}$ & & & & \\
\hline \multirow{5}{*}{6800} & 0 & 0.0 & 0.50 & 0.49 & 0.79 & 0.60 & -0.65 & 0.54 & 12.78 & 12.38 & 20.16 & 15.20 & 16.47 & 13.79 & 0.00 & 0.00 & 0.00 & - \\
\hline & 726 & 105.3 & 0.37 & 1.37 & 0.65 & 1.36 & -0.51 & 1.36 & 9.46 & 34.85 & 16.54 & 34.47 & 13.00 & 34.66 & 0.04 & 0.25 & 0.26 & 9.45 \\
\hline & 1452 & 210.5 & 0.36 & 1.82 & 0.64 & 1.84 & -0.50 & 1.83 & 9.26 & 46.11 & 16.25 & 46.70 & 12.76 & 46.40 & 0.05 & 0.40 & 0.40 & 6.50 \\
\hline & 2177 & 315.8 & 0.41 & 2.16 & 0.66 & 2.21 & -0.53 & 2.18 & 10.47 & 54.76 & 16.67 & 56.16 & 13.57 & 55.46 & 0.04 & 0.50 & 0.51 & 3.99 \\
\hline & 2903 & 421.1 & 0.51 & 2.45 & 0.71 & 2.51 & -0.61 & 2.48 & 12.84 & 62.13 & 18.01 & 63.88 & 15.42 & 63.01 & 0.01 & 0.60 & 0.60 & 1.22 \\
\hline \multirow{5}{*}{9000} & 0 & 0.0 & 0.44 & 0.53 & 0.67 & 0.58 & -0.56 & 0.55 & 11.17 & 13.45 & 17.03 & 14.67 & 14.10 & 14.06 & 0.00 & 0.00 & 0.00 & - \\
\hline & 726 & 105.3 & 0.35 & 1.19 & 0.61 & 1.14 & -0.48 & 1.16 & 8.98 & 30.21 & 15.47 & 28.97 & 12.23 & 29.59 & 0.02 & 0.19 & 0.19 & 6.87 \\
\hline & 1452 & 210.5 & 0.38 & 1.60 & 0.61 & 1.57 & -0.49 & 1.59 & 9.60 & 40.74 & 15.53 & 39.97 & 12.56 & 40.35 & 0.02 & 0.32 & 0.32 & 3.34 \\
\hline & 2177 & 315.8 & 0.41 & 1.89 & 0.63 & 1.89 & -0.52 & 1.89 & 10.30 & 47.94 & 16.10 & 48.02 & 13.20 & 47.98 & 0.01 & 0.41 & 0.41 & 1.52 \\
\hline & 2903 & 421.1 & 0.47 & 2.12 & 0.69 & 2.12 & -0.58 & 2.12 & 11.95 & 53.81 & 17.53 & 53.76 & 14.74 & 53.78 & -0.01 & 0.48 & 0.48 & -0.92 \\
\hline \multirow{5}{*}{10800} & 0 & 0.0 & 0.46 & 0.57 & 0.56 & 0.53 & -0.51 & 0.55 & 11.75 & 14.39 & 14.18 & 13.41 & 12.96 & 13.90 & 0.00 & 0.00 & 0.00 & - \\
\hline & 726 & 105.3 & 0.36 & 1.09 & 0.57 & 0.98 & -0.46 & 1.04 & 9.14 & 27.80 & 14.47 & 24.78 & 11.81 & 26.29 & 0.01 & 0.15 & 0.15 & 5.33 \\
\hline & 1452 & 210.5 & 0.35 & 1.44 & 0.55 & 1.36 & -0.45 & 1.40 & 8.85 & 36.48 & 13.99 & 34.42 & 11.42 & 35.45 & 0.02 & 0.26 & 0.26 & 4.09 \\
\hline & 2177 & 315.8 & 0.37 & 1.69 & 0.57 & 1.64 & -0.47 & 1.66 & 9.47 & 42.82 & 14.50 & 41.68 & 11.98 & 42.25 & 0.01 & 0.34 & 0.34 & 1.98 \\
\hline & 2903 & 421.1 & 0.43 & 1.91 & 0.61 & 1.89 & -0.52 & 1.90 & 10.82 & 48.60 & 15.47 & 48.10 & 13.14 & 48.35 & 0.00 & 0.42 & 0.42 & -0.30 \\
\hline \multirow{5}{*}{13200} & 0 & 0.0 & 0.38 & 0.63 & 0.61 & 0.39 & -0.50 & 0.51 & 9.73 & 16.01 & 15.48 & 9.88 & 12.60 & 12.94 & 0.00 & 0.00 & 0.00 & - \\
\hline & 726 & 105.3 & 0.35 & 1.10 & 0.64 & 0.78 & -0.49 & 0.94 & 8.84 & 28.01 & 16.28 & 19.93 & 12.56 & 23.97 & 0.00 & 0.13 & 0.13 & 0.22 \\
\hline & 1452 & 210.5 & 0.34 & 1.48 & 0.65 & 1.10 & -0.50 & 1.29 & 8.66 & 37.49 & 16.63 & 27.86 & 12.64 & 32.68 & 0.00 & 0.24 & 0.24 & -0.12 \\
\hline & 2177 & 315.8 & 0.27 & 1.40 & 0.31 & 0.95 & -0.29 & 1.18 & 6.80 & 35.68 & 7.99 & 24.25 & 7.39 & 29.97 & 0.06 & 0.21 & 0.22 & 17.01 \\
\hline & 2903 & 421.1 & 0.31 & 1.64 & 0.38 & 1.17 & -0.35 & 1.41 & 7.76 & 41.78 & 9.77 & 29.81 & 8.77 & 35.79 & 0.05 & 0.28 & 0.28 & 9.53 \\
\hline
\end{tabular}




\section{APPENDIX B: PAD METAL TEMPERATURES}

Table 13: LOP Pad Metal Temperatures

\begin{tabular}{|c|c|c|c|c|c|c|c|c|c|c|c|c|c|c|c|c|c|c|c|c|c|c|c|c|c|}
\hline \multirow{3}{*}{$\begin{array}{c}\text { Running } \\
\text { Speed [rpm] }\end{array}$} & \multirow{3}{*}{$\begin{array}{c}\text { Unit } \\
\text { Loading } \\
{[\mathrm{kPa}]}\end{array}$} & \multirow{3}{*}{$\begin{array}{c}\text { Unit } \\
\text { Loading } \\
\text { [psi] }\end{array}$} & \multirow{3}{*}{$\mathrm{T}_{\mathrm{in}}\left[{ }^{\circ} \mathrm{C}\right]$} & \multirow{3}{*}{$\mathrm{T}_{\text {out }}\left[{ }^{\circ} \mathrm{C}\right]$} & \multicolumn{21}{|c|}{ Pad Temperatures $\left({ }^{\circ} \mathrm{C}\right)$} \\
\hline & & & & & \multicolumn{11}{|c|}{$\operatorname{Pad} 3\left[^{\circ}\right]$} & \multicolumn{6}{|c|}{ Pad $4\left[^{\circ}\right]$} & \multicolumn{2}{|c|}{$\operatorname{Pad} 1\left[^{\circ}\right]$} & \multicolumn{2}{|c|}{$\operatorname{Pad} 2\left[^{\circ}\right]$} \\
\hline & & & & & 0 & 1 & 2 & 3 & 4 & 5 & 6 & 7 & 8 & 9 & 10 & $\mathrm{~T} 11$ & $\mathrm{~T} 12$ & $\mathrm{~T} 13$ & $\mathrm{~T} 14$ & $\mathrm{~T} 15$ & $\mathrm{~T} 16$ & $\mathrm{~T} 17$ & $\mathrm{~T} 18$ & T19 & $\mathrm{T} 20$ \\
\hline \multirow{5}{*}{6800} & 0 & 0.0 & 43.9 & 47.7 & 49.1 & 51.4 & 54.3 & 56.9 & 61.2 & 61.9 & 54.0 & 48.0 & 50.2 & 54.9 & 54.1 & 45.9 & 47.8 & 49.8 & 51.4 & 57.0 & 49.1 & 48.9 & 62.9 & 46.3 & 54.8 \\
\hline & 726 & 105.3 & 43.8 & 48.3 & 54.6 & 57.7 & 61.7 & 65.2 & 70.3 & 69.3 & 57.7 & 51.4 & 54.3 & 60.2 & 58.5 & 45.9 & 47.6 & 49.5 & 50.9 & 56.4 & 48.9 & 45.7 & 53.6 & 47.0 & 56.2 \\
\hline & 1452 & 210.5 & 43.7 & 49.0 & 58.6 & 62.4 & 67.2 & 71.4 & 77.4 & 75.0 & 60.6 & 53.9 & 57.4 & 64.5 & 61.9 & 46.1 & 47.9 & 49.8 & 51.2 & 56.9 & 49.3 & 44.9 & 50.0 & 48.0 & 57.5 \\
\hline & 2177 & 315.8 & 43.8 & 49.4 & 61.8 & 65.8 & 71.0 & 75.6 & 82.1 & 77.9 & 62.7 & 55.7 & 59.6 & 67.1 & 63.6 & 46.3 & 48.2 & 50.2 & 51.8 & 57.7 & 50.1 & 44.6 & 48.4 & 49.1 & 58.4 \\
\hline & 2903 & 421.1 & 43.8 & 49.7 & 64.2 & 68.0 & 73.4 & 77.6 & 82.8 & 77.4 & 69.6 & 57.8 & 61.6 & 68.2 & 63.0 & 46.3 & 48.5 & 50.8 & 52.6 & 59.1 & 51.3 & 48.7 & 52.3 & 48.0 & 53.8 \\
\hline \multirow{5}{*}{9000} & 0 & 0.0 & 43.5 & 52.4 & 52.8 & 56.3 & 60.9 & 65.1 & 72.3 & 72.4 & 48.7 & 50.6 & 54.0 & 61.4 & 59.2 & 47.1 & 50.2 & 53.6 & 56.2 & 65.2 & 53.1 & 50.4 & 67.5 & 47.0 & 55.1 \\
\hline & 726 & 105.3 & 43.5 & 52.9 & 57.9 & 62.6 & 68.5 & 73.6 & 82.3 & 80.2 & 62.5 & 54.0 & 58.3 & 67.1 & 63.8 & 47.3 & 50.0 & 53.1 & 55.3 & 64.1 & 52.6 & 47.8 & 57.8 & 47.2 & 57.3 \\
\hline & 1452 & 210.5 & 43.5 & 53.0 & 62.0 & 67.6 & 74.2 & 79.8 & 89.6 & 85.1 & 65.3 & 56.6 & 61.4 & 71.2 & 67.0 & 47.5 & 50.3 & 53.2 & 55.4 & 64.1 & 52.9 & 46.8 & 53.4 & 47.9 & 59.1 \\
\hline & 2177 & 315.8 & 43.5 & 53.3 & 65.2 & 71.4 & 78.5 & 84.6 & 95.2 & 87.7 & 67.6 & 58.5 & 63.6 & 74.0 & 68.9 & 48.1 & 50.9 & 54.0 & 56.3 & 65.6 & 54.2 & 46.5 & 51.7 & 49.4 & 60.9 \\
\hline & 2903 & 421.1 & 43.6 & 52.8 & 67.9 & 74.7 & 82.2 & 88.9 & 99.8 & 88.6 & 69.4 & 60.1 & 65.5 & 76.1 & 69.9 & 48.3 & 51.3 & 54.8 & 57.2 & 67.3 & 55.8 & 46.0 & 50.4 & 50.5 & 62.4 \\
\hline \multirow{5}{*}{10800} & 0 & $\begin{array}{l}0.0 \\
\end{array}$ & 43.9 & 54.7 & 50.6 & 54.1 & 57.6 & 61.0 & 67.5 & 70.0 & 61.8 & 50.4 & 53.3 & 60.7 & 60.2 & 57.2 & 63.5 & 69.9 & 73.9 & 84.6 & 64.0 & 52.7 & 71.0 & 54.9 & 72.3 \\
\hline & 726 & 105.3 & 43.9 & 54.8 & 57.0 & 62.8 & 69.7 & 75.9 & 86.7 & 85.6 & 64.1 & 54.1 & 59.0 & 70.0 & 67.6 & 48.8 & 52.0 & 55.4 & 57.9 & 68.6 & 55.3 & 49.3 & 61.2 & 48.4 & 60.8 \\
\hline & 1452 & 210.5 & 43.8 & 55.0 & 61.0 & 68.3 & 76.1 & 83.0 & 93.9 & 91.2 & 67.2 & 56.8 & 62.3 & 74.5 & 71.3 & 49.1 & 52.3 & 55.7 & 58.1 & 68.7 & 56.0 & 48.1 & 56.3 & 49.0 & 62.5 \\
\hline & 2177 & 315.8 & 43.9 & 55.0 & 64.5 & 72.7 & 81.1 & 88.5 & 100.6 & 93.8 & 69.8 & 58.9 & 64.8 & 77.8 & 73.6 & 49.4 & 52.8 & 56.2 & 58.8 & 69.6 & 57.1 & 47.4 & 53.7 & 50.2 & 64.0 \\
\hline & 2903 & 421.1 & 43.9 & 54.9 & 67.7 & 76.9 & 85.9 & 94.0 & 106.1 & 95.1 & 72.0 & 60.9 & 67.2 & 80.5 & 75.0 & 49.6 & 53.1 & 56.8 & 59.6 & 71.4 & 58.4 & 46.9 & 52.2 & 51.3 & 65.8 \\
\hline \multirow{5}{*}{13200} & 0 & 0.0 & 44.7 & 57.8 & 55.3 & 58.8 & 63.4 & 68.1 & 76.7 & 80.0 & 62.6 & 52.2 & 56.1 & 65.6 & 64.7 & 51.6 & 55.6 & 59.4 & 62.2 & 74.1 & 60.3 & 54.6 & 74.6 & 51.4 & 63.8 \\
\hline & 726 & 105.3 & 44.7 & 57.8 & 57.9 & 62.5 & 68.5 & 74.5 & 85.1 & 87.8 & 65.3 & 54.3 & 59.0 & 70.4 & 68.9 & 51.2 & 55.0 & 58.7 & 61.5 & 74.0 & 60.1 & 52.1 & 65.9 & 51.4 & 65.1 \\
\hline & 1452 & 210.5 & 44.5 & 57.8 & 60.6 & 66.8 & 74.3 & 81.6 & 94.4 & 95.0 & 68.2 & 56.4 & 61.9 & 75.4 & 72.7 & 51.0 & 54.9 & 58.7 & 61.5 & 74.3 & 60.3 & 50.3 & 60.4 & 51.8 & 66.4 \\
\hline & 2177 & 315.8 & 44.4 & 58.1 & 63.9 & 71.5 & 80.2 & 88.8 & 102.3 & 99.3 & 71.1 & 58.6 & 64.9 & 79.8 & 76.1 & 51.3 & 55.3 & 59.3 & 62.2 & 75.7 & 61.4 & 49.7 & 57.7 & 52.6 & 68.3 \\
\hline & 2903 & 421.1 & 44.4 & 58.2 & 67.6 & 77.0 & 87.0 & 96.8 & 111.0 & 102.0 & 74.2 & 61.0 & 68.1 & 84.0 & 78.8 & 51.6 & 55.7 & 59.8 & 62.9 & 77.3 & 62.3 & 49.1 & 55.8 & 53.3 & 70.5 \\
\hline
\end{tabular}


Table 14: LBP Pad Metal Temperatures

\begin{tabular}{|c|c|c|c|c|c|c|c|c|c|c|c|c|c|c|c|c|c|c|c|c|c|c|c|c|c|}
\hline \multirow{3}{*}{$\begin{array}{l}\text { Running } \\
\text { Speed [rpm] }\end{array}$} & \multirow{3}{*}{\begin{tabular}{|c} 
Unit \\
Loading \\
[kPa]
\end{tabular}} & \multirow{3}{*}{\begin{tabular}{|c} 
Unit \\
Loading \\
[psi]
\end{tabular}} & \multirow{3}{*}{$\mathrm{T}_{\mathrm{in}}\left[{ }^{\circ} \mathrm{C}\right]$} & \multirow{3}{*}{$\mathrm{T}_{\text {out }}\left[{ }^{[} \mathrm{C}\right]$} & \multicolumn{21}{|c|}{ Pad Temperatures $\left({ }^{\circ} \mathrm{C}\right)$} \\
\hline & & & & & & & & & & Pad & & & & & & & & & & & & & & & \\
\hline & & & & & 0 & 1 & 2 & 3 & 4 & 5 & 6 & 7 & 8 & 9 & 10 & $\mathrm{~T} 11$ & $\mathrm{~T} 12$ & $\mathrm{~T} 13$ & $\mathrm{~T} 14$ & $\mathrm{~T} 15$ & $\mathrm{~T} 16$ & T17 & $\mathrm{T} 18$ & T19 & $\mathrm{T} 20$ \\
\hline \multirow{5}{*}{6800} & 0 & 0.0 & 130.7 & 49.2 & 48.2 & 50.4 & 52.7 & 54.9 & 58.5 & 59.9 & 56.4 & 48.0 & 49.8 & 54.0 & 53.1 & 54.5 & 58.4 & 62.4 & 64.9 & 70.3 & 56.8 & 48.9 & 61.0 & 51.1 & 60.3 \\
\hline & 726 & 105.3 & 130.7 & 50.7 & 54.1 & 57.4 & 61.2 & 64.3 & 68.5 & 68.0 & 61.7 & 51.9 & 54.7 & 60.1 & 57.7 & 57.1 & 62.2 & 67.4 & 70.6 & 76.0 & 60.3 & 48.4 & 54.8 & 49.4 & 56.8 \\
\hline & 1452 & 210.5 & 130.7 & 51.7 & 58.8 & 62.2 & 66.6 & 70.1 & 74.9 & 72.8 & 65.2 & 54.5 & 57.7 & 63.7 & 60.2 & 58.0 & 64.2 & 70.4 & 74.2 & 80.3 & 62.9 & 48.8 & 53.6 & 48.8 & 55.5 \\
\hline & 2177 & 315.8 & 130.7 & 52.6 & 62.0 & 65.5 & 70.4 & 74.2 & 79.4 & 75.7 & 67.6 & 56.4 & 59.9 & 66.2 & 61.8 & 58.4 & 65.7 & 72.7 & 77.0 & 82.8 & 64.8 & 48.8 & 52.9 & 48.4 & 54.6 \\
\hline & 2903 & 421.1 & 130.7 & 53.4 & 64.2 & 68.0 & 73.4 & 77.6 & 82.8 & 77.4 & 69.6 & 57.8 & 61.6 & 68.2 & 63.0 & 58.9 & 67.2 & 74.8 & 79.5 & 84.2 & 66.3 & 48.7 & 52.3 & 48.0 & 53.8 \\
\hline \multirow{5}{*}{9000} & 0 & 0.0 & 130.7 & 54.8 & 49.7 & 52.6 & 55.6 & 58.4 & 63.7 & 65.6 & 59.4 & 49.5 & 51.9 & 58.0 & 57.2 & 55.6 & 61.1 & 66.7 & 70.2 & 78.4 & 60.6 & 51.0 & 66.6 & 53.2 & 67.1 \\
\hline & 726 & 105.3 & 130.7 & 56.2 & 54.1 & 58.6 & 63.6 & 67.9 & 74.2 & 74.3 & 64.6 & 52.9 & 56.3 & 64.2 & 62.1 & 57.9 & 65.0 & 71.9 & 76.2 & 84.9 & 64.6 & 50.7 & 60.0 & 51.8 & 63.0 \\
\hline & 1452 & 210.5 & 130.7 & 57.1 & 58.7 & 63.8 & 69.8 & 74.8 & 81.6 & 79.8 & 68.4 & 55.5 & 59.6 & 68.2 & 64.8 & 58.8 & 67.0 & 75.1 & 80.2 & 89.6 & 68.4 & 50.6 & 57.7 & 50.8 & 60.3 \\
\hline & 2177 & 315.8 & 130.7 & 57.7 & 62.5 & 67.8 & 74.3 & 79.6 & 86.9 & 83.1 & 71.2 & 57.5 & 61.9 & 70.9 & 66.0 & 59.4 & 68.8 & 77.9 & 83.6 & 92.7 & 71.6 & 50.1 & 56.4 & 50.2 & 58.6 \\
\hline & 2903 & 421.1 & 130.7 & 59.1 & 65.6 & 71.0 & 78.1 & 84.0 & 92.1 & 86.1 & 73.7 & 59.2 & 64.1 & 73.8 & 68.5 & 59.5 & 70.1 & 80.2 & 86.6 & 95.0 & 74.0 & 50.1 & 56.0 & 50.0 & 57.7 \\
\hline \multirow{5}{*}{10800} & 0 & 0.0 & 130.7 & 58.7 & 50.6 & 54.1 & 57.6 & 61.0 & 67.5 & 70.0 & 61.8 & 50.4 & 53.3 & 60.7 & 60.2 & 57.2 & 63.5 & 69.9 & 73.9 & 84.6 & 64.0 & 52.7 & 71.0 & 54.9 & 72.3 \\
\hline & 726 & 105.3 & 130.7 & 59.7 & 53.7 & 59.0 & 64.5 & 69.5 & 77.4 & 78.3 & 66.4 & 53.1 & 57.0 & 66.5 & 65.0 & 59.2 & 67.0 & 74.7 & 79.7 & 91.1 & 69.0 & 51.7 & 63.9 & 53.4 & 67.2 \\
\hline & 1452 & 210.5 & 130.7 & 60.1 & 57.2 & 63.6 & 70.4 & 76.4 & 85.0 & 84.3 & 70.2 & 55.6 & 60.1 & 70.9 & 68.6 & 60.3 & 69.4 & 78.3 & 84.0 & 95.8 & 72.6 & 51.6 & 61.0 & 52.4 & 64.2 \\
\hline & 2177 & 315.8 & 130.7 & 60.5 & 60.6 & 67.7 & 75.3 & 82.0 & 91.6 & 88.7 & 73.3 & 57.6 & 62.7 & 74.5 & 71.4 & 60.9 & 71.1 & 81.3 & 87.8 & 99.7 & 75.9 & 51.7 & 60.0 & 52.1 & 62.4 \\
\hline & 2903 & 421.1 & 130.7 & 61.0 & 64.2 & 71.7 & 80.1 & 87.4 & 97.8 & 91.8 & 76.3 & 59.7 & 65.3 & 77.7 & 73.4 & 61.7 & 73.3 & 84.6 & 91.9 & 102.1 & 78.7 & 51.6 & 59.0 & 51.7 & 61.1 \\
\hline \multirow{5}{*}{13200} & 0 & 0.0 & 130.7 & 61.7 & 52.9 & 55.9 & 59.5 & 63.1 & 69.6 & 73.7 & 64.7 & 51.8 & 55.0 & 62.9 & 62.4 & 60.8 & 67.7 & 74.1 & 78.8 & 92.8 & 70.7 & 54.8 & 73.7 & 56.9 & 72.1 \\
\hline & 726 & 105.3 & 130.7 & 62.3 & 55.7 & 59.3 & 64.3 & 68.9 & 76.7 & 80.6 & 68.3 & 53.7 & 57.5 & 67.0 & 65.8 & 62.0 & 70.5 & 78.6 & 84.4 & 99.8 & 75.0 & 54.0 & 68.2 & 56.2 & 68.7 \\
\hline & 1452 & 210.5 & 130.7 & 62.7 & 58.4 & 62.8 & 68.7 & 74.4 & 83.5 & 87.1 & 71.7 & 55.6 & 60.0 & 71.0 & 69.2 & 62.8 & 72.9 & 82.7 & 89.6 & 105.0 & 78.2 & 53.6 & 65.8 & 56.2 & 66.8 \\
\hline & 2177 & 315.8 & 130.7 & 60.9 & 56.0 & 61.8 & 68.4 & 74.7 & 85.2 & 88.2 & 69.5 & 54.3 & 59.0 & 70.9 & 69.0 & 58.6 & 66.8 & 75.9 & 82.3 & 99.7 & 74.0 & 51.8 & 63.4 & 54.8 & 68.3 \\
\hline & 2903 & 421.1 & 130.7 & 61.8 & 58.5 & 64.7 & 72.0 & 79.0 & 90.5 & 92.8 & 72.4 & 56.0 & 61.1 & 74.2 & 71.8 & 59.7 & 68.8 & 79.0 & 86.4 & 104.3 & 77.5 & 52.0 & 62.9 & 55.2 & 67.3 \\
\hline
\end{tabular}




\section{APPENDIX C: THERMAL PAD DEFLECTION}

\begin{tabular}{|c|c|c|c|c|c|c|}
\hline Orientation & Speed (rpm) & Pad Number & Machined Pad Radius (mm) & Preload & Thermal Change in Pad Radius (mm) & Resulting Preload \\
\hline \multirow{8}{*}{ LOP } & \multirow{4}{*}{6800} & 3 (Loaded Pad) & 0.112 & 0.495 & 0.026 & 0.589 \\
\hline & & 4 & 0.112 & 0.381 & 0.016 & 0.457 \\
\hline & & 1 & 0.112 & 0.495 & 0.016 & 0.559 \\
\hline & & 2 & 0.112 & 0.381 & 0.016 & 0.460 \\
\hline & \multirow{4}{*}{13200} & 3 (Loaded Pad) & 0.112 & 0.516 & 0.034 & 0.628 \\
\hline & & 4 & 0.112 & 0.403 & 0.021 & 0.497 \\
\hline & & 1 & 0.112 & 0.516 & 0.020 & 0.588 \\
\hline & & 2 & 0.112 & 0.403 & 0.020 & 0.492 \\
\hline \multirow{8}{*}{ LBP } & \multirow{4}{*}{6800} & 3 & 0.112 & 0.389 & 0.025 & 0.500 \\
\hline & & 4 & 0.112 & 0.417 & 0.027 & 0.530 \\
\hline & & 1 & 0.112 & 0.389 & 0.016 & 0.464 \\
\hline & & 2 & 0.112 & 0.417 & 0.016 & 0.489 \\
\hline & \multirow{4}{*}{13200} & 3 & 0.112 & 0.432 & 0.030 & 0.552 \\
\hline & & 4 & 0.112 & 0.438 & 0.036 & 0.574 \\
\hline & & 1 & 0.112 & 0.432 & 0.020 & 0.518 \\
\hline & & 2 & 0.112 & 0.438 & 0.020 & 0.523 \\
\hline
\end{tabular}




\section{APPENDIX D: ROTORDYNAMIC COEFFICIENTS}

\section{Table 15: LOP Experimental Rotordynamic Coefficients}

\begin{tabular}{|c|c|c|c|c|c|c|c|c|c|c|c|c|c|c|c|c|c|c|c|c|c|c|c|c|c|c|}
\hline \multirow{3}{*}{$\begin{array}{c}\text { Running } \\
\text { Speed [rpm] }\end{array}$} & \multirow{3}{*}{$\begin{array}{c}\text { Unit Loading } \\
\text { [kPa] }\end{array}$} & \multirow{3}{*}{$\begin{array}{c}\text { Unit Loading } \\
\text { [psi] }\end{array}$} & \multicolumn{12}{|c|}{ Rotordynamic Coefficients } & \multicolumn{12}{|c|}{ Uncertainties } \\
\hline & & & \multicolumn{4}{|c|}{ Stiffness [MN/m] } & \multicolumn{4}{|c|}{ Damping [kN-s/m] } & \multicolumn{4}{|c|}{ Added Mass [kg] } & \multicolumn{4}{|c|}{ Stiffness [MN/m] } & \multicolumn{4}{|c|}{ Damping [kN-s/m] } & \multicolumn{4}{|c|}{ Added Mass [kg] } \\
\hline & & & $\mathrm{Kxx}$ & Kxy & Kyx & Kyy & $c x x$ & Cxy & Cyx & Cyy & Mxx & Mxy & Myx & Myy & $\mathrm{Kxx}$ & Kxy & Kyx & Kyy & $C x x$ & $c_{x y}$ & Cyx & $c_{y y}$ & Mxx & Mxy & Myx & Myy \\
\hline \multirow{5}{*}{6800} & 0 & 0.0 & 97.0 & -12.6 & -25.1 & 192.3 & 225.8 & -6.5 & -11.3 & 300.7 & -24.2 & -35.5 & -37.7 & -29.1 & 44.1 & 29.5 & 59.2 & 49.6 & 14.9 & 17.8 & 25.0 & 35.2 & 39.9 & 26.7 & 53.5 & 44.9 \\
\hline & 726 & 105.3 & 120.9 & -13.4 & -3.1 & 267.3 & 222.8 & 10.9 & -20.8 & 288.4 & -3.4 & -37.3 & 6.4 & -14.2 & 11.3 & 6.9 & 10.9 & 42.0 & 7.6 & 4.7 & 6.3 & 13.5 & 10.2 & 6.3 & 9.9 & 38.0 \\
\hline & 1452 & 10.5 & 136.4 & -11.9 & -1.2 & 410.8 & 233.4 & 15.1 & -17.3 & 286.0 & -7.9 & -36.4 & 7.7 & -10.0 & 12.3 & 3.6 & 20.5 & 34.5 & 8.7 & & 8.7 & 23.8 & 11.1 & 3.2 & 18.5 & 31.2 \\
\hline & 2177 & 315.8 & 155.3 & -6.3 & -8.1 & 562.5 & 247.5 & 14.0 & -19.3 & 279.5 & -14.5 & -33.1 & 4.3 & -5.2 & 10.1 & 5.5 & 5.0 & 30.3 & 7.5 & 3.8 & 5.0 & 26.6 & 9.1 & 5.0 & 4.5 & 27.4 \\
\hline & 2903 & 1.1 & 180.1 & -3.5 & -10.5 & 687.7 & 264.2 & 13.2 & -19.8 & 265.6 & -22.3 & -32.0 & 4.4 & -3.2 & 10.8 & 6.0 & 3. & 31.0 & 8.3 & & & 28.9 & 9.7 & 5.5 & 3.4 & 28.0 \\
\hline \multirow{5}{*}{9000} & 0 & & 144.9 & -22.4 & -12.5 & 264.3 & 227.0 & 8.3 & -15.4 & 271.2 & -4.3 & -35.1 & -11.6 & -65.1 & 16.7 & 8.0 & 8. & 36. & 10.4 & 7 & 6.1 & 24.6 & 15.1 & 7.3 & 7.5 & 33.2 \\
\hline & 726 & 105.3 & 155.5 & -23.5 & -9.0 & 363.6 & 231.2 & 16.8 & -20.4 & 272.2 & -9.3 & -39.4 & -0.6 & -13.6 & 15.9 & 5.5 & 9. & 37.8 & 8.4 & 4. & 3.3 & 22.1 & 14.4 & 5.0 & 8.4 & 34.2 \\
\hline & 1452 & & 175.2 & $\begin{array}{l}-21.1 \\
\end{array}$ & -11.5 & 490.3 & 235.5 & $\begin{array}{l}10.0 \\
16.4\end{array}$ & -21.2 & 257.2 & -12.2 & $\begin{array}{r}-39.4 \\
\end{array}$ & -0.8 & -4.3 & 14.7 & 5.4 & 7. & 29. & 7.5 & 5 & 2.8 & 28.3 & 13.3 & 4.9 & 6.7 & 26.8 \\
\hline & 2177 & 315.8 & 201.4 & -16.3 & -14.7 & 605.0 & 242.8 & 14.3 & -20.1 & 248.8 & -15.0 & -35.4 & -0.7 & -0.9 & 13.6 & 6.3 & 5.6 & 26. & 7.4 & 5. & 2.6 & 28.4 & 12.3 & 5.7 & 5.0 & 23.9 \\
\hline & 2903 & & 228.7 & -12.7 & -17.4 & 726.1 & 255.8 & 12. & -20.4 & 234.9 & -20.7 & -35.1 & 0.3 & 7.7 & 13.3 & 7.4 & 4. & 26 & 7.7 & & & & & & & 23.8 \\
\hline \multirow{5}{*}{10800} & $x^{-1}$ & & 173.8 & -22.2 & -22.3 & 297.1 & 227.1 & -0.7 & -10.2 & 264.0 & -16.6 & -26.2 & -24.9 & -66.2 & 16.2 & 5.6 & 7.4 & 30. & 10.9 & 7.2 & 7.6 & 22.1 & 14.6 & 5.1 & 6.7 & 27.2 \\
\hline & 726 & 105.3 & 185.2 & -23.0 & -15.6 & 383.7 & 228.5 & 9.9 & -18.1 & 253.8 & -17.0 & -28.6 & -8.5 & -12.9 & 17.9 & 6.7 & 5.4 & 41. & 10.7 & 4.8 & 3.2 & 21.8 & 16.2 & 6.0 & 4.9 & 37.9 \\
\hline & 1452 & & 206.9 & -25.3 & -17.3 & 496.0 & 230.6 & 15.5 & -19.8 & 239.6 & -17.7 & -32.9 & $\begin{array}{l}-7.6 \\
\end{array}$ & -3.9 & 15.9 & 5.8 & 5.0 & 29. & 9.7 & 3.9 & 2.7 & 23.3 & 14.4 & 5.2 & 4.5 & 26.4 \\
\hline & 2177 & & 231.8 & -23.9 & -19.6 & 605.7 & 236.1 & 16.8 & -19.6 & 235.2 & -18.7 & -35.8 & -6.4 & 1.7 & 14.2 & 5.9 & 5.1 & 25.9 & 9.1 & 4.4 & 2.8 & 27.6 & 12.9 & 5.3 & 4.7 & 23.5 \\
\hline & & & 259.6 & -20.8 & -20.9 & 728.6 & 247.5 & 16.2 & -21.7 & 218.9 & -23.5 & -38.7 & -4.2 & 15.3 & 13.9 & 6.6 & 4.3 & 25.4 & 9.4 & 6.0 & 2.9 & & 12.6 & 6.0 & 3.9 & 23.0 \\
\hline \multirow{5}{*}{13200} & 0 & 0 & 208.1 & -2.5 & -36.7 & 306.0 & 208.9 & -30.1 & 9.1 & 246.9 & -19.2 & -12.7 & -30.7 & -64.0 & 10.2 & 7.4 & 9.1 & 27.4 & 8.0 & 9.6 & 11.5 & 23.2 & 9.2 & 6.7 & 8.2 & 24.8 \\
\hline & 726 & 105.3 & 217.5 & -2.5 & -31.9 & 382.5 & 211.6 & -18.9 & 0.2 & 237.3 & -18.1 & -8.8 & -16.1 & -10.9 & 12.9 & 6.1 & 4.8 & 36. & 8.4 & 5.3 & 2.5 & 14.3 & 11.7 & 5.5 & 4.3 & 32.6 \\
\hline & 1452 & & 238.2 & -19.3 & -33.2 & 476.7 & 217.3 & 0.2 & -2.7 & 231.9 & -19.3 & -23.7 & -16.6 & -6.1 & 11.8 & 4.8 & 3.2 & 28. & 8.3 & 2.2 & 2.5 & 26.3 & 10.7 & 4.4 & 2.9 & 26.0 \\
\hline & 2177 & 315.8 & 265.7 & -23.2 & -35.8 & 583.4 & 222.1 & 7.7 & -3.0 & 226.3 & -19.2 & -29.1 & -16.2 & 2.5 & 10.6 & 5.3 & 2.3 & 24.2 & 7.8 & 2.6 & 3.0 & 27.6 & 9.6 & 4.8 & 2.1 & 21.9 \\
\hline & 2903 & 421.1 & 293.9 & -24.7 & -38.3 & 705.9 & 232.0 & 11.7 & -5.4 & 210.1 & -22.9 & -34.8 & -15.8 & 13.0 & 10.6 & 5.6 & 2.2 & 24.4 & 8.3 & 4.2 & 3.6 & 33.2 & 9.6 & 5.0 & 1.9 & 22.1 \\
\hline
\end{tabular}


Table 16: LBP Experimental Rotordynamic Coefficients

\begin{tabular}{|c|c|c|c|c|c|c|c|c|c|c|c|c|c|c|c|c|c|c|c|c|c|c|c|c|c|c|}
\hline \multirow{3}{*}{$\begin{array}{c}\text { Running } \\
\text { Speed [rpm] }\end{array}$} & \multirow{3}{*}{$\begin{array}{c}\text { Unit Loading } \\
{[\mathrm{KPa}]}\end{array}$} & \multirow{3}{*}{$\begin{array}{c}\text { Unit Loading } \\
\text { [psi] }\end{array}$} & \multicolumn{12}{|c|}{ Rotordynamic Coefficients } & \multicolumn{12}{|c|}{ Uncertainties } \\
\hline & & & \multicolumn{4}{|c|}{ Stiffness [MN/m] } & \multicolumn{4}{|c|}{ Damping [kN-s/m] } & \multicolumn{4}{|c|}{ Added Mass [kg] } & \multicolumn{4}{|c|}{ Stiffness [MN/m] } & \multicolumn{4}{|c|}{ Damping $[\mathrm{kN}-\mathrm{s} / \mathrm{m}]$} & \multicolumn{4}{|c|}{ Added Mass [kg] } \\
\hline & & & $\mathrm{Kxx}$ & Kxy & Kyx & Kyy & Cxx & Cxy & Cyx & Cyy & Mxx & Mxy & Myx & Myy & $\mathrm{Kxx}$ & Kxy & Кyx & Kyy & $\mathrm{Cxx}$ & Cxy & Cyx & Cyy & Mxx & Mxy & Myx & Myy \\
\hline \multirow{5}{*}{6800} & 0 & 0.0 & 175.8 & -51.0 & -48.9 & 168.7 & 232.0 & -22.4 & -29.2 & 237.9 & -50.5 & -38.1 & -9.1 & -54.0 & 8.1 & 4.6 & 14.4 & 29.6 & 6.5 & 7.7 & 10.3 & 18.2 & 7.4 & 4.1 & 13.0 & 26.8 \\
\hline & 726 & 105.3 & 212.9 & -57.9 & -56.4 & 224.0 & 215.3 & -20.6 & -27.1 & 215.1 & -42.4 & -32.5 & 6.7 & -40.4 & 5.7 & 9.0 & 10.3 & 34.5 & 4.6 & 4.1 & 8.7 & 13.6 & 5.1 & 8.1 & 9.3 & 31.2 \\
\hline & 1452 & 210.5 & 256.2 & -60.8 & -67.5 & 291.0 & 185.8 & -30.1 & -26.8 & 181.6 & -32.9 & -24.7 & -10.3 & -36.7 & 5.6 & 5.4 & 16.6 & 19.1 & 3.8 & 4.2 & 12.2 & 10.2 & 5.1 & 4.9 & 15.0 & 17.3 \\
\hline & 2177 & 315.8 & 294.7 & -63.9 & -71.6 & 345.4 & 165.5 & -36.9 & -33.9 & 163.2 & -27.1 & -19.0 & -12.9 & -37.6 & 5.9 & 4.4 & 14.8 & 28.9 & 4.1 & 3.1 & 15.9 & 29.9 & 5.3 & 4.0 & 13.4 & 26.2 \\
\hline & 2903 & 421.1 & 323.2 & -72.6 & -85.4 & 387.0 & 158.4 & -43.8 & -23.2 & 159.4 & -22.1 & -20.2 & -23.4 & -41.4 & 4.8 & 22.8 & 14.9 & 43.1 & 7.6 & 11.5 & 12.1 & 25.7 & 2.2 & 10.7 & 7.0 & 20.2 \\
\hline \multirow{5}{*}{9000} & 0 & 0.0 & 221.9 & -69.1 & -57.9 & 200.0 & 219.0 & -9.4 & -18.1 & 227.0 & -52.4 & -43.4 & -12.6 & -69.5 & 11.7 & 11.9 & 10.3 & 33.9 & 12.0 & 6.9 & 15.1 & 23.7 & 10.6 & 10.8 & 9.3 & 30.6 \\
\hline & 726 & 105.3 & 251.7 & -71.6 & -66.4 & 257.6 & 200.7 & -12.7 & -21.4 & 196.4 & -36.1 & -35.1 & -9.3 & -35.0 & 9.2 & 9.5 & 8.0 & 32.5 & 7.0 & 4.1 & 6.5 & 11.5 & 8.3 & 8.6 & 7.2 & 29.4 \\
\hline & 1452 & 210.5 & 286.6 & -73.2 & -71.5 & 316.7 & 176.4 & -24.1 & -30.4 & 169.0 & -27.6 & -27.5 & -7.6 & -27.1 & 7.9 & 4.9 & 5.8 & 19.0 & 5.2 & 3.4 & 6.3 & 8.9 & 7.2 & 4.5 & 5.2 & 17.2 \\
\hline & 2177 & 315.8 & 316.5 & -75.3 & -76.7 & 362.0 & 159.2 & -31.1 & -33.9 & 154.6 & -23.0 & -23.9 & -8.6 & -22.0 & 7.6 & 4.8 & 7.9 & 36.4 & 5.5 & 3.4 & 6.5 & 12.2 & 6.9 & 4.3 & 7.1 & 33.0 \\
\hline & 2903 & 421.1 & 339.0 & -77.4 & -86.9 & 411.1 & 146.3 & -35.3 & -38.1 & 138.1 & -20.4 & -19.5 & -15.4 & -18.5 & 7.2 & 4.1 & 12.8 & 19.1 & 5.4 & 3.0 & 13.1 & 15.4 & 6.5 & 3.7 & 11.6 & 17.3 \\
\hline \multirow{5}{*}{10800} & 0 & 0.0 & 247.9 & -71.8 & -89.8 & 240.4 & 206.5 & -17.2 & -11.2 & 215.4 & -75.6 & -36.6 & -59.5 & -75.2 & 29.2 & 8.2 & 41.4 & 29.2 & 9.1 & 19.7 & 11.9 & 24.2 & 26.4 & 7.5 & 37.5 & 26.5 \\
\hline & 726 & 105.3 & 278.5 & -74.5 & -74.8 & 280.7 & 193.3 & -14.2 & -15.7 & 186.8 & -40.0 & -28.9 & -16.9 & -38.8 & 10.5 & 8.6 & 7.1 & 30.0 & 7.7 & 4.7 & 6.8 & 15.5 & 9.5 & 7.8 & 6.4 & 27.2 \\
\hline & 1452 & 210.5 & 306.2 & -77.1 & -80.2 & 332.0 & 171.4 & -22.8 & -27.6 & 161.6 & -29.7 & -23.0 & -17.2 & -25.0 & 9.0 & 5.6 & 10.8 & 17.4 & 5.9 & 3.8 & 7.0 & 14.2 & 8.2 & 5.0 & 9.7 & 15.7 \\
\hline & 2177 & 315.8 & 331.9 & -80.4 & -85.4 & 376.7 & 155.9 & -29.1 & -31.4 & 145.4 & -25.0 & -19.6 & -11.5 & -20.4 & 8.1 & 4.8 & 9.1 & 17.6 & 5.5 & 2.5 & 8.5 & 13.3 & 7.3 & 4.3 & 8.3 & 15.9 \\
\hline & 2903 & 421.1 & 353.0 & -84.8 & -90.8 & 421.8 & 145.5 & -33.4 & -34.6 & 131.1 & -22.5 & -18.2 & -12.4 & -18.7 & 7.5 & 3.6 & 6.3 & 13.3 & 5.8 & 2.6 & 8.3 & 13.5 & 6.8 & 3.3 & 5.7 & 12.1 \\
\hline \multirow{5}{*}{13200} & 0 & 0.0 & 288.3 & -60.8 & -93.7 & 275.6 & 174.8 & -42.3 & -20.2 & 192.0 & -35.0 & 0.8 & -15.4 & -45.2 & 5.1 & 3.7 & 10.1 & 25.2 & 4.0 & 8.7 & 7.2 & 19.2 & 4.6 & 3.4 & 9.1 & 22.8 \\
\hline & 726 & 105.3 & 310.0 & -74.6 & -98.5 & 311.1 & 164.1 & -35.4 & -19.5 & 170.9 & -26.8 & -3.9 & -14.9 & -29.3 & 5.8 & 8.3 & 6.7 & 26.2 & 4.3 & 9.0 & 4.6 & 10.7 & 5.3 & 7.5 & 6.1 & 23.7 \\
\hline & 1452 & 210.5 & 336.3 & -87.0 & -101.7 & 350.7 & 150.5 & -31.8 & -22.7 & 153.4 & -21.7 & -7.2 & -11.2 & -24.3 & 5.2 & 5.4 & 6.3 & 18.0 & 4.6 & 8.2 & 6.1 & 10.0 & 4.7 & 4.9 & 5.7 & 16.3 \\
\hline & 2177 & 315.8 & 325.6 & -72.0 & -83.9 & 347.5 & 153.3 & -32.6 & -21.0 & 151.9 & -21.7 & -8.4 & -4.9 & -21.6 & 7.6 & 6.2 & 16.2 & 23.8 & 4.7 & 7.1 & 13.3 & 10.5 & 6.9 & 5.6 & 14.7 & 21.5 \\
\hline & 2903 & 421.1 & 348.8 & -81.5 & -91.8 & 381.1 & 144.9 & -32.7 & -27.8 & 142.1 & -19.3 & -11.1 & -10.2 & -19.4 & 6.1 & 5.3 & 5.3 & 14.9 & 3.9 & 5.2 & 6.3 & 11.0 & 5.5 & 4.8 & 4.8 & 13.5 \\
\hline
\end{tabular}




\section{APPENDIX E: WFR CALCULATION}

From the homogeneous solution for the equations of motion of the rotor and bearing supports, the whirl frequency ration $\phi$ is obtained from the following quartic equations, San Andrés [24]:

$$
\frac{\mathrm{M}_{\mathrm{r}}}{\mathrm{K}_{\mathrm{r}}} \alpha_{\mathrm{i}} \omega_{\mathrm{s}}^{4}-\left[1+\alpha_{\mathrm{i}}+\frac{\mathrm{K}_{\mathrm{eq}}}{\mathrm{K}_{\mathrm{r}}}\right] \omega_{\mathrm{s}}^{2}+\frac{\mathrm{K}_{\mathrm{eq}}}{\mathrm{M}_{\mathrm{r}}}=0
$$

and,

$$
\phi^{4} \mathrm{I}_{4}+\phi^{2}\left(\mathrm{I}_{2}-1\right)+\phi_{\mathrm{o}}^{2}
$$

where,

$$
\begin{gathered}
\alpha_{\mathrm{i}}=\frac{\left(\mathrm{M}_{\mathrm{xx}}+\mathrm{M}_{\mathrm{yy}}\right)-2 \mathrm{I}_{1}}{2 \mathrm{M}_{\mathrm{r}}} \\
K_{e q}=\frac{K_{x x} C_{y y}+C_{x x} K_{y y}-C_{y x} K_{x y}-C_{x y} K_{y x}}{C_{x x}+C_{y y}} \\
I_{2}=\frac{C_{y x} M_{x y}+C_{x y} M_{y x}}{C_{x x}+C_{y y}} \\
M_{y x}+K_{y x} M_{x y}-I_{1}\left(K_{x x}+K_{y y}\right)+2 K_{e q} I_{1} \\
C_{x x} C_{y y}-C_{x y} C_{y x}
\end{gathered}
$$

and,

$$
\phi_{o}^{2}=\frac{\left(K_{e q}-K_{x x}\right)\left(K_{e q}-K_{y y}\right)-K_{x y} K_{y x}}{\Omega_{s}^{2}\left(C_{x x} C_{y y}-C_{x y} C_{y x}\right)}
$$




\section{APPENDIX F: LBP DYNAMIC STIFFNESS}

As with predictions generated in the LOP orientation, the hot clearance

measurements were used in modeling the predictions; giving a more accurate representation than a cold clearance measurement of the bearing clearance. The baseline results, shown in Figure 12 and Figure 13, were subtracted from the dynamic stiffness to obtain the dynamic response of the fluid-film only.

The following figure presents the measured and predicted dynamic stiffness functions for the LBP orientation at $6.8 \mathrm{krpm}$. Figure 57 shows the predictions at $725 \mathrm{kPa}$ while Figure 58 shows the predictions at $2903 \mathrm{kPa}$. 

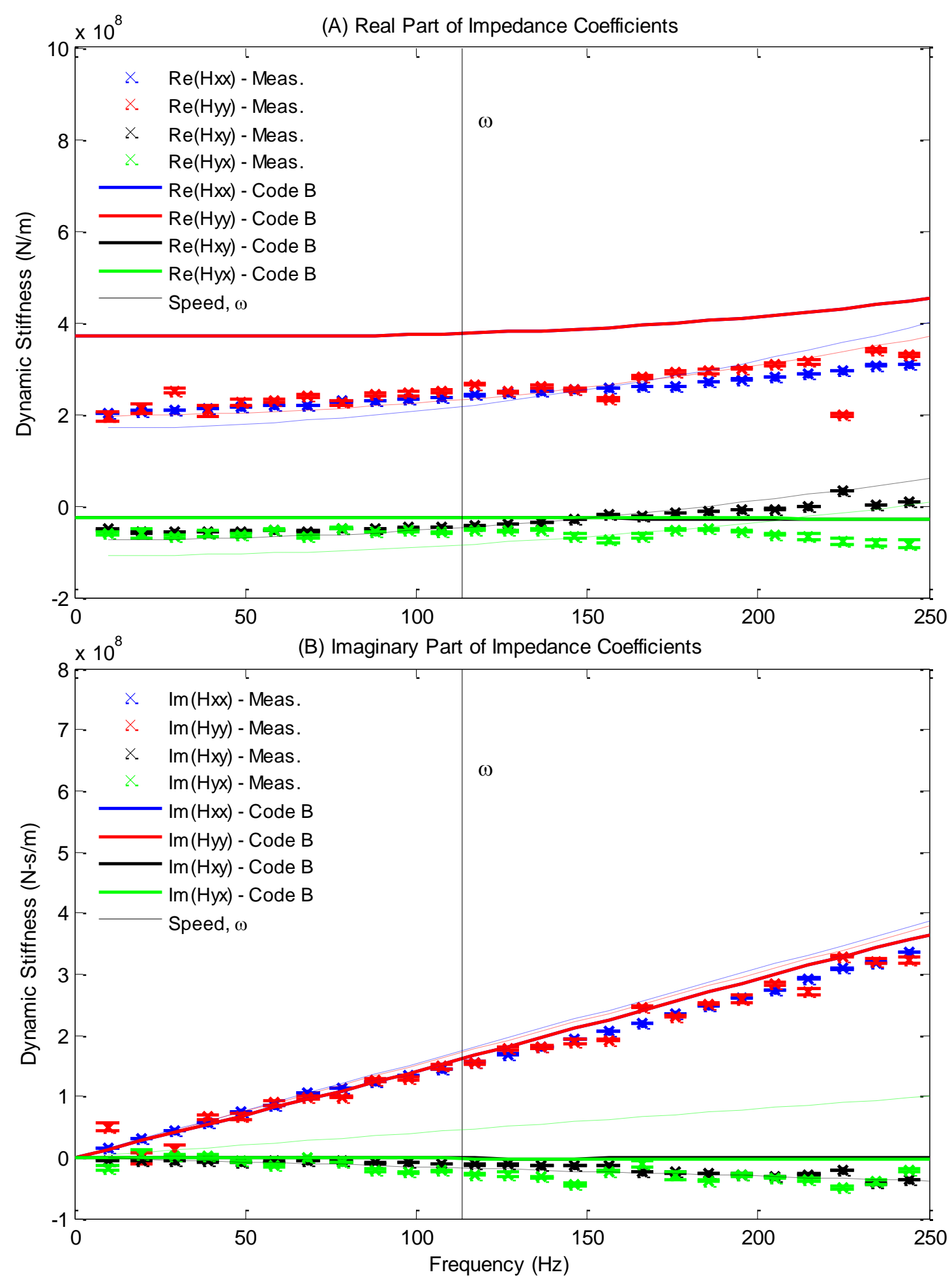

Figure 57: LBP Components of Measurements and Predicted (Code B) Bearing Impedance Coefficients at 6,800 rpm with $725 \mathrm{kPa}(105.3 \mathrm{psi})$ Static Load 

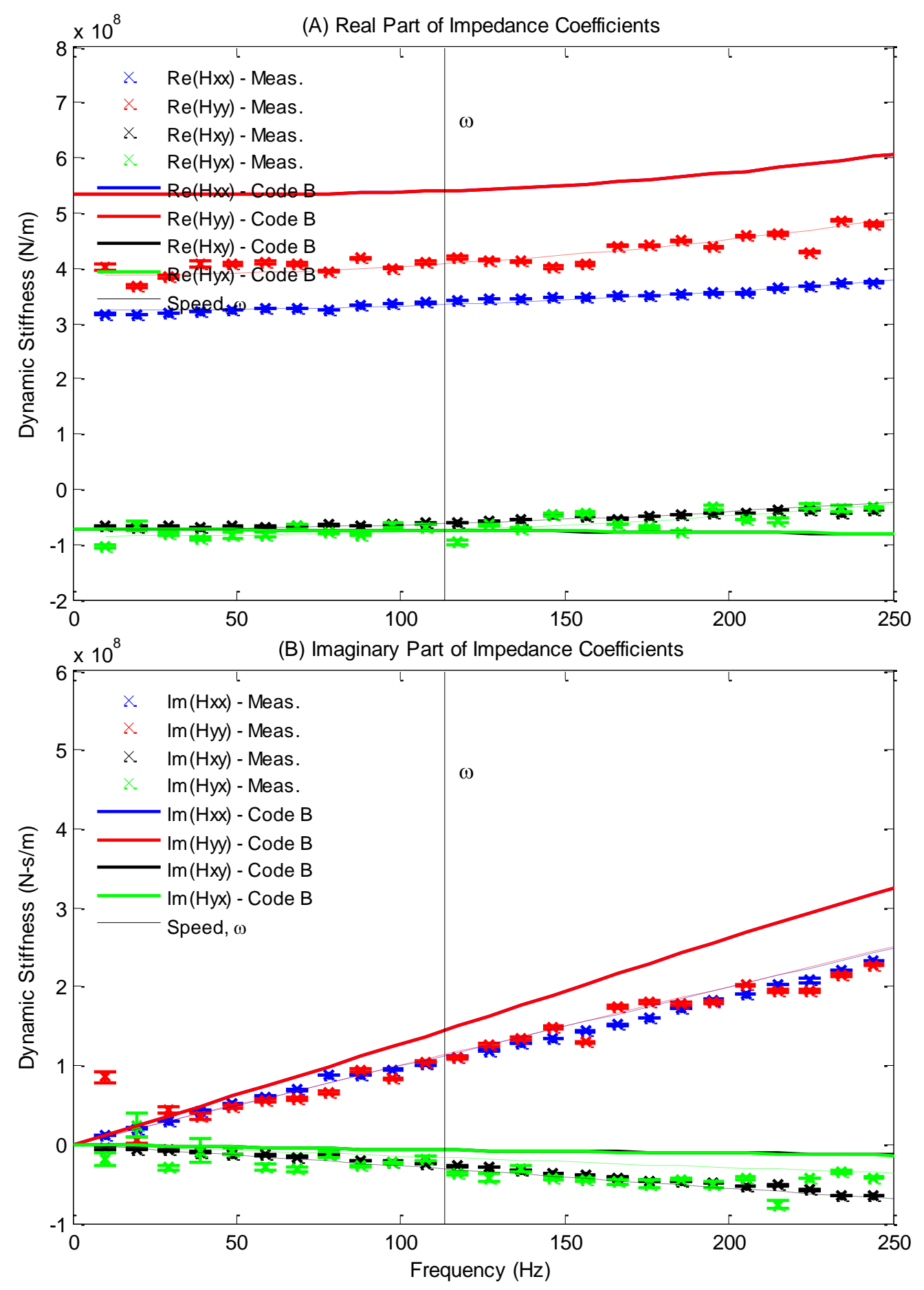

Figure 58: LBP Components of Measurements and Predicted (Code B) Bearing Impedance Coefficients at 6,800 rpm with $2903 \mathrm{kPa}(421.1 \mathrm{psi})$ Static Load 
In the unloaded case, $\operatorname{Re}\left(\boldsymbol{H}_{y y}\right)=\operatorname{Re}\left(\boldsymbol{H}_{x x}\right)$, and in the loaded case $\operatorname{Re}\left(\boldsymbol{H}_{y y}\right)$ is greater than $\operatorname{Re}\left(\boldsymbol{H}_{x x}\right)$, showing slight orthotropy. In the loaded case, the $\operatorname{Re}\left(\boldsymbol{H}_{x y}\right)$ and $\operatorname{Re}\left(\boldsymbol{H}_{\boldsymbol{y} x}\right)$ are similar. Similar to the lightly loaded LOP orientation, at larger frequencies $\operatorname{Re}\left(\boldsymbol{H}_{x y}\right)$ and $\operatorname{Re}\left(\boldsymbol{H}_{y x}\right)$ have opposite signs, suggesting an impact on stability (See Whirl Frequency Ratio). Both figures show frequency-independent direct-damping coefficients. For both cases, measured $\operatorname{Im}\left(\boldsymbol{H}_{x x}\right)$ have the same value as $\operatorname{Im}\left(\boldsymbol{H}_{\boldsymbol{y} y}\right) \cdot \operatorname{Im}\left(\boldsymbol{H}_{\boldsymbol{x} y}\right)$ and $\operatorname{Im}\left(\boldsymbol{H}_{\boldsymbol{y} x}\right)$ are both negative and become slightly more negative as $\Omega$ increases.

Direct dynamic-stiffness predictions are the same $\left[\operatorname{Re}\left(\boldsymbol{H}_{x x}\right)=\operatorname{Re}\left(\boldsymbol{H}_{y y}\right), \operatorname{Im}\left(\boldsymbol{H}_{x x}\right)=\right.$ $\left.\operatorname{Im}\left(\boldsymbol{H}_{\boldsymbol{y} y}\right)\right]$ regardless of load, while measured values change with load. $\operatorname{Re}\left(\boldsymbol{H}_{x x}\right)$ and $\operatorname{Re}\left(\boldsymbol{H}_{y y}\right)$ predictions are more accurately predicted at the lightly loaded case. At around $150 \mathrm{~Hz}$ the stiffness predictions begin to increase, making predictions worse. $\operatorname{Im}\left(\boldsymbol{H}_{x x}\right)$ and $\operatorname{Im}\left(\boldsymbol{H}_{y y}\right)$ are predicted very accurately in the lightly loaded case, but become lower than predicted as load increases. For the most part, measured and predicted $\operatorname{Im}\left(\boldsymbol{H}_{x y}\right)$ and $\operatorname{Im}\left(\boldsymbol{H}_{y x}\right)$ are slightly less than zero, and decrease with increasing $\Omega$.

Figure 59 and Figure 60 show the LBP predictions at $13.2 \mathrm{krpm}$. 

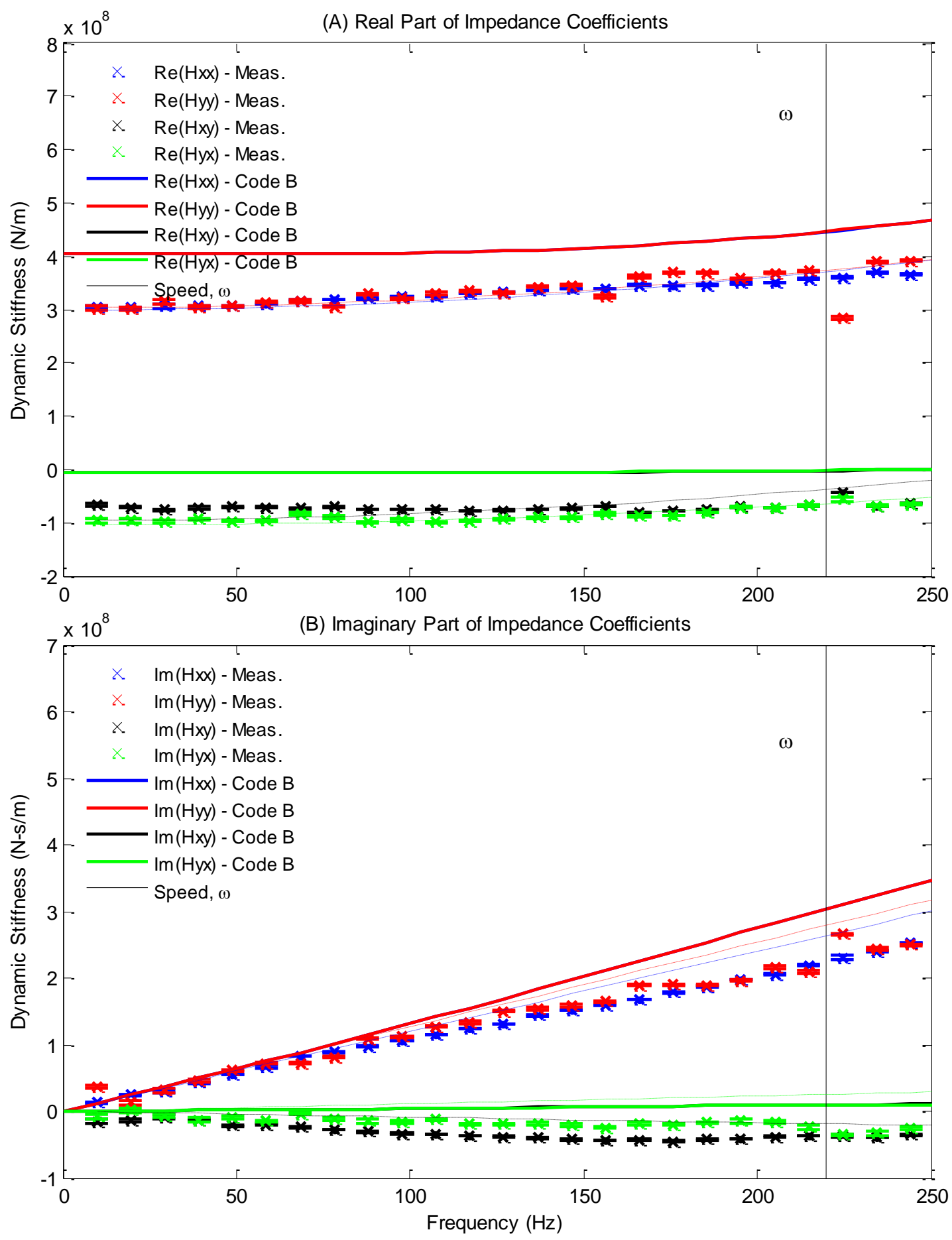

Figure 59: LBP Components of Measurements and Predicted (Code B) Bearing Impedance Coefficients at $13.2 \mathrm{krpm}$ with $725 \mathrm{kPa}(105.3 \mathrm{psi})$ Static Load 

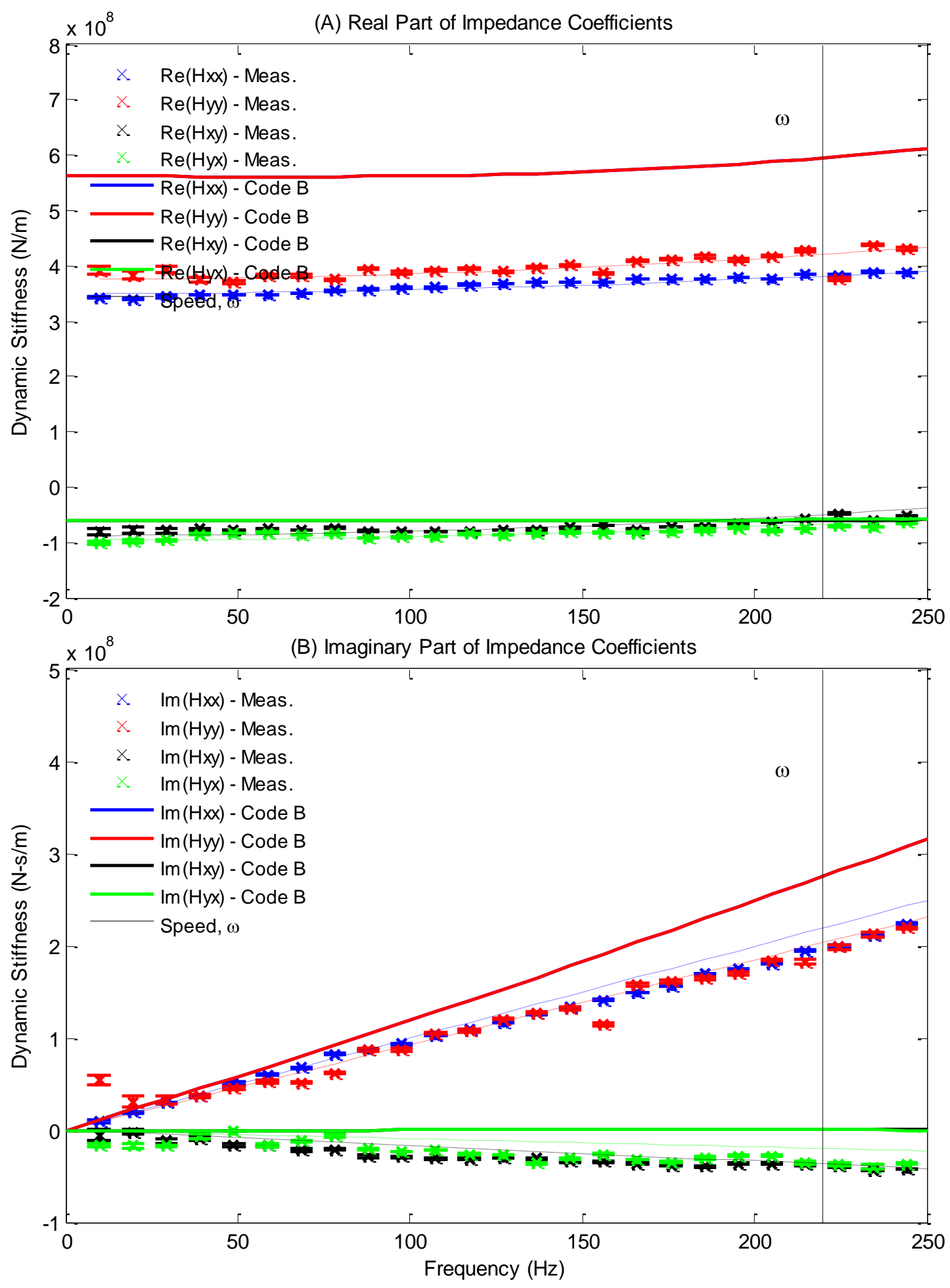

Figure 60: LBP Components of Measurements and Predicted (Code B) Bearing Impedance Coefficients at $13.2 \mathrm{krpm}$ with $2903 \mathrm{kPa}$ (421.1 psi) Static Load 
As with the $6.8 \mathrm{krpm}$ case, at $13.2 \mathrm{krpm}$ measured $\operatorname{Re}\left(\boldsymbol{H}_{\boldsymbol{y} \boldsymbol{y}}\right)=\operatorname{Re}\left(\boldsymbol{H}_{\boldsymbol{x} x}\right)$ in the lightly loaded case. In the loaded case, $\operatorname{Re}\left(\boldsymbol{H}_{\boldsymbol{y} \boldsymbol{y}}\right)$ is slightly larger than $\operatorname{Re}\left(\boldsymbol{H}_{\boldsymbol{x} x}\right)$, showing slight orthotropy. In the loaded case, measured $\operatorname{Re}\left(\boldsymbol{H}_{\boldsymbol{x} x}\right)$ and $\operatorname{Re}\left(\boldsymbol{H}_{\boldsymbol{y} y}\right)$ shows no dependency on $\Omega$. In both cases, $\operatorname{Re}\left(\boldsymbol{H}_{x y}\right)$ and $\operatorname{Re}\left(\boldsymbol{H}_{\boldsymbol{y} x}\right)$ terms are comparable at high frequencies and approximately equal to $-1 \mathrm{MN} / \mathrm{m}$.

Both figures show that $\operatorname{Im}\left(\boldsymbol{H}_{x \boldsymbol{x}}\right)$ and $\operatorname{Im}\left(\boldsymbol{H}_{\boldsymbol{y} y}\right)$ increases linearly with increasing frequency, resulting in frequency-independent direct damping coefficients. $\operatorname{Im}\left(\boldsymbol{H}_{\boldsymbol{y} y}\right)=$ $\operatorname{Im}\left(\boldsymbol{H}_{\boldsymbol{x} x}\right)$ in both cases. Both $\operatorname{Im}\left(\boldsymbol{H}_{\boldsymbol{y} y}\right)$ and $\operatorname{Im}\left(\boldsymbol{H}_{\boldsymbol{x} x}\right)$ slightly decrease with increasing frequency.

Predictions for $\left(\operatorname{Re}\left(\boldsymbol{H}_{x \boldsymbol{x}}\right)\right.$ and $\left.\operatorname{Re}\left(\boldsymbol{H}_{y y}\right)\right)$ are the same regardless of load while measured values change with applied static load. $\operatorname{Re}\left(\boldsymbol{H}_{x \boldsymbol{x}}\right)$ and $\operatorname{Re}\left(\boldsymbol{H}_{\boldsymbol{y} y}\right)$ predictions are more accurate for the lightly loaded case, but are larger than measurements regardless of orientation. At around $150 \mathrm{~Hz}$ the $\operatorname{Re}\left(\boldsymbol{H}_{\boldsymbol{x} x}\right)$ and $\operatorname{Re}\left(\boldsymbol{H}_{\boldsymbol{y} y}\right)$ predictions begin to increase, making predictions worse. The model is more accurate at predicting $\operatorname{Im}\left(\boldsymbol{H}_{\boldsymbol{x} x}\right)$ and $\operatorname{Im}\left(\boldsymbol{H}_{\boldsymbol{y} y}\right)$ at lower frequencies. Measured $\operatorname{Im}\left(\boldsymbol{H}_{\boldsymbol{x} x}\right)$ and $\operatorname{Im}\left(\boldsymbol{H}_{\boldsymbol{y} \boldsymbol{y}}\right)$ values are smaller than predicted and become more so as load and speed increase. For the most part, $\operatorname{Im}\left(\boldsymbol{H}_{\boldsymbol{x} y}\right)$ and $\operatorname{Im}\left(\boldsymbol{H}_{\boldsymbol{y} x}\right)$ predictions are zero or slightly less than zero while measured $\operatorname{Im}\left(\boldsymbol{H}_{\boldsymbol{x} y}\right)$ and $\operatorname{Im}\left(\boldsymbol{H}_{\boldsymbol{y} x}\right)$ values are less than zero.

In comparing the LBP orientation to the LOP orientation (Figure 40 - Figure 60), very different results were found. The LOP orientation showed significant orthotropy, while the LBP did not. For the lightly loaded case, a comparable $\operatorname{Re}\left(\boldsymbol{H}_{\boldsymbol{y} y}\right)$ value was 
obtained, but as load increased the difference in $\operatorname{Re}\left(\boldsymbol{H}_{y y}\right)$ and $\operatorname{Re}\left(\boldsymbol{H}_{x x}\right)$ coefficients became greater.

Overall, both the LOP and LBP orientations show that the frequency dependency of the test bearing was modeled well with a $[\mathrm{K}][\mathrm{C}][\mathrm{M}]$ model. When a static load is applied the $\operatorname{Re}\left(\boldsymbol{H}_{x x}\right)$ and $\operatorname{Re}\left(\boldsymbol{H}_{y y}\right)$ are not dependent on $\Omega$. In both orientations, $\operatorname{Im}\left(\boldsymbol{H}_{y y}\right)$ and $\operatorname{Im}\left(\boldsymbol{H}_{x x}\right)$ increase linearly with $\Omega$, allowing for frequency independent damping coefficients. 


\section{APPENDIX G: LBP IMPORTANCE OF PAD FLEXIBILITY}

To look at the effects that pad flexibility has on predicting the impedance coefficients in the LBP orientation, a series of predictions were created with Code B by changing the magnitude of the pad's calculated bending stiffness from Eq. (27). Figure 61 presents the measured and predicted $K_{x x}$ and $K_{y y}$ predictions for Code A and Code B in the LBP configuration.

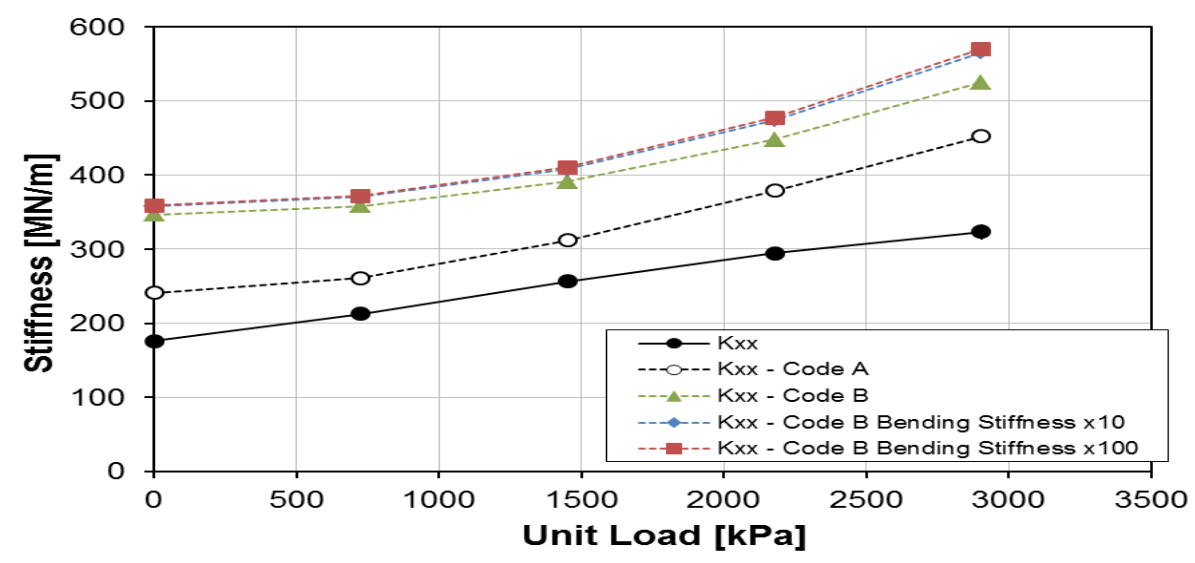

(A) $K_{x x}$ at $6.8 \mathrm{krpm}$

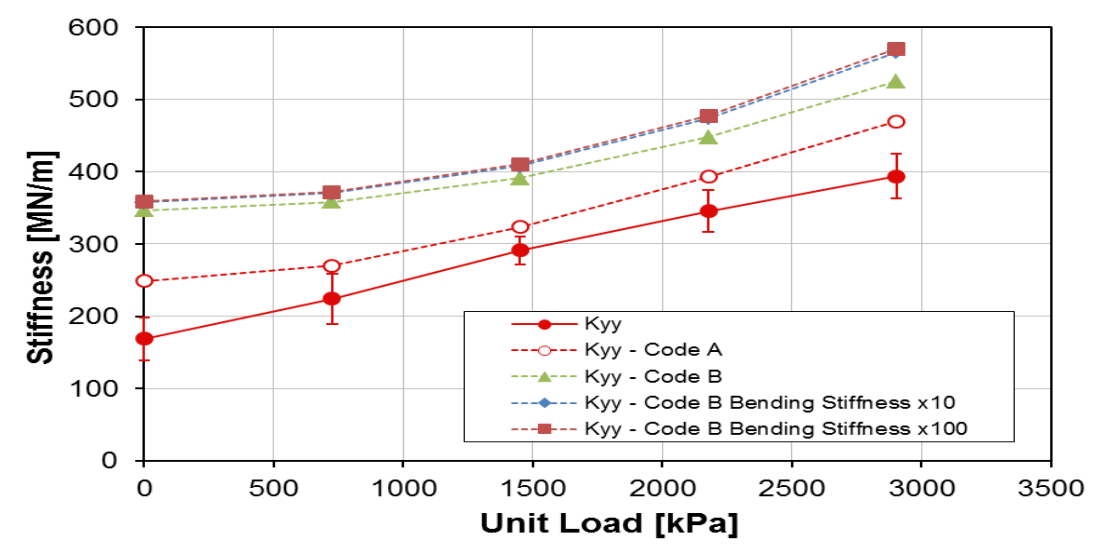

(B) $K_{y y}$ at $6.8 \mathrm{krpm}$

Figure 61: Measured and Predicted Direct Stiffness Coefficients for LBP Orientation 
As seen from Figure 61, Code B predicted higher $K_{x x}$ and $K_{y y}$ values than Code A. Code A predicts $K_{x x}$ and $K_{y y}$ much more accurately than Code B. Changing the bending stiffness from its actual value by a factor of 10 or by a factor of 100 in Code B, showed a $3 \%$ increase in predictions for $K_{x x}$ and $K_{y y}$.

Figure 62 presents measured and predicted $K_{x x}$ and $K_{y y}$ values for Code A and Code B in the LBP configuration at $13.2 \mathrm{krpm}$.

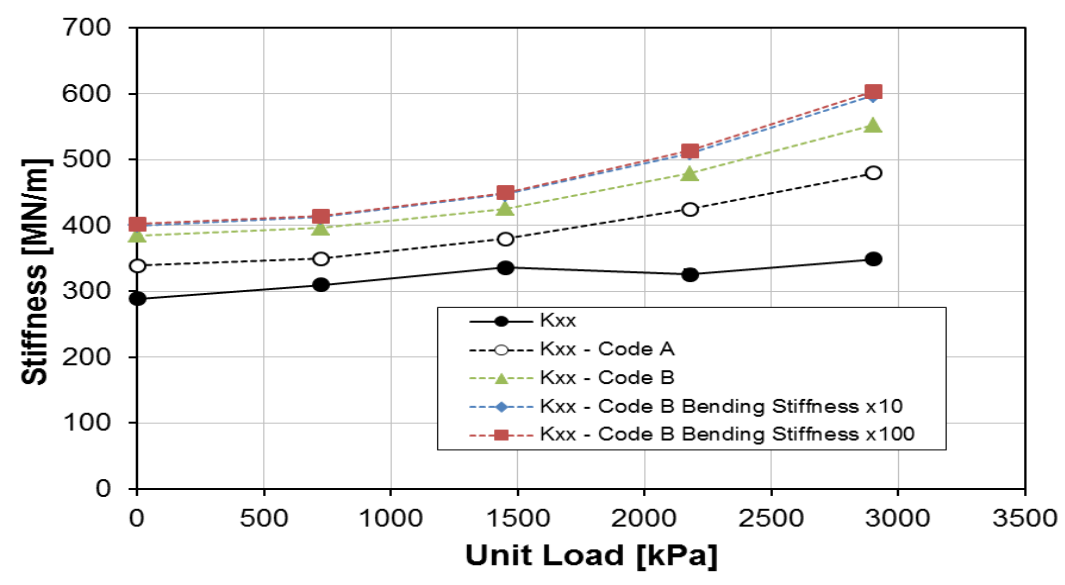

(A) $K_{x x}$ at $13.2 \mathrm{krpm}$

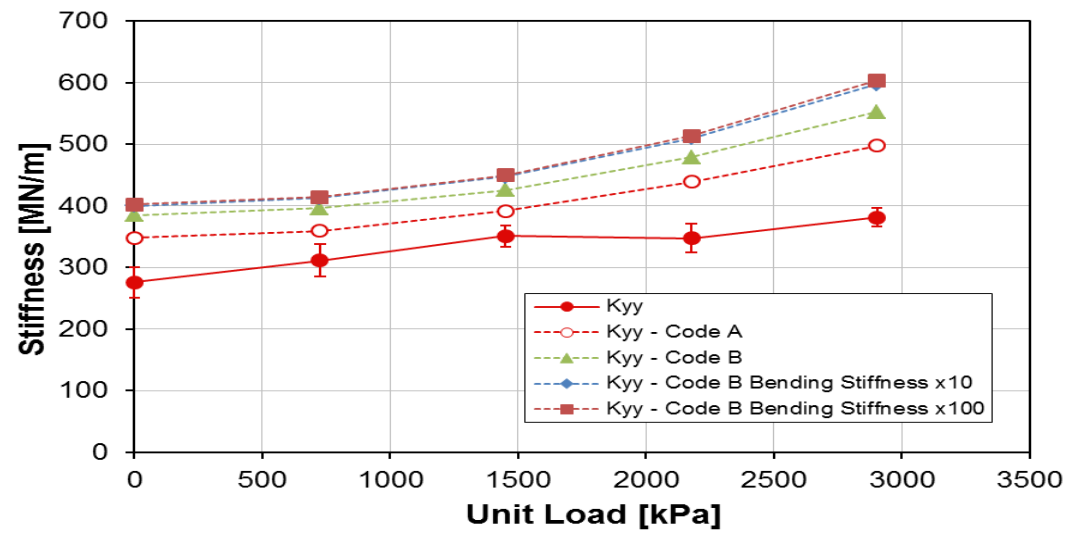

(B) $K_{y y}$ at $13.2 \mathrm{krpm}$

Figure 62: Measured and Predicted Direct Stiffness Coefficients for LBP Orientation 
As with the $6.8 \mathrm{krpm}$ case, Code B predicted higher $K_{x x}$ and $K_{y y}$ values than Code A, and Code A predicts $K_{x x}$ and $K_{y y}$ more accurately than Code B. Changing the bending stiffness from its actual value by a factor of 10 or by a factor of 100 in Code B, showed a $9 \%$ increase in predictions for $K_{x x}$ and $K_{y y}$.

Overall, changing the bending stiffness from its actual value by a factor of 10 or by a factor of 100 in Code B showed a 3-9\% increase in predictions for $K_{x x}$ and $K_{y y}$. Similar to the LOP orientation, for a flexible pad an increase in bending stiffness can have a large effect on predictions; however, for a more rigid pad an increase in pad bending stiffness will have a much lesser effect. When the bending stiffness was increased by a factor of 10 to a factor of 100 , no changes in predictions resulted. These findings suggest that if the calculated bending stiffness of $22 \mathrm{MN}$ was 10 times greater, then the pads would be effectively rigid.

Figure 63 presents the measured and predicted direct damping coefficients for Code A and Code B in the LBP configuration.

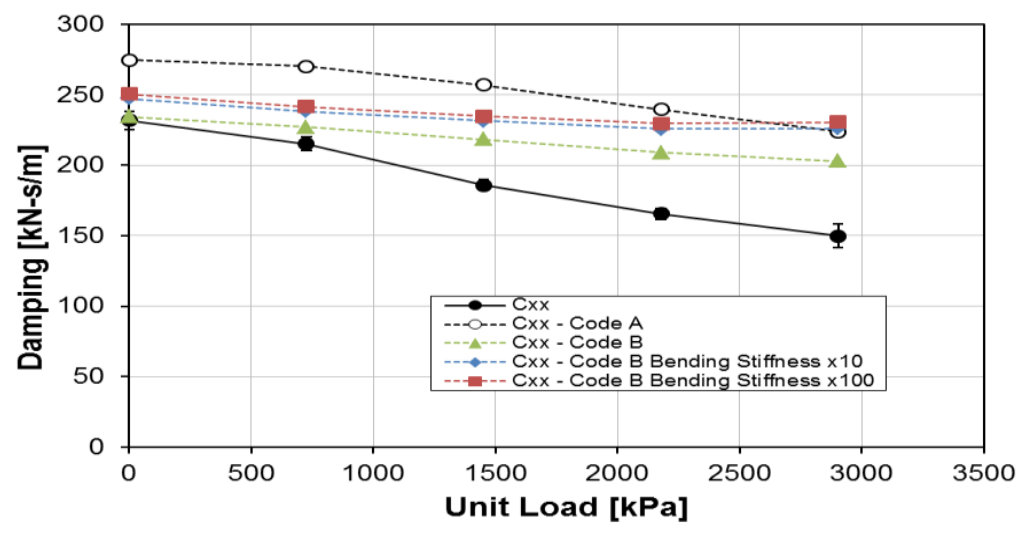

(A) $C_{x x}$ at $6.8 \mathrm{krpm}$ 


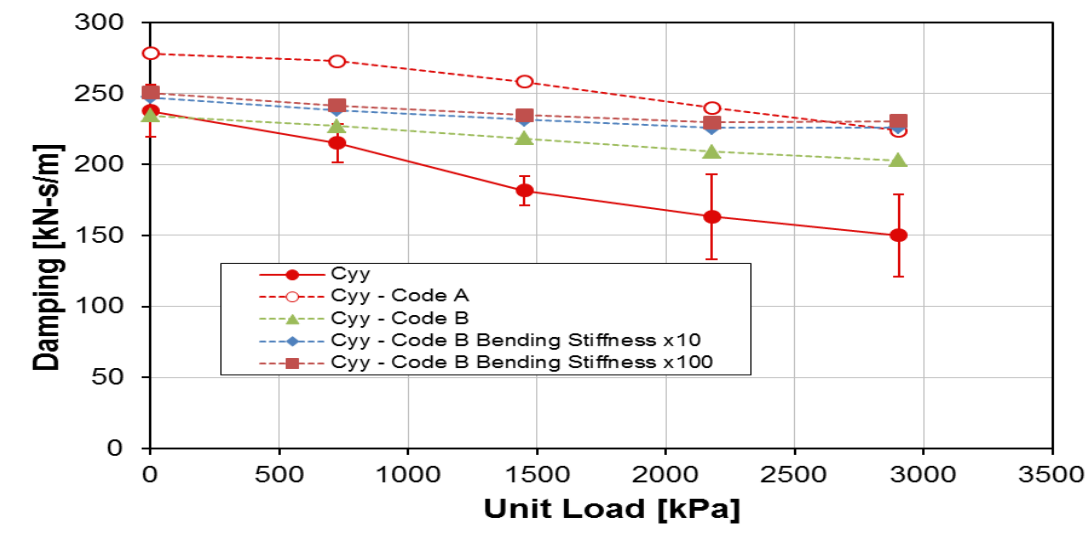

(B) $C_{y y}$ at $6.8 \mathrm{krpm}$

Figure 63: Measured and Predicted Direct Stiffness Coefficients for LBP Orientation

Figure 63, shows that both codes predict $C_{x x}$ and $C_{y y}$ to be greater than measured values. At $6.8 \mathrm{krpm}$, Code $\mathrm{B}$ predicts $C_{x x}$ and $C_{y y}$ more accurately than Code A. Changing the bending stiffness from its actual value by a factor of 10 in Code B showed a $5 \%$ increase in predictions for $C_{x x}$ and $C_{y y}$. When the bending stiffness was increased from a factor of 10 to a factor of 100, very slight changes in predictions were made.

Figure 64 presents the measured and predicted $C_{x x}$ and $C_{y y}$ for Code $\mathrm{A}$ and Code $\mathrm{B}$ in the LBP configuration at $13.2 \mathrm{krpm}$.

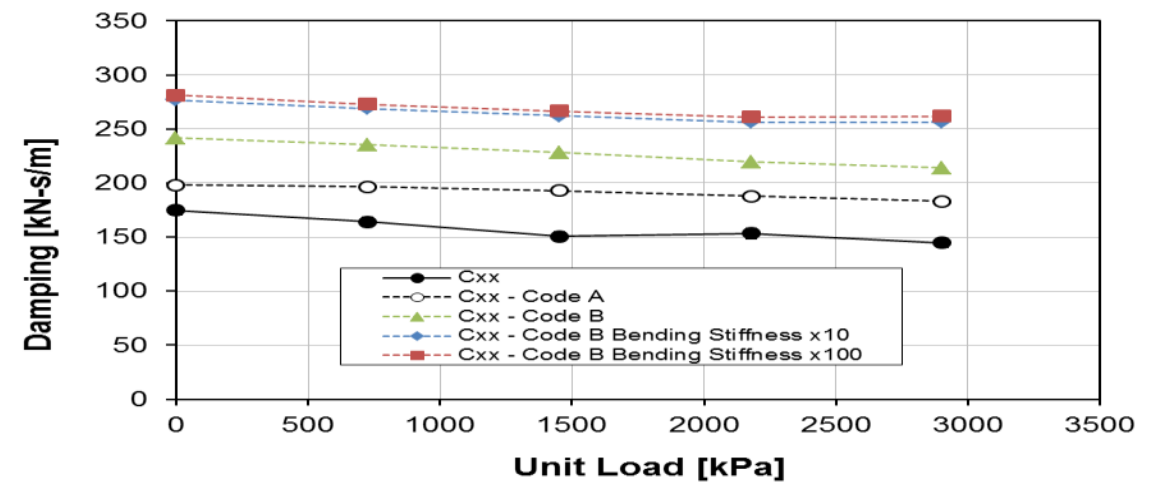

(A) $\mathrm{C}_{x x}$ at $13.2 \mathrm{krpm}$ 


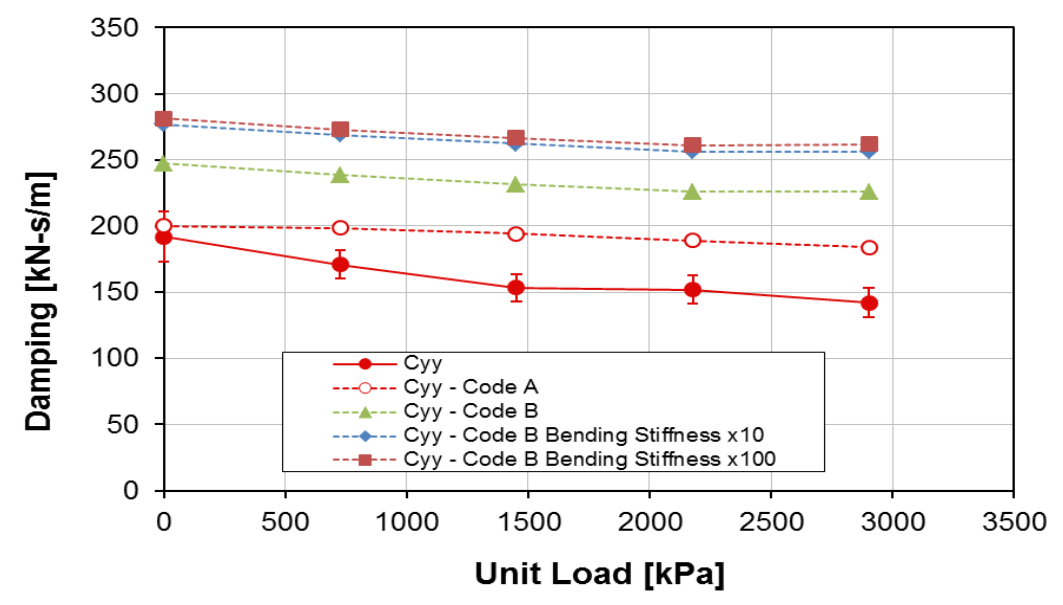

(B) $\mathrm{C}_{y y}$ at $13.2 \mathrm{krpm}$

Figure 64: Measured and Predicted Direct Stiffness Coefficients for LBP Orientation

At $13.2 \mathrm{krpm}$ Code B predicts $C_{x x}$ and $C_{y y}$ to be greater than Code A. As speed increases, Code A predicts $C_{x x}$ and $C_{y y}$ more accurately than Code B. Changing the bending stiffness from its actual value by a factor of 10 in Code B showed an $18 \%$ increase in predictions for $C_{x x}$ and $C_{y y}$.

Overall, increasing the bending stiffness used in Code B typically caused a 3-9\% increase in $K_{x x}$ and $K_{y y}$, and a 5-18\% increase in $C_{x x}$ and $C_{y y}$. In all cases, increasing the calculated bending stiffness, given in Eq. (27) by a factor of ten to hundred times caused slight if any change in $K_{x x}, K_{y y}, C_{x x}$, and $C_{y y}$. For a more flexible pad, an increase in bending stiffness can have a large effect on predictions; however, for a nearly rigid pad, an increase in pad bending stiffness will have much less effect. These findings suggest that if the calculated bending stiffness of $22 \mathrm{MN}$ were 10 times greater, then the pads could be considered rigid. 
Results show that the pad's structural bending stiffness can be an important factor in predicting impedance coefficients. Even though the pads tested in this thesis are extremely stiff, changes are still seen in Code B's predictions when the magnitude of the pad's bending stiffness is increased, especially in $C_{x x}$ and $C_{y y}$. Overall, Code A predicts $K_{x x}$ and $K_{y y}$ more accurately than Code B in both load orientations. In the LBP orientation, Code B predicts $C_{x x}$ and $C_{y y}$ more accurately at low rotor speeds. Code A predicts $C_{x x}$ and $C_{y y}$ more accurately at high rotor speeds. 


\section{APPENDIX H: EXPERIMENTAL DYNAMIC STIFFNESS}

\section{Load on Pad}

Table 17: Dynamic Stiffness Real and Imaginary Parts at $6800 \mathrm{rpm}$ and $0 \mathrm{kPa}(\mathrm{MN} / \mathrm{m})$

\begin{tabular}{|c|c|c|c|c|c|c|c|c|c|c|c|c|c|c|c|c|}
\hline $\mathrm{f}(\mathrm{Hz})$ & $\mathrm{R}\left(\mathrm{H}_{\mathrm{xx}}\right)$ & $\mathrm{R}\left(\mathrm{H}_{\mathrm{xy}}\right)$ & $\mathrm{R}\left(\mathrm{H}_{\mathrm{yx}}\right)$ & $\mathrm{R}\left(\mathrm{H}_{\mathrm{yy}}\right)$ & $\mathrm{I}\left(\mathrm{H}_{\mathrm{xx}}\right)$ & $\mathrm{I}\left(\mathrm{H}_{\mathrm{xy}}\right)$ & $\mathrm{I}\left(\mathrm{H}_{\mathrm{yx}}\right)$ & $\mathrm{I}\left(\mathrm{H}_{\mathrm{yy}}\right)$ & $\Delta \mathrm{R}\left(\mathrm{H}_{\mathrm{xx}}\right)$ & $\Delta \mathrm{R}\left(\mathrm{H}_{\mathrm{xy}}\right)$ & $\Delta \mathrm{R}\left(\mathrm{H}_{\mathrm{yx}}\right)$ & $\Delta \mathrm{R}\left(\mathrm{H}_{\mathrm{yy}}\right)$ & $\Delta \mathrm{I}\left(\mathrm{H}_{\mathrm{xx}}\right)$ & $\Delta \mathrm{I}\left(\mathrm{H}_{\mathrm{xy}}\right)$ & $\Delta \mathrm{I}\left(\mathrm{H}_{\mathrm{yx}}\right)$ & $\Delta \mathrm{I}\left(\mathrm{H}_{\mathrm{yy}}\right)$ \\
\hline 9.8 & 97.4 & -13.4 & -20.1 & 193.6 & 15.7 & 0.6 & -3.4 & 54.5 & -0.2 & -1.5 & -0.2 & -3.9 & -0.2 & -1.1 & -0.3 & -2.4 \\
\hline 19.5 & 99.3 & -7.1 & -16.6 & 155.8 & 30.2 & 0.4 & -0.2 & 42.3 & -0.1 & -1.0 & -0.2 & -4.3 & -0.1 & -0.6 & -0.2 & -2.1 \\
\hline 29.3 & 100.1 & -14.5 & -19.9 & 198.0 & 47.6 & -5.4 & -4.9 & 86.7 & -0.1 & -1.0 & -0.2 & -3.7 & -0.1 & -0.4 & -0.1 & -1.7 \\
\hline 39.1 & 99.8 & -12.3 & -16.8 & 169.9 & 60.9 & -2.1 & -1.2 & 72.3 & -0.1 & -0.9 & -0.2 & -3.3 & -0.2 & -0.3 & -0.2 & -1.7 \\
\hline 48.8 & 106.1 & -17.7 & -13.6 & 172.4 & 76.0 & -2.1 & -3.2 & 97.5 & -0.1 & -1.0 & -0.2 & -3.4 & -0.2 & -0.4 & -0.2 & -1.9 \\
\hline 58.6 & 109.2 & -7.9 & -9.4 & 198.9 & 88.8 & -2.8 & -3.3 & 119.8 & -0.1 & -0.9 & -0.2 & -3.2 & -0.3 & -0.3 & -0.2 & -1.7 \\
\hline 68.4 & 110.9 & -5.7 & -10.6 & 204.2 & 100.5 & -3.7 & -8.9 & 123.7 & -0.1 & -0.9 & -0.2 & -3.5 & -0.2 & -0.3 & -0.1 & -1.5 \\
\hline 78.1 & 113.7 & -3.7 & -5.9 & 206.6 & 114.4 & -5.5 & -15.1 & 148.6 & -0.2 & -0.8 & -0.2 & -3.3 & -0.2 & -0.4 & -0.3 & -1.7 \\
\hline 87.9 & 111.8 & -4.8 & -10.1 & 211.3 & 127.3 & -6.9 & -13.4 & 159.9 & -0.2 & -0.8 & -0.2 & -3.2 & -0.3 & -0.3 & -0.1 & -1.8 \\
\hline 97.7 & 117.6 & -3.0 & -3.7 & 205.5 & 133.3 & -7.9 & -17.3 & 162.7 & -0.2 & -0.9 & -0.2 & -3.4 & -0.2 & -0.4 & -0.2 & -2.1 \\
\hline 107.4 & 115.9 & 1.8 & -0.4 & 211.8 & 151.9 & -8.0 & -8.9 & 180.8 & -0.3 & -1.0 & -0.5 & -3.5 & -0.6 & -0.4 & -0.7 & -2.3 \\
\hline 117.2 & 116.7 & 3.0 & 1.6 & 216.1 & 155.4 & -6.6 & -20.7 & 205.6 & -0.6 & -1.4 & -2.1 & -4.5 & -1.4 & -0.9 & -1.7 & -2.5 \\
\hline 127.0 & 118.0 & 6.4 & 1.0 & 229.3 & 168.6 & -13.5 & -22.5 & 183.8 & -0.3 & -0.9 & -0.3 & -3.4 & -0.3 & -0.5 & -0.6 & -1.9 \\
\hline 136.7 & 111.7 & 6.7 & 1.4 & 217.8 & 179.4 & -9.2 & -32.2 & 207.8 & -0.2 & -0.9 & -0.4 & -3.5 & -0.3 & -0.2 & -0.5 & -1.9 \\
\hline 146.5 & 122.1 & 12.1 & 8.6 & 231.4 & 190.5 & -7.0 & -30.4 & 219.0 & -0.2 & -0.8 & -0.2 & -3.5 & -0.2 & -0.3 & -0.4 & -1.8 \\
\hline 156.3 & 111.6 & 22.0 & 3.0 & 173.4 & 202.2 & 5.9 & -28.6 & 324.9 & -0.1 & -0.9 & -0.6 & -3.5 & -0.2 & -0.3 & -0.4 & -1.6 \\
\hline 166.0 & 106.5 & 34.6 & 3.9 & 227.0 & 215.2 & 0.4 & -40.0 & 281.5 & -0.4 & -0.9 & -0.1 & -3.4 & -0.2 & -0.4 & -0.3 & -2.0 \\
\hline 175.8 & 97.2 & 39.5 & -6.2 & 273.7 & 236.6 & -6.4 & -40.6 & 344.8 & -0.2 & -0.9 & -0.3 & -3.6 & -0.3 & -0.3 & -0.4 & -1.8 \\
\hline 185.5 & 103.1 & 51.7 & -5.7 & 251.0 & 237.1 & -3.6 & -36.7 & 306.0 & -0.3 & -1.0 & -0.6 & -3.3 & -0.5 & -0.5 & -0.3 & -2.1 \\
\hline 195.3 & 94.1 & 68.6 & 0.7 & 289.6 & 257.7 & -11.7 & -37.2 & 361.2 & -0.5 & -0.8 & -0.4 & -3.4 & -0.2 & -0.6 & -0.4 & -1.7 \\
\hline 205.1 & 105.3 & 46.6 & $\begin{array}{l}-7.3 \\
\end{array}$ & 239.3 & 283.0 & -25.1 & -36.7 & 370.6 & -0.4 & $\begin{array}{l}-1.0 \\
\end{array}$ & -0.2 & -3.4 & -0.5 & -1.0 & -0.3 & -2.3 \\
\hline 214.8 & 91.1 & 83.0 & -35.7 & 247.5 & 341.4 & -38.2 & -2.1 & 398.8 & -1.2 & -1.4 & -0.5 & -3.5 & -0.5 & -0.8 & -1.1 & -2.9 \\
\hline 224.6 & 102.1 & 82.8 & -22.4 & 252.9 & 341.3 & -39.7 & 17.7 & 415.9 & -0.5 & -1.3 & -0.9 & -4.2 & -0.4 & -0.5 & -1.6 & -3.3 \\
\hline 234.4 & 282.4 & -32.6 & 235.5 & 110.5 & 370.9 & 72.8 & 93.0 & 570.7 & -1.9 & -1.9 & -6.8 & -6.9 & -2.5 & -2.3 & -4.6 & -6.2 \\
\hline 244.1 & 186.1 & 87.1 & 106.5 & 323.2 & 358.2 & -20.1 & -10.3 & 513.6 & -0.9 & -2.0 & -1.7 & -5.1 & -2.1 & -1.8 & -1.9 & -3.3 \\
\hline 253.9 & 134.8 & 115.6 & 37.5 & 346.3 & 407.5 & -61.1 & 72.6 & 418.7 & -1.1 & $\begin{array}{l}-1.3 \\
\end{array}$ & $\begin{array}{l}-1.6 \\
\end{array}$ & -4.6 & -0.7 & -0.7 & -0.8 & -2.3 \\
\hline 263.7 & 190.5 & 62.5 & 200.3 & 311.5 & 367.9 & -94.3 & 12.3 & 389.6 & -1.7 & -2.2 & -0.8 & -4.4 & -3.5 & -2.7 & -7.8 & -7.1 \\
\hline 273.4 & 133.3 & 63.7 & 72.8 & 260.7 & 395.9 & -118.8 & 12.2 & 326.4 & -0.5 & -1.4 & -1.0 & -6.2 & -1.5 & -1.5 & -1.2 & -2.0 \\
\hline 283.2 & 259.4 & 35.3 & 351.6 & 217.8 & 410.7 & -208.9 & -108.8 & 245.3 & -5.4 & -7.1 & -12.1 & -13.1 & -5.0 & -3.5 & -6.9 & -7.3 \\
\hline 293.0 & 148.9 & 73.2 & 189.6 & 270.1 & 383.8 & -99.3 & -44.4 & 485.3 & -1.4 & -1.8 & -4.7 & -7.3 & -1.9 & -2.4 & -3.4 & -5.0 \\
\hline 302.7 & 84.7 & 117.5 & 114.0 & 331.6 & 403.6 & -131.8 & -52.3 & 436.5 & -1.0 & -2.4 & -3.0 & -5.2 & -0.9 & -0.8 & -1.2 & -4.1 \\
\hline 312.5 & 110.6 & 122.0 & 53.6 & 435.2 & 450.7 & -92.0 & -94.8 & 512.5 & -2.0 & -2.0 & -1.5 & -5.6 & -1.0 & -0.8 & -2.1 & -3.9 \\
\hline 322.3 & 163.8 & 42.5 & 104.5 & 262.9 & 569.4 & -238.5 & -129.3 & 394.8 & -8.7 & -4.7 & -5.3 & -5.2 & -2.9 & -4.3 & -5.3 & -5.4 \\
\hline 332.0 & 153.2 & 4.8 & -5.1 & 355.9 & 565.9 & -189.8 & -173.9 & 463.5 & -7.2 & -5.7 & -6.5 & -6.8 & -2.6 & -2.3 & -4.3 & -4.6 \\
\hline 341.8 & 180.2 & 20.0 & -63.8 & 351.8 & 549.1 & -144.7 & -174.6 & 461.2 & -10.9 & -12.6 & $\begin{array}{l}-13.7 \\
\end{array}$ & $\begin{array}{l}-12.1 \\
\end{array}$ & -9.5 & -6.3 & -8.1 & -9.4 \\
\hline
\end{tabular}


Table 18: Dynamic Stiffness Real and Imaginary Parts at $6800 \mathrm{rpm}$ and $783 \mathrm{kPa}(\mathrm{MN} / \mathrm{m})$

\begin{tabular}{|c|c|c|c|c|c|c|c|c|c|c|c|c|c|c|c|c|}
\hline $\mathrm{f}(\mathrm{Hz})$ & $\mathrm{R}\left(\mathrm{H}_{\mathrm{xx}}\right)$ & $\mathrm{R}\left(\mathrm{H}_{\mathrm{xy}}\right)$ & $\mathrm{R}\left(\mathrm{H}_{\mathrm{yx}}\right)$ & $\mathrm{R}\left(\mathrm{H}_{\mathrm{yv}}\right)$ & $\mathrm{I}\left(\mathrm{H}_{\mathrm{xx}}\right)$ & $\mathrm{I}\left(\mathrm{H}_{\mathrm{xy}}\right)$ & $\mathrm{I}\left(\mathrm{H}_{\mathrm{yx}}\right)$ & $\mathrm{I}\left(\mathrm{H}_{\mathrm{yv}}\right)$ & $\Delta \mathrm{R}\left(\mathrm{H}_{\mathrm{xx}}\right)$ & $\Delta \mathrm{R}\left(\mathrm{H}_{\mathrm{xy}}\right)$ & $\Delta \mathrm{R}\left(\mathrm{H}_{\mathrm{yx}}\right)$ & $\Delta \mathrm{R}\left(\mathrm{H}_{\mathrm{vv}}\right)$ & $\Delta \mathrm{I}\left(\mathrm{H}_{\mathrm{xx}}\right)$ & $\Delta \mathrm{I}\left(\mathrm{H}_{\mathrm{xy}}\right)$ & $\Delta \mathrm{I}\left(\mathrm{H}_{\mathrm{vx}}\right)$ & $\Delta \mathrm{I}\left(\mathrm{H}_{\mathrm{yv}}\right)$ \\
\hline 9.8 & 109.0 & -9.5 & -14.4 & 255.9 & 15.5 & 0.8 & -2.4 & 65.5 & -0.2 & -1.7 & -0.2 & -1.8 & -0.1 & -1.4 & -0.1 & -1.2 \\
\hline 19.5 & 110.9 & -9.4 & -12.7 & 235.7 & 31.1 & -0.3 & 0.4 & 23.4 & -0.2 & -1.4 & -0.1 & -1.6 & -0.1 & -0.7 & -0.1 & -1.0 \\
\hline 29.3 & 110.1 & -10.5 & -13.8 & 276.6 & 46.3 & 1.6 & 0.3 & 41.9 & -0.1 & -0.7 & -0.2 & -1.6 & -0.1 & -0.3 & -0.1 & -1.0 \\
\hline 39.1 & 110.0 & -10.8 & -12.5 & 264.8 & 60.0 & 2.8 & -1.2 & 74.1 & -0.1 & -0.5 & -0.1 & -1.5 & -0.2 & -0.4 & -0.1 & -0.9 \\
\hline 48.8 & 119.8 & -10.3 & -7.7 & 257.1 & 76.1 & 3.9 & -3.6 & 109.1 & -0.2 & -0.4 & -0.1 & -1.3 & -0.2 & -0.5 & -0.2 & -1.0 \\
\hline 58.6 & 119.6 & -7.8 & -7.3 & 272.6 & 88.8 & 4.6 & -5.9 & 123.2 & -0.1 & -0.4 & -0.1 & -1.4 & -0.2 & -0.4 & -0.2 & -1.0 \\
\hline 68.4 & 119.7 & -6.2 & -9.1 & 281.9 & 104.7 & 8.3 & -0.9 & 134.4 & -0.1 & -0.4 & -0.3 & -1.4 & -0.2 & -0.3 & -0.1 & -1.0 \\
\hline 78.1 & 124.6 & -1.2 & -1.8 & 266.6 & 114.7 & 6.4 & -7.4 & 145.9 & -0.2 & -0.4 & -0.2 & -1.4 & -0.2 & -0.2 & -0.3 & -0.8 \\
\hline 97.7 & 129.1 & 1.6 & -2.2 & 284.5 & 135.9 & 4.6 & -12.3 & 177.7 & -0.2 & -0.4 & -0.3 & -1.6 & -0.1 & -0.3 & -0.2 & -1.1 \\
\hline 107.4 & 128.1 & 3.1 & -0.9 & 290.5 & 154.8 & 5.3 & -13.2 & 199.5 & -0.4 & -0.5 & -0.5 & -2.3 & -0.4 & -0.5 & -0.6 & -1.2 \\
\hline 117.2 & 130.4 & 3.9 & -0.4 & 289.8 & 158.5 & 5.5 & -19.0 & 217.7 & -0.9 & -0.8 & -1.1 & -3.0 & -0.7 & -1.2 & -1.7 & -2.2 \\
\hline 127.0 & 131.0 & 6.2 & 2.2 & 273.2 & 172.6 & 6.1 & -20.0 & 233.0 & -0.3 & -0.5 & -0.4 & -1.6 & -0.2 & -0.3 & -0.4 & -1.3 \\
\hline 136.7 & 127.3 & 8.9 & 1.6 & 274.4 & 180.8 & 6.9 & -23.9 & 238.5 & -0.2 & -0.4 & -0.3 & -1.4 & -0.3 & -0.3 & -0.2 & -1.0 \\
\hline 146.5 & 139.5 & 14.8 & 5.6 & 271.2 & 196.6 & 9.5 & -25.9 & 246.8 & -0.2 & -0.4 & -0.3 & -1.5 & -0.2 & -0.3 & -0.2 & -0.8 \\
\hline 156.3 & 134.6 & 25.0 & -1.4 & 250.0 & 212.7 & 17.2 & -24.4 & 268.4 & -0.2 & -0.3 & -0.3 & -1.4 & -0.2 & -0.3 & -0.2 & -1.1 \\
\hline 166.0 & 128.8 & 22.9 & -1.0 & 304.8 & 219.9 & 11.1 & -34.4 & 315.7 & -0.2 & -0.3 & -0.2 & -1.6 & -0.3 & -0.3 & -0.1 & -0.9 \\
\hline 185.5 & 136.7 & 36.8 & -4.0 & 305.0 & 265.4 & 14.4 & -29.8 & 333.0 & -0.2 & -0.3 & -0.2 & -1.3 & -0.5 & -0.3 & -0.2 & -0.9 \\
\hline 195.3 & 137.3 & 42.5 & -6.8 & 292.4 & 259.9 & 11.5 & -34.9 & 345.1 & -0.1 & -0.2 & -0.2 & -1.5 & -0.2 & -0.3 & -0.2 & -0.9 \\
\hline 205.1 & 129.2 & 48.0 & -13.5 & 316.3 & 283.3 & 15.8 & -27.1 & 375.9 & -0.4 & -0.2 & -0.1 & -1.5 & -0.2 & -0.2 & -0.2 & -0.9 \\
\hline 214.8 & 121.8 & 52.0 & -15.9 & 306.5 & 294.1 & 18.5 & -29.4 & 372.0 & -0.1 & -0.2 & -0.1 & -1.4 & -0.3 & -0.3 & -0.2 & -0.8 \\
\hline 224.6 & 121.2 & 83.3 & -16.6 & 161.4 & 327.9 & 33.5 & -23.6 & 400.1 & -0.2 & -0.3 & -0.5 & $\begin{array}{l}-1.7 \\
\end{array}$ & -0.5 & -0.5 & -0.2 & -1.6 \\
\hline 234.4 & 108.8 & 64.6 & -37.0 & 331.5 & 346.8 & 8.3 & -18.3 & 435.5 & -0.4 & -0.4 & -0.4 & -1.6 & -0.7 & -0.4 & -0.8 & -0.9 \\
\hline 244.1 & 125.8 & 69.1 & -29.6 & 336.0 & 347.5 & 4.7 & -13.6 & 442.3 & -0.3 & -0.3 & -0.1 & -1.4 & -0.2 & -0.2 & -0.2 & -0.9 \\
\hline 253.9 & 124.4 & 70.7 & -29.5 & 355.3 & 353.6 & 6.3 & -5.0 & 452.9 & -0.2 & -0.3 & -0.2 & $\begin{array}{l}-1.6 \\
\end{array}$ & -0.3 & -0.2 & -0.2 & -0.9 \\
\hline 263.7 & 122.6 & 73.0 & -30.8 & 310.7 & 367.6 & 8.6 & 4.6 & 439.9 & -0.2 & -0.3 & -0.2 & -1.5 & -0.1 & -0.3 & -0.3 & -0.9 \\
\hline 273.4 & 116.1 & 95.1 & -34.3 & 172.2 & 394.9 & 31.5 & 19.8 & 438.0 & -0.2 & -0.4 & -0.3 & -1.8 & -0.4 & -0.3 & -0.2 & -1.3 \\
\hline 283.2 & 108.7 & 72.6 & -33.9 & 309.8 & 409.0 & 3.9 & 21.6 & 464.3 & -0.2 & -0.3 & -0.2 & -1.4 & -0.2 & -0.3 & -0.3 & -0.9 \\
\hline 293.0 & 103.9 & 128.2 & -33.0 & 282.5 & 429.1 & 1.0 & 65.7 & 676.5 & -0.3 & -1.0 & -0.5 & -3.4 & -0.4 & -0.7 & -1.0 & -3.5 \\
\hline 302.7 & 98.7 & 143.1 & -57.7 & 414.1 & 490.3 & -22.2 & 121.6 & 732.9 & -0.7 & -1.3 & -1.3 & -2.6 & -0.7 & -0.4 & -0.7 & -4.0 \\
\hline 312.5 & 74.3 & 228.5 & -265.2 & 15.1 & 613.3 & 167.1 & 171.0 & 864.6 & -2.8 & -3.4 & -4.3 & -4.6 & -3.3 & -1.9 & -5.4 & -8.5 \\
\hline 322.3 & 167.0 & 277.5 & 51.7 & 360.2 & 629.6 & 40.4 & 440.0 & 875.9 & -2.4 & -3.2 & -8.1 & -9.8 & -2.6 & -3.4 & -6.0 & -5.1 \\
\hline 332.0 & 625.2 & 161.6 & 553.6 & 478.7 & 331.1 & -119.8 & 96.2 & 439.0 & -9.3 & -2.7 & -5.1 & -3.9 & -4.6 & -2.4 & -6.2 & -1.9 \\
\hline 341.8 & 392.5 & 156.3 & 284.5 & 381.0 & 455.8 & -10.2 & 43.0 & 456.8 & -7.5 & -4.0 & -4.9 & -3.1 & -11.2 & -3.5 & -6.9 & -3.3 \\
\hline
\end{tabular}


Table 19: Dynamic Stiffness Real and Imaginary Parts at $6800 \mathrm{rpm}$ and $1567 \mathrm{kPa}(\mathrm{MN} / \mathrm{m})$

\begin{tabular}{|c|c|c|c|c|c|c|c|c|c|c|c|c|c|c|c|c|}
\hline $\mathrm{f}(\mathrm{Hz})$ & $\mathrm{R}\left(\mathrm{H}_{\mathrm{xx}}\right)$ & $\mathrm{R}\left(\mathrm{H}_{\mathrm{xy}}\right)$ & $\mathrm{R}\left(\mathrm{H}_{\mathrm{yX}}\right)$ & $\mathrm{R}\left(\mathrm{H}_{\mathrm{yv}}\right)$ & $\mathrm{I}\left(\mathrm{H}_{\mathrm{xx}}\right)$ & $\mathrm{I}\left(\mathrm{H}_{\mathrm{xy}}\right)$ & $\mathrm{I}\left(\mathrm{H}_{\mathrm{yX}}\right)$ & $\mathrm{I}\left(\mathrm{H}_{\mathrm{yv}}\right)$ & $\Delta \mathrm{R}\left(\mathrm{H}_{\mathrm{xx}}\right)$ & $\Delta \mathrm{R}\left(\mathrm{H}_{\mathrm{xy}}\right)$ & $\Delta \mathrm{R}\left(\mathrm{H}_{\mathrm{yx}}\right)$ & $\Delta \mathrm{R}\left(\mathrm{H}_{\mathrm{vv}}\right)$ & $\Delta \mathrm{I}\left(\mathrm{H}_{\mathrm{xx}}\right)$ & $\Delta \mathrm{I}\left(\mathrm{H}_{\mathrm{xy}}\right)$ & $\Delta \mathrm{I}\left(\mathrm{H}_{\mathrm{vX}}\right)$ & $\Delta \mathrm{I}\left(\mathrm{H}_{\mathrm{vy}}\right)$ \\
\hline 9.8 & 127.7 & -12.6 & -16.0 & 428.4 & 15.5 & 3.3 & -3.2 & 121.6 & -0.3 & -1.5 & -0.3 & -2.5 & -0.1 & -0.8 & -0.3 & -1.5 \\
\hline 19.5 & 129.3 & -9.5 & -13.2 & 387.6 & 31.1 & 4.4 & 0.2 & 39.0 & -0.4 & -0.8 & -0.2 & -2.1 & -0.1 & -0.5 & -0.1 & -1.3 \\
\hline 29.3 & 128.1 & -12.8 & -14.1 & 441.5 & 47.8 & 4.8 & -0.3 & 35.1 & -0.3 & -0.4 & -0.2 & -1.8 & 0.0 & -0.5 & -0.1 & -1.1 \\
\hline 39.1 & 128.0 & -12.2 & -12.5 & 421.2 & 61.6 & 4.6 & -1.9 & 62.9 & -0.2 & -0.4 & -0.2 & -1.6 & -0.2 & -0.4 & -0.1 & -0.9 \\
\hline 48.8 & 138.2 & -11.0 & -6.8 & 392.8 & 76.9 & 7.5 & -3.2 & 112.3 & -0.3 & -0.5 & -0.2 & -1.9 & -0.1 & -0.3 & -0.1 & -1.1 \\
\hline 58.6 & 137.2 & -7.5 & -6.9 & 412.0 & 90.7 & 8.8 & -6.2 & 109.3 & -0.2 & -0.3 & -0.1 & -1.6 & -0.2 & -0.4 & -0.2 & -1.2 \\
\hline 68.4 & 137.0 & -8.3 & -9.5 & 418.7 & 103.5 & 10.7 & -8.9 & 112.7 & -0.4 & -0.4 & -0.2 & -1.6 & -0.2 & -0.2 & -0.3 & -1.2 \\
\hline 78.1 & 142.7 & 0.5 & -3.1 & 402.9 & 117.8 & 13.2 & -8.8 & 139.2 & -0.3 & -0.3 & -0.2 & -1.7 & -0.3 & -0.3 & -0.3 & -0.9 \\
\hline 87.9 & 139.3 & -0.3 & -6.8 & 427.7 & 135.8 & 11.1 & -9.4 & 180.6 & -0.3 & -0.4 & -0.2 & -1.4 & -0.3 & -0.3 & -0.2 & -1.1 \\
\hline 97.7 & 146.4 & 4.0 & -5.1 & 422.5 & 141.4 & 11.3 & -15.1 & 169.1 & -0.3 & -0.4 & -0.3 & -1.6 & -0.2 & -0.3 & -0.3 & -1.1 \\
\hline 107.4 & 145.9 & 6.6 & -4.3 & 430.9 & 159.9 & 12.1 & -13.0 & 192.1 & -0.5 & -0.2 & -0.5 & -2.1 & -0.4 & -0.6 & -0.9 & -1.2 \\
\hline 117.2 & 122.0 & 8.4 & 61.0 & 435.5 & 186.8 & 15.9 & 16.7 & 212.4 & -17.8 & -4.8 & -65.6 & -8.3 & -25.1 & -3.8 & -21.2 & -12.0 \\
\hline 127.0 & 149.8 & 11.3 & -3.3 & 403.5 & 180.4 & 12.4 & -20.7 & 233.7 & -0.4 & -0.6 & -0.4 & -2.1 & -0.2 & -0.5 & -0.6 & -1.5 \\
\hline 136.7 & 146.1 & 15.7 & -3.6 & 394.0 & 189.1 & 12.7 & -23.3 & 252.0 & -0.3 & -0.3 & -0.3 & -2.1 & -0.2 & -0.5 & -0.3 & -1.0 \\
\hline 146.5 & 160.9 & 20.0 & 0.5 & 392.7 & 204.9 & 14.7 & -24.0 & 254.3 & -0.2 & -0.4 & -0.5 & -1.6 & -0.4 & -0.3 & -0.3 & -1.0 \\
\hline 156.3 & 154.5 & 27.3 & -3.7 & 396.6 & 223.5 & 19.0 & -25.0 & 255.5 & -0.3 & -0.2 & -0.3 & -1.6 & -0.4 & -0.4 & -0.2 & -0.9 \\
\hline 166.0 & 150.6 & 25.1 & -5.5 & 430.1 & 228.9 & 13.8 & -29.3 & 315.8 & -0.3 & -0.3 & -0.2 & -1.7 & -0.5 & -0.4 & -0.2 & -1.0 \\
\hline 175.8 & 138.8 & 29.5 & -6.5 & 416.3 & 249.7 & 16.9 & -28.7 & 327.3 & -0.4 & -0.3 & -0.2 & -1.6 & -0.4 & -0.3 & -0.1 & -1.0 \\
\hline 185.5 & 159.4 & 38.7 & -8.0 & 429.9 & 275.6 & 18.7 & -28.4 & 330.0 & -0.3 & -0.2 & -0.4 & -1.6 & -0.7 & -0.4 & -0.4 & -0.8 \\
\hline 195.3 & 160.4 & 44.5 & -9.5 & 419.6 & 268.7 & 16.1 & -30.1 & 343.1 & -0.2 & -0.3 & -0.2 & $\begin{array}{l}-1.4 \\
\end{array}$ & -0.5 & -0.3 & -0.4 & -0.9 \\
\hline 205.1 & 152.8 & 47.3 & -14.1 & 455.2 & 297.2 & 19.5 & -25.9 & 378.8 & -0.3 & -0.3 & -0.1 & -1.7 & -0.5 & -0.2 & -0.4 & -0.9 \\
\hline 214.8 & 145.7 & 52.6 & -16.4 & 438.4 & 306.5 & 24.4 & -26.6 & 366.9 & -0.2 & -0.2 & -0.1 & -1.6 & -0.5 & -0.3 & -0.5 & -0.9 \\
\hline 224.6 & 148.0 & 68.7 & -16.4 & 340.4 & 343.5 & 35.0 & -16.7 & 363.7 & -0.2 & -0.3 & -0.6 & -1.6 & -0.5 & -0.3 & -0.7 & -0.9 \\
\hline 234.4 & 130.9 & 64.8 & -45.7 & 465.5 & 369.3 & 13.1 & -3.4 & 438.1 & -3.8 & -1.7 & -21.4 & -2.9 & -14.5 & -1.7 & -22.8 & -5.0 \\
\hline 244.1 & 155.7 & 69.4 & -21.3 & 475.4 & 361.3 & 5.4 & -16.0 & 461.0 & -0.4 & -0.4 & -0.3 & -1.9 & -0.6 & -0.5 & -0.4 & -1.4 \\
\hline 253.9 & 154.1 & 70.4 & -20.3 & 464.1 & 364.6 & 19.1 & -11.4 & 447.7 & -0.2 & -0.2 & -0.1 & -1.8 & -0.4 & -0.2 & -0.3 & -0.8 \\
\hline 263.7 & 155.4 & 73.5 & -21.9 & 438.6 & 381.9 & 17.9 & -6.8 & 444.6 & -0.1 & -0.3 & -0.3 & -1.8 & -0.4 & -0.4 & -0.4 & -0.9 \\
\hline 273.4 & 158.7 & 84.9 & -22.1 & 343.9 & 404.8 & 32.9 & 4.0 & 417.1 & -0.3 & -0.3 & -0.2 & -1.8 & -0.7 & -0.3 & -0.4 & -0.9 \\
\hline 283.2 & 152.9 & 73.1 & -23.3 & 439.0 & 418.8 & 10.1 & -1.9 & 457.1 & -0.5 & -0.3 & -0.4 & -1.8 & -0.5 & -0.3 & -0.4 & -0.9 \\
\hline 293.0 & 151.5 & 82.3 & -28.1 & 392.0 & 434.7 & 39.7 & 11.4 & 477.3 & -0.5 & -0.2 & -0.4 & -1.7 & -0.5 & -0.3 & -0.3 & -0.8 \\
\hline 302.7 & 153.6 & 133.3 & -49.2 & 253.2 & 469.6 & 74.2 & 19.1 & 588.3 & -0.4 & -0.5 & -0.6 & -2.0 & -1.2 & -0.4 & -0.5 & -0.9 \\
\hline 312.5 & 132.8 & 117.2 & -53.5 & 296.7 & 490.0 & 98.5 & 23.7 & 546.7 & -0.7 & -0.4 & -1.4 & -2.1 & -0.8 & -0.5 & -0.5 & -1.7 \\
\hline 322.3 & 146.6 & 111.9 & -49.9 & 343.1 & 507.2 & 85.4 & 54.2 & 536.7 & -0.8 & -0.5 & -1.3 & -2.2 & -1.2 & -0.7 & -0.4 & -1.1 \\
\hline 332.0 & 159.5 & 114.9 & -13.4 & 607.6 & 558.4 & 3.3 & 119.7 & 660.0 & -2.0 & -1.0 & -2.7 & -2.7 & -2.4 & -0.6 & -1.5 & -1.7 \\
\hline 341.8 & 154.9 & 136.3 & -35.4 & 532.2 & 672.1 & 97.4 & 176.8 & 585.1 & -1.9 & -1.2 & -1.2 & -2.0 & -2.2 & -0.9 & -3.1 & -2.0 \\
\hline
\end{tabular}


Table 20: Dynamic Stiffness Real and Imaginary Parts at $6800 \mathrm{rpm}$ and $2350 \mathrm{kPa}(\mathrm{MN} / \mathrm{m})$

\begin{tabular}{|c|c|c|c|c|c|c|c|c|c|c|c|c|c|c|c|c|}
\hline $\mathrm{f}(\mathrm{Hz})$ & $\mathrm{R}\left(\mathrm{H}_{\mathrm{xx}}\right)$ & $\mathrm{R}\left(\mathrm{H}_{\mathrm{xy}}\right)$ & $\mathrm{R}\left(\mathrm{H}_{\mathrm{yx}}\right)$ & $\mathrm{R}\left(\mathrm{H}_{\mathrm{yv}}\right)$ & $\mathrm{I}\left(\mathrm{H}_{\mathrm{xx}}\right)$ & $\mathrm{I}\left(\mathrm{H}_{\mathrm{xy}}\right)$ & $\mathrm{I}\left(\mathrm{H}_{\mathrm{yx}}\right)$ & $\mathrm{I}\left(\mathrm{H}_{\mathrm{yv}}\right)$ & $\Delta R\left(H_{x x}\right)$ & $\Delta \mathrm{R}\left(\mathrm{H}_{\mathrm{xy}}\right)$ & $\Delta \mathrm{R}\left(\mathrm{H}_{\mathrm{yx}}\right)$ & $\Delta R\left(H_{y v}\right)$ & $\Delta \mathrm{I}\left(\mathrm{H}_{\mathrm{xx}}\right)$ & $\Delta \mathrm{I}\left(\mathrm{H}_{\mathrm{xy}}\right)$ & $\Delta \mathrm{I}\left(\mathrm{H}_{\mathrm{yx}}\right)$ & $\Delta \mathrm{I}\left(\mathrm{H}_{\mathrm{yv}}\right)$ \\
\hline 9.8 & 146.5 & -7.1 & -16.3 & 602.6 & 16.1 & 5.4 & -3.0 & 142.1 & -0.2 & -1.6 & -0.3 & -2.7 & -0.2 & -3.3 & -0.3 & -2.0 \\
\hline 19.5 & 148.4 & -7.9 & -14.2 & 549.7 & 32.4 & 4.1 & -0.8 & 54.4 & -0.2 & -1.1 & -0.2 & -1.8 & -0.3 & -0.9 & -0.2 & -1.2 \\
\hline 29.3 & 147.1 & -9.7 & -14.0 & 579.1 & 51.1 & 5.5 & -1.5 & 43.8 & -0.1 & -1.0 & -0.2 & -1.8 & -0.2 & -0.5 & -0.2 & -1.2 \\
\hline 39.1 & 147.2 & -8.6 & -13.0 & 564.1 & 65.6 & 6.7 & -3.2 & 70.6 & -0.1 & -0.6 & -0.2 & -1.4 & -0.2 & -0.6 & -0.1 & -1.1 \\
\hline 48.8 & 157.3 & -6.7 & -7.8 & 541.9 & 80.3 & 8.8 & -4.3 & 115.1 & -0.2 & -0.6 & -0.1 & -1.7 & -0.2 & -0.5 & -0.2 & -0.9 \\
\hline 58.6 & 156.3 & -4.2 & -8.0 & 563.9 & 96.0 & 8.2 & -7.8 & 97.9 & -0.1 & -0.6 & -0.3 & -1.5 & -0.3 & -0.4 & -0.4 & -1.0 \\
\hline 68.4 & 156.4 & -3.1 & -9.5 & 569.4 & 109.8 & 9.5 & -10.7 & 105.9 & -0.2 & -0.4 & -0.3 & -1.7 & -0.2 & -0.3 & -0.2 & -0.9 \\
\hline 78.1 & 161.6 & 6.1 & -5.3 & 550.8 & 125.4 & 15.6 & -8.2 & 139.5 & -0.1 & -0.3 & -0.1 & -1.5 & 0.0 & -0.3 & -0.3 & -0.9 \\
\hline 87.9 & 159.5 & 4.8 & -8.6 & 576.7 & 144.6 & 11.7 & -11.5 & 182.0 & -0.2 & -0.3 & -0.4 & -1.6 & -0.2 & -0.4 & -0.2 & -1.0 \\
\hline 97.7 & 166.2 & 8.3 & -8.7 & 567.0 & 150.5 & 11.4 & -16.1 & 166.2 & -0.2 & -0.3 & -0.3 & -1.5 & -0.2 & -0.3 & -0.4 & -1.2 \\
\hline 107.4 & 166.7 & 12.6 & -7.3 & 580.4 & 171.4 & 11.3 & -15.4 & 190.3 & -0.4 & -0.5 & -0.9 & -2.4 & -0.6 & -0.4 & -1.0 & -1.5 \\
\hline 117.2 & 166.8 & 14.2 & -4.7 & 572.0 & 177.9 & 11.0 & -20.4 & 213.5 & -1.1 & -0.3 & -2.4 & -3.5 & -1.0 & -1.0 & -2.3 & -2.0 \\
\hline 127.0 & 169.6 & 16.9 & -7.4 & 550.4 & 192.4 & 12.7 & -20.1 & 233.3 & -0.2 & -0.4 & -0.7 & -1.6 & -0.4 & -0.4 & -0.6 & -1.5 \\
\hline 136.7 & 166.5 & 20.5 & -7.7 & 545.5 & 202.4 & 12.6 & -23.1 & 252.7 & -0.3 & -0.3 & -0.4 & -1.7 & -0.2 & -0.4 & -0.4 & -1.0 \\
\hline 146.5 & 183.4 & 25.7 & -5.9 & 536.7 & 218.6 & 13.1 & -24.5 & 258.5 & -0.5 & -0.3 & -0.4 & -1.7 & -0.2 & -0.4 & -0.3 & -1.0 \\
\hline 156.3 & 177.6 & 31.9 & -8.7 & 544.9 & 239.2 & 16.4 & -25.0 & 246.6 & -0.2 & -0.3 & -0.4 & -1.5 & -0.3 & -0.3 & -0.4 & -0.9 \\
\hline 166.0 & 174.2 & 28.0 & -11.1 & 577.3 & 245.2 & 9.3 & -27.9 & 313.3 & -0.2 & -0.3 & -0.2 & -1.6 & -0.2 & -0.3 & -0.2 & -0.9 \\
\hline 175.8 & 163.3 & 32.3 & -11.1 & 568.9 & 268.1 & 13.2 & -26.8 & 325.5 & -0.2 & -0.3 & -0.2 & -1.6 & -0.2 & -0.3 & -0.2 & -0.9 \\
\hline 185.5 & 186.8 & 40.3 & -12.9 & 577.9 & 294.6 & 15.3 & -27.0 & 323.2 & -0.2 & -0.2 & -0.3 & -1.6 & -0.5 & -0.3 & -0.5 & -0.9 \\
\hline 195.3 & 186.7 & 43.4 & -13.1 & 568.5 & 285.8 & 14.1 & -26.5 & 327.4 & -0.3 & -0.3 & -0.2 & -1.5 & -0.3 & -0.3 & -0.3 & -0.8 \\
\hline 205.1 & 181.5 & 46.9 & -15.7 & 592.5 & 317.2 & 18.1 & -22.9 & 365.0 & -0.4 & -0.3 & -0.4 & -1.6 & -0.2 & -0.3 & -0.3 & -0.8 \\
\hline 214.8 & 174.4 & 52.1 & -16.7 & 581.7 & 327.7 & 24.1 & -24.3 & 354.2 & -0.3 & -0.4 & -0.4 & -1.7 & -0.3 & -0.4 & -0.3 & -0.8 \\
\hline 224.6 & 179.9 & 72.0 & -18.3 & 499.6 & 367.7 & 25.4 & -19.0 & 381.5 & -0.3 & -0.3 & -1.2 & -1.8 & -0.8 & -0.5 & -0.8 & -1.2 \\
\hline 234.4 & 167.9 & 57.9 & -24.5 & 614.6 & 380.3 & 12.3 & -19.5 & 417.2 & -0.4 & -0.3 & -0.8 & -1.7 & -0.9 & -0.3 & -1.2 & -1.4 \\
\hline 244.1 & 192.2 & 65.4 & -20.5 & 593.9 & 385.0 & 14.7 & -14.6 & 424.0 & -0.4 & -0.2 & -0.3 & -1.7 & -0.2 & -0.2 & -0.2 & -0.8 \\
\hline 253.9 & 190.0 & 65.0 & -17.9 & 609.2 & 386.5 & 22.1 & -10.1 & 423.3 & -0.2 & -0.3 & -0.2 & -1.4 & -0.3 & -0.3 & -0.2 & -0.9 \\
\hline 263.7 & 192.4 & 73.7 & -17.1 & 560.3 & 403.5 & 27.9 & -6.3 & 426.1 & -0.3 & -0.2 & -0.3 & -1.5 & -0.2 & -0.2 & -0.3 & -1.0 \\
\hline 273.4 & 203.3 & 83.2 & -18.7 & 484.5 & 428.1 & 39.7 & 0.2 & 397.0 & -0.3 & -0.3 & -0.2 & -1.5 & -0.3 & -0.3 & -0.1 & -0.9 \\
\hline 283.2 & 193.9 & 67.6 & -19.4 & 592.7 & 438.5 & 13.6 & -8.8 & 443.0 & -0.3 & -0.3 & -0.2 & -1.6 & -0.4 & -0.3 & -0.4 & -1.0 \\
\hline 293.0 & 197.1 & 79.7 & -20.5 & 541.3 & 455.0 & 44.4 & 2.8 & 457.1 & -0.2 & -0.3 & -0.3 & -1.6 & -0.5 & -0.2 & -0.2 & -0.9 \\
\hline 302.7 & 202.8 & 106.7 & -18.1 & 449.7 & 475.5 & 74.9 & 12.6 & 478.1 & -0.3 & -0.2 & -0.3 & -1.5 & -0.5 & -0.4 & -0.2 & -1.0 \\
\hline 312.5 & 187.4 & 110.3 & -31.0 & 475.0 & 501.2 & 96.7 & 8.3 & 482.1 & -0.3 & -0.3 & -0.2 & -1.5 & -0.7 & -0.3 & -0.3 & -0.9 \\
\hline 322.3 & 201.6 & 105.8 & -34.5 & 515.6 & 509.7 & 77.1 & 29.2 & 504.6 & -0.5 & -0.4 & -0.4 & -1.6 & -0.6 & -0.3 & -0.3 & -1.0 \\
\hline 332.0 & 227.9 & 159.0 & 1.3 & 870.6 & 516.9 & -106.0 & 137.7 & 939.5 & -0.2 & -0.9 & -1.3 & -3.2 & -1.0 & -0.8 & -0.8 & -1.4 \\
\hline 341.8 & 205.0 & 101.0 & -13.8 & 688.0 & 595.6 & 60.5 & 76.5 & 574.7 & -1.4 & -13.6 & -6.4 & -12.9 & -6.8 & -3.3 & -5.0 & -13.0 \\
\hline
\end{tabular}


Table 21: Dynamic Stiffness Real and Imaginary Parts at $6800 \mathrm{rpm}$ and $3134 \mathrm{kPa}(\mathrm{MN} / \mathrm{m})$

\begin{tabular}{|c|c|c|c|c|c|c|c|c|c|c|c|c|c|c|c|c|}
\hline $\mathrm{f}(\mathrm{Hz})$ & $\mathrm{R}\left(\mathrm{H}_{\mathrm{xx}}\right)$ & $\mathrm{R}\left(\mathrm{H}_{\mathrm{xy}}\right)$ & $\mathrm{R}\left(\mathrm{H}_{\mathrm{yx}}\right)$ & $\mathrm{R}\left(\mathrm{H}_{\mathrm{vy}}\right)$ & $\mathrm{I}\left(\mathrm{H}_{\mathrm{xx}}\right)$ & $\mathrm{I}\left(\mathrm{H}_{\mathrm{xy}}\right)$ & $\mathrm{I}\left(\mathrm{H}_{\mathrm{yx}}\right)$ & $\mathrm{I}\left(\mathrm{H}_{\mathrm{yv}}\right)$ & $\Delta \mathrm{R}\left(\mathrm{H}_{\mathrm{xx}}\right)$ & $\Delta \mathrm{R}\left(\mathrm{H}_{\mathrm{xy}}\right)$ & $\Delta \mathrm{R}\left(\mathrm{H}_{\mathrm{yx}}\right)$ & $\Delta \mathrm{R}\left(\mathrm{H}_{\mathrm{vv}}\right)$ & $\Delta \mathrm{I}\left(\mathrm{H}_{\mathrm{xx}}\right)$ & $\Delta \mathrm{I}\left(\mathrm{H}_{\mathrm{xy}}\right)$ & $\Delta \mathrm{I}\left(\mathrm{H}_{\mathrm{yx}}\right)$ & $\Delta \mathrm{I}\left(\mathrm{H}_{\mathrm{yv}}\right)$ \\
\hline 9.8 & 171.7 & -10.7 & -16.6 & 731.8 & 17.6 & 7.3 & -2.4 & 138.8 & -0.1 & -0.8 & -0.3 & -3.5 & -0.2 & -3.0 & -0.2 & -2.5 \\
\hline 19.5 & 173.3 & -5.8 & -14.7 & 676.0 & 34.9 & 5.1 & -1.8 & 57.3 & -0.1 & -1.5 & -0.2 & -2.8 & -0.1 & -1.5 & -0.2 & -2.8 \\
\hline 29.3 & 171.8 & -6.6 & -14.6 & 698.4 & 55.0 & 6.2 & -3.0 & 33.1 & -0.2 & -0.7 & -0.3 & -1.7 & -0.1 & -0.3 & -0.1 & -1.6 \\
\hline 39.1 & 172.4 & -7.2 & -13.6 & 676.7 & 71.4 & 7.6 & -4.9 & 72.0 & -0.3 & -0.7 & -0.2 & -1.7 & -0.2 & -0.6 & -0.2 & -1.5 \\
\hline 48.8 & 183.8 & -4.0 & -8.9 & 663.5 & 85.5 & 9.9 & -5.8 & 116.9 & -0.2 & -0.5 & -0.3 & -1.7 & -0.3 & -0.5 & -0.3 & -1.5 \\
\hline 58.6 & 182.3 & -0.8 & -9.6 & 689.8 & 103.1 & 8.3 & -9.4 & 92.1 & -0.1 & -0.2 & -0.2 & -1.5 & -0.3 & -0.6 & -0.3 & -1.2 \\
\hline 68.4 & 183.3 & 0.4 & -11.3 & 700.8 & 118.5 & 9.7 & -12.9 & 101.4 & -0.2 & -0.4 & -0.3 & -1.6 & -0.2 & -0.5 & -0.2 & -1.0 \\
\hline 78.1 & 186.6 & 7.1 & -11.5 & 672.7 & 134.4 & 19.5 & -9.7 & 146.5 & -0.1 & -0.5 & -0.4 & -1.8 & -0.3 & -0.4 & -0.1 & -1.1 \\
\hline 87.9 & 187.4 & 7.7 & -11.3 & 707.3 & 156.8 & 11.7 & -13.4 & 181.4 & -0.3 & -0.4 & -0.5 & -1.5 & -0.2 & -0.3 & -0.3 & -1.4 \\
\hline 97.7 & 193.7 & 11.3 & -11.9 & 692.7 & 161.9 & 10.8 & -18.3 & 160.8 & -0.3 & -0.5 & -0.5 & -1.7 & -0.1 & -0.3 & -0.4 & -1.2 \\
\hline 107.4 & 196.0 & 15.8 & -10.9 & 708.0 & 183.7 & 11.3 & -17.5 & 180.9 & -0.6 & -0.4 & -1.8 & -3.0 & -0.5 & -0.7 & -0.9 & -1.8 \\
\hline 117.2 & 194.8 & 16.0 & -5.4 & 692.1 & 192.5 & 8.8 & -23.5 & 210.6 & -3.7 & -2.1 & -8.7 & -3.4 & -1.7 & -1.4 & -6.5 & -6.8 \\
\hline 127.0 & 199.0 & 20.1 & -11.2 & 672.4 & 207.2 & 11.6 & -21.3 & 225.2 & -0.1 & -0.5 & -1.2 & -2.3 & -0.5 & -0.5 & -0.4 & -1.6 \\
\hline 136.7 & 194.4 & 24.7 & -12.2 & 671.0 & 217.7 & 10.9 & -24.4 & 246.6 & -0.3 & -0.4 & -0.7 & -1.7 & -0.4 & -0.5 & -0.6 & -1.3 \\
\hline 146.5 & 215.2 & 31.1 & -10.1 & 666.4 & 233.5 & 8.2 & -26.8 & 264.8 & -0.4 & -0.4 & -0.2 & -1.7 & -0.3 & -0.4 & -0.8 & -1.7 \\
\hline 156.3 & 211.3 & 35.8 & -12.5 & 675.8 & 256.7 & 13.4 & -25.5 & 236.5 & -0.2 & -0.3 & -0.1 & -1.6 & -0.3 & -0.2 & -0.4 & -1.1 \\
\hline 166.0 & 206.8 & 29.3 & -15.6 & 702.5 & 261.7 & 6.9 & -28.0 & 297.2 & -0.3 & -0.3 & -0.2 & -1.5 & -0.3 & -0.4 & -0.4 & -1.1 \\
\hline 175.8 & 197.8 & 34.5 & -15.3 & 694.2 & 288.2 & 10.8 & -26.8 & 317.5 & -0.2 & -0.3 & -0.1 & -1.4 & -0.2 & -0.2 & -0.2 & -1.0 \\
\hline 185.5 & 226.0 & 42.0 & -16.6 & 699.0 & 313.0 & 12.2 & -26.8 & 304.2 & -0.2 & -0.3 & -0.5 & -1.6 & -0.4 & -0.3 & -0.4 & -0.9 \\
\hline 195.3 & 222.2 & 43.9 & -17.1 & 692.1 & 302.2 & 12.2 & -26.1 & 307.8 & -0.3 & -0.3 & -0.3 & $\begin{array}{l}-1.4 \\
\end{array}$ & -0.3 & -0.4 & -0.4 & -1.0 \\
\hline 205.1 & 220.4 & 48.5 & -17.9 & 707.3 & 338.1 & 17.6 & -22.3 & 340.0 & -0.4 & -0.3 & -0.3 & -1.5 & -0.4 & -0.2 & -0.4 & -1.0 \\
\hline 214.8 & 211.5 & 55.5 & -18.4 & 690.2 & 347.9 & 23.9 & -24.7 & 335.3 & -0.3 & -0.2 & -0.3 & $\begin{array}{l}-1.4 \\
\end{array}$ & -0.3 & -0.3 & -0.3 & -1.0 \\
\hline 224.6 & 221.6 & 67.3 & -19.8 & 621.4 & 392.6 & 31.8 & -18.1 & 329.1 & -0.2 & -0.2 & -0.3 & -1.7 & -0.6 & -0.3 & -0.5 & -1.4 \\
\hline 234.4 & 208.0 & 55.9 & -25.6 & 743.7 & 405.1 & 10.0 & -19.3 & 400.5 & -0.9 & -0.4 & -1.7 & -2.1 & -0.7 & -0.6 & -2.6 & -1.6 \\
\hline 244.1 & 235.6 & 66.1 & -20.6 & 713.9 & 409.4 & 13.4 & -14.3 & 403.5 & -0.4 & -0.3 & -0.4 & -1.5 & -0.2 & -0.3 & -0.4 & -1.1 \\
\hline 253.9 & 232.9 & 66.6 & -17.8 & 722.4 & 410.3 & 24.0 & -10.2 & 396.7 & -0.2 & -0.2 & -0.2 & -1.5 & -0.3 & -0.3 & -0.4 & -1.0 \\
\hline 263.7 & 238.1 & 74.9 & -15.1 & 676.6 & 427.8 & 29.9 & -6.1 & 397.2 & -0.2 & -0.2 & -0.1 & -1.5 & -0.1 & -0.3 & -0.3 & -1.0 \\
\hline 273.4 & 255.1 & 88.5 & -18.5 & 597.2 & 454.0 & 43.3 & -0.6 & 368.0 & -0.2 & -0.4 & -0.2 & -1.6 & -0.3 & -0.2 & -0.3 & -1.1 \\
\hline 283.2 & 246.0 & 69.0 & -15.7 & 724.0 & 462.4 & 8.2 & -14.0 & 429.7 & -0.4 & -0.4 & -0.3 & -1.9 & -0.5 & -0.4 & -0.2 & -1.2 \\
\hline 293.0 & 251.2 & 95.9 & -14.0 & 644.2 & 476.6 & 40.5 & -0.9 & 463.1 & -0.5 & -0.3 & -0.6 & -1.6 & -0.3 & -0.4 & -0.2 & -1.0 \\
\hline 302.7 & 260.1 & 115.5 & -10.4 & 611.3 & 492.8 & 54.7 & 9.3 & 487.4 & -0.4 & -0.3 & -0.3 & -2.4 & -0.5 & -0.7 & -0.3 & -1.2 \\
\hline 312.5 & 249.0 & 108.6 & -25.9 & 679.0 & 522.4 & 69.5 & 4.8 & 465.8 & -0.3 & -0.4 & -0.5 & -2.5 & -0.6 & -0.9 & -0.4 & -2.9 \\
\hline 322.3 & 262.2 & 174.8 & -28.2 & 494.1 & 525.5 & 83.8 & 17.9 & 570.1 & -0.7 & -1.0 & -1.2 & -7.5 & -0.6 & -4.1 & -0.4 & -9.2 \\
\hline 332.0 & 289.4 & 373.5 & -33.9 & 636.8 & 540.1 & -166.6 & 84.5 & 1416.3 & -0.9 & -10.9 & -1.9 & -33.1 & -1.0 & -7.0 & -2.1 & -7.9 \\
\hline 341.8 & 285.9 & 119.1 & -36.6 & 831.8 & 606.2 & 30.8 & 59.4 & 561.6 & -1.3 & -0.9 & -1.6 & -6.3 & -0.7 & -2.4 & -1.4 & -4.7 \\
\hline
\end{tabular}


Table 22: Dynamic Stiffness Real and Imaginary Parts at $9000 \mathrm{rpm}$ and $0 \mathrm{kPa}(\mathrm{MN} / \mathrm{m})$

\begin{tabular}{|c|c|c|c|c|c|c|c|c|c|c|c|c|c|c|c|c|}
\hline $\mathrm{f}(\mathrm{Hz})$ & $\mathrm{R}\left(\mathrm{H}_{\mathrm{xx}}\right)$ & $\mathrm{R}\left(\mathrm{H}_{\mathrm{xy}}\right)$ & $\mathrm{R}\left(\mathrm{H}_{\mathrm{yx}}\right)$ & $\mathrm{R}\left(\mathrm{H}_{\mathrm{vv}}\right)$ & $\mathrm{I}\left(\mathrm{H}_{\mathrm{xx}}\right)$ & $\mathrm{I}\left(\mathrm{H}_{\mathrm{xy}}\right)$ & $\mathrm{I}\left(\mathrm{H}_{\mathrm{yx}}\right)$ & $\mathrm{I}\left(\mathrm{H}_{\mathrm{yv}}\right)$ & $\Delta \mathrm{R}\left(\mathrm{H}_{\mathrm{xx}}\right)$ & $\Delta \mathrm{R}\left(\mathrm{H}_{\mathrm{xy}}\right)$ & $\Delta \mathrm{R}\left(\mathrm{H}_{\mathrm{yx}}\right)$ & $\Delta \mathrm{R}\left(\mathrm{H}_{\mathrm{vv}}\right)$ & $\Delta \mathrm{I}\left(\mathrm{H}_{\mathrm{xx}}\right)$ & $\Delta \mathrm{I}\left(\mathrm{H}_{\mathrm{xv}}\right)$ & $\Delta \mathrm{I}\left(\mathrm{H}_{\mathrm{yx}}\right)$ & $\Delta \mathrm{I}\left(\mathrm{H}_{\mathrm{vv}}\right)$ \\
\hline 9.8 & 133.3 & -13.7 & -15.6 & 219.5 & 10.7 & 13.3 & 4.4 & -52.0 & -0.3 & -1.4 & -0.4 & -4.6 & -0.4 & -1.0 & -0.2 & -1.8 \\
\hline 19.5 & 131.9 & -16.5 & -17.8 & 197.8 & 25.2 & -0.7 & -2.4 & 34.1 & -0.2 & -1.3 & -0.1 & -4.2 & -0.2 & -1.0 & -0.3 & -3.6 \\
\hline 29.3 & 130.9 & -20.8 & -18.5 & 227.2 & 57.8 & 5.0 & 3.2 & 38.2 & -0.1 & -0.9 & -0.2 & -4.0 & -0.1 & -0.6 & -0.1 & -2.1 \\
\hline 39.1 & 127.4 & -20.4 & -20.4 & 250.2 & 70.1 & 3.6 & -2.0 & 80.3 & -0.1 & -1.4 & -0.1 & -3.5 & -0.2 & -0.5 & -0.2 & -2.4 \\
\hline 48.8 & 137.3 & -21.0 & -18.1 & 280.1 & 69.9 & 7.0 & -0.7 & 110.5 & -0.1 & -0.9 & -0.1 & -3.4 & -0.2 & -0.4 & -0.4 & -1.8 \\
\hline 58.6 & 142.1 & -15.8 & -13.6 & 290.0 & 94.8 & 4.8 & -0.7 & 129.8 & -0.3 & -1.1 & -0.2 & -3.4 & -0.2 & -0.5 & -0.2 & -2.0 \\
\hline 68.4 & 147.2 & -13.2 & -13.3 & 292.8 & 106.4 & 3.0 & -3.5 & 133.9 & -0.1 & -0.9 & -0.2 & -3.2 & -0.2 & -0.4 & -0.2 & -1.9 \\
\hline 78.1 & 144.1 & -12.3 & -8.2 & 303.4 & 119.2 & 3.2 & -10.1 & 149.6 & -0.1 & -0.8 & -0.1 & -3.4 & -0.1 & -0.3 & -0.2 & -1.6 \\
\hline 87.9 & 154.6 & -9.8 & -5.2 & 319.9 & 137.9 & 2.9 & -4.9 & 169.0 & -0.1 & -0.9 & -0.1 & -3.6 & -0.2 & -0.4 & -0.1 & -2.1 \\
\hline 97.7 & 148.7 & -6.3 & -6.4 & 302.6 & 143.8 & 1.4 & -15.0 & 172.1 & -0.1 & -0.9 & -0.1 & -3.2 & -0.1 & -0.4 & -0.2 & -1.7 \\
\hline 107.4 & 158.4 & -3.5 & -5.0 & 299.2 & 159.1 & 1.2 & -8.7 & 181.7 & -0.1 & -0.9 & -0.2 & -3.2 & -0.2 & -0.5 & -0.2 & -1.7 \\
\hline 117.2 & 152.2 & -4.6 & -5.2 & 325.6 & 174.1 & 0.2 & -13.4 & 214.4 & -0.1 & -0.8 & -0.2 & -3.2 & -0.2 & -0.4 & -0.3 & -1.8 \\
\hline 127.0 & 151.9 & -0.8 & -3.4 & 330.3 & 185.1 & -2.7 & -15.1 & 192.8 & -0.2 & -1.0 & -0.2 & -3.4 & -0.2 & -0.3 & -0.4 & -1.9 \\
\hline 136.7 & 146.0 & -0.1 & 1.5 & 332.4 & 197.1 & -3.3 & -17.7 & 186.7 & -0.1 & -0.8 & -0.5 & -3.5 & -0.3 & -0.5 & -0.4 & -1.9 \\
\hline 146.5 & 170.8 & 3.5 & 6.4 & 338.2 & 200.4 & -5.2 & -14.3 & 204.5 & -0.7 & -2.0 & -1.7 & -4.7 & -0.9 & -1.4 & -1.2 & -4.4 \\
\hline 156.3 & 170.3 & 5.9 & 7.9 & 289.3 & 216.1 & 3.7 & -18.1 & 320.6 & -0.4 & -1.1 & -1.0 & -3.8 & -0.5 & -0.4 & -0.8 & -1.9 \\
\hline 166.0 & 162.3 & 9.5 & 5.8 & 332.6 & 225.1 & 1.3 & -21.1 & 272.5 & -0.4 & -0.8 & -0.3 & -3.9 & -0.3 & -0.5 & -0.3 & -1.6 \\
\hline 175.8 & 146.0 & 10.2 & 6.9 & 379.7 & 251.6 & 4.4 & -18.0 & 313.2 & -0.3 & -1.0 & -0.3 & -3.6 & -0.3 & -0.3 & -0.4 & -2.0 \\
\hline 185.5 & 166.8 & 18.5 & 9.2 & 363.9 & 246.4 & 6.8 & -27.0 & 282.9 & -0.1 & -0.9 & -0.3 & -3.4 & -0.3 & -0.4 & -0.3 & -1.7 \\
\hline 195.3 & 171.0 & 25.7 & 18.0 & 390.8 & 251.0 & 3.1 & -26.8 & 339.1 & -0.2 & -0.9 & -0.4 & -3.5 & -0.3 & -0.5 & -0.6 & -1.7 \\
\hline 205.1 & 158.0 & 28.8 & 7.2 & 375.3 & 279.9 & 17.0 & -26.0 & 349.6 & -0.4 & -0.8 & -0.1 & -3.6 & -0.2 & -0.4 & -0.2 & -2.2 \\
\hline 214.8 & 140.1 & 33.2 & 2.3 & 360.0 & 302.3 & 21.6 & -27.2 & 383.5 & -0.4 & -1.0 & -0.2 & -4.0 & -0.4 & -0.5 & -0.2 & -1.8 \\
\hline 224.6 & 152.4 & 53.7 & 9.0 & 354.6 & 341.2 & 13.8 & -18.1 & 374.8 & -0.4 & -1.4 & -0.4 & -3.9 & -0.5 & -0.6 & -0.3 & -2.7 \\
\hline 234.4 & 139.5 & 61.0 & 6.6 & 381.1 & 345.4 & 14.8 & -17.1 & 386.1 & -0.2 & -1.2 & -0.2 & -4.2 & -0.2 & -0.6 & -0.6 & -2.0 \\
\hline 244.1 & 128.7 & 77.8 & -0.2 & 425.2 & 358.1 & 36.0 & 0.3 & 432.4 & -0.3 & -1.2 & -0.3 & -5.7 & -0.2 & -1.3 & -0.4 & -4.1 \\
\hline 253.9 & 135.0 & 100.6 & -4.4 & 490.1 & 368.6 & 38.0 & 20.1 & 426.4 & -0.1 & -1.2 & -0.7 & -6.4 & -0.5 & -2.3 & -0.3 & -4.7 \\
\hline 263.7 & 145.5 & 93.0 & 0.2 & 429.7 & 393.5 & 18.4 & 28.6 & 432.9 & -0.5 & -1.2 & -0.8 & -4.5 & -0.4 & -2.1 & -0.8 & -4.5 \\
\hline 273.4 & 202.4 & 150.0 & 99.0 & 497.7 & 428.6 & 30.1 & -32.5 & 406.1 & -1.0 & -1.8 & -1.1 & -4.4 & -1.1 & -1.0 & -1.3 & -4.1 \\
\hline 283.2 & 221.1 & 229.2 & 167.2 & 673.3 & 445.0 & 17.7 & 34.0 & 341.3 & -1.5 & -4.3 & -3.4 & -7.1 & -1.4 & -1.9 & -1.7 & -9.8 \\
\hline 293.0 & 238.1 & 104.6 & 207.4 & 388.7 & 328.5 & -119.9 & -162.9 & 198.0 & -0.9 & -2.1 & -1.4 & -8.7 & -2.0 & -2.3 & -5.1 & -7.4 \\
\hline 302.7 & 184.0 & 212.7 & 11.8 & 458.1 & 375.2 & -108.2 & -121.0 & 360.1 & -1.1 & -2.6 & -0.9 & -4.1 & -0.7 & -2.1 & -1.0 & -3.4 \\
\hline 312.5 & 203.2 & 97.5 & 32.1 & 467.3 & 436.2 & -95.7 & -40.2 & 314.0 & -0.8 & -6.7 & -0.8 & -5.2 & -3.1 & -2.9 & -2.0 & -3.2 \\
\hline 322.3 & 153.5 & 90.4 & 37.4 & 377.3 & 402.9 & -47.2 & -42.2 & 387.5 & -0.7 & -1.8 & -0.9 & -3.8 & -0.6 & -0.5 & -0.5 & -1.9 \\
\hline 332.0 & 165.9 & 101.6 & 28.1 & 399.6 & 384.7 & -85.3 & -64.1 & 354.2 & -0.6 & -1.0 & -1.0 & -3.8 & -0.4 & -0.7 & -1.1 & -2.6 \\
\hline 341.8 & 88.6 & 96.4 & 100.7 & 420.9 & 392.6 & -62.2 & -31.0 & 338.1 & -1.2 & -1.3 & -2.9 & -5.0 & -2.8 & -2.2 & -2.2 & -2.1 \\
\hline
\end{tabular}


Table 23: Dynamic Stiffness Real and Imaginary Parts at $9000 \mathrm{rpm}$ and $783 \mathrm{kPa}(\mathrm{MN} / \mathrm{m})$

\begin{tabular}{|c|c|c|c|c|c|c|c|c|c|c|c|c|c|c|c|c|}
\hline $\mathrm{f}(\mathrm{Hz})$ & $\mathrm{R}\left(\mathrm{H}_{\mathrm{xx}}\right)$ & $\mathrm{R}\left(\mathrm{H}_{\mathrm{xy}}\right)$ & $\mathrm{R}\left(\mathrm{H}_{\mathrm{yx}}\right)$ & $\mathrm{R}\left(\mathrm{H}_{\mathrm{yv}}\right)$ & $\mathrm{I}\left(\mathrm{H}_{\mathrm{xx}}\right)$ & $\mathrm{I}\left(\mathrm{H}_{\mathrm{xy}}\right)$ & $\mathrm{I}\left(\mathrm{H}_{\mathrm{vx}}\right)$ & $\mathrm{I}\left(\mathrm{H}_{\mathrm{vv}}\right)$ & $\Delta \mathrm{R}\left(\mathrm{H}_{\mathrm{xx}}\right)$ & $\Delta \mathrm{R}\left(\mathrm{H}_{\mathrm{xy}}\right)$ & $\Delta \mathrm{R}\left(\mathrm{H}_{\mathrm{yx}}\right)$ & $\Delta \mathrm{R}\left(\mathrm{H}_{\mathrm{yv}}\right)$ & $\Delta \mathrm{I}\left(\mathrm{H}_{\mathrm{xx}}\right)$ & $\Delta \mathrm{I}\left(\mathrm{H}_{\mathrm{xy}}\right)$ & $\Delta \mathrm{I}\left(\mathrm{H}_{\mathrm{vx}}\right)$ & $\Delta \mathrm{I}\left(\mathrm{H}_{\mathrm{yv}}\right)$ \\
\hline 9.8 & 145.3 & -27.5 & -19.1 & 335.7 & 13.4 & 5.0 & -3.8 & 103.2 & -0.4 & -1.5 & -0.2 & -2.8 & -0.3 & -1.3 & -0.4 & -2.5 \\
\hline 19.5 & 142.8 & -23.5 & -15.8 & 326.8 & 25.7 & 5.9 & 1.5 & 23.2 & -0.2 & -0.8 & -0.2 & -2.0 & -0.1 & -0.6 & -0.2 & -1.5 \\
\hline 29.3 & 140.9 & -25.6 & -18.1 & 366.1 & 57.5 & 5.1 & 3.0 & 26.8 & -0.1 & -0.4 & -0.3 & -1.7 & -0.1 & -0.6 & -0.1 & -1.1 \\
\hline 39.1 & 140.4 & -23.8 & -17.1 & 356.7 & 69.5 & 7.6 & -0.1 & 73.9 & -0.2 & -0.6 & -0.1 & -1.4 & -0.2 & -0.6 & -0.2 & -1.2 \\
\hline 48.8 & 152.7 & -22.0 & -12.6 & 340.6 & 74.9 & 8.9 & -2.8 & 120.6 & -0.1 & -0.3 & -0.1 & -1.5 & -0.2 & -0.5 & -0.2 & -1.3 \\
\hline 58.6 & 152.1 & -20.0 & -11.4 & 361.5 & 96.4 & 9.8 & -4.4 & 128.5 & -0.1 & -0.5 & -0.1 & -1.4 & -0.2 & -0.4 & -0.2 & -1.0 \\
\hline 68.4 & 155.1 & -16.2 & -9.7 & 375.3 & 112.4 & 16.0 & 0.1 & 132.4 & -0.2 & -0.5 & -0.1 & -1.4 & -0.2 & -0.4 & -0.2 & -1.0 \\
\hline 78.1 & 156.9 & -10.6 & -6.9 & 362.3 & 122.8 & 13.9 & -5.0 & 150.6 & -0.2 & -0.5 & -0.3 & $\begin{array}{l}-1.4 \\
\end{array}$ & -0.2 & -0.4 & -0.1 & -0.9 \\
\hline 87.9 & 163.6 & -10.0 & -7.0 & 389.2 & 141.1 & 12.7 & -7.1 & 186.2 & -0.2 & -0.4 & -0.1 & -1.5 & -0.2 & -0.4 & -0.1 & -0.8 \\
\hline 97.7 & 162.6 & -5.0 & -6.4 & 383.9 & 148.1 & 13.0 & -10.3 & 172.9 & -0.3 & -0.3 & -0.3 & -1.4 & -0.1 & -0.3 & -0.1 & -0.9 \\
\hline 107.4 & 170.2 & -1.2 & -4.4 & 394.0 & 161.9 & 13.8 & -11.9 & 190.7 & -0.2 & -0.5 & -0.2 & -1.5 & -0.2 & -0.3 & -0.1 & -0.9 \\
\hline 117.2 & 161.7 & 0.0 & -5.8 & 396.7 & 177.2 & 12.6 & -14.7 & 214.4 & -0.2 & -0.3 & -0.2 & -1.5 & -0.2 & -0.3 & -0.1 & -0.9 \\
\hline 127.0 & 167.8 & 3.5 & -4.6 & 379.6 & 187.2 & 12.6 & -16.9 & 226.1 & -0.2 & -0.3 & -0.2 & -1.6 & -0.2 & -0.3 & -0.2 & -1.1 \\
\hline 136.7 & 162.6 & 6.3 & -3.4 & 380.3 & 202.4 & 11.3 & -18.2 & 235.8 & -0.3 & -0.5 & -0.5 & -1.5 & -0.4 & -0.4 & -0.2 & -1.1 \\
\hline 146.5 & 180.2 & 12.3 & -0.4 & 377.4 & 204.7 & 11.8 & -16.9 & 233.8 & -0.6 & -0.7 & -0.9 & -2.8 & -0.6 & -1.1 & -1.0 & -1.6 \\
\hline 156.3 & 186.5 & 22.1 & -4.8 & 360.9 & 220.1 & 15.4 & -15.6 & 251.2 & -0.7 & -0.7 & -0.7 & -1.9 & -0.5 & -0.7 & -1.0 & -1.9 \\
\hline 166.0 & 176.4 & 17.7 & 0.4 & 407.5 & 231.2 & 12.2 & -22.6 & 285.9 & -0.5 & -0.5 & -0.4 & -1.7 & -0.4 & -0.4 & -0.5 & -1.1 \\
\hline 175.8 & 169.3 & 19.1 & -1.3 & 392.3 & 259.4 & 15.3 & -22.6 & 301.8 & -0.4 & -0.3 & -0.3 & -1.7 & -0.2 & -0.4 & -0.3 & -1.2 \\
\hline 185.5 & 182.0 & 25.9 & 1.9 & 402.7 & 257.7 & 15.8 & $\begin{array}{l}-25.4 \\
\end{array}$ & 303.5 & -0.2 & -0.3 & -0.1 & -1.8 & -0.3 & -0.3 & -0.2 & -1.1 \\
\hline 195.3 & 189.1 & 33.6 & 0.9 & 384.7 & 265.6 & 16.1 & -29.0 & 312.1 & -0.2 & -0.3 & -0.3 & -1.6 & -0.2 & -0.4 & -0.1 & -0.9 \\
\hline 205.1 & 177.7 & 38.8 & -4.9 & 406.9 & 292.1 & 24.5 & -27.5 & 352.1 & -0.5 & -0.2 & -0.3 & -1.7 & -0.3 & -0.3 & -0.2 & -1.0 \\
\hline 214.8 & 157.9 & 44.3 & -4.5 & 387.1 & 307.0 & 29.5 & -31.9 & 343.6 & -0.3 & -0.3 & -0.2 & -1.5 & -0.3 & -0.4 & -0.1 & -1.1 \\
\hline 224.6 & 176.3 & 68.5 & -17.6 & 277.1 & 336.8 & 32.7 & -29.5 & 386.6 & -0.3 & -0.3 & -0.2 & $\begin{array}{l}-1.7 \\
\end{array}$ & -0.5 & -0.3 & -0.3 & -0.8 \\
\hline 234.4 & 158.1 & 58.6 & -20.3 & 411.7 & 348.7 & 20.9 & -31.4 & 407.0 & -0.5 & -0.3 & -0.2 & -1.6 & -0.3 & -0.4 & -0.2 & -1.1 \\
\hline 244.1 & 151.7 & 66.3 & -21.0 & 416.3 & 352.1 & 20.0 & -32.5 & 419.7 & -0.3 & -0.2 & -0.2 & -1.5 & -0.2 & -0.4 & -0.1 & -0.9 \\
\hline 253.9 & 160.1 & 70.5 & -28.8 & 436.7 & 364.1 & 20.5 & -23.3 & 436.2 & -0.3 & -0.3 & -0.4 & -1.9 & -0.4 & -0.4 & -0.3 & -1.1 \\
\hline 263.7 & 169.0 & 78.0 & -32.4 & 387.8 & 382.6 & 22.9 & -15.1 & 422.4 & -0.3 & -0.3 & -0.2 & -1.4 & -0.2 & -0.3 & -0.2 & -1.0 \\
\hline 273.4 & 162.8 & 99.0 & -47.3 & 268.5 & 413.6 & 38.5 & -2.2 & 443.9 & -0.3 & -0.3 & -0.6 & -1.6 & -0.3 & -0.3 & -0.3 & -1.6 \\
\hline 283.2 & 179.5 & 83.0 & -35.2 & 381.5 & 417.6 & 22.3 & 6.2 & 448.0 & -0.3 & -0.2 & -0.5 & -1.5 & -0.3 & -0.3 & -0.2 & -1.0 \\
\hline 293.0 & 178.9 & 133.0 & -39.9 & 384.7 & 419.8 & 12.1 & 54.1 & 656.4 & -0.4 & -1.1 & -0.6 & -7.4 & -0.3 & -1.1 & -0.9 & -3.3 \\
\hline 302.7 & 175.6 & 137.0 & -48.8 & 492.1 & 457.9 & -2.4 & 84.6 & 682.2 & -1.1 & -2.2 & -2.1 & -6.7 & -0.9 & -1.5 & -3.6 & -9.2 \\
\hline 312.5 & 153.7 & 186.3 & -176.2 & 286.9 & 538.9 & 92.6 & 88.5 & 748.9 & -0.9 & -1.5 & -2.9 & -3.0 & -1.1 & -0.6 & -2.6 & -4.3 \\
\hline 322.3 & 187.8 & 194.8 & -53.8 & 498.7 & 484.8 & -6.0 & 277.6 & 836.6 & -0.6 & -4.0 & -5.2 & -13.1 & -2.3 & -2.8 & -2.5 & -7.9 \\
\hline 332.0 & 244.7 & 196.7 & -9.7 & 532.3 & 595.0 & 48.8 & 260.3 & 623.5 & -1.7 & -1.3 & -1.3 & -3.0 & -1.6 & -1.0 & -2.5 & -2.0 \\
\hline 341.8 & 301.7 & 247.8 & 133.0 & 593.0 & 651.2 & 52.2 & 322.6 & 581.1 & -1.7 & -1.0 & -4.0 & -3.9 & -1.4 & -1.2 & -3.3 & -3.1 \\
\hline
\end{tabular}


Table 24: Dynamic Stiffness Real and Imaginary Parts at $9000 \mathrm{rpm}$ and $1567 \mathrm{kPa}$ (MN/m)

\begin{tabular}{|c|c|c|c|c|c|c|c|c|c|c|c|c|c|c|c|c|}
\hline $\mathrm{f}(\mathrm{Hz})$ & $\mathrm{R}\left(\mathrm{H}_{\mathrm{xx}}\right)$ & $\mathrm{R}\left(\mathrm{H}_{\mathrm{xy}}\right)$ & $\mathrm{R}\left(\mathrm{H}_{\mathrm{yX}}\right)$ & $\mathrm{R}\left(\mathrm{H}_{\mathrm{yv}}\right)$ & $\mathrm{I}\left(\mathrm{H}_{\mathrm{xx}}\right)$ & $\mathrm{I}\left(\mathrm{H}_{\mathrm{xy}}\right)$ & $\mathrm{I}\left(\mathrm{H}_{\mathrm{yx}}\right)$ & $\mathrm{I}\left(\mathrm{H}_{\mathrm{yv}}\right)$ & $\Delta \mathrm{R}\left(\mathrm{H}_{\mathrm{xx}}\right)$ & $\Delta \mathrm{R}\left(\mathrm{H}_{\mathrm{xy}}\right)$ & $\Delta \mathrm{R}\left(\mathrm{H}_{\mathrm{yx}}\right)$ & $\Delta \mathrm{R}\left(\mathrm{H}_{\mathrm{vv}}\right)$ & $\Delta \mathrm{I}\left(\mathrm{H}_{\mathrm{xx}}\right)$ & $\Delta \mathrm{I}\left(\mathrm{H}_{\mathrm{xy}}\right)$ & $\Delta \mathrm{I}\left(\mathrm{H}_{\mathrm{yx}}\right)$ & $\Delta \mathrm{I}\left(\mathrm{H}_{\mathrm{vv}}\right)$ \\
\hline 9.8 & 165.7 & -26.5 & -21.3 & 478.4 & 14.8 & 5.9 & -4.4 & 148.0 & -0.1 & -1.2 & -0.3 & -2.7 & -0.5 & -2.9 & -0.4 & -2.7 \\
\hline 19.5 & 163.9 & -26.1 & -20.1 & 476.5 & 28.4 & 8.1 & 0.3 & 51.5 & -0.2 & -1.6 & -0.2 & -1.9 & -0.3 & -1.1 & -0.2 & -2.2 \\
\hline 29.3 & 161.9 & -23.5 & -19.8 & 524.1 & 57.6 & 5.9 & 2.3 & 26.7 & -0.4 & -0.9 & -0.3 & -2.2 & -0.2 & -0.3 & -0.2 & -1.3 \\
\hline 39.1 & 161.4 & -22.2 & -17.4 & 491.6 & 68.6 & 9.6 & 0.2 & 58.4 & -0.2 & -0.5 & -0.2 & -1.9 & -0.2 & -0.5 & -0.2 & -0.8 \\
\hline 48.8 & 172.9 & -20.1 & -12.7 & 466.0 & 76.4 & 11.5 & -2.5 & 112.8 & -0.3 & -0.3 & -0.1 & -1.5 & -0.2 & -0.5 & -0.2 & -1.2 \\
\hline 58.6 & 172.4 & -18.9 & -11.6 & 492.2 & 97.3 & 12.3 & -3.7 & 102.2 & -0.2 & -0.6 & -0.1 & -2.1 & -0.3 & -0.3 & -0.2 & -1.1 \\
\hline 68.4 & 175.7 & -16.9 & -12.3 & 497.8 & 109.4 & 13.8 & -6.0 & 103.1 & -0.2 & -0.5 & -0.1 & -1.4 & -0.3 & -0.5 & -0.2 & -1.3 \\
\hline 78.1 & 177.9 & -8.3 & -7.6 & 481.5 & 125.1 & 18.3 & -4.6 & 130.2 & -0.1 & -0.3 & -0.1 & -1.6 & -0.1 & -0.2 & -0.1 & -1.0 \\
\hline 87.9 & 183.2 & -7.7 & -8.6 & 505.0 & 144.1 & 17.2 & -8.2 & 173.3 & -0.2 & -0.3 & -0.1 & -1.7 & -0.2 & -0.5 & -0.1 & -1.1 \\
\hline 97.7 & 183.0 & -3.7 & -8.1 & 502.4 & 152.0 & 16.8 & -11.9 & 153.1 & -0.3 & -0.4 & -0.2 & -1.6 & -0.2 & -0.4 & -0.2 & -1.1 \\
\hline 107.4 & 190.9 & 0.3 & -8.2 & 515.4 & 166.2 & 17.1 & -13.6 & 172.5 & -0.3 & -0.3 & -0.2 & -1.8 & -0.2 & -0.4 & -0.2 & -0.9 \\
\hline 117.2 & 182.6 & 3.5 & -8.8 & 509.2 & 179.8 & 16.5 & -16.7 & 195.1 & -0.1 & -0.5 & -0.2 & -1.3 & -0.2 & -0.2 & -0.2 & -1.2 \\
\hline 127.0 & 189.0 & 7.6 & -6.7 & 486.5 & 193.3 & 18.0 & -17.9 & 212.7 & -0.2 & -0.4 & -0.3 & -1.9 & -0.2 & -0.4 & -0.5 & -1.2 \\
\hline 136.7 & 183.2 & 12.8 & -7.2 & 472.2 & 208.0 & 18.1 & -19.5 & 230.6 & -0.2 & -0.5 & -0.3 & -1.9 & -0.2 & -0.5 & -0.3 & -1.1 \\
\hline 146.5 & 202.4 & 18.5 & -5.6 & 472.4 & 210.5 & 16.9 & -18.5 & 232.3 & -0.6 & -1.0 & -0.6 & -3.4 & -0.4 & -1.5 & -1.0 & -3.0 \\
\hline 156.3 & 207.4 & 26.6 & -4.3 & 476.7 & 230.6 & 18.0 & -20.9 & 229.1 & -0.4 & -1.1 & -0.6 & -2.9 & -0.3 & -0.5 & -0.8 & -2.7 \\
\hline 166.0 & 199.4 & 22.1 & -4.8 & 511.5 & 237.5 & 15.4 & -23.0 & 275.5 & -0.1 & -0.4 & -0.4 & -1.8 & -0.3 & -0.5 & -0.3 & -0.9 \\
\hline 175.8 & 190.8 & 26.9 & -4.7 & 498.5 & 264.7 & 17.0 & -26.0 & 296.0 & -0.2 & -0.4 & -0.3 & -1.6 & -0.3 & -0.4 & -0.3 & -1.4 \\
\hline 185.5 & 205.4 & 33.7 & -2.9 & 498.9 & 264.1 & 16.3 & -27.2 & 293.8 & -0.3 & -0.4 & -0.2 & -2.3 & -0.3 & -0.2 & -0.2 & -1.4 \\
\hline 195.3 & 210.1 & 38.7 & -4.9 & 492.1 & 275.1 & 15.9 & -28.8 & 295.9 & -0.3 & -0.4 & -0.1 & $\begin{array}{l}-1.7 \\
\end{array}$ & -0.2 & -0.5 & -0.3 & -1.0 \\
\hline 205.1 & 204.4 & 42.0 & -8.9 & 522.9 & 296.7 & 19.4 & -28.5 & 332.5 & -0.5 & -0.3 & -0.1 & -1.7 & -0.5 & -0.4 & -0.2 & -1.4 \\
\hline 214.8 & 184.6 & 48.6 & -9.8 & 502.0 & 309.5 & 23.7 & -31.6 & 329.4 & -0.2 & -0.4 & -0.1 & -2.2 & -0.4 & -0.4 & -0.3 & -1.3 \\
\hline 224.6 & 200.3 & 61.0 & -14.1 & 422.3 & 340.9 & 26.1 & -26.4 & 337.5 & -0.4 & -0.5 & -0.2 & -2.6 & -0.7 & -0.5 & -0.2 & -0.9 \\
\hline 234.4 & 185.7 & 57.0 & -18.7 & 523.8 & 348.9 & 14.6 & -33.2 & 386.2 & -0.5 & -0.3 & -0.2 & -1.6 & -0.5 & -0.3 & -0.1 & -1.1 \\
\hline 244.1 & 180.5 & 66.9 & -20.4 & 526.9 & 356.9 & 11.1 & -31.1 & 417.6 & -0.3 & -0.3 & -0.2 & -1.7 & -0.3 & -0.3 & -0.1 & -1.5 \\
\hline 253.9 & 188.3 & 70.0 & -24.2 & 515.8 & 367.5 & 19.6 & -28.6 & 417.7 & -0.2 & -0.4 & -0.1 & $\begin{array}{l}-1.7 \\
\end{array}$ & -0.4 & -0.2 & -0.2 & -0.9 \\
\hline 263.7 & 196.2 & 74.9 & -27.8 & 491.1 & 387.4 & 19.7 & -22.4 & 407.0 & -0.3 & -0.2 & -0.2 & -2.0 & -0.3 & -0.3 & -0.1 & -1.2 \\
\hline 273.4 & 198.0 & 86.5 & -31.5 & 403.8 & 412.0 & 30.0 & -14.6 & 390.0 & -0.3 & -0.3 & -0.2 & -2.4 & -0.4 & -0.5 & -0.1 & -1.1 \\
\hline 283.2 & 208.8 & 82.0 & -33.3 & 481.3 & 420.6 & 13.9 & -11.4 & 419.9 & -0.3 & -0.3 & -0.2 & -1.8 & -0.4 & -0.3 & -0.1 & -1.3 \\
\hline 293.0 & 202.7 & 91.3 & -37.6 & 449.3 & 422.3 & 28.9 & -3.3 & 452.6 & -0.2 & -0.3 & -0.2 & -2.3 & -0.4 & -0.5 & -0.2 & -1.1 \\
\hline 302.7 & 202.1 & 129.7 & -56.1 & 365.9 & 458.2 & 41.2 & 0.8 & 577.9 & -0.6 & -0.5 & -1.0 & -3.9 & -0.9 & -0.7 & -0.8 & -1.2 \\
\hline 312.5 & 193.6 & 121.2 & -61.2 & 424.0 & 489.5 & 52.1 & 7.1 & 539.4 & -0.4 & -1.0 & -0.6 & -5.4 & -0.7 & -1.0 & -0.7 & -1.3 \\
\hline 322.3 & 186.3 & 119.4 & -55.2 & 423.6 & 477.1 & 45.4 & 31.5 & 533.0 & -0.6 & -0.4 & -0.5 & -3.7 & -0.4 & -0.7 & -0.5 & -1.0 \\
\hline 332.0 & 208.8 & 109.1 & -46.8 & 610.5 & 514.1 & 9.0 & 76.1 & 577.4 & -0.2 & -0.4 & -0.2 & -1.7 & -0.3 & -0.4 & -0.4 & -1.3 \\
\hline 341.8 & 190.1 & 123.7 & -57.2 & 553.1 & 553.4 & 47.7 & 104.5 & 547.2 & -0.6 & -0.4 & -0.7 & -2.2 & -0.9 & -0.6 & -0.5 & -1.4 \\
\hline
\end{tabular}


Table 25: Dynamic Stiffness Real and Imaginary Parts at $9000 \mathrm{rpm}$ and $2350 \mathrm{kPa}(\mathrm{MN} / \mathrm{m})$

\begin{tabular}{|c|c|c|c|c|c|c|c|c|c|c|c|c|c|c|c|c|}
\hline $\mathrm{f}(\mathrm{Hz})$ & $\mathrm{R}\left(\mathrm{H}_{\mathrm{xx}}\right)$ & $\mathrm{R}\left(\mathrm{H}_{\mathrm{xy}}\right)$ & $\mathrm{R}\left(\mathrm{H}_{\mathrm{yX}}\right)$ & $\mathrm{R}\left(\mathrm{H}_{\mathrm{yv}}\right)$ & $\mathrm{I}\left(\mathrm{H}_{\mathrm{xx}}\right)$ & $\mathrm{I}\left(\mathrm{H}_{\mathrm{xy}}\right)$ & $\mathrm{I}\left(\mathrm{H}_{\mathrm{yX}}\right)$ & $\mathrm{I}\left(\mathrm{H}_{\mathrm{yv}}\right)$ & $\Delta \mathrm{R}\left(\mathrm{H}_{\mathrm{xx}}\right)$ & $\Delta \mathrm{R}\left(\mathrm{H}_{\mathrm{xy}}\right)$ & $\Delta \mathrm{R}\left(\mathrm{H}_{\mathrm{yx}}\right)$ & $\Delta \mathrm{R}\left(\mathrm{H}_{\mathrm{vv}}\right)$ & $\Delta \mathrm{I}\left(\mathrm{H}_{\mathrm{xx}}\right)$ & $\Delta \mathrm{I}\left(\mathrm{H}_{\mathrm{xy}}\right)$ & $\Delta \mathrm{I}\left(\mathrm{H}_{\mathrm{vX}}\right)$ & $\Delta \mathrm{I}\left(\mathrm{H}_{\mathrm{vy}}\right)$ \\
\hline 9.8 & 191.9 & -24.2 & -24.1 & 617.0 & 14.5 & 11.8 & -3.6 & 151.1 & -0.7 & -3.9 & -0.3 & -2.0 & -0.5 & -3.4 & -0.3 & -2.9 \\
\hline 19.5 & 191.0 & -18.3 & -22.6 & 608.6 & 29.7 & 7.9 & -0.1 & 61.0 & -0.4 & -1.4 & -0.3 & -5.1 & -0.2 & -1.8 & -0.2 & -1.9 \\
\hline 29.3 & 189.5 & -20.1 & -20.8 & 616.2 & 58.8 & 5.0 & 1.1 & 37.3 & -0.3 & -1.5 & -0.3 & -2.6 & -0.2 & -0.6 & -0.3 & -2.1 \\
\hline 39.1 & 188.3 & -19.3 & -19.4 & 592.7 & 69.9 & 8.9 & 0.7 & 55.8 & -0.2 & -0.6 & -0.3 & -2.4 & -0.3 & -1.2 & -0.4 & -1.2 \\
\hline 48.8 & 199.4 & -17.6 & -14.9 & 574.8 & 78.7 & 10.8 & -2.0 & 98.6 & -0.2 & -0.4 & -0.2 & -1.8 & -0.2 & -0.6 & -0.3 & -1.3 \\
\hline 58.6 & 198.8 & -14.4 & -13.7 & 613.0 & 99.5 & 10.1 & -3.6 & 93.2 & -0.2 & -0.9 & -0.1 & -2.4 & -0.2 & -0.3 & -0.2 & -1.6 \\
\hline 68.4 & 203.8 & -12.4 & -14.4 & 617.2 & 112.5 & 12.5 & -6.1 & 97.6 & -0.2 & -0.3 & -0.2 & -1.5 & -0.1 & -0.5 & -0.3 & -1.1 \\
\hline 78.1 & 204.9 & -3.0 & -11.0 & 595.7 & 129.9 & 18.1 & -3.8 & 133.3 & -0.3 & -0.3 & -0.2 & -1.6 & -0.1 & -0.4 & -0.2 & -1.1 \\
\hline 87.9 & 210.2 & -4.8 & -11.4 & 617.9 & 148.5 & 15.7 & -9.2 & 173.6 & -0.2 & -0.3 & -0.1 & -1.7 & -0.3 & -0.4 & -0.2 & -1.1 \\
\hline 97.7 & 210.4 & -1.2 & -11.3 & 611.9 & 156.6 & 15.1 & -12.0 & 149.2 & -0.2 & -0.5 & -0.3 & -1.8 & -0.2 & -0.5 & -0.2 & -1.2 \\
\hline 107.4 & 217.0 & 2.7 & -11.7 & 631.1 & 171.0 & 14.7 & -13.7 & 167.1 & -0.1 & -0.3 & -0.1 & -2.0 & -0.3 & -0.2 & -0.3 & -1.0 \\
\hline 117.2 & 210.9 & 5.7 & -12.0 & 619.0 & 185.3 & 15.6 & -17.6 & 188.4 & -0.2 & -0.3 & -0.1 & -1.5 & -0.2 & -0.4 & -0.2 & -1.1 \\
\hline 127.0 & 216.3 & 10.2 & -11.8 & 595.0 & 199.3 & 16.9 & -18.6 & 208.3 & -0.3 & -0.4 & -0.2 & -1.7 & -0.3 & -0.3 & -0.6 & $\begin{array}{l}-1.4 \\
\end{array}$ \\
\hline 136.7 & 211.0 & 15.0 & -11.8 & 581.2 & 214.0 & 17.9 & -19.8 & 220.8 & -0.4 & -0.4 & -0.4 & -2.0 & -0.2 & -0.4 & -0.6 & -0.9 \\
\hline 146.5 & 230.0 & 21.7 & -9.1 & 580.0 & 218.7 & 16.2 & -19.3 & 229.9 & -0.8 & -1.1 & -1.4 & -2.4 & -0.6 & -0.5 & -1.1 & -2.6 \\
\hline 156.3 & 234.1 & 28.2 & -9.7 & 583.4 & 238.8 & 16.2 & -20.6 & 221.3 & -0.5 & -1.2 & -2.1 & -3.4 & -0.8 & -1.0 & -0.6 & -1.9 \\
\hline 166.0 & 227.8 & 23.7 & -10.8 & 617.1 & 246.2 & 11.6 & -22.8 & 269.4 & -0.2 & -0.5 & -0.7 & -2.2 & -0.7 & -0.4 & -0.6 & -1.1 \\
\hline 175.8 & 219.6 & 28.5 & -10.7 & 609.0 & 272.7 & 13.1 & -25.0 & 296.8 & -0.2 & -0.4 & -0.4 & -1.5 & -0.4 & -0.4 & -0.1 & -1.3 \\
\hline 185.5 & 236.4 & 33.7 & -9.8 & 613.4 & 274.3 & 12.8 & -24.9 & 280.0 & -0.1 & -0.6 & -0.3 & -1.9 & -0.4 & -0.3 & -0.4 & -1.6 \\
\hline 195.3 & 238.3 & 36.6 & -10.8 & 604.9 & 283.9 & 12.2 & -27.0 & 284.9 & -0.3 & -0.5 & -0.3 & $\begin{array}{l}-1.7 \\
\end{array}$ & -0.6 & -0.3 & -0.3 & -1.3 \\
\hline 205.1 & 234.0 & 41.6 & -13.1 & 625.1 & 306.4 & 16.5 & -26.3 & 324.1 & -0.5 & -0.5 & -0.1 & -2.1 & -0.3 & -0.6 & -0.2 & -1.4 \\
\hline 214.8 & 217.8 & 46.6 & -13.0 & 618.3 & 318.0 & 19.3 & -28.5 & 323.7 & -0.3 & -0.5 & -0.3 & -1.8 & -0.5 & -0.4 & -0.4 & -1.2 \\
\hline 224.6 & 230.3 & 58.3 & -16.2 & 544.4 & 350.4 & 19.3 & -26.1 & 338.8 & -0.4 & -0.4 & -0.2 & -1.5 & -0.7 & -0.3 & -0.3 & -1.1 \\
\hline 234.4 & 220.4 & 52.0 & -19.1 & 637.2 & 358.4 & 12.5 & -28.1 & 373.9 & -0.3 & -0.5 & -0.3 & -1.7 & -0.3 & -0.4 & -0.2 & -1.3 \\
\hline 244.1 & 214.1 & 59.6 & -20.2 & 618.8 & 367.8 & 15.2 & -28.0 & 374.6 & -0.3 & -0.4 & -0.2 & -1.7 & -0.5 & -0.5 & -0.1 & -1.8 \\
\hline 253.9 & 222.4 & 63.3 & -25.6 & 624.7 & 380.8 & 21.0 & -24.0 & 386.3 & -0.3 & -0.2 & -0.3 & -1.8 & -0.6 & -0.5 & -0.3 & -1.1 \\
\hline 263.7 & 229.6 & 71.5 & -26.0 & 587.0 & 400.0 & 22.8 & -21.0 & 390.6 & -0.4 & -0.2 & -0.2 & -2.0 & -0.5 & -0.5 & -0.3 & -1.2 \\
\hline 273.4 & 237.2 & 80.5 & -30.0 & 510.7 & 424.2 & 32.6 & -15.9 & 364.7 & -0.2 & -0.3 & -0.2 & -1.9 & -0.5 & -0.5 & -0.2 & -1.4 \\
\hline 283.2 & 244.6 & 74.0 & -30.9 & 594.9 & 433.2 & 14.2 & -15.4 & 399.9 & -0.2 & -0.3 & -0.2 & -2.0 & -0.5 & -0.4 & -0.2 & -1.8 \\
\hline 293.0 & 242.7 & 88.0 & -31.4 & 544.9 & 433.4 & 33.1 & -6.4 & 430.8 & -0.2 & -0.4 & -0.4 & -2.2 & -0.5 & -0.6 & -0.3 & -1.1 \\
\hline 302.7 & 242.1 & 105.0 & -39.0 & 490.0 & 470.5 & 35.8 & 7.7 & 448.6 & -10.4 & -9.4 & -16.7 & -7.4 & -4.2 & -12.4 & -2.6 & -15.6 \\
\hline 312.5 & 240.7 & 92.2 & -42.2 & 722.5 & 495.8 & 7.4 & 8.6 & 518.9 & -0.4 & -0.4 & -0.3 & -2.0 & -0.9 & -0.6 & -0.5 & -1.5 \\
\hline 322.3 & 231.4 & 125.8 & -42.6 & 460.6 & 488.8 & 63.4 & 7.9 & 506.2 & -0.4 & -0.5 & -0.5 & -2.7 & -0.7 & -0.9 & -0.4 & -2.4 \\
\hline 332.0 & 272.9 & 132.6 & -57.4 & 786.6 & 504.8 & -51.1 & 113.5 & 744.2 & -0.2 & -0.3 & -0.4 & -2.4 & -0.5 & -0.4 & -0.7 & -1.3 \\
\hline 341.8 & 243.2 & 115.4 & -53.2 & 669.8 & 549.9 & 36.0 & 61.7 & 529.2 & -0.5 & -0.3 & -0.2 & -1.5 & -0.8 & -0.6 & -0.5 & -1.2 \\
\hline
\end{tabular}


Table 26: Dynamic Stiffness Real and Imaginary Parts at $9000 \mathrm{rpm}$ and $3134 \mathrm{kPa}$ (MN/m)

\begin{tabular}{|c|c|c|c|c|c|c|c|c|c|c|c|c|c|c|c|c|}
\hline $\mathrm{f}(\mathrm{Hz})$ & $\mathrm{R}\left(\mathrm{H}_{\mathrm{xx}}\right)$ & $\mathrm{R}\left(\mathrm{H}_{\mathrm{xy}}\right)$ & $\mathrm{R}\left(\mathrm{H}_{\mathrm{yX}}\right)$ & $\mathrm{R}\left(\mathrm{H}_{\mathrm{yv}}\right)$ & $\mathrm{I}\left(\mathrm{H}_{\mathrm{xx}}\right)$ & $\mathrm{I}\left(\mathrm{H}_{\mathrm{xy}}\right)$ & $\mathrm{I}\left(\mathrm{H}_{\mathrm{yX}}\right)$ & $\mathrm{I}\left(\mathrm{H}_{\mathrm{yv}}\right)$ & $\Delta \mathrm{R}\left(\mathrm{H}_{\mathrm{xx}}\right)$ & $\Delta \mathrm{R}\left(\mathrm{H}_{\mathrm{xy}}\right)$ & $\Delta \mathrm{R}\left(\mathrm{H}_{\mathrm{yx}}\right)$ & $\Delta \mathrm{R}\left(\mathrm{H}_{\mathrm{vv}}\right)$ & $\Delta \mathrm{I}\left(\mathrm{H}_{\mathrm{xx}}\right)$ & $\Delta \mathrm{I}\left(\mathrm{H}_{\mathrm{xy}}\right)$ & $\Delta \mathrm{I}\left(\mathrm{H}_{\mathrm{vX}}\right)$ & $\Delta \mathrm{I}\left(\mathrm{H}_{\mathrm{vy}}\right)$ \\
\hline 9.8 & 219.2 & -19.8 & -25.4 & 749.3 & 15.1 & 13.9 & -4.1 & 153.6 & -0.9 & -2.0 & -0.4 & -3.9 & -0.5 & -3.2 & -1.1 & -1.7 \\
\hline 19.5 & 217.8 & -17.1 & -22.9 & 719.7 & 31.7 & 10.3 & -1.2 & 85.0 & -0.2 & -2.6 & -0.5 & -2.5 & -0.5 & -2.2 & -0.4 & -2.0 \\
\hline 29.3 & 216.7 & -19.1 & -22.7 & 738.1 & 61.7 & 5.2 & 0.4 & 31.5 & -0.4 & -2.1 & -0.3 & -1.8 & -0.4 & -1.4 & -0.3 & -1.9 \\
\hline 39.1 & 216.9 & -16.9 & -21.1 & 716.4 & 74.2 & 8.6 & -0.8 & 51.4 & -0.3 & -0.7 & -0.3 & -1.8 & -0.3 & -1.1 & -0.2 & -1.4 \\
\hline 48.8 & 227.5 & -14.3 & -16.3 & 708.3 & 82.2 & 11.2 & -3.3 & 94.8 & -0.3 & -0.7 & -0.2 & -1.5 & -0.2 & -0.9 & -0.2 & -1.1 \\
\hline 58.6 & 227.3 & -11.5 & -15.0 & 740.7 & 104.6 & 9.7 & -5.2 & 82.1 & -0.2 & -0.4 & -0.2 & -1.8 & -0.2 & -0.4 & -0.4 & -0.9 \\
\hline 68.4 & 232.4 & -8.6 & -16.2 & 737.5 & 118.6 & 12.5 & -8.2 & 87.5 & -0.3 & -0.5 & -0.4 & -1.6 & -0.2 & -0.4 & -0.2 & -0.9 \\
\hline 78.1 & 231.6 & -1.8 & -18.0 & 705.0 & 137.8 & 23.3 & -3.1 & 133.0 & -0.2 & -0.3 & -0.2 & -1.7 & -0.2 & -0.5 & -0.2 & -0.8 \\
\hline 87.9 & 240.1 & -1.5 & -14.2 & 735.9 & 156.1 & 14.8 & -11.3 & 163.6 & -0.2 & -0.3 & -0.2 & -1.5 & -0.2 & -0.5 & -0.2 & -1.0 \\
\hline 97.7 & 240.3 & 2.4 & -14.7 & 720.9 & 165.4 & 14.4 & -14.6 & 135.9 & -0.2 & -0.5 & -0.4 & -1.7 & -0.3 & -0.3 & -0.1 & -1.0 \\
\hline 107.4 & 247.2 & 7.0 & -14.8 & 743.0 & 179.9 & 14.9 & -15.6 & 155.2 & -0.2 & -0.3 & -0.2 & -1.5 & -0.4 & -0.5 & -0.1 & -1.2 \\
\hline 117.2 & 241.6 & 10.7 & -15.8 & 731.8 & 196.1 & 15.2 & -19.1 & 173.9 & -0.1 & -0.3 & -0.3 & -1.7 & -0.3 & -0.3 & -0.3 & -1.0 \\
\hline 127.0 & 246.8 & 15.4 & -15.2 & 705.0 & 210.4 & 17.0 & -20.5 & 195.4 & -0.4 & -0.3 & -0.4 & -1.8 & -0.1 & -0.5 & -0.5 & -1.1 \\
\hline 136.7 & 243.6 & 21.1 & -16.1 & 692.0 & 225.8 & 16.7 & -22.3 & 215.5 & -0.5 & -0.7 & -0.7 & -2.0 & -0.4 & -0.6 & -0.8 & -1.4 \\
\hline 146.5 & 261.0 & 28.8 & -13.8 & 690.7 & 231.5 & 13.3 & -20.1 & 236.2 & -1.2 & -1.3 & -1.6 & -3.2 & -0.8 & -1.2 & -2.4 & -2.7 \\
\hline 156.3 & 266.9 & 31.4 & -14.5 & 704.9 & 252.5 & 11.3 & -22.9 & 207.9 & -1.1 & -0.9 & -1.7 & -3.1 & -0.8 & -1.0 & -2.1 & -2.4 \\
\hline 166.0 & 261.2 & 27.2 & -16.8 & 729.5 & 259.6 & 8.1 & -24.5 & 256.9 & -0.4 & -0.6 & -0.9 & -1.9 & -0.4 & -0.4 & -0.8 & -1.2 \\
\hline 175.8 & 254.8 & 31.8 & -16.1 & 721.8 & 286.2 & 9.5 & -25.8 & 284.2 & -0.6 & -0.5 & -0.7 & -1.5 & -0.3 & -0.5 & -0.4 & -1.0 \\
\hline 185.5 & 270.3 & 37.5 & -14.9 & 726.3 & 290.0 & 10.5 & -26.4 & 268.4 & -0.3 & -0.6 & -0.4 & $\begin{array}{l}-1.7 \\
\end{array}$ & -0.5 & -0.3 & -0.3 & -1.1 \\
\hline 195.3 & 273.8 & 41.3 & -16.3 & 707.4 & 298.9 & 10.9 & -25.7 & 268.1 & -0.3 & -0.6 & -0.4 & $\begin{array}{l}-1.7 \\
\end{array}$ & -0.4 & -0.4 & -0.4 & $\begin{array}{l}-1.1 \\
\end{array}$ \\
\hline 205.1 & 270.2 & 44.2 & -17.0 & 734.4 & 322.5 & 12.6 & -25.9 & 305.2 & -0.4 & -0.4 & -0.4 & -1.5 & -0.3 & -0.4 & -0.2 & -1.1 \\
\hline 214.8 & 256.3 & 50.9 & -17.1 & 714.0 & 335.5 & 18.0 & -27.3 & 298.7 & -0.3 & -0.5 & -0.3 & -1.5 & -0.4 & -0.3 & -0.4 & -1.2 \\
\hline 224.6 & 268.8 & 58.7 & -19.4 & 655.2 & 367.3 & 17.9 & -24.0 & 303.1 & -0.3 & -0.4 & -0.4 & -1.8 & -0.5 & -0.5 & -0.2 & -0.8 \\
\hline 234.4 & 260.1 & 52.2 & -23.1 & 747.4 & 376.8 & 7.4 & -26.4 & 352.6 & -0.3 & -0.4 & -0.2 & -1.5 & -0.1 & -0.4 & -0.2 & -1.0 \\
\hline 244.1 & 255.4 & 62.5 & -22.5 & 716.4 & 387.1 & 11.2 & -26.7 & 358.1 & -0.3 & -0.3 & -0.2 & -1.5 & -0.2 & -0.3 & -0.2 & -1.0 \\
\hline 253.9 & 261.9 & 63.1 & -26.4 & 728.6 & 399.5 & 17.4 & -23.5 & 363.2 & -0.3 & -0.4 & -0.2 & -1.5 & -0.5 & -0.3 & -0.3 & -0.8 \\
\hline 263.7 & 271.1 & 70.4 & -25.2 & 688.6 & 418.6 & 22.8 & -19.5 & 359.0 & -0.2 & -0.3 & -0.1 & -1.5 & -0.4 & -0.4 & -0.2 & -0.9 \\
\hline 273.4 & 282.3 & 81.8 & -29.1 & 621.9 & 444.6 & 29.2 & -15.0 & 346.9 & -0.4 & -0.3 & -0.1 & -1.5 & -0.4 & -0.3 & -0.3 & -0.9 \\
\hline 283.2 & 289.9 & 75.9 & -30.0 & 708.9 & 452.0 & 6.6 & -15.3 & 402.3 & -0.2 & -0.4 & -0.2 & -1.4 & -0.4 & -0.4 & -0.1 & -0.9 \\
\hline 293.0 & 290.4 & 86.7 & -29.9 & 644.1 & 454.0 & 35.1 & -6.2 & 394.6 & -0.3 & -0.6 & -0.4 & -1.6 & -0.3 & -0.4 & -0.3 & -1.1 \\
\hline 302.7 & 293.3 & 104.1 & -30.8 & 607.9 & 484.3 & 43.7 & 1.7 & 431.8 & -1.5 & -1.0 & -2.0 & -2.3 & -2.0 & -1.6 & -3.7 & -3.5 \\
\hline 312.5 & 295.8 & 184.3 & -56.1 & 608.2 & 521.0 & 14.3 & -7.0 & 721.1 & -0.4 & -0.9 & -0.5 & -2.0 & -0.6 & -0.8 & -0.8 & -3.1 \\
\hline 322.3 & 286.0 & 118.2 & -33.8 & 589.6 & 509.1 & 61.7 & 9.0 & 450.5 & -0.4 & -0.6 & -0.3 & -2.0 & -0.6 & -0.4 & -0.1 & -1.1 \\
\hline 332.0 & 302.5 & 268.3 & -91.8 & 428.8 & 558.1 & 14.4 & -37.9 & 888.8 & -0.5 & -1.1 & -1.2 & -5.9 & -0.3 & -1.8 & -0.7 & -3.6 \\
\hline 341.8 & 299.0 & 108.4 & -39.2 & 827.5 & 564.2 & 10.4 & 37.9 & 527.5 & -0.5 & -0.5 & -0.2 & -1.5 & -0.6 & -0.4 & -0.5 & -1.2 \\
\hline
\end{tabular}


Table 27: Dynamic Stiffness Real and Imaginary Parts at $10800 \mathrm{rpm}$ and $0 \mathrm{kPa}(\mathrm{MN} / \mathrm{m})$

\begin{tabular}{|c|c|c|c|c|c|c|c|c|c|c|c|c|c|c|c|c|}
\hline $\mathrm{f}(\mathrm{Hz})$ & $\mathrm{R}\left(\mathrm{H}_{\mathrm{xx}}\right)$ & $\mathrm{R}\left(\mathrm{H}_{\mathrm{xy}}\right)$ & $\mathrm{R}\left(\mathrm{H}_{\mathrm{yx}}\right)$ & $\mathrm{R}\left(\mathrm{H}_{\mathrm{yv}}\right)$ & $\mathrm{I}\left(\mathrm{H}_{\mathrm{xx}}\right)$ & $\mathrm{I}\left(\mathrm{H}_{\mathrm{xy}}\right)$ & $\mathrm{I}\left(\mathrm{H}_{\mathrm{yx}}\right)$ & $\mathrm{I}\left(\mathrm{H}_{\mathrm{yv}}\right)$ & $\Delta \mathrm{R}\left(\mathrm{H}_{\mathrm{xx}}\right)$ & $\Delta \mathrm{R}\left(\mathrm{H}_{\mathrm{xy}}\right)$ & $\Delta \mathrm{R}\left(\mathrm{H}_{\mathrm{yx}}\right)$ & $\Delta \mathrm{R}\left(\mathrm{H}_{\mathrm{yv}}\right)$ & $\Delta \mathrm{I}\left(\mathrm{H}_{\mathrm{xx}}\right)$ & $\Delta \mathrm{I}\left(\mathrm{H}_{\mathrm{xy}}\right)$ & $\Delta \mathrm{I}\left(\mathrm{H}_{\mathrm{yx}}\right)$ & $\Delta \mathrm{I}\left(\mathrm{H}_{\mathrm{yv}}\right)$ \\
\hline 9.8 & 163.2 & -19.2 & -21.6 & 267.1 & 12.0 & 6.9 & 0.6 & -4.8 & -0.4 & -2.5 & -0.8 & -4.8 & -0.3 & -1.9 & -0.5 & -3.5 \\
\hline 19.5 & 162.2 & -17.2 & -22.8 & 245.7 & 28.1 & -0.4 & -3.4 & 9.4 & -0.3 & -2.5 & -0.2 & -4.0 & -0.4 & -1.8 & -0.4 & -2.5 \\
\hline 29.3 & 160.9 & -24.8 & -22.6 & 294.1 & 57.5 & -2.4 & 0.8 & 56.4 & -0.3 & -1.6 & -0.3 & -3.8 & -0.2 & -1.3 & -0.3 & -2.3 \\
\hline 39.1 & 157.2 & -25.9 & -22.2 & 294.6 & 71.6 & -0.3 & -3.6 & 72.4 & -0.2 & -1.7 & -0.7 & -3.9 & -0.4 & -1.6 & -0.3 & -2.7 \\
\hline 48.8 & 165.7 & -24.0 & -22.7 & 291.1 & 74.4 & 4.8 & -1.6 & 100.4 & -0.2 & -1.2 & -0.3 & -3.5 & -0.3 & -0.5 & -0.3 & -2.7 \\
\hline 58.6 & 173.8 & -16.5 & -16.3 & 309.8 & 97.4 & 0.0 & -3.0 & 129.2 & -0.2 & -1.0 & -0.2 & -3.6 & -0.2 & -0.4 & -0.2 & -2.2 \\
\hline 68.4 & 176.4 & -17.5 & -15.9 & 314.5 & 110.1 & -0.7 & -4.7 & 129.7 & -0.1 & -1.1 & -0.3 & -3.7 & -0.2 & -0.5 & -0.2 & -1.8 \\
\hline 78.1 & 175.9 & -17.6 & -11.0 & 318.6 & 124.6 & -0.7 & -12.4 & 142.3 & -0.1 & -1.5 & -0.2 & -3.4 & -0.3 & -0.4 & -0.2 & -2.1 \\
\hline 87.9 & 185.8 & -15.0 & -8.7 & 338.2 & 144.0 & 0.0 & -10.9 & 157.9 & -0.1 & -0.9 & -0.6 & -3.6 & -0.2 & -0.5 & -0.2 & -2.8 \\
\hline 97.7 & 181.7 & -10.1 & -11.3 & 330.3 & 150.6 & -1.5 & -17.2 & 173.4 & -0.3 & -1.1 & -0.3 & -3.4 & -0.2 & -0.4 & -0.2 & -1.7 \\
\hline 107.4 & 190.5 & -5.6 & -8.0 & 327.9 & 165.6 & -1.9 & -12.2 & 187.8 & -0.2 & -0.9 & -0.3 & -3.1 & -0.2 & -0.6 & -0.1 & -1.7 \\
\hline 117.2 & 187.1 & -7.0 & -12.3 & 343.0 & 180.6 & -2.9 & -16.4 & 214.8 & -0.1 & -1.2 & -0.3 & -3.4 & -0.2 & -0.6 & -0.4 & -1.7 \\
\hline 127.0 & 189.6 & -2.2 & -10.4 & 359.9 & 192.9 & -7.0 & -14.3 & 191.2 & -0.3 & -1.5 & -0.3 & -3.7 & -0.3 & -0.5 & -0.3 & -2.0 \\
\hline 136.7 & 187.5 & 0.2 & -8.3 & 363.3 & 205.1 & -9.6 & -18.5 & 191.7 & -0.2 & -1.0 & -0.3 & -3.5 & -0.3 & -0.5 & -0.6 & -2.0 \\
\hline 146.5 & 210.3 & 3.9 & 0.0 & 380.7 & 209.3 & -15.7 & -12.3 & 205.5 & -0.3 & -1.5 & -0.4 & -3.3 & -0.2 & -0.9 & -0.3 & -2.1 \\
\hline 156.3 & 209.2 & 3.9 & 1.2 & 329.2 & 221.7 & -7.4 & -14.6 & 328.4 & -0.2 & -1.0 & -0.7 & -3.2 & -0.4 & -0.5 & -0.9 & -1.7 \\
\hline 166.0 & 205.2 & 4.9 & -1.2 & 371.2 & 229.7 & -10.4 & -15.8 & 275.6 & -0.5 & -1.0 & -0.7 & -4.2 & -0.4 & -0.9 & -0.2 & -2.5 \\
\hline 175.8 & 193.2 & 5.0 & 3.6 & 427.1 & 253.7 & -9.6 & -8.3 & 311.9 & -0.4 & -2.1 & -1.8 & -5.0 & -1.1 & -0.8 & -0.9 & -3.8 \\
\hline 185.5 & 212.0 & 9.9 & 6.1 & 397.8 & 249.6 & -6.4 & -21.6 & 273.2 & -1.0 & -1.8 & -2.1 & -6.6 & -1.2 & -2.0 & -1.1 & -3.3 \\
\hline 195.3 & 217.1 & 16.8 & 29.6 & 432.9 & 252.5 & -10.1 & -12.7 & 329.8 & -0.7 & -1.2 & $\begin{array}{l}-1.1 \\
\end{array}$ & -4.1 & -0.7 & -0.5 & -0.3 & -2.6 \\
\hline 205.1 & 207.0 & 16.4 & 25.6 & 411.0 & 276.7 & 3.8 & -13.1 & 337.7 & -0.6 & -1.2 & -0.4 & -3.8 & -0.3 & -0.6 & -0.6 & $\begin{array}{l}-1.7 \\
\end{array}$ \\
\hline 214.8 & 190.9 & 15.7 & 8.0 & 394.7 & 297.7 & 7.0 & -11.6 & 362.1 & -0.5 & -1.0 & -0.5 & -3.2 & -0.3 & -0.5 & -0.4 & -2.4 \\
\hline 224.6 & 205.5 & 36.0 & 24.9 & 408.0 & 328.7 & 6.2 & -9.9 & 357.0 & -0.3 & -1.2 & -0.7 & -3.9 & -0.4 & -0.4 & -0.3 & -1.8 \\
\hline 234.4 & 197.2 & 31.8 & 41.0 & 405.8 & 332.6 & 5.5 & -16.3 & 359.6 & -0.2 & -0.8 & -0.7 & -3.3 & -0.1 & -0.8 & -0.5 & -2.6 \\
\hline 244.1 & 185.1 & 49.4 & 37.5 & 447.1 & 348.7 & 22.5 & 16.7 & 416.7 & -0.3 & -1.2 & -0.3 & -4.0 & -0.8 & -0.7 & -1.6 & -2.9 \\
\hline 253.9 & 201.8 & 77.0 & 57.6 & 501.1 & 361.7 & 7.4 & 32.1 & 349.0 & -0.3 & -1.9 & -0.5 & -5.0 & -0.9 & -0.5 & -2.0 & -2.4 \\
\hline 263.7 & 197.9 & 84.2 & 43.9 & 476.4 & 379.4 & 18.3 & 22.9 & 397.2 & -0.9 & -1.2 & -0.9 & -3.8 & -0.5 & -1.0 & -2.3 & -3.3 \\
\hline 273.4 & 224.5 & 122.5 & 64.3 & 500.1 & 376.9 & -4.9 & -78.8 & 296.2 & -1.5 & -2.1 & -3.2 & -5.4 & -0.9 & -1.2 & -2.8 & $\begin{array}{l}-4.1 \\
\end{array}$ \\
\hline 283.2 & 280.5 & 185.5 & 210.5 & 625.0 & 393.7 & -60.0 & -25.8 & 192.5 & -3.7 & -2.1 & -7.0 & -5.2 & -5.0 & -5.6 & -10.9 & -13.1 \\
\hline 293.0 & 271.8 & 115.3 & 289.5 & 523.3 & 307.8 & -69.6 & -211.6 & 211.8 & -2.5 & -3.3 & -3.5 & -7.5 & -3.3 & -1.6 & -7.9 & -6.3 \\
\hline 302.7 & 197.0 & 107.6 & -10.0 & 361.9 & 386.1 & -35.3 & -134.8 & 342.5 & -1.1 & -2.2 & -1.2 & -6.3 & -1.7 & -1.3 & -4.8 & -4.9 \\
\hline 312.5 & 253.1 & 97.3 & 48.3 & 413.0 & 425.9 & -54.9 & -77.4 & 362.6 & -1.8 & -2.6 & -1.4 & -4.0 & -2.6 & -1.3 & -1.8 & -3.0 \\
\hline 322.3 & 192.7 & 109.4 & 42.0 & 422.8 & 385.7 & -25.2 & -96.8 & 411.8 & -1.1 & -1.5 & -1.1 & -4.1 & -0.6 & -1.2 & -1.3 & -2.9 \\
\hline 332.0 & 174.6 & 85.6 & -3.8 & 385.7 & 390.5 & -23.6 & -114.8 & 380.2 & -0.7 & -1.6 & -0.9 & -4.5 & -1.2 & -0.7 & -2.2 & -1.9 \\
\hline 341.8 & 163.4 & 126.8 & 24.3 & 420.3 & 411.7 & -20.8 & -90.7 & 389.3 & -2.4 & -1.3 & -2.5 & -3.6 & -1.1 & -1.9 & -1.0 & -2.7 \\
\hline
\end{tabular}


Table 28: Dynamic Stiffness Real and Imaginary Parts at $10800 \mathrm{rpm}$ and $783 \mathrm{kPa}(\mathrm{MN} / \mathrm{m})$

\begin{tabular}{|c|c|c|c|c|c|c|c|c|c|c|c|c|c|c|c|c|}
\hline $\mathrm{f}(\mathrm{Hz})$ & $\mathrm{R}\left(\mathrm{H}_{\mathrm{xx}}\right)$ & $\mathrm{R}\left(\mathrm{H}_{\mathrm{xy}}\right)$ & $\mathrm{R}\left(\mathrm{H}_{\mathrm{yx}}\right)$ & $\mathrm{R}\left(\mathrm{H}_{\mathrm{yv}}\right)$ & $\mathrm{I}\left(\mathrm{H}_{\mathrm{xx}}\right)$ & $\mathrm{I}\left(\mathrm{H}_{\mathrm{xy}}\right)$ & $\mathrm{I}\left(\mathrm{H}_{\mathrm{yx}}\right)$ & $\mathrm{I}\left(\mathrm{H}_{\mathrm{vv}}\right)$ & $\Delta \mathrm{R}\left(\mathrm{H}_{\mathrm{xx}}\right)$ & $\Delta \mathrm{R}\left(\mathrm{H}_{\mathrm{xy}}\right)$ & $\Delta \mathrm{R}\left(\mathrm{H}_{\mathrm{yx}}\right)$ & $\Delta \mathrm{R}\left(\mathrm{H}_{\mathrm{yv}}\right)$ & $\Delta \mathrm{I}\left(\mathrm{H}_{\mathrm{xx}}\right)$ & $\Delta \mathrm{I}\left(\mathrm{H}_{\mathrm{xy}}\right)$ & $\Delta \mathrm{I}\left(\mathrm{H}_{\mathrm{vx}}\right)$ & $\Delta \mathrm{I}\left(\mathrm{H}_{\mathrm{yv}}\right)$ \\
\hline 9.8 & 174.1 & -25.4 & -20.9 & 349.8 & 14.8 & 4.1 & -5.9 & 90.8 & -0.6 & -2.4 & -0.8 & -3.8 & -0.5 & -1.1 & -0.4 & -1.6 \\
\hline 19.5 & 171.4 & -23.0 & -17.9 & 348.6 & 28.5 & 1.1 & 1.4 & 16.5 & -0.4 & $\begin{array}{l}-1.4 \\
\end{array}$ & -0.3 & -3.1 & -0.4 & -0.6 & -0.4 & -2.6 \\
\hline 29.3 & 170.4 & -25.7 & -21.1 & 386.4 & 57.1 & 4.3 & 1.9 & 32.5 & -0.3 & -1.5 & -0.3 & -2.7 & -0.4 & -0.9 & -0.1 & -1.8 \\
\hline 39.1 & 169.7 & -26.2 & -20.7 & 375.0 & 70.6 & 5.9 & -1.1 & 73.8 & -0.2 & -0.7 & -0.1 & -1.4 & -0.2 & -0.6 & -0.5 & -1.5 \\
\hline 48.8 & 180.9 & -25.1 & -16.2 & 361.9 & 78.0 & 4.7 & -3.9 & 112.9 & -0.4 & -0.8 & -0.2 & -2.1 & -0.2 & -0.5 & -0.2 & -1.0 \\
\hline 58.6 & 181.9 & -24.0 & -15.2 & 378.6 & 99.2 & 5.7 & -5.3 & 121.4 & -0.1 & -0.5 & -0.1 & -1.9 & -0.2 & -0.7 & -0.2 & -1.1 \\
\hline 68.4 & 185.6 & -19.2 & -13.6 & 389.9 & 116.5 & 12.2 & -0.4 & 128.0 & -0.3 & -0.5 & -0.3 & -1.6 & -0.3 & -0.3 & -0.4 & -1.6 \\
\hline 78.1 & 187.2 & -14.2 & -10.4 & 379.0 & 127.3 & 9.4 & -5.9 & 145.2 & -0.1 & -0.5 & -0.2 & -1.5 & -0.1 & -0.3 & -0.3 & -1.0 \\
\hline 87.9 & 194.4 & -14.4 & -11.0 & 405.6 & 145.4 & 7.7 & -8.0 & 178.0 & -0.2 & -0.6 & -0.1 & -1.7 & -0.3 & -0.6 & -0.2 & -1.2 \\
\hline 97.7 & 193.9 & -8.8 & -10.0 & 400.2 & 154.2 & 7.2 & -9.9 & 169.9 & -0.4 & -0.3 & -0.2 & -1.7 & -0.1 & -0.4 & -0.2 & -1.1 \\
\hline 107.4 & 201.4 & -5.4 & -8.3 & 410.4 & 166.1 & 8.0 & -11.9 & 188.5 & -0.4 & -0.4 & -0.4 & $\begin{array}{l}-1.4 \\
\end{array}$ & -0.3 & -0.3 & -0.3 & -1.0 \\
\hline 117.2 & 196.5 & -3.6 & -9.9 & 416.9 & 183.0 & 6.3 & -16.1 & 208.3 & -0.1 & -0.4 & -0.2 & -1.7 & -0.3 & -0.4 & -0.3 & -0.9 \\
\hline 127.0 & 203.6 & -1.1 & -8.7 & 402.3 & 193.2 & 5.4 & -16.9 & 221.3 & -0.2 & -0.5 & -0.3 & -1.5 & -0.3 & -0.6 & -0.4 & -1.3 \\
\hline 136.7 & 201.6 & 1.5 & -7.8 & 404.3 & 209.2 & 3.2 & -18.6 & 229.8 & -0.3 & -0.5 & -0.2 & -1.6 & -0.4 & -0.4 & -0.3 & -1.2 \\
\hline 146.5 & 216.5 & 6.1 & -5.0 & 401.6 & 210.4 & 3.3 & -17.7 & 227.3 & -0.2 & -0.3 & -0.2 & -1.8 & -0.4 & -0.6 & -0.3 & -1.2 \\
\hline 156.3 & 226.7 & 15.9 & -10.5 & 379.7 & 223.4 & 6.6 & -11.2 & 237.9 & -0.2 & -0.4 & -0.2 & -1.5 & -0.3 & -0.6 & -0.4 & -1.2 \\
\hline 166.0 & 217.5 & 9.3 & -4.1 & 433.2 & 235.8 & 2.7 & -19.6 & 273.3 & -0.5 & -0.6 & -0.4 & -1.9 & -0.3 & -0.6 & -0.3 & -1.6 \\
\hline 175.8 & 212.1 & 9.6 & -2.2 & 423.0 & 257.3 & 3.0 & -17.0 & 285.0 & -1.0 & -1.6 & -0.6 & -3.5 & -0.5 & -1.4 & -1.3 & -2.9 \\
\hline 185.5 & 223.9 & 13.0 & 1.7 & 429.9 & 257.5 & 4.0 & -18.7 & 284.7 & -0.7 & -1.0 & -0.6 & -3.1 & -0.6 & -1.6 & -1.2 & -2.4 \\
\hline 195.3 & 232.8 & 17.3 & 3.5 & 412.6 & 261.4 & 5.0 & -21.3 & 291.4 & -0.3 & -0.8 & -0.4 & -1.7 & -0.4 & -0.5 & -0.3 & -1.6 \\
\hline 205.1 & 222.9 & 20.5 & 3.1 & 427.9 & 283.8 & 12.9 & -20.9 & 318.7 & -0.6 & -0.4 & -0.2 & -1.8 & -0.3 & -0.3 & -0.2 & -1.2 \\
\hline 214.8 & 203.9 & 23.9 & 3.7 & 411.1 & 297.9 & 19.7 & -26.8 & 310.6 & -0.3 & -0.4 & -0.3 & -1.6 & -0.2 & -0.4 & -0.2 & -1.1 \\
\hline 224.6 & 218.8 & 47.9 & -5.3 & 280.3 & 321.9 & 26.0 & -25.2 & 358.9 & -0.3 & -0.5 & -0.3 & -2.6 & -0.6 & -0.5 & -0.2 & $\begin{array}{l}-1.4 \\
\end{array}$ \\
\hline 234.4 & 200.6 & 32.0 & -3.8 & 427.2 & 332.8 & 17.9 & -29.6 & 365.6 & -0.3 & -0.4 & -0.2 & -1.7 & -0.3 & -0.4 & -0.2 & -1.1 \\
\hline 244.1 & 193.9 & 40.1 & -2.7 & 424.0 & 337.1 & 21.2 & -35.3 & 376.4 & -0.3 & -0.2 & -0.2 & $\begin{array}{l}-1.4 \\
\end{array}$ & -0.2 & -0.4 & -0.2 & -1.0 \\
\hline 253.9 & 198.7 & 45.2 & -9.2 & 437.6 & 349.3 & 26.6 & -30.9 & 394.1 & -0.3 & -0.4 & -0.1 & -1.7 & -0.3 & -0.5 & -0.2 & -0.9 \\
\hline 263.7 & 204.8 & 53.1 & -14.5 & 390.1 & 368.7 & 34.6 & -25.1 & 381.0 & -0.2 & -0.4 & -0.3 & -1.4 & -0.3 & -0.3 & -0.3 & -1.0 \\
\hline 273.4 & 197.2 & 76.7 & -27.8 & 254.5 & 395.3 & 54.4 & -14.7 & 404.5 & -0.3 & -0.3 & -0.2 & -1.7 & -0.3 & -0.5 & -0.2 & -1.4 \\
\hline 283.2 & 208.6 & 60.2 & -21.2 & 381.1 & 404.6 & 40.2 & -15.4 & 414.6 & -0.3 & -0.4 & -0.2 & -1.4 & -0.3 & -0.2 & -0.3 & -0.9 \\
\hline 293.0 & 207.1 & 122.3 & -19.0 & 363.5 & 408.4 & 30.0 & 32.1 & 659.8 & -0.4 & -1.0 & -0.7 & -3.6 & -0.3 & -0.4 & -0.7 & -3.8 \\
\hline 302.7 & 195.8 & 121.6 & -40.5 & 491.3 & 451.2 & 19.6 & 34.9 & 662.5 & -0.5 & -1.1 & -0.3 & -2.2 & -0.5 & -0.5 & -0.5 & -3.8 \\
\hline 312.5 & 193.4 & 199.0 & -157.5 & 242.7 & 523.4 & 122.0 & 81.1 & 755.0 & -0.8 & -0.9 & -1.2 & -2.8 & -0.8 & -1.1 & -1.1 & -2.7 \\
\hline 322.3 & 209.3 & 208.2 & -45.0 & 427.0 & 483.5 & 34.6 & 208.2 & 843.3 & -1.3 & -1.9 & -1.8 & -6.8 & -1.1 & -1.8 & -2.8 & -3.8 \\
\hline 332.0 & 288.1 & 214.1 & -37.3 & 513.5 & 632.3 & 102.1 & 258.5 & 633.5 & -0.8 & -0.7 & -0.8 & -2.3 & -1.2 & -0.8 & -1.5 & $\begin{array}{l}-1.6 \\
\end{array}$ \\
\hline 341.8 & 390.8 & 291.0 & 163.2 & 613.6 & 660.0 & 86.8 & 326.5 & 587.3 & -5.1 & -1.7 & -7.7 & -5.1 & -4.7 & -3.8 & -1.9 & -3.7 \\
\hline
\end{tabular}


Table 29: Dynamic Stiffness Real and Imaginary Parts at $10800 \mathrm{rpm}$ and $1567 \mathrm{kPa}$ (MN/m)

\begin{tabular}{|c|c|c|c|c|c|c|c|c|c|c|c|c|c|c|c|c|}
\hline $\mathrm{f}(\mathrm{Hz})$ & $\mathrm{R}\left(\mathrm{H}_{\mathrm{xx}}\right)$ & $\mathrm{R}\left(\mathrm{H}_{\mathrm{xy}}\right)$ & $\mathrm{R}\left(\mathrm{H}_{\mathrm{yx}}\right)$ & $\mathrm{R}\left(\mathrm{H}_{\mathrm{yv}}\right)$ & $\mathrm{I}\left(\mathrm{H}_{\mathrm{xx}}\right)$ & $\mathrm{I}\left(\mathrm{H}_{\mathrm{xy}}\right)$ & $\mathrm{I}\left(\mathrm{H}_{\mathrm{yx}}\right)$ & $\mathrm{I}\left(\mathrm{H}_{\mathrm{yv}}\right)$ & $\Delta \mathrm{R}\left(\mathrm{H}_{\mathrm{xx}}\right)$ & $\Delta \mathrm{R}\left(\mathrm{H}_{\mathrm{xy}}\right)$ & $\Delta \mathrm{R}\left(\mathrm{H}_{\mathrm{yx}}\right)$ & $\Delta \mathrm{R}\left(\mathrm{H}_{\mathrm{vy}}\right)$ & $\Delta \mathrm{I}\left(\mathrm{H}_{\mathrm{xx}}\right)$ & $\Delta \mathrm{I}\left(\mathrm{H}_{\mathrm{xy}}\right)$ & $\Delta \mathrm{I}\left(\mathrm{H}_{\mathrm{yx}}\right)$ & $\Delta \mathrm{I}\left(\mathrm{H}_{\mathrm{vv}}\right)$ \\
\hline 9.8 & 196.3 & -33.3 & -22.7 & 475.8 & 15.4 & 7.4 & -4.3 & 117.3 & -0.3 & -3.4 & -0.4 & -2.7 & -0.4 & -2.6 & -0.6 & -4.5 \\
\hline 19.5 & 194.7 & -28.4 & -24.4 & 483.5 & 28.8 & 6.9 & -1.2 & 50.8 & -0.5 & -1.7 & -0.4 & -3.2 & -0.6 & -2.6 & -0.5 & -2.3 \\
\hline 29.3 & 194.3 & -27.6 & -23.0 & 524.0 & 57.6 & 7.5 & 0.7 & 40.3 & -0.4 & -1.4 & -0.3 & -2.4 & -0.5 & -1.1 & -0.3 & -1.8 \\
\hline 39.1 & 192.9 & -26.2 & -22.4 & 503.6 & 68.4 & 7.0 & -0.2 & 58.5 & -0.3 & -1.6 & -0.5 & -2.1 & -0.3 & -1.0 & -0.2 & -2.1 \\
\hline 48.8 & 203.2 & -26.7 & -17.3 & 473.4 & 77.9 & 8.8 & -2.7 & 102.2 & -0.4 & -0.9 & -0.1 & -1.6 & -0.3 & -0.6 & -0.3 & -1.1 \\
\hline 58.6 & 204.4 & -23.7 & -15.8 & 491.9 & 99.2 & 10.1 & -3.3 & 96.6 & -0.2 & -0.7 & -0.2 & -1.9 & -0.2 & -1.1 & -0.4 & -1.2 \\
\hline 68.4 & 207.7 & -22.9 & -16.7 & 498.7 & 110.7 & 11.6 & -6.1 & 99.7 & -0.1 & -0.8 & -0.2 & -2.1 & -0.3 & -0.6 & -0.7 & -1.4 \\
\hline 78.1 & 210.7 & -14.5 & -11.3 & 486.3 & 127.2 & 14.5 & -4.0 & 123.6 & -0.3 & -0.5 & -0.1 & -1.9 & -0.2 & -0.6 & -0.4 & -1.4 \\
\hline 87.9 & 217.1 & -14.1 & -12.3 & 508.7 & 145.6 & 13.1 & -7.3 & 162.2 & -0.2 & -0.3 & -0.2 & -1.8 & -0.4 & -0.7 & -0.3 & -1.1 \\
\hline 97.7 & 216.2 & -10.4 & -11.6 & 505.5 & 154.5 & 13.4 & -9.8 & 149.4 & -0.2 & -0.4 & -0.3 & -1.6 & -0.2 & -0.7 & -0.3 & -1.3 \\
\hline 107.4 & 223.6 & -6.2 & -11.2 & 514.9 & 166.9 & 13.3 & -13.0 & 169.4 & -0.2 & -0.6 & -0.2 & -1.4 & -0.2 & -0.5 & -0.4 & -1.2 \\
\hline 117.2 & 217.6 & -3.8 & -10.9 & 512.3 & 181.3 & 12.4 & -15.4 & 188.5 & -0.2 & -0.5 & -0.1 & -1.5 & -0.2 & -0.5 & -0.3 & -1.0 \\
\hline 127.0 & 224.7 & -0.7 & -9.6 & 496.2 & 194.0 & 14.5 & -15.7 & 207.3 & -0.3 & -0.4 & -0.2 & -1.5 & -0.4 & -0.4 & -0.1 & $\begin{array}{l}-1.0 \\
\end{array}$ \\
\hline 136.7 & 221.3 & 4.3 & -9.7 & 484.5 & 210.9 & 14.7 & -18.9 & 221.1 & -0.4 & -0.6 & -0.3 & -1.8 & -0.4 & -0.3 & -0.1 & -1.2 \\
\hline 146.5 & 238.1 & 8.8 & -7.4 & 489.7 & 212.0 & 15.0 & -18.9 & 223.3 & -0.2 & -0.3 & -0.2 & -1.5 & -0.2 & -0.6 & -0.4 & -1.1 \\
\hline 156.3 & 247.0 & 17.1 & -8.6 & 483.1 & 229.8 & 15.1 & -18.5 & 215.2 & -0.3 & -0.4 & -0.6 & -1.6 & -0.3 & -0.4 & -0.3 & -1.3 \\
\hline 166.0 & 238.6 & 10.9 & -7.5 & 524.3 & 237.2 & 11.6 & -19.6 & 266.4 & -0.5 & -0.6 & -0.8 & -2.3 & -0.7 & -0.5 & -0.4 & -1.1 \\
\hline 175.8 & 231.7 & 16.0 & -6.1 & 512.2 & 260.9 & 13.9 & -21.4 & 276.0 & -0.6 & -1.3 & -2.3 & -2.5 & -1.6 & -1.5 & -1.2 & -3.3 \\
\hline 185.5 & 246.1 & 19.5 & -1.7 & 509.9 & 260.5 & 12.7 & -23.0 & 275.8 & -0.6 & -1.5 & -2.0 & -2.6 & -1.5 & -0.7 & -1.1 & -3.0 \\
\hline 195.3 & 251.0 & 24.5 & -2.3 & 502.6 & 270.5 & 13.6 & -24.4 & 280.6 & -0.2 & -0.3 & -0.9 & -2.3 & -0.9 & -0.7 & -0.4 & -1.0 \\
\hline 205.1 & 245.5 & 25.9 & -3.1 & 524.4 & 286.4 & 18.1 & -23.9 & 306.9 & -0.6 & -0.6 & -0.4 & -1.6 & -0.7 & -0.5 & -0.6 & -1.4 \\
\hline 214.8 & 227.6 & 32.0 & -3.2 & 505.5 & 298.6 & 24.0 & -28.5 & 299.8 & -0.2 & -0.3 & -0.3 & -1.5 & -0.4 & -0.4 & -0.6 & -1.1 \\
\hline 224.6 & 242.3 & 43.5 & -3.9 & 420.3 & 325.6 & 29.0 & -24.6 & 308.5 & -0.5 & -0.3 & -0.3 & -1.7 & -0.6 & -0.6 & -0.3 & -1.0 \\
\hline 234.4 & 227.4 & 39.4 & -6.8 & 522.4 & 333.4 & 19.7 & -33.8 & 352.0 & -0.6 & -0.4 & -0.3 & -1.6 & -0.2 & -0.4 & -0.1 & -1.2 \\
\hline 244.1 & 221.0 & 47.1 & -6.6 & 527.6 & 340.4 & 18.6 & -36.3 & 371.9 & -0.3 & -0.5 & -0.3 & -1.9 & -0.2 & -0.6 & -0.5 & $\begin{array}{l}-1.2 \\
\end{array}$ \\
\hline 253.9 & 226.8 & 56.6 & -10.2 & 501.1 & 351.4 & 30.3 & -35.7 & 384.4 & -0.2 & -0.4 & -0.5 & -1.4 & -0.2 & -0.4 & -0.2 & -1.3 \\
\hline 263.7 & 231.6 & 59.8 & -14.9 & 484.1 & 371.0 & 34.0 & -31.9 & 370.2 & -0.3 & -0.3 & -0.5 & $\begin{array}{l}-1.7 \\
\end{array}$ & -0.3 & -0.4 & -0.2 & -0.9 \\
\hline 273.4 & 230.6 & 72.8 & -19.3 & 389.4 & 391.6 & 47.0 & -27.3 & 357.3 & -0.4 & -0.3 & -0.2 & -1.8 & -0.6 & -0.4 & -0.5 & -0.9 \\
\hline 283.2 & 238.9 & 68.3 & -24.8 & 476.4 & 402.7 & 32.8 & -28.5 & 391.2 & -0.3 & -0.3 & -0.5 & -1.4 & -0.7 & -0.3 & -0.3 & -1.0 \\
\hline 293.0 & 231.1 & 83.2 & -29.3 & 427.5 & 407.8 & 51.2 & -21.6 & 421.4 & -0.3 & -0.3 & -0.4 & -1.5 & -0.6 & -0.4 & -0.3 & -1.2 \\
\hline 302.7 & 228.8 & 132.0 & -51.2 & 323.8 & 447.5 & 66.8 & -22.0 & 558.7 & -0.5 & -0.6 & -0.6 & -2.1 & -0.8 & -0.6 & -0.6 & -1.3 \\
\hline 312.5 & 216.9 & 129.9 & -54.9 & 353.0 & 475.4 & 86.6 & -19.7 & 514.5 & -1.0 & -0.4 & -0.5 & -1.7 & -0.8 & -0.4 & -0.6 & -1.4 \\
\hline 322.3 & 216.0 & 126.9 & -55.9 & 387.2 & 466.9 & 74.9 & 6.4 & 510.5 & -0.7 & -0.2 & -0.4 & -1.7 & -0.8 & -0.6 & -0.2 & -1.1 \\
\hline 332.0 & 234.9 & 118.1 & -58.1 & 599.7 & 512.3 & 31.7 & 52.8 & 565.1 & -0.9 & -0.6 & -0.3 & -1.7 & -0.5 & -0.4 & -0.3 & -1.2 \\
\hline 341.8 & 226.6 & 139.0 & -69.5 & 536.9 & 548.1 & 71.7 & 87.1 & 534.6 & -1.5 & -0.9 & -1.3 & -2.1 & -1.1 & -0.6 & -1.6 & -1.5 \\
\hline
\end{tabular}


Table 30: Dynamic Stiffness Real and Imaginary Parts at $10800 \mathrm{rpm}$ and $2350 \mathrm{kPa}(\mathrm{MN} / \mathrm{m})$

\begin{tabular}{|c|c|c|c|c|c|c|c|c|c|c|c|c|c|c|c|c|}
\hline $\mathrm{f}(\mathrm{Hz})$ & $\mathrm{R}\left(\mathrm{H}_{\mathrm{xx}}\right)$ & $\mathrm{R}\left(\mathrm{H}_{\mathrm{xy}}\right)$ & $\mathrm{R}\left(\mathrm{H}_{\mathrm{yx}}\right)$ & $\mathrm{R}\left(\mathrm{H}_{\mathrm{yv}}\right)$ & $\mathrm{I}\left(\mathrm{H}_{\mathrm{xx}}\right)$ & $\mathrm{I}\left(\mathrm{H}_{\mathrm{xy}}\right)$ & $\mathrm{I}\left(\mathrm{H}_{\mathrm{yx}}\right)$ & $\mathrm{I}\left(\mathrm{H}_{\mathrm{yv}}\right)$ & $\Delta \mathrm{R}\left(\mathrm{H}_{\mathrm{xx}}\right)$ & $\Delta \mathrm{R}\left(\mathrm{H}_{\mathrm{xy}}\right)$ & $\Delta \mathrm{R}\left(\mathrm{H}_{\mathrm{yx}}\right)$ & $\Delta \mathrm{R}\left(\mathrm{H}_{\mathrm{vy}}\right)$ & $\Delta \mathrm{I}\left(\mathrm{H}_{\mathrm{xx}}\right)$ & $\Delta \mathrm{I}\left(\mathrm{H}_{\mathrm{xy}}\right)$ & $\Delta \mathrm{I}\left(\mathrm{H}_{\mathrm{yx}}\right)$ & $\Delta \mathrm{I}\left(\mathrm{H}_{\mathrm{vv}}\right)$ \\
\hline 9.8 & 222.3 & -33.3 & -26.4 & 574.0 & 15.3 & 14.1 & -6.6 & 147.8 & -0.7 & -2.6 & -1.0 & -4.7 & -0.8 & -4.2 & -0.8 & -3.5 \\
\hline 19.5 & 221.1 & -22.3 & -27.1 & 611.1 & 29.0 & 10.8 & -0.7 & 50.4 & -0.3 & -2.5 & -0.5 & -4.2 & -0.6 & -4.2 & -0.5 & -4.3 \\
\hline 29.3 & 219.0 & -26.2 & -25.1 & 627.3 & 58.9 & 4.8 & 1.3 & 38.9 & -0.5 & -1.3 & -0.5 & -3.9 & -0.4 & -1.3 & -0.3 & -2.9 \\
\hline 39.1 & 218.0 & -26.8 & -25.0 & 604.1 & 69.2 & 7.1 & 0.6 & 57.7 & -0.2 & -1.3 & -0.6 & -3.9 & -0.3 & -1.4 & -0.4 & -1.8 \\
\hline 48.8 & 228.8 & -24.4 & -19.3 & 581.1 & 78.2 & 8.6 & -1.7 & 99.3 & -0.3 & -0.9 & -0.1 & -1.7 & -0.4 & -1.3 & -0.2 & -2.3 \\
\hline 58.6 & 229.6 & -22.3 & -17.3 & 610.3 & 99.6 & 8.9 & -3.1 & 88.8 & -0.4 & -1.3 & -0.2 & -3.7 & -0.4 & -0.8 & -0.5 & -1.9 \\
\hline 68.4 & 234.8 & -19.0 & -18.2 & 615.4 & 111.7 & 9.9 & -4.9 & 91.4 & -0.3 & -0.8 & -0.2 & -2.0 & -0.6 & -0.5 & -0.4 & -1.7 \\
\hline 78.1 & 236.2 & -10.7 & -13.6 & 600.6 & 130.3 & 16.0 & -2.0 & 127.0 & -0.2 & -0.5 & -0.4 & -2.2 & -0.2 & -0.7 & -0.5 & -1.0 \\
\hline 87.9 & 241.3 & -11.9 & -14.1 & 618.9 & 147.5 & 14.4 & -7.9 & 161.5 & -0.4 & -0.3 & -0.2 & -1.9 & -0.4 & -0.6 & -0.2 & -1.9 \\
\hline 97.7 & 242.7 & -8.7 & -14.1 & 610.8 & 157.1 & 14.5 & -10.5 & 141.1 & -0.3 & -0.5 & -0.2 & -2.6 & -0.2 & -0.4 & -0.5 & -1.4 \\
\hline 107.4 & 248.6 & -5.5 & -13.5 & 624.3 & 169.3 & 14.5 & -13.3 & 161.5 & -0.3 & -0.5 & -0.3 & -1.4 & -0.4 & -0.3 & -0.4 & -1.4 \\
\hline 117.2 & 243.6 & -1.7 & -13.5 & 617.8 & 184.5 & 15.5 & -16.4 & 182.7 & -0.1 & -0.4 & -0.4 & -1.9 & -0.3 & -0.6 & -0.3 & -1.6 \\
\hline 127.0 & 249.6 & 1.2 & -13.5 & 597.9 & 198.5 & 17.6 & -17.8 & 201.8 & -0.2 & -0.6 & -0.3 & -1.8 & -0.2 & -0.4 & -0.4 & -1.2 \\
\hline 136.7 & 246.1 & 6.1 & -13.6 & 587.2 & 214.0 & 18.7 & -19.2 & 213.3 & -0.3 & -0.4 & -0.3 & -2.4 & -0.2 & -0.5 & -0.4 & -1.7 \\
\hline 146.5 & 263.5 & 12.9 & -11.0 & 588.0 & 216.8 & 17.6 & -18.4 & 220.0 & -0.3 & -0.5 & -0.4 & -1.7 & -0.1 & -0.6 & -0.5 & -1.1 \\
\hline 156.3 & 269.7 & 21.3 & -11.7 & 583.5 & 234.3 & 17.8 & -18.7 & 206.4 & -0.4 & -0.6 & -0.3 & -1.7 & -0.3 & -0.5 & -0.5 & -1.5 \\
\hline 166.0 & 263.1 & 15.1 & -11.5 & 624.7 & 243.0 & 14.2 & -20.1 & 259.3 & -0.5 & -0.7 & -0.9 & -1.4 & -0.4 & -0.4 & -0.8 & -2.2 \\
\hline 175.8 & 255.8 & 22.0 & -9.0 & 611.4 & 266.2 & 15.8 & -20.6 & 274.2 & -1.5 & -1.6 & -2.0 & -5.0 & -1.0 & -1.6 & -1.8 & -2.5 \\
\hline 185.5 & 270.9 & 25.8 & -5.9 & 613.9 & 268.0 & 16.9 & -21.7 & 265.9 & -1.5 & -1.2 & -1.3 & -4.2 & -0.9 & -2.2 & -2.6 & -3.6 \\
\hline 195.3 & 274.4 & 28.1 & -6.5 & 604.3 & 277.1 & 16.4 & -24.3 & 272.9 & -0.6 & -1.2 & -1.1 & -2.6 & -0.8 & -0.5 & -0.6 & -2.1 \\
\hline 205.1 & 271.3 & 34.4 & -7.3 & 615.6 & 295.0 & 21.1 & -25.1 & 302.2 & -0.9 & -0.4 & -0.5 & -2.3 & -0.8 & -0.7 & -0.3 & -1.4 \\
\hline 214.8 & 256.4 & 40.2 & -7.4 & 609.3 & 306.3 & 24.1 & -27.7 & 301.2 & -0.3 & -0.3 & -0.4 & -3.2 & -0.8 & -0.6 & -0.4 & -1.2 \\
\hline 224.6 & 267.8 & 52.5 & -8.3 & 537.9 & 334.2 & 23.8 & -27.4 & 323.3 & -0.3 & -0.8 & -0.4 & -2.2 & -0.4 & -0.3 & -0.3 & -2.1 \\
\hline 234.4 & 257.8 & 45.8 & -10.6 & 628.5 & 342.4 & 18.4 & -31.7 & 348.1 & -0.3 & -0.5 & -0.3 & -2.1 & -0.2 & -0.3 & -0.5 & -1.2 \\
\hline 244.1 & 251.4 & 54.7 & -12.2 & 609.2 & 350.2 & 20.9 & -33.1 & 352.3 & -0.2 & -0.5 & -0.2 & -2.0 & -0.2 & -0.5 & -0.4 & $\begin{array}{l}-1.9 \\
\end{array}$ \\
\hline 253.9 & 257.4 & 60.2 & -16.1 & 610.7 & 363.0 & 26.4 & -31.9 & 367.3 & -0.5 & -0.4 & -0.1 & -2.0 & -0.7 & -0.9 & -0.4 & -1.4 \\
\hline 263.7 & 263.1 & 68.2 & -18.8 & 574.7 & 382.3 & 31.1 & -31.6 & 372.5 & -0.2 & -0.3 & -0.3 & -2.3 & -0.7 & -0.8 & -0.4 & -1.6 \\
\hline 273.4 & 266.0 & 77.3 & -22.2 & 495.5 & 401.4 & 42.1 & -26.3 & 346.1 & -0.4 & -0.4 & -0.3 & -2.3 & -0.9 & -0.7 & -0.4 & -1.2 \\
\hline 283.2 & 272.3 & 69.9 & -27.7 & 587.2 & 412.8 & 26.3 & -28.3 & 382.7 & -1.0 & -0.5 & -0.3 & -1.9 & -0.4 & -0.4 & -0.4 & -1.0 \\
\hline 293.0 & 269.0 & 87.0 & -28.4 & 536.5 & 415.0 & 43.6 & -20.5 & 412.8 & -0.5 & -0.5 & -0.3 & -1.7 & -0.8 & -0.4 & -0.4 & -2.7 \\
\hline 302.7 & 266.3 & 111.8 & -32.3 & 464.6 & 448.7 & 62.5 & -15.8 & 447.6 & -0.2 & -0.9 & -0.3 & -4.1 & -1.1 & -0.6 & -0.7 & -1.2 \\
\hline 312.5 & 262.3 & 106.5 & -36.0 & 592.5 & 478.1 & 52.1 & -13.3 & 462.9 & -0.7 & -0.3 & -0.4 & -2.1 & -1.4 & -0.5 & -0.6 & -1.7 \\
\hline 322.3 & 256.6 & 158.4 & -51.2 & 419.1 & 476.8 & 67.7 & -16.4 & 564.2 & -0.6 & -1.0 & -1.4 & -6.5 & -0.9 & -2.4 & -0.4 & -6.3 \\
\hline 332.0 & 290.6 & 133.4 & -43.8 & 794.7 & 490.0 & -42.7 & 84.3 & 710.7 & -0.4 & -1.4 & -0.9 & -3.6 & -0.4 & -0.9 & -0.4 & -3.1 \\
\hline 341.8 & 273.1 & 130.6 & -61.6 & 656.1 & 536.2 & 43.4 & 48.1 & 521.2 & -0.9 & -0.6 & -0.5 & -2.2 & -0.9 & -0.5 & -0.6 & -1.5 \\
\hline
\end{tabular}


Table 31: Dynamic Stiffness Real and Imaginary Parts at $10800 \mathrm{rpm}$ and $3134 \mathrm{kPa}(\mathrm{MN} / \mathrm{m})$

\begin{tabular}{|c|c|c|c|c|c|c|c|c|c|c|c|c|c|c|c|c|}
\hline $\mathrm{f}(\mathrm{Hz})$ & $\mathrm{R}\left(\mathrm{H}_{\mathrm{xx}}\right)$ & $\mathrm{R}\left(\mathrm{H}_{\mathrm{xy}}\right)$ & $\mathrm{R}\left(\mathrm{H}_{\mathrm{yx}}\right)$ & $\mathrm{R}\left(\mathrm{H}_{\mathrm{yv}}\right)$ & $\mathrm{I}\left(\mathrm{H}_{\mathrm{xx}}\right)$ & $\mathrm{I}\left(\mathrm{H}_{\mathrm{xy}}\right)$ & $\mathrm{I}\left(\mathrm{H}_{\mathrm{yx}}\right)$ & $\mathrm{I}\left(\mathrm{H}_{\mathrm{yv}}\right)$ & $\Delta \mathrm{R}\left(\mathrm{H}_{\mathrm{xx}}\right)$ & $\Delta R\left(H_{x y}\right)$ & $\Delta \mathrm{R}\left(\mathrm{H}_{\mathrm{yx}}\right)$ & $\Delta R\left(H_{y v}\right)$ & $\Delta \mathrm{I}\left(\mathrm{H}_{\mathrm{xx}}\right)$ & $\Delta \mathrm{I}\left(\mathrm{H}_{\mathrm{xy}}\right)$ & $\Delta \mathrm{I}\left(\mathrm{H}_{\mathrm{yx}}\right)$ & $\Delta \mathrm{I}\left(\mathrm{H}_{\mathrm{yv}}\right)$ \\
\hline 9.8 & 249.4 & -28.7 & -28.4 & 746.7 & 17.7 & 11.6 & -5.5 & 148.6 & -1.1 & -2.5 & -0.9 & -4.4 & -0.9 & -2.5 & -1.5 & -2.6 \\
\hline 19.5 & 248.7 & -20.3 & -26.2 & 731.5 & 33.0 & 5.3 & -1.8 & 88.8 & -0.4 & -3.3 & -0.5 & -2.4 & -0.3 & -3.2 & -0.9 & -3.8 \\
\hline 29.3 & 247.8 & -23.8 & -26.1 & 735.8 & 61.7 & 9.2 & -0.5 & 32.7 & -0.5 & -0.6 & -0.4 & -2.5 & -0.8 & -1.6 & -0.3 & -3.1 \\
\hline 39.1 & 246.9 & -25.6 & -24.7 & 720.4 & 72.4 & 8.8 & -0.9 & 46.8 & -0.4 & -0.9 & -0.4 & -2.5 & -0.2 & -1.5 & -0.7 & -2.1 \\
\hline 48.8 & 257.1 & -21.6 & -20.6 & 708.5 & 81.9 & 11.2 & -2.4 & 84.7 & -0.2 & -0.7 & -0.3 & -3.0 & -0.2 & -0.7 & -0.2 & -1.6 \\
\hline 58.6 & 258.7 & -18.7 & -18.9 & 737.7 & 104.1 & 9.3 & -4.4 & 72.4 & -0.2 & -0.7 & -0.3 & -3.2 & -0.3 & -0.3 & -0.2 & -1.4 \\
\hline 68.4 & 263.8 & -16.7 & -18.8 & 737.3 & 117.8 & 12.6 & -7.0 & 80.8 & -0.4 & -0.5 & -0.4 & -2.0 & -0.3 & -0.4 & -0.2 & -0.9 \\
\hline 78.1 & 263.2 & -8.5 & -19.6 & 707.6 & 137.8 & 24.3 & -0.4 & 124.8 & -0.2 & -0.4 & -0.2 & -2.3 & -0.1 & -0.4 & -0.3 & -1.4 \\
\hline 87.9 & 271.2 & -9.5 & -15.7 & 733.5 & 154.6 & 16.9 & -9.7 & 154.1 & -0.3 & -0.5 & -0.1 & -2.7 & -0.4 & -0.8 & -0.3 & -0.9 \\
\hline 97.7 & 272.5 & -4.2 & -15.9 & 719.7 & 164.8 & 17.3 & -12.5 & 127.3 & -0.5 & -0.3 & -0.2 & -2.2 & -0.4 & -0.4 & -0.5 & -1.4 \\
\hline 107.4 & 278.8 & 0.4 & -16.0 & 740.3 & 177.1 & 16.5 & -15.4 & 145.3 & -0.1 & -0.5 & -0.1 & -3.2 & -0.3 & -0.5 & -0.2 & -0.9 \\
\hline 117.2 & 274.3 & 3.2 & -15.9 & 729.2 & 193.9 & 17.3 & -18.5 & 163.4 & -0.2 & -0.5 & -0.3 & -2.5 & -0.3 & -0.3 & -0.4 & -0.9 \\
\hline 127.0 & 280.5 & 8.3 & -15.8 & 704.2 & 207.5 & 19.4 & -20.4 & 184.6 & -0.5 & -0.5 & -0.3 & -2.9 & -0.3 & -0.5 & -0.2 & -1.3 \\
\hline 136.7 & 277.5 & 14.1 & -16.2 & 690.6 & 223.4 & 19.4 & -21.5 & 203.3 & -0.3 & -0.4 & -0.5 & -2.7 & -0.4 & -0.3 & -0.2 & -1.5 \\
\hline 146.5 & 295.1 & 20.9 & -14.8 & 693.4 & 227.4 & 16.7 & -21.8 & 220.1 & -0.2 & -0.5 & -0.3 & -2.0 & -0.3 & -0.5 & -0.3 & -1.3 \\
\hline 156.3 & 301.0 & 26.9 & -14.9 & 701.0 & 245.5 & 16.6 & -21.5 & 189.4 & -0.3 & -0.6 & -0.4 & -2.5 & -0.6 & -0.4 & -0.6 & -1.3 \\
\hline 166.0 & 295.9 & 21.5 & -16.2 & 727.9 & 254.5 & 13.5 & -23.9 & 239.1 & -0.8 & -0.6 & -0.8 & -3.0 & -0.6 & -0.8 & -0.9 & -1.8 \\
\hline 175.8 & 290.2 & 27.8 & -13.5 & 716.3 & 277.8 & 15.5 & -25.6 & 261.3 & -2.0 & -2.5 & -3.0 & -3.5 & -1.9 & $\begin{array}{l}-1.7 \\
\end{array}$ & -3.9 & -4.9 \\
\hline 185.5 & 305.5 & 33.2 & -11.0 & 720.4 & 282.2 & 14.9 & -27.2 & 248.7 & -1.0 & -0.9 & -1.9 & -4.6 & -1.2 & -1.0 & -1.9 & -2.4 \\
\hline 195.3 & 308.5 & 37.9 & -12.6 & 700.1 & 290.2 & 16.5 & -27.4 & 249.0 & -0.8 & -0.7 & -0.6 & -3.0 & -0.5 & -0.7 & -1.2 & -1.8 \\
\hline 205.1 & 305.6 & 42.5 & -13.3 & 721.2 & 309.8 & 18.6 & -28.0 & 282.8 & -0.6 & -0.6 & -0.5 & -3.7 & -0.5 & -0.4 & -0.5 & -1.0 \\
\hline 214.8 & 293.4 & 51.0 & -13.0 & 700.6 & 322.5 & 23.6 & -29.5 & 279.5 & -0.4 & -0.4 & -0.5 & -3.5 & -0.5 & -0.4 & -0.4 & -1.2 \\
\hline 224.6 & 305.8 & 59.4 & -13.1 & 637.8 & 349.0 & 23.6 & -27.5 & 282.2 & -0.3 & -0.9 & -0.6 & -4.7 & -0.5 & -0.4 & -0.2 & -1.5 \\
\hline 234.4 & 296.1 & 52.4 & -16.4 & 732.9 & 358.5 & 12.8 & -31.6 & 331.7 & -0.4 & -0.3 & -0.3 & -2.3 & -0.5 & -0.5 & -0.2 & $\begin{array}{l}-1.3 \\
\end{array}$ \\
\hline 244.1 & 290.4 & 63.5 & -16.5 & 702.3 & 367.4 & 15.1 & -34.5 & 335.2 & -0.7 & -0.5 & -0.3 & -2.5 & -0.5 & -0.3 & -0.2 & -1.4 \\
\hline 253.9 & 295.5 & 66.2 & -20.7 & 708.5 & 379.8 & 21.2 & -33.0 & 341.9 & -0.2 & -0.4 & -0.3 & -3.1 & -0.4 & -0.7 & -0.4 & -1.0 \\
\hline 263.7 & 302.0 & 73.4 & -21.0 & 669.4 & 398.2 & 27.5 & -29.6 & 337.4 & -0.3 & -0.3 & -0.1 & -3.1 & -0.3 & -0.6 & -0.4 & -1.8 \\
\hline 273.4 & 309.1 & 84.6 & -26.6 & 598.7 & 419.9 & 33.5 & -27.3 & 324.2 & -0.4 & -0.7 & -0.3 & -4.4 & -0.4 & -0.5 & -0.4 & -1.1 \\
\hline 283.2 & 315.4 & 76.3 & -30.6 & 693.6 & 429.4 & 12.1 & -29.4 & 379.2 & -0.3 & -0.5 & -0.3 & -2.5 & -0.4 & -0.6 & -0.3 & $\begin{array}{l}-1.1 \\
\end{array}$ \\
\hline 293.0 & 314.8 & 92.8 & -31.1 & 618.9 & 432.7 & 40.3 & -18.9 & 376.9 & -0.4 & -0.3 & -0.3 & -3.8 & -0.4 & -0.7 & -0.3 & -1.6 \\
\hline 302.7 & 315.6 & 113.9 & -33.4 & 578.8 & 463.7 & 50.4 & -14.6 & 416.1 & -0.2 & -0.9 & -0.4 & -5.5 & -0.7 & -1.1 & -0.4 & -1.5 \\
\hline 312.5 & 320.5 & 191.5 & -60.7 & 642.1 & 498.9 & -7.9 & -8.3 & 752.1 & -0.5 & -1.2 & -1.4 & -9.3 & -0.9 & -4.0 & -0.6 & -11.2 \\
\hline 322.3 & 309.8 & 134.0 & -39.1 & 552.8 & 490.2 & 66.6 & -3.6 & 437.0 & -0.6 & -1.0 & -0.6 & -6.1 & -0.6 & -1.1 & -0.5 & -1.2 \\
\hline 332.0 & 340.2 & 298.1 & -146.5 & 470.9 & 550.2 & -38.7 & -38.9 & 1015.7 & -1.4 & -4.9 & -6.4 & -11.2 & -1.8 & -9.6 & -1.6 & -31.8 \\
\hline 341.8 & 325.9 & 122.4 & -53.9 & 803.4 & 547.8 & 10.2 & 27.2 & 515.2 & -0.6 & -0.2 & -0.4 & -2.4 & -0.6 & -0.7 & -0.5 & -1.1 \\
\hline
\end{tabular}


Table 32: Dynamic Stiffness Real and Imaginary Parts at $13200 \mathrm{rpm}$ and $0 \mathrm{kPa}(\mathrm{MN} / \mathrm{m})$

\begin{tabular}{|c|c|c|c|c|c|c|c|c|c|c|c|c|c|c|c|c|}
\hline $\mathrm{f}(\mathrm{Hz})$ & $\mathrm{R}\left(\mathrm{H}_{\mathrm{xx}}\right)$ & $\mathrm{R}\left(\mathrm{H}_{\mathrm{xy}}\right)$ & $\mathrm{R}\left(\mathrm{H}_{\mathrm{yx}}\right)$ & $\mathrm{R}\left(\mathrm{H}_{\mathrm{yv}}\right)$ & $\mathrm{I}\left(\mathrm{H}_{\mathrm{xx}}\right)$ & $\mathrm{I}\left(\mathrm{H}_{\mathrm{xy}}\right)$ & $\mathrm{I}\left(\mathrm{H}_{\mathrm{vx}}\right)$ & $\mathrm{I}\left(\mathrm{H}_{\mathrm{yv}}\right)$ & $\Delta \mathrm{R}\left(\mathrm{H}_{\mathrm{xx}}\right)$ & $\Delta R\left(H_{x y}\right)$ & $\Delta \mathrm{R}\left(\mathrm{H}_{\mathrm{vx}}\right)$ & $\Delta R\left(H_{\mathrm{yv}}\right)$ & $\Delta \mathrm{I}\left(\mathrm{H}_{\mathrm{xx}}\right)$ & $\Delta \mathrm{I}\left(\mathrm{H}_{\mathrm{xy}}\right)$ & $\Delta \mathrm{I}\left(\mathrm{H}_{\mathrm{yx}}\right)$ & $\Delta \mathrm{I}\left(\mathrm{H}_{\mathrm{vv}}\right)$ \\
\hline 9.8 & 202.8 & -3.5 & -25.9 & 307.0 & 10.7 & 9.5 & 8.3 & -59.4 & -1.3 & -4.4 & -1.7 & -10.1 & -1.2 & -4.1 & -1.1 & -5.3 \\
\hline 19.5 & 202.2 & -0.8 & -30.5 & 255.2 & 25.3 & -2.6 & -10.2 & 34.0 & -0.9 & -4.6 & -0.4 & -6.5 & -0.6 & -3.4 & -0.7 & -4.8 \\
\hline 29.3 & 203.3 & -8.7 & -33.6 & 303.7 & 49.8 & 0.7 & -2.0 & 35.7 & -0.4 & -2.3 & -0.8 & -7.2 & -0.9 & -0.5 & -1.1 & -3.6 \\
\hline 39.1 & 197.5 & -8.8 & -36.7 & 307.2 & 59.8 & -5.3 & -0.2 & 45.6 & -0.9 & -2.4 & -0.4 & -4.4 & -0.6 & -2.9 & -0.3 & -2.5 \\
\hline 48.8 & 203.9 & -4.3 & -39.0 & 313.8 & 65.9 & -1.4 & -0.8 & 78.0 & -0.9 & -2.3 & -0.5 & -3.8 & -0.4 & -1.2 & -1.0 & -3.8 \\
\hline 58.6 & 210.8 & 2.5 & -31.0 & 327.0 & 86.3 & -5.8 & -2.2 & 106.8 & -0.3 & -1.8 & -0.7 & -4.7 & -0.5 & -1.3 & -1.0 & -2.1 \\
\hline 68.4 & 212.8 & 2.2 & -34.6 & 328.0 & 95.9 & -10.2 & -4.5 & 101.9 & -0.5 & -1.5 & -0.7 & -3.4 & -0.4 & -0.8 & -0.9 & -3.0 \\
\hline 78.1 & 210.7 & 1.3 & -29.0 & 324.2 & 111.0 & -13.2 & -6.7 & 115.2 & -0.3 & -1.2 & -0.5 & -3.6 & -0.5 & -0.6 & -0.5 & -2.5 \\
\hline 87.9 & 220.4 & 9.1 & -19.9 & 374.7 & 127.0 & -19.9 & 8.9 & 148.7 & -0.5 & -1.9 & -0.3 & -4.2 & -0.5 & -1.8 & -0.5 & -2.5 \\
\hline 97.7 & 214.7 & 6.6 & -27.7 & 333.2 & 136.4 & -19.6 & -8.3 & 147.5 & -0.7 & -1.5 & -0.8 & -4.4 & -0.5 & -0.9 & -0.8 & -2.6 \\
\hline 107.4 & 220.7 & 8.0 & -25.0 & 326.6 & 150.0 & -24.5 & -3.5 & 162.9 & -0.7 & -1.9 & -0.8 & -4.6 & -0.8 & -0.9 & -0.6 & -2.1 \\
\hline 117.2 & 220.2 & 9.0 & -22.6 & 339.3 & 163.8 & -26.7 & 0.0 & 192.4 & -0.7 & -1.1 & -0.4 & -3.6 & -0.4 & -1.0 & -0.8 & -2.2 \\
\hline 127.0 & 220.2 & 10.2 & -21.8 & 349.7 & 177.2 & -32.1 & 4.1 & 175.7 & -0.6 & -1.7 & -0.6 & -3.7 & -0.4 & -0.6 & -0.5 & -2.0 \\
\hline 136.7 & 222.4 & 10.7 & -15.8 & 358.6 & 190.7 & -38.4 & 2.2 & 175.6 & -0.2 & -1.1 & -0.5 & -3.7 & -0.4 & -1.6 & -0.9 & -2.2 \\
\hline 146.5 & 238.0 & 9.2 & -11.0 & 374.3 & 192.8 & -45.9 & 2.8 & 185.8 & -0.6 & -1.1 & -0.5 & -3.6 & -0.5 & -0.7 & -0.9 & -2.7 \\
\hline 156.3 & 236.9 & 5.4 & -11.9 & 320.4 & 203.0 & -38.8 & 3.9 & 306.8 & -0.3 & -1.3 & -1.0 & -3.9 & -0.4 & -0.7 & -1.0 & -2.2 \\
\hline 166.0 & 237.3 & 6.8 & -4.5 & 364.3 & 217.2 & -44.7 & -2.5 & 249.5 & -0.9 & -1.6 & -0.8 & -3.3 & -0.6 & -0.8 & -0.8 & -2.5 \\
\hline 175.8 & 228.6 & 11.0 & 6.9 & 413.5 & 236.8 & -46.8 & 3.1 & 288.9 & -0.8 & -1.4 & -0.8 & -4.7 & -0.5 & -0.8 & -0.7 & -2.2 \\
\hline 185.5 & 244.5 & 10.1 & -7.5 & 386.9 & 233.6 & -42.0 & -2.0 & 263.6 & -0.5 & -1.4 & -0.5 & -4.0 & -0.6 & -1.3 & -0.7 & -3.1 \\
\hline 195.3 & 250.8 & 9.2 & 18.8 & 427.3 & 234.5 & -46.4 & 4.4 & 313.3 & -0.5 & -0.9 & -0.4 & -3.7 & -0.8 & -0.8 & -0.7 & -2.0 \\
\hline 205.1 & 238.2 & 10.1 & 12.9 & 416.5 & 256.1 & -32.3 & 12.5 & 332.4 & -1.2 & -1.5 & -0.7 & -3.7 & -0.7 & -0.6 & -0.9 & -2.4 \\
\hline 214.8 & 233.0 & 13.0 & 2.1 & 399.9 & 275.6 & -32.4 & 14.4 & 338.5 & -0.6 & -2.1 & -1.0 & -4.4 & -1.0 & -1.0 & -0.6 & -4.1 \\
\hline 224.6 & 251.5 & 23.3 & 25.0 & 418.9 & 297.9 & -42.8 & 14.3 & 337.8 & -0.7 & -1.5 & -1.9 & -6.1 & $\begin{array}{l}-1.6 \\
\end{array}$ & -1.5 & -1.8 & -2.6 \\
\hline 234.4 & 245.0 & 25.4 & 47.5 & 433.3 & 303.4 & -24.5 & 19.6 & 357.9 & -0.3 & -1.5 & -0.9 & -4.0 & -0.5 & -0.7 & -1.5 & -1.6 \\
\hline 244.1 & 234.4 & 44.0 & 37.1 & 476.6 & 322.5 & -18.6 & 64.2 & 395.7 & -0.8 & -1.9 & -0.3 & -4.3 & -0.7 & -1.2 & -1.0 & -2.8 \\
\hline 253.9 & 249.8 & 47.4 & 85.8 & 517.7 & 339.6 & -22.7 & 80.0 & 353.5 & -0.5 & -1.6 & -2.1 & -6.4 & -0.6 & -1.2 & -1.8 & -3.4 \\
\hline 263.7 & 265.2 & 62.9 & 131.0 & 524.1 & 343.5 & -48.1 & 76.5 & 329.9 & -0.5 & -1.7 & -1.2 & -5.6 & -1.1 & -1.4 & -3.6 & -3.2 \\
\hline 273.4 & 268.9 & 77.9 & 110.6 & 495.1 & 336.1 & -47.2 & $\begin{array}{l}-17.2 \\
\end{array}$ & 278.7 & -1.5 & -1.5 & -3.5 & -4.7 & -0.8 & -0.8 & -1.6 & -3.3 \\
\hline 283.2 & 337.5 & 104.4 & 271.6 & 539.6 & 294.2 & -115.7 & -136.0 & 103.7 & -3.6 & -5.6 & -6.0 & -11.8 & -6.6 & -2.5 & -12.1 & -6.2 \\
\hline 293.0 & 284.2 & 47.3 & 240.2 & 460.3 & 237.9 & -92.5 & -298.3 & 179.2 & -2.8 & -2.1 & -5.2 & -7.4 & -1.5 & -1.1 & -4.9 & -6.2 \\
\hline 302.7 & 196.7 & 40.3 & -5.9 & 357.7 & 323.6 & -64.8 & -119.6 & 311.3 & -0.7 & -1.1 & -0.7 & -3.9 & -0.6 & -1.4 & -1.3 & -2.6 \\
\hline 312.5 & 236.3 & 21.5 & 41.9 & 413.3 & 394.5 & -54.8 & -52.2 & 332.1 & -1.5 & -2.6 & -2.1 & -4.1 & -2.2 & -1.2 & -1.9 & -2.4 \\
\hline 322.3 & 232.3 & 50.2 & 95.2 & 398.4 & 334.3 & -28.1 & -110.6 & 372.4 & -0.7 & -1.2 & -1.1 & -4.1 & -1.0 & -0.8 & -2.6 & -2.7 \\
\hline 332.0 & 209.6 & 21.8 & 41.7 & 367.6 & 324.7 & -40.3 & -119.3 & 330.9 & -0.6 & -1.3 & -1.6 & -4.7 & -0.7 & -0.6 & -1.6 & -2.3 \\
\hline 341.8 & 195.6 & 55.6 & 85.6 & 405.8 & 344.5 & -40.5 & -86.5 & 323.0 & -1.5 & -1.7 & -2.2 & -4.2 & -1.0 & -1.2 & -1.6 & -2.6 \\
\hline
\end{tabular}


Table 33: Dynamic Stiffness Real and Imaginary Parts at $13200 \mathrm{rpm}$ and $783 \mathrm{kPa}(\mathrm{MN} / \mathrm{m})$

\begin{tabular}{|c|c|c|c|c|c|c|c|c|c|c|c|c|c|c|c|c|}
\hline $\mathrm{f}(\mathrm{Hz})$ & $\mathrm{R}\left(\mathrm{H}_{\mathrm{xx}}\right)$ & $\mathrm{R}\left(\mathrm{H}_{\mathrm{xy}}\right)$ & $\mathrm{R}\left(\mathrm{H}_{\mathrm{yx}}\right)$ & $\mathrm{R}\left(\mathrm{H}_{\mathrm{yv}}\right)$ & $\mathrm{I}\left(\mathrm{H}_{\mathrm{xx}}\right)$ & $\mathrm{I}\left(\mathrm{H}_{\mathrm{xy}}\right)$ & $\mathrm{I}\left(\mathrm{H}_{\mathrm{vx}}\right)$ & $\mathrm{I}\left(\mathrm{H}_{\mathrm{vv}}\right)$ & $\Delta \mathrm{R}\left(\mathrm{H}_{\mathrm{xx}}\right)$ & $\Delta \mathrm{R}\left(\mathrm{H}_{\mathrm{xy}}\right)$ & $\Delta \mathrm{R}\left(\mathrm{H}_{\mathrm{yx}}\right)$ & $\Delta \mathrm{R}\left(\mathrm{H}_{\mathrm{yv}}\right)$ & $\Delta \mathrm{I}\left(\mathrm{H}_{\mathrm{xx}}\right)$ & $\Delta \mathrm{I}\left(\mathrm{H}_{\mathrm{xy}}\right)$ & $\Delta \mathrm{I}\left(\mathrm{H}_{\mathrm{vx}}\right)$ & $\Delta \mathrm{I}\left(\mathrm{H}_{\mathrm{yv}}\right)$ \\
\hline 9.8 & 213.6 & -9.0 & -26.6 & 364.2 & 15.2 & -6.0 & -8.0 & 62.0 & -1.0 & -3.7 & -0.7 & -4.2 & -1.0 & -1.0 & -1.7 & -6.9 \\
\hline 19.5 & 208.9 & 1.5 & -28.6 & 373.4 & 23.6 & 5.7 & -3.4 & 12.2 & -1.1 & -3.7 & -0.7 & -8.2 & -1.0 & -2.9 & -0.4 & -3.7 \\
\hline 29.3 & 209.9 & -7.3 & -33.1 & 389.0 & 50.4 & -0.8 & 1.5 & 29.8 & -0.7 & -2.3 & -1.2 & -2.8 & -1.0 & -1.6 & -1.1 & -3.9 \\
\hline 39.1 & 205.8 & -5.0 & -36.2 & 379.0 & 62.4 & -1.9 & 0.8 & 61.1 & -0.6 & -1.3 & -0.6 & -4.3 & -0.7 & -2.3 & -0.7 & -2.3 \\
\hline 48.8 & 214.5 & -4.2 & -32.0 & 367.5 & 67.7 & -8.3 & -4.1 & 89.5 & -0.6 & -1.2 & -0.6 & -2.1 & -0.3 & -1.6 & -0.5 & -3.5 \\
\hline 58.6 & 217.5 & -4.9 & -32.4 & 380.7 & 86.8 & -6.3 & -5.4 & 101.1 & -0.4 & -1.5 & -0.9 & -2.3 & -0.5 & -1.4 & -0.7 & -1.3 \\
\hline 68.4 & 220.4 & -3.3 & -30.5 & 386.6 & 103.6 & -1.3 & 2.6 & 110.7 & -0.5 & -1.2 & -0.7 & -2.5 & -0.4 & -1.3 & -0.2 & -2.1 \\
\hline 78.1 & 219.4 & 1.0 & -27.6 & 373.3 & 114.6 & -7.4 & -2.0 & 124.1 & -0.6 & -1.1 & -0.5 & -1.8 & -0.8 & -0.6 & -0.6 & -1.8 \\
\hline 87.9 & 225.8 & 0.4 & -28.3 & 397.4 & 131.4 & -10.1 & -0.6 & 154.5 & -0.6 & -1.2 & -0.3 & -2.2 & -0.4 & -0.9 & -0.6 & -1.3 \\
\hline 97.7 & 223.5 & 4.3 & -28.0 & 389.1 & 140.7 & -11.1 & 0.6 & 152.9 & -0.3 & -0.6 & -0.5 & -2.6 & -0.1 & -1.1 & -0.3 & -1.5 \\
\hline 107.4 & 229.2 & 4.3 & -26.7 & 399.5 & 152.0 & -13.9 & 1.0 & 174.2 & -0.8 & -0.9 & -0.6 & -1.8 & -0.5 & -0.8 & -0.6 & $\begin{array}{l}-1.3 \\
\end{array}$ \\
\hline 117.2 & 225.2 & 5.5 & -22.9 & 402.7 & 167.9 & -15.6 & 1.2 & 188.5 & -0.5 & -0.7 & -0.3 & -2.3 & -0.3 & -0.9 & -0.4 & -1.7 \\
\hline 127.0 & 232.8 & 7.2 & -21.8 & 391.4 & 178.7 & -19.5 & -0.6 & 203.7 & -0.3 & -1.0 & -0.3 & -1.6 & -0.6 & -1.0 & -0.5 & -1.4 \\
\hline 136.7 & 231.9 & 7.1 & -16.2 & 396.8 & 194.8 & -23.7 & 0.9 & 212.1 & -0.2 & -0.6 & -0.4 & -2.1 & -0.4 & -0.8 & -0.4 & -1.4 \\
\hline 146.5 & 242.5 & 7.9 & -15.4 & 393.5 & 195.8 & -25.5 & -0.5 & 213.9 & -0.4 & -0.4 & -0.5 & -2.2 & -0.3 & -0.8 & -0.5 & -1.7 \\
\hline 156.3 & 255.7 & 14.9 & -21.4 & 367.8 & 205.4 & -23.7 & 4.5 & 223.6 & -0.7 & -0.8 & -0.4 & -1.4 & -0.3 & -1.1 & -0.9 & -1.4 \\
\hline 166.0 & 245.4 & 7.1 & -8.8 & 419.7 & 221.5 & -26.3 & -1.9 & 260.6 & -0.4 & -0.5 & -1.0 & -1.7 & -0.4 & -0.4 & -0.5 & -1.7 \\
\hline 175.8 & 243.8 & 5.3 & -9.5 & 414.8 & 238.8 & -30.2 & 0.0 & 269.9 & -0.4 & -1.2 & -0.3 & -2.1 & -0.3 & -1.1 & -0.4 & -1.9 \\
\hline 185.5 & 255.1 & 6.5 & -7.1 & 421.1 & 239.3 & -28.5 & $\begin{array}{l}-1.4 \\
\end{array}$ & 270.8 & -0.4 & -0.6 & -0.7 & -1.6 & -0.8 & -0.7 & -1.0 & -2.1 \\
\hline 195.3 & 262.7 & 8.8 & -4.6 & 406.6 & 245.6 & -28.8 & -0.5 & 279.3 & -0.8 & -0.9 & -0.6 & -2.3 & -0.6 & -1.1 & -0.3 & -1.6 \\
\hline 205.1 & 254.0 & 9.9 & -2.5 & 422.1 & 261.9 & -21.4 & 2.4 & 301.4 & -0.7 & -0.7 & -1.0 & -1.7 & -0.7 & -0.9 & -0.6 & -1.4 \\
\hline 214.8 & 239.6 & 11.7 & 1.2 & 409.0 & 277.9 & -18.7 & -2.8 & 295.0 & -1.0 & -0.8 & -0.8 & -1.8 & -0.9 & -0.6 & -1.3 & -1.8 \\
\hline 224.6 & 256.4 & 27.9 & -10.3 & 286.9 & 299.1 & -18.1 & 3.0 & 341.0 & -1.1 & -1.4 & -0.7 & -5.0 & -1.0 & -3.1 & $\begin{array}{l}-1.3 \\
\end{array}$ & -1.9 \\
\hline 234.4 & 241.8 & 8.4 & 0.6 & 429.1 & 309.1 & -22.2 & 1.2 & 343.0 & -1.0 & -1.2 & -0.3 & -1.7 & -0.5 & -0.8 & -0.3 & -1.5 \\
\hline 244.1 & 237.0 & 13.8 & 5.6 & 427.2 & 310.8 & -17.7 & 0.9 & 350.9 & -0.2 & -0.5 & -0.3 & -2.3 & -0.6 & -0.6 & -0.4 & -1.8 \\
\hline 253.9 & 239.8 & 13.8 & 4.9 & 443.5 & 321.1 & -10.7 & 5.8 & 366.0 & -0.6 & -0.9 & -0.5 & -1.9 & -0.6 & -0.8 & -0.1 & -1.2 \\
\hline 263.7 & 243.9 & 15.1 & 3.9 & 400.3 & 332.0 & -3.1 & 9.9 & 352.0 & -0.3 & -0.7 & -0.3 & -1.8 & -0.8 & -0.4 & -0.3 & -1.3 \\
\hline 273.4 & 240.5 & 32.8 & -5.9 & 284.9 & 353.9 & 9.2 & 19.7 & 374.5 & -0.4 & -0.3 & -0.4 & -1.8 & -0.4 & -0.4 & -0.3 & -1.0 \\
\hline 283.2 & 243.4 & 13.1 & 11.1 & 392.1 & 362.0 & 5.9 & 18.6 & 376.1 & -0.3 & -0.6 & -0.5 & -1.8 & -0.5 & -0.4 & -0.2 & -1.0 \\
\hline 293.0 & 244.1 & 55.8 & 21.9 & 395.6 & 364.2 & -2.8 & 75.3 & 579.2 & -0.6 & -1.3 & -1.2 & -3.1 & -0.5 & -0.7 & -0.2 & -3.0 \\
\hline 302.7 & 234.4 & 61.8 & 15.6 & 469.8 & 394.6 & -0.7 & 88.6 & 599.6 & -0.4 & $\begin{array}{l}-1.4 \\
\end{array}$ & -0.7 & -4.3 & -0.6 & -0.9 & -0.5 & -2.0 \\
\hline 312.5 & 225.2 & 99.9 & -84.0 & 281.7 & 454.7 & 80.9 & 117.8 & 614.4 & -0.6 & -0.6 & -0.8 & -2.4 & -0.8 & -0.7 & -2.2 & -2.8 \\
\hline 322.3 & 258.6 & 127.9 & 30.1 & 390.5 & 423.8 & 27.8 & 269.2 & 730.6 & -1.8 & -2.3 & -3.2 & -4.7 & -1.7 & -1.7 & -1.0 & -1.7 \\
\hline 332.0 & 290.0 & 107.7 & 68.0 & 480.8 & 599.7 & 117.0 & 266.4 & 552.7 & -4.0 & -2.1 & -1.5 & -2.4 & -2.1 & -1.4 & -1.4 & -1.5 \\
\hline 341.8 & 438.6 & 191.2 & 308.0 & 573.9 & 535.9 & 70.7 & 192.0 & 472.1 & -1.1 & -1.1 & -1.0 & -2.1 & -5.7 & -2.8 & -5.0 & -3.2 \\
\hline
\end{tabular}


Table 34: Dynamic Stiffness Real and Imaginary Parts at $13200 \mathrm{rpm}$ and $1567 \mathrm{kPa}$ (MN/m)

\begin{tabular}{|c|c|c|c|c|c|c|c|c|c|c|c|c|c|c|c|c|}
\hline $\mathrm{f}(\mathrm{Hz})$ & $\mathrm{R}\left(\mathrm{H}_{\mathrm{xx}}\right)$ & $\mathrm{R}\left(\mathrm{H}_{\mathrm{xy}}\right)$ & $\mathrm{R}\left(\mathrm{H}_{\mathrm{yx}}\right)$ & $\mathrm{R}\left(\mathrm{H}_{\mathrm{yv}}\right)$ & $\mathrm{I}\left(\mathrm{H}_{\mathrm{xx}}\right)$ & $\mathrm{I}\left(\mathrm{H}_{\mathrm{xy}}\right)$ & $\mathrm{I}\left(\mathrm{H}_{\mathrm{yx}}\right)$ & $\mathrm{I}\left(\mathrm{H}_{\mathrm{yv}}\right)$ & $\Delta \mathrm{R}\left(\mathrm{H}_{\mathrm{xx}}\right)$ & $\Delta \mathrm{R}\left(\mathrm{H}_{\mathrm{xy}}\right)$ & $\Delta \mathrm{R}\left(\mathrm{H}_{\mathrm{yx}}\right)$ & $\Delta \mathrm{R}\left(\mathrm{H}_{\mathrm{yv}}\right)$ & $\Delta \mathrm{I}\left(\mathrm{H}_{\mathrm{xX}}\right)$ & $\Delta \mathrm{I}\left(\mathrm{H}_{\mathrm{xy}}\right)$ & $\Delta \mathrm{I}\left(\mathrm{H}_{\mathrm{vX}}\right)$ & $\Delta \mathrm{I}\left(\mathrm{H}_{\mathrm{yv}}\right)$ \\
\hline 9.8 & 233.3 & -23.5 & -32.1 & 469.3 & 16.8 & 4.7 & -9.8 & 134.1 & -0.9 & -3.6 & -0.8 & -9.4 & -1.2 & -2.8 & -1.8 & -4.9 \\
\hline 19.5 & 233.2 & -17.3 & -30.1 & 462.8 & 24.8 & -0.2 & -3.4 & 51.9 & -0.5 & -6.1 & -0.9 & -6.6 & -1.0 & -2.4 & -1.2 & -5.6 \\
\hline 29.3 & 231.6 & -18.3 & -35.2 & 504.4 & 52.1 & -1.5 & 1.0 & 25.8 & -1.6 & -2.6 & -1.1 & -2.8 & -1.1 & -3.1 & -1.5 & -5.2 \\
\hline 39.1 & 226.6 & -22.3 & -36.3 & 484.5 & 62.5 & 2.0 & -0.7 & 57.2 & -0.3 & -1.6 & -0.6 & -3.7 & -0.4 & -0.8 & -0.7 & -3.0 \\
\hline 48.8 & 237.3 & -21.8 & -32.6 & 455.0 & 69.8 & -1.2 & -4.7 & 99.6 & -0.5 & -0.8 & -0.3 & -2.6 & -0.6 & -1.1 & -1.0 & -1.8 \\
\hline 58.6 & 238.5 & -16.0 & -30.9 & 474.1 & 89.9 & 0.3 & -4.2 & 91.1 & -0.5 & -0.6 & -0.6 & -2.0 & -0.7 & -0.7 & -0.5 & -1.0 \\
\hline 68.4 & 238.2 & -19.0 & -36.3 & 482.8 & 100.8 & 3.5 & -4.4 & 95.5 & -0.5 & -0.6 & -1.1 & -1.9 & -0.5 & -0.6 & -0.5 & -1.2 \\
\hline 78.1 & 241.9 & -11.8 & -28.6 & 466.7 & 115.9 & 3.3 & -1.8 & 116.7 & -0.2 & -0.5 & -0.4 & -1.8 & -0.2 & -0.7 & -0.5 & -1.2 \\
\hline 87.9 & 247.1 & -14.9 & -28.2 & 486.8 & 134.4 & 1.6 & -1.2 & 157.9 & -0.4 & -0.5 & -0.1 & -1.6 & -0.3 & -1.4 & -0.2 & -1.2 \\
\hline 97.7 & 246.6 & -9.9 & -27.6 & 486.9 & 143.8 & 2.1 & -0.6 & 142.3 & -0.3 & -0.7 & -0.3 & -1.9 & -0.4 & -0.5 & -0.7 & -1.9 \\
\hline 107.4 & 251.4 & -6.3 & -26.6 & 493.3 & 155.2 & 2.2 & -0.9 & 164.7 & -0.1 & -0.6 & -0.4 & -2.4 & -0.2 & -0.7 & -0.4 & -1.3 \\
\hline 117.2 & 246.1 & -5.0 & -24.2 & 493.0 & 171.2 & 1.2 & 0.0 & 180.9 & -0.2 & -0.7 & -0.3 & -2.1 & -0.4 & -0.8 & -0.3 & -1.3 \\
\hline 127.0 & 253.3 & -1.5 & -20.5 & 474.3 & 183.2 & 0.2 & -0.7 & 199.8 & -0.5 & -0.9 & -0.3 & -1.5 & -0.6 & -0.5 & -0.5 & $\begin{array}{l}-1.3 \\
\end{array}$ \\
\hline 136.7 & 252.0 & 2.8 & -18.3 & 466.4 & 201.3 & -0.8 & -2.2 & 214.0 & -0.3 & -1.0 & -0.4 & -1.6 & -0.5 & -0.5 & -0.2 & -1.3 \\
\hline 146.5 & 264.4 & 5.3 & -16.5 & 469.0 & 200.2 & -1.4 & -2.0 & 214.0 & -0.3 & -0.8 & -0.6 & -1.9 & -0.4 & -0.6 & -0.4 & -1.1 \\
\hline 156.3 & 276.7 & 12.6 & -16.9 & 465.4 & 216.2 & 1.4 & -3.3 & 207.5 & -0.3 & -0.5 & -0.4 & -1.5 & -0.7 & -0.5 & -0.2 & -1.7 \\
\hline 166.0 & 266.5 & 5.2 & -11.9 & 505.0 & 227.6 & -1.4 & -1.9 & 255.1 & -0.4 & -0.8 & -0.5 & -1.7 & -0.7 & -0.6 & -0.4 & -1.2 \\
\hline 175.8 & 262.5 & 8.2 & -8.6 & 492.3 & 247.9 & -1.9 & -5.0 & 267.4 & -0.7 & -0.7 & -0.4 & -2.2 & -0.4 & -0.6 & -0.6 & $\begin{array}{l}-1.3 \\
\end{array}$ \\
\hline 185.5 & 276.1 & 13.5 & -8.1 & 493.9 & 246.7 & -1.8 & -4.0 & 263.8 & -0.5 & -0.6 & -0.8 & -1.7 & -0.5 & -0.9 & -0.3 & -2.0 \\
\hline 195.3 & 282.2 & 17.8 & -6.5 & 484.4 & 257.7 & -3.0 & -6.0 & 269.6 & -0.5 & -0.3 & -0.4 & -1.9 & -0.8 & -0.7 & -0.4 & $\begin{array}{l}-1.7 \\
\end{array}$ \\
\hline 205.1 & 277.9 & 18.6 & -6.7 & 511.2 & 268.9 & 3.1 & -0.2 & 295.7 & -1.0 & -1.0 & -0.3 & -2.2 & -0.6 & -0.6 & $\begin{array}{l}-1.4 \\
\end{array}$ & -1.5 \\
\hline 214.8 & 262.6 & 25.8 & -4.6 & 490.7 & 282.0 & 3.7 & -3.5 & 288.2 & -0.9 & $\begin{array}{l}-1.4 \\
\end{array}$ & -1.0 & -3.1 & -0.6 & -1.2 & -1.9 & -2.4 \\
\hline 224.6 & 280.3 & 32.3 & -0.5 & 406.5 & 306.8 & 3.4 & -0.5 & 298.5 & -2.4 & -1.7 & -1.2 & -3.3 & -1.1 & -1.5 & -2.5 & -2.2 \\
\hline 234.4 & 267.2 & 24.3 & -0.5 & 511.9 & 314.1 & -0.8 & -5.5 & 339.5 & -1.0 & -0.8 & -0.6 & -1.9 & -1.0 & -0.5 & -0.7 & -1.7 \\
\hline 244.1 & 263.0 & 32.2 & 3.4 & 514.4 & 318.7 & -4.2 & -5.2 & 375.0 & -0.3 & -0.5 & -0.2 & -2.2 & -0.5 & -0.8 & -0.3 & -1.5 \\
\hline 253.9 & 265.3 & 33.6 & 5.0 & 503.1 & 325.8 & 9.3 & -3.5 & 361.6 & -0.6 & -0.5 & -0.5 & -2.2 & -0.4 & -0.4 & -0.4 & -1.1 \\
\hline 263.7 & 270.8 & 34.2 & 4.5 & 482.2 & 338.9 & 11.6 & $\begin{array}{l}-1.1 \\
\end{array}$ & 353.3 & -0.4 & -0.3 & -0.2 & -1.9 & -0.3 & -0.7 & -0.5 & -2.1 \\
\hline 273.4 & 267.7 & 44.0 & 4.2 & 393.0 & 354.7 & 21.4 & -0.5 & 336.8 & -0.4 & -0.7 & -0.3 & -2.5 & -0.6 & -0.6 & -0.3 & -1.8 \\
\hline 283.2 & 272.4 & 34.8 & 7.1 & 474.0 & 363.0 & 13.1 & -0.4 & 362.9 & -0.5 & -0.3 & -0.4 & -1.5 & -0.5 & -0.8 & -0.3 & -1.6 \\
\hline 293.0 & 264.5 & 49.7 & 5.3 & 430.1 & 370.1 & 33.8 & 4.2 & 391.9 & -0.4 & -0.6 & -0.4 & -2.4 & -0.3 & -0.7 & -0.2 & -1.7 \\
\hline 302.7 & 259.2 & 84.8 & -3.5 & 345.6 & 398.8 & 47.3 & 6.9 & 505.4 & -0.4 & -0.5 & -0.6 & -3.7 & -0.7 & -1.0 & -0.5 & -1.4 \\
\hline 312.5 & 246.2 & 83.6 & -2.5 & 375.5 & 419.9 & 66.1 & 6.5 & 474.7 & -0.6 & -0.6 & -0.8 & -6.6 & -0.7 & -1.6 & -0.6 & -3.0 \\
\hline 322.3 & 242.3 & 83.9 & 0.6 & 392.8 & 415.1 & 63.2 & 21.4 & 469.8 & -0.5 & -0.4 & -0.7 & -3.8 & -0.7 & -1.1 & -0.4 & -2.7 \\
\hline 332.0 & 249.0 & 75.3 & 18.9 & 592.9 & 460.4 & 30.6 & 64.7 & 536.5 & -0.8 & -1.2 & -0.3 & -1.9 & -0.7 & -0.9 & -0.9 & -1.5 \\
\hline 341.8 & 241.9 & 89.2 & 11.6 & 534.1 & 494.4 & 71.6 & 78.8 & 480.5 & -1.3 & -0.8 & -0.8 & -1.9 & -0.6 & -0.4 & -1.6 & -1.8 \\
\hline
\end{tabular}


Table 35: Dynamic Stiffness Real and Imaginary Parts at $13200 \mathrm{rpm}$ and $2350 \mathrm{kPa}(\mathrm{MN} / \mathrm{m})$

\begin{tabular}{|c|c|c|c|c|c|c|c|c|c|c|c|c|c|c|c|c|}
\hline $\mathrm{f}(\mathrm{Hz})$ & $\mathrm{R}\left(\mathrm{H}_{\mathrm{xx}}\right)$ & $\mathrm{R}\left(\mathrm{H}_{\mathrm{xy}}\right)$ & $\mathrm{R}\left(\mathrm{H}_{\mathrm{yx}}\right)$ & $\mathrm{R}\left(\mathrm{H}_{\mathrm{yv}}\right)$ & $\mathrm{I}\left(\mathrm{H}_{\mathrm{xx}}\right)$ & $\mathrm{I}\left(\mathrm{H}_{\mathrm{xy}}\right)$ & $\mathrm{I}\left(\mathrm{H}_{\mathrm{yx}}\right)$ & $\mathrm{I}\left(\mathrm{H}_{\mathrm{yv}}\right)$ & $\Delta \mathrm{R}\left(\mathrm{H}_{\mathrm{xx}}\right)$ & $\Delta \mathrm{R}\left(\mathrm{H}_{\mathrm{xy}}\right)$ & $\Delta \mathrm{R}\left(\mathrm{H}_{\mathrm{yx}}\right)$ & $\Delta \mathrm{R}\left(\mathrm{H}_{\mathrm{vy}}\right)$ & $\Delta \mathrm{I}\left(\mathrm{H}_{\mathrm{xx}}\right)$ & $\Delta \mathrm{I}\left(\mathrm{H}_{\mathrm{xy}}\right)$ & $\Delta \mathrm{I}\left(\mathrm{H}_{\mathrm{yx}}\right)$ & $\Delta \mathrm{I}\left(\mathrm{H}_{\mathrm{vv}}\right)$ \\
\hline 9.8 & 263.1 & -21.9 & -35.5 & 576.0 & 15.7 & 4.6 & -12.4 & 147.2 & -1.5 & -5.2 & -1.2 & -6.8 & -1.3 & -9.1 & -2.3 & -3.8 \\
\hline 19.5 & 261.8 & -19.4 & -35.0 & 582.0 & 26.5 & 5.6 & -4.7 & 46.8 & -1.0 & -3.3 & -1.3 & -9.3 & -1.2 & -5.6 & -1.2 & -9.6 \\
\hline 29.3 & 259.1 & -29.7 & -38.1 & 596.1 & 54.3 & 1.2 & 2.2 & 35.2 & -1.2 & -2.3 & -2.3 & -3.2 & -0.6 & -1.5 & -1.4 & -4.7 \\
\hline 39.1 & 254.7 & -24.6 & -37.2 & 588.5 & 62.8 & 6.2 & -0.1 & 60.2 & -0.8 & -2.1 & -1.6 & -2.5 & -1.2 & -3.1 & -1.0 & -2.6 \\
\hline 48.8 & 263.7 & -22.5 & -34.3 & 560.0 & 71.3 & 3.4 & -2.9 & 97.4 & -0.4 & -1.2 & -1.1 & -2.6 & -0.3 & -1.3 & -0.6 & -1.7 \\
\hline 58.6 & 265.8 & -24.8 & -34.5 & 589.0 & 90.7 & 3.4 & -2.8 & 84.2 & -0.6 & -1.5 & -0.3 & -2.6 & -0.6 & -0.9 & -0.8 & -2.3 \\
\hline 68.4 & 267.8 & -19.9 & -35.6 & 591.9 & 100.4 & 6.3 & -2.0 & 82.2 & -0.5 & -0.6 & -0.3 & -1.8 & -0.4 & -0.4 & -0.3 & -1.3 \\
\hline 78.1 & 269.5 & -13.1 & -29.8 & 572.0 & 120.3 & 9.0 & 3.2 & 118.0 & -0.6 & -0.5 & -0.4 & -1.9 & -0.3 & -0.6 & -0.5 & -1.2 \\
\hline 87.9 & 274.1 & -16.2 & -31.0 & 593.9 & 135.5 & 7.4 & 0.3 & 151.9 & -0.4 & -0.7 & -0.3 & -1.7 & -0.7 & -0.7 & -0.4 & -1.2 \\
\hline 97.7 & 274.5 & -12.7 & -30.3 & 588.7 & 147.3 & 6.9 & 0.0 & 135.0 & -0.8 & -0.6 & -0.3 & -2.4 & -0.1 & -0.4 & -0.5 & -1.3 \\
\hline 107.4 & 278.5 & $\begin{array}{l}-7.1 \\
\end{array}$ & -29.5 & 600.6 & 156.6 & 7.9 & 0.7 & 156.1 & -0.2 & -0.3 & -0.3 & -2.0 & -0.2 & -0.6 & -0.5 & -1.1 \\
\hline 117.2 & 274.0 & -5.9 & -27.3 & 595.1 & 173.0 & 8.1 & 0.2 & 175.3 & -0.4 & -0.3 & -0.5 & -1.6 & -0.4 & -0.5 & -0.3 & -1.4 \\
\hline 127.0 & 280.3 & -2.4 & -23.8 & 572.2 & 186.8 & 8.4 & -1.5 & 195.6 & -0.3 & -0.6 & -0.8 & -2.6 & -0.4 & -0.5 & -0.5 & -1.1 \\
\hline 136.7 & 275.9 & 0.5 & -23.1 & 564.5 & 204.1 & 7.1 & -1.1 & 206.3 & -0.8 & -0.6 & -0.4 & -1.8 & -0.4 & -0.6 & -0.5 & -1.8 \\
\hline 146.5 & 292.0 & 5.4 & -19.6 & 559.1 & 204.2 & 7.0 & -3.4 & 211.1 & -0.6 & -0.4 & -0.7 & -1.4 & -0.3 & -0.3 & -0.5 & -1.3 \\
\hline 156.3 & 301.4 & 14.2 & -17.7 & 560.6 & 222.3 & 9.8 & -3.8 & 194.4 & -0.5 & -0.4 & -0.6 & -1.8 & -0.6 & -0.3 & -0.4 & -1.0 \\
\hline 166.0 & 293.4 & 6.3 & -17.1 & 596.0 & 232.4 & 5.6 & -2.6 & 248.0 & -0.2 & -0.6 & -0.3 & -1.5 & -0.7 & -0.4 & -0.6 & -1.3 \\
\hline 175.8 & 288.3 & 11.7 & -13.2 & 586.5 & 252.8 & 6.7 & -3.4 & 267.3 & -0.4 & -0.5 & -0.3 & -1.6 & -0.8 & -0.5 & -0.3 & -0.9 \\
\hline 185.5 & 303.2 & 17.0 & -12.2 & 587.2 & 251.9 & 7.9 & -4.2 & 258.2 & -0.3 & -0.5 & -0.5 & -1.5 & -0.8 & -0.7 & -0.7 & -1.3 \\
\hline 195.3 & 306.6 & 21.5 & -9.9 & 578.9 & 263.4 & 7.5 & -6.5 & 260.6 & -0.4 & -0.5 & -0.5 & -1.8 & -0.4 & -0.6 & -0.3 & -1.0 \\
\hline 205.1 & 305.9 & 26.3 & -9.6 & 600.1 & 277.2 & 11.1 & -3.5 & 295.3 & -0.7 & -0.6 & -0.7 & -2.3 & -0.5 & -1.0 & -0.7 & -1.4 \\
\hline 214.8 & 291.3 & 32.6 & -4.8 & 581.9 & 289.8 & 13.4 & -6.4 & 290.3 & -1.4 & -1.6 & -0.4 & -2.2 & -0.5 & -1.1 & $\begin{array}{l}-1.7 \\
\end{array}$ & -2.6 \\
\hline 224.6 & 306.3 & 40.6 & -4.8 & 516.3 & 314.2 & 9.1 & -1.5 & 307.6 & -2.6 & -1.2 & -0.8 & -3.8 & -0.9 & -1.5 & -3.6 & -1.9 \\
\hline 234.4 & 297.8 & 31.4 & -3.5 & 606.0 & 321.1 & 6.5 & -5.6 & 337.8 & -1.0 & -0.8 & -0.5 & -1.7 & -0.5 & -0.9 & -1.0 & -2.0 \\
\hline 244.1 & 291.6 & 39.4 & -0.1 & 588.8 & 326.9 & 8.8 & -6.8 & 337.7 & -0.6 & -0.4 & -0.2 & -1.8 & -0.4 & -0.5 & -0.8 & $\begin{array}{l}-1.4 \\
\end{array}$ \\
\hline 253.9 & 297.7 & 42.3 & -1.1 & 600.5 & 335.4 & 15.3 & -6.0 & 350.1 & -0.5 & -0.4 & -0.5 & -1.6 & -0.6 & -0.6 & -0.5 & -1.0 \\
\hline 263.7 & 303.1 & 48.0 & 0.2 & 558.2 & 350.0 & 18.8 & -4.5 & 354.0 & -0.7 & -0.6 & -0.6 & -1.7 & -0.5 & -0.4 & -0.3 & -1.1 \\
\hline 273.4 & 303.1 & 55.1 & 1.4 & 482.9 & 363.3 & 28.3 & -4.8 & 327.4 & -0.7 & -0.6 & -0.4 & -1.9 & -0.6 & -0.3 & -0.2 & -1.0 \\
\hline 283.2 & 307.5 & 44.0 & 2.3 & 573.9 & 372.4 & 15.9 & -7.2 & 359.9 & -0.6 & -0.4 & -0.3 & -2.0 & -0.5 & -0.5 & -0.3 & -0.9 \\
\hline 293.0 & 300.2 & 60.3 & 4.8 & 528.7 & 375.3 & 34.5 & -3.3 & 386.8 & -0.3 & -0.4 & -0.4 & -1.7 & -0.5 & -0.5 & -0.5 & -0.8 \\
\hline 302.7 & 295.4 & 84.0 & 3.5 & 456.7 & 400.6 & 51.8 & 0.2 & 419.8 & -0.2 & -0.3 & -0.3 & -2.0 & -0.6 & -0.3 & -0.2 & -1.2 \\
\hline 312.5 & 288.3 & 83.7 & -2.4 & 540.2 & 425.0 & 53.5 & 0.0 & 430.5 & -0.5 & -0.3 & -0.5 & -3.1 & -0.9 & -0.4 & -0.4 & -1.3 \\
\hline 322.3 & 284.0 & 91.3 & -7.1 & 546.9 & 421.6 & 39.0 & 5.3 & 489.5 & -0.7 & -0.9 & -0.4 & -1.7 & -0.9 & -0.5 & -0.3 & -2.1 \\
\hline 332.0 & 311.0 & 103.0 & -23.2 & 761.7 & 445.5 & -34.0 & 93.7 & 698.8 & -0.7 & -1.0 & -1.3 & -3.4 & -0.3 & -1.5 & -0.8 & -2.7 \\
\hline 341.8 & 284.5 & 97.4 & -1.7 & 640.9 & 479.1 & 46.5 & 32.6 & 480.3 & -0.4 & -0.4 & -0.9 & -2.2 & -0.7 & -0.4 & -0.8 & -1.6 \\
\hline
\end{tabular}


Table 36: Dynamic Stiffness Real and Imaginary Parts at $13200 \mathrm{rpm}$ and $3134 \mathrm{kPa}$ (MN/m)

\begin{tabular}{|c|c|c|c|c|c|c|c|c|c|c|c|c|c|c|c|c|}
\hline $\mathrm{f}(\mathrm{Hz})$ & $\mathrm{R}\left(\mathrm{H}_{\mathrm{xx}}\right)$ & $\mathrm{R}\left(\mathrm{H}_{\mathrm{xy}}\right)$ & $\mathrm{R}\left(\mathrm{H}_{\mathrm{yx}}\right)$ & $\mathrm{R}\left(\mathrm{H}_{\mathrm{yv}}\right)$ & $\mathrm{I}\left(\mathrm{H}_{\mathrm{xx}}\right)$ & $\mathrm{I}\left(\mathrm{H}_{\mathrm{xy}}\right)$ & $\mathrm{I}\left(\mathrm{H}_{\mathrm{yx}}\right)$ & $\mathrm{I}\left(\mathrm{H}_{\mathrm{yv}}\right)$ & $\Delta \mathrm{R}\left(\mathrm{H}_{\mathrm{xx}}\right)$ & $\Delta \mathrm{R}\left(\mathrm{H}_{\mathrm{xy}}\right)$ & $\Delta \mathrm{R}\left(\mathrm{H}_{\mathrm{yx}}\right)$ & $\Delta \mathrm{R}\left(\mathrm{H}_{\mathrm{yv}}\right)$ & $\Delta \mathrm{I}\left(\mathrm{H}_{\mathrm{xX}}\right)$ & $\Delta \mathrm{I}\left(\mathrm{H}_{\mathrm{xy}}\right)$ & $\Delta \mathrm{I}\left(\mathrm{H}_{\mathrm{vX}}\right)$ & $\Delta \mathrm{I}\left(\mathrm{H}_{\mathrm{yv}}\right)$ \\
\hline 9.8 & 288.6 & -27.9 & -39.4 & 701.1 & 18.6 & -1.6 & -14.4 & 165.0 & -3.1 & -5.8 & -0.7 & -6.4 & -1.4 & -3.3 & -1.5 & -7.6 \\
\hline 19.5 & 288.0 & -23.9 & -41.1 & 716.4 & 28.4 & 0.6 & -5.4 & 90.7 & -1.2 & -3.3 & -1.6 & -7.8 & -1.1 & -4.1 & -1.2 & -4.2 \\
\hline 29.3 & 286.3 & -26.8 & -39.5 & 712.2 & 55.9 & 7.2 & 2.1 & 34.9 & -0.9 & -1.9 & -0.6 & -4.1 & -0.9 & -4.2 & -0.8 & -3.3 \\
\hline 39.1 & 284.5 & -24.5 & -40.2 & 703.7 & 65.9 & 6.7 & -0.3 & 45.2 & -0.6 & -2.0 & -1.0 & -1.7 & -0.6 & -1.6 & -1.1 & -2.6 \\
\hline 48.8 & 293.2 & -24.4 & -36.5 & 692.0 & 74.6 & 7.4 & -2.3 & 83.2 & -0.6 & -1.2 & -1.1 & -2.9 & -0.4 & -1.1 & -0.7 & -2.1 \\
\hline 58.6 & 293.5 & -24.4 & -36.0 & 713.4 & 95.8 & 6.8 & 0.1 & 72.3 & -0.6 & -0.9 & -0.9 & -2.8 & -0.4 & -1.0 & -0.9 & -1.5 \\
\hline 68.4 & 299.6 & -20.6 & -36.3 & 717.2 & 107.5 & 9.3 & -2.2 & 77.2 & -0.2 & -0.7 & -0.7 & -2.1 & -0.6 & -0.9 & -0.6 & -1.8 \\
\hline 78.1 & 297.0 & -15.4 & -35.7 & 687.2 & 128.5 & 16.7 & 8.4 & 114.7 & -0.4 & -0.7 & -0.3 & -2.2 & -0.4 & -0.8 & -0.4 & -1.2 \\
\hline 87.9 & 305.1 & -16.3 & -32.0 & 713.1 & 142.4 & 11.2 & -1.5 & 147.8 & -0.4 & -0.7 & -0.6 & -2.6 & -0.4 & -0.6 & -0.6 & -1.5 \\
\hline 97.7 & 304.6 & -11.9 & -31.4 & 699.6 & 153.1 & 10.9 & -2.4 & 121.6 & -0.5 & -0.6 & -0.6 & -1.8 & -0.6 & -0.6 & -0.5 & -1.3 \\
\hline 107.4 & 310.1 & -7.1 & -30.4 & 718.4 & 163.7 & 12.3 & -2.2 & 139.4 & -0.4 & -0.4 & -0.4 & -2.2 & -0.2 & -0.9 & -0.4 & -1.5 \\
\hline 117.2 & 304.5 & -5.1 & -28.7 & 710.4 & 181.0 & 12.8 & -3.5 & 156.6 & -0.3 & -0.4 & -0.4 & -1.7 & -0.4 & -0.4 & -0.6 & -0.9 \\
\hline 127.0 & 311.3 & -0.3 & -26.0 & 686.6 & 194.3 & 15.6 & -3.8 & 174.7 & -0.5 & -0.3 & -0.5 & -1.8 & -0.4 & -0.6 & -0.9 & $\begin{array}{l}-1.3 \\
\end{array}$ \\
\hline 136.7 & 307.4 & 5.3 & -24.7 & 672.1 & 211.5 & 14.2 & -4.5 & 193.5 & -0.2 & -0.5 & -0.4 & -1.9 & -0.4 & -0.3 & -0.2 & -1.2 \\
\hline 146.5 & 324.0 & 12.1 & -22.8 & 672.2 & 213.7 & 10.8 & -6.5 & 212.1 & -0.4 & -0.4 & -0.6 & -1.7 & -0.6 & -0.5 & -0.5 & -1.3 \\
\hline 156.3 & 332.6 & 18.4 & -21.2 & 677.6 & 231.3 & 13.4 & -5.9 & 181.7 & -0.5 & -0.6 & -0.5 & -2.2 & -0.6 & -0.6 & -0.3 & -1.2 \\
\hline 166.0 & 327.4 & 11.8 & -20.8 & 705.0 & 241.1 & 10.6 & -5.5 & 228.3 & -0.4 & -0.5 & -0.5 & -1.5 & -0.7 & -0.6 & -0.6 & -1.0 \\
\hline 175.8 & 321.0 & 16.6 & -16.3 & 694.6 & 263.0 & 12.0 & -6.0 & 254.5 & -0.4 & -0.7 & -0.7 & -2.1 & -0.2 & -0.6 & -0.5 & -1.2 \\
\hline 185.5 & 336.0 & 23.6 & -15.5 & 700.3 & 264.1 & 13.1 & -6.9 & 236.7 & -0.6 & -0.5 & -0.2 & -1.7 & -0.4 & -0.5 & -0.7 & -1.5 \\
\hline 195.3 & 339.5 & 30.2 & -13.2 & 680.9 & 274.8 & 13.1 & -7.5 & 236.7 & -0.2 & -0.6 & -0.6 & $\begin{array}{l}-1.7 \\
\end{array}$ & -0.6 & -0.4 & -1.1 & -1.6 \\
\hline 205.1 & 337.8 & 34.7 & -12.5 & 701.3 & 289.3 & 15.1 & -6.2 & 271.1 & -0.9 & -0.8 & -0.6 & -2.2 & -0.5 & -1.0 & $\begin{array}{l}-1.1 \\
\end{array}$ & -1.3 \\
\hline 214.8 & 324.6 & 43.0 & -10.1 & 677.8 & 302.5 & 16.9 & -7.3 & 268.0 & -1.9 & -1.4 & -2.2 & -3.1 & -1.3 & $\begin{array}{l}-1.7 \\
\end{array}$ & -2.7 & -3.8 \\
\hline 224.6 & 342.1 & 47.6 & -7.6 & 621.3 & 329.3 & 15.8 & -7.8 & 271.3 & -2.1 & $\begin{array}{l}-1.4 \\
\end{array}$ & -2.4 & -3.9 & -1.7 & -1.5 & -2.4 & -2.4 \\
\hline 234.4 & 334.9 & 39.0 & -6.6 & 715.5 & 335.6 & 7.1 & -8.5 & 319.7 & -0.8 & -0.7 & -1.2 & -2.5 & -0.8 & -0.9 & -0.5 & -1.7 \\
\hline 244.1 & 329.4 & 51.5 & -2.9 & 687.7 & 341.2 & 9.3 & -11.1 & 322.6 & -0.5 & -0.5 & -0.9 & -2.0 & -0.4 & -0.4 & -0.6 & -1.9 \\
\hline 253.9 & 332.8 & 53.9 & -3.9 & 694.7 & 351.5 & 16.8 & -10.1 & 329.1 & -0.1 & -0.4 & -0.8 & -1.5 & -0.9 & -0.6 & -0.4 & -1.2 \\
\hline 263.7 & 338.7 & 59.6 & -1.8 & 656.9 & 364.0 & 21.5 & $\begin{array}{l}-8.4 \\
\end{array}$ & 319.9 & -0.2 & -0.5 & -0.7 & -1.6 & -0.2 & -0.5 & -0.7 & -1.2 \\
\hline 273.4 & 343.3 & 68.7 & -1.6 & 589.0 & 380.2 & 26.3 & -9.4 & 306.9 & -0.4 & -0.7 & -0.4 & -1.9 & -0.6 & -0.3 & -0.6 & -0.9 \\
\hline 283.2 & 346.1 & 56.5 & -0.3 & 683.5 & 387.7 & 8.9 & -12.8 & 353.0 & -0.6 & -0.6 & -0.2 & -1.8 & -0.4 & -0.6 & -0.4 & -1.0 \\
\hline 293.0 & 342.6 & 76.8 & 0.5 & 610.5 & 389.0 & 34.4 & -8.4 & 357.0 & -0.3 & -0.4 & -0.6 & -1.8 & -0.6 & -0.4 & -0.7 & -1.3 \\
\hline 302.7 & 340.1 & 97.6 & 0.8 & 569.0 & 413.9 & 42.6 & -5.3 & 398.9 & -0.6 & -0.6 & -0.1 & -1.6 & -0.8 & -0.5 & -0.9 & -1.8 \\
\hline 312.5 & 335.4 & 155.1 & -14.8 & 660.5 & 442.2 & -15.0 & -12.5 & 717.7 & -1.1 & -1.7 & -0.7 & -4.5 & -0.7 & -1.0 & -0.6 & -3.7 \\
\hline 322.3 & 327.7 & 112.7 & 0.7 & 541.7 & 436.3 & 60.9 & -3.7 & 407.8 & -0.7 & -0.3 & -0.4 & -2.0 & -0.9 & -0.4 & -0.2 & -1.2 \\
\hline 332.0 & 337.6 & 247.0 & -49.3 & 432.6 & 485.5 & -13.9 & -50.1 & 899.8 & -0.6 & -2.7 & -0.6 & -8.7 & -0.5 & -1.6 & -1.3 & -5.1 \\
\hline 341.8 & 333.3 & 99.9 & -2.1 & 795.3 & 489.4 & 12.3 & 12.6 & 482.9 & -0.7 & -0.5 & -0.6 & -2.5 & -1.0 & -0.7 & -0.4 & -1.2 \\
\hline
\end{tabular}




\section{Load In-between Pad}

Table 37: Dynamic Stiffness Real and Imaginary Parts at $6800 \mathrm{rpm}$ and $0 \mathrm{kPa}(\mathrm{MN} / \mathrm{m})$

\begin{tabular}{|c|c|c|c|c|c|c|c|c|c|c|c|c|c|c|c|c|}
\hline $\mathrm{f}(\mathrm{Hz})$ & $\mathrm{R}\left(\mathrm{H}_{\mathrm{xx}}\right)$ & $\mathrm{R}\left(\mathrm{H}_{\mathrm{xy}}\right)$ & $\mathrm{R}\left(\mathrm{H}_{\mathrm{yx}}\right)$ & $\mathrm{R}\left(\mathrm{H}_{\mathrm{yy}}\right)$ & $\mathrm{I}\left(\mathrm{H}_{\mathrm{xx}}\right)$ & $\mathrm{I}\left(\mathrm{H}_{\mathrm{xy}}\right)$ & $\mathrm{I}\left(\mathrm{H}_{\mathrm{yx}}\right)$ & $\mathrm{I}\left(\mathrm{H}_{\mathrm{yy}}\right)$ & $\Delta \mathrm{R}\left(\mathrm{H}_{\mathrm{xx}}\right)$ & $\Delta \mathrm{R}\left(\mathrm{H}_{\mathrm{xy}}\right)$ & $\Delta \mathrm{R}\left(\mathrm{H}_{\mathrm{yx}}\right)$ & $\Delta \mathrm{R}\left(\mathrm{H}_{\mathrm{yy}}\right)$ & $\Delta \mathrm{I}\left(\mathrm{H}_{\mathrm{xx}}\right)$ & $\Delta \mathrm{I}\left(\mathrm{H}_{\mathrm{xy}}\right)$ & $\Delta \mathrm{I}\left(\mathrm{H}_{\mathrm{yx}}\right)$ & $\Delta \mathrm{I}\left(\mathrm{H}_{\mathrm{yy}}\right)$ \\
\hline 9.8 & 166.1 & -52.4 & -69.8 & 196.9 & 15.9 & 1.0 & -8.2 & 61.6 & -0.5 & -1.7 & -1.5 & -6.8 & -0.3 & -0.6 & -1.9 & -4.4 \\
\hline 19.5 & 165.5 & -42.9 & -75.1 & 152.9 & 33.6 & -2.5 & -17.9 & 24.1 & -0.2 & -0.9 & -1.9 & -7.3 & -0.1 & -0.4 & -3.0 & -5.7 \\
\hline 29.3 & 169.8 & -48.6 & -48.5 & 159.6 & 52.5 & 1.2 & 10.5 & 51.7 & -0.2 & -1.0 & -0.8 & -4.9 & -0.2 & -0.5 & -2.0 & -3.5 \\
\hline 39.1 & 173.3 & -50.4 & -29.3 & 131.2 & 67.4 & -2.5 & 11.9 & 66.1 & -0.1 & -0.9 & -2.4 & -4.2 & -0.1 & -0.4 & -2.4 & -2.6 \\
\hline 48.8 & 178.7 & -49.0 & -58.6 & 155.1 & 79.3 & -2.9 & -9.2 & 80.6 & -0.2 & -0.8 & -2.3 & -4.3 & -0.2 & -0.3 & -1.0 & -1.8 \\
\hline 58.6 & 185.3 & -44.6 & -46.3 & 172.8 & 96.3 & -2.1 & -19.2 & 98.6 & -0.2 & -0.8 & -1.4 & -4.0 & -0.2 & -0.3 & -1.2 & -2.5 \\
\hline 68.4 & 189.2 & -44.4 & -50.1 & 185.4 & 109.1 & -5.0 & -17.4 & 102.9 & -0.1 & -0.8 & -0.7 & -3.8 & -0.1 & -0.4 & -1.8 & -2.1 \\
\hline 78.1 & 192.6 & -41.7 & -43.3 & 191.8 & 123.3 & -6.2 & -1.9 & 113.5 & -0.2 & -0.8 & -0.3 & -3.6 & -0.1 & -0.3 & -0.9 & -2.2 \\
\hline 87.9 & 197.4 & -38.1 & -46.8 & 204.6 & 134.8 & -8.2 & -4.7 & 138.4 & -0.1 & -0.9 & -0.6 & -4.1 & -0.2 & -0.4 & -0.8 & -2.4 \\
\hline 97.7 & 201.2 & -37.7 & -41.0 & 192.7 & 147.4 & -8.4 & -22.9 & 141.2 & -0.1 & -0.9 & -0.8 & -4.0 & -0.2 & -0.5 & -0.5 & -2.3 \\
\hline 107.4 & 207.0 & -37.0 & -47.4 & 193.5 & 158.2 & -7.7 & -27.1 & 158.9 & -0.3 & -1.6 & -0.8 & -3.6 & -0.5 & -0.6 & -0.8 & -2.3 \\
\hline 117.2 & 209.2 & -31.7 & -24.9 & 199.0 & 170.4 & -10.2 & -16.9 & 168.1 & -0.7 & -1.6 & -1.3 & -4.5 & -0.8 & -1.3 & -0.8 & -2.7 \\
\hline 127.0 & 213.5 & -27.0 & -32.0 & 209.1 & 183.4 & -10.1 & -28.1 & 162.9 & -0.3 & -0.9 & -1.3 & -3.3 & -0.3 & -0.6 & -1.8 & -2.2 \\
\hline 136.7 & 217.3 & -24.5 & -24.7 & 209.5 & 197.8 & -15.1 & -25.8 & 184.2 & -0.2 & -1.0 & -1.3 & -3.7 & -0.3 & -0.3 & -0.7 & -2.5 \\
\hline 146.5 & 222.8 & -21.9 & -32.8 & 231.3 & 208.3 & -13.5 & -40.2 & 199.9 & -0.2 & -0.8 & -1.5 & -3.4 & -0.1 & -0.5 & -0.7 & -2.4 \\
\hline 156.3 & 225.4 & -17.8 & -34.1 & 167.4 & 220.8 & -9.0 & -40.0 & 288.5 & -0.2 & -0.8 & -1.0 & -3.3 & -0.2 & -0.3 & -1.5 & -2.0 \\
\hline 166.0 & 229.0 & -10.9 & -39.7 & 230.2 & 234.3 & -13.5 & -43.9 & 247.1 & -0.3 & -0.9 & -1.8 & -3.4 & -0.2 & -0.3 & -0.8 & -2.3 \\
\hline 175.8 & 238.0 & -4.3 & -44.2 & 282.0 & 251.3 & -18.8 & -50.0 & 292.4 & -0.2 & -0.7 & -1.2 & -4.5 & -0.2 & -0.4 & -1.0 & -3.0 \\
\hline 185.5 & 238.5 & 5.1 & -35.0 & 249.2 & 263.0 & -20.9 & -44.2 & 247.8 & -0.1 & -0.8 & -1.4 & -3.4 & -0.3 & -0.3 & -0.6 & -2.0 \\
\hline 195.3 & 246.6 & 12.2 & -42.0 & 293.5 & 274.0 & -24.9 & -42.0 & 313.3 & -0.1 & -0.9 & -1.8 & -3.9 & -0.3 & -0.3 & -0.9 & -2.0 \\
\hline 205.1 & 250.5 & 17.1 & -30.7 & 273.1 & 290.7 & -28.4 & -27.6 & 301.8 & -0.5 & -0.9 & -2.1 & -4.0 & -0.2 & -0.3 & -1.3 & -2.1 \\
\hline 214.8 & 265.9 & 22.0 & -34.1 & 245.1 & 320.3 & -33.1 & -35.5 & 325.6 & -0.3 & -0.9 & -1.8 & -4.2 & -0.3 & -0.3 & -1.9 & -2.3 \\
\hline 224.6 & 287.9 & 18.8 & -47.4 & 257.2 & 327.0 & -42.0 & -39.7 & 342.7 & -0.6 & -1.0 & -2.0 & -3.9 & -0.5 & -0.7 & -1.1 & -2.2 \\
\hline 234.4 & 289.1 & 24.3 & -34.7 & 286.2 & 345.5 & -52.9 & -31.5 & 336.1 & -0.2 & -0.8 & -0.6 & -3.9 & -0.3 & -0.3 & -1.3 & -2.4 \\
\hline 244.1 & 287.4 & 42.5 & -20.3 & 271.8 & 366.8 & -56.2 & -21.3 & 355.1 & -0.2 & -1.1 & -1.7 & -5.0 & -0.2 & -0.3 & -2.4 & -2.6 \\
\hline 253.9 & 302.9 & 55.3 & -65.7 & 295.0 & 376.0 & -60.4 & -40.6 & 386.3 & -0.5 & -1.1 & -2.0 & -4.2 & -0.6 & -0.5 & -2.2 & -2.9 \\
\hline 263.7 & 295.0 & 25.5 & -25.7 & 299.2 & 382.0 & -47.9 & -10.0 & 400.1 & -0.3 & -1.0 & -4.0 & -5.0 & -0.3 & -0.7 & -3.0 & -2.1 \\
\hline 273.4 & 301.0 & 36.9 & 11.5 & 300.2 & 412.1 & -57.0 & 9.7 & 389.2 & -0.2 & -0.9 & -1.8 & -3.9 & -0.6 & -0.4 & -2.6 & -2.4 \\
\hline 283.2 & 309.2 & 59.8 & -13.3 & 299.5 & 439.7 & -42.9 & 18.8 & 431.2 & -0.5 & -1.0 & -0.4 & -4.5 & -1.3 & -0.8 & -2.3 & -2.6 \\
\hline 293.0 & 278.4 & 55.9 & 13.1 & 328.9 & 492.0 & -11.0 & 28.3 & 492.5 & -0.6 & -0.9 & -1.6 & -4.5 & -0.9 & -1.5 & -5.0 & -2.6 \\
\hline 302.7 & 372.5 & 61.5 & 51.0 & 351.8 & 531.6 & -31.0 & 77.0 & 590.3 & -0.7 & -1.3 & -3.0 & -6.0 & -1.4 & -1.8 & -6.8 & -4.3 \\
\hline 312.5 & 586.8 & 110.1 & 163.9 & 571.4 & 826.9 & 129.5 & 345.5 & 910.3 & -4.6 & -9.4 & -14.3 & -10.5 & -10.2 & -4.6 & -17.5 & -17.0 \\
\hline 322.3 & 626.5 & 324.3 & 210.0 & 541.9 & 1068.2 & 167.3 & 469.2 & 826.3 & -11.7 & -8.5 & -14.0 & -7.5 & -21.3 & -10.6 & -14.7 & -14.1 \\
\hline 332.0 & 1346.1 & 438.4 & 2021.1 & 1882.6 & -461.2 & -1544.8 & -735.4 & -1191.1 & -217.7 & -277.1 & -205.4 & -328.2 & -118.5 & -46.0 & -262.2 & -190.2 \\
\hline 341.8 & 213.4 & 29.3 & 244.4 & 764.8 & 37.8 & -288.4 & -708.8 & -0.4 & -42.9 & -47.1 & -36.1 & -26.6 & -76.3 & -27.0 & -37.6 & -25.0 \\
\hline
\end{tabular}


Table 38: Dynamic Stiffness Real and Imaginary Parts at $6800 \mathrm{rpm}$ and $783 \mathrm{kPa}(\mathrm{MN} / \mathrm{m})$

\begin{tabular}{|c|c|c|c|c|c|c|c|c|c|c|c|c|c|c|c|c|}
\hline $\mathrm{f}(\mathrm{Hz})$ & $\mathrm{R}\left(\mathrm{H}_{\mathrm{xx}}\right)$ & $\mathrm{R}\left(\mathrm{H}_{\mathrm{xy}}\right)$ & $\mathrm{R}\left(\mathrm{H}_{\mathrm{yx}}\right)$ & $\mathrm{R}\left(\mathrm{H}_{\mathrm{yy}}\right)$ & $\mathrm{I}\left(\mathrm{H}_{\mathrm{xx}}\right)$ & $\mathrm{I}\left(\mathrm{H}_{\mathrm{xy}}\right)$ & $\mathrm{I}\left(\mathrm{H}_{\mathrm{yx}}\right)$ & $\mathrm{I}\left(\mathrm{H}_{\mathrm{yy}}\right)$ & $\Delta \mathrm{R}\left(\mathrm{H}_{\mathrm{xx}}\right)$ & $\Delta \mathrm{R}\left(\mathrm{H}_{\mathrm{xy}}\right)$ & $\Delta \mathrm{R}\left(\mathrm{H}_{\mathrm{yx}}\right)$ & $\Delta R\left(H_{y y}\right)$ & $\Delta \mathrm{I}\left(\mathrm{H}_{\mathrm{xx}}\right)$ & $\Delta \mathrm{I}\left(\mathrm{H}_{\mathrm{xy}}\right)$ & $\Delta \mathrm{I}\left(\mathrm{H}_{\mathrm{yx}}\right)$ & $\Delta \mathrm{I}\left(\mathrm{H}_{\mathrm{yy}}\right)$ \\
\hline 9.8 & 202.9 & -50.8 & -59.2 & 194.4 & 15.1 & -4.4 & -17.4 & 49.8 & -0.5 & -1.4 & -3.2 & -10.3 & -0.4 & -1.4 & -3.3 & -5.7 \\
\hline 19.5 & 206.8 & -58.0 & -60.9 & 213.6 & 30.9 & -4.7 & 5.9 & -0.6 & -0.2 & -1.0 & -11.3 & -10.2 & -0.2 & -0.6 & -6.2 & -8.9 \\
\hline 29.3 & 207.7 & -55.7 & $\begin{array}{l}-68.4 \\
\end{array}$ & 250.9 & 44.6 & -6.4 & 1.7 & 12.2 & -0.2 & -0.4 & -2.9 & -5.0 & -0.1 & -0.4 & -2.8 & -8.9 \\
\hline 39.1 & 211.3 & -56.7 & -61.3 & 207.2 & 57.4 & -6.5 & 1.4 & 65.8 & -0.3 & -0.4 & -7.7 & -11.5 & -0.3 & -0.5 & -4.0 & -4.3 \\
\hline 48.8 & 216.3 & -55.2 & -63.6 & 225.5 & 73.6 & -8.6 & -6.1 & 66.3 & -0.2 & -0.4 & -2.8 & -6.1 & -0.1 & -0.3 & -1.2 & -4.7 \\
\hline 58.6 & 218.4 & -54.4 & -52.9 & 228.3 & 85.2 & -6.7 & -13.7 & 89.1 & -0.2 & -0.4 & -1.5 & -2.9 & -0.2 & -0.4 & -2.3 & -3.1 \\
\hline 68.4 & 220.0 & -55.5 & -67.2 & 240.4 & 104.8 & -4.8 & -0.5 & 97.7 & -0.2 & -0.4 & -2.5 & -4.4 & -0.2 & -0.3 & -0.8 & -2.1 \\
\hline 78.1 & 227.7 & -50.3 & -48.4 & 224.2 & 112.3 & -6.8 & -8.5 & 98.8 & -0.1 & -0.4 & -0.5 & -3.9 & -0.1 & -0.3 & -0.9 & -2.0 \\
\hline 87.9 & 229.0 & -50.5 & -58.0 & 243.3 & 123.5 & -9.2 & -21.2 & 126.3 & -0.2 & -0.2 & -0.5 & -3.1 & -0.2 & -0.4 & -1.5 & -1.6 \\
\hline 97.7 & 233.5 & -47.9 & -55.1 & 245.6 & 133.6 & -8.4 & -24.9 & 128.4 & -0.2 & -0.4 & -1.4 & -4.5 & -0.1 & -0.4 & -1.0 & -2.8 \\
\hline 107.4 & 236.7 & -46.5 & -58.1 & 250.4 & 144.8 & -9.9 & -22.1 & 148.8 & -0.6 & -1.0 & -1.0 & -3.4 & -0.3 & -0.4 & -2.2 & -4.3 \\
\hline 117.2 & 242.1 & -43.2 & -52.8 & 265.2 & 155.3 & -11.5 & -28.2 & 154.1 & -0.7 & -0.6 & -2.2 & -1.7 & -1.0 & -1.5 & -0.8 & -2.6 \\
\hline 127.0 & 246.3 & -40.2 & -55.1 & 249.6 & 168.7 & -11.9 & -28.1 & 178.4 & -0.1 & -0.5 & -0.7 & -1.5 & -0.4 & -0.4 & -4.0 & -2.6 \\
\hline 136.7 & 249.2 & -35.0 & -52.9 & 260.5 & 180.9 & -13.4 & -32.5 & 181.2 & -0.2 & -0.4 & -2.3 & -2.7 & -0.3 & -0.3 & -1.9 & -2.0 \\
\hline 146.5 & 252.9 & -28.4 & -66.4 & 253.4 & 192.7 & -14.0 & -44.2 & 188.9 & -0.1 & -0.2 & -5.0 & -3.0 & -0.2 & -0.3 & -2.3 & -3.8 \\
\hline 156.3 & 256.7 & -17.8 & -75.1 & 233.6 & 205.9 & -13.8 & -22.9 & 192.1 & -0.1 & -0.3 & -6.0 & -3.2 & -0.2 & -0.2 & -1.1 & -0.9 \\
\hline 166.0 & 260.8 & -21.8 & -65.6 & 281.0 & 219.0 & -23.0 & -10.1 & 246.4 & -0.1 & -0.3 & -4.2 & -1.9 & -0.2 & -0.3 & -5.7 & -2.0 \\
\hline 175.8 & 261.8 & -16.9 & -51.8 & 291.1 & 233.8 & -24.8 & -30.0 & 231.0 & -0.2 & -0.2 & -1.5 & -3.7 & -0.2 & -0.2 & -5.6 & -2.4 \\
\hline 185.5 & 269.8 & -12.5 & -51.4 & 293.7 & 246.9 & -25.7 & -38.6 & 251.6 & -0.2 & -0.3 & -3.0 & -5.6 & -0.3 & -0.2 & -1.1 & -1.6 \\
\hline 195.3 & 275.7 & -8.9 & -55.7 & 299.5 & 261.7 & -27.7 & -28.5 & 259.4 & -0.2 & -0.2 & -1.2 & -2.6 & -0.2 & -0.3 & -2.5 & -5.2 \\
\hline 205.1 & 279.7 & -7.0 & -62.7 & 307.3 & 274.3 & -30.6 & -33.5 & 283.6 & -0.3 & -0.2 & -2.0 & -3.4 & -0.2 & -0.3 & -1.4 & -2.5 \\
\hline 214.8 & 288.8 & -1.3 & -67.3 & 314.3 & 293.0 & -27.7 & -36.8 & 270.7 & -0.1 & -0.3 & -5.5 & -4.9 & -0.3 & -0.3 & -3.3 & -4.9 \\
\hline 224.6 & 295.7 & 33.7 & -77.0 & 198.5 & 308.9 & -20.7 & -49.2 & 328.6 & -0.2 & -0.3 & -6.0 & -2.9 & -0.5 & -0.3 & -2.8 & -1.8 \\
\hline 234.4 & 306.8 & 1.4 & -80.0 & 340.4 & 318.9 & -42.9 & -39.4 & 320.9 & -0.3 & -0.3 & -6.9 & -2.8 & -0.2 & -0.3 & -3.8 & -4.2 \\
\hline 244.1 & 308.1 & 7.7 & -83.2 & 329.6 & 336.5 & -37.1 & -21.6 & 323.2 & -0.2 & -0.4 & -7.9 & -3.3 & -0.2 & -0.3 & -2.2 & -5.2 \\
\hline 253.9 & 319.2 & 6.8 & -97.3 & 342.7 & 357.8 & -40.5 & -39.1 & 326.7 & -0.2 & -0.4 & -9.7 & -2.3 & -0.4 & -0.3 & -7.2 & -3.0 \\
\hline 263.7 & 328.8 & 18.8 & -105.8 & 344.8 & 375.1 & -33.9 & -15.6 & 342.5 & -0.1 & -0.3 & -11.7 & -5.2 & -0.2 & -0.4 & -6.3 & -2.3 \\
\hline 273.4 & 340.2 & 50.5 & -115.8 & 232.3 & 406.8 & -8.9 & 26.4 & 373.3 & -0.3 & -0.5 & -16.3 & -5.6 & -0.5 & -0.5 & -5.3 & -3.2 \\
\hline 283.2 & 342.8 & 13.9 & -114.4 & 331.1 & 425.7 & -22.6 & 27.2 & 356.3 & -0.3 & -0.3 & -16.0 & -4.6 & -0.4 & -0.6 & -2.8 & -2.6 \\
\hline 293.0 & 363.4 & 75.8 & -154.2 & 259.7 & 485.0 & 13.5 & 81.7 & 457.2 & -0.4 & -1.6 & -19.9 & $\begin{array}{l}-7.3 \\
\end{array}$ & -0.9 & -0.4 & -2.8 & -3.2 \\
\hline 302.7 & 480.0 & 288.3 & -249.8 & 403.5 & 544.8 & -82.6 & 362.1 & 952.9 & -2.9 & -4.3 & -22.6 & -11.3 & -1.8 & -5.2 & -10.8 & -11.3 \\
\hline 312.5 & 432.9 & 159.3 & -188.9 & 399.1 & 685.0 & 40.9 & 305.7 & 559.4 & -1.6 & -3.2 & -27.7 & -13.5 & -2.6 & -0.9 & -15.7 & -25.9 \\
\hline 322.3 & 598.9 & 204.8 & 223.1 & 701.2 & 813.6 & -30.9 & 721.3 & 619.8 & -2.9 & -2.1 & -32.9 & -25.7 & -6.3 & -2.2 & -26.5 & -18.1 \\
\hline 332.0 & 1138.6 & 349.8 & 620.4 & 787.8 & 1053.0 & 11.2 & 1055.8 & 604.1 & -17.2 & -5.6 & -44.9 & -24.7 & -4.8 & -3.6 & -42.4 & -14.2 \\
\hline 341.8 & 616.3 & 50.1 & 545.1 & 564.1 & -208.2 & -312.6 & -465.4 & 185.3 & -40.9 & -28.5 & -24.8 & -20.7 & -53.1 & -22.1 & -68.7 & -24.3 \\
\hline
\end{tabular}


Table 39: Dynamic Stiffness Real and Imaginary Parts at $6800 \mathrm{rpm}$ and $1567 \mathrm{kPa}(\mathrm{MN} / \mathrm{m})$

\begin{tabular}{|c|c|c|c|c|c|c|c|c|c|c|c|c|c|c|c|c|}
\hline $\mathrm{f}(\mathrm{Hz})$ & $\mathrm{R}\left(\mathrm{H}_{\mathrm{xx}}\right)$ & $\mathrm{R}\left(\mathrm{H}_{\mathrm{xy}}\right)$ & $\mathrm{R}\left(\mathrm{H}_{\mathrm{yx}}\right)$ & $\mathrm{R}\left(\mathrm{H}_{\mathrm{yv}}\right)$ & $\mathrm{I}\left(\mathrm{H}_{\mathrm{xx}}\right)$ & $\mathrm{I}\left(\mathrm{H}_{\mathrm{xy}}\right)$ & $\mathrm{I}\left(\mathrm{H}_{\mathrm{yx}}\right)$ & $\mathrm{I}\left(\mathrm{H}_{\mathrm{yv}}\right)$ & $\Delta \mathrm{R}\left(\mathrm{H}_{\mathrm{xx}}\right)$ & $\Delta \mathrm{R}\left(\mathrm{H}_{\mathrm{xy}}\right)$ & $\Delta \mathrm{R}\left(\mathrm{H}_{\mathrm{yx}}\right)$ & $\Delta \mathrm{R}\left(\mathrm{H}_{\mathrm{yv}}\right)$ & $\Delta \mathrm{I}\left(\mathrm{H}_{\mathrm{xX}}\right)$ & $\Delta \mathrm{I}\left(\mathrm{H}_{\mathrm{xy}}\right)$ & $\Delta \mathrm{I}\left(\mathrm{H}_{\mathrm{vX}}\right)$ & $\Delta \mathrm{I}\left(\mathrm{H}_{\mathrm{yv}}\right)$ \\
\hline 9.8 & 247.5 & -58.1 & -72.9 & 285.7 & 13.2 & -4.9 & -31.4 & 37.0 & -0.4 & -0.5 & -1.0 & -5.3 & -0.4 & -0.6 & -8.0 & -2.6 \\
\hline 19.5 & 248.8 & -60.8 & -115.9 & 314.1 & 25.0 & -6.1 & -27.9 & -6.6 & -0.2 & -1.0 & -8.7 & -8.0 & -0.2 & -0.8 & -10.6 & -4.4 \\
\hline 29.3 & 251.5 & -59.5 & -61.1 & 283.3 & 38.8 & -7.4 & -14.0 & 23.5 & -0.2 & -0.7 & -2.1 & -2.3 & -0.2 & -0.5 & -1.3 & -2.2 \\
\hline 39.1 & 255.2 & -60.9 & -42.4 & 290.9 & 51.7 & -8.7 & 20.5 & 43.8 & -0.2 & -0.3 & -4.4 & -2.8 & -0.3 & -0.4 & -7.9 & -2.9 \\
\hline 48.8 & 259.1 & -59.1 & -59.9 & 289.2 & 64.9 & -10.4 & -2.9 & 58.8 & -0.2 & -0.5 & -2.5 & -2.1 & -0.1 & -0.4 & -3.4 & -1.6 \\
\hline 58.6 & 261.0 & -58.7 & -53.3 & 295.3 & 74.8 & -9.9 & -17.7 & 74.5 & -0.1 & -0.3 & -3.5 & -2.0 & -0.3 & -0.4 & -1.1 & -1.6 \\
\hline 68.4 & 260.6 & -58.2 & -71.8 & 303.4 & 85.8 & -11.1 & -13.6 & 70.5 & -0.3 & -0.4 & -1.9 & -1.7 & -0.2 & -0.3 & -2.6 & -1.5 \\
\hline 78.1 & 268.7 & -55.0 & -49.6 & 290.4 & 100.0 & -11.1 & -16.9 & 81.4 & -0.2 & -0.4 & -2.9 & -1.9 & -0.2 & -0.3 & -2.8 & -1.2 \\
\hline 87.9 & 269.2 & -55.9 & -64.0 & 311.7 & 108.1 & -13.8 & -28.8 & 116.0 & -0.2 & -0.3 & -1.3 & -1.6 & -0.2 & -0.4 & -1.0 & -1.1 \\
\hline 97.7 & 272.8 & -52.8 & -67.5 & 303.2 & 116.1 & -13.8 & -20.9 & 107.9 & -0.5 & -0.4 & -2.8 & -1.8 & -0.3 & -0.4 & -1.4 & -1.1 \\
\hline 107.4 & 275.6 & -51.0 & -65.7 & 313.5 & 126.9 & -15.8 & -14.5 & 126.6 & -0.5 & -0.7 & -1.2 & -2.0 & -0.4 & -0.3 & -1.3 & -1.2 \\
\hline 117.2 & 281.3 & -53.6 & -59.9 & 321.7 & 134.6 & -15.1 & -40.9 & 140.6 & -4.9 & -4.4 & -8.1 & -11.6 & -5.8 & -8.2 & -4.8 & -4.3 \\
\hline 127.0 & 283.3 & -45.8 & -59.9 & 310.1 & 146.6 & -18.3 & -30.3 & 151.1 & -0.5 & -0.5 & -1.1 & -1.6 & -0.5 & -0.6 & -0.8 & $\begin{array}{l}-1.3 \\
\end{array}$ \\
\hline 136.7 & 286.1 & -41.6 & -64.5 & 312.7 & 157.3 & -20.1 & -42.2 & 159.6 & -0.3 & -0.4 & -2.0 & -1.8 & -0.3 & -0.2 & -1.4 & -1.4 \\
\hline 146.5 & 289.0 & -36.4 & -51.1 & 315.7 & 168.0 & -22.4 & -26.4 & 166.2 & -0.1 & -0.2 & -1.3 & -2.1 & -0.2 & -0.4 & -1.5 & -1.1 \\
\hline 156.3 & 289.0 & -29.3 & -51.8 & 306.7 & 179.2 & -23.5 & -22.0 & 157.4 & -0.1 & -0.3 & -3.6 & -2.1 & -0.2 & -0.2 & -1.9 & -1.2 \\
\hline 166.0 & 293.9 & -33.5 & -57.6 & 337.8 & 189.0 & -30.2 & -33.6 & 200.1 & -0.2 & -0.3 & -0.7 & -1.8 & -0.2 & -0.3 & -2.1 & -2.0 \\
\hline 175.8 & 293.3 & -28.0 & -59.0 & 339.8 & 200.1 & -32.5 & -42.5 & 208.1 & -0.3 & -0.3 & -1.3 & -1.5 & -0.2 & -0.3 & -2.3 & $\begin{array}{l}-1.3 \\
\end{array}$ \\
\hline 185.5 & 299.6 & -26.0 & -55.4 & 344.4 & 213.5 & -33.9 & -30.7 & 211.8 & -0.2 & -0.3 & -1.6 & -1.8 & -0.4 & -0.2 & -0.9 & $\begin{array}{l}-1.3 \\
\end{array}$ \\
\hline 195.3 & 303.0 & -20.7 & -56.2 & 343.4 & 228.6 & -38.0 & -30.1 & 222.3 & -0.2 & -0.2 & -2.6 & $\begin{array}{l}-1.7 \\
\end{array}$ & -0.3 & -0.2 & -2.7 & -1.4 \\
\hline 205.1 & 305.6 & -18.3 & -52.1 & 363.8 & 237.3 & -42.6 & -24.4 & 245.3 & -0.4 & -0.3 & -1.8 & -2.0 & -0.2 & -0.3 & -2.7 & -1.0 \\
\hline 214.8 & 313.9 & -13.3 & -34.9 & 367.2 & 251.3 & -42.1 & -40.9 & 234.6 & -0.3 & -0.3 & -1.2 & -1.5 & -0.3 & -0.2 & -2.8 & -1.3 \\
\hline 224.6 & 320.8 & -1.8 & -54.9 & 310.6 & 262.0 & -41.7 & -27.0 & 249.7 & -0.3 & -0.2 & -1.9 & -1.5 & -0.4 & -0.3 & -2.0 & -1.3 \\
\hline 234.4 & 329.9 & -15.6 & -51.8 & 393.5 & 275.0 & -56.4 & -29.2 & 268.7 & -0.7 & -0.6 & -2.2 & -1.9 & -0.2 & -0.4 & -2.8 & -1.6 \\
\hline 244.1 & 332.1 & -12.5 & -38.6 & 389.4 & 288.1 & -54.6 & -23.9 & 275.1 & -0.5 & -0.2 & -2.9 & -1.9 & -0.2 & -0.3 & -5.1 & -1.3 \\
\hline 253.9 & 335.0 & -6.9 & -47.6 & 406.6 & 300.6 & -55.8 & -1.6 & 291.9 & -0.5 & -0.3 & -3.7 & -2.0 & -0.3 & -0.3 & -6.8 & -1.5 \\
\hline 263.7 & 344.2 & -0.9 & -28.0 & 398.3 & 317.2 & -52.1 & 10.4 & 286.9 & -0.5 & -0.2 & -6.7 & -2.2 & -0.4 & -0.2 & -8.7 & $\begin{array}{l}-1.7 \\
\end{array}$ \\
\hline 273.4 & 349.7 & 11.2 & -37.6 & 337.3 & 333.5 & -42.6 & -13.1 & 281.4 & -0.7 & -0.3 & -5.5 & -2.2 & -0.4 & -0.2 & -3.0 & -1.0 \\
\hline 283.2 & 354.9 & -6.0 & -39.9 & 406.1 & 352.6 & -56.2 & 10.1 & 302.6 & -0.7 & -0.3 & -5.7 & -2.4 & -0.5 & -0.2 & -5.2 & -1.6 \\
\hline 293.0 & 363.8 & 11.8 & -27.6 & 388.4 & 368.0 & -38.4 & 26.6 & 324.6 & -0.8 & -0.3 & -2.8 & -2.9 & -0.7 & -0.2 & -6.7 & -1.6 \\
\hline 302.7 & 369.2 & 50.2 & -21.2 & 344.5 & 399.9 & -18.3 & 35.2 & 383.8 & -0.9 & -0.3 & -3.7 & -3.1 & -0.9 & -0.6 & -3.0 & -1.4 \\
\hline 312.5 & 377.2 & 13.1 & -20.0 & 497.5 & 426.7 & -53.0 & 67.1 & 331.8 & -0.9 & -0.3 & -4.8 & -4.2 & -1.2 & -0.4 & -9.2 & -2.9 \\
\hline 322.3 & 389.1 & 104.3 & -15.7 & 364.6 & 484.1 & 8.2 & 113.3 & 444.6 & -1.4 & -0.7 & -7.5 & -7.4 & -1.5 & -0.9 & -11.5 & -8.5 \\
\hline 332.0 & 418.3 & 42.5 & 78.6 & 557.0 & 506.0 & -86.5 & 171.7 & 391.1 & -0.6 & -0.4 & -3.9 & -6.5 & -1.4 & -0.5 & -9.6 & -5.0 \\
\hline 341.8 & 522.4 & 96.1 & 158.9 & 568.9 & 596.6 & -44.0 & 225.3 & 390.4 & -1.6 & -0.6 & -12.5 & -6.7 & -1.8 & -1.0 & -16.5 & -5.7 \\
\hline
\end{tabular}


Table 40: Dynamic Stiffness Real and Imaginary Parts at $6800 \mathrm{rpm}$ and $2350 \mathrm{kPa}(\mathrm{MN} / \mathrm{m})$

\begin{tabular}{|c|c|c|c|c|c|c|c|c|c|c|c|c|c|c|c|c|}
\hline $\mathrm{f}(\mathrm{Hz})$ & $\mathrm{R}\left(\mathrm{H}_{\mathrm{xx}}\right)$ & $\mathrm{R}\left(\mathrm{H}_{\mathrm{xy}}\right)$ & $\mathrm{R}\left(\mathrm{H}_{\mathrm{yx}}\right)$ & $\mathrm{R}\left(\mathrm{H}_{\mathrm{yv}}\right)$ & $\mathrm{I}\left(\mathrm{H}_{\mathrm{xx}}\right)$ & $\mathrm{I}\left(\mathrm{H}_{\mathrm{xy}}\right)$ & $\mathrm{I}\left(\mathrm{H}_{\mathrm{yx}}\right)$ & $\mathrm{I}\left(\mathrm{H}_{\mathrm{yv}}\right)$ & $\Delta \mathrm{R}\left(\mathrm{H}_{\mathrm{xx}}\right)$ & $\Delta \mathrm{R}\left(\mathrm{H}_{\mathrm{xy}}\right)$ & $\Delta \mathrm{R}\left(\mathrm{H}_{\mathrm{yx}}\right)$ & $\Delta \mathrm{R}\left(\mathrm{H}_{\mathrm{yv}}\right)$ & $\Delta \mathrm{I}\left(\mathrm{H}_{\mathrm{xx}}\right)$ & $\Delta \mathrm{I}\left(\mathrm{H}_{\mathrm{xy}}\right)$ & $\Delta \mathrm{I}\left(\mathrm{H}_{\mathrm{yx}}\right)$ & $\Delta \mathrm{I}\left(\mathrm{H}_{\mathrm{yv}}\right)$ \\
\hline 9.8 & 285.5 & -63.7 & -66.5 & 281.0 & 12.0 & -3.1 & -61.5 & 149.7 & -0.8 & -0.7 & -3.1 & -12.7 & -0.6 & -1.0 & -13.1 & -11.0 \\
\hline 19.5 & 285.6 & -65.5 & -109.4 & 405.7 & 23.0 & -8.2 & -22.5 & -40.5 & -0.2 & -0.6 & -4.9 & -8.2 & -0.2 & -0.5 & -17.6 & -8.7 \\
\hline 29.3 & 289.3 & -64.5 & -53.6 & 328.1 & 34.4 & -6.6 & -28.4 & 67.7 & -0.3 & -0.5 & -3.3 & -4.2 & -0.2 & -0.6 & -3.5 & -5.3 \\
\hline 39.1 & 293.4 & -63.6 & -46.8 & 340.8 & 46.4 & -8.8 & 24.6 & 36.7 & -0.3 & -0.3 & -2.0 & -2.2 & -0.3 & -0.4 & -18.8 & -4.3 \\
\hline 48.8 & 296.4 & -63.3 & -82.6 & 361.3 & 58.5 & -10.8 & 0.9 & 48.5 & -0.1 & -0.2 & -5.3 & -3.0 & -0.1 & -0.4 & -4.3 & -1.9 \\
\hline 58.6 & 299.3 & -63.5 & -66.3 & 365.3 & 67.0 & -10.6 & -22.1 & 59.0 & -0.2 & -0.5 & -2.2 & -1.7 & -0.3 & -0.4 & -3.6 & -1.5 \\
\hline 68.4 & 298.2 & -62.3 & -78.4 & 366.1 & 77.2 & -12.7 & -5.4 & 62.7 & -0.2 & -0.3 & -5.2 & -2.3 & -0.2 & -0.2 & -6.8 & -2.0 \\
\hline 78.1 & 306.3 & -57.2 & -61.0 & 348.9 & 92.9 & -12.2 & -14.6 & 71.5 & -0.2 & -0.3 & -0.3 & -2.1 & -0.1 & -0.3 & -4.4 & -1.6 \\
\hline 87.9 & 306.2 & -60.4 & -71.5 & 366.5 & 97.3 & -17.4 & -24.0 & 99.6 & -0.2 & -0.3 & -1.3 & -1.6 & -0.3 & -0.3 & -0.5 & -1.6 \\
\hline 97.7 & 309.3 & -57.5 & -62.0 & 356.2 & 104.4 & -18.0 & -22.3 & 89.0 & -0.3 & -0.3 & -4.6 & -2.1 & -0.4 & -0.5 & -1.1 & -1.0 \\
\hline 107.4 & 311.6 & -56.5 & -67.4 & 367.4 & 113.6 & -20.7 & -29.2 & 117.9 & -0.5 & -0.6 & -3.6 & -2.0 & -0.8 & -0.8 & -3.2 & -1.9 \\
\hline 117.2 & 316.1 & -54.8 & -61.8 & 370.1 & 121.2 & -24.1 & -43.2 & 121.6 & -1.7 & -2.7 & -7.0 & -3.6 & -1.3 & -1.0 & -4.5 & -3.5 \\
\hline 127.0 & 318.4 & -51.6 & -69.3 & 370.9 & 131.3 & -25.2 & -40.3 & 139.0 & -0.5 & -0.5 & -0.8 & -2.1 & -0.4 & -0.7 & -4.8 & -2.1 \\
\hline 136.7 & 320.3 & -47.2 & -64.8 & 367.7 & 140.2 & -27.6 & -33.1 & 148.7 & -0.3 & -0.4 & -0.4 & -2.0 & -0.3 & -0.4 & -3.4 & $\begin{array}{l}-1.7 \\
\end{array}$ \\
\hline 146.5 & 322.4 & -43.7 & -49.1 & 369.5 & 149.1 & -30.9 & -32.1 & 152.2 & -0.2 & -0.3 & -1.8 & -1.9 & -0.2 & -0.2 & -2.4 & -1.6 \\
\hline 156.3 & 322.3 & -38.7 & -48.6 & 361.1 & 158.7 & -32.6 & -29.5 & 136.2 & -0.1 & -0.3 & -2.6 & -2.4 & -0.3 & -0.3 & -2.8 & -1.3 \\
\hline 166.0 & 326.2 & -43.3 & -64.1 & 388.3 & 167.7 & -37.4 & -50.5 & 181.1 & -0.1 & -0.3 & -3.1 & -1.9 & -0.4 & -0.3 & -5.1 & -3.0 \\
\hline 175.8 & 326.6 & -39.5 & -59.9 & 397.7 & 177.3 & -41.3 & -51.9 & 196.2 & -0.3 & -0.2 & -2.6 & -2.2 & -0.2 & -0.2 & -7.1 & -2.5 \\
\hline 185.5 & 329.8 & -37.0 & -57.7 & 398.4 & 189.7 & -43.5 & -34.8 & 190.7 & -0.2 & -0.2 & -0.9 & -2.4 & -0.3 & -0.2 & -1.6 & -1.5 \\
\hline 195.3 & 332.8 & -33.1 & -53.9 & 401.7 & 203.4 & -46.2 & -40.7 & 196.9 & -0.2 & -0.4 & -3.1 & -2.4 & -0.2 & -0.3 & -2.9 & $\begin{array}{l}-1.3 \\
\end{array}$ \\
\hline 205.1 & 333.9 & -31.1 & -53.6 & 413.4 & 211.2 & -49.2 & -31.4 & 218.1 & -0.4 & -0.3 & -2.9 & -2.1 & -0.3 & -0.2 & -1.8 & -1.0 \\
\hline 214.8 & 342.9 & -27.9 & -40.4 & 428.1 & 223.5 & -51.7 & -53.7 & 214.0 & -0.2 & -0.3 & -3.3 & -2.3 & -0.3 & -0.3 & -3.8 & -1.3 \\
\hline 224.6 & 346.7 & -18.8 & -43.3 & 374.7 & 232.9 & -52.8 & -36.7 & 221.1 & -0.3 & -0.4 & -5.1 & -2.1 & -0.5 & -0.3 & -0.9 & -1.4 \\
\hline 234.4 & 354.7 & -30.5 & -50.5 & 444.7 & 244.1 & -62.3 & -40.7 & 236.3 & -0.5 & -0.3 & -6.1 & -2.6 & -0.2 & -0.3 & -5.2 & -1.9 \\
\hline 244.1 & 356.8 & -26.5 & -39.8 & 444.9 & 256.5 & -62.1 & -38.8 & 247.9 & -0.4 & -0.3 & -2.9 & -2.2 & -0.2 & -0.2 & -1.3 & -1.6 \\
\hline 253.9 & 360.1 & -22.5 & -31.6 & 454.5 & 266.2 & -60.5 & -25.1 & 250.5 & -0.7 & -0.4 & -5.0 & -2.1 & -0.4 & -0.2 & $\begin{array}{l}-1.1 \\
\end{array}$ & -1.6 \\
\hline 263.7 & 365.1 & -16.6 & -18.3 & 452.7 & 279.9 & -60.1 & -30.6 & 253.5 & -0.5 & -0.3 & -4.4 & -2.2 & -0.2 & -0.3 & -4.6 & -2.2 \\
\hline 273.4 & 370.9 & -8.5 & -25.9 & 408.5 & 293.8 & -57.9 & -35.8 & 244.3 & -0.7 & -0.4 & -1.7 & -1.9 & -0.4 & -0.3 & -2.8 & -2.9 \\
\hline 283.2 & 375.3 & -20.2 & -22.0 & 464.6 & 308.9 & -68.9 & -28.5 & 269.3 & -1.0 & -0.4 & -2.7 & -2.0 & -0.4 & -0.3 & -5.4 & -2.3 \\
\hline 293.0 & 384.1 & -5.4 & -15.3 & 449.8 & 319.9 & -54.3 & -15.6 & 288.7 & -0.9 & -0.4 & -7.0 & -2.7 & -0.4 & -0.3 & -2.6 & -2.9 \\
\hline 302.7 & 384.1 & 11.5 & -7.7 & 438.9 & 340.7 & -44.1 & -20.1 & 317.6 & -1.2 & -0.3 & -6.8 & -3.7 & -0.8 & -0.2 & -6.6 & -4.0 \\
\hline 312.5 & 392.7 & -12.7 & -4.7 & 584.3 & 360.7 & -83.4 & -9.5 & 315.5 & -1.0 & -0.8 & -2.4 & -3.9 & -1.2 & -0.4 & -1.8 & -3.8 \\
\hline 322.3 & 403.5 & 32.8 & 28.4 & 459.4 & 381.8 & -34.3 & 20.5 & 320.9 & -1.5 & -0.5 & -3.5 & -3.9 & -1.2 & -0.5 & -3.6 & -5.9 \\
\hline 332.0 & 435.9 & 25.0 & 50.7 & 609.7 & 385.7 & -165.9 & 83.1 & 423.0 & -1.5 & -0.9 & -3.1 & -10.7 & -0.9 & -0.8 & -5.0 & -3.7 \\
\hline 341.8 & 437.5 & 32.1 & 105.2 & 601.8 & 422.6 & -84.9 & 34.8 & 335.7 & -16.7 & -2.6 & -21.8 & -10.5 & -24.1 & -4.0 & -22.6 & -2.7 \\
\hline
\end{tabular}


Table 41: Dynamic Stiffness Real and Imaginary Parts at $6800 \mathrm{rpm}$ and $3134 \mathrm{kPa}(\mathrm{MN} / \mathrm{m})$

\begin{tabular}{|c|c|c|c|c|c|c|c|c|c|c|c|c|c|c|c|c|}
\hline $\mathrm{f}(\mathrm{Hz})$ & $\mathrm{R}\left(\mathrm{H}_{\mathrm{xx}}\right)$ & $\mathrm{R}\left(\mathrm{H}_{\mathrm{xy}}\right)$ & $\mathrm{R}\left(\mathrm{H}_{\mathrm{yx}}\right)$ & $\mathrm{R}\left(\mathrm{H}_{\mathrm{yv}}\right)$ & $\mathrm{I}\left(\mathrm{H}_{\mathrm{xx}}\right)$ & $\mathrm{I}\left(\mathrm{H}_{\mathrm{xy}}\right)$ & $\mathrm{I}\left(\mathrm{H}_{\mathrm{yx}}\right)$ & $\mathrm{I}\left(\mathrm{H}_{\mathrm{yv}}\right)$ & $\Delta \mathrm{R}\left(\mathrm{H}_{\mathrm{xx}}\right)$ & $\Delta \mathrm{R}\left(\mathrm{H}_{\mathrm{xy}}\right)$ & $\Delta \mathrm{R}\left(\mathrm{H}_{\mathrm{yx}}\right)$ & $\Delta \mathrm{R}\left(\mathrm{H}_{\mathrm{yv}}\right)$ & $\Delta \mathrm{I}\left(\mathrm{H}_{\mathrm{xx}}\right)$ & $\Delta \mathrm{I}\left(\mathrm{H}_{\mathrm{xy}}\right)$ & $\Delta \mathrm{I}\left(\mathrm{H}_{\mathrm{yx}}\right)$ & $\Delta \mathrm{I}\left(\mathrm{H}_{\mathrm{yv}}\right)$ \\
\hline 9.8 & 317.1 & -67.0 & -103.3 & 402.2 & 11.3 & -4.9 & -18.4 & 85.4 & -0.4 & -1.6 & -3.2 & -6.6 & -0.5 & -1.5 & -8.5 & -7.1 \\
\hline 19.5 & 314.9 & -68.1 & -67.2 & 367.5 & 20.3 & -5.7 & 24.6 & 5.8 & -0.3 & -1.2 & -8.2 & -3.8 & -0.5 & -0.9 & -14.5 & -4.5 \\
\hline 29.3 & 318.5 & -67.7 & -80.1 & 385.6 & 30.3 & -7.1 & -29.2 & 43.2 & -0.2 & -0.5 & -3.0 & -3.0 & -0.1 & -0.8 & -2.7 & -3.7 \\
\hline 39.1 & 322.2 & -68.5 & -89.9 & 408.7 & 42.7 & -9.8 & -7.6 & 36.1 & -0.2 & -0.7 & -3.2 & -5.3 & -0.2 & -0.6 & -14.9 & -4.3 \\
\hline 48.8 & 324.6 & -67.8 & -83.6 & 406.9 & 52.6 & -12.0 & -8.2 & 48.1 & -0.1 & -0.4 & -5.2 & -3.1 & -0.1 & -0.4 & -3.4 & -1.9 \\
\hline 58.6 & 328.3 & -68.1 & -83.1 & 409.8 & 60.9 & -13.3 & -28.9 & 55.8 & -0.2 & -0.4 & -3.9 & -2.6 & -0.2 & -0.3 & -3.6 & -2.5 \\
\hline 68.4 & 326.3 & -66.9 & -67.3 & 407.3 & 69.3 & -15.7 & -31.3 & 58.3 & -0.2 & -0.3 & -5.1 & -2.4 & -0.3 & -0.3 & -3.6 & -1.8 \\
\hline 78.1 & 324.6 & -64.8 & -79.2 & 394.1 & 88.1 & -13.4 & -13.1 & 66.2 & -0.2 & -0.3 & -1.8 & -1.8 & -0.2 & -0.4 & -4.1 & -1.7 \\
\hline 87.9 & 333.9 & -65.5 & -83.0 & 418.3 & 88.4 & -21.0 & -27.0 & 94.1 & -0.2 & -0.4 & -1.2 & -1.9 & -0.4 & -0.4 & -1.2 & -1.4 \\
\hline 97.7 & 336.6 & -62.7 & -65.8 & 400.3 & 95.0 & -21.8 & -23.1 & 83.5 & -0.5 & -0.5 & -3.9 & -2.0 & -0.6 & -0.3 & -0.9 & -1.3 \\
\hline 107.4 & 337.5 & -61.5 & -69.8 & 411.4 & 102.6 & -24.2 & -17.9 & 104.8 & -0.4 & -0.6 & -4.9 & -3.2 & -1.5 & -1.3 & -2.7 & -1.2 \\
\hline 117.2 & 341.6 & -60.4 & -96.1 & 419.3 & 110.3 & -27.4 & -35.8 & 110.1 & -1.2 & -0.9 & -4.8 & -2.5 & -0.9 & -0.7 & -2.0 & -1.6 \\
\hline 127.0 & 343.9 & -58.3 & -64.4 & 414.6 & 119.0 & -28.9 & -41.8 & 125.9 & -0.5 & -0.4 & -1.1 & -2.0 & -0.3 & -0.4 & -5.1 & -1.7 \\
\hline 136.7 & 345.5 & -53.8 & -71.7 & 412.6 & 128.5 & -32.8 & -29.9 & 134.1 & -0.4 & -0.3 & -1.2 & -1.8 & -0.2 & -0.4 & -4.1 & -1.5 \\
\hline 146.5 & 346.9 & -47.1 & -47.4 & 401.4 & 134.8 & -36.3 & -42.8 & 148.7 & -0.3 & -0.3 & -3.1 & -2.2 & -0.1 & -0.2 & -1.5 & -1.5 \\
\hline 156.3 & 347.2 & -48.8 & -43.8 & 407.2 & 143.5 & -38.2 & -45.3 & 130.0 & -0.3 & -0.2 & -3.5 & -2.4 & -0.2 & -0.3 & -1.9 & -1.4 \\
\hline 166.0 & 350.3 & -53.5 & -63.8 & 440.7 & 151.5 & -41.8 & -47.4 & 175.0 & -0.2 & -0.2 & -1.1 & -2.3 & -0.3 & -0.3 & -3.6 & -1.6 \\
\hline 175.8 & 350.5 & -49.6 & -69.7 & 441.4 & 161.0 & -45.9 & -49.8 & 180.3 & -0.3 & -0.3 & -2.5 & -1.8 & -0.4 & -0.2 & -5.4 & -2.2 \\
\hline 185.5 & 352.5 & -47.4 & $\begin{array}{l}-77.4 \\
\end{array}$ & 449.7 & 171.9 & -46.8 & -43.8 & 178.7 & -0.2 & -0.2 & -1.6 & -1.7 & -0.3 & -0.3 & -1.1 & -1.5 \\
\hline 195.3 & 354.6 & -42.4 & -32.9 & 438.1 & 183.4 & -49.2 & -50.4 & 180.0 & -0.3 & -0.2 & -4.4 & -2.4 & -0.3 & -0.2 & -3.5 & -2.1 \\
\hline 205.1 & 354.8 & -42.2 & -55.1 & 458.6 & 190.7 & -52.3 & -42.1 & 202.0 & -0.5 & -0.2 & -1.0 & -2.3 & -0.3 & -0.3 & -2.3 & -1.4 \\
\hline 214.8 & 363.3 & -37.1 & -56.7 & 462.5 & 202.9 & -51.5 & $\begin{array}{l}-76.3 \\
\end{array}$ & 194.2 & -0.3 & -0.3 & -3.4 & -2.1 & -0.4 & -0.3 & -4.6 & -2.0 \\
\hline 224.6 & 366.9 & -37.3 & -30.5 & 429.2 & 208.3 & -57.1 & -42.7 & 194.4 & -0.6 & -0.6 & -4.6 & -2.3 & -3.1 & -0.8 & -0.9 & -1.6 \\
\hline 234.4 & 374.0 & -44.0 & -34.6 & 486.7 & 221.1 & -65.2 & -34.1 & 214.2 & -0.4 & -0.3 & -5.0 & -2.1 & -0.2 & -0.3 & -2.1 & -2.1 \\
\hline 244.1 & 374.4 & -37.9 & -32.2 & 480.0 & 232.5 & -64.3 & -41.8 & 227.3 & -0.4 & -0.2 & -1.4 & -2.1 & -0.3 & -0.2 & $\begin{array}{l}-1.7 \\
\end{array}$ & -1.3 \\
\hline 253.9 & 375.3 & -34.1 & -35.9 & 499.0 & 241.1 & -62.4 & -28.3 & 229.4 & -0.4 & -0.2 & -2.5 & $\begin{array}{l}-1.7 \\
\end{array}$ & -0.5 & -0.3 & -3.5 & -1.6 \\
\hline 263.7 & 379.4 & -29.5 & -3.0 & 490.1 & 252.3 & -62.6 & -44.5 & 226.1 & -0.4 & -0.3 & -5.8 & -2.1 & -0.3 & -0.2 & -2.0 & -1.4 \\
\hline 273.4 & 384.9 & -21.1 & -19.5 & 443.2 & 264.3 & -60.3 & -56.7 & 214.7 & -0.5 & -0.3 & -1.3 & -1.9 & -0.6 & -0.3 & -2.6 & -1.3 \\
\hline 283.2 & 389.9 & -35.7 & -8.7 & 507.3 & 279.0 & -71.2 & -51.4 & 243.3 & -0.7 & -0.2 & -3.5 & -2.3 & -0.5 & -0.3 & -2.1 & -1.3 \\
\hline 293.0 & 396.7 & -18.4 & -12.7 & 486.3 & 288.4 & -59.9 & -26.6 & 263.5 & -0.7 & -0.3 & -1.4 & -2.8 & -0.5 & -0.3 & -2.5 & -2.3 \\
\hline 302.7 & 396.1 & -4.0 & -5.4 & 474.6 & 304.5 & -55.1 & -51.1 & 284.2 & -0.9 & -0.3 & -2.3 & -1.7 & -0.9 & -0.4 & -4.7 & -1.8 \\
\hline 312.5 & 408.6 & -0.7 & -24.0 & 705.5 & 319.3 & -183.5 & -16.7 & 460.3 & -1.1 & -0.8 & -2.5 & -5.6 & -0.9 & -1.2 & -2.9 & -4.0 \\
\hline 322.3 & 410.2 & 10.3 & 26.8 & 497.9 & 333.0 & -49.2 & -6.9 & 300.0 & -1.4 & -0.4 & -3.8 & -2.1 & -0.8 & -0.3 & -2.8 & -3.1 \\
\hline 332.0 & 429.6 & 127.6 & 0.7 & 527.7 & 377.9 & -136.3 & -1.0 & 519.2 & -1.6 & -1.2 & -2.6 & -8.4 & -1.0 & -2.1 & -1.6 & -9.2 \\
\hline 341.8 & 430.5 & -13.0 & 57.1 & 682.7 & 383.5 & -109.6 & 0.3 & 310.0 & -1.9 & -1.0 & -5.0 & -2.7 & -1.0 & -0.4 & -3.0 & -3.0 \\
\hline
\end{tabular}


Table 42: Dynamic Stiffness Real and Imaginary Parts at $9000 \mathrm{rpm}$ and $0 \mathrm{kPa}(\mathrm{MN} / \mathrm{m})$

\begin{tabular}{|c|c|c|c|c|c|c|c|c|c|c|c|c|c|c|c|c|}
\hline $\mathrm{f}(\mathrm{Hz})$ & $\mathrm{R}\left(\mathrm{H}_{\mathrm{xx}}\right)$ & $\mathrm{R}\left(\mathrm{H}_{\mathrm{xy}}\right)$ & $\mathrm{R}\left(\mathrm{H}_{\mathrm{yx}}\right)$ & $\mathrm{R}\left(\mathrm{H}_{\mathrm{yv}}\right)$ & $\mathrm{I}\left(\mathrm{H}_{\mathrm{xx}}\right)$ & $\mathrm{I}\left(\mathrm{H}_{\mathrm{xy}}\right)$ & $\mathrm{I}\left(\mathrm{H}_{\mathrm{vX}}\right)$ & $\mathrm{I}\left(\mathrm{H}_{\mathrm{yv}}\right)$ & $\Delta \mathrm{R}\left(\mathrm{H}_{\mathrm{xx}}\right)$ & $\Delta \mathrm{R}\left(\mathrm{H}_{\mathrm{xy}}\right)$ & $\Delta \mathrm{R}\left(\mathrm{H}_{\mathrm{yx}}\right)$ & $\Delta \mathrm{R}\left(\mathrm{H}_{\mathrm{vv}}\right)$ & $\Delta \mathrm{I}\left(\mathrm{H}_{\mathrm{xx}}\right)$ & $\Delta \mathrm{I}\left(\mathrm{H}_{\mathrm{xv}}\right)$ & $\Delta \mathrm{I}\left(\mathrm{H}_{\mathrm{yx}}\right)$ & $\Delta \mathrm{I}\left(\mathrm{H}_{\mathrm{vv}}\right)$ \\
\hline 9.8 & 212.3 & -68.4 & -50.5 & 177.3 & 7.4 & 11.2 & 59.8 & -59.1 & -0.6 & -2.1 & -3.1 & $\begin{array}{l}-9.7 \\
\end{array}$ & -0.9 & -1.9 & -7.3 & -5.8 \\
\hline 19.5 & 211.3 & -57.0 & -42.4 & 149.8 & 36.2 & -4.5 & -23.5 & 60.6 & -0.3 & -1.5 & -2.6 & -8.0 & -0.4 & -0.7 & -2.4 & -4.3 \\
\hline 29.3 & 215.0 & -60.1 & -65.5 & 169.4 & 49.4 & 5.8 & -1.6 & 30.7 & -0.2 & -0.9 & -3.0 & -11.3 & -0.3 & -0.5 & -2.1 & -2.9 \\
\hline 39.1 & 217.2 & -65.4 & -55.8 & 175.9 & 63.5 & -1.4 & -13.2 & 72.0 & -0.2 & -0.8 & -1.9 & -4.7 & -0.5 & -0.6 & -2.2 & -2.7 \\
\hline 48.8 & 224.3 & -68.1 & -72.0 & 200.3 & 75.8 & -1.5 & 3.6 & 77.2 & -0.2 & -1.0 & -1.5 & -6.6 & -0.2 & -0.7 & -1.0 & -3.7 \\
\hline 58.6 & 231.7 & -61.4 & -64.9 & 225.0 & 93.4 & -2.0 & 2.1 & 98.3 & -0.2 & -1.1 & -1.0 & -3.7 & -0.2 & -0.2 & -1.6 & -2.5 \\
\hline 68.4 & 235.9 & -58.0 & -62.7 & 222.4 & 104.8 & -2.5 & -10.5 & 106.3 & -0.3 & -1.0 & -1.1 & -3.4 & -0.2 & -0.4 & -0.4 & -2.6 \\
\hline 78.1 & 239.3 & -57.0 & -60.9 & 229.0 & 121.0 & -6.1 & -15.2 & 121.3 & -0.1 & -0.9 & -0.8 & -4.3 & -0.3 & -0.3 & -0.9 & -2.7 \\
\hline 87.9 & 242.4 & -54.1 & -58.3 & 250.5 & 129.8 & -5.6 & -14.3 & 147.5 & -0.1 & -0.9 & -0.5 & -3.6 & -0.3 & -0.5 & -0.6 & -2.5 \\
\hline 97.7 & 248.9 & -52.8 & -54.3 & 244.2 & 140.9 & -4.4 & -15.2 & 141.0 & -0.3 & -0.9 & -0.8 & -3.5 & -0.2 & -0.4 & -1.4 & -2.3 \\
\hline 107.4 & 254.1 & -48.9 & -46.1 & 227.8 & 147.8 & -0.1 & -10.4 & 154.2 & -0.2 & -0.9 & -0.9 & -3.8 & -0.3 & -0.3 & -1.1 & -2.9 \\
\hline 117.2 & 259.8 & -45.1 & -49.1 & 264.9 & 161.7 & -10.3 & -19.7 & 176.6 & -0.1 & -1.0 & -2.2 & -3.7 & -0.2 & -0.3 & -1.2 & -2.0 \\
\hline 127.0 & 264.3 & -40.8 & -47.7 & 266.1 & 173.8 & -10.0 & -14.3 & 155.0 & -0.2 & -0.9 & -1.4 & -3.9 & -0.3 & -0.6 & -1.2 & -1.9 \\
\hline 136.7 & 270.9 & -45.5 & -51.0 & 270.9 & 186.2 & -13.0 & -21.4 & 160.7 & -0.3 & -1.2 & -1.1 & -3.5 & -0.2 & -0.4 & -1.7 & -3.0 \\
\hline 146.5 & 275.7 & -39.3 & -46.0 & 283.6 & 192.7 & -8.0 & -15.1 & 174.2 & -0.5 & -2.5 & -1.2 & -4.5 & -0.3 & -0.9 & -2.3 & -2.8 \\
\hline 156.3 & 274.5 & -34.7 & -37.9 & 226.8 & 205.6 & -6.1 & -22.1 & 278.0 & -0.4 & -0.9 & -1.4 & -4.1 & -0.3 & -1.5 & -1.3 & -2.8 \\
\hline 166.0 & 280.1 & -29.7 & -28.9 & 274.7 & 213.8 & -2.5 & -32.1 & 219.3 & -0.4 & -1.1 & -1.8 & -3.5 & -0.3 & -0.4 & -1.0 & -2.3 \\
\hline 175.8 & 283.5 & -22.9 & -38.0 & 335.1 & 227.5 & -9.1 & -22.9 & 269.6 & -0.3 & -1.0 & -0.7 & -5.4 & -0.4 & -0.6 & -1.7 & -2.5 \\
\hline 185.5 & 278.0 & -13.2 & -41.5 & 297.3 & 241.1 & -5.4 & -40.0 & 227.4 & -0.4 & -0.9 & -1.6 & -3.8 & -0.4 & -0.8 & -0.7 & -1.7 \\
\hline 195.3 & 287.4 & -5.3 & -25.1 & 336.1 & 246.6 & $\begin{array}{l}-1.1 \\
\end{array}$ & -29.4 & 289.7 & -0.4 & -0.9 & -1.2 & -3.2 & -0.2 & -0.4 & -1.6 & -1.8 \\
\hline 205.1 & 286.8 & 8.6 & -46.0 & 317.4 & 274.2 & -10.9 & -33.9 & 296.4 & -0.4 & -1.1 & -1.2 & -3.9 & -0.2 & -0.4 & -1.4 & -2.2 \\
\hline 214.8 & 323.4 & 7.1 & -31.8 & 304.8 & 303.7 & 1.4 & -22.7 & 320.8 & -1.0 & -1.1 & -2.0 & -3.7 & -0.4 & -0.6 & -4.1 & -2.9 \\
\hline 224.6 & 334.0 & -2.3 & -35.3 & 296.1 & 298.9 & -10.2 & -27.3 & 326.4 & -0.6 & $\begin{array}{l}-1.1 \\
\end{array}$ & -2.3 & -3.6 & -0.3 & -0.6 & -2.3 & -2.2 \\
\hline 234.4 & 334.0 & 23.1 & -33.5 & 353.1 & 330.5 & -31.2 & -10.2 & 320.3 & -0.4 & -1.1 & -2.1 & -4.0 & -1.2 & -0.4 & -2.9 & -2.1 \\
\hline 244.1 & 353.5 & 66.6 & -38.8 & 347.3 & 377.6 & -34.4 & 6.7 & 351.1 & -0.5 & -1.1 & -1.1 & -3.8 & -1.0 & -0.7 & -2.5 & -3.2 \\
\hline 253.9 & 321.8 & 112.6 & -69.3 & 369.1 & 407.8 & -11.8 & 11.7 & 400.7 & -1.3 & $\begin{array}{l}-1.7 \\
\end{array}$ & -2.1 & -3.9 & -4.0 & -1.2 & -5.2 & -3.6 \\
\hline 263.7 & 316.1 & 82.6 & -71.1 & 391.5 & 438.6 & 7.2 & 37.7 & 434.2 & -1.9 & -1.4 & -6.4 & -5.1 & -2.7 & -0.8 & -3.0 & -3.3 \\
\hline 273.4 & 424.3 & 144.2 & 49.3 & 428.6 & 511.5 & 23.7 & 92.3 & 496.9 & -8.8 & -2.7 & $\begin{array}{l}-4.7 \\
\end{array}$ & -6.1 & -4.3 & -2.0 & -6.0 & -3.9 \\
\hline 283.2 & 539.1 & 414.8 & 183.9 & 727.7 & 543.6 & 72.4 & 187.6 & 642.3 & -6.8 & -11.2 & $\begin{array}{l}-4.7 \\
\end{array}$ & -11.4 & -5.9 & -5.5 & $\begin{array}{l}-7.0 \\
\end{array}$ & -8.2 \\
\hline 293.0 & 726.4 & 397.3 & 630.4 & 1055.0 & 236.9 & -586.5 & -209.8 & -255.9 & -23.0 & -34.8 & -37.4 & -59.6 & -21.0 & -10.1 & -37.2 & -23.1 \\
\hline 302.7 & 628.4 & 708.7 & 658.7 & 1233.6 & -67.2 & 70.8 & -509.1 & 1324.1 & -26.4 & -121.2 & -78.5 & -106.5 & -105.3 & -73.6 & -128.6 & -172.2 \\
\hline 312.5 & 289.7 & -35.7 & -243.7 & 389.8 & 437.7 & -311.2 & -74.9 & 21.3 & -6.1 & -6.1 & -11.7 & -12.8 & -6.6 & -7.3 & -7.0 & -10.7 \\
\hline 322.3 & 522.0 & -95.3 & 139.0 & 304.1 & 269.3 & -313.8 & -198.9 & 149.7 & -11.3 & -6.2 & -7.5 & -11.5 & -5.5 & -8.1 & -10.7 & -7.6 \\
\hline 332.0 & 383.8 & -15.8 & 62.5 & 383.8 & 407.2 & -226.0 & -205.8 & 242.2 & -2.3 & -2.5 & -5.8 & -6.3 & -1.8 & -1.9 & -8.5 & -10.3 \\
\hline 341.8 & 393.5 & -26.9 & -12.6 & 438.7 & 357.4 & -153.4 & -149.7 & 213.3 & -3.1 & -3.6 & -3.4 & -6.1 & -5.9 & -1.7 & -8.2 & -4.5 \\
\hline
\end{tabular}


Table 43: Dynamic Stiffness Real and Imaginary Parts at $9000 \mathrm{rpm}$ and $783 \mathrm{kPa}(\mathrm{MN} / \mathrm{m})$

\begin{tabular}{|c|c|c|c|c|c|c|c|c|c|c|c|c|c|c|c|c|}
\hline $\mathrm{f}(\mathrm{Hz})$ & $\mathrm{R}\left(\mathrm{H}_{\mathrm{xx}}\right)$ & $\mathrm{R}\left(\mathrm{H}_{\mathrm{xy}}\right)$ & $\mathrm{R}\left(\mathrm{H}_{\mathrm{yX}}\right)$ & $\mathrm{R}\left(\mathrm{H}_{\mathrm{yv}}\right)$ & $\mathrm{I}\left(\mathrm{H}_{\mathrm{xx}}\right)$ & $\mathrm{I}\left(\mathrm{H}_{\mathrm{xy}}\right)$ & $\mathrm{I}\left(\mathrm{H}_{\mathrm{vx}}\right)$ & $\mathrm{I}\left(\mathrm{H}_{\mathrm{yv}}\right)$ & $\Delta \mathrm{R}\left(\mathrm{H}_{\mathrm{xx}}\right)$ & $\Delta \mathrm{R}\left(\mathrm{H}_{\mathrm{xy}}\right)$ & $\Delta \mathrm{R}\left(\mathrm{H}_{\mathrm{yx}}\right)$ & $\Delta \mathrm{R}\left(\mathrm{H}_{\mathrm{yv}}\right)$ & $\Delta \mathrm{I}\left(\mathrm{H}_{\mathrm{xx}}\right)$ & $\Delta \mathrm{I}\left(\mathrm{H}_{\mathrm{xy}}\right)$ & $\Delta \mathrm{I}\left(\mathrm{H}_{\mathrm{yx}}\right)$ & $\Delta \mathrm{I}\left(\mathrm{H}_{\mathrm{yy}}\right)$ \\
\hline 9.8 & 238.0 & -61.9 & -74.9 & 239.8 & 14.4 & -4.4 & -11.9 & 26.3 & -0.6 & -1.7 & -1.4 & -5.7 & -0.6 & -1.6 & -2.7 & -8.6 \\
\hline 19.5 & 241.8 & -67.6 & -54.0 & 219.1 & 31.7 & -8.8 & 11.8 & 16.2 & -0.3 & -1.3 & -4.6 & -6.4 & -0.5 & -1.2 & -6.2 & -7.7 \\
\hline 29.3 & 242.4 & -66.0 & -71.9 & 259.1 & 43.8 & -7.4 & -16.7 & 34.4 & -0.3 & -1.3 & -2.9 & -4.3 & -0.3 & -0.3 & -2.7 & -4.3 \\
\hline 39.1 & 245.6 & -67.6 & -76.4 & 256.1 & 55.0 & -7.6 & -12.7 & 65.2 & -0.3 & -0.9 & -1.6 & -3.0 & -0.2 & -0.6 & -3.8 & -2.2 \\
\hline 48.8 & 251.3 & -65.7 & -60.8 & 249.0 & 70.8 & -9.6 & 1.8 & 74.1 & -0.3 & -0.3 & -0.5 & -2.0 & -0.2 & -0.5 & -0.5 & -1.7 \\
\hline 58.6 & 253.6 & -65.9 & -73.3 & 263.1 & 83.5 & -8.2 & -12.1 & 89.8 & -0.2 & -0.4 & -1.6 & -2.3 & -0.5 & -0.7 & -0.9 & -1.8 \\
\hline 68.4 & 258.6 & -66.6 & -66.9 & 265.3 & 102.2 & -6.6 & -3.7 & 98.3 & -0.4 & -0.4 & -0.9 & -1.9 & -0.3 & -0.4 & -2.0 & -1.7 \\
\hline 78.1 & 263.7 & -62.1 & -59.3 & 257.0 & 108.6 & -7.8 & -8.2 & 101.3 & -0.2 & -0.4 & -1.0 & -1.8 & -0.2 & -0.5 & -0.5 & -1.2 \\
\hline 87.9 & 266.4 & -63.6 & -62.5 & 282.8 & 119.2 & -9.6 & -16.8 & 128.9 & -0.2 & -0.4 & -0.5 & -1.4 & -0.2 & -0.3 & -1.3 & -1.6 \\
\hline 97.7 & 271.0 & -60.6 & -61.3 & 276.5 & 128.2 & -8.5 & -20.4 & 128.8 & -0.3 & -0.3 & -0.8 & -1.9 & -0.3 & -0.3 & -2.8 & -1.8 \\
\hline 107.4 & 274.1 & -59.1 & -65.5 & 285.5 & 138.8 & -9.6 & -16.4 & 147.6 & -0.1 & -0.4 & -0.3 & -1.5 & -0.3 & -0.5 & -0.4 & -1.1 \\
\hline 117.2 & 280.5 & -56.3 & -64.8 & 294.5 & 147.7 & -10.4 & -24.1 & 155.1 & -0.2 & -0.3 & -0.8 & -2.3 & -0.2 & -0.3 & -1.1 & -1.3 \\
\hline 127.0 & 284.7 & -53.9 & -61.6 & 290.8 & 158.4 & -10.4 & -20.3 & 164.6 & -0.3 & -0.4 & -0.9 & -2.1 & -0.2 & -0.3 & -1.5 & -1.2 \\
\hline 136.7 & 288.0 & -49.5 & -60.2 & 299.0 & 170.2 & -10.1 & -28.6 & 169.4 & -0.5 & -0.3 & -1.8 & -1.7 & -0.2 & -0.4 & -0.6 & -1.1 \\
\hline 146.5 & 290.0 & -43.9 & -51.0 & 298.3 & 179.8 & -12.1 & -18.2 & 172.0 & -1.4 & -1.1 & -1.9 & -2.0 & -0.3 & -0.6 & -1.7 & -2.4 \\
\hline 156.3 & 294.9 & -33.7 & -47.0 & 274.8 & 189.6 & -10.3 & -18.9 & 171.0 & -1.4 & -0.6 & -3.8 & -2.7 & -0.7 & -0.8 & -1.1 & -1.4 \\
\hline 166.0 & 298.4 & -40.1 & -47.9 & 317.3 & 200.9 & -16.1 & -30.7 & 210.1 & -0.4 & -0.4 & -1.7 & -1.7 & -0.6 & -0.5 & -3.1 & -2.2 \\
\hline 175.8 & 298.7 & -34.5 & -54.1 & 319.2 & 212.9 & -17.1 & -27.6 & 211.7 & -0.4 & -0.3 & -1.7 & -2.0 & -0.6 & -0.3 & -2.0 & -1.4 \\
\hline 185.5 & 302.5 & -30.2 & -51.0 & 323.3 & 224.5 & -15.1 & -23.1 & 215.2 & -0.4 & -0.3 & -1.5 & -1.6 & -0.5 & -0.4 & -1.0 & -1.4 \\
\hline 195.3 & 305.0 & -22.3 & -48.9 & 315.2 & 240.0 & -14.7 & -30.3 & 231.3 & -0.2 & -0.3 & $\begin{array}{l}-1.9 \\
\end{array}$ & -1.5 & -0.3 & -0.3 & -1.5 & $\begin{array}{l}-1.4 \\
\end{array}$ \\
\hline 205.1 & 306.5 & -17.7 & -51.4 & 326.4 & 249.2 & -14.3 & -19.3 & 250.3 & -0.5 & -0.3 & -1.2 & -2.0 & -0.4 & -0.4 & -0.4 & -1.5 \\
\hline 214.8 & 313.1 & $\begin{array}{l}-7.7 \\
\end{array}$ & -44.7 & 325.8 & 271.1 & -11.1 & -25.0 & 247.8 & -0.2 & -0.2 & -1.8 & -1.6 & -0.4 & -0.4 & -2.1 & -1.6 \\
\hline 224.6 & 319.4 & 28.5 & -54.9 & 227.1 & 287.7 & -3.9 & -25.4 & 298.9 & -0.3 & -0.4 & -2.2 & -2.1 & -0.4 & -0.4 & -2.4 & -1.2 \\
\hline 234.4 & 328.7 & 1.0 & -54.7 & 351.0 & 299.2 & -24.9 & -31.7 & 286.8 & -0.4 & -0.4 & -2.6 & -2.2 & -0.3 & -0.3 & -0.8 & -1.2 \\
\hline 244.1 & 327.2 & 7.2 & -47.5 & 351.4 & 321.0 & -23.9 & -22.9 & 296.7 & -0.4 & -0.3 & -3.3 & -2.2 & -0.2 & -0.3 & -1.4 & -1.9 \\
\hline 253.9 & 340.1 & 13.0 & -52.7 & 370.5 & 344.5 & -25.8 & 15.0 & 312.5 & -0.2 & -0.3 & -3.8 & -2.1 & -0.4 & -0.3 & -3.1 & -1.9 \\
\hline 263.7 & 349.0 & 31.1 & -51.7 & 356.1 & 363.2 & -18.5 & 20.5 & 320.1 & -0.2 & -0.3 & -4.9 & -2.7 & -0.2 & -0.6 & -2.7 & -1.2 \\
\hline 273.4 & 370.5 & 72.4 & -42.2 & 268.3 & 394.4 & 0.0 & 29.2 & 362.7 & -0.3 & -1.0 & -4.4 & -4.1 & -0.6 & -0.7 & -3.2 & -3.0 \\
\hline 283.2 & 368.9 & 34.6 & -47.9 & 362.7 & 423.0 & -5.4 & 51.6 & 358.8 & -0.3 & -0.3 & -7.5 & -3.8 & -0.4 & -0.8 & -2.3 & -2.3 \\
\hline 293.0 & 404.5 & 159.3 & -29.4 & 400.6 & 454.3 & -51.2 & 141.1 & 579.9 & -1.5 & -0.9 & -6.1 & -6.0 & -0.7 & -1.8 & -4.8 & -4.9 \\
\hline 302.7 & 397.4 & 76.8 & 4.5 & 568.8 & 495.8 & -102.6 & 171.2 & 465.9 & -7.0 & -9.1 & -13.9 & -13.3 & -6.6 & -3.6 & -15.8 & -26.9 \\
\hline 312.5 & 553.8 & 163.7 & 215.3 & 747.2 & 438.3 & -268.9 & 302.6 & 436.1 & -2.7 & -1.4 & -6.3 & -9.6 & -2.0 & -2.7 & -13.4 & -10.2 \\
\hline 322.3 & 772.5 & 315.1 & 334.7 & 760.5 & 870.3 & -58.4 & 924.8 & 646.5 & -8.6 & -4.9 & -13.6 & -18.0 & -12.2 & -3.1 & -35.1 & -14.7 \\
\hline 332.0 & 1747.3 & 479.7 & 1441.2 & 936.0 & 244.7 & -367.2 & 240.3 & 188.3 & -35.9 & -10.1 & -45.1 & -23.5 & -29.6 & -14.5 & -33.4 & -14.7 \\
\hline 341.8 & 510.5 & 19.7 & 355.6 & 456.5 & -156.9 & -281.7 & -526.4 & 137.7 & -6.4 & -3.2 & -9.9 & -7.6 & -4.9 & -1.6 & -15.2 & -7.2 \\
\hline
\end{tabular}


Table 44: Dynamic Stiffness Real and Imaginary Parts at $9000 \mathrm{rpm}$ and $1567 \mathrm{kPa}$ (MN/m)

\begin{tabular}{|c|c|c|c|c|c|c|c|c|c|c|c|c|c|c|c|c|}
\hline $\mathrm{f}(\mathrm{Hz})$ & $\mathrm{R}\left(\mathrm{H}_{\mathrm{xx}}\right)$ & $\mathrm{R}\left(\mathrm{H}_{\mathrm{xy}}\right)$ & $\mathrm{R}\left(\mathrm{H}_{\mathrm{yX}}\right)$ & $\mathrm{R}\left(\mathrm{H}_{\mathrm{yv}}\right)$ & $\mathrm{I}\left(\mathrm{H}_{\mathrm{xx}}\right)$ & $\mathrm{I}\left(\mathrm{H}_{\mathrm{xy}}\right)$ & $\mathrm{I}\left(\mathrm{H}_{\mathrm{yx}}\right)$ & $\mathrm{I}\left(\mathrm{H}_{\mathrm{yv}}\right)$ & $\Delta \mathrm{R}\left(\mathrm{H}_{\mathrm{xx}}\right)$ & $\Delta \mathrm{R}\left(\mathrm{H}_{\mathrm{xy}}\right)$ & $\Delta \mathrm{R}\left(\mathrm{H}_{\mathrm{yx}}\right)$ & $\Delta \mathrm{R}\left(\mathrm{H}_{\mathrm{vv}}\right)$ & $\Delta \mathrm{I}\left(\mathrm{H}_{\mathrm{xx}}\right)$ & $\Delta \mathrm{I}\left(\mathrm{H}_{\mathrm{xy}}\right)$ & $\Delta \mathrm{I}\left(\mathrm{H}_{\mathrm{vX}}\right)$ & $\Delta \mathrm{I}\left(\mathrm{H}_{\mathrm{vy}}\right)$ \\
\hline 9.8 & 274.4 & -65.0 & -72.2 & 317.6 & 13.5 & -5.4 & -10.1 & 34.4 & -0.5 & -2.3 & -0.8 & -2.1 & -0.3 & -1.3 & -2.7 & -3.7 \\
\hline 19.5 & 276.1 & -71.9 & -62.4 & 286.6 & 25.3 & -6.5 & 10.5 & 9.0 & -0.4 & -1.7 & -4.2 & -3.3 & -0.4 & -0.8 & -4.4 & -6.4 \\
\hline 29.3 & 278.9 & -68.4 & -75.6 & 335.9 & 38.9 & -10.5 & -13.1 & 18.8 & -0.3 & -0.9 & -1.8 & -5.5 & -0.4 & -0.7 & -1.0 & -3.1 \\
\hline 39.1 & 282.5 & -68.6 & -71.9 & 322.1 & 50.2 & -11.4 & -17.3 & 41.3 & -0.3 & -0.7 & -3.5 & -2.9 & -0.1 & -0.2 & -3.0 & -2.1 \\
\hline 48.8 & 286.8 & -68.2 & -65.1 & 313.2 & 63.1 & -12.9 & -13.5 & 60.0 & -0.2 & -0.4 & -0.4 & -1.7 & -0.2 & -0.3 & -1.2 & -1.2 \\
\hline 58.6 & 289.2 & -68.8 & -71.6 & 323.0 & 73.5 & -12.5 & -22.9 & 70.6 & -0.5 & -0.5 & -1.3 & -2.0 & -0.2 & -0.3 & -1.0 & -1.7 \\
\hline 68.4 & 289.1 & -69.6 & -68.6 & 318.6 & 84.1 & -13.7 & -19.8 & 64.7 & -0.4 & -0.6 & -0.5 & -1.9 & -0.3 & -0.4 & -1.0 & -1.4 \\
\hline 78.1 & 297.0 & -66.1 & -64.5 & 311.4 & 98.0 & -13.5 & -20.8 & 76.7 & -0.2 & -0.3 & -0.7 & -1.6 & -0.2 & -0.2 & -0.6 & -1.4 \\
\hline 87.9 & 298.7 & -68.8 & -73.6 & 336.0 & 105.5 & -15.1 & -24.0 & 103.5 & -0.2 & -0.4 & -0.3 & -1.6 & -0.3 & -0.3 & -0.6 & -1.5 \\
\hline 97.7 & 301.8 & -66.2 & -70.9 & 324.9 & 113.0 & -15.0 & -18.8 & 105.4 & -0.3 & -0.5 & -0.5 & -1.5 & -0.1 & -0.4 & -1.0 & -1.0 \\
\hline 107.4 & 305.2 & -64.8 & -70.8 & 335.6 & 122.9 & -16.6 & -23.0 & 121.5 & -0.1 & -0.3 & -0.6 & -2.0 & -0.2 & -0.4 & -0.6 & -1.4 \\
\hline 117.2 & 310.5 & -63.0 & -73.6 & 339.0 & 130.9 & -16.9 & -35.3 & 129.0 & -0.2 & -0.3 & -0.6 & -1.5 & -0.4 & -0.3 & -0.6 & -1.2 \\
\hline 127.0 & 312.7 & -59.6 & -69.2 & 334.2 & 140.8 & -17.1 & -28.7 & 141.9 & -0.3 & -0.4 & -0.8 & -1.8 & -0.2 & -0.3 & -0.5 & $\begin{array}{l}-1.0 \\
\end{array}$ \\
\hline 136.7 & 315.7 & -54.6 & -73.7 & 339.5 & 149.9 & -17.1 & -30.8 & 149.2 & -0.4 & -0.5 & -0.6 & -1.8 & -0.3 & -0.7 & -0.4 & -1.5 \\
\hline 146.5 & 317.9 & -50.7 & -59.9 & 340.7 & 159.8 & -20.2 & -28.4 & 152.0 & -1.2 & -1.3 & -0.8 & -2.7 & -0.4 & -1.2 & -1.3 & -1.8 \\
\hline 156.3 & 317.8 & -43.1 & -59.6 & 324.9 & 169.0 & -20.1 & -25.4 & 142.3 & -0.7 & -1.2 & -1.9 & -3.0 & -0.4 & -1.1 & -0.6 & -2.1 \\
\hline 166.0 & 322.2 & -48.6 & -64.7 & 360.0 & 178.2 & -24.0 & -33.5 & 183.4 & -0.3 & -0.4 & -0.5 & -2.9 & -0.6 & -0.6 & -1.4 & -1.3 \\
\hline 175.8 & 321.4 & -41.9 & -65.4 & 358.2 & 187.3 & -25.6 & -38.6 & 187.2 & -0.3 & -0.4 & -0.3 & -1.9 & -0.3 & -0.5 & -1.1 & -1.2 \\
\hline 185.5 & 325.1 & -38.2 & -56.9 & 361.4 & 200.5 & -25.4 & -36.0 & 192.5 & -0.2 & -0.4 & -0.2 & -1.8 & -0.3 & -0.3 & -0.7 & -1.2 \\
\hline 195.3 & 326.5 & -31.3 & -61.3 & 355.3 & 213.7 & -26.2 & -32.5 & 203.0 & -0.2 & -0.3 & $\begin{array}{l}-1.2 \\
\end{array}$ & -2.3 & -0.2 & -0.4 & -0.9 & -1.2 \\
\hline 205.1 & 326.6 & -27.8 & -57.7 & 372.7 & 222.5 & -30.2 & -37.4 & 226.3 & -0.4 & -0.3 & -0.9 & -1.9 & -0.3 & -0.3 & -0.9 & -1.2 \\
\hline 214.8 & 334.5 & -19.2 & -51.0 & 374.1 & 236.5 & -29.5 & -41.3 & 218.1 & -0.2 & -0.4 & -1.6 & -2.5 & -0.3 & -0.5 & -0.7 & -1.6 \\
\hline 224.6 & 337.6 & -8.8 & -55.2 & 320.6 & 248.0 & -30.1 & -34.6 & 231.5 & -0.1 & -0.3 & -1.1 & -2.3 & -0.4 & -0.6 & -0.4 & -1.0 \\
\hline 234.4 & 344.7 & -16.1 & -62.2 & 388.3 & 261.8 & -43.4 & -37.7 & 256.0 & -0.3 & -0.4 & -1.3 & -2.0 & -0.2 & -0.3 & -0.8 & -1.2 \\
\hline 244.1 & 346.2 & -10.0 & -51.4 & 385.7 & 277.2 & -43.8 & -39.5 & 265.4 & -0.3 & -0.3 & -0.9 & -2.4 & -0.2 & -0.2 & -0.6 & -1.3 \\
\hline 253.9 & 348.5 & -5.1 & -55.2 & 411.6 & 293.0 & -48.0 & -32.2 & 281.7 & -0.2 & -0.3 & -2.2 & -2.0 & -0.3 & -0.3 & -2.0 & -1.5 \\
\hline 263.7 & 356.6 & 1.8 & -44.7 & 403.8 & 309.0 & -45.1 & -21.1 & 275.3 & -0.1 & -0.3 & -2.2 & -2.4 & -0.2 & -0.4 & -1.2 & -1.4 \\
\hline 273.4 & 361.2 & 16.1 & -44.4 & 336.9 & 327.7 & -37.9 & -22.1 & 270.6 & -0.2 & -0.3 & -0.8 & -2.7 & -0.3 & -0.7 & -1.6 & -1.9 \\
\hline 283.2 & 369.2 & 2.6 & -46.5 & 408.2 & 349.3 & -50.9 & -8.8 & 301.5 & -0.2 & -0.3 & -1.0 & -2.4 & -0.3 & -0.3 & -0.8 & -1.3 \\
\hline 293.0 & 377.1 & 22.7 & -41.4 & 384.1 & 364.7 & -38.4 & -0.6 & 323.9 & -0.3 & -0.3 & -1.7 & -2.3 & -0.3 & -0.7 & -0.7 & -2.5 \\
\hline 302.7 & 384.4 & 63.6 & -31.3 & 333.5 & 397.2 & -19.9 & 14.9 & 375.6 & -0.4 & -1.0 & -1.2 & -2.1 & -0.5 & -1.3 & -1.3 & -4.6 \\
\hline 312.5 & 396.8 & 38.7 & -27.7 & 447.4 & 426.9 & -40.8 & 30.6 & 346.7 & -0.4 & -0.4 & -2.3 & -2.0 & -0.6 & -0.7 & -1.1 & -3.6 \\
\hline 322.3 & 418.3 & 54.0 & 14.3 & 488.3 & 438.7 & -74.5 & 103.2 & 412.1 & -1.8 & -0.9 & -2.6 & -2.7 & -1.9 & -1.6 & -3.8 & -5.3 \\
\hline 332.0 & 439.1 & 41.4 & 38.5 & 560.1 & 512.0 & -74.3 & 146.0 & 373.5 & -0.3 & -0.4 & -2.6 & -6.0 & -0.4 & -0.3 & -1.9 & -3.7 \\
\hline 341.8 & 551.2 & 108.3 & 165.8 & 583.0 & 575.6 & -55.8 & 197.4 & 377.1 & -1.5 & -0.6 & -3.8 & -8.5 & -1.2 & -0.9 & -5.6 & -2.1 \\
\hline
\end{tabular}


Table 45: Dynamic Stiffness Real and Imaginary Parts at $9000 \mathrm{rpm}$ and $2350 \mathrm{kPa}(\mathrm{MN} / \mathrm{m})$

\begin{tabular}{|c|c|c|c|c|c|c|c|c|c|c|c|c|c|c|c|c|}
\hline $\mathrm{f}(\mathrm{Hz})$ & $\mathrm{R}\left(\mathrm{H}_{\mathrm{xx}}\right)$ & $\mathrm{R}\left(\mathrm{H}_{\mathrm{xy}}\right)$ & $\mathrm{R}\left(\mathrm{H}_{\mathrm{yx}}\right)$ & $\mathrm{R}\left(\mathrm{H}_{\mathrm{yv}}\right)$ & $\mathrm{I}\left(\mathrm{H}_{\mathrm{xx}}\right)$ & $\mathrm{I}\left(\mathrm{H}_{\mathrm{xy}}\right)$ & $\mathrm{I}\left(\mathrm{H}_{\mathrm{yx}}\right)$ & $\mathrm{I}\left(\mathrm{H}_{\mathrm{yv}}\right)$ & $\Delta R\left(H_{x x}\right)$ & $\Delta R\left(H_{x y}\right)$ & $\Delta \mathrm{R}\left(\mathrm{H}_{\mathrm{yx}}\right)$ & $\Delta \mathrm{R}\left(\mathrm{H}_{\mathrm{yv}}\right)$ & $\Delta \mathrm{I}\left(\mathrm{H}_{\mathrm{xx}}\right)$ & $\Delta \mathrm{I}\left(\mathrm{H}_{\mathrm{xy}}\right)$ & $\Delta \mathrm{I}\left(\mathrm{H}_{\mathrm{yx}}\right)$ & $\Delta \mathrm{I}\left(\mathrm{H}_{\mathrm{yv}}\right)$ \\
\hline 9.8 & 306.9 & -71.4 & -85.3 & 411.8 & 11.6 & -5.4 & -16.1 & 5.1 & -1.2 & -1.1 & -5.2 & -5.0 & -0.7 & -2.3 & -5.4 & -15.4 \\
\hline 19.5 & 305.2 & -73.0 & -69.2 & 256.9 & 24.7 & -10.0 & -20.5 & 55.3 & -0.5 & -1.5 & -7.1 & -19.9 & -0.5 & -1.2 & -17.3 & -11.8 \\
\hline 29.3 & 308.7 & -70.5 & -76.8 & 404.6 & 34.8 & -10.1 & -10.4 & -8.7 & -0.6 & -1.0 & -9.3 & -5.8 & -0.2 & -0.6 & -3.8 & -8.2 \\
\hline 39.1 & 311.9 & -71.4 & -61.4 & 361.0 & 45.8 & -10.9 & -9.1 & 32.0 & -0.4 & -0.8 & -6.6 & -3.3 & -0.3 & -0.8 & -11.4 & -4.2 \\
\hline 48.8 & 315.9 & -71.9 & -70.8 & 356.6 & 57.9 & -13.2 & -8.6 & 52.1 & -0.3 & -0.8 & -1.5 & -2.9 & -0.1 & -0.5 & -0.8 & -2.0 \\
\hline 58.6 & 317.9 & -71.7 & -72.8 & 374.7 & 67.9 & -12.9 & -23.7 & 59.5 & -0.7 & -0.5 & -8.6 & -3.6 & -0.5 & -0.5 & -1.1 & -2.4 \\
\hline 68.4 & 318.7 & -71.8 & -77.7 & 363.7 & 77.4 & -15.3 & -16.7 & 46.8 & -0.4 & -0.5 & -2.5 & -2.4 & -0.3 & -0.4 & -5.3 & -2.8 \\
\hline 78.1 & 326.4 & -68.0 & -68.9 & 355.4 & 92.9 & -14.5 & -14.9 & 62.9 & -0.1 & -0.4 & -1.7 & -2.3 & -0.2 & -0.3 & -1.9 & -2.0 \\
\hline 87.9 & 326.7 & -71.9 & -78.4 & 378.5 & 96.4 & -18.1 & -27.5 & 91.5 & -0.1 & -0.2 & -0.3 & -1.7 & -0.2 & -0.4 & -2.1 & -1.5 \\
\hline 97.7 & 329.6 & -69.7 & -74.1 & 366.1 & 103.2 & -18.4 & -27.4 & 94.3 & -0.3 & -0.4 & -2.4 & -2.8 & -0.3 & -0.3 & -1.1 & -1.8 \\
\hline 107.4 & 332.6 & -68.5 & -79.2 & 380.1 & 111.8 & -19.5 & -29.6 & 107.5 & -0.2 & -0.3 & -2.0 & -2.8 & -0.3 & -0.3 & -2.8 & -1.6 \\
\hline 117.2 & 336.8 & -66.5 & -78.5 & 375.1 & 119.2 & -20.6 & -35.3 & 119.9 & -0.1 & -0.3 & -4.1 & -2.9 & -0.3 & -0.3 & -1.5 & -1.8 \\
\hline 127.0 & 339.6 & -63.1 & -73.9 & 372.8 & 127.8 & -20.6 & -34.7 & 125.1 & -0.3 & -0.4 & -1.3 & -2.4 & -0.4 & -0.5 & -2.5 & -1.6 \\
\hline 136.7 & 341.5 & -58.6 & -74.9 & 384.9 & 136.9 & -23.1 & -33.4 & 129.6 & -0.4 & -0.5 & -1.6 & -3.4 & -0.6 & -0.4 & -2.2 & -1.9 \\
\hline 146.5 & 343.3 & -53.4 & -67.9 & 392.3 & 143.4 & -25.0 & -30.2 & 132.2 & -1.1 & -1.1 & -1.3 & -3.3 & -1.4 & -1.4 & -2.1 & -2.0 \\
\hline 156.3 & 343.3 & -49.0 & -60.1 & 370.3 & 153.5 & -26.2 & -32.6 & 131.9 & -1.1 & -0.9 & -4.1 & -2.5 & -1.0 & -0.8 & -3.1 & -3.1 \\
\hline 166.0 & 347.2 & -53.6 & -75.5 & 401.6 & 160.8 & -30.3 & -35.3 & 162.0 & -0.6 & -0.5 & -2.6 & -2.0 & -0.6 & -0.4 & -1.5 & -2.4 \\
\hline 175.8 & 347.2 & -48.3 & -78.0 & 402.8 & 168.7 & -32.7 & -40.9 & 169.0 & -0.4 & -0.3 & -2.7 & -3.2 & -0.5 & -0.4 & -4.5 & -2.2 \\
\hline 185.5 & 348.6 & -44.5 & $\begin{array}{l}-69.1 \\
\end{array}$ & 402.1 & 180.8 & -33.2 & -32.2 & 173.6 & -0.2 & -0.4 & -3.3 & -2.7 & -0.3 & -0.3 & -0.6 & -1.6 \\
\hline 195.3 & 349.5 & -39.0 & -62.6 & 387.7 & 192.1 & -35.8 & -37.1 & 184.5 & -0.2 & -0.4 & -4.3 & -2.8 & -0.3 & -0.3 & -5.1 & -2.0 \\
\hline 205.1 & 349.4 & -33.8 & -61.8 & 399.7 & 200.0 & -37.9 & -37.6 & 211.0 & -0.4 & -0.3 & -2.4 & -2.7 & -0.2 & -0.3 & -2.5 & -2.7 \\
\hline 214.8 & 357.1 & -28.0 & -56.6 & 411.0 & 213.0 & -40.1 & -50.4 & 209.8 & -0.1 & -0.3 & -4.9 & -3.1 & -0.3 & -0.4 & -5.5 & -2.5 \\
\hline 224.6 & 357.5 & -16.4 & -55.2 & 357.9 & 223.1 & -44.9 & -45.2 & 220.2 & -0.3 & -0.3 & -2.1 & -3.5 & -0.4 & -0.3 & -2.5 & -3.4 \\
\hline 234.4 & 364.8 & -28.0 & -57.1 & 419.1 & 234.7 & -55.0 & -47.2 & 239.1 & -0.4 & -0.3 & -1.9 & -2.6 & -0.2 & -0.4 & -1.4 & -1.2 \\
\hline 244.1 & 364.7 & -22.8 & -52.9 & 420.8 & 247.9 & -55.4 & -41.3 & 247.8 & -0.2 & -0.3 & -3.4 & -3.1 & -0.3 & -0.3 & -2.9 & -2.7 \\
\hline 253.9 & 366.6 & -17.9 & -51.5 & 440.8 & 259.6 & -55.1 & -34.0 & 262.0 & -0.3 & -0.3 & -2.4 & -2.3 & -0.3 & -0.2 & -3.0 & -3.6 \\
\hline 263.7 & 370.4 & -11.0 & -48.4 & 437.0 & 275.0 & -57.9 & -32.2 & 262.5 & -0.3 & -0.3 & -1.0 & -3.1 & -0.2 & -0.3 & -4.1 & -3.4 \\
\hline 273.4 & 376.3 & -2.5 & -45.8 & 378.7 & 290.2 & -52.9 & -36.8 & 247.7 & -0.3 & -0.3 & -2.9 & -2.8 & -0.4 & -0.4 & -3.7 & -2.4 \\
\hline 283.2 & 383.5 & -16.5 & -45.7 & 451.8 & 307.3 & -67.5 & -32.7 & 294.8 & -0.2 & -0.2 & -2.7 & -2.8 & -0.3 & -0.3 & -3.3 & -3.5 \\
\hline 293.0 & 391.0 & 2.8 & -28.4 & 414.2 & 318.2 & -54.2 & -18.4 & 295.8 & -0.4 & -0.3 & -3.1 & -5.1 & -0.4 & -0.3 & -5.0 & -4.1 \\
\hline 302.7 & 392.0 & 24.2 & -28.5 & 390.3 & 339.3 & -43.8 & -11.2 & 321.0 & -0.4 & -0.4 & -4.1 & -5.2 & -0.7 & -0.3 & -3.9 & -6.8 \\
\hline 312.5 & 400.8 & -10.1 & -38.8 & 556.6 & 358.3 & -95.2 & -1.9 & 327.5 & -0.4 & -0.4 & -4.5 & -3.8 & -0.7 & -0.5 & -4.5 & -9.4 \\
\hline 322.3 & 407.6 & 56.8 & -7.9 & 404.1 & 379.1 & -34.4 & 15.7 & 370.6 & -0.4 & -0.5 & -3.3 & -6.2 & -0.6 & -0.3 & -5.0 & -11.6 \\
\hline 332.0 & 413.8 & -2.4 & 35.0 & 617.8 & 395.5 & -125.7 & 57.6 & 350.5 & -0.2 & -0.6 & -4.3 & -9.6 & -0.4 & -0.5 & -3.2 & -9.4 \\
\hline 341.8 & 457.8 & 34.4 & 58.3 & 581.1 & 445.4 & -76.8 & 87.6 & 343.1 & -0.6 & -0.4 & -3.0 & -10.0 & -0.6 & -0.3 & -5.9 & -7.7 \\
\hline
\end{tabular}


Table 46: Dynamic Stiffness Real and Imaginary Parts at $9000 \mathrm{rpm}$ and 3134 kPa (MN/m)

\begin{tabular}{|c|c|c|c|c|c|c|c|c|c|c|c|c|c|c|c|c|}
\hline $\mathrm{f}(\mathrm{Hz})$ & $\mathrm{R}\left(\mathrm{H}_{\mathrm{xx}}\right)$ & $\mathrm{R}\left(\mathrm{H}_{\mathrm{xy}}\right)$ & $\mathrm{R}\left(\mathrm{H}_{\mathrm{yx}}\right)$ & $\mathrm{R}\left(\mathrm{H}_{\mathrm{yv}}\right)$ & $\mathrm{I}\left(\mathrm{H}_{\mathrm{xx}}\right)$ & $\mathrm{I}\left(\mathrm{H}_{\mathrm{xy}}\right)$ & $\mathrm{I}\left(\mathrm{H}_{\mathrm{yx}}\right)$ & $\mathrm{I}\left(\mathrm{H}_{\mathrm{yv}}\right)$ & $\Delta \mathrm{R}\left(\mathrm{H}_{\mathrm{xx}}\right)$ & $\Delta \mathrm{R}\left(\mathrm{H}_{\mathrm{xy}}\right)$ & $\Delta \mathrm{R}\left(\mathrm{H}_{\mathrm{yx}}\right)$ & $\Delta \mathrm{R}\left(\mathrm{H}_{\mathrm{yv}}\right)$ & $\Delta \mathrm{I}\left(\mathrm{H}_{\mathrm{xx}}\right)$ & $\Delta \mathrm{I}\left(\mathrm{H}_{\mathrm{xy}}\right)$ & $\Delta \mathrm{I}\left(\mathrm{H}_{\mathrm{yx}}\right)$ & $\Delta \mathrm{I}\left(\mathrm{H}_{\mathrm{yv}}\right)$ \\
\hline 9.8 & 331.6 & -75.3 & -95.8 & 461.0 & 11.2 & -6.0 & -40.3 & 76.2 & -1.6 & -1.4 & -3.1 & -6.5 & -1.6 & -4.2 & -7.8 & -10.1 \\
\hline 19.5 & 327.8 & -74.0 & -120.0 & 402.4 & 21.1 & -10.3 & -38.9 & 40.3 & -0.5 & -0.7 & -4.1 & -4.9 & -0.4 & -1.6 & -4.5 & -5.8 \\
\hline 29.3 & 332.6 & -74.1 & -67.3 & 420.1 & 30.0 & -8.7 & -8.8 & 21.9 & -0.7 & -1.0 & -1.8 & -2.4 & -0.4 & -0.8 & -1.3 & -2.4 \\
\hline 39.1 & 335.3 & -75.9 & -75.2 & 411.5 & 42.8 & -11.6 & 21.9 & 18.9 & -0.5 & -0.9 & -2.3 & -2.7 & -0.6 & -0.7 & -5.4 & -2.6 \\
\hline 48.8 & 338.7 & -74.9 & -87.7 & 409.3 & 53.6 & -13.6 & -9.3 & 39.7 & -0.2 & -0.6 & -2.5 & -2.1 & -0.3 & -0.8 & -1.3 & -1.7 \\
\hline 58.6 & 343.0 & -75.1 & -77.8 & 414.8 & 61.6 & -14.5 & -25.5 & 52.7 & -0.3 & -0.4 & -2.3 & -2.0 & -0.3 & -0.8 & -1.5 & -1.7 \\
\hline 68.4 & 340.0 & -74.4 & -84.5 & 410.4 & 70.4 & -17.8 & -15.8 & 46.6 & -0.3 & -0.4 & -1.4 & -1.6 & -0.2 & -0.3 & -0.8 & -1.2 \\
\hline 78.1 & 339.6 & -72.6 & -93.0 & 398.9 & 90.6 & -15.3 & -3.3 & 58.8 & -0.2 & -0.4 & -1.9 & -2.0 & -0.1 & -0.4 & -1.8 & -1.3 \\
\hline 87.9 & 348.6 & -75.3 & -80.8 & 421.0 & 88.0 & -20.9 & -26.5 & 84.5 & -0.3 & -0.5 & -0.3 & -1.7 & -0.3 & -0.2 & -1.7 & -1.2 \\
\hline 97.7 & 352.4 & -73.1 & -74.8 & 408.9 & 95.9 & -21.7 & -21.5 & 78.5 & -0.2 & -0.4 & -0.4 & -2.0 & -0.1 & -0.3 & -2.7 & -1.3 \\
\hline 107.4 & 353.6 & -72.0 & -75.8 & 417.6 & 103.3 & -22.7 & -30.1 & 96.7 & -0.2 & -0.3 & -1.3 & -1.8 & -0.2 & -0.3 & -2.0 & -1.2 \\
\hline 117.2 & 358.0 & -70.7 & -82.5 & 420.7 & 108.3 & -23.9 & -39.3 & 101.2 & -0.4 & -0.3 & -0.8 & -1.9 & -0.3 & -0.4 & -1.8 & -1.2 \\
\hline 127.0 & 360.6 & -67.3 & -77.0 & 415.8 & 117.1 & -24.5 & -43.9 & 116.7 & -0.4 & -0.6 & -1.6 & -1.9 & -0.3 & -0.3 & -1.5 & -1.3 \\
\hline 136.7 & 362.2 & -62.5 & -72.7 & 422.3 & 126.3 & -27.2 & -37.7 & 121.3 & -0.6 & -0.4 & -1.1 & -1.8 & -0.2 & -0.5 & -1.1 & -1.0 \\
\hline 146.5 & 362.4 & -55.2 & -59.6 & 415.5 & 133.1 & -28.9 & -35.8 & 124.1 & -1.4 & -1.4 & -1.2 & -2.2 & -0.6 & -1.3 & -0.6 & -2.5 \\
\hline 156.3 & 363.2 & -56.3 & -60.4 & 416.5 & 141.0 & -31.9 & -39.8 & 110.2 & -1.1 & -1.2 & -2.2 & -2.5 & -1.0 & -0.9 & -0.8 & -2.1 \\
\hline 166.0 & 366.3 & -60.0 & -77.6 & 433.4 & 147.6 & -35.1 & -50.3 & 152.5 & -0.2 & -0.5 & -1.0 & -2.6 & -0.6 & -0.7 & -0.8 & -2.3 \\
\hline 175.8 & 366.2 & -55.0 & -68.8 & 435.9 & 156.0 & -38.3 & -52.2 & 158.5 & -0.4 & -0.4 & -1.6 & -1.6 & -0.6 & -0.4 & -1.8 & -1.6 \\
\hline 185.5 & 368.3 & -51.5 & -72.0 & 441.2 & 166.8 & -38.7 & -46.8 & 155.9 & -0.2 & -0.5 & -0.9 & -1.7 & -0.4 & -0.4 & -1.7 & -1.1 \\
\hline 195.3 & 368.5 & -46.2 & -66.3 & 431.4 & 177.3 & -41.4 & -44.3 & 167.1 & -0.2 & -0.3 & -2.4 & $\begin{array}{l}-1.8 \\
\end{array}$ & -0.4 & -0.4 & -0.7 & $\begin{array}{l}-1.4 \\
\end{array}$ \\
\hline 205.1 & 367.5 & -43.0 & -63.8 & 446.1 & 184.4 & -44.8 & -41.4 & 186.4 & -0.5 & -0.3 & -0.9 & $\begin{array}{l}-1.7 \\
\end{array}$ & -0.3 & -0.3 & -2.5 & -1.2 \\
\hline 214.8 & 375.4 & -35.7 & -55.5 & 449.1 & 194.9 & -44.8 & -58.9 & 185.1 & -0.2 & -0.3 & -0.9 & -1.6 & -0.5 & -0.4 & -4.9 & -1.5 \\
\hline 224.6 & 375.3 & -34.1 & -55.6 & 415.8 & 203.9 & -49.8 & -44.7 & 182.6 & -0.3 & -0.3 & -2.2 & -2.2 & -0.4 & -0.3 & -2.9 & -1.3 \\
\hline 234.4 & 381.5 & -41.2 & -55.9 & 473.7 & 214.6 & -59.6 & -45.6 & 212.6 & -0.4 & -0.3 & -1.7 & -2.3 & -0.2 & -0.4 & -2.3 & -1.1 \\
\hline 244.1 & 381.1 & -34.0 & -53.1 & 470.5 & 227.3 & -60.6 & -45.5 & 220.1 & -0.2 & -0.2 & -0.4 & -1.9 & -0.1 & -0.4 & -2.2 & -1.2 \\
\hline 253.9 & 381.8 & -30.4 & -44.4 & 483.0 & 237.7 & -60.1 & -37.0 & 227.4 & -0.2 & -0.3 & -3.1 & -1.9 & -0.5 & -0.4 & -2.6 & $\begin{array}{l}-1.7 \\
\end{array}$ \\
\hline 263.7 & 385.3 & -25.2 & -37.3 & 478.6 & 250.4 & -60.0 & -44.6 & 220.7 & -0.3 & -0.2 & -2.2 & -2.0 & -0.2 & -0.3 & -2.5 & -1.5 \\
\hline 273.4 & 390.2 & -15.9 & -38.2 & 431.4 & 263.9 & -58.6 & -42.1 & 210.7 & -0.2 & -0.2 & -1.6 & -2.0 & -0.3 & -0.3 & -2.6 & -1.4 \\
\hline 283.2 & 397.1 & -27.7 & -34.0 & 489.9 & 279.1 & -69.9 & -43.4 & 247.2 & -0.2 & -0.3 & -2.2 & -1.8 & -0.3 & -0.3 & -2.3 & -1.3 \\
\hline 293.0 & 403.8 & -12.9 & -26.4 & 470.3 & 287.9 & -58.2 & -36.2 & 250.2 & -0.3 & -0.3 & -1.2 & -3.2 & -0.3 & -0.3 & -1.2 & -1.1 \\
\hline 302.7 & 403.2 & 4.4 & -15.7 & 461.0 & 305.8 & -56.1 & -43.4 & 273.7 & -0.4 & -0.6 & -1.9 & -2.1 & -0.8 & -0.8 & -3.3 & -1.7 \\
\hline 312.5 & 406.9 & 22.6 & -19.7 & 602.6 & 315.5 & -154.5 & -33.2 & 415.6 & -0.5 & -2.5 & -1.8 & -8.8 & -0.8 & -2.7 & -2.3 & -2.1 \\
\hline 322.3 & 417.8 & 22.4 & 1.1 & 472.9 & 332.7 & -47.8 & -14.3 & 287.9 & -0.4 & -0.5 & -1.9 & -2.9 & -0.4 & -0.2 & -2.3 & -3.8 \\
\hline 332.0 & 450.3 & 28.1 & -7.9 & 630.3 & 337.1 & -219.7 & 33.9 & 474.5 & -0.6 & -0.3 & -1.7 & -11.7 & -0.3 & -0.9 & -2.5 & -5.2 \\
\hline 341.8 & 442.3 & 2.2 & 34.6 & 631.5 & 386.1 & -98.4 & 7.8 & 309.4 & -0.4 & -0.4 & -4.0 & -4.6 & -0.4 & -0.5 & -4.2 & -1.6 \\
\hline
\end{tabular}


Table 47: Dynamic Stiffness Real and Imaginary Parts at $10800 \mathrm{rpm}$ and $0 \mathrm{kPa}(\mathrm{MN} / \mathrm{m})$

\begin{tabular}{|c|c|c|c|c|c|c|c|c|c|c|c|c|c|c|c|c|}
\hline $\mathrm{f}(\mathrm{Hz})$ & $\mathrm{R}\left(\mathrm{H}_{\mathrm{xx}}\right)$ & $\mathrm{R}\left(\mathrm{H}_{\mathrm{xy}}\right)$ & $\mathrm{R}\left(\mathrm{H}_{\mathrm{yx}}\right)$ & $\mathrm{R}\left(\mathrm{H}_{\mathrm{yv}}\right)$ & $\mathrm{I}\left(\mathrm{H}_{\mathrm{xx}}\right)$ & $\mathrm{I}\left(\mathrm{H}_{\mathrm{xy}}\right)$ & $\mathrm{I}\left(\mathrm{H}_{\mathrm{yx}}\right)$ & $\mathrm{I}\left(\mathrm{H}_{\mathrm{yv}}\right)$ & $\Delta \mathrm{R}\left(\mathrm{H}_{\mathrm{xx}}\right)$ & $\Delta \mathrm{R}\left(\mathrm{H}_{\mathrm{xy}}\right)$ & $\Delta \mathrm{R}\left(\mathrm{H}_{\mathrm{yx}}\right)$ & $\Delta \mathrm{R}\left(\mathrm{H}_{\mathrm{vv}}\right)$ & $\Delta \mathrm{I}\left(\mathrm{H}_{\mathrm{xx}}\right)$ & $\Delta \mathrm{I}\left(\mathrm{H}_{\mathrm{xv}}\right)$ & $\Delta \mathrm{I}\left(\mathrm{H}_{\mathrm{yx}}\right)$ & $\Delta \mathrm{I}\left(\mathrm{H}_{\mathrm{yv}}\right)$ \\
\hline 9.8 & 239.1 & -57.9 & -75.2 & 244.3 & 0.3 & 32.5 & 11.8 & -37.9 & -0.6 & -1.1 & -3.0 & -5.9 & -1.5 & -3.7 & -1.6 & -5.0 \\
\hline 19.5 & 248.8 & -64.8 & -74.6 & 222.1 & 33.2 & 3.1 & -5.5 & 26.9 & -1.1 & -3.1 & -1.3 & -6.5 & -0.5 & -1.2 & -2.1 & -4.5 \\
\hline 29.3 & 249.1 & -62.2 & -72.4 & 239.4 & 44.7 & 17.8 & 1.4 & 15.3 & -0.4 & -2.0 & -0.6 & -4.5 & -1.0 & -1.1 & -1.6 & -3.4 \\
\hline 39.1 & 248.9 & -67.6 & -67.2 & 207.1 & 60.0 & 3.2 & -4.4 & 52.7 & -0.3 & -1.6 & -0.9 & -3.8 & -0.3 & -1.2 & -0.9 & -2.7 \\
\hline 48.8 & 258.3 & -75.7 & -80.4 & 231.3 & 73.2 & 2.2 & 0.6 & 77.1 & -0.5 & -0.9 & -0.5 & -3.7 & -0.3 & -1.0 & -1.4 & -2.5 \\
\hline 58.6 & 269.8 & -72.4 & -66.9 & 255.0 & 86.3 & -3.2 & -9.3 & 103.7 & -0.6 & -1.2 & -0.8 & -4.3 & -0.6 & -0.7 & -1.1 & -2.4 \\
\hline 68.4 & 270.8 & -66.4 & -72.9 & 256.8 & 102.3 & -4.0 & -10.4 & 106.4 & -0.4 & -0.9 & -0.8 & -3.5 & -0.4 & -0.5 & -0.9 & -2.2 \\
\hline 78.1 & 276.1 & -65.8 & -75.0 & 263.4 & 117.4 & -7.1 & -13.4 & 118.4 & -0.7 & -1.0 & -0.7 & -4.0 & -0.3 & -0.5 & -0.9 & -2.0 \\
\hline 87.9 & 280.4 & -67.8 & -70.8 & 288.7 & 123.6 & -4.1 & -3.3 & 131.3 & -0.2 & -1.1 & -1.2 & -4.3 & -0.3 & -0.6 & -0.3 & -2.5 \\
\hline 97.7 & 285.1 & -58.7 & -69.5 & 273.9 & 137.4 & -8.7 & -18.8 & 139.2 & -0.3 & -1.3 & -1.2 & -3.8 & -0.3 & -0.4 & -0.9 & -1.8 \\
\hline 107.4 & 286.8 & -53.8 & -60.3 & 264.9 & 144.3 & -5.7 & -8.3 & 155.5 & -0.3 & -0.8 & -1.1 & -4.0 & -0.3 & -0.8 & -0.8 & -1.8 \\
\hline 117.2 & 297.0 & -51.4 & -62.8 & 296.0 & 155.6 & -10.0 & -13.0 & 169.5 & -0.4 & -0.9 & -1.1 & -3.8 & -0.1 & -0.3 & -1.2 & -2.1 \\
\hline 127.0 & 304.2 & -48.6 & -56.6 & 307.7 & 172.9 & -15.3 & $\begin{array}{l}-7.7 \\
\end{array}$ & 157.7 & -0.3 & -1.1 & -0.7 & -4.2 & -0.3 & -0.4 & -0.9 & -3.0 \\
\hline 136.7 & 313.8 & -57.5 & -50.3 & 303.8 & 183.6 & -13.5 & -6.9 & 150.0 & -0.3 & -1.1 & -0.6 & -4.5 & -0.6 & -0.5 & -0.7 & -2.3 \\
\hline 146.5 & 312.1 & -47.8 & -46.3 & 311.9 & 185.7 & -8.3 & -12.7 & 172.0 & -0.3 & -0.8 & -0.9 & -3.9 & -0.2 & -0.6 & -0.7 & -2.2 \\
\hline 156.3 & 316.1 & -41.3 & -42.7 & 264.5 & 203.5 & -13.9 & -19.7 & 269.9 & -0.2 & -1.0 & -2.1 & -3.6 & -0.3 & -0.5 & -0.5 & -1.9 \\
\hline 166.0 & 321.9 & -29.0 & -42.5 & 326.5 & 202.5 & -11.4 & -19.5 & 222.2 & -0.6 & -1.0 & -1.0 & -4.8 & -0.6 & -0.5 & -0.7 & -2.1 \\
\hline 175.8 & 324.0 & -31.4 & -49.0 & 377.1 & 218.9 & -19.3 & -17.2 & 254.3 & -1.0 & -1.5 & -1.8 & -4.2 & -1.9 & -0.9 & -2.0 & -3.5 \\
\hline 185.5 & 319.4 & -18.3 & -41.0 & 349.5 & 238.4 & -13.0 & -14.3 & 222.6 & -0.7 & -2.1 & -1.4 & -5.8 & -2.0 & -1.7 & -1.4 & -3.9 \\
\hline 195.3 & 322.8 & -12.6 & -28.0 & 384.4 & 235.3 & 6.3 & $\begin{array}{l}-19.1 \\
\end{array}$ & 296.6 & -0.6 & -1.6 & -1.9 & -4.5 & -0.6 & -0.8 & -2.1 & -2.5 \\
\hline 205.1 & 348.0 & 3.1 & -7.2 & 375.6 & 262.7 & -32.4 & -17.4 & 276.0 & -1.4 & -1.6 & -0.5 & -4.2 & -0.5 & -0.5 & -1.5 & -3.2 \\
\hline 214.8 & 359.0 & -7.4 & -19.1 & 365.6 & 286.0 & 16.3 & -22.8 & 317.7 & -0.7 & -1.0 & -0.7 & -3.9 & -0.6 & -0.7 & -3.4 & -3.9 \\
\hline 224.6 & 367.3 & 1.4 & -35.1 & 350.3 & 297.6 & 4.7 & -18.8 & 323.3 & -0.5 & -1.9 & -2.8 & -3.7 & -1.5 & -0.5 & -2.0 & -3.4 \\
\hline 234.4 & 466.0 & 10.4 & 115.4 & 427.6 & 312.5 & -91.8 & 40.3 & 259.1 & -1.1 & -3.4 & -4.2 & -3.7 & -1.7 & -1.4 & -1.2 & -3.6 \\
\hline 244.1 & 484.6 & 9.0 & 143.8 & 385.5 & 298.1 & -68.9 & -30.5 & 309.1 & -1.0 & -3.8 & -3.1 & -4.1 & -1.3 & -2.6 & -1.3 & -3.2 \\
\hline 253.9 & 469.6 & 137.7 & 169.7 & 562.0 & 260.8 & -75.7 & -102.4 & 332.2 & -3.0 & -3.3 & -4.8 & -5.6 & -3.2 & -2.7 & -4.2 & -4.5 \\
\hline 263.7 & 480.3 & 92.2 & 242.9 & 505.1 & 321.6 & -128.2 & -115.0 & 267.4 & -2.1 & -1.8 & -5.8 & -5.4 & -2.5 & -2.1 & -5.3 & -6.0 \\
\hline 273.4 & 715.6 & 224.3 & 344.8 & 600.8 & 338.2 & -17.4 & -113.4 & 504.4 & -5.3 & -6.0 & -11.2 & $\begin{array}{l}-9.1 \\
\end{array}$ & -11.6 & $\begin{array}{l}-7.2 \\
\end{array}$ & -13.0 & $\begin{array}{l}-7.1 \\
\end{array}$ \\
\hline 283.2 & 276.8 & 67.8 & -50.0 & 578.6 & 192.3 & -500.2 & -428.2 & -143.6 & -3.6 & -6.4 & -3.2 & -11.7 & -5.7 & -10.8 & -6.7 & -11.2 \\
\hline 293.0 & 405.8 & 89.3 & 59.8 & 421.8 & 392.3 & -209.9 & -339.6 & 163.1 & -3.3 & -3.7 & -7.6 & -4.6 & -2.3 & -1.7 & -2.2 & -5.5 \\
\hline 302.7 & 403.6 & -164.4 & -107.7 & 108.4 & 421.3 & -128.9 & -14.5 & 216.5 & -3.5 & -3.3 & -3.8 & -14.5 & -2.2 & -7.8 & -6.8 & -7.2 \\
\hline 312.5 & 576.9 & -69.2 & -54.7 & 378.6 & 407.4 & -205.5 & 84.2 & 209.5 & -2.4 & -1.8 & -3.2 & -6.7 & -2.2 & -1.8 & -8.3 & -4.0 \\
\hline 322.3 & 591.6 & 22.6 & 4.0 & 441.4 & 497.0 & -235.2 & -87.0 & 231.4 & -4.3 & -3.2 & -10.3 & -5.6 & -3.8 & -1.8 & -5.3 & -5.9 \\
\hline 332.0 & 396.1 & 50.6 & -45.2 & 477.8 & 546.2 & -166.3 & -160.9 & 158.9 & -2.8 & -3.7 & -3.6 & -4.9 & -1.3 & -2.4 & -3.2 & -5.4 \\
\hline 341.8 & 504.0 & -44.5 & -25.2 & 449.8 & 437.0 & -120.1 & -53.4 & 182.0 & -2.3 & -4.5 & -4.2 & -6.4 & -2.0 & -2.0 & -4.2 & -3.6 \\
\hline
\end{tabular}


Table 48: Dynamic Stiffness Real and Imaginary Parts at $10800 \mathrm{rpm}$ and $783 \mathrm{kPa}(\mathrm{MN} / \mathrm{m})$

\begin{tabular}{|c|c|c|c|c|c|c|c|c|c|c|c|c|c|c|c|c|}
\hline $\mathrm{f}(\mathrm{Hz})$ & $\mathrm{R}\left(\mathrm{H}_{\mathrm{xx}}\right)$ & $\mathrm{R}\left(\mathrm{H}_{\mathrm{xv}}\right)$ & $\mathrm{R}\left(\mathrm{H}_{\mathrm{yx}}\right)$ & $\mathrm{R}\left(\mathrm{H}_{\mathrm{yv}}\right)$ & $\mathrm{I}\left(\mathrm{H}_{\mathrm{xx}}\right)$ & $\mathrm{I}\left(\mathrm{H}_{\mathrm{xy}}\right)$ & $\mathrm{I}\left(\mathrm{H}_{\mathrm{yx}}\right)$ & $\mathrm{I}\left(\mathrm{H}_{\mathrm{yv}}\right)$ & $\Delta \mathrm{R}\left(\mathrm{H}_{\mathrm{xx}}\right)$ & $\Delta \mathrm{R}\left(\mathrm{H}_{\mathrm{xy}}\right)$ & $\Delta \mathrm{R}\left(\mathrm{H}_{\mathrm{yx}}\right)$ & $\Delta \mathrm{R}\left(\mathrm{H}_{\mathrm{yv}}\right)$ & $\Delta \mathrm{I}\left(\mathrm{H}_{\mathrm{xx}}\right)$ & $\Delta \mathrm{I}\left(\mathrm{H}_{\mathrm{xv}}\right)$ & $\Delta \mathrm{I}\left(\mathrm{H}_{\mathrm{yx}}\right)$ & $\Delta \mathrm{I}\left(\mathrm{H}_{\mathrm{yv}}\right)$ \\
\hline 9.8 & 263.9 & -67.2 & -69.7 & 272.8 & 14.3 & -1.0 & -19.2 & 61.4 & -1.0 & -2.4 & -3.6 & -7.1 & -1.2 & -1.9 & -1.4 & -4.7 \\
\hline 19.5 & 267.4 & -66.8 & -62.1 & 250.2 & 31.4 & -5.3 & 22.7 & 9.2 & -0.6 & -1.7 & -5.9 & -7.1 & -1.0 & -1.7 & -3.7 & -2.2 \\
\hline 29.3 & 268.1 & -69.9 & -82.9 & 281.3 & 43.7 & -9.8 & -7.2 & 37.2 & -1.0 & -1.0 & -2.8 & -3.2 & -0.8 & -1.1 & -2.4 & -3.2 \\
\hline 39.1 & 271.6 & -70.7 & -75.8 & 268.6 & 54.1 & -8.1 & -12.2 & 66.9 & -0.7 & -1.1 & -2.3 & -2.8 & -0.3 & -0.4 & -2.5 & -2.1 \\
\hline 48.8 & 277.9 & -70.8 & -68.7 & 271.0 & 68.3 & -10.8 & -3.9 & 77.4 & -0.4 & -0.5 & -0.8 & -2.1 & -0.5 & -0.6 & -1.2 & -1.7 \\
\hline 58.6 & 279.9 & -69.8 & -81.6 & 281.7 & 81.3 & -9.2 & -6.6 & 89.2 & -0.3 & -0.3 & -1.9 & -2.0 & -0.5 & -1.1 & -1.6 & -1.6 \\
\hline 68.4 & 284.6 & -71.7 & -75.2 & 280.7 & 100.9 & -8.2 & -1.0 & 93.3 & -0.6 & -1.1 & -0.5 & -1.8 & -0.5 & -0.9 & -0.9 & -2.1 \\
\hline 78.1 & 291.7 & -67.2 & -68.6 & 279.7 & 106.3 & -10.5 & -8.6 & 98.8 & -0.4 & -0.6 & -0.5 & -1.8 & -0.4 & -0.5 & -1.3 & -1.3 \\
\hline 87.9 & 294.2 & -69.0 & -71.2 & 306.5 & 117.2 & -12.0 & -10.0 & 125.7 & -0.3 & -0.7 & -1.3 & -1.6 & -0.3 & -0.4 & -0.8 & -1.2 \\
\hline 97.7 & 299.9 & -67.0 & -66.9 & 301.4 & 126.6 & -12.5 & -13.5 & 128.8 & -0.5 & -0.7 & -1.3 & -1.7 & -0.2 & -0.3 & -1.7 & -1.4 \\
\hline 107.4 & 302.7 & -65.1 & -75.1 & 311.3 & 136.7 & -12.8 & -13.7 & 146.0 & -0.3 & -0.5 & -1.1 & -1.6 & -0.5 & -0.3 & -1.2 & -1.2 \\
\hline 117.2 & 309.1 & -62.7 & -72.6 & 319.7 & 144.7 & -13.3 & -18.1 & 150.8 & -0.4 & -0.5 & -1.6 & -2.4 & -0.4 & -0.4 & -2.4 & -1.7 \\
\hline 127.0 & 315.2 & -59.4 & -66.1 & 316.6 & 155.0 & -13.1 & -19.1 & 163.3 & -0.3 & -0.5 & -0.8 & $\begin{array}{l}-1.9 \\
\end{array}$ & -0.2 & -0.2 & $\begin{array}{l}-1.6 \\
\end{array}$ & $\begin{array}{l}-1.3 \\
\end{array}$ \\
\hline 136.7 & 318.9 & -55.5 & -60.8 & 330.4 & 166.7 & -14.8 & -18.6 & 166.1 & -0.2 & -0.5 & -1.9 & -1.9 & -0.3 & -0.5 & -1.0 & -1.4 \\
\hline 146.5 & 322.1 & -50.5 & -59.5 & 329.0 & 174.8 & -15.7 & -13.8 & 166.7 & -0.3 & -0.3 & -0.6 & -2.3 & -0.2 & -0.6 & -1.5 & -1.6 \\
\hline 156.3 & 327.3 & -41.2 & -51.0 & 304.9 & 181.5 & -15.2 & -21.5 & 165.1 & -0.1 & -0.5 & -2.6 & -1.8 & -0.4 & -0.4 & -1.5 & -1.2 \\
\hline 166.0 & 331.0 & -49.1 & -56.8 & 345.5 & 193.8 & -21.1 & -20.9 & 198.9 & -0.5 & -0.6 & -0.6 & -2.1 & -0.7 & -0.7 & -2.2 & -1.4 \\
\hline 175.8 & 331.8 & -43.6 & -53.0 & 345.1 & 204.2 & -23.1 & -13.9 & 199.0 & -0.8 & -0.7 & -1.9 & -2.7 & -1.0 & -2.1 & -1.7 & -2.1 \\
\hline 185.5 & 334.2 & -40.7 & -45.0 & 353.3 & 214.8 & -19.2 & -15.1 & 206.4 & -0.9 & -3.0 & -2.4 & -2.1 & -1.2 & -1.1 & -2.4 & -4.1 \\
\hline 195.3 & 338.6 & -35.4 & -43.0 & 343.4 & 229.0 & -18.5 & -14.2 & 218.3 & -0.5 & -0.7 & -1.4 & -2.6 & -0.5 & -0.9 & -1.2 & -1.1 \\
\hline 205.1 & 340.2 & -32.2 & -44.7 & 354.5 & 236.9 & -17.8 & -19.8 & 236.7 & -0.4 & -0.3 & -1.0 & -1.7 & -0.4 & -0.5 & -1.2 & -1.5 \\
\hline 214.8 & 350.0 & -21.9 & -40.7 & 355.1 & 260.9 & -10.6 & -20.5 & 230.9 & -0.4 & -0.7 & -2.8 & $\begin{array}{l}-1.7 \\
\end{array}$ & -0.4 & -0.4 & -1.7 & -1.3 \\
\hline 224.6 & 356.0 & 9.7 & -44.9 & 266.9 & 274.8 & -5.1 & -18.6 & 274.8 & -0.2 & -0.4 & -2.7 & -2.1 & -0.5 & -0.4 & -1.9 & -1.2 \\
\hline 234.4 & 360.3 & -15.0 & -42.2 & 377.1 & 285.6 & -19.2 & -21.1 & 267.8 & -0.4 & -0.3 & -2.5 & -1.8 & -0.5 & -0.6 & -1.2 & -1.6 \\
\hline 244.1 & 357.9 & -8.8 & -40.4 & 379.0 & 309.9 & -16.8 & -20.1 & 280.6 & -0.3 & -0.4 & -2.2 & -1.8 & -0.4 & -0.4 & -2.5 & -1.9 \\
\hline 253.9 & 370.5 & 0.4 & -33.8 & 390.1 & 330.2 & -13.7 & -0.9 & 299.2 & -0.4 & -0.3 & -3.4 & -1.6 & -0.6 & -0.4 & -4.0 & -1.3 \\
\hline 263.7 & 379.2 & 17.5 & -32.3 & 373.1 & 348.9 & -0.8 & 5.6 & 304.7 & -0.4 & -0.4 & -4.4 & -1.6 & -0.5 & -0.6 & -3.4 & -1.3 \\
\hline 273.4 & 405.1 & 62.2 & -45.6 & 285.9 & 398.7 & 25.6 & 33.6 & 351.8 & -0.6 & -0.6 & -2.9 & -1.8 & -0.5 & -0.7 & -5.1 & -1.5 \\
\hline 283.2 & 401.5 & 30.7 & -26.1 & 377.4 & 420.9 & 31.7 & 33.2 & 366.0 & -0.5 & -0.4 & -5.2 & -2.5 & -0.4 & -0.6 & -3.1 & -3.3 \\
\hline 293.0 & 485.5 & 194.0 & -11.3 & 426.5 & 477.3 & -20.7 & 200.4 & 585.5 & -0.8 & -1.1 & -5.7 & -4.0 & $\begin{array}{l}-1.1 \\
\end{array}$ & -2.0 & -3.1 & -5.8 \\
\hline 302.7 & 461.4 & 90.9 & 81.1 & 639.7 & 500.4 & -117.8 & 222.1 & 416.3 & -1.1 & -1.1 & -2.5 & -6.0 & -1.6 & -0.7 & -5.0 & -3.7 \\
\hline 312.5 & 627.7 & 91.3 & 387.0 & 686.0 & 275.1 & -331.2 & 175.6 & 286.4 & -3.4 & -2.5 & -9.2 & -9.8 & -3.3 & -2.1 & -3.3 & -5.1 \\
\hline 322.3 & 923.6 & 33.1 & 1249.4 & 627.1 & -299.1 & -418.6 & -596.6 & -29.7 & -13.0 & -2.5 & -20.7 & -10.8 & -4.5 & -4.1 & -26.3 & -8.8 \\
\hline 332.0 & 884.0 & 53.9 & 692.1 & 535.7 & -617.0 & -431.1 & -864.5 & -7.9 & -11.5 & -2.2 & -21.0 & -8.2 & -12.6 & -5.6 & -15.8 & -8.6 \\
\hline 341.8 & 404.9 & 8.7 & 151.5 & 441.4 & -89.3 & -211.6 & -458.9 & 195.2 & -2.0 & -0.7 & -3.9 & -3.8 & -2.2 & -1.3 & -14.3 & -7.0 \\
\hline
\end{tabular}


Table 49: Dynamic Stiffness Real and Imaginary Parts at $10800 \mathrm{rpm}$ and $1567 \mathrm{kPa}$ (MN/m)

\begin{tabular}{|c|c|c|c|c|c|c|c|c|c|c|c|c|c|c|c|c|}
\hline $\mathrm{f}(\mathrm{Hz})$ & $\mathrm{R}\left(\mathrm{H}_{\mathrm{xx}}\right)$ & $\mathrm{R}\left(\mathrm{H}_{\mathrm{xy}}\right)$ & $\mathrm{R}\left(\mathrm{H}_{\mathrm{yx}}\right)$ & $\mathrm{R}\left(\mathrm{H}_{\mathrm{yv}}\right)$ & $\mathrm{I}\left(\mathrm{H}_{\mathrm{xx}}\right)$ & $\mathrm{I}\left(\mathrm{H}_{\mathrm{xy}}\right)$ & $\mathrm{I}\left(\mathrm{H}_{\mathrm{vx}}\right)$ & $\mathrm{I}\left(\mathrm{H}_{\mathrm{vv}}\right)$ & $\Delta \mathrm{R}\left(\mathrm{H}_{\mathrm{xx}}\right)$ & $\Delta \mathrm{R}\left(\mathrm{H}_{\mathrm{xy}}\right)$ & $\Delta \mathrm{R}\left(\mathrm{H}_{\mathrm{yx}}\right)$ & $\Delta \mathrm{R}\left(\mathrm{H}_{\mathrm{yv}}\right)$ & $\Delta \mathrm{I}\left(\mathrm{H}_{\mathrm{xx}}\right)$ & $\Delta \mathrm{I}\left(\mathrm{H}_{\mathrm{xy}}\right)$ & $\Delta \mathrm{I}\left(\mathrm{H}_{\mathrm{vx}}\right)$ & $\Delta \mathrm{I}\left(\mathrm{H}_{\mathrm{yv}}\right)$ \\
\hline 9.8 & 293.8 & -69.7 & -83.3 & 330.9 & 12.7 & -1.6 & -25.9 & 72.5 & -1.4 & -1.8 & -3.1 & -6.7 & -0.7 & -1.9 & -2.4 & -3.5 \\
\hline 19.5 & 293.7 & -68.9 & -107.8 & 343.4 & 25.0 & -6.6 & -4.1 & 18.5 & -0.9 & -2.8 & -5.7 & -8.1 & -0.9 & -0.9 & -4.2 & -5.2 \\
\hline 29.3 & 298.4 & -71.4 & -73.6 & 337.8 & 38.6 & -11.9 & -12.7 & 31.6 & -0.7 & -1.9 & -1.6 & -5.5 & -0.3 & $\begin{array}{l}-1.4 \\
\end{array}$ & -1.0 & -1.6 \\
\hline 39.1 & 301.5 & -73.5 & -61.8 & 326.8 & 48.0 & -12.1 & -5.5 & 45.6 & -1.1 & -1.2 & -2.6 & -4.4 & -0.2 & -0.7 & -2.5 & -2.3 \\
\hline 48.8 & 305.9 & -73.0 & -71.8 & 324.5 & 61.9 & -15.2 & -9.9 & 61.3 & -0.5 & -0.7 & -0.6 & -2.1 & -0.3 & -0.4 & -1.0 & -2.3 \\
\hline 58.6 & 307.6 & -73.0 & -78.3 & 330.5 & 72.8 & -13.0 & -16.2 & 65.6 & -0.6 & -0.9 & -2.4 & -1.8 & -0.4 & -0.6 & -0.9 & -1.4 \\
\hline 68.4 & 308.7 & -74.0 & -77.9 & 331.8 & 83.8 & -16.0 & -21.7 & 68.0 & -0.4 & -0.8 & -1.2 & -1.7 & -0.5 & -0.5 & -0.9 & -1.5 \\
\hline 78.1 & 317.2 & -71.3 & -68.3 & 323.7 & 97.7 & -15.5 & -12.5 & 73.3 & -0.3 & -0.5 & -0.8 & -1.9 & -0.4 & -0.6 & -1.3 & -1.1 \\
\hline 87.9 & 318.9 & -74.6 & -75.8 & 345.4 & 105.5 & -17.3 & -19.2 & 105.3 & -0.2 & -0.5 & -1.4 & -1.6 & -0.3 & -0.4 & -0.5 & -1.3 \\
\hline 97.7 & 321.8 & -73.4 & -74.6 & 339.1 & 112.3 & -17.6 & -18.3 & 102.2 & -0.3 & -0.6 & -1.5 & -1.6 & -0.3 & -0.4 & -0.7 & -1.2 \\
\hline 107.4 & 325.1 & -72.0 & -75.4 & 347.2 & 122.0 & -18.6 & -20.5 & 122.9 & -0.3 & -0.5 & -0.6 & -1.6 & -0.4 & -0.4 & -0.8 & $\begin{array}{l}-1.3 \\
\end{array}$ \\
\hline 117.2 & 331.2 & -70.4 & -73.6 & 352.7 & 130.1 & -18.3 & -30.3 & 125.6 & -0.3 & -0.3 & -1.3 & -1.9 & -0.2 & -0.3 & -0.7 & -0.9 \\
\hline 127.0 & 334.6 & -67.0 & -70.3 & 348.4 & 139.6 & -17.8 & -30.0 & 142.8 & -0.3 & -0.5 & -0.5 & -1.5 & -0.5 & -0.2 & -0.2 & -1.2 \\
\hline 136.7 & 337.3 & -62.6 & -67.7 & 351.5 & 149.5 & -18.5 & -28.7 & 146.1 & -0.4 & -0.5 & -0.7 & -1.6 & -0.4 & -0.5 & -0.7 & -1.0 \\
\hline 146.5 & 341.0 & -57.6 & -58.0 & 355.7 & 157.0 & -20.5 & -27.3 & 150.6 & -0.3 & -0.4 & -0.8 & -2.1 & -0.1 & -0.3 & -1.0 & -1.2 \\
\hline 156.3 & 342.3 & -50.9 & -51.9 & 339.2 & 166.2 & -21.5 & -30.0 & 140.0 & -0.3 & -0.4 & -2.7 & -1.8 & -0.6 & -0.4 & -1.5 & -1.0 \\
\hline 166.0 & 346.3 & -57.0 & -68.6 & 374.9 & 174.5 & -25.0 & -39.2 & 180.4 & -0.3 & -0.4 & -1.8 & -2.2 & -0.6 & -0.5 & -2.2 & -1.5 \\
\hline 175.8 & 345.2 & -50.5 & -66.6 & 374.7 & 182.0 & -27.3 & -36.8 & 179.9 & -0.9 & -1.2 & -1.9 & -1.9 & -1.2 & -0.5 & -1.3 & -2.1 \\
\hline 185.5 & 348.9 & -48.5 & -57.9 & 376.7 & 193.0 & -25.3 & -29.5 & 186.0 & -0.5 & -1.2 & -2.2 & -3.1 & -1.5 & -1.4 & -1.4 & $\begin{array}{l}-1.6 \\
\end{array}$ \\
\hline 195.3 & 351.4 & -43.3 & -57.9 & 371.9 & 207.2 & -28.3 & -26.0 & 195.0 & -0.3 & -0.6 & -2.5 & -1.7 & -0.6 & -0.5 & -2.0 & -1.4 \\
\hline 205.1 & 351.0 & -41.1 & -57.6 & 384.9 & 213.5 & -26.9 & -29.8 & 208.5 & -0.5 & -0.5 & -1.0 & -1.6 & -0.3 & -0.4 & -2.6 & -1.2 \\
\hline 214.8 & 358.4 & -34.2 & -44.9 & 388.4 & 229.0 & -26.3 & -34.9 & 202.3 & -0.4 & -0.4 & -0.9 & -1.6 & -0.3 & -0.4 & -1.5 & -1.3 \\
\hline 224.6 & 361.2 & -23.0 & -40.4 & 332.6 & 237.3 & -24.7 & -29.3 & 212.0 & -0.2 & -0.3 & -3.0 & -1.9 & -0.4 & -0.3 & -2.0 & -1.2 \\
\hline 234.4 & 366.7 & -30.0 & -47.8 & 402.0 & 251.4 & -35.6 & -36.8 & 236.1 & -0.3 & -0.4 & -2.1 & -1.7 & -0.2 & -0.3 & -1.8 & -1.2 \\
\hline 244.1 & 366.1 & -17.6 & -36.1 & 385.5 & 266.2 & -32.4 & -34.4 & 252.4 & -0.3 & -0.4 & -2.6 & -1.6 & -0.4 & -0.3 & -1.6 & -1.2 \\
\hline 253.9 & 366.8 & -13.9 & -35.4 & 404.4 & 281.2 & -31.9 & -24.4 & 259.2 & -0.3 & -0.4 & -4.4 & -1.6 & -0.4 & -0.3 & -1.2 & -1.1 \\
\hline 263.7 & 373.5 & $\begin{array}{l}-7.7 \\
\end{array}$ & -29.0 & 408.4 & 301.1 & -32.4 & -19.0 & 257.7 & -0.3 & -0.4 & -4.9 & -1.7 & -0.5 & -0.3 & -1.9 & -1.0 \\
\hline 273.4 & 378.7 & 6.8 & -26.1 & 348.5 & 321.1 & -23.9 & -24.4 & 253.5 & -0.3 & -0.4 & -1.6 & -1.5 & -0.5 & -0.3 & -3.3 & -1.1 \\
\hline 283.2 & 385.2 & -4.3 & -26.3 & 410.9 & 343.9 & -35.1 & -12.3 & 281.2 & -0.2 & -0.4 & -2.8 & -2.1 & -0.4 & -0.5 & -3.8 & -1.3 \\
\hline 293.0 & 391.9 & 17.5 & -21.4 & 391.7 & 362.1 & -21.6 & -8.8 & 308.2 & -0.4 & -0.4 & -1.4 & -2.0 & -0.3 & -0.5 & -2.6 & -1.3 \\
\hline 302.7 & 394.5 & 74.8 & -23.0 & 326.2 & 403.7 & 3.7 & -4.2 & 374.1 & -0.5 & -1.0 & -1.8 & -2.3 & -0.6 & -0.8 & -6.2 & -1.9 \\
\hline 312.5 & 407.4 & 82.8 & -31.4 & 402.2 & 443.9 & 1.2 & 13.4 & 372.2 & -0.9 & -0.9 & -1.9 & -2.3 & -1.0 & -0.8 & -3.8 & -2.0 \\
\hline 322.3 & 426.1 & 77.8 & -4.6 & 417.2 & 490.2 & 2.3 & 81.4 & 387.5 & -1.3 & -0.8 & -2.6 & -2.4 & -0.8 & -0.8 & -4.5 & -1.6 \\
\hline 332.0 & 459.7 & 53.0 & 57.6 & 559.6 & 544.2 & -64.7 & 149.9 & 368.3 & -0.8 & -0.7 & -1.9 & -2.8 & -0.6 & -0.5 & -5.4 & -1.9 \\
\hline 341.8 & 628.1 & 130.4 & 209.7 & 593.2 & 659.5 & -26.1 & 246.0 & 371.5 & -1.9 & -0.6 & -7.0 & -3.2 & -2.2 & -0.9 & -2.0 & -2.0 \\
\hline
\end{tabular}


Table 50: Dynamic Stiffness Real and Imaginary Parts at $10800 \mathrm{rpm}$ and $2350 \mathrm{kPa}(\mathrm{MN} / \mathrm{m})$

\begin{tabular}{|c|c|c|c|c|c|c|c|c|c|c|c|c|c|c|c|c|}
\hline $\mathrm{f}(\mathrm{Hz})$ & $\mathrm{R}\left(\mathrm{H}_{\mathrm{xX}}\right)$ & $\mathrm{R}\left(\mathrm{H}_{\mathrm{xy}}\right)$ & $\mathrm{R}\left(\mathrm{H}_{\mathrm{yx}}\right)$ & $\mathrm{R}\left(\mathrm{H}_{\mathrm{yv}}\right)$ & $\mathrm{I}\left(\mathrm{H}_{\mathrm{xx}}\right)$ & $\mathrm{I}\left(\mathrm{H}_{\mathrm{xy}}\right)$ & $\mathrm{I}\left(\mathrm{H}_{\mathrm{vx}}\right)$ & $\mathrm{I}\left(\mathrm{H}_{\mathrm{yv}}\right)$ & $\Delta \mathrm{R}\left(\mathrm{H}_{\mathrm{xx}}\right)$ & $\Delta \mathrm{R}\left(\mathrm{H}_{\mathrm{xy}}\right)$ & $\Delta \mathrm{R}\left(\mathrm{H}_{\mathrm{yx}}\right)$ & $\Delta \mathrm{R}\left(\mathrm{H}_{\mathrm{yv}}\right)$ & $\Delta \mathrm{I}\left(\mathrm{H}_{\mathrm{xx}}\right)$ & $\Delta \mathrm{I}\left(\mathrm{H}_{\mathrm{xy}}\right)$ & $\Delta \mathrm{I}\left(\mathrm{H}_{\mathrm{yX}}\right)$ & $\Delta \mathrm{I}\left(\mathrm{H}_{\mathrm{yv}}\right)$ \\
\hline 9.8 & 321.2 & -73.6 & -92.5 & 405.7 & 12.2 & -6.1 & -33.4 & 69.2 & -1.4 & -1.2 & -2.1 & -4.5 & -1.6 & -3.9 & -5.2 & -3.5 \\
\hline 19.5 & 320.1 & -77.9 & -110.6 & 363.9 & 21.8 & -4.2 & -8.3 & 13.5 & -1.5 & -1.3 & -6.5 & -4.8 & -0.9 & -2.8 & -11.1 & -3.6 \\
\hline 29.3 & 325.7 & -76.6 & -80.5 & 390.7 & 32.6 & -7.7 & -18.4 & 30.3 & -0.9 & -1.5 & -3.1 & -3.3 & -0.8 & -1.2 & -2.1 & -3.0 \\
\hline 39.1 & 327.3 & -76.6 & -71.6 & 373.6 & 44.8 & -10.1 & 3.2 & 35.7 & -0.6 & -1.6 & -1.1 & -2.9 & -1.1 & -0.8 & -8.1 & -3.2 \\
\hline 48.8 & 331.2 & -76.2 & -83.0 & 370.5 & 56.3 & -14.1 & -9.3 & 55.7 & -0.6 & -0.8 & -1.9 & -2.1 & -0.7 & -1.2 & -0.9 & -2.0 \\
\hline 58.6 & 334.0 & -76.6 & -80.8 & 378.0 & 65.7 & -14.3 & -18.4 & 51.5 & -0.3 & -0.7 & -3.8 & -2.1 & -0.7 & -0.7 & -2.1 & -1.9 \\
\hline 68.4 & 332.1 & -77.0 & -81.6 & 379.0 & 76.9 & -18.4 & -14.9 & 53.4 & -0.4 & -0.5 & -2.4 & -1.8 & -0.4 & -0.8 & -1.9 & -1.5 \\
\hline 78.1 & 341.9 & -72.9 & -73.9 & 366.9 & 91.7 & -17.4 & -7.7 & 61.0 & -0.2 & -0.5 & -1.4 & -1.6 & -0.2 & -0.3 & -0.7 & -1.4 \\
\hline 87.9 & 342.1 & -78.2 & -84.0 & 387.9 & 95.0 & -20.2 & -21.7 & 92.0 & -0.4 & -0.6 & -1.1 & -1.6 & -0.4 & -0.7 & -2.5 & -1.3 \\
\hline 97.7 & 346.4 & -77.4 & -74.0 & 377.3 & 102.6 & -20.7 & -20.6 & 86.8 & -0.4 & -0.5 & -1.4 & -1.7 & -0.4 & -0.7 & -1.1 & -1.1 \\
\hline 107.4 & 348.0 & -75.7 & -84.5 & 390.1 & 110.5 & -21.3 & -26.0 & 105.4 & -0.3 & -0.3 & -2.2 & -1.8 & -0.3 & -0.5 & -1.2 & -1.1 \\
\hline 117.2 & 352.7 & -74.6 & -79.6 & 388.3 & 118.1 & -22.3 & -34.3 & 112.6 & -0.2 & -0.4 & -1.5 & -1.7 & -0.3 & -0.5 & -1.0 & -1.1 \\
\hline 127.0 & 356.5 & -72.3 & -80.9 & 386.6 & 128.1 & -23.3 & -37.9 & 126.1 & -0.2 & -0.6 & -0.8 & $\begin{array}{l}-1.7 \\
\end{array}$ & -0.2 & -0.5 & $\begin{array}{l}-1.7 \\
\end{array}$ & -1.1 \\
\hline 136.7 & 358.9 & -67.7 & -76.5 & 389.8 & 136.2 & -23.5 & -38.4 & 129.2 & -0.3 & -0.3 & -0.4 & -1.4 & -0.3 & -0.5 & -2.2 & -1.1 \\
\hline 146.5 & 361.6 & -63.9 & -69.5 & 393.5 & 144.0 & -26.6 & -32.0 & 133.6 & -0.3 & -0.6 & -1.0 & -1.6 & -0.3 & -0.5 & -1.2 & -1.1 \\
\hline 156.3 & 362.1 & -58.1 & -69.8 & 380.3 & 151.6 & -27.1 & -26.6 & 120.0 & -0.5 & -0.4 & -0.8 & -1.5 & -0.3 & -0.4 & -1.6 & -1.0 \\
\hline 166.0 & 365.9 & -63.6 & -77.2 & 407.8 & 158.2 & -30.2 & -35.9 & 162.8 & -0.4 & -0.3 & -0.8 & -1.5 & -0.4 & -0.5 & -1.0 & -1.4 \\
\hline 175.8 & 365.6 & -58.4 & -79.0 & 410.0 & 165.3 & -32.5 & -37.3 & 165.3 & -0.9 & -1.0 & -2.8 & -1.9 & -1.5 & -0.7 & -2.8 & -1.9 \\
\hline 185.5 & 367.8 & -56.1 & -66.6 & 411.2 & 177.3 & -32.6 & -34.0 & 166.8 & -0.9 & -1.5 & -2.5 & -2.6 & -1.7 & $\begin{array}{l}-1.4 \\
\end{array}$ & $\begin{array}{l}-1.4 \\
\end{array}$ & -1.6 \\
\hline 195.3 & 370.2 & -52.1 & -66.4 & 408.2 & 188.6 & -33.5 & -28.8 & 171.7 & -0.4 & -0.5 & -1.6 & -1.8 & -0.5 & -0.7 & -2.6 & -1.4 \\
\hline 205.1 & 369.4 & -47.4 & -67.9 & 417.0 & 194.7 & -35.4 & -32.5 & 193.4 & -0.6 & -0.5 & -1.3 & -1.6 & -0.5 & -0.3 & -1.6 & -1.2 \\
\hline 214.8 & 376.8 & -41.6 & -61.9 & 425.8 & 207.0 & -35.5 & -44.9 & 187.8 & -0.6 & -0.3 & -3.0 & -1.9 & -0.3 & -0.4 & -4.4 & $\begin{array}{l}-1.4 \\
\end{array}$ \\
\hline 224.6 & 376.9 & -31.8 & -63.3 & 372.9 & 216.3 & -38.8 & -39.9 & 199.8 & -0.3 & -0.4 & -1.5 & -1.9 & -0.5 & -0.3 & -2.0 & $\begin{array}{l}-1.4 \\
\end{array}$ \\
\hline 234.4 & 382.4 & -40.4 & -61.1 & 435.5 & 227.1 & -45.1 & -43.6 & 215.6 & -0.5 & -0.3 & -1.2 & -1.8 & -0.3 & -0.5 & -3.2 & -1.7 \\
\hline 244.1 & 382.1 & -33.9 & -60.1 & 432.5 & 241.2 & -44.6 & -42.9 & 224.4 & -0.3 & -0.3 & -1.8 & $\begin{array}{l}-1.7 \\
\end{array}$ & -0.4 & -0.2 & -0.8 & -1.1 \\
\hline 253.9 & 382.5 & -28.3 & -62.5 & 447.9 & 253.1 & -44.4 & -37.4 & 235.0 & -0.5 & -0.3 & -2.5 & -1.6 & -0.5 & -0.3 & -2.7 & -1.2 \\
\hline 263.7 & 386.9 & -18.1 & -50.6 & 437.8 & 269.4 & -45.0 & -32.3 & 238.4 & -0.3 & -0.3 & -1.0 & -2.2 & -0.4 & -0.4 & -3.0 & -1.5 \\
\hline 273.4 & 392.6 & -10.5 & -47.7 & 387.7 & 284.4 & -40.0 & -37.6 & 225.6 & -0.4 & -0.3 & -1.4 & -2.2 & -0.4 & -0.5 & -1.8 & -1.1 \\
\hline 283.2 & 397.5 & -22.2 & -54.6 & 452.7 & 302.9 & -51.1 & -32.1 & 258.7 & -0.2 & -0.4 & -1.9 & -1.7 & -0.5 & -0.4 & -2.6 & -1.5 \\
\hline 293.0 & 404.4 & -3.2 & -46.7 & 429.8 & 316.7 & -43.0 & -20.7 & 278.5 & -0.3 & -0.5 & $\begin{array}{l}-1.4 \\
\end{array}$ & -2.5 & -0.6 & -0.6 & -1.1 & -1.1 \\
\hline 302.7 & 404.3 & 21.8 & -44.2 & 402.0 & 339.9 & -33.6 & -13.2 & 306.9 & -0.2 & -0.6 & -1.8 & -2.7 & -0.6 & -0.4 & -1.5 & -1.2 \\
\hline 312.5 & 413.4 & 18.5 & -51.9 & 477.8 & 364.0 & -41.8 & -0.6 & 303.8 & -0.3 & -0.4 & -1.9 & -3.4 & -0.7 & -0.6 & -1.8 & -2.7 \\
\hline 322.3 & 428.2 & 50.3 & -44.0 & 499.7 & 396.7 & -83.8 & 23.5 & 404.4 & -0.5 & -2.1 & -2.9 & -2.7 & -0.8 & -0.9 & -2.7 & -3.0 \\
\hline 332.0 & 432.4 & 3.7 & 14.8 & 631.3 & 411.8 & -128.7 & 68.7 & 358.6 & -0.3 & -0.3 & -2.3 & -3.1 & -0.5 & -0.6 & -3.5 & -1.7 \\
\hline 341.8 & 485.8 & 40.5 & 39.9 & 589.3 & 473.5 & -65.9 & 85.5 & 325.5 & -0.6 & -0.4 & -5.0 & -3.1 & -0.8 & -0.5 & -5.0 & -1.7 \\
\hline
\end{tabular}


Table 51: Dynamic Stiffness Real and Imaginary Parts at $10800 \mathrm{rpm}$ and $3134 \mathrm{kPa}(\mathrm{MN} / \mathrm{m})$

\begin{tabular}{|c|c|c|c|c|c|c|c|c|c|c|c|c|c|c|c|c|}
\hline $\mathrm{f}(\mathrm{Hz})$ & $\mathrm{R}\left(\mathrm{H}_{\mathrm{xx}}\right)$ & $\mathrm{R}\left(\mathrm{H}_{\mathrm{xy}}\right)$ & $\mathrm{R}\left(\mathrm{H}_{\mathrm{yx}}\right)$ & $\mathrm{R}\left(\mathrm{H}_{\mathrm{yv}}\right)$ & $\mathrm{I}\left(\mathrm{H}_{\mathrm{xx}}\right)$ & $\mathrm{I}\left(\mathrm{H}_{\mathrm{xy}}\right)$ & $\mathrm{I}\left(\mathrm{H}_{\mathrm{yx}}\right)$ & $\mathrm{I}\left(\mathrm{H}_{\mathrm{yv}}\right)$ & $\Delta \mathrm{R}\left(\mathrm{H}_{\mathrm{xx}}\right)$ & $\Delta \mathrm{R}\left(\mathrm{H}_{\mathrm{xy}}\right)$ & $\Delta \mathrm{R}\left(\mathrm{H}_{\mathrm{yx}}\right)$ & $\Delta \mathrm{R}\left(\mathrm{H}_{\mathrm{yv}}\right)$ & $\Delta \mathrm{I}\left(\mathrm{H}_{\mathrm{xx}}\right)$ & $\Delta \mathrm{I}\left(\mathrm{H}_{\mathrm{xy}}\right)$ & $\Delta \mathrm{I}\left(\mathrm{H}_{\mathrm{yx}}\right)$ & $\Delta \mathrm{I}\left(\mathrm{H}_{\mathrm{yv}}\right)$ \\
\hline 9.8 & 343.9 & -85.7 & -94.8 & 440.7 & 9.7 & -1.9 & -34.4 & 64.5 & -1.8 & -4.8 & -1.3 & -5.5 & -2.0 & -6.4 & -3.3 & -4.7 \\
\hline 19.5 & 343.9 & -79.0 & -106.0 & 418.4 & 21.1 & -12.2 & -16.6 & 32.6 & -1.3 & -3.6 & -2.4 & -7.2 & -1.8 & -3.4 & -3.9 & -4.8 \\
\hline 29.3 & 345.2 & -81.7 & -82.5 & 425.5 & 28.9 & -6.3 & -14.3 & 26.8 & -0.4 & -1.0 & -2.4 & -5.0 & -0.9 & -0.8 & -3.7 & -2.1 \\
\hline 39.1 & 349.5 & -80.4 & -83.4 & 422.3 & 42.7 & -11.6 & 1.7 & 31.8 & -0.4 & -0.8 & -2.3 & -2.4 & -1.3 & -0.7 & -3.5 & -1.6 \\
\hline 48.8 & 352.7 & -82.0 & -90.5 & 427.6 & 53.4 & -14.9 & -10.7 & 42.5 & -0.2 & -0.6 & -1.0 & -2.1 & -0.7 & -0.5 & -1.0 & -2.0 \\
\hline 58.6 & 355.3 & -82.2 & -85.1 & 427.3 & 60.5 & -14.6 & -19.6 & 46.0 & -1.2 & -0.6 & -2.7 & -2.7 & -0.7 & -0.7 & -1.4 & -1.3 \\
\hline 68.4 & 354.2 & -80.8 & -86.8 & 427.1 & 70.7 & -17.2 & -15.3 & 45.6 & -0.5 & -0.4 & -1.4 & -2.7 & -0.6 & -0.4 & -0.5 & -1.1 \\
\hline 78.1 & 355.8 & -80.9 & -89.7 & 409.9 & 91.9 & -18.2 & -4.6 & 55.4 & -0.4 & -0.5 & -0.9 & -2.2 & -0.5 & -0.5 & -0.9 & -1.5 \\
\hline 87.9 & 362.8 & -82.7 & -86.8 & 433.5 & 88.2 & -21.6 & -24.1 & 82.5 & -0.3 & -0.3 & -0.5 & -2.0 & -0.4 & -0.5 & -1.2 & -1.5 \\
\hline 97.7 & 367.2 & -81.4 & -81.6 & 422.4 & 95.5 & -22.2 & -22.3 & 72.6 & -0.4 & -0.6 & -0.8 & -2.2 & -0.5 & -0.5 & -0.4 & -1.1 \\
\hline 107.4 & 367.8 & -80.1 & -86.0 & 433.7 & 104.1 & -23.6 & -28.1 & 93.1 & -0.1 & -0.3 & -1.9 & -2.6 & -0.3 & -0.4 & -0.6 & -1.2 \\
\hline 117.2 & 372.0 & -78.8 & -85.7 & 433.5 & 110.2 & -24.3 & -33.5 & 96.0 & -0.5 & -0.4 & -0.9 & -1.9 & -0.4 & -0.4 & -1.7 & -1.1 \\
\hline 127.0 & 375.1 & -76.0 & -85.9 & 427.8 & 118.1 & -24.6 & -34.2 & 112.4 & -0.4 & -0.6 & -0.5 & -2.0 & -0.5 & -0.3 & -1.0 & -1.4 \\
\hline 136.7 & 378.0 & -71.7 & -81.0 & 431.8 & 128.3 & -27.9 & -39.3 & 118.7 & -0.2 & -0.4 & -1.2 & -2.5 & -0.3 & -0.3 & -0.7 & -1.0 \\
\hline 146.5 & 380.7 & -65.7 & -73.3 & 425.0 & 133.8 & -28.8 & -33.8 & 122.8 & -0.3 & -0.5 & -1.1 & -2.9 & -0.2 & -0.4 & -0.5 & -2.5 \\
\hline 156.3 & 380.5 & -64.9 & -76.6 & 427.6 & 142.0 & -32.0 & -30.9 & 104.4 & -0.5 & -0.5 & -1.9 & -2.5 & -0.4 & -0.3 & -1.3 & -1.4 \\
\hline 166.0 & 383.7 & -68.8 & -81.6 & 448.0 & 147.7 & -33.9 & -40.7 & 150.1 & -0.4 & -0.4 & -0.7 & -2.3 & -0.7 & -0.8 & -0.8 & -1.4 \\
\hline 175.8 & 383.7 & -63.0 & -82.9 & 453.1 & 154.5 & -35.3 & -42.0 & 148.5 & -1.7 & -2.7 & -1.5 & -2.9 & -1.1 & -2.1 & -2.9 & -5.1 \\
\hline 185.5 & 384.7 & -61.2 & -74.1 & 451.5 & 166.2 & -38.5 & -36.3 & 151.9 & -1.2 & -0.9 & -2.3 & -2.7 & -1.2 & -0.6 & -1.8 & -1.1 \\
\hline 195.3 & 386.6 & -56.5 & -69.1 & 444.9 & 175.9 & -38.8 & -38.4 & 155.2 & -0.5 & -0.4 & -0.9 & $\begin{array}{l}-1.9 \\
\end{array}$ & -0.4 & -0.8 & -2.5 & $\begin{array}{l}-1.3 \\
\end{array}$ \\
\hline 205.1 & 386.2 & -53.6 & -71.6 & 457.4 & 182.6 & -42.4 & -37.2 & 175.0 & -0.5 & -0.5 & -1.6 & -2.3 & -0.4 & -0.5 & -1.9 & -1.1 \\
\hline 214.8 & 394.3 & -47.6 & -64.0 & 461.4 & 192.1 & -40.7 & -50.5 & 168.3 & -0.3 & -0.5 & -1.6 & -2.3 & -0.8 & -0.6 & -2.6 & -1.3 \\
\hline 224.6 & 393.9 & -46.1 & -66.3 & 429.3 & 201.2 & -45.0 & -44.1 & 168.1 & -0.5 & -0.6 & -2.7 & -2.9 & -0.4 & -0.5 & -1.1 & -1.0 \\
\hline 234.4 & 398.4 & -49.8 & -65.2 & 480.5 & 211.2 & -53.7 & -49.1 & 201.6 & -0.5 & -0.6 & -1.6 & -2.5 & -0.2 & -0.7 & -0.5 & -1.1 \\
\hline 244.1 & 397.0 & -40.8 & -62.4 & 472.6 & 223.8 & -54.0 & -46.7 & 211.1 & -0.6 & -0.3 & -1.3 & -2.3 & -0.2 & -0.5 & $\begin{array}{l}-1.7 \\
\end{array}$ & -1.0 \\
\hline 253.9 & 397.4 & -37.3 & -64.3 & 487.0 & 235.4 & -54.0 & -44.9 & 216.9 & -0.5 & -0.4 & -3.2 & -2.4 & -0.3 & -0.5 & -0.5 & -1.1 \\
\hline 263.7 & 401.4 & -31.1 & -55.6 & 481.3 & 248.1 & -53.0 & -41.9 & 210.5 & -0.3 & -0.5 & -2.3 & -2.7 & -0.5 & -0.7 & -2.1 & -1.2 \\
\hline 273.4 & 404.5 & -24.0 & -54.9 & 441.9 & 262.9 & -53.8 & -44.0 & 202.8 & -0.3 & -0.4 & -1.1 & -2.3 & -0.4 & -0.5 & -1.4 & -1.1 \\
\hline 283.2 & 409.5 & -32.4 & -54.1 & 494.1 & 279.8 & -64.9 & -44.0 & 238.6 & -0.4 & -0.6 & -2.4 & -2.3 & -0.2 & -0.2 & -2.1 & -1.8 \\
\hline 293.0 & 417.9 & -16.4 & -47.4 & 472.9 & 290.1 & -53.1 & -30.2 & 249.7 & -0.4 & -0.6 & -1.3 & -2.5 & -0.4 & -0.7 & -1.4 & -1.8 \\
\hline 302.7 & 416.8 & 2.0 & -45.3 & 462.7 & 311.5 & -52.1 & -31.8 & 276.7 & -0.4 & -1.1 & -1.8 & -3.0 & -0.5 & -0.2 & -1.8 & -2.6 \\
\hline 312.5 & 416.2 & 68.2 & -27.4 & 463.0 & 324.4 & -76.8 & -25.8 & 375.7 & -0.6 & -3.5 & -2.7 & -5.6 & -1.2 & -6.0 & -2.7 & -13.9 \\
\hline 322.3 & 435.6 & 17.9 & -25.0 & 481.7 & 344.2 & -46.4 & -1.4 & 284.1 & -0.6 & -1.3 & -3.4 & -3.6 & -0.5 & -0.9 & -2.6 & -2.4 \\
\hline 332.0 & 474.8 & 132.0 & -31.7 & 518.2 & 368.1 & -180.3 & 49.4 & 518.1 & -1.5 & -6.5 & -3.5 & -15.7 & -1.5 & -6.7 & -4.5 & -7.2 \\
\hline 341.8 & 467.3 & -4.7 & 26.0 & 650.4 & 404.9 & -110.0 & 21.8 & 310.4 & -0.7 & -1.0 & -1.3 & -4.7 & -0.7 & -1.7 & -1.9 & -2.0 \\
\hline
\end{tabular}


Table 52: Dynamic Stiffness Real and Imaginary Parts at $13200 \mathrm{rpm}$ and $0 \mathrm{kPa}(\mathrm{MN} / \mathrm{m})$

\begin{tabular}{|c|c|c|c|c|c|c|c|c|c|c|c|c|c|c|c|c|}
\hline $\mathrm{f}(\mathrm{Hz})$ & $\mathrm{R}\left(\mathrm{H}_{\mathrm{xx}}\right)$ & $\mathrm{R}\left(\mathrm{H}_{\mathrm{xy}}\right)$ & $\mathrm{R}\left(\mathrm{H}_{\mathrm{yx}}\right)$ & $\mathrm{R}\left(\mathrm{H}_{\mathrm{yv}}\right)$ & $\mathrm{I}\left(\mathrm{H}_{\mathrm{xx}}\right)$ & $\mathrm{I}\left(\mathrm{H}_{\mathrm{xy}}\right)$ & $\mathrm{I}\left(\mathrm{H}_{\mathrm{yx}}\right)$ & $\mathrm{I}\left(\mathrm{H}_{\mathrm{yv}}\right)$ & $\Delta \mathrm{R}\left(\mathrm{H}_{\mathrm{xx}}\right)$ & $\Delta \mathrm{R}\left(\mathrm{H}_{\mathrm{xy}}\right)$ & $\Delta \mathrm{R}\left(\mathrm{H}_{\mathrm{yx}}\right)$ & $\Delta \mathrm{R}\left(\mathrm{H}_{\mathrm{yv}}\right)$ & $\Delta \mathrm{I}\left(\mathrm{H}_{\mathrm{xx}}\right)$ & $\Delta \mathrm{I}\left(\mathrm{H}_{\mathrm{xy}}\right)$ & $\Delta \mathrm{I}\left(\mathrm{H}_{\mathrm{vX}}\right)$ & $\Delta \mathrm{I}\left(\mathrm{H}_{\mathrm{yv}}\right)$ \\
\hline 9.8 & 279.6 & -62.3 & -111.2 & 277.2 & 9.8 & -13.3 & 2.4 & 64.9 & -3.0 & -3.1 & -5.4 & -9.5 & -3.0 & -1.6 & -2.6 & -7.5 \\
\hline 19.5 & 283.5 & -62.7 & -103.2 & 281.7 & 22.4 & -0.6 & -10.8 & 35.2 & -1.6 & -2.1 & -3.4 & -8.7 & -0.9 & -2.4 & -4.0 & -3.6 \\
\hline 29.3 & 286.8 & -60.1 & -92.8 & 293.7 & 34.7 & -8.3 & 1.1 & 70.0 & -1.3 & -1.7 & -6.4 & -8.4 & -1.5 & -0.9 & -3.7 & -5.2 \\
\hline 39.1 & 286.3 & -62.6 & -70.8 & 241.5 & 45.6 & -10.4 & 3.5 & 32.1 & -1.2 & -1.8 & -2.3 & -9.1 & -1.2 & -1.2 & -2.3 & -3.8 \\
\hline 48.8 & 287.9 & -58.5 & -89.4 & 265.4 & 57.2 & -16.4 & -15.7 & 56.1 & -0.6 & -1.4 & -2.3 & -3.9 & -0.4 & -0.7 & -1.5 & -2.3 \\
\hline 58.6 & 292.4 & -57.4 & -79.2 & 278.8 & 73.4 & -19.7 & 1.9 & 64.4 & -0.6 & -1.3 & -1.5 & -4.9 & -1.7 & -1.0 & -2.8 & -3.9 \\
\hline 68.4 & 295.0 & -58.1 & -87.2 & 292.8 & 81.2 & -22.6 & -15.9 & 71.9 & -0.8 & -1.2 & -2.4 & -5.0 & -1.2 & -0.6 & -2.2 & -3.2 \\
\hline 78.1 & 298.8 & -59.1 & -88.9 & 283.8 & 93.7 & -28.3 & -9.0 & 84.3 & -0.8 & -1.0 & -2.4 & -3.8 & -0.7 & -0.5 & -2.3 & -3.2 \\
\hline 87.9 & 300.6 & -57.2 & -87.1 & 296.6 & 103.8 & -31.7 & -15.1 & 116.7 & -0.5 & -1.2 & -1.3 & -4.2 & -1.0 & -0.5 & -1.6 & -3.3 \\
\hline 97.7 & 303.2 & -58.7 & -87.8 & 288.6 & 113.2 & -36.7 & -23.2 & 114.7 & -0.7 & -1.2 & -0.8 & -4.3 & -1.1 & -0.9 & -2.5 & -2.1 \\
\hline 107.4 & 307.0 & -60.7 & -89.5 & 288.8 & 122.1 & -39.6 & -16.2 & 129.4 & -0.7 & $\begin{array}{l}-1.2 \\
\end{array}$ & -1.0 & -3.8 & $\begin{array}{l}-1.0 \\
\end{array}$ & -0.7 & -0.9 & -1.8 \\
\hline 117.2 & 311.8 & -62.4 & -81.5 & 293.8 & 133.1 & -44.0 & -14.5 & 146.7 & -0.3 & -1.3 & -1.3 & -3.9 & -0.6 & -0.7 & -2.0 & -4.0 \\
\hline 127.0 & 315.1 & -62.5 & -90.6 & 313.2 & 142.5 & -46.6 & -24.4 & 138.7 & -1.0 & -1.1 & -1.8 & -4.2 & -0.2 & -0.7 & -1.1 & -2.2 \\
\hline 136.7 & 319.6 & -63.4 & -89.0 & 311.1 & 152.7 & -48.3 & -19.2 & 146.3 & -0.5 & -1.3 & -1.7 & -5.4 & -0.5 & -0.5 & -0.7 & -2.7 \\
\hline 146.5 & 324.7 & -63.4 & -83.5 & 332.0 & 161.7 & -49.9 & -16.4 & 162.1 & -0.6 & -1.0 & -1.4 & -3.9 & -0.3 & -0.8 & -0.9 & -3.8 \\
\hline 156.3 & 327.0 & -67.6 & -87.4 & 277.8 & 170.4 & -48.6 & -13.7 & 245.0 & -0.5 & -1.0 & -3.3 & -5.0 & -0.7 & -0.4 & -2.2 & -2.5 \\
\hline 166.0 & 330.0 & -67.4 & -80.4 & 327.0 & 178.1 & -51.5 & -6.4 & 194.6 & -0.6 & -1.1 & -1.8 & -4.7 & -0.8 & -0.6 & -2.8 & -3.1 \\
\hline 175.8 & 331.6 & -63.8 & -74.9 & 375.8 & 191.2 & -50.7 & -10.5 & 242.8 & -0.8 & -0.8 & -0.5 & -4.8 & -0.4 & -0.9 & -0.9 & -3.4 \\
\hline 185.5 & 334.7 & -62.3 & -73.8 & 349.1 & 200.8 & -51.0 & -14.6 & 198.3 & -0.5 & -0.9 & -2.9 & -5.1 & -0.9 & -0.6 & -1.7 & -2.5 \\
\hline 195.3 & 337.3 & -58.7 & -73.7 & 384.4 & 211.8 & -52.7 & -22.3 & 251.1 & -0.4 & -0.8 & -3.1 & -3.8 & -0.4 & -0.3 & -3.1 & -2.5 \\
\hline 205.1 & 344.4 & -66.2 & -61.2 & 358.1 & 219.9 & -52.5 & -17.1 & 241.6 & -0.9 & -1.1 & -2.7 & -5.6 & -1.1 & -0.7 & -2.5 & -3.1 \\
\hline 214.8 & 350.2 & -61.3 & -60.2 & 342.1 & 236.4 & -48.7 & -28.8 & 255.3 & -0.5 & -1.6 & -2.0 & -4.5 & -1.2 & -1.1 & -1.5 & -3.3 \\
\hline 224.6 & 360.3 & -62.7 & -60.0 & 340.1 & 245.5 & -47.4 & -37.3 & 273.3 & -2.8 & -2.1 & -2.2 & -6.5 & -4.8 & -1.7 & -3.3 & -3.4 \\
\hline 234.4 & 362.0 & -61.6 & -52.8 & 367.0 & 250.1 & -43.5 & -45.1 & 274.4 & -0.8 & -1.0 & $\begin{array}{l}-1.3 \\
\end{array}$ & -4.4 & -1.2 & -0.7 & -1.0 & -3.2 \\
\hline 244.1 & 365.1 & -57.4 & -65.2 & 370.0 & 269.8 & -45.1 & -35.4 & 286.6 & -0.5 & -1.1 & -2.4 & -4.8 & -0.4 & -0.4 & -2.8 & -2.8 \\
\hline 253.9 & 366.8 & -50.9 & -65.4 & 378.1 & 286.1 & -40.7 & -29.1 & 296.1 & -0.7 & -0.9 & -3.6 & -4.7 & -0.4 & -0.5 & -2.8 & -4.2 \\
\hline 263.7 & 376.9 & -52.3 & -84.0 & 365.9 & 302.6 & -34.1 & -13.7 & 324.3 & -0.8 & -0.9 & -9.3 & -5.3 & -0.4 & -0.5 & -1.2 & -3.2 \\
\hline 273.4 & 389.8 & -47.9 & -50.3 & 381.0 & 307.7 & -31.2 & -17.2 & 312.6 & -0.5 & $\begin{array}{l}-1.1 \\
\end{array}$ & -5.8 & -4.7 & -0.6 & -0.7 & -4.6 & -3.3 \\
\hline 283.2 & 389.7 & -35.6 & -73.6 & 384.9 & 334.0 & -7.0 & 0.5 & 349.0 & -0.5 & -1.2 & -8.4 & -4.5 & -0.5 & -0.6 & -3.2 & -4.1 \\
\hline 293.0 & 392.9 & -30.0 & -83.6 & 386.9 & 366.8 & -5.2 & 21.4 & 393.4 & -0.6 & -0.9 & -8.9 & -4.6 & -0.6 & -0.5 & -2.5 & -4.9 \\
\hline 302.7 & 412.1 & -20.4 & -80.1 & 384.6 & 413.2 & 31.3 & 82.9 & 445.3 & -0.6 & -1.1 & -11.4 & -6.1 & -0.6 & -1.1 & -5.1 & -6.6 \\
\hline 312.5 & 470.1 & 35.6 & -55.3 & 458.6 & 512.3 & 78.9 & 240.5 & 516.7 & -1.4 & -1.6 & -12.3 & -11.6 & -1.2 & -1.4 & -14.5 & -10.1 \\
\hline 322.3 & 550.3 & 126.2 & 22.0 & 464.0 & 605.3 & 234.1 & 372.6 & 779.7 & -1.5 & -2.5 & -12.3 & -13.3 & -2.9 & -2.7 & -5.4 & -8.5 \\
\hline 332.0 & 1481.6 & 1191.8 & 1262.4 & 2072.8 & 534.3 & -203.6 & 731.8 & 720.7 & -40.3 & -31.1 & -59.9 & -48.0 & -35.9 & -57.6 & -71.9 & -98.7 \\
\hline 341.8 & 407.7 & 30.6 & 148.1 & 675.9 & -37.8 & -472.5 & -557.9 & -199.7 & -2.7 & -4.9 & -16.0 & -22.8 & -3.4 & -3.4 & -15.5 & -15.3 \\
\hline
\end{tabular}


Table 53: Dynamic Stiffness Real and Imaginary Parts at $13200 \mathrm{rpm}$ and $783 \mathrm{kPa}(\mathrm{MN} / \mathrm{m})$

\begin{tabular}{|c|c|c|c|c|c|c|c|c|c|c|c|c|c|c|c|c|}
\hline $\mathrm{f}(\mathrm{Hz})$ & $\mathrm{R}\left(\mathrm{H}_{\mathrm{xx}}\right)$ & $\mathrm{R}\left(\mathrm{H}_{\mathrm{xy}}\right)$ & $\mathrm{R}\left(\mathrm{H}_{\mathrm{yx}}\right)$ & $\mathrm{R}\left(\mathrm{H}_{\mathrm{yv}}\right)$ & $\mathrm{I}\left(\mathrm{H}_{\mathrm{xx}}\right)$ & $\mathrm{I}\left(\mathrm{H}_{\mathrm{xy}}\right)$ & $\mathrm{I}\left(\mathrm{H}_{\mathrm{yx}}\right)$ & $\mathrm{I}\left(\mathrm{H}_{\mathrm{yv}}\right)$ & $\Delta \mathrm{R}\left(\mathrm{H}_{\mathrm{xx}}\right)$ & $\Delta \mathrm{R}\left(\mathrm{H}_{\mathrm{xy}}\right)$ & $\Delta \mathrm{R}\left(\mathrm{H}_{\mathrm{yx}}\right)$ & $\Delta \mathrm{R}\left(\mathrm{H}_{\mathrm{yv}}\right)$ & $\Delta \mathrm{I}\left(\mathrm{H}_{\mathrm{xX}}\right)$ & $\Delta \mathrm{I}\left(\mathrm{H}_{\mathrm{xy}}\right)$ & $\Delta \mathrm{I}\left(\mathrm{H}_{\mathrm{vX}}\right)$ & $\Delta \mathrm{I}\left(\mathrm{H}_{\mathrm{yv}}\right)$ \\
\hline 9.8 & 305.0 & -65.7 & -95.6 & 302.0 & 13.0 & -15.0 & -7.7 & 36.6 & -3.2 & -2.3 & -3.8 & -3.9 & -1.9 & -2.6 & -3.4 & -2.1 \\
\hline 19.5 & 303.3 & -70.8 & -95.5 & 302.8 & 25.2 & -13.3 & 1.3 & 12.8 & -1.8 & -1.3 & -4.0 & -2.8 & -1.2 & -1.9 & -3.1 & -2.8 \\
\hline 29.3 & 306.5 & -75.8 & -98.5 & 314.8 & 30.5 & -8.2 & -7.0 & 31.9 & -3.8 & -1.6 & -2.3 & -3.5 & -2.4 & -3.6 & -1.6 & -3.3 \\
\hline 39.1 & 306.1 & -72.0 & -93.4 & 304.6 & 43.0 & -13.3 & -12.7 & 45.5 & -0.9 & -1.8 & -2.0 & -2.9 & -1.7 & -0.9 & -3.3 & -1.9 \\
\hline 48.8 & 306.4 & -69.9 & -96.7 & 306.0 & 55.4 & -21.0 & -9.4 & 61.2 & -0.8 & -1.5 & -0.4 & -1.7 & -0.7 & -1.0 & -1.5 & -1.4 \\
\hline 58.6 & 309.8 & -71.1 & -95.7 & 314.0 & 66.8 & -20.0 & -14.3 & 71.5 & -1.1 & -0.6 & -1.3 & -1.8 & -1.5 & -1.1 & -0.9 & -1.4 \\
\hline 68.4 & 317.1 & -73.4 & -83.7 & 316.6 & 82.3 & -24.0 & -4.0 & 72.4 & -0.5 & -1.2 & -1.9 & -2.4 & -0.7 & -0.8 & -0.8 & -1.4 \\
\hline 78.1 & 317.7 & -70.4 & -89.6 & 305.3 & 89.0 & -27.8 & -11.8 & 80.8 & -0.4 & -0.7 & -2.3 & -2.1 & -0.5 & -0.6 & -1.6 & -1.1 \\
\hline 87.9 & 320.4 & -74.5 & -98.6 & 329.4 & 97.2 & -30.5 & -14.4 & 108.8 & -0.7 & -0.6 & -1.1 & -1.9 & -1.1 & -1.2 & -2.9 & -1.6 \\
\hline 97.7 & 325.2 & -74.4 & -94.6 & 320.8 & 105.9 & -33.6 & -16.6 & 112.0 & -0.3 & -0.5 & -2.8 & -1.8 & -0.5 & -0.5 & -2.6 & -1.5 \\
\hline 107.4 & 324.8 & -75.5 & -98.7 & 330.3 & 114.7 & -34.4 & -12.5 & 126.6 & -1.0 & -0.6 & -0.9 & -2.2 & -0.7 & -0.6 & -1.4 & -1.2 \\
\hline 117.2 & 329.7 & -77.5 & -96.9 & 334.6 & 123.9 & -36.6 & -18.6 & 133.5 & -0.4 & -0.6 & -0.9 & -1.8 & -0.5 & -0.3 & -1.3 & -1.4 \\
\hline 127.0 & 332.4 & -77.2 & -92.8 & 330.5 & 131.4 & -38.2 & $\begin{array}{l}-19.4 \\
\end{array}$ & 150.5 & -0.6 & -0.8 & -0.9 & -1.7 & -0.5 & -0.7 & -2.0 & $\begin{array}{l}-1.4 \\
\end{array}$ \\
\hline 136.7 & 336.2 & -75.0 & -90.8 & 342.0 & 144.2 & -39.9 & -18.1 & 154.0 & -0.5 & -0.8 & -1.1 & -1.7 & -0.5 & -0.5 & -1.5 & -1.6 \\
\hline 146.5 & 339.1 & -73.3 & -90.2 & 345.8 & 151.5 & -42.3 & -21.1 & 158.3 & -0.8 & -0.6 & -1.4 & -1.6 & -0.5 & -0.7 & -1.8 & -1.6 \\
\hline 156.3 & 339.5 & -68.8 & -83.2 & 324.3 & 159.5 & -43.8 & -24.2 & 164.8 & -0.4 & -0.9 & -2.0 & -1.9 & -0.9 & -0.4 & -1.5 & -1.6 \\
\hline 166.0 & 345.2 & -80.1 & -87.9 & 362.1 & 167.8 & -42.6 & -19.1 & 189.4 & -0.9 & -0.5 & -0.4 & -1.8 & -0.6 & -0.7 & -1.9 & -1.3 \\
\hline 175.8 & 344.8 & -77.0 & -86.8 & 369.1 & 178.7 & -45.4 & -20.2 & 189.9 & -0.4 & -0.4 & -1.0 & -1.7 & -0.6 & -0.5 & -1.1 & $\begin{array}{l}-1.4 \\
\end{array}$ \\
\hline 185.5 & 346.0 & -75.0 & -81.3 & 368.8 & 186.9 & -42.1 & -17.1 & 189.2 & -0.6 & -0.4 & -0.6 & -1.5 & -0.7 & -0.5 & -1.1 & $\begin{array}{l}-1.7 \\
\end{array}$ \\
\hline 195.3 & 349.1 & -70.7 & -71.9 & 357.8 & 198.2 & -41.2 & -14.7 & 196.2 & -0.8 & -0.8 & -1.4 & $\begin{array}{l}-1.7 \\
\end{array}$ & -0.6 & -0.5 & -3.2 & -1.6 \\
\hline 205.1 & 350.7 & -72.0 & -72.3 & 368.2 & 205.1 & -38.2 & -17.0 & 216.0 & -1.0 & -0.6 & -0.8 & -1.9 & -1.0 & -0.4 & -2.1 & -1.3 \\
\hline 214.8 & 357.5 & -67.0 & -67.5 & 372.3 & 218.9 & -36.3 & -23.9 & 209.4 & -1.0 & -0.9 & -1.1 & -2.3 & -1.1 & -0.4 & -2.7 & -1.8 \\
\hline 224.6 & 360.3 & -42.7 & -56.2 & 284.2 & 230.9 & -36.8 & -35.6 & 265.9 & -2.3 & -0.7 & -3.5 & -2.3 & -2.8 & -1.2 & -1.1 & -1.9 \\
\hline 234.4 & 369.0 & -68.8 & -68.8 & 389.4 & 239.6 & -39.6 & -32.8 & 243.1 & -0.6 & -0.5 & -1.3 & -1.7 & -1.1 & -0.4 & -3.0 & -1.9 \\
\hline 244.1 & 366.1 & -64.3 & -65.7 & 391.7 & 253.6 & -35.5 & -25.0 & 249.9 & -0.6 & -0.5 & -1.9 & -1.9 & -0.3 & -0.3 & -2.4 & $\begin{array}{l}-1.4 \\
\end{array}$ \\
\hline 253.9 & 368.5 & -60.3 & -65.1 & 405.1 & 265.7 & -31.3 & -22.1 & 261.8 & -0.5 & -0.3 & -2.0 & -2.1 & -0.4 & -0.4 & $\begin{array}{l}-1.9 \\
\end{array}$ & -1.7 \\
\hline 263.7 & 375.0 & -51.8 & -61.0 & 380.7 & 281.6 & -25.5 & -16.8 & 257.1 & -0.4 & -0.4 & $\begin{array}{l}-1.4 \\
\end{array}$ & -1.8 & -0.5 & -0.6 & -3.9 & -1.5 \\
\hline 273.4 & 381.7 & -22.9 & -57.5 & 291.4 & 294.2 & -12.4 & -15.2 & 288.1 & -0.4 & -0.4 & -2.4 & -1.7 & -0.8 & -0.5 & -1.6 & -1.7 \\
\hline 283.2 & 380.9 & -48.3 & -58.3 & 378.0 & 313.0 & -17.8 & -12.8 & 286.5 & -0.7 & -0.4 & -2.2 & -1.8 & -0.7 & -0.4 & -3.4 & -1.8 \\
\hline 293.0 & 388.3 & 21.6 & -49.6 & 352.8 & 322.9 & -33.6 & 5.3 & 467.0 & -0.5 & -1.4 & -2.1 & -4.2 & -0.3 & -1.3 & -2.7 & -1.4 \\
\hline 302.7 & 386.3 & -25.9 & -46.5 & 506.3 & 352.1 & -67.8 & 21.3 & 422.5 & -0.5 & -1.0 & -2.7 & -3.7 & -1.1 & -1.2 & -3.2 & -3.0 \\
\hline 312.5 & 424.2 & 63.0 & -43.4 & 528.8 & 369.9 & -73.2 & 103.6 & 549.2 & -0.8 & -0.7 & -3.4 & -5.2 & -0.9 & -2.7 & -2.6 & -2.4 \\
\hline 322.3 & 417.2 & 61.1 & -48.9 & 427.2 & 425.0 & 5.4 & 97.7 & 538.6 & -0.5 & -1.5 & -3.5 & -3.0 & -1.0 & -0.7 & -4.9 & -4.2 \\
\hline 332.0 & 445.8 & 29.0 & -42.0 & 463.0 & 524.1 & 58.6 & 164.8 & 436.9 & -0.7 & -0.5 & -3.9 & -4.8 & -0.7 & -1.0 & -6.0 & -4.1 \\
\hline 341.8 & 700.1 & 191.6 & 142.5 & 552.6 & 660.5 & 145.0 & 356.9 & 553.9 & -3.7 & -2.2 & -4.9 & -5.0 & -2.4 & -1.9 & -9.9 & -6.7 \\
\hline
\end{tabular}


Table 54: Dynamic Stiffness Real and Imaginary Parts at $13200 \mathrm{rpm}$ and $1567 \mathrm{kPa}(\mathrm{MN} / \mathrm{m})$

\begin{tabular}{|c|c|c|c|c|c|c|c|c|c|c|c|c|c|c|c|c|}
\hline $\mathrm{f}(\mathrm{Hz})$ & $\mathrm{R}\left(\mathrm{H}_{\mathrm{xx}}\right)$ & $\mathrm{R}\left(\mathrm{H}_{\mathrm{xy}}\right)$ & $\mathrm{R}\left(\mathrm{H}_{\mathrm{yx}}\right)$ & $\mathrm{R}\left(\mathrm{H}_{\mathrm{yv}}\right)$ & $\mathrm{I}\left(\mathrm{H}_{\mathrm{xx}}\right)$ & $\mathrm{I}\left(\mathrm{H}_{\mathrm{xy}}\right)$ & $\mathrm{I}\left(\mathrm{H}_{\mathrm{yx}}\right)$ & $\mathrm{I}\left(\mathrm{H}_{\mathrm{yv}}\right)$ & $\Delta \mathrm{R}\left(\mathrm{H}_{\mathrm{xx}}\right)$ & $\Delta \mathrm{R}\left(\mathrm{H}_{\mathrm{xy}}\right)$ & $\Delta \mathrm{R}\left(\mathrm{H}_{\mathrm{yx}}\right)$ & $\Delta \mathrm{R}\left(\mathrm{H}_{\mathrm{vy}}\right)$ & $\Delta \mathrm{I}\left(\mathrm{H}_{\mathrm{xx}}\right)$ & $\Delta \mathrm{I}\left(\mathrm{H}_{\mathrm{xy}}\right)$ & $\Delta \mathrm{I}\left(\mathrm{H}_{\mathrm{yx}}\right)$ & $\Delta \mathrm{I}\left(\mathrm{H}_{\mathrm{vv}}\right)$ \\
\hline 9.8 & 331.6 & -83.4 & -91.4 & 351.3 & 22.6 & -19.5 & 3.1 & 41.5 & -6.0 & -5.4 & -5.4 & -5.9 & -5.0 & -2.7 & -5.2 & -4.9 \\
\hline 19.5 & 330.7 & -85.4 & -96.4 & 352.9 & 23.7 & -14.8 & -3.8 & 26.8 & -1.3 & -4.1 & -1.9 & -7.0 & -1.3 & -3.7 & -1.3 & -4.7 \\
\hline 29.3 & 336.1 & -83.8 & -109.4 & 359.9 & 29.7 & -14.1 & -12.4 & 23.4 & -2.1 & -3.3 & -1.7 & -2.3 & -2.4 & -2.1 & -3.7 & -2.9 \\
\hline 39.1 & 334.7 & -84.9 & -96.4 & 345.2 & 39.3 & -12.8 & -20.7 & 43.3 & -1.2 & -1.9 & -2.0 & -2.9 & -1.5 & -1.5 & -2.9 & -1.8 \\
\hline 48.8 & 335.2 & -81.7 & -98.1 & 344.3 & 52.6 & -19.4 & -12.5 & 57.9 & -1.4 & -1.4 & -1.8 & -1.9 & -0.5 & -0.7 & -1.2 & -1.2 \\
\hline 58.6 & 334.3 & -82.3 & -99.9 & 353.5 & 59.9 & -20.7 & -18.7 & 59.9 & -1.0 & -0.9 & -2.1 & -2.1 & -1.2 & -0.8 & -2.0 & -1.8 \\
\hline 68.4 & 332.8 & -81.5 & -102.4 & 356.2 & 71.3 & -22.1 & -20.4 & 62.5 & -0.7 & -1.1 & -0.9 & -1.7 & -0.9 & -0.9 & -1.0 & -2.2 \\
\hline 78.1 & 344.3 & -83.3 & -94.0 & 345.7 & 83.8 & -25.1 & -8.0 & 65.7 & -0.8 & -0.5 & -0.7 & -1.9 & -0.9 & -0.8 & -1.1 & -1.2 \\
\hline 87.9 & 346.3 & -86.9 & -100.3 & 364.3 & 90.1 & -27.8 & -16.5 & 95.1 & -1.0 & -0.6 & -1.4 & -1.6 & -0.5 & -0.5 & -2.2 & -1.6 \\
\hline 97.7 & 347.8 & -86.7 & -94.0 & 355.2 & 98.1 & -30.3 & -20.3 & 94.6 & -0.7 & -0.6 & -1.0 & -1.6 & -1.2 & -0.8 & -1.1 & -1.3 \\
\hline 107.4 & 348.8 & -87.6 & -103.7 & 365.0 & 105.5 & -30.8 & -20.9 & 114.5 & -0.7 & -1.0 & -1.5 & -2.0 & -0.3 & -0.7 & -1.4 & -1.2 \\
\hline 117.2 & 352.9 & -87.4 & -103.1 & 369.1 & 113.0 & -31.7 & -20.7 & 118.0 & -0.5 & -0.6 & -0.8 & -1.7 & -0.4 & -0.6 & -0.6 & -1.5 \\
\hline 127.0 & 355.6 & -86.3 & -96.6 & 363.4 & 122.4 & -33.2 & -22.5 & 133.6 & -0.2 & -0.4 & -0.9 & $\begin{array}{l}-1.8 \\
\end{array}$ & -0.5 & -0.7 & -0.5 & $\begin{array}{l}-1.7 \\
\end{array}$ \\
\hline 136.7 & 356.4 & -83.9 & -94.4 & 367.8 & 132.2 & -33.9 & -24.0 & 141.4 & -0.4 & -0.7 & -0.7 & -2.3 & -0.4 & -0.6 & -1.1 & -1.4 \\
\hline 146.5 & 360.7 & -83.5 & -92.2 & 372.2 & 138.1 & -34.2 & -23.5 & 144.2 & -0.5 & -0.5 & -0.7 & -1.6 & -0.5 & -0.5 & -2.2 & -1.3 \\
\hline 156.3 & 361.0 & -78.1 & -85.8 & 356.6 & 146.6 & -34.5 & -26.7 & 134.7 & -1.0 & -0.5 & -1.4 & -1.7 & -0.6 & -0.6 & -1.9 & -1.5 \\
\hline 166.0 & 363.8 & -86.2 & -94.8 & 391.7 & 153.5 & -38.0 & -22.3 & 175.2 & -0.5 & -0.4 & -0.7 & -2.0 & -0.7 & -0.9 & -0.8 & -1.2 \\
\hline 175.8 & 364.5 & -83.4 & -92.1 & 389.6 & 163.8 & -39.1 & -28.5 & 177.1 & -0.7 & -0.4 & -1.2 & -2.1 & -0.5 & -0.8 & -0.6 & -1.5 \\
\hline 185.5 & 367.8 & -82.7 & -93.3 & 396.2 & 172.7 & -37.4 & -20.0 & 175.0 & -0.8 & -0.4 & -0.8 & -2.0 & -0.8 & -0.5 & -1.3 & -2.1 \\
\hline 195.3 & 369.3 & -78.8 & -86.4 & 389.4 & 181.2 & -36.1 & -17.4 & 183.1 & -0.7 & -0.5 & -0.7 & -1.9 & -0.9 & -0.7 & $\begin{array}{l}-1.9 \\
\end{array}$ & -1.6 \\
\hline 205.1 & 368.8 & -76.5 & -84.7 & 402.1 & 188.3 & -34.6 & -20.6 & 198.8 & -1.0 & -1.0 & -1.3 & -1.6 & -0.8 & -0.5 & -2.1 & -1.6 \\
\hline 214.8 & 374.5 & -71.4 & -77.7 & 407.3 & 199.7 & -32.5 & -25.2 & 190.9 & -1.3 & -1.0 & -2.6 & -2.9 & -1.0 & -1.8 & -1.2 & $\begin{array}{l}-1.4 \\
\end{array}$ \\
\hline 224.6 & 378.5 & -63.9 & -72.1 & 344.6 & 209.0 & -31.2 & -32.7 & 201.0 & -4.3 & -1.7 & -4.7 & -2.6 & -4.1 & -1.4 & -3.8 & -2.5 \\
\hline 234.4 & 382.3 & -73.6 & -75.3 & 420.3 & 221.3 & -39.9 & -37.3 & 224.8 & -0.7 & -0.5 & -1.6 & -2.3 & -1.2 & -0.5 & -2.4 & -1.4 \\
\hline 244.1 & 380.8 & -62.4 & -74.6 & 407.8 & 232.7 & -36.4 & -27.9 & 239.4 & -0.3 & -0.4 & -1.1 & -2.3 & -0.5 & -0.5 & -1.6 & -1.7 \\
\hline 253.9 & 380.7 & -59.5 & $\begin{array}{l}-70.7 \\
\end{array}$ & 417.9 & 242.5 & -31.3 & -27.0 & 242.3 & -0.5 & -0.6 & -1.1 & -1.6 & -0.9 & -0.5 & $\begin{array}{l}-1.6 \\
\end{array}$ & -1.5 \\
\hline 263.7 & 385.2 & -55.8 & -75.6 & 423.1 & 255.9 & -30.1 & -23.3 & 237.1 & -0.4 & -0.4 & -3.5 & -1.8 & -0.4 & -0.4 & -1.8 & -1.5 \\
\hline 273.4 & 389.1 & -42.6 & -61.0 & 353.8 & 266.7 & -21.6 & -15.2 & 231.1 & -0.7 & -0.3 & -1.2 & -1.8 & -0.6 & -0.3 & -2.8 & -1.7 \\
\hline 283.2 & 392.7 & -54.6 & $\begin{array}{r}-73.1 \\
\end{array}$ & 420.9 & 282.2 & -30.8 & -15.9 & 256.5 & -0.4 & -0.4 & -2.1 & -1.7 & -0.6 & -0.4 & -0.9 & -1.5 \\
\hline 293.0 & 397.0 & -38.1 & -57.1 & 389.8 & 294.6 & -14.9 & -13.7 & 281.2 & -0.4 & -0.3 & -1.2 & -2.1 & -0.7 & -0.7 & -1.4 & -1.5 \\
\hline 302.7 & 389.1 & 19.0 & -49.5 & 302.3 & 317.7 & 4.2 & -17.8 & 364.5 & -0.3 & -0.7 & -1.7 & -2.5 & -0.7 & -0.5 & -1.3 & -1.9 \\
\hline 312.5 & 396.4 & 18.2 & -55.6 & 367.2 & 339.2 & 9.3 & -12.4 & 350.4 & -0.6 & -0.5 & -2.0 & -3.0 & -0.6 & -0.4 & -3.0 & -2.6 \\
\hline 322.3 & 405.7 & 10.5 & -55.3 & 375.4 & 357.9 & 9.6 & 7.2 & 359.3 & -0.6 & -0.8 & -3.5 & -1.8 & -0.6 & -0.5 & -1.4 & -3.0 \\
\hline 332.0 & 413.0 & -16.2 & -40.0 & 525.0 & 390.0 & -38.9 & 39.4 & 361.5 & -0.4 & -0.4 & -3.1 & -2.2 & -0.6 & -0.9 & -3.0 & -2.7 \\
\hline 341.8 & 447.6 & 14.1 & -6.0 & 508.1 & 434.4 & 7.5 & 69.6 & 359.5 & -1.0 & -0.5 & -1.9 & -2.3 & -1.2 & -0.9 & -2.7 & -2.1 \\
\hline
\end{tabular}


Table 55: Dynamic Stiffness Real and Imaginary Parts at $13200 \mathrm{rpm}$ and $2350 \mathrm{kPa}(\mathrm{MN} / \mathrm{m})$

\begin{tabular}{|c|c|c|c|c|c|c|c|c|c|c|c|c|c|c|c|c|}
\hline $\mathrm{f}(\mathrm{Hz})$ & $\mathrm{R}\left(\mathrm{H}_{\mathrm{xx}}\right)$ & $\mathrm{R}\left(\mathrm{H}_{\mathrm{xy}}\right)$ & $\mathrm{R}\left(\mathrm{H}_{\mathrm{yx}}\right)$ & $\mathrm{R}\left(\mathrm{H}_{\mathrm{yv}}\right)$ & $\mathrm{I}\left(\mathrm{H}_{\mathrm{xx}}\right)$ & $\mathrm{I}\left(\mathrm{H}_{\mathrm{xy}}\right)$ & $\mathrm{I}\left(\mathrm{H}_{\mathrm{yx}}\right)$ & $\mathrm{I}\left(\mathrm{H}_{\mathrm{vv}}\right)$ & $\Delta \mathrm{R}\left(\mathrm{H}_{\mathrm{xx}}\right)$ & $\Delta \mathrm{R}\left(\mathrm{H}_{\mathrm{xy}}\right)$ & $\Delta \mathrm{R}\left(\mathrm{H}_{\mathrm{yx}}\right)$ & $\Delta \mathrm{R}\left(\mathrm{H}_{\mathrm{yv}}\right)$ & $\Delta \mathrm{I}\left(\mathrm{H}_{\mathrm{xx}}\right)$ & $\Delta \mathrm{I}\left(\mathrm{H}_{\mathrm{xy}}\right)$ & $\Delta \mathrm{I}\left(\mathrm{H}_{\mathrm{vx}}\right)$ & $\Delta \mathrm{I}\left(\mathrm{H}_{\mathrm{yv}}\right)$ \\
\hline 9.8 & 315.9 & -70.9 & -94.2 & 384.6 & 11.2 & -9.3 & -8.8 & 51.0 & -1.6 & -6.1 & -4.8 & -14.5 & -1.5 & -3.7 & -2.2 & -7.1 \\
\hline 19.5 & 314.3 & -62.8 & -42.9 & 302.6 & 26.1 & -10.0 & 40.4 & 4.7 & -1.7 & -0.7 & -7.2 & -4.5 & $\begin{array}{l}-1.1 \\
\end{array}$ & -4.1 & -12.5 & -7.8 \\
\hline 29.3 & 318.8 & -66.3 & -110.4 & 373.6 & 30.6 & -9.1 & -28.8 & 34.2 & -1.1 & -2.8 & -6.5 & -7.5 & $\begin{array}{l}-1.3 \\
\end{array}$ & -2.2 & -1.9 & -7.3 \\
\hline 39.1 & 323.0 & -69.5 & -93.7 & 346.5 & 41.6 & -16.3 & -43.4 & 42.9 & -0.7 & -1.7 & -2.7 & -1.9 & -1.1 & -2.4 & -5.0 & -3.5 \\
\hline 48.8 & 326.1 & -68.4 & -81.6 & 340.4 & 53.8 & -18.2 & -5.5 & 53.5 & -0.6 & -1.4 & -1.3 & -2.8 & -0.7 & -1.7 & -1.6 & -2.9 \\
\hline 58.6 & 326.8 & -68.4 & -88.9 & 350.7 & 64.5 & -20.9 & -10.1 & 59.1 & -0.5 & -1.2 & -1.9 & -3.2 & -0.7 & -1.4 & -1.5 & -1.5 \\
\hline 68.4 & 325.6 & -69.4 & -88.2 & 346.9 & 73.5 & -23.4 & -18.6 & 62.1 & -0.9 & -0.5 & -1.8 & -2.7 & -0.6 & -0.5 & -1.4 & -2.2 \\
\hline 78.1 & 332.6 & -66.7 & -62.6 & 336.6 & 86.5 & -24.1 & -21.5 & 67.5 & -0.4 & -0.7 & -3.7 & -2.1 & -0.4 & -1.1 & -2.2 & -1.9 \\
\hline 87.9 & 334.3 & -71.4 & -78.2 & 358.5 & 93.0 & -29.1 & -15.5 & 92.9 & -0.5 & -0.9 & -2.5 & -3.1 & -0.6 & -0.7 & -1.1 & -1.3 \\
\hline 97.7 & 338.7 & -71.8 & -76.7 & 350.4 & 100.2 & -30.4 & -24.2 & 95.7 & -0.6 & -1.0 & -2.7 & -2.0 & -0.2 & -0.4 & -1.7 & -1.7 \\
\hline 107.4 & 339.4 & -71.7 & -91.1 & 360.7 & 109.3 & -32.5 & -19.3 & 113.6 & -0.5 & -0.6 & -2.1 & -2.7 & -0.4 & $\begin{array}{l}-1.3 \\
\end{array}$ & -1.3 & -1.1 \\
\hline 117.2 & 344.9 & -72.9 & -78.8 & 360.7 & 115.7 & -31.8 & -25.0 & 116.9 & -0.5 & -0.6 & -1.4 & -1.7 & -0.4 & -0.6 & -1.1 & -1.3 \\
\hline 127.0 & 346.4 & -71.8 & -77.4 & 356.7 & 124.1 & -33.6 & -20.2 & 128.3 & -0.8 & -0.5 & -1.9 & -3.2 & -0.2 & -0.6 & -1.4 & -1.4 \\
\hline 136.7 & 350.8 & -69.8 & -89.1 & 366.8 & 132.2 & -32.5 & -29.6 & 138.5 & -0.2 & -0.6 & -1.2 & -3.1 & -0.2 & -0.5 & -2.5 & -1.5 \\
\hline 146.5 & 350.2 & -65.5 & -81.3 & 368.5 & 142.2 & -34.8 & -15.2 & 145.3 & -0.3 & -0.4 & -3.4 & -2.4 & -0.5 & -1.0 & -1.5 & -2.3 \\
\hline 156.3 & 349.5 & -61.9 & -78.4 & 354.4 & 149.6 & -37.3 & -23.1 & 133.3 & -0.6 & -0.8 & -2.5 & -1.8 & -0.3 & -0.6 & -1.2 & -3.7 \\
\hline 166.0 & 356.6 & -71.5 & -77.3 & 387.8 & 157.9 & -38.7 & -13.9 & 169.4 & -0.6 & -0.9 & -2.8 & -5.1 & -0.4 & -0.5 & -2.6 & -3.2 \\
\hline 175.8 & 357.1 & -68.1 & -81.4 & 389.0 & 165.7 & -40.1 & -19.3 & 167.9 & -0.5 & -0.6 & -1.9 & -3.2 & -0.3 & -0.7 & -2.4 & -1.7 \\
\hline 185.5 & 357.8 & -67.0 & -88.1 & 388.8 & 176.5 & -36.0 & -23.6 & 174.6 & -0.6 & -0.5 & -3.1 & -2.2 & -0.6 & -0.6 & -1.6 & $\begin{array}{l}-1.3 \\
\end{array}$ \\
\hline 195.3 & 360.8 & -61.7 & -60.9 & 374.2 & 187.2 & -37.0 & -11.8 & 180.7 & -0.3 & -0.5 & -2.6 & -2.7 & -0.4 & -0.5 & -2.6 & -2.2 \\
\hline 205.1 & 356.1 & -57.9 & -78.4 & 392.3 & 191.1 & -36.4 & -15.9 & 201.2 & -0.5 & -0.4 & -3.1 & -2.1 & -0.7 & -0.5 & -2.9 & -1.4 \\
\hline 214.8 & 364.0 & -52.5 & -77.1 & 393.8 & 203.6 & -35.0 & -19.6 & 189.7 & -1.0 & -2.0 & -3.5 & -3.2 & -1.5 & -1.9 & -4.6 & -2.3 \\
\hline 224.6 & 362.9 & -44.3 & -74.5 & 341.3 & 210.6 & -34.8 & -27.6 & 204.9 & -1.0 & -1.0 & -3.3 & -3.1 & -1.0 & -0.9 & -2.2 & -2.0 \\
\hline 234.4 & 370.0 & -53.7 & -80.8 & 409.5 & 222.3 & -39.7 & -40.3 & 224.2 & -0.9 & -0.7 & -2.8 & -2.1 & -0.4 & -0.6 & -4.8 & -2.1 \\
\hline 244.1 & 368.3 & -48.1 & -62.8 & 401.8 & 237.4 & -38.3 & -28.9 & 235.3 & -0.6 & -0.4 & -3.8 & -3.0 & -0.3 & -0.4 & -3.4 & -2.4 \\
\hline 253.9 & 365.3 & -35.8 & -60.2 & 409.7 & 249.0 & -39.1 & -26.5 & 266.5 & -0.5 & -0.5 & -3.2 & -4.2 & -0.3 & -0.9 & -2.7 & -2.1 \\
\hline 263.7 & 370.1 & -33.6 & -67.7 & 405.6 & 264.9 & -32.4 & -20.5 & 243.2 & -0.3 & -0.6 & -4.1 & -3.3 & -0.3 & -0.5 & -4.3 & -2.3 \\
\hline 273.4 & 372.1 & -21.0 & -60.0 & 342.7 & 279.0 & -24.6 & -16.6 & 235.3 & -0.6 & -0.5 & -5.6 & -3.3 & -0.3 & -0.3 & -1.9 & -3.2 \\
\hline 283.2 & 377.1 & -32.3 & -72.5 & 414.0 & 299.8 & -36.8 & -18.1 & 268.9 & -0.5 & -0.4 & -5.9 & -2.8 & -0.5 & -0.5 & -3.7 & -3.2 \\
\hline 293.0 & 382.0 & -10.4 & -61.5 & 375.4 & 312.9 & -20.8 & -3.2 & 291.3 & -0.5 & -0.4 & -3.2 & -4.9 & -0.4 & -0.4 & -1.5 & -4.9 \\
\hline 302.7 & 376.9 & 23.8 & -47.7 & 326.4 & 337.8 & -3.1 & 10.8 & 339.0 & -0.5 & -0.4 & -5.2 & -3.8 & -0.5 & -0.4 & -3.2 & -6.9 \\
\hline 312.5 & 387.6 & 3.2 & -55.6 & 450.3 & 363.8 & -24.0 & 12.6 & 316.2 & -0.5 & -0.5 & -4.2 & -2.6 & -1.0 & -0.7 & -3.4 & -10.5 \\
\hline 322.3 & 399.6 & 113.6 & -68.6 & 384.5 & 391.9 & -45.8 & 57.6 & 524.2 & -1.7 & -1.2 & -7.0 & -4.2 & -1.3 & -3.1 & -4.8 & -16.4 \\
\hline 332.0 & 406.6 & 14.0 & -57.6 & 532.5 & 451.5 & -60.2 & 90.2 & 356.6 & -0.8 & -0.2 & -6.8 & -11.4 & -0.9 & -1.3 & -4.8 & -5.9 \\
\hline 341.8 & 466.1 & 59.4 & -15.8 & 514.6 & 498.2 & -28.1 & 122.5 & 368.1 & -1.2 & -0.9 & -9.8 & -7.5 & -1.2 & -1.0 & -6.5 & -4.9 \\
\hline
\end{tabular}


Table 56: Dynamic Stiffness Real and Imaginary Parts at $13200 \mathrm{rpm}$ and $3134 \mathrm{kPa}$ (MN/m)

\begin{tabular}{|c|c|c|c|c|c|c|c|c|c|c|c|c|c|c|c|c|}
\hline $\mathrm{f}(\mathrm{Hz})$ & $\mathrm{R}\left(\mathrm{H}_{\mathrm{xx}}\right)$ & $\mathrm{R}\left(\mathrm{H}_{\mathrm{xy}}\right)$ & $\mathrm{R}\left(\mathrm{H}_{\mathrm{yx}}\right)$ & $\mathrm{R}\left(\mathrm{H}_{\mathrm{yv}}\right)$ & $\mathrm{I}\left(\mathrm{H}_{\mathrm{xx}}\right)$ & $\mathrm{I}\left(\mathrm{H}_{\mathrm{xy}}\right)$ & $\mathrm{I}\left(\mathrm{H}_{\mathrm{yx}}\right)$ & $\mathrm{I}\left(\mathrm{H}_{\mathrm{yv}}\right)$ & $\Delta \mathrm{R}\left(\mathrm{H}_{\mathrm{xx}}\right)$ & $\Delta \mathrm{R}\left(\mathrm{H}_{\mathrm{xy}}\right)$ & $\Delta \mathrm{R}\left(\mathrm{H}_{\mathrm{yx}}\right)$ & $\Delta \mathrm{R}\left(\mathrm{H}_{\mathrm{yv}}\right)$ & $\Delta \mathrm{I}\left(\mathrm{H}_{\mathrm{xx}}\right)$ & $\Delta \mathrm{I}\left(\mathrm{H}_{\mathrm{xy}}\right)$ & $\Delta \mathrm{I}\left(\mathrm{H}_{\mathrm{yx}}\right)$ & $\Delta \mathrm{I}\left(\mathrm{H}_{\mathrm{yv}}\right)$ \\
\hline 9.8 & 342.1 & -81.8 & -100.4 & 391.3 & 9.4 & -5.7 & -16.7 & 54.3 & -1.8 & -5.9 & -1.9 & -7.8 & -2.2 & -6.3 & -1.8 & -4.5 \\
\hline 19.5 & 340.0 & -78.7 & -99.0 & 383.0 & 19.7 & -2.1 & -17.1 & 30.9 & -1.5 & -5.2 & -2.6 & -6.2 & -0.9 & -2.7 & -2.7 & -5.8 \\
\hline 29.3 & 344.6 & -78.4 & -95.5 & 392.8 & 29.8 & -12.0 & -16.8 & 32.5 & -1.7 & -4.5 & -1.4 & -6.3 & -1.0 & -2.8 & -1.2 & -4.6 \\
\hline 39.1 & 347.4 & -75.6 & -85.3 & 374.7 & 36.4 & -9.3 & -6.6 & 37.5 & -1.3 & -1.9 & -2.0 & -3.9 & -1.1 & -2.5 & -2.0 & -2.1 \\
\hline 48.8 & 347.5 & -78.1 & -83.6 & 371.2 & 50.8 & -16.5 & -1.0 & 45.9 & -0.7 & -1.1 & -0.9 & -3.2 & -1.3 & -1.7 & -0.4 & -1.4 \\
\hline 58.6 & 347.7 & -76.1 & -82.8 & 382.2 & 60.1 & -17.1 & -16.6 & 52.7 & -0.8 & -1.6 & -0.6 & -2.1 & -0.4 & -1.5 & -1.4 & -1.8 \\
\hline 68.4 & 349.6 & -78.0 & -86.8 & 381.1 & 67.5 & -21.4 & -11.8 & 51.4 & -0.5 & -0.7 & -0.8 & -2.4 & -1.0 & -2.0 & -1.3 & -1.2 \\
\hline 78.1 & 354.6 & -74.4 & -84.4 & 375.0 & 82.4 & -20.7 & -6.2 & 61.7 & -0.8 & -0.9 & -0.8 & -1.5 & -0.9 & -1.0 & -1.4 & -1.1 \\
\hline 87.9 & 357.4 & -79.7 & -92.5 & 394.8 & 87.0 & -28.1 & -20.4 & 87.2 & -0.9 & -1.4 & -0.8 & -2.1 & -0.6 & -1.3 & -0.5 & -1.2 \\
\hline 97.7 & 360.3 & -80.7 & -90.7 & 386.6 & 93.5 & -28.8 & -23.4 & 86.7 & -0.6 & -1.0 & -1.4 & -2.7 & -0.5 & -0.6 & -0.3 & -1.6 \\
\hline 107.4 & 360.8 & -79.9 & -89.5 & 391.1 & 102.2 & -30.5 & -21.6 & 105.1 & -0.6 & -0.5 & -0.6 & -1.9 & -0.4 & -0.6 & -0.7 & -1.2 \\
\hline 117.2 & 365.7 & -80.4 & -84.7 & 394.8 & 108.7 & -31.5 & -26.4 & 108.0 & -0.6 & -0.7 & -0.7 & -1.9 & -0.4 & -1.1 & -0.7 & -1.5 \\
\hline 127.0 & 367.6 & $\begin{array}{l}-78.2 \\
\end{array}$ & -86.9 & 389.7 & 116.6 & -30.5 & -26.4 & 120.1 & -0.8 & -0.7 & -0.5 & -1.4 & -0.6 & -0.4 & -0.4 & -1.0 \\
\hline 136.7 & 370.5 & -76.8 & -83.1 & 396.7 & 125.9 & -31.0 & -35.9 & 127.4 & -0.4 & -1.0 & -0.8 & -1.5 & -0.6 & -0.9 & -1.1 & -1.2 \\
\hline 146.5 & 369.7 & -72.9 & -81.4 & 401.4 & 133.3 & -34.2 & -30.2 & 132.0 & -0.4 & -0.7 & -1.0 & -1.9 & -0.7 & -0.6 & -0.9 & -1.9 \\
\hline 156.3 & 369.9 & -69.0 & -82.4 & 386.3 & 141.0 & -33.8 & -26.2 & 115.3 & -0.3 & -0.4 & -0.3 & -2.0 & -0.5 & -0.9 & -0.5 & -1.5 \\
\hline 166.0 & 375.4 & -76.6 & -82.3 & 408.6 & 148.7 & -36.4 & -31.9 & 157.8 & -0.2 & -0.4 & -0.6 & -1.7 & -0.3 & -0.6 & -0.6 & -1.2 \\
\hline 175.8 & 375.2 & -72.6 & -80.5 & 411.0 & 156.2 & -38.3 & -34.8 & 161.4 & -0.3 & -0.4 & -0.5 & -1.6 & -0.5 & -0.5 & -0.6 & -1.5 \\
\hline 185.5 & 376.1 & $\begin{array}{l}-71.1 \\
\end{array}$ & $\begin{array}{l}-78.1 \\
\end{array}$ & 416.4 & 170.0 & -39.4 & -30.7 & 165.0 & -0.8 & -0.7 & -1.7 & -1.8 & -0.5 & -0.7 & -1.6 & -1.9 \\
\hline 195.3 & 379.8 & -66.8 & -73.7 & 411.0 & 175.1 & -36.2 & -27.9 & 169.3 & -0.3 & -0.3 & $\begin{array}{l}-1.2 \\
\end{array}$ & -2.1 & -0.3 & -0.7 & -0.5 & $\begin{array}{l}-1.6 \\
\end{array}$ \\
\hline 205.1 & 375.8 & -62.5 & -78.7 & 417.3 & 181.0 & -36.3 & -27.6 & 184.2 & -0.4 & -0.5 & -0.8 & -2.2 & -0.4 & -0.7 & -0.3 & -1.5 \\
\hline 214.8 & 385.2 & -59.1 & -75.0 & 428.8 & 194.7 & -37.9 & -35.3 & 182.7 & -1.0 & -0.8 & -1.0 & -2.4 & -0.8 & -1.0 & -1.2 & -1.9 \\
\hline 224.6 & 381.7 & -48.2 & -69.9 & 376.8 & 199.5 & -39.3 & -36.7 & 198.3 & -2.0 & -1.7 & -1.7 & -3.1 & -1.7 & -1.5 & -2.2 & -2.1 \\
\hline 234.4 & 388.5 & -59.5 & -71.9 & 437.7 & 211.1 & -43.5 & -39.7 & 212.3 & -0.8 & -0.8 & -1.1 & -1.8 & -0.8 & -0.5 & -2.0 & -2.0 \\
\hline 244.1 & 388.1 & -52.4 & -64.2 & 430.7 & 223.7 & -41.7 & -36.5 & 219.2 & -0.6 & -0.4 & -1.3 & $\begin{array}{l}-1.7 \\
\end{array}$ & -0.6 & -0.3 & -0.7 & -1.2 \\
\hline 253.9 & 387.2 & -45.2 & -65.7 & 438.8 & 233.5 & -37.3 & -38.5 & 228.0 & -0.3 & -0.7 & -1.0 & -2.1 & -0.5 & -0.7 & -0.5 & -1.1 \\
\hline 263.7 & 390.0 & -38.0 & -58.5 & 433.4 & 248.1 & -37.6 & -33.5 & 227.8 & -0.2 & -0.4 & -0.9 & -1.6 & -0.3 & -0.4 & -0.3 & -1.3 \\
\hline 273.4 & 393.3 & -28.0 & -53.6 & 383.5 & 261.1 & -33.4 & -30.0 & 216.6 & -0.5 & -0.3 & -0.9 & -1.6 & -0.5 & -0.5 & -0.8 & -1.4 \\
\hline 283.2 & 399.4 & -39.6 & -57.3 & 451.3 & 278.4 & -47.0 & -35.0 & 250.9 & -0.7 & -0.6 & -0.9 & -2.1 & -0.7 & -0.4 & -0.7 & -1.4 \\
\hline 293.0 & 404.0 & -18.9 & -46.8 & 411.9 & 288.6 & -30.2 & -27.1 & 267.6 & -0.5 & -0.7 & -1.5 & -1.5 & -0.3 & -0.4 & -1.4 & -1.6 \\
\hline 302.7 & 399.3 & 4.1 & -44.1 & 379.9 & 309.2 & -17.8 & -18.0 & 289.5 & -0.4 & -0.2 & -1.2 & -1.9 & -0.6 & -0.4 & -1.5 & -2.7 \\
\hline 312.5 & 407.0 & -20.1 & -48.1 & 530.2 & 330.1 & -59.6 & -20.2 & 293.2 & -0.5 & -0.6 & -1.3 & -3.1 & -0.6 & -0.5 & -1.2 & -2.7 \\
\hline 322.3 & 412.0 & 37.1 & -35.1 & 373.9 & 346.9 & -5.3 & -2.5 & 328.6 & -0.7 & -0.5 & -1.6 & -3.0 & -0.7 & -0.7 & -1.8 & -1.6 \\
\hline 332.0 & 416.1 & -12.0 & -18.4 & 589.1 & 383.5 & -104.9 & 17.7 & 351.5 & -0.4 & -0.8 & -1.1 & -2.7 & -0.3 & -0.7 & -1.9 & -1.8 \\
\hline 341.8 & 453.4 & 22.3 & 9.5 & 551.7 & 419.3 & -54.6 & 38.1 & 335.1 & -0.7 & -0.6 & -1.6 & -1.9 & -0.7 & -0.7 & -2.0 & -2.8 \\
\hline
\end{tabular}

